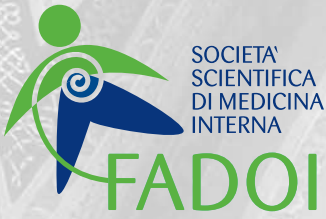

FEDERAZIONE DELLE ASSOCIAZION DEI DIRIGENTI OSPEDALIERI INTERNISTI

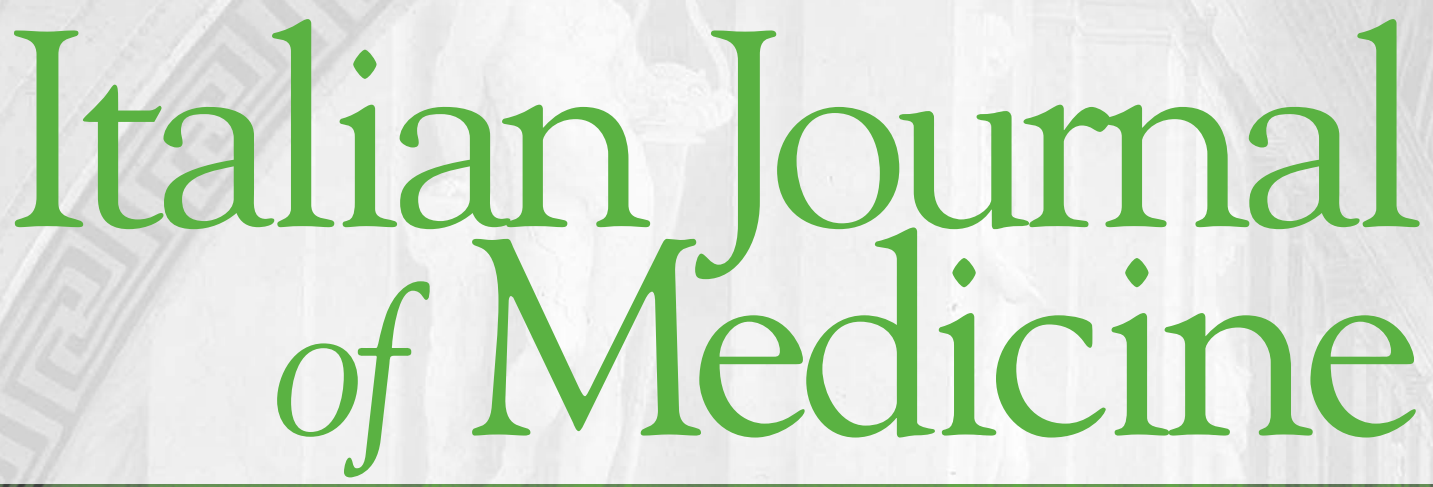

Organo Ufficiale della Federazione delle Associazioni dei Dirigenti Ospedalieri Internisti - FADOI

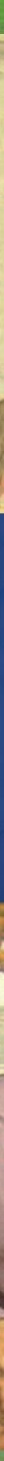

Indicizzata in:

EMBASE e Scopus
XV CONGRESSO

NAZIONALE FADOI

Bologna, 16-19 maggio 2010 

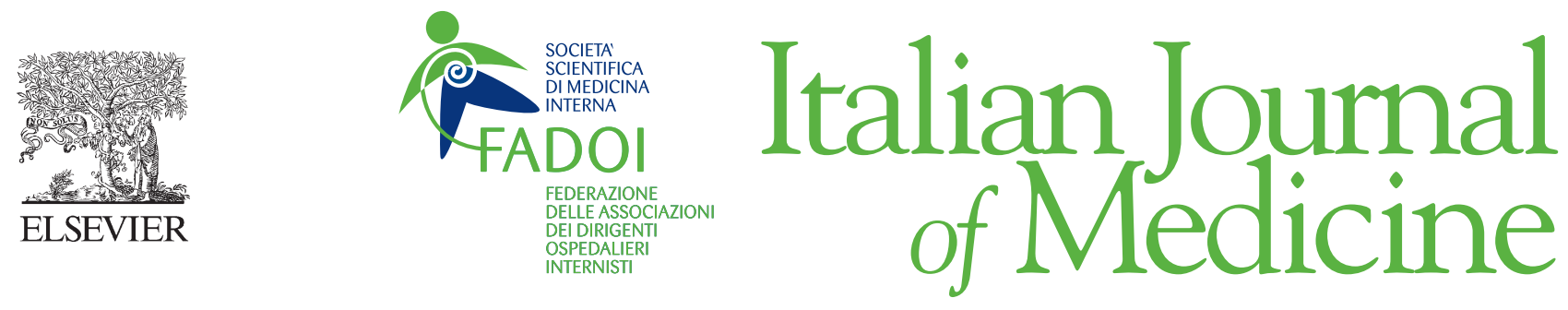

Organo Ufficiale della Federazione delle Associazioni dei Dirigenti Ospedalieri Internisti - FADOI

Editor in Chief Roberto Nardi (Bologna)

Co-Editors Giorgio Ballardini (Rimini), Giuseppe Chesi (Scandiano, RE), Giovanni Gulli (Savigliano, CN), Giovanni Scanelli (Ferrara)

Emeritus Editors Vito Cagli (Roma), Sandro Fontana (Biella), Italo Portioli (Reggio Emilia)

Editorial Board Gianfranco Gensini (Firenze), Giancarlo Agnelli (Perugia), Franco Berti (Roma), Mauro Campanini (Novara), Massimo Campieri (Bologna), Mario Cottone (Palermo), Domenico Cucinotta (Bologna), Francesco d'Amore (Roma), Pier Paolo Di Micco (Napoli), Salvatore Di Rosa (Palermo), Leonardo Fabbri (Modena), Andrea Fontanella (Napoli), Massimo Giusti (Torino), Gualberto Gussoni (Milano), Ido Iori (Reggio Emilia), Giancarlo Landini (Firenze), Dario Manfellotto (Roma), Pietro Marino (Milano), Antonino Mazzone (Legnano, MI), Giovanni Mathieu (Torino), Carlo Nozzoli (Firenze), Stefano Pallanti (Firenze, New York), Domenico Panuccio (Bologna), Claudio Puoti (Roma), Generoso Uomo (Napoli), Giuseppe Remuzzi (Bergamo), Carlo Salvarani (Reggio Emilia), Filippo Salvati (Chieti), Mario Visconti (Napoli), Maurizio Ventrucci (Bologna), Paolo Verdecchia (Assisi), Giorgio Vescovo (Vicenza), Claudio Vitali (Piombino), Walter Ricciardi (Roma)

Young Editors Dimitriy Arioli (Reggio Emilia), Micaela La Regina (La Spezia), Francesco Corradi (Firenze), Adolfo lacopino (Messina), Maicol Onesta (Fabriano), Sirio Fiorino (Bologna)

International Board

Stefan D. Anker (Berlino, Germania), Edgardo Arena (Buenos Aires, Argentina), Isabelle Bourdel-Marchasson (Bordeaux, Francia), Vito M. Campese (Los Angeles, USA), Roberto Cataldi Amatriain (Buenos Aires, Argentina), Antonio Ceriello (Barcellona, Spagna), Andrew Davenport (Londra, UK), Ralph A. DeFronzo (San Antonio, USA), Leonidas Duntas (Atene, Grecia), Ariel Estruch (Buenos Aires, Argentina), Samuel Z. Goldhaber (Boston, USA), Gene G. Hunder (Rochester, USA), Ana M. Israel (Buenos Aires, Argentina), James R. Jett (Denver, USA), Dan Justo (Tel Aviv, Israele), Anna Modelska (Poznan, Polonia), Manuel Monreal (Badalona, Spagna), Marco Pahor (Gainesville, USA), Piotr Ponikowski (Wroclaw, Polonia), Cornel C. Sieber (Nürnberg, Germania), Astrid Stuckelberger (Ginevra, Svizzera), Bernardo Tanur (Santa Fe, Messico), Inder Anand (Minneapolis, USA)

Italian Journal of Medicine

Organo Ufficiale della Federazione delle Associazioni dei Dirigenti Ospedalieri Internisti - FADOI è indicizzata in Scopus ed EMBASE 


\section{Italian Journal of Medicine}

Organo Ufficiale FADOI

SOMMARIO CONTENTS
S1 Introduzione: broncopneumopatia cronica ostruttiva e comorbilità croniche
C. Nozzoli, G. Genuini, L.M. Fabbri

S3 Invecchiamento, infiammazione sistemica e malattie croniche complesse C. Franceschi, P. Pauletto, R.A. Incalzi, L.M. Fabbri

S14 Linee guida sulla BPCO non associata a comorbilità croniche L. Corbetta, F. Luppi, R.A. Incalzi

S22 BPCO e scompenso cardiaco C. Nozzoli, G. Mathieu, G. Gensini

S38 BPCO e vasculopatie P. Pauletto, M. Rattazzi

S46 BPCO e cardiopatia ischemica D. Panuccio

S55 BPCO e ipertensione arteriosa F. Colombo

S57 BPCO e tromboembolismo venoso P. Roversi, M. Campanini

S67 BPCO e nefropatie croniche F. Salvati, A. Santoro, C. Pedone

S75 BPCO, obesità, sindrome metabolica e diabete G. Gulli and V. Miselli

S81 BPCO e depressione/ansia

F. Boni, A. Corsonello, D. Panuccio

S91 BPCO e deficit cognitivo F. Boni, A. Corsonello, D. Panuccio

S96 BPCO e osteoporosi

M. Grandi, C. Sacchetti, P. Montanari, G. Scanelli

S104 BPCO e malattie reumatiche

A. Sciascera, A. Mazzone 
SOMMARIO CONTENTS
S109 BPCO e malattie dell'apparato digerente F. Cipollini

S119 BPCO ed emopatie

G. Chesi, A. Grechi, E. Spaggiari, G. Bonardi, M. Sole Simonini, E. Rottoli, A. Mazzone

S128 BPCO e tumori

R. Biasioli, L. Pavan, A. Grechi

S135 Le infezioni come comorbilità della BPCO

F. Luppi, B. Beghè, P. Roversi

S142 BPCO nell'anziano

R. Antonelli Incalzi, M. Giusti

S151 BPCO, sindrome delle apnee ostruttive del sonno e disturbi del sonno G. Vagheggini, M. Digiorgio, S. Reitano

S159 Complessità del paziente con insufficienza respiratoria cronica associata a BPCO

F. Sgambato, E. Clini

S171 Metodologia clinica, strumenti di valutazione e gestione dei pazienti anziani affetti da BPCO e comorbilità croniche R. Nardi, L. Corbetta, M. Muratori, G. Belmonte, G. Scanelli, G. Mathieu

S179 Policronicità e politerapia in fase cronica e di riacutizzazione A. Sacchetta, P. Marino

S186 Valutazione preoperatoria e preparazione a intervento chirurgico nei pazienti affetti da BPCO e comorbilità croniche A. Marchioni, S. Butani 


\title{
Introduzione: broncopneumopatia cronica ostruttiva e comorbilità croniche
}

\author{
Carlo Nozzoli, Gianfranco Genuini, Leonardo M. Fabbri
}

La broncopneumopatia cronica ostruttiva (BPCO) è una sindrome che si sviluppa negli adulti fumatori fino a raggiungere prevalenze nell'ordine del $20 \%$ negli anziani di età superiore a 70 anni [1,2]. La BPCO è caratterizzata da sintomi respiratori cronici e ostruzione bronchiale non reversibile, evolutiva, associata a un'abnorme risposta infiammatoria polmonare all'inalazione di fumo e/o altre particelle e gas nocivi professionali o ambientali.

Il fumo di sigaretta costituisce il principale fattore di rischio per l'insorgenza della BPCO, che rappresenta la più frequente malattia polmonare cronica a evoluzione invalidante nell'adulto.

A livello mondiale, la BPCO è responsabile di 4 morti al minuto e l'Organizzazione Mondiale della Sanità (OMS) prevede che sarà la terza causa di morte entro il 2030, seconda solo a malattie cardiovascolari e tumori. L'OMS stima che 80 milioni di persone siano affette da COPD da moderata a grave e che oltre 2 milioni di persone l'anno muoiano primariamente per BPCO. In Italia si stima che esistano circa 6 milioni di soggetti affetti da BPCO, che costituisce una delle prime cause di ricovero in ospedale e causa circa 20.000 morti l'anno, con costi sociali e umani enormi [1].

La BPCO, pur riconosciuta primariamente come malattia respiratoria, non è una patologia limitata all'apparato respiratorio, ma si diffonde a livello sistemico. Infatti la causa prima di BPCO, il fumo, ha effetti sistemici che oltre a provocare BPCO possono contribuire allo sviluppo di malattie croniche [3] - tra cui malattie cardiovascolari, metaboliche, renali e tumori - coadiuvati in questo da altri fattori di rischio quali l'iperlipidemia, l'obesità, l'ipertensione e la sedentarietà. La BPCO e le malattie croniche a essa associate si sviluppano in particolare nell'anziano e l'invecchiamento, di per sé, costituisce un fattore amplificante per il loro sviluppo in sinergia con $i$ fattori di rischio sopra menzionati [4-6].

La presenza di comorbilità croniche aggrava notevolmente le condizioni e la prognosi dei pazienti affetti da
BPCO [7]. Infatti, il decesso dei pazienti affetti da BPCO è causato prevalentemente dalle comorbilità cardiovascolari e dai tumori, più che dalle complicanze della BPCO stessa. Inoltre, la riduzione della funzionalità respiratoria aumenta il rischio di complicazioni/mortalità per cause extrapolmonari quali aritmie maggiori, eventi coronarici e cardiovascolari, infarto cerebrale ed embolia polmonare, indipendentemente dagli effetti del fumo, suggerendo che le condizioni extrapolmonari associate a limitazione del flusso aereo potrebbero essere anche più rilevanti per la gravità dei sintomi, la qualità di vita e la prognosi dei pazienti rispetto alle anomalie polmonari tipiche della BPCO [5-7].

In considerazione di quanto sopra, le comorbilità croniche della BPCO devono essere accuratamente ricercate e valutate per un appropriato inquadramento diagnostico e di gravità del paziente affetto da BPCO. Inoltre, tenuto conto che le terapie abitualmente indicate e praticate nella BPCO hanno efficacia limitata, sono puramente sintomatiche e non modificano la storia naturale della malattia, il paziente con BPCO va trattato non solo per la parte respiratoria, ma anche per le comorbilità in particolare cardiovascolari, in quanto vi sono evidenze che un'impostazione terapeutica a tutto campo sia in grado di modificare sia la morbilità sia la mortalità di tali pazienti [8].

Le considerazioni sopra esposte costituiscono il razionale della monografia intitolata "Broncopneumopatia cronica ostruttiva e comorbilità croniche" promossa dalla Federazione delle Associazioni dei Dirigenti Ospedalieri Internisti (FADOI) che abbiamo qui il privilegio di presentare. La manografia, frutto dell'intenso lavoro di numerosi colleghi internisti e specialisti, affronta in dettaglio i fattori di rischio della BPCO e delle sue comorbilità croniche, le manifestazioni cliniche e i trattamenti delle principali singole malattie croniche. L'opera è del tutto nuova e originale e siamo certi che costituirà una pietra miliare per l'impostazione di raccomandazioni terapeutiche adeguate per pazienti affetti da BPCO e relative comorbilità. La presentiamo con 
orgoglio nell'auspicio che rappresenti un utile strumento di apprendimento e di lavoro.

\section{Bibliografia}

[1] Global Initiative on Obstructive Lung Disease. www.goldcopd.org (accessed 16 April 2010).

[2] Niewoehner DE. Clinical practice. Outpatient management of severe COPD. N Engl J Med 2010;362(15):1407-16.

[3] Yanbaeva DG, Dentener MA, Creutzberg EC, Wesseling G, Wouters EF. Systemic effects of smoking. Chest 2007;131(5):1557-66.
[4] Fabbri LM, Rabe KF. From COPD to chronic systemic inflammatory syndrome? Lancet 2007;370(9589):797-9.

[5] Fabbri LM, Luppi F, Beghé B, Rabe KF. Complex chronic comorbidities of COPD. Eur Respir J 2008;31(1):204-12.

[6] Mannino DM, Watt G, Hole D, Gillis C, Hart C, McConnachie A, et al. The natural history of chronic obstructive pulmonary disease. Eur Respir J 2006;27(3):627-43.

[7] Mannino DM, Thorn D, Swensen A, Holguin F. Prevalence and outcomes of diabetes, hypertension and cardiovascular disease in COPD. Eur Respir J 2008;32(4):962-9.

[8] Luppi F, Franco F, Beghé B, Fabbri LM. Treatment of chronic obstructive pulmonary disease and its comorbidities. Proc Am Thorac Soc 2008;5(8):848-56. 


\title{
Invecchiamento, infiammazione sistemica e malattie croniche complesse
}

\author{
Claudio Franceschi, Paolo Pauletto, Raffaele A. Incalzi, Leonardo M. Fabbri
}

\section{Messaggi chiave}

- L'invecchiamento è associato a modificazioni strutturali organo-specifiche, sistemiche e immunologiche in senso proinfiammatorio ("inflamm-ageing").

- Il cumulo delle modificazioni strutturali e immunologiche legate all'invecchiamento con fattori di rischio (quali fumo, inquinamento, iperdislipidemia, obesità) porta, nell'anziano, allo sviluppo di concomitanti malattie croniche.

- Il cumulo delle modificazioni strutturali e immunologiche a carico dell'apparato respiratorio con fattori di rischio quali fumo e inquinamento porta all'aumentato rischio di sviluppo di broncopneumopatia cronica ostruttiva, fibrosi polmonare idiopatica e tumori polmonari.

- Il cumulo delle modificazioni strutturali e immunologiche a carico dell'apparato cardiocircolatorio con fattori di rischio endogeni ed esogeni porta allo sviluppo di aterosclerosi, ipertensione, vasculopatie coronariche e periferiche e scompenso cardiaco.

- Altre malattie croniche che si sviluppano nell'anziano sono una generale condizione di fragilità, malattie nervose (Parkinson, Alzheimer), osteoporosi, nefropatie croniche, malattie cutanee.

\section{Introduzione}

Senectus ipsat morbu.

La citazione latina sintetizza la moderna visione dell'invecchiamento come l'insieme di progressive alterazioni strutturali e funzionali che si sviluppano a carico di vari organi e tessuti anche in apparente assenza di maggiori fattori di rischio esogeni, e che di per sé costituiscono una deviazione rispetto a strutture e funzioni presenti in età e condizioni ottimali. Esempi pertinenti al presente trattato sono: 1) le alterazioni strutturali dell'apparato respiratorio associate all'età che portano a un decadimento della funzionalità respiratoria in senso ostruttivo e alterazioni degli scambi gassosi simili a quelli osservabili nella broncopneumopatia cronica ostruttiva (BPCO); 2) le alterazioni strutturali e funzionali associate all'età, che sono in gran parte simili alle alterazioni strutturali dell'aterosclerosi.

La sovrapposizione delle alterazioni biologiche, strutturali e funzionali associate all'età e dei fattori rischio endogeni, per esempio genetici, ed esogeni, quali fumo, inquinamento, infezioni, cattive abitudini di vita (dieta ipercalorica, vita sedentaria, stress), iperdislipidemia, ipertensione, conduce allo sviluppo simultaneo di più malattie croniche (come vasculopatie coronariche e periferiche, in particolare aterosclerosi) e alle loro conseguenze (infarto del miocardio, scompenso cardiaco, ictus cerebri ecc.), a BPCO, diabete mellito di tipo 2 e alla fragilità del soggetto anziano. Diabete, dislipidemie, ipertensione e aterosclerosi sono intimamente connesse tra loro e costituiscono uno dei maggiori problemi sanitari del mondo industrializzato e, in prospettiva, anche dei Paesi in via di sviluppo.

Oggi si ritiene che le patologie dell'invecchiamento non siano associate tra di loro in modo casuale, ma che esista un terreno comune costituito da atteggiamento biologico proinfiammatorio collegato all'invecchiamento ("inflammageing") che potrebbe rappresentare il "trait d'union" fra le diverse malattie croniche. 


\section{Invecchiamento}

L'invecchiamento è il risultato di un complesso processo a carico di cellule, tessuti, organi e sistemi che si sviluppa in conseguenza dello sbilanciamento della risposta individuale agli stimoli intrinseci ed estrinseci. Tale processo comporta una progressiva fragilità dell'individuo, con predisposizione allo sviluppo di malattie croniche e morte.

Tipiche espressioni dell'invecchiamento sono la formazione di rughe, l'imbianchimento e la perdita dei capelli, la riduzione della massa muscolare (sarcopenia) che associata ad alterazioni osteoarticolari determina un condizione di limitata motilità e tolleranza allo sforzo, e lo sviluppo di una condizione di fragilità psicofisica cui contribuiscono condizioni croniche quali il Parkinson e l'Alzheimer.

L'invecchiamento è accompagnato da un graduale aumento di citochine e mediatori infiammatori (per esempio, proteina C-reattiva) che produce uno stato di latente infiammazione cronica, responsabile di alterazioni strutturali a carico di vari organi e quindi dello sviluppo di un progressivo stato di fragilità e di malattie croniche. Il contributo di diversi tessuti (tessuto adiposo, muscolatura) e/o organi (cervello, fegato), sistemi (immunologico, flora intestinale) a tale processo, elegantemente sintetizzato nell'espressione inglese "inflamm-ageing", è variabile e porta nei singoli individui a diverse espressioni patologiche organo-specifiche e/o sistemiche.

Seppur l'infiammazione rappresenti un importante e complesso meccanismo di difesa che coinvolge varie cellule, organi e tessuti, la sua cronicizzazione e disregolazione può comportare modificazioni strutturali deleterie (per esempio, atrofia muscolare e del sistema nervoso centrale) e vere e proprie malattie croniche. L'invecchiamento di per sé è associato a modificazioni ormonali, biologiche e immunologiche in senso proinfiammatorio, concetto riassunto nel sintetico termine "inflamm-ageing" ( fig. 1). Nell'ambito del processo infiammatorio cronico associato all'invecchiamento svolgono un ruolo chiave alcuni meccanismi molecolari di base che coinvolgono tessuti chiave (per esempio tessuti adiposo, muscolare e nervoso centrale), organi (cervello e fegato), sistemi (sistema immunologico) ed ecosistemi (flora intestinale) (fig. 2).

Queste diverse strutture contribuiscono in maniera diversa al processo infiammatorio cronico associato all'invecchiamento con effetti che possono essere sia organospecifici sia sistemici. Le prime fasi del processo sono organo-specifiche, per esempio la demenza senile per il cervello, l'epatite cronica o la cirrosi per il fegato, la cachessia per la muscolatura, l'enfisema per il polmone. Successivamente il processo diviene sistemico e interessa

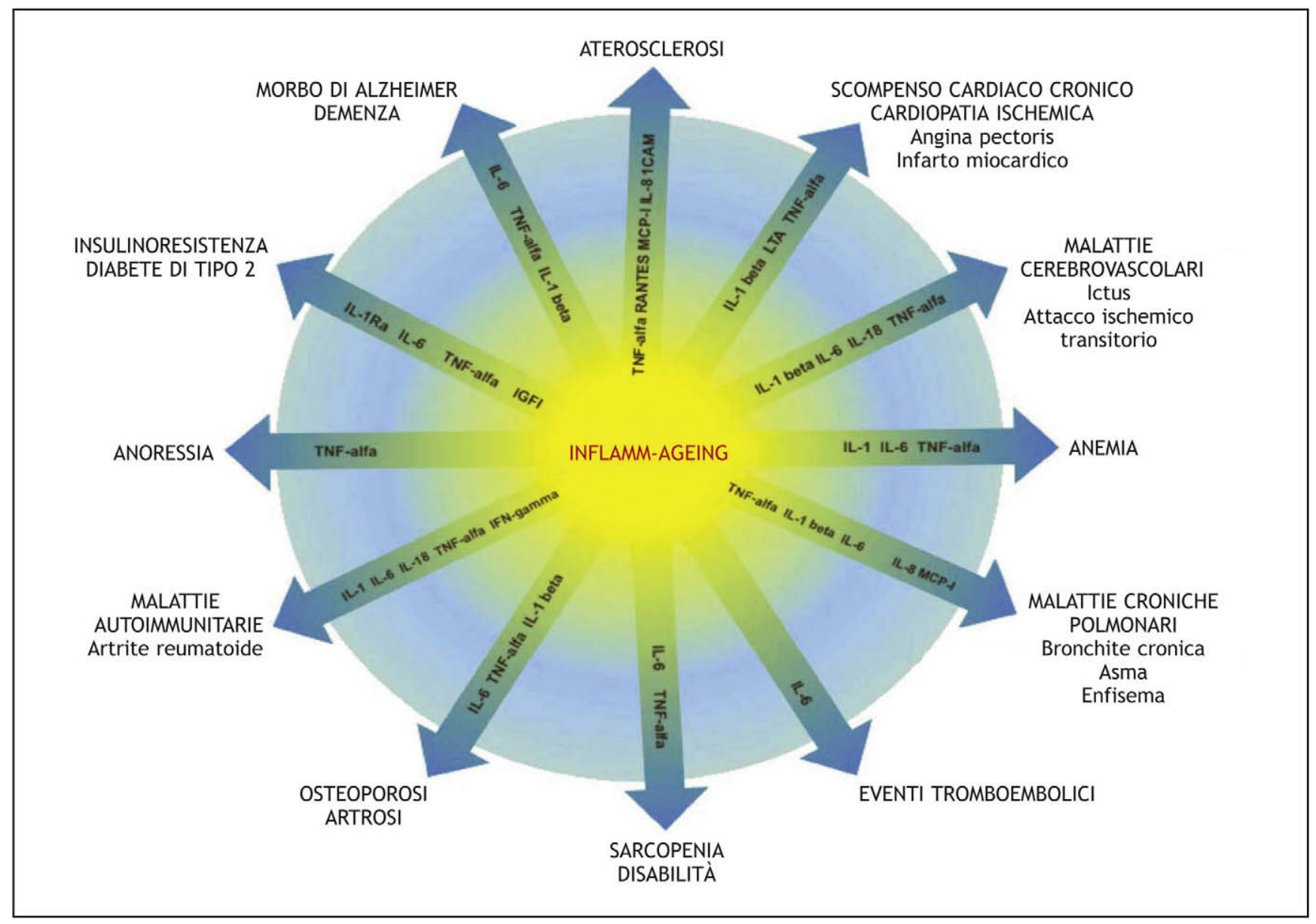

Figura 1 Associazione fra invecchiamento e modificazioni ormonali, biologiche e immunologiche in senso proinfiammatorio riassumibili nella definizione "inflamm-ageing". 


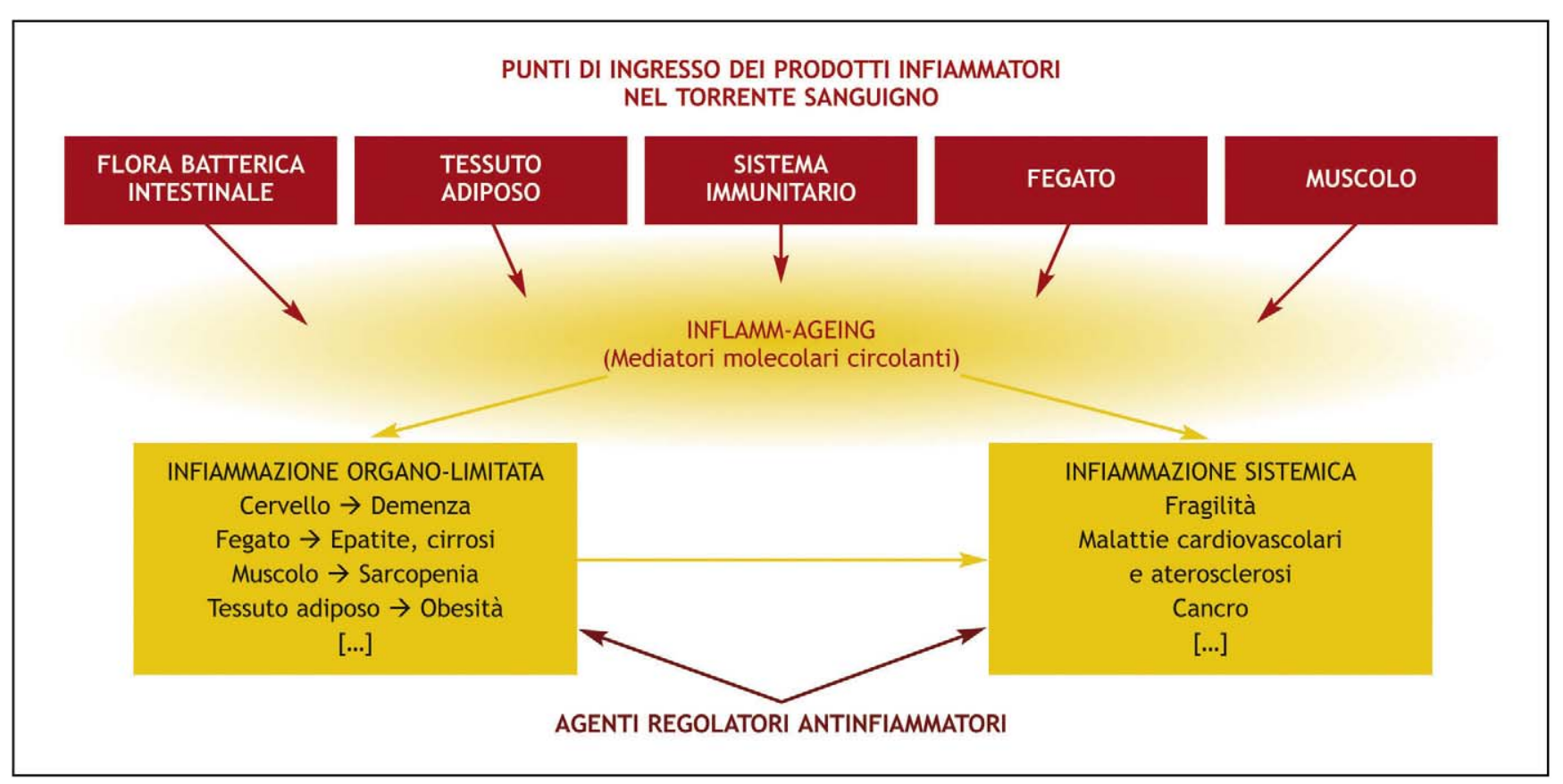

Figura 2 Meccanismi molecolari a carico di tessuti quali l'adiposo, il muscolare e il nervoso centrale, organi quali cervello e fegato, sistemi quali l'immunologico ed ecosistemi (flora intestinale).

più organi e sistemi come nelle malattie cardiovascolari croniche e nei tumori. È possibile che la flogosi sistemica sia conseguente al continuo rilascio di citochine e mediatori infiammatori da parte degli organi inizialmente interessati, ma non è escluso che vi possa essere un autonomo sviluppo di un vero e proprio processo sistemico. Infatti, lo stesso processo di invecchiamento cellulare porta alla produzione e secrezione, da parte di tutti i tipi cellulari, di fattori proinfiammatori solubili (fenotipo secretorio) il cui ruolo non è ancora definito, ma che potrebbe essere autocrino/paracrino o anche proinfiammatorio di per sé.

Alla base del processo infiammatorio cronico associato al'invecchiamento giocano un ruolo chiave variazioni

Tabella 1 Principali modificazioni del sistema immunitario durante il processo di invecchiamento fisiologico.

- Diminuzione dei linfociti T naïve e aumento delle cellule di memoria

- Aumento delle cellule T attivate CD28-

- Aumento delle cellule responsive ad antigeni del Cytomegalovirus

- Diminuzione dell'attività di output del timo

- Diminuzione del numero di linfociti $T_{\text {REC+ }}$ in periferia

- Elevato numero di espansioni monoclonali e oligoclonali dei sistemi B e T

- Riduzione del repertorio dei linfociti B e T

- Aumentata risposta di tipo $\mathrm{TH}_{2}$

- Aumento della produzione di citochine proinfiammatorie (in particolare IL-1, IL-6 e TNF-alfa)

- Diminuzione della funzionalità dei neutrofili e dei monociti

- Aumento del numero di cellule natural killer

- Diminuzione della funzionalità delle cellule dendritiche

Fonte: Ferrari AU, et al. J Appl Physiol 2003;95(6):2591-7. ormonali quali la riduzione di cortisolo e ormoni sessuali. In assenza di fattori di rischio endogeni (genetici) ed esogeni (fumo, obesità), l'infiammazione cronica associata all'invecchiamento non è incompatibile con la longevità, come dimostrato dai simultanei livelli elevati di alcune citochine proinfiammatorie (IL-1, IL-6, TNF-alfa), ma anche di citochine antinfiammatorie (per esempio IL-10, TGFbeta).

Nell'insieme, quindi, l'invecchiamento del sistema neuro-immuno-endocrino si tradurrebbe in un'alterazione dei processi immunitari con prevalenza degli helper T2 favorenti i fenomeni autoimmunitari, le infezioni batteriche e l'infiammazione cronica, l'ossidazione delle LDL e l'aterosclerosi, la comparsa di tumori (gli helper T1, invece, hanno proprietà citotossiche). Inoltre, aumenta la prevalenza di autoanticorpi - per esempio antitiroide, verso il fattore reumatoide, anticardiolipina - in anziani sani o fragili, ma senza patologie specificamente correlate con questo tipo di anticorpi. Alte concentrazione di IL-6 marcano i soggetti a rischio di disabilità. Le principali alterazioni immunologiche e biologiche associate all'invecchiamento sono riassunte nella tabella 1 e descritte in dettaglio in recenti rassegne bibliografiche [1-13].

\section{Invecchiamento, apparato respiratorio, malattie respiratorie croniche}

L'invecchiamento è associato a modificazioni biologiche sistemiche, descritte nella precedente sezione, che si sviluppano in parallelo a modificazioni strutturali e funzionali dell'apparato respiratorio tali da alterarne fondamentalmente le caratteristiche e i meccanismi omeostatici di difesa $[14,15]$. 


\section{Modificazioni respiratorie associate all'invecchiamento}

I cambiamenti nella composizione della matrice polmonare e in particolare di elastina e collageno portano a un rimodellamento delle vie aeree e del parenchima polmonare, che determina:

- riduzione delle forza di ritorno elastico del polmone;

- allargamento dei dotti e degli alveoli polmonari;

- riduzione della superficie di scambio gassoso;

- riduzione del numero di capillari per alveolo.

Queste alterazioni portano a un collasso dei bronchioli respiratori, con conseguente riduzione del loro lume fino alla chiusura, che si accentua nel corso dell'espirazione. Le modificazioni descritte ricordano il quadro anatomopatologico dell'enfisema, con l'eccezione della mancanza di distruzione della pareti alveolari presente nell'enfisema.

Insieme con la riduzione del ritorno elastico, si sviluppano altre alterazioni con conseguenze funzionali:

- irrigidimento della cassa toracica dovuto a

- ridotta mobilità delle articolazioni costo-vertebrali,

o riduzione dello spessore dei dischi intervertebrali,

- calcificazione delle cartilagini intercostali,

- progressiva cifo-scoliosi;

- riduzione di forza dei muscoli respiratori dovuta a

- riduzione della forza del diaframma,

- riduzione della sezione dei muscoli intercostali,

- perdita di efficienza del sistema muscoli intercostali/ cassa toracica;

- modificazioni del controllo nervoso del respiro con

- idotta risposta a ipossia e ipercapnia,

- accentuazione delle turbe respiratorie associate al sonno.

L'insieme delle modificazioni sopra descritte si traduce nelle alterazioni spirometriche caratteristiche dell'invecchiamento:

- riduzione della capacità vitale (CV);

- simultaneo aumento del volume residuo (VR) senza modificazioni significative della capacità polmonare totale (CPT);

- riduzione del rapporto fra volume espiratorio massimo al secondo (VEMS) e CV (< VEMS/CV);

- aumento del rapporto fra VR e CPT (> VR/CPT).

Inoltre, le alterazioni strutturali sopra descritte, e in particolare la riduzione della superficie alveolare disponibile per gli scambi gassosi con parallela diminuzione del numero di capillari per alveolo, porta a un progressivo calo dell'efficienza degli scambi gassosi con riduzione della pressione parziale di ossigeno sciolto nel sangue arterioso $\left(<\mathrm{PaO}_{2}\right)$, della saturazione arteriosa $\left(\mathrm{SaO}_{2}\right)$ e del consumo di ossigeno sotto sforzo.

Le modificazioni degli scambi gassosi, insieme alle simultanee modificazioni cardiovascolari, scheletriche e muscolari, determinano una progressiva limitazione della tolleranza allo sforzo.

L'insieme delle alterazioni sopra descritte, combinate con le modificazioni delle caratteristiche del sonno che si sviluppano con l'invecchiamento, comportano un'accentuazione dei disturbi respiratori associati al sonno.

L'invecchiamento dell'organismo è anche accompagnato da un progressivo declino sia dell'immunità cellulo-mediata sia dell'immunità umorale (si veda sopra). A livello polmonare ciò si traduce in una ridotta clearance muco-ciliare, in un aumento del numero di linfociti e neutrofili e in una modificata e ridotta funzione macrofagica, fattori questi che sono l'espressione di una diminuita immunità acquisita e di un'aumentata risposta aspecifica dell'immunità innata.

\section{Malattie respiratorie croniche nell'anziano}

Oltre alle modificazioni strutturali e funzionali sopra descritte, l'invecchiamento si associa al momento di massimo accumulo dei fattori di rischio esogeni responsabili delle più frequenti malattie respiratorie croniche, in particolare fumo, inquinanti ambientali, lavorativi e domestici, effetti cronici di eventuali pregresse patologie respiratorie acute (infezioni batteriche o virali, intossicazioni acute, traumi ecc.) [16].

Le malattie croniche dell'apparato respiratorio più frequenti nell'anziano risultano quindi essere:

- le malattie ostruttive del polmone (BPCO e asma);

- il tumore del polmone;

- le malattie infettive respiratorie;

- le malattie infiltrative diffuse del polmone.

\section{Malattie ostruttive del polmone (BPCO e asma)}

L'incidenza di BPCO inizia dall'età di circa 40 anni e progredisce con il trascorrere del tempo. Poiché per la conferma diagnostica gli studi epidemiologici utilizzano il criterio di un rapporto FEV1/FVC $<0,7$ dopo broncodilatatore, l'incidenza e la prevalenza di BPCO possono risultare sottostimate nei soggetti di età inferiore a 50 anni e sovrastimate dopo i 70 anni. Il motivo è che $i$ "normali" limiti inferiori di FEV1/FVC tendono a essere $>0,7$ prima dei 50 anni e $<0,7$ sopra i 70 anni, e la broncodilatazione non annulla questo effetto in particolare negli anziani [17]. Ciò significa, tuttavia, che l'effetto cumulativo maggiore dei fattori di rischio di BPCO, e in particolare il fumo, si sovrappone al normale decadimento della funzione respiratoria e porta a un fenotipo particolare di BPCO, rappresentato dalla BPCO dell'anziano [18]. A questo diverso fenotipo si aggiungono le altre modificazioni sistemiche associate all'inquinamento e le più frequenti comorbilità croniche [19]. L'insieme di tali osservazioni conduce alla necessità di sviluppare specifiche linee guida per la gestione della BPCO e delle comorbilità croniche dell'anziano, che costituisce lo scopo principale della presente monografia [20].

Analogamente l'asma, malattia a frequente insorgenza in età giovanile, modifica le proprie caratteristiche nell'anziano. Per esempio, l'iperresponsività bronchiale e la reversibilità dell'ostruzione bronchiale, patognomoniche dall'asma in età infantile e adulta, si modificano con l'età e di questo occorre tenere conto soprattutto per quanto riguarda la diagnosi differenziale con la BPCO [21].

\section{Tumore del polmone}

L'incidenza e la prevalenza del tumore del polmone sono notoriamente collegate all'età e al sesso (prevalenza nei maschi anche se in crescente aumento nelle femmine). 
Tabella 2 Fattori di rischio per polmonite batterica nell'anziano.

- Disfunzione dei sistemi di difesa immunitari

- Soppressione immunitaria

- Farmaci (per esempio corticosteroidi)

- Malattie sistemiche (per esempio neoplasia maligna, insufficienza renale)

- Declino associato all'età

- Predisposizione all'aspirazione delle vie aeree superiori oppure delle secrezioni orali

- Disfunzione del sistema nervoso centrale

- Disturbi della deglutizione

- Farmaci sedativi

- Riduzione dei meccanismi di clearance

- Riflessi meccanici (tosse)

- Clearance orale (flusso salivare)

- Clearance muco-ciliare

- Accesso a un centro di cure mediche

- Recente ospedalizzazione

- Accesso a un centro di cure a lungo termine

- Disfunzioni organiche

- Malattie del parenchima polmonare

- Altre malattie (cardiache, renali, epatiche)

- Malattie croniche (diabete, patologie reumatologiche)

- Malnutrizione calorico-proteica oppure ipoalbuminemia

- Fumo di tabacco

- Alcolismo

- Infezioni virali

Fonte: Meyer KC. Proc Am Thorac Soc 2005;2(5):433-9.

Il tumore del polmone è spesso associato ad altre forme respiratorie croniche, in particolare la BPCO [22].

\section{Malattie infettive respiratorie}

La ridotta immunità acquisita e l'aumentata risposta aspecifica dell'immunità innata possono compromettere la risposta immune del polmone a noxae patogene di varia natura, e simultaneamente aumentare in maniera dannosa la risposta infiammatoria aspecifica. Tali modificazioni morfofunzionali possono contribuire a spiegare la più elevata incidenza e severità di alcune pneumopatie, tra cui le malattie infiltrative diffuse del polmone e in particolare la fibrosi polmonare idiopatica (FPI) e le infezioni polmonari, specie le polmoniti sia batteriche sia virali [14]. I principali fattori di rischio per l'aumento delle polmoniti batteriche nell'anziano sono riportate nella tabella 2 .

\section{Malattie infiltrative diffuse del polmone}

L'invecchiamento è stato associato a modificazioni della matrice extracellulare tipiche della FPI, con incremento del contenuto in fibre collagene e fibronectina e riduzione delle fibre elastiche a causa della minore attività proteolitica delle metalloproteasi della matrice extracellulare. Inoltre, l'invecchiamento delle cellule staminali, che partecipano sia alla costruzione sia al mantenimento dell'integrità - tra gli altri - del parenchima polmonare, può contribuire a tale aspetto della senescenza del polmone. In pratica, poiché nell'età avanzata la riserva di cellule staminali è ridotta, risulta ridotto anche il potenziale rigenerativo tissutale [23].

Il prototipo delle malattie infiltrative diffuse, e quella che più aumenta con l'età, è la FPI. La FPI inizia verosimilmente con un danno all'epitelio alveolare conseguente a microinsulti vari (aspirazione, infezioni ecc.) cui segue un abnorme processo riparativo caratterizzato da migrazione, proliferazione e differenziazione dei fibroblasti in miofibroblasti; questi si aggregano in foci proliferativi e portano a eccessiva e irreversibile deposizione di collageno denso che sostituisce la decrescente elastina.

Il sovrapporsi, da una parte, delle variazioni funzionali respiratorie associate all'invecchiamento e, dall'altra, l'accumularsi di fattori di rischio, in particolare il fumo, porta spesso a forme miste sia delle alterazioni ventilatorie ostruttive/restrittive che anatomopatologico di fibrosi ed enfisema [24].

\section{Invecchiamento, apparato cardiocircolatorio e malattie cardiovascolari}

Le modificazioni cardiovascolari associate all'invecchiamento sono state descritte in un'elegante rassegna di Ferrari et al. [25] (tabella 3).

Le principali modificazioni anatomiche cardiache associate all'invecchiamento sono:

- aumento di peso del cuore, ipertrofia ventricolare sinistra;

- torsione a destra con restringimento dell'istmo di uscita dal ventricolo sinistro;

- diminuzione di numero e aumento di dimensione dei cardiomiociti;

- aumento del collagene intercellulare;

- degenerazione dell'innervazione simpatica.

Le principali modificazioni funzionali cardiache associate all'invecchiamento sono:

- preservati funzionalità sistolica, volume di eiezione, portata cardiaca;

- minima riduzione della frequenza cardiaca;

- riduzione iniziale della prima fase del riempimento diastolico compensata da un aumento del riempimento telediastolico;

- associate modificazioni ecografiche (E/A velocity ratio);

- ridotta risposta beta-adrenergica, per cui per mantenere la portata cardiaca sotto sforzo si verificano aumento dei volumi di riempimento telediastolico e telesistolico;

- ritardato rilassamento, prolungato tempo di contrazione. Le principali modificazioni anatomiche vascolari associate all'invecchiamento riguardano le arterie di grosso e medio calibro:

- ispessimento delle pareti e allargamento del lume;

- ipertrofia delle tonache intima e media;

- macroscopica preservazione dell'endotelio;

- modificazioni morfologiche delle cellule endoteliali;

- infiltrazione subendoteliale da parte di cellule muscolari lisce vascolari;

- aumento di deposito di collagene, elastina, proteoglicani;

- aumento dell'infiltrato leucocitario e macrofagico;

- aumento di mediatori infiammatori nell'intima;

- calcificazione. 
Tabella 3 Effetti dell'invecchiamento sulle principali caratteristiche funzionali e strutturali del sistema cardiovascolare.

\begin{tabular}{lll}
\hline \multicolumn{1}{c}{ Cambiamenti cardiaci } & & \multicolumn{1}{c}{ Cambiamenti vascolari } \\
\hline Peso cardiaco & $\uparrow$ & Spessore della parete arteriosa (intima-media) \\
\hline Dimensioni dei cardiomiociti & $\uparrow$ & Collagene subendoteliale \\
\hline Numero di cardiomiociti & $\downarrow$ & Elastina \\
\hline Collagene in cross-linking & $\uparrow$ & Frammentazione dell'elastina \\
\hline Frazione di eiezione & $=$ & Proteoglicani \\
\hline Volume sistolico & $=$ & Attività delle MMP \\
\hline Gittata cardiaca & $=$ & Migrazione intimale/Proliferazione di VSMC \\
\hline Riempimento prediastolico & $\downarrow$ & Distensibilità arteriosa \\
\hline Riempimento telediastolico & $\uparrow$ & Velocità dell'onda di polso \\
\hline Risposta cronotropa a stimolo beta-adrenergico/catecolamine & $\downarrow$ & Resistenza totale periferica \\
\hline Risposta inotropa a stimolo beta-adrenergico/catecolamine & $\downarrow$ & Permeabilità endoteliale \\
\hline Risposta inotropa alla digitale & $\downarrow$ & Rilascio di ossido nitrico endoteliale \\
\hline Picco della gittata cardiaca al massimo sforzo & $\downarrow$ & Marcatori/mediatori infiammatori \\
\hline Funzione lusitropica & $\downarrow$ & Attività della SOD \\
\hline Rilascio di peptidi natriuretici & $\uparrow$ & Vasodilatazione beta-adrenergico-mediata \\
\hline
\end{tabular}

Legenda: $\downarrow$ diminuito; $\uparrow$ aumentato; = invariato; MMP = metalloproteasi della matrice; VSMC = cellule del muscolo liscio vascolare; SOD $=$ superossidodismutasi.

Fonte: Ferrari AU, et al. J Appl Physiol 2003;95(6):2591-7.

Le principali modificazioni funzionali vascolari associate all'invecchiamento sono:

- ridotta distensibilità con aumento della pulse wave velocity, > grandi vasi, associato a

- ridotta risposta dilatatrice della muscolatura liscia;

- ridotto numero e ridotta funzionalità dei recettori beta;

- aumento della rigidità della parete dovuta ai tre meccanismi di cui sopra;

- aumento delle resistenze periferiche;

- aumento della pressione sistolica e di polso.

Le alterazioni sopra descritte, pur osservate in soggetti normali privi di fattori di rischio, sono analoghe a quelle osservabili nel processo aterosclerotico, che è associato tuttavia non solo ad aumentata rigidità delle pareti vascolari, ma anche ad alterazioni focali necrotiche e infiammatorie, stenosi vascolari e formazione di placche (si veda infra).

Le conseguenze delle "fisiologiche" alterazioni associate all'invecchiamento sopra descritte possono essere sintetizzate nei seguenti punti:

- alterazione funzionale diastolica, che predispone allo scompenso cardiaco diastolico, più frequente negli anziani;

- sommazione di effetti delle onde anterograda e retrograda con aumento della pressione sistolica e conseguenti danno a carico dei vasi, aumento del lavoro cardiaco e del consumo di ossigeno, ipertrofia ventricolare sinistra, rischio di ictus, ridotta funzionalità renale;

- alterazioni strutturali e in particolare endoteliali a carico delle coronarie, predisponenti al rischio coronarico;

- ridotta funzionalità dei barorecettori e della risposta betaagonista, che altera la regolazione della pressione arteriosa con aumentato rischio di episodi ipotensivi posturali e/o postprandiali, e aumentato rischio di aritmie;

- alterazioni strutturali associate a quelle idroelettrolitiche (descritte in altre parti), che comportano disidratazione tissutale.

Aterosclerosi con conseguenti vasculopatie coronarica, periferica e cerebrale, malattia coronarica, ipertensione, scompenso cardiaco, infarto, ictus, disfunzione erettile costituiscono le principali cause di malattia e morte nell'anziano, e sono dovute al sovrapporsi dei principali fattori di rischio individuali (familiarità, genetica) e ambientali (fumo, dislipidemia, iperalimentazione, sedentarietà, inquinamento ambientale o domestico ecc.).

Poiché vi è una sorta di continuità e contiguità fra le alterazioni strutturali e funzionali associate all'età e le alterazioni strutturali e funzionali associate alle malattie cardiovascolari croniche, è spesso difficile porre la diagnosi; ciò vale in particolare per le condizioni subcliniche, nelle quali la diagnosi non può che fondarsi su parametri anatomopatologici e strumentali (diagnostica per immagini, esami strumentali, esami di laboratorio).

Analogamente complesso è il riconoscimento delle singole entità croniche, in quanto le malattie cardiovascolari sono spesso associate ad altre condizioni croniche che si manifestano con sintomi o segni simili (per esempio dispnea), la natura dei quali (per esempio respiratoria, cardiaca o mista), è spesso impossibile da determinare.

Le principali alterazioni immunologiche e biologiche del sistema cardiovascolare associate all'invecchiamento sono descritte in dettaglio in recenti rassegne bibliografiche [25-38]. 


\section{Invecchiamento e malattie croniche a carico di altri organi/apparati}

\section{Senescenza dell'apparato muscolo-scheletrico}

- Cartilagine articolare: presenta uno spessore ridotto ed è meno deformabile che nell'adulto. In alcune articolazioni, come la tibiotarsica, vi è un discreto equilibrio tra processi anabolici e catabolici del condrocita; in altre, come il ginocchio, specie nelle donne, vi è una prevalenza dei processi anabolici ed è documentata un'abnorme produzione di citochine in rapporto a sollecitazioni anomale.

- Membrana sinoviale e liquido sinoviale: si osservano una ridotta produzione di liquido e un minore contenuto di acido ialuronico e condroitina-solfato.

- Muscolo: si ha una riduzione progressiva, età-correlata, della massa muscolare (sarcopenia) a causa di: senescenza delle fibre muscolari volontarie e alterazioni età-dipendenti del loro metabolismo; effetti di eventuali patologie misconosciute; modificazioni età-dipendenti dell'assetto ormonale; possibile stato infiammatorio cronico; carenze nutrizionali.

- Tendini: si riducono elasticità e deformabilità sotto carico in relazione a una diminuzione dei glucosoaminoglicani e a un aumento del collagene. Tale involuzione sarebbe rallentata dall'attività fisica.

- Osso: con l'invecchiamento l'attività osteoclastica prevale su quella osteoblastica. La causa principale di questa alterazione omeostatica è la riduzione dei livelli di estrogeni, ma vi contribuiscono anche il calo degli androgeni, la carenza di vitamina $D$ e il conseguente incremento del paratormone, fattori nutrizionali ecc. Il fumo in sé accelera sensibilmente il catabolismo osseo, specie nelle donne, riducendo l'effetto dell'estradiolo. Esistono differenze interindividuali nell'invecchiamento dell'osso:

- la fragilità dell'osso può prevalere nelle ossa trabecolari e nelle ossa lunghe, ciò in rapporto a fattori ereditari per le fratture vertebrali nelle donne, ma non per le fratture del femore. La diversa distribuzione dei due tipi di recettori degli estrogeni (nelle ossa lunghe prevalgono gli alfa, mentre in quelle trabecolari i beta) potrebbe spiegare la selettività;

- la tipologia del rimaneggiamento osseo. La maggiore deposizione dell'osso corticale nei maschi anziani determina un ingrandimento della sezione trasversale e, quindi, una maggiore resistenza, indipendentemente dall'entità del riassorbimento endostiale. L'ingrandimento della sezione dell'osso, infatti, riduce il carico per ogni unità di area e ne aumenta la resistenza. Nel soggetto molto anziano però si verifica l'erosione dell'osso corticale: un osso di sezione maggiore e più sottile diventa più fragile.

\section{Conseguenze funzionali}

Possono ascriversi all'invecchiamento in sé (meccanismo primitivo alla base di osteopenia e sarcopenia, mediato dalle citochine), al disuso (meccanismo secondario) e alla progressiva perdita dell'azione modulante degli estrogeni e dell'ormone della crescita in primo luogo. si tratta di:

- ridotta mobilità, valutabile per esempio in base a: riduzione progressiva nella velocità del cammino in condizioni standard o in presenza di ostacoli; percentuale di anziani in grado di percorrere una data distanza; numero crescente, in rapporto all'età, degli anziani che non escono più di casa;

- sedentarietà, caratteristica dell'età avanzata: vi influiscono la ridotta flessibilità articolare e il calo della massa e della forza muscolare, che determinano nell'anziano una perdita di fiducia nelle proprie capacità funzionali, riducendone ulteriormente la mobilità. Il coesistere di osteoartrosi comporta, tramite il dolore, impotenza funzionale e limita la mobilità. Dolore e impotenza funzionale fanno altresì parte della sintomatologia dell'osteoporosi. II dolore osteoarticolare e la limitazione funzionale che ne consegue peggiorano la perdita di massa e forza muscolari.

L'attività fisica, praticata regolarmente, interrompe questo circolo vizioso in quanto:

- determina una riduzione dei livelli della citochina infiammatoria IL-6, che sembra svolgere un ruolo di primo piano nella fisiopatologia della sarcopenia e nel determinismo della disabilità;

- specie se associata a supplementazione dietetica, aumenta la forza e la massa muscolari anche nei molto anziani ospiti delle nursing home;

- è in grado di aumentare il consumo di ossigeno anche del muscolo invecchiato, di stimolare la produzione di IGF-1 da parte del muscolo stesso e di migliorarne il trofismo;

- ha un effetto positivo sulla perdita minerale ossea e sulle conseguenze dell'osteoporosi;

- ha prodotto risultati positivi anche negli anziani fragili con preesistente compromissione della performance motoria.

Le alterazioni del sistema muscoloscheletrico nel corso dell'invecchiamento sono state descritte in recenti rassegne bibliografiche $[39,40]$.

\section{Senescenza del sistema nervoso centrale}

Gli aspetti anatomici sono:

- diminuzione del volume e del peso del cervello per involuzione della sostanza grigia e, successivamente, della sostanza bianca (riduzione del 13\% nella corteccia, del $35 \%$ nell'ippocampo, del $26 \%$ nella sostanza bianca);

- accumulo diffuso di amiloide, presenza sporadica di placche senili (amiloide organizzata) e "tangle" neurofibrillari, quasi esclusivamente nell'amigdala e nell'ippocampo. Questa evoluzione è modulata da fattori genetici: aumentata espressione dei geni correlati con la flogosi a scapito di quelli correlati con il metabolismo proteico e la sintesi del DNA; aumento delle proteasi e, quindi, della produzione di precursori dell'amiloide; in presenza di apolipoproteinaE4, in soggetti normali, declino mnesico accelerato.

Alla base delle alterazioni anatomiche vi sarebbero vari meccanismi: alterata omeostasi intracellulare del calcio che favorisce apoptosi ed eccitotossicità; riduzione in differenti aree del numero e/o della funzionalità dei recettori colinergici, dopaminergici (riduzione dimostrata con la PET anche nell'uomo parallelamente al deficit mnesico), serotoninergici e glutammatergici, e conseguente alterata reciproca modulazione tra i diversi tipi di trasmissione nervosa; ipoperfusione cerebrale e ridotta autoregolazione del flusso; aumentata sintesi di citochine infiammatorie e aumento dei processi di perossidazione da parte di microglia e astrociti; 
danno neuronale in diverse aree cerebrali da ipercortisolismo relativo.

\section{Conseguenze sulle funzioni cerebrali}

- Deficit della memoria secondaria e rallentamento dei processi ideativi e logico-deduttivi; preservati quelli visuospaziali, il linguaggio e le funzioni prassiche. L'encoding (memorizzazione volontaria di informazioni), a sede frontale, perde la selettività (destra per le immagini, sinistra per le parole) tipica del giovane.

- La funzione intellettiva, è preservata, ma si differenzia rispetto al giovane: la capacità critica e l'esperienza migliorano con l'età, la capacità ideativa e propositiva si riducono. Tuttavia, la creatività può rimanere inalterata, come si può osservare nelle opere d'arte di musicisti e pittori nella loro vecchiaia.

- Il livello di scolarità e l'attività culturale, forse tramite un'azione sulla plasticità neuronale, favoriscono una vecchiaia attiva.

- Turbe del sonno: aumento delle durata delle fasi 1 e 2 e marcata riduzione a carico delle fasi 3 e 4, con ripetuti episodi di risveglio e riduzione della durata della fase REM.

- Alterazioni nell'equilibrio e nel cammino: compaiono in 1 ultraottantenne su 4, sono accompagnate da una progressiva iperintensità della sostanza bianca alla RMN, non correlano con ipertensione o deficit cognitivo.

\section{Invecchiamento vs patologia}

Le differenze tra cervello senile e malattie neurodegenerative, in particolare l'Alzheimer, non sono qualitative, ma quantitative: riguardano l'entità e la distribuzione delle alterazioni.

Sul piano funzionale, la condizione denominata "mild cognitive impairment", nelle sue varianti amnestica e prassica, designa uno stato ad alto rischio di progressione verso l'Alzheimer. Anche la depressione può precedere di vari anni la demenza. Pertanto il limite tra normalità e patologia è spesso sfumato e difficilmente interpretabile a priori. Le turbe del sonno e la sindrome sleep-apnea correlano significativamente con il deterioramento cognitivo. L'incidenza delle cadute aumenta del 30\% dopo i 70 anni; si ritiene che tale incremento rifletta soprattutto problemi neurologici.

\section{Sistema nervoso periferico}

Alterazioni diverse delle fibre della sensibilità dolorifica di tipo $\mathrm{C}$ e di tipo A, come se si trattasse di una peculiare neuropatia periferica, assai frequente nell'età avanzata. Alla diminuzione della funzione neurorecettoriale sarebbero legate anche le alterazioni età-dipendenti della funzione erettile.

Le alterazioni del sistema nervoso nel corso dell'invecchiamento sono state descritte in recenti rassegne bibliografiche [41-45].

\section{Senescenza dell'ematopoiesi}

Principali modificazioni età-dipendenti

- Ridotta risposta degli eritroblasti senili all'eritropoietina.
- Aumento di citochine infiammatorie che inibiscono la produzione dell'eritropoietina da parte del rene e, al contrario, stimolano $\mathrm{i}$ fattori di crescita delle cellule dell'infiammazione.

- Nell'invecchiamento, danni del DNA e/o una progressiva alterazione dei meccanismi di riparazione di tali danni potrebbero essere responsabili dell'eritropoiesi inefficace per un aumento dei fenomeni di apoptosi.

\section{Conseguenze sull'eritropoiesi normale}

La frequenza degli stati di anemizzazione e delle forme mieloproliferative fanno parte del fenotipo della fragilità tipica della vecchiaia e rimandano a una flogosi cronica su base infettiva o neoplastica o legata all'invecchiamento stesso

\section{Invecchiamento vs patologia}

- Nell'anziano con note di fragilità si osserva una correlazione inversa tra livelli sierici di emoglobina e citochine.

- L'alta prevalenza di sindromi mielodisplastiche riflette l'eritropoiesi inefficace.

- L'alta prevalenza di patologie linfoproliferative e specie del mieloma rimanda a un difetto di regolazione dell'emopoiesi.

- La presenza di anemia e anche livelli di emoglobina nei quintili inferiori di normalità si sono dimostrati fattori indipendenti di disabilità negli ultrasettantenni.

Le alterazioni dell'emopoiesi nel corso dell'invecchiamento sono state descritte in recenti rassegne bibliografiche $[46,47]$.

\section{Senescenza del rene}

- Aspetti anatomici: il peso del rene passa da 150-200 g a 30 anni fino a $100-150 \mathrm{~g}$ a 90 anni; il volume si riduce del $40 \%$. La perdita di tessuto prevale nella corticale (glomeruli e tubuli sclerotici: in età giovanile meno dell'1\%, a 80 anni tra il $10 \%$ e il $30 \%$ ) e dipende da modificazioni vascolari: le arteriole afferente ed efferente del glomerulo sono entrambe atrofiche nella corticale; nella parte iuxtamidollare, invece, l'atrofia è asimmetrica con formazione di fistole artero-venose. La conseguenza è un flusso ridotto nella corticale e paradossalmente aumentato nella iuxtamidollare. I tubuli prossimali hanno minore lunghezza e sono presenti diverticoli (causa delle cisti renali particolarmente frequenti nell'anziano?). Nell'interstizio vi è lieve o moderata fibrosi.

- Aspetti funzionali: il flusso renale passa da $600 \mathrm{~mL} / \mathrm{min}$ a 20 anni a $300 \mathrm{~mL} / \mathrm{min}$ a 80 anni per la riduzione etàdipendente della portata cardiaca e le alterazioni delle arterie renali di maggior calibro. Ne consegue una ridotta risposta fisiologica (carico salino) o farmacologica (acetilcolina) nell'anziano rispetto al giovane. Il filtrato glomerulare (FG), stabile dall'adolescenza fino a 35 anni, si riduce di $8-10 \mathrm{~mL} / \mathrm{min} / 1,73 \mathrm{~m}^{2}$ di superficie corporea per decade. Tuttavia, nel $30 \%$ degli anziani seguiti nello studio longitudinale di Baltimora la clearance della creatinina, che sovrastima lievemente il FG, non si è modificata nell'arco di 23 anni. Alla riduzione della clearance della creatinina non si accompagna un pari aumento della creatininemia, che al contrario si riduce a causa della diminuzione della massa magra (sarcopenia). 
- Funzione tubulare: il trasporto tubulare dell'acido paraamino-ippurico e del glucosio diminuisce progressivamente con l'età, ma parallelamente alla caduta del FG. Si tratta, quindi, di un fenomeno secondario alla riduzione etàdipendente del numero dei nefroni. La soglia di secrezione del glucosio aumenta con l'età. Altre conseguenze della caduta del numero dei nefroni sono: la diminuzione del riassorbimento sia degli aminoacidi sia del $\mathrm{Na}^{+}$; la riduzione dell'escrezione degli acidi con conseguente ridotta capacità di rispondere a un carico acido.

- Omeostasi idroelettrolitica: vi è la tendenza a una maggiore perdita di sodio. Infatti l'attività reninica plasmatica è ridotta, specie dopo dieta iposodica e in posizione ortostatica, mentre la risposta dell'aldosterone all'ormone adrenocorticotropo non si modifica. La ridotta risposta dieta iposodica e in posizione ortostatica dipende, quindi, da una scarsa risposta reninica e non da alterazioni del corticosurrene. Nell'anziano i livelli di peptide natriuretico atriale (ANP) sono aumentati (responsabili delle alterazioni nell'omeostasi di $\mathrm{Na}^{+}$oppure ridotta risposta età-dipendente al peptide?). Il potassio totale dell'organismo si riduce e il potassio scambiabile cala del $20 \%$. La diminuzione del FG e la depressione del sistema renina-angiotensina predispongono l'anziano all'iperkaliemia.

- Omeostasi dell'acqua: l'acqua totale corporea diminuisce con l'età (55-60\% a 20 anni, 45-55\% a 80 anni), specie nella donna a causa del maggior aumento della massa grassa. La vasopressina $(A D H)$ basale non distingue l'anziano dal giovane, ma la risposta al carico salino è maggiore nell'anziano. La capacità di concentrare le urine si riduce per varie possibili cause: ridotta risposta all'ADH dei tubuli renali oppure aumento del flusso nella midollare e del carico di soluti nei nefroni residui o diminuita permeabilità all'acqua del dotto collettore. In ultima analisi, sia la ridotta capacità di concentrare sia quella di diluire le urine sotto carico sarebbero dovute alla riduzione numerica dei nefroni e al ridotto FG. La nicturia è un fenomeno frequente. È indipendente dall'ipertrofia prostatica, essendo presente anche nella donna e nell'uomo dopo prostatectomia. È forse legata a un alterato ritmo circadiano dell'ADH e a un eccesivo aumento notturno dell'ANP.

\section{Invecchiamento vs patologia}

La diminuzione dei nefroni e del FG porta a insufficienza renale più rapidamente che nel giovane in presenza di danno renale o ipovolemia (abbassamento della soglia uremica).

L'eliminazione renale dei farmaci idrosolubili, la cui quota prevalente si trova immodificata nelle urine, è in generale ridotta nell'anziano.

Nell'anziano si ha predisposizione a squilibri idroelettrolitici di varia origine, in particolare:

- iponatremia: da riduzione di $\mathrm{Na}^{+}$totale. Ridotta risposta del sistema renina-angiotensina-aldosterone e predisposizione all'iperincrezione di ADH ne favoriscono l'insorgenza in diversi contesti (patologie croniche come cirrosi epatica e scompenso cardiaco, vomito, diarrea);

- ipernatremia (ipovolemica): vi contribuiscono, da una parte, la depressione del sistema renina-angiotensinaaldosterone e, dall'altra, l'ipodipsia, tipica dell'anziano e presente anche dopo carico salino;

- ipopotassiemia: nelle persone anziane è favorita dalla deplezione potassica età-dipendente;
- iperpotassiemia: la depressione del sistema renina-angiotensina-aldosterone e la riduzione del FG portano il rene senile a funzionare in prossimità della soglia di tolleranza per l'escrezione del potassio. Vari fattori (farmaci K-ritentivi, supplementazioni dietetiche con $\mathrm{K}^{+}$, stati di catabolismo muscolare o sanguinamenti con liberazione $\mathrm{di}^{+}$dai globuli rossi) determinano facilmente nell'anziano fragile iperpotassiemie anche gravi, spesso associate a insufficienza renale.

Nell'anziano inoltre si osservano:

- ridotta capacità di termoregolazione: è legata, unitamente ad altre modificazioni della composizione corporea, alla diminuzione dell'acqua totale dell'organismo;

- nicturia: è forse legata a un alterato ritmo circadiano dell'ADH e a un eccesivo aumento notturno dell'ANP. Può quindi essere indipendente dall'ipertrofia prostatica o da altri problemi urologici.

Le alterazioni del rene nel corso dell'invecchiamento sono state descritte in recenti rassegne bibliografiche [48-50].

\section{Senescenza del sistema neuro-immuno-endocrino}

Non si può considerare isolatamente il sistema endocrino perché esso coopera con quello nervoso nel determinare la risposta allo stress, cioè a qualsiasi condizione capace di alterare l'omeostasi cellulare. Fondamentale al riguardo è l'asse ipotalamo-ipofisi-surrene (IIS), in cui il ruolo primario è rivestito dal CRH (Corticotropin-Releasing Hormone), particolarmente rappresentato nei centri nervosi che modulano l'umore, l'ansietà e la risposta allo stress (ipotalamo, amigdala, locus coeruleus e rafe; negli ultimi due centri predominano i neuroni monoaminergici). L'asse neuroendocrino è fortemente correlato con il sistema immunitario. Lo stress acuto può aumentare le difese immunitarie, mentre lo stress cronico le può fortemente deprimere. È noto che lo stress facilita l'insorgenza di malattie infettive. L'asse ipotalamosurrene risulta attivato in presenza di danno tissutale, infiammazione e infezione e una sua alterazione, come nella senescenza, si riflette sulla capacità di risposta a queste situazioni. L'invecchiamento determina un'iperattivazione dell'asse IIS a causa del difetto nel controllo retrogrado (diminuito numero e ridotta funzione di mineralcorticoidi e glucocorticoidi, con conseguente danno neuronale a livello di ipotalamo e ulteriore compromissione del feedback del sistema).

Lo stress cronico determina un invecchiamento pari ad almeno dieci anni, com'è stato dedotto recentemente dall'entità dell'accorciamento dei telomeri. L'invecchiamento patologico peggiora ulteriormente la capacità di risposta allo stress. Per esempio, nella malattia di Alzheimer la secrezione di cortisolo è aumentata. Nel caso dell'invecchiamento normale, cioè privo di malattie importanti, il sistema NIE potrebbe essere stato rimodulato positivamente dalla "ormesi". Per esempio, un precondizionamento con stress di lieve entità (restrizioni periodiche del cibo oppure dell'attività fisica negli animali da esperimento) allunga la vita, riducendo soprattutto il danno da stress ossidativo e favorendo l'adattamento e la plasticità neuronali. Una desincronizzazione dell'asse neuro-immuno-endocrino sarebbe alla base dei disturbi del sonno, assai frequenti nell'età avanzata. 
Per le alterazioni del sistema immunoendocrino nel corso dell'invecchiamento si rimanda alle rassegne bibliografiche generali [1-13].

\section{Bibliografia}

[1] Bauer ME, Jeckel CM, Luz C. The role of stress factors during aging of the immune system. Ann N Y Acad Sci 2009;1153: 139-52.

[2] Capri M, Monti D, Salvioli S, Lescai F, Pierini M, Altilia S, et al. Complexity of anti-immunosenescence strategies in humans. Artif Organs 2006;30(10):730-42.

[3] Cevenini E, Caruso C, Candore G, Capri M, Nuzzo D, Duro G, et al. Age-related inflammation: the contribution of different organs, tissues and systems. How to face it for therapeutic approaches. Curr Pharm Des 2010;16(6):609-18.

[4] Chung HY, Cesari M, Anton S, Marzetti E, Giovannini S, Seo AY, et al. Molecular inflammation: underpinnings of aging and agerelated diseases. Ageing Res Rev 2009;8(1):18-30.

[5] De Martinis M, Franceschi C, Monti D, Ginaldi L. Apoptosis remodeling in immunosenescence: implications for strategies to delay ageing. Curr Med Chem 2007;14(13):1389-97.

[6] De Martinis M, Franceschi C, Monti D, Ginaldi L. Inflammation markers predicting frailty and mortality in the elderly. Exp Mol Pathol 2006;80(3):219-27.

[7] Giunta B, Fernandez F, Nikolic WV, Obregon D, Rrapo E, Town T, et al. Inflammaging as a prodrome to Alzheimer's disease. J Neuroinflammation 2008;5:51.

[8] Olivieri F, Antonicelli R, Cardelli M, Marchegiani F, Cavallone L, Mocchegiani E, et al. Genetic polymorphisms of inflammatory cytokines and myocardial infarction in the elderly. Mech Ageing Dev 2006;127(6):552-9.

[9] Ostan R, Bucci L, Capri M, Salvioli S, Scurti M, Pini E, et al. Immunosenescence and immunogenetics of human longevity. Neuroimmunomodulation 2008;15(4-6):224-40.

[10] Perry VH, Cunningham C, Holmes C. Systemic infections and inflammation affect chronic neurodegeneration. Nat Rev Immunol 2007;7(2):161-7.

[11] Sansoni P, Vescovini R, Fagnoni F, Biasini C, Zanni F, Zanlari L, et al. The immune system in extreme longevity. Exp Gerontol 2008;43(2):61-5.

[12] Teeling JL, Perry VH. Systemic infection and inflammation in acute CNS injury and chronic neurodegeneration: underlying mechanisms. Neuroscience 2009;158(3):1062-73.

[13] Vasto S, Carruba G, Lio D, Colonna-Romano G, Di Bona D, Candore $\mathrm{G}$, et al. Inflammation, ageing and cancer. Mech Ageing Dev 2009;130(1-2):40-5.

[14] Meyer KC. Aging. Proc Am Thorac Soc 2005;2(5):433-9.

[15] Rennard SI, Maciewicz RA. Development and aging: susceptibility to COPD. Proc Am Thorac Soc 2009;6:7.

[16] Bellia V, Antonelli Incalzi R (eds). Respiratory Diseases in the Elderly. Eur Respir Monogr 2009. p. 43.

[17] Rabe KF, Hurd S, Anzueto A, Barnes PJ, Buist SA, Calverley P, et al., Global Initiative for Chronic Obstructive Lung Disease. Global strategy for the diagnosis, management, and prevention of chronic obstructive pulmonary disease: GOLD executive summary. Am J Respir Crit Care Med 2007; 176(6):532-55.

[18] Gooneratne NS, Patel NP, Corcoran A. Chronic obstructive pulmonary disease diagnosis and management in older adults. J Am Geriatr Soc 2010;58:1153-62.

[19] Fabbri LM, Luppi F, Beghé B, Rabe KF. Complex chronic comorbidities of COPD. Eur Respir J 2008;31(1):204-12.

[20] Boyd CM, Darer J, Boult C, Fried LP, Boult L, Wu AW. Clinical practice guidelines and quality of care for older patients with multiple comorbid diseases: implications for pay for performance. JAMA 2005;294(6):716-24.
[21] Gibson PG, McDonald VM, Marks GB. Asthma in older adults. Lancet 2010;376(9743):803-13.

[22] Blanchard EM, Arnaoutakis K, Hesketh PJ. Lung cancer in octogenarians. J Thorac Oncol 2010;5(6):909-16.

[23] Selman M, Spagnolo P, Richeldi L. Interstitial lung disease in the elderly. In: Bellia V, Antonelli Incalzi R (eds). Respiratory Diseases in the Elderly. Eur Respir Monogr 2009; 43:Chapt 11.

[24] Cottin V, Le Pavec J, Prévot G, Mal H, Humbert M, Simonneau G, et al., GERM"O"P. Pulmonary hypertension in patients with combined pulmonary fibrosis and emphysema syndrome. Eur Respir J 2010;35(1):105-11.

[25] Ferrari AU, Radaelli A, Centola M. Invited review: aging and the cardiovascular system. J Appl Physiol 2003;95(6):2591-7.

[26] Capell BC, Collins FS, Nabel EG. Mechanisms of cardiovascular disease in accelerated aging syndromes. Circ Res 2007;101(1): $13-26$.

[27] Costopoulos C, Liew TV, Bennett M. Ageing and atherosclerosis: Mechanisms and therapeutic options. Biochem Pharmacol 2008;75(6):1251-61.

[28] Libby P, Ridker PM, Hansson GK, Leducq Transatlantic Network on Atherothrombosis. Inflammation in atherosclerosis: from pathophysiology to practice. J Am Coll Cardiol 2009;54(23): 2129-38.

[29] Feinstein SB. Diabetes mellitus and noninvasive imaging of atherosclerosis. Am J Cardiol 2007;99(4A):89-95B.

[30] Ferdinandy P, Schulz R, Baxter GF. Interaction of cardiovascular risk factors with myocardial ischemia/reperfusion injury, preconditioning, and postconditioning. Pharmacol Rev 2007;59(4): 418-58.

[31] Foresta C, Caretta N, Corona G, Fabbri A, Francavilla S, Jannini $\mathrm{E}$, et al. Clinical and metabolic evaluation of subjects with erectile dysfunction: a review with a proposal flowchart. Int J Androl 2009;32(3):198-211.

[32] Hofbauer LC, Brueck CC, Shanahan CM, Schoppet M, Dobnig H. Vascular calcification and osteoporosis - From clinical observation towards molecular understanding. Osteoporos Int 2007;18(3):251-9.

[33] Li JJ, Zhu CG, Yu B, Liu YX, Yu MY. The role of inflammation in coronary artery calcification. Ageing Res Rev 2007;6(4): 263-70.

[34] Libby P. Inflammation and cardiovascular disease mechanisms. Am J Clin Nutr 2006;83(2):456-60.

[35] Pepine CJ, Nichols WW. The pathophysiology of chronic ischemic heart disease. Clin Cardiol 2007;30(2 Suppl 1):14-9.

[36] Spinetti G, Kraenkel N, Emanueli C, Madeddu P. Diabetes and vessel wall remodelling: from mechanistic insights to regenerative therapies. Cardiovasc Res 2008;78(2):265-73.

[37] Vanhoutte PM. Endothelial dysfunction: the first step toward coronary arteriosclerosis. Circ J 2009;73(4):595-601.

[38] Wong LS, Oeseburg H, de Boer RA, van Gilst WH, van Veldhuisen DJ, van der Harst P. Telomere biology in cardiovascular disease: the TERC $-1-$ mouse as a model for heart failure and ageing. Cardiovasc Res 2009;81(2):244-52.

[39] Freemont AJ, Hoyland JA. Morphology, mechanisms and pathology of musculoskeletal ageing. J Pathol 2007;211(2): 252-9.

[40] Barbieri M, Ferrucci L, Ragno E, Corsi A, Bandinelli S, Bonafè M, et al. Chronic inflammation and the effect of IGF-I on muscle strength and power in older persons. Am J Physiol Endocrinol Metab 2003;284(3):E481-7.

[41] Chakour MC, Gibson SJ, Bradbeer M, Helme RD. The effect of age on A delta- and $\mathrm{C}$-fibre thermal pain perception. Pain 1996;64(1):143-52.

[42] Fjell AM, Walhovd KB. Structural brain changes in aging: courses, causes and cognitive consequences. Rev Neurosci 2010;21(3):187-221.

[43] Anderton BH. Ageing of the brain. Mech Ageing Dev 2002;123(7): 811-7. 
[44] Logan JM, Sanders AL, Snyder AZ, Morris JC, Buckner RL. Underrecruitment and nonselective recruitment: dissociable neural mechanisms associated with aging. Neuron 2002;33(5):827-40.

[45] Mayeux R, Small SA, Tang M, Tycko B, Stern Y. Memory performance in healthy elderly without Alzheimer's disease: effects of time and apolipoprotein-E. Neurobiol Aging 2001;22(4):683-9.

[46] Ershler WB. Biological interactions of aging and anemia: a focus on cytokines. J Am Geriatr Soc 2003;51(3 Suppl):S18-21.

[47] Rothstein G. Disordered hematopoiesis and myelodysplasia in the elderly. J Am Geriatr Soc 2003;51(3 Suppl):S22-6.
[48] Davis PJ, Davis FB. Water excretion in the elderly. Endocrinol Metab Clin North Am 1987;16(4):867-75.

[49] Lindeman RD, Tobin J, Shock NW. Longitudinal studies on the rate of decline in renal function with age. J Am Geriatr Soc 1985;33(4):278-85.

[50] Tsunoda K, Abe K, Goto T, Yasujima M, Sato M, Omata K, et al. Effect of age on the renin-angiotensin-aldosterone system in normal subjects: simultaneous measurement of active and inactive renin, renin substrate, and aldosterone in plasma. $\mathrm{J}$ Clin Endocrinol Metab 1986;62(2):384-9. 


\title{
Linee guida sulla BPCO non associata a comorbilità croniche
}

\author{
Lorenzo Corbetta, Fabrizio Luppi, Raffaele A. Incalzi
}

\section{Messaggi chiave}

- La broncopneumopatia cronica ostruttiva (BPCO) è una malattia respiratoria cronica prevenibile e trattabile che può presentarsi singolarmente o associata a significativi effetti e comorbilità extrapolmonari che ne aumentano la complessità.

- Il fattore individuale che è meglio documentato è il deficit ereditario severo di alfa-1-antitripsina. Il principale fattore ambientale è rappresentato dal fumo di sigaretta, al punto che le conoscenze sulla BPCO riguardano quasi esclusivamente i pazienti fumatori.

- La diagnosi di BPCO si basa sulla presenza, all'anamnesi, di fattori di rischio e sulla documentazione con spirometria di una persistente riduzione del flusso aereo.

- La presenza di ostruzione delle vie aeree non reversibile viene definita dalla presenza di un rapporto VEMS/CVF < 0,7 misurato 30 minuti dopo la somministrazione di $400 \mu \mathrm{g}$ di salbutamolo per via inalatoria.

- La classificazione di gravità della BPCO attualmente include 4 stadi identificati sulla base della percentuale di riduzione rispetto al teorico del VEMS postbroncodilatatore: Stadio I - BPCO lieve; Stadio II - BPCO moderata; Stadio III - BPCO grave; Stadio IV - BPCO molto grave.
- Il trattamento della BPCO stabile dovrebbe essere caratterizzato da un progressivo incremento della terapia in relazione alla gravità della malattia e si basa su interventi educazionali (compresa la cessazione del fumo), farmacologici (prevalentemente broncodilatatori con l'aggiunta di steroidi inalatori negli stadi moderati/gravi) e non farmacologici (riabilitazione, ossigenoterapia e, più raramente, trattamenti chirurgici ed endoscopici di riduzione volumetrica polmonare).

- Le riacutizzazioni rappresentano eventi frequenti nella storia naturale della BPCO.

- I broncodilatatori a rapida insorgenza d'azione

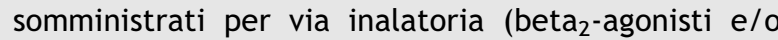
anticolinergici) e i glucocorticoidi sistemici, preferibilmente orali, sono i farmaci di scelta per il trattamento domiciliare delle riacutizzazioni della BPCO. I pazienti che presentano riacutizzazioni con segni clinici di infezione bronchiale (cioè aumento del volume e viraggio di colore dell'escreato e/o febbre) possono trarre beneficio da una terapia antibiotica.

- Le riacutizzazioni con insufficienza respiratoria vengono trattate con buona percentuale di successo mediante ventilazione meccanica non invasiva.
Negli ultimi anni la BPCO ha ricevuto un'attenzione maggiore a livello mondiale a seguito della segnalazione, da parte delle istituzioni sanitarie internazionali, che mortalità e morbilità associate a questa malattia cronica erano in progressivo aumento. Dal 2001, in seguito alla pubblicazione delle prime linee guida internazionali da parte del Progetto GOLD (Global Initiative for Obstructive Lung Disease), sono state approntate le versioni nazionali nei vari Paesi. Il presente contributo riporta le raccomandazioni dell'adattamento italiano 2009 del Progetto Mondiale BPCO (www.goldcopd.org) basato 
sull'aggiornamento 2008 delle linee guida internazionali GOLD (www.goldcopd.org) ed ERS/ATS del 2004 (www. ersnet.org) [1-3].

\section{Definizione}

La BPCO è una malattia respiratoria cronica prevenibile e trattabile associata a significativi effetti e comorbilità extrapolmonari che possono contribuire alla sua gravità.

Le alterazioni broncopolmonari sono costituite da un'ostruzione al flusso persistente ed evolutiva legata a rimodellamento delle vie aeree periferiche ed enfisema.

L'ostruzione al flusso, il rimodellamento delle vie aeree periferiche e l'enfisema sono dovuti a un'abnorme risposta infiammatoria (delle vie aeree e del parenchima polmonare) e sistemica all'inalazione del fumo di sigaretta o di altri inquinanti (come polveri, gas, vapori irritanti) e a infezioni ricorrenti [1].

\section{Fattori di rischio}

I fattori di rischio per BPCO comprendono i fattori individuali e l'esposizione ad agenti ambientali. La malattia di solito deriva dall'interazione fra questi due diversi tipi di fattori.

Il fattore individuale meglio documentato è il deficit ereditario severo di alfa-1-antitripsina [4]. Sono state identificate altre condizioni genetiche potenzialmente candidate nella patogenesi della BPCO, tra cui il deficit intermedio di alfa-1-antitripsina.

I principali fattori ambientali (tabella 1) sono rappresentati dal fumo di sigaretta, attivo e passivo, da polveri e sostanze chimiche (vapori, irritanti, fumi) in ambiente professionale, dall'inquinamento degli ambienti interni ed esterni.

\section{Fumo di sigaretta}

Il fumo di sigaretta è la principale causa di BPCO. In Italia fumano 12,2 milioni di persone (il 28,6\% dei maschi e il 20,3\% delle femmine). L'Organizzazione Mondiale della Sanità stima nel mondo oltre 1 miliardo di fumatori, con un aumento oltre 1,6 miliardi nel 2025. Nei Paesi a basso-medio tenore di vita la percentuale di fumatori sta crescendo in modo allarmante. Circa il 30\% dei fumatori (> 10 pack-years: numero di sigarette giornaliere $x$ anni di fumo/20) di età superiore a 40 anni presenta una limitazione al flusso aereo. Il $40-50 \%$ circa dei fumatori sviluppa BPCO [5].

\section{Diagnosi e monitoraggio}

La diagnosi di BPCO si basa sulla presenza, all'anamnesi, di fattori di rischio e sulla documentazione di una persistente riduzione del flusso aereo, in presenza/assenza di sintomi, dopo aver escluso altre cause di broncostruzione cronica. La spirometria rappresenta il test strumentale maggiormente standardizzato, più riproducibile e oggettivo e costituisce il gold standard per la diagnosi e l'inquadramento della BPCO. Gli operatori sanitari che trattano pazienti con BPCO dovrebbero avere la possibilità di eseguire una spirometria senza difficoltà.

\section{Indicazioni alla spirometria}

I soggetti con:

- presenza di fattori di rischio (congeniti e acquisiti),

- e/o dispnea cronica,

- e/o progressiva intolleranza all'esercizio fisico,

- e/o con tosse cronica ed espettorato, dovrebbero essere sottoposti a spirometria per valutare la presenza di riduzione del flusso aereo.

L'ostruzione delle vie aeree non reversibile viene definita dalla presenza di un rapporto VEMS/CVF $<0,7$ misurato 30 minuti dopo la somministrazione di $400 \mu \mathrm{g}$ di salbutamolo per via inalatoria $[1,3]$. Poiché questo cut-off fisso non considera l'andamento fisiologico correlato all'età, determinando una sottostima della riduzione del flusso aereo nei soggetti giovani e una sovrastima nei soggetti di età superiore a 50 anni, la task force ATS/ERS per la standardizzazione della spirometria raccomanda di basare la diagnosi sul limite inferiore della norma (LLN) $\left(<5^{\circ}\right.$ percentile del valore teorico) [6].

In presenza di ostruzione come qui definita, la gravità dell'ostruzione viene valutata sulla base del valore percentuale del VEMS postbroncodilatatore rispetto valore teorico (tabella 2).

Tabella 1 Fattori di rischio.

\begin{tabular}{ll}
\hline Ambientali & Individuali \\
\hline Fumo di sigaretta & Deficit di alfa-1-antitripsina \\
\hline Fumo attivo & Altri fattori genetici \\
\hline Fumo passivo & Stress ossidativo \\
\hline Fumo materno & Età \\
\hline Inquinamento esterno e interno & Comorbilità \\
\hline Esposizione professionale (polveri organiche/inorganiche) & Sesso femminile \\
\hline Stato socioeconomico/povertà & Basso peso alla nascita, scarso accrescimento polmonare \\
\hline Nutrizione & \\
\hline Infezioni & \\
\hline
\end{tabular}


Tabella 2 Classificazione spirometrica di gravità della BPCO.

\begin{tabular}{|c|c|c|}
\hline \multicolumn{2}{|c|}{ Stadio } & Caratteristiche \\
\hline 1 & BPCO lieve & VEMS $/$ CFV $<0,7 ;$ VEMS $\leq 80 \%$ del teorico \\
\hline II & BPCO moderata & VEMS $/ C F V<0,7 ; 50 \%<$ VEMS $<80 \%$ \\
\hline III & BPCO grave & VEMS $/ C F V<0,7 ; 30 \%<$ VEMS $<50 \%$ \\
\hline IV & BPCO molto grave & $\begin{array}{l}\text { VEMS } / C F V<0,7 ; \text { VEMS }<30 \% \text { del teorico o VEMS }<50 \% \text { del teorico } \\
\text { in presenza di insufficienza respiratoria }\left(\mathrm{PaO}_{2}<60 \mathrm{mmHg}\right)\end{array}$ \\
\hline
\end{tabular}

Fonti: Progetto Mondiale Broncopneumopatia Cronica Ostruttiva. Aggiornamento 2009 adattamento italiano. http://www.goldcopd.it; Rabe KF, et al. Am J Respir Crit Care Med 2007;176(6):532-55; Celli BR, et al. Eur Respir J 2004;23(6):932-46.

\section{Classificazione di gravità}

La classificazione di gravità della BPCO attualmente include quattro stadi identificati sulla base della spirometria postbroncodilatatore:

- Stadio I - BPCO lieve;

- Stadio II - BPCO moderata;

- Stadio III - BPCO grave;

- Stadio IV - BPCO molto grave.

Non esiste una perfetta correlazione tra il grado di limitazione al flusso aereo e la presenza dei sintomi. La stadiazione spirometrica costituisce un approccio pragmatico finalizzato all'uso pratico e dovrebbe essere considerata solo come uno strumento didattico e un indicatore generale per l'approccio terapeutico iniziale.

Una quinta categoria, Stadio $0-$ A rischio, presente nelle prime linee guida internazionali del 2001, non è attualmente inclusa come stadio della BPCO poiché vi sono evidenze solo incomplete che gli individui che rientrano nella definizione "A rischio" (tosse cronica, espettorazione, spirometria normale) necessariamente progrediscano verso lo Stadio I BPCO Lieve. Tuttavia, resta valida l'importanza del messaggio per la salute pubblica: la tosse cronica e l'espettorazione non normale dovrebbero costituire motivo di ricerca delle/a cause/a sottostanti.

L'impatto della malattia sul singolo paziente non dipende soltanto dal grado di limitazione al flusso aereo, ma anche dalla gravità dei sintomi e da altri fattori concomitanti fra cui le comorbilità (tabella 3).

Tabella 3 Ulteriori fattori determinanti la prognosi nella BPCO.

\begin{tabular}{l}
\hline Dispnea \\
\hline Frequenza e gravità delle riacutizzazioni \\
\hline Grado di intolleranza allo sforzo fisico \\
\hline Malnutrizione $\left(\mathrm{BMI}<21 \mathrm{~kg} / \mathrm{m}^{2}\right)$ \\
\hline Insufficienza respiratoria $\left(\mathrm{PaO}_{2}<60 \mathrm{mmHg}\right)$ \\
\hline Ipercapnia $\left(\mathrm{PaCO}_{2}>45 \mathrm{mmHg}\right)$ \\
\hline Nuore polmonare \\
\hline
\end{tabular}

Fonte: Progetto Mondiale Broncopneumopatia Cronica Ostruttiva. Aggiornamento 2009 adattamento italiano. http://www. goldcopd.it.

\section{Altri esami raccomandati per la diagnosi}

- Misura dei volumi polmonari: capacità vitale inspiratoria, capacità inspiratoria, volume residuo, capacità polmonare totale (CPT). La CPT è necessaria per la valutazione differenziale tra pattern ostruttivo atipico e restrittivo. Può essere ottenuta con metodo pletismografico o con il metodo della diluizione dell'elio in circuito chiuso (le due metodiche non sono sovrapponibili a causa della diversa tecnica impiegata: la prima misura tutta l'aria contenuta nei polmoni, la seconda solo quella contenuta nelle sezioni comunicanti con le vie aeree).

- Test del transfer del CO: per valutare il danno parenchimale e l'alterata distribuzione della ventilazione alveolare. Una riduzione del $\mathrm{CO}>50 \%$ del teorico indica presenza di enfisema.

- Pulsossimetria $\left(\mathrm{SaO}_{2}\right)$ : per misurare la desaturazione arteriosa a riposo, sotto sforzo e nel sonno, e per selezionare $i$ pazienti in cui è indicata l'emogasanalisi arteriosa.

- Emogasanalisi arteriosa: per diagnosticare l'insufficienza respiratoria e/o l'ipercapnia quando $\mathrm{HbSaO}_{2}<95-96 \%$.

- Test da sforzo al cicloergometro: per valutare la tolleranza all'esercizio fisico e la disabilità in previsione di una riabilitazione respiratoria.

- Test di valutazione della forza dei muscoli respiratori: pressione respiratoria massimale, pressione transdiaframmatica ecc.

- Polisonnografia (in pazienti con sintomi suggestivi di apnee notturne, ipossiemia o insufficienza cardiaca destra non motivati dalla gravità della BPCO).

- Esame emocromocitometrico: per valutare la presenza di poliglobulia.

- Elettrocardiogramma ed ecocardiografia: nei pazienti con insufficienza respiratoria per valutare l'ipertensione sistolica polmonare e il cuore polmonare cronico.

- BODE index.

I parametri di seguito riportati, assieme al VEMS (percentuale rispetto al teorico), permettono di calcolare il BODE index, che è fattore prognostico di mortalità $[7,8]$.

- Test del cammino (6 minuti): distanza percorsa camminando alla massima velocità per 6 minuti.

- Body Mass Index (BMI): peso (kg) diviso altezza al quadrato $\left(\mathrm{m}^{2}\right)$.

- Grado di dispnea cronica (scala del Medical Research Council):

- 1 - dispnea per esercizio intenso;

- 2 - dispnea camminando a passo veloce in pianura 0 camminando in leggera salita; 
- 3 - impossibilità a mantenere il passo dei coetanei o necessità di fermarsi per la dispnea camminando al proprio passo in pianura;

- 4 - necessità di fermarsi per la dispnea dopo aver percorso $100 \mathrm{~m}$ o dopo pochi minuti in pianura;

- 5 - impossibilità a uscire di casa a causa della dispnea.

\section{Esami radiologici}

- La radiografia del torace è raramente diagnostica nella BPCO lieve/moderata, ma fornisce dettagli interessanti nelle forme più avanzate; può essere utile nella diagnosi differenziale o nella diagnosi di patologie concomitanti. Le alterazioni radiologiche più comunemente associate alla BPCO sono: segni di iperinsufflazione (come appiattimento del diaframma e aumento dello spazio retrosternale); ipertrasparenza dei polmoni; rarefazione e/o redistribuzione del disegno vascolare; bolle enfisematose; marcato ispessimento delle pareti bronchiali. Possono essere individuate bronchiectasie varicoidi o sacciformi, a contenuto aereo oppure contenenti fluido o livelli idroaerei. Possono essere visibili i segni di ipertensione arteriosa polmonare con cuore polmonare cronico. La radiografia del torace è utile nella valutazione delle gravi riacutizzazioni della BPCO (per esempio, scompenso cardiaco, polmoniti infettive, pneumotorace).

- La tomografia computerizzata (TC) del torace non è consigliata quale indagine di routine della BPCO. La TC trova utili applicazioni in casi selezionati: pianificazione di un intervento chirurgico [9]; sospetta associazione di BPCO e di patologia infiltrativa diffusa "interstiziale"; deficit funzionale e/o riduzione della DLCO non spiegabili sulla base del quadro clinico e del radiogramma; deficit di alfa-1antitripsina (prognosi e follow-up); diagnosi differenziale tra le varie patologie (per esempio, enfisema vs bronchiolite); valutazione di riacutizzazioni severe, specie per escludere embolia polmonare (TC spirale con contrasto) e diagnosi di patologia concomitante.

- La TC ad alta risoluzione (HRCT) consente la diagnosi preclinica dell'enfisema; aiuta a evidenziare il contributo relativo dell'ostruzione delle vie aeree e della distruzione enfisematosa alla limitazione del flusso aereo, caratteristica della BPCO; consente di valutare tipo prevalente di enfisema, sede, gravità o estensione (score visivo o TC quantitativa), di valutare la prognosi (insieme con altri indici clinico-funzionali) e di eseguire un follow-up non invasivo.

\section{Dosaggio di alfa-1-antitripsina}

Il test diagnostico per il deficit di alfa-1-antitripsina è indicato:

- nei soggetti con BPCO (con enfisema) senza altri evidenti fattori di rischio e/o a insorgenza precoce (età $<45$ anni);

- in fratelli/sorelle di soggetti con deficit di alfa-1-antitripsina (livello evidenza A).

\section{Trattamento della BPCO stabile}

\section{Obiettivi}

- Prevenire la progressione della malattia.
- Migliorare i sintomi.

- Migliorare la tolleranza allo sforzo.

- Migliorare lo stato di salute.

- Prevenire e curare le riacutizzazioni.

- Prevenire e trattare le complicanze.

- Ridurre la mortalità.

- Minimizzare gli effetti collaterali della terapia.

Il trattamento della BPCO stabile dovrebbe essere caratterizzato da un progressivo incremento della terapia in relazione alla gravità della malattia e si basa su interventi educazionali (compresa la cessazione del fumo), interventi farmacologici e interventi non farmacologici.

\section{Azioni contro il fumo di sigaretta e altre azioni preventive}

La cessazione del fumo è considerato l'intervento più efficace ed economicamente più vantaggioso, nella maggior parte delle persone, per ridurre il rischio di sviluppare la BPCO e arrestarne la progressione (Evidenza A).

Importanti obiettivi per prevenire l'insorgenza e l'evoluzione della BPCO sono la riduzione dell'esposizione complessiva al fumo di tabacco, alle polveri, ai fumi, ai gas in ambito professionale, all'inquinamento degli ambienti interni ed esterni. In particolare vanno incoraggiate le normative che vietino il fumo negli ambienti pubblici e nei luoghi di lavoro e va sensibilizzata la popolazione sulla necessità di non fumare nelle abitazioni.

Un trattamento per la dipendenza dall'abitudine tabagica è efficace e dovrebbe essere proposto a ogni fumatore (Evidenza A) [10]. Alcuni tipi di intervento sono risultati $i$ più efficaci (Evidenza $A$ ): il sostegno comportamentale e la terapia farmacologica.

Terapia farmacologica per la cessazione del fumo Sono disponibili diverse terapie farmacologiche efficaci (Evidenza A) e almeno una di queste dovrebbe essere somministrata in aggiunta ai consigli pratici laddove necessario e in assenza di controindicazioni.

Sono considerati di prima scelta i seguenti farmaci: terapia sostitutiva nicotinica, bupropione a lento rilascio e vareniclina (Evidenza A).

\section{Educazione del paziente e somministrazione dei farmaci}

L'educazione sanitaria del paziente affetto da BPCO può migliorare la sua capacità di gestire la malattia [11]. È inoltre utile per raggiungere altri obiettivi, quale la cessazione dall'abitudine tabagica (Evidenza $A$ ).

\section{Terapia farmacologica}

- La terapia farmacologica regolare è importante per ridurre le riacutizzazioni, migliorare i sintomi, migliorare la qualità di vita, aumentare la tolleranza allo sforzo (Evidenza $A$ ) e può aumentare la sopravvivenza (Evidenza $B$ ).

- I risultati di due grandi trial clinici recentemente pubblicati indicano che le terapie inalatorie attualmente disponibili possono migliorare la prognosi nei pazienti con BPCO $[12,13]$. 


\section{Broncodilatatori}

- I broncodilatatori hanno un ruolo centrale nel trattamento della BPCO.

- La via di somministrazione raccomandata è quella inalatoria.

- I broncodilatatori a lunga durata d'azione sono i farmaci più efficaci nel trattamento regolare (Evidenza A) per controllare o migliorare i sintomi e lo stato di salute.

- I beta $a_{2}$-agonisti e gli anticolinergici a lunga durata d'azione sono i broncodilatatori di prima scelta (Evidenza A).

- L'aggiunta di teofillina, in considerazione dei possibili effetti collaterali e della necessità di monitoraggio dei livelli plasmatici, deve essere valutata nel singolo paziente in termini di rapporto rischio/beneficio.

- La somministrazione di broncodilatatori a lunga durata d'azione (formoterolo, salmeterolo, tiotropio) è più efficace di quella dei farmaci a breve durata d'azione (Evidenza $A$ ) e può migliorare la compliance $[14,15]$.

- L'uso di più broncodilatatori a diverso meccanismo d'azione migliora l'efficacia del trattamento (Evidenza A).

- L'efficacia dei broncodilatatori va valutata in termini sia di miglioramento funzionale (dell'ostruzione bronchiale e/o dell'iperinflazione polmonare) sia di miglioramento dei sintomi, della tolleranza allo sforzo e della qualità di vita (Evidenza A).

- La mancata risposta spirometrica, in presenza di miglioramento soggettivo (sintomi), non è motivo di interruzione del trattamento.

\section{Steroidi inalatori}

Il trattamento regolare con corticosteroidi inalatori è indicato nei pazienti con VEMS $\leq 50 \%$ del teorico (Stadio III - BPCO grave e Stadio IV - BPCO molto grave) con riacutizzazioni frequenti ( 3 o più negli ultimi 3 anni) trattate con corticosteroidi sistemici e/o antibiotici (Evidenza A). Il trattamento regolare con corticosteroidi inalatori dei pazienti con BPCO grave (Stadio III) o molto grave (Stadio IV) determina un miglioramento dei sintomi, della funzione polmonare, della tolleranza allo sforzo e della qualità di vita, nonché una riduzione del numero e della gravità delle riacutizzazioni (Evidenza A).

Terapia combinata con corticosteroidi inalatori + beta $_{2^{-}}$ agonisti a lunga durata d'azione

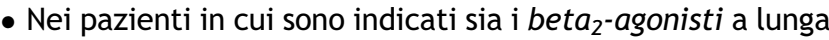
durata d'azione sia i corticosteroidi inalatori (BPCO moderata/grave, molto grave), la somministrazione di questi farmaci in combinazione mostra una migliore efficacia su diversi parametri clinico-funzionali rispetto ai singoli componenti (Evidenza A).

- L'uso delle combinazioni precostituite (salmeterolo + fluticasone, formoterolo + budesonide) può migliorare l'aderenza al trattamento (Evidenza $C$ ).

- In un recente studio clinico prospettico randomizzato e controllato condotto su oltre 6.000 pazienti [13] l'associazione salmeterolo + fluticasone ha ridotto la mortalità (obiettivo primario dello studio) del $17,5 \%$, riduzione ai limiti della significatività statistica.

- A supporto dei precedenti studi condotti in pazienti più gravi, nello stesso studio [13] tale combinazione è risultata superiore ai singoli componenti e al placebo su alcuni importanti parametri clinici (stato di salute, frequenza delle riacutizzazioni, uso di steroidi orali) in pazienti con
VEMS prebroncodilatatore $<60 \%$ e senza storia di frequenti riacutizzazioni.

- I risultati [13] supportano l'uso di questa terapia in pazienti di gravità spirometrica minore rispetto a quelli indicati dalle linee guida precedenti (VEMS prebroncodilatatore $<$ $60 \%$ ). Tale raccomandazione è stata approvata dall'autorità regolatoria europea (EMEA) e italiana (AIFA).

\section{Altri trattamenti}

- Inibitori delle fosfodiesterasi-4 (PDE-4): agiscono aumentando la concentrazione cellulare dell'AMP ciclico ed esplicando effetti antinfiammatori. In studi randomizzati e controllati gli inibitori delle PDE-4, cilomilast e roflumilast, non ancora in commercio nel nostro Paese, hanno permesso di intravedere qualche potenzialità allo scopo di attenuare il declino della funzione respiratoria e le riacutizzazioni della malattia $[15,16]$.

- La vaccinazione antinfluenzale riduce del 50\% la comparsa di patologie gravi e la mortalità (Evidenza A) [17].

- Le vaccinazioni antinfluenzale e antipneumococcica per via parenterale dovrebbero essere proposte a tutti i pazienti con BPCO (Evidenza B) [18].

- Gli antiossidanti possono ridurre la frequenza delle riacutizzazioni nei soggetti non in trattamento regolare con steroidi inalatori (Evidenza B) [19].

- Gli immunomodulanti possono ridurre la frequenza delle riacutizzazioni, tuttavia non vi sono sufficienti evidenze per raccomandarne l'uso [20].

- Per altri farmaci (mucolitici, antitussivi, stimolanti respiratori ecc.) l'evidenza di efficacia è scarsa [21].

\section{Terapie non farmacologiche}

- Riabilitazione.

- Terapia chirurgica.

- Ossigenoterapia lungo termine.

- Ventilazione meccanica a lungo termine.

\section{Riabilitazione}

Il trattamento riabilitativo strutturato è in grado di determinare un miglioramento della capacità di esercizio fisico, della dispnea e della qualità della vita (Evidenza $A)$ indipendentemente dal livello di ostruzione delle vie aeree (Evidenza $B$ ) e dalla presenza di insufficienza respiratoria (Evidenza $C$ ).

Risultati positivi sono riscontrati in programmi in regime di degenza, di day-hospital e domiciliare (Evidenza A). L'opzione migliore può dipendere da fattori legati al paziente.

L'effetto positivo ottenuto in seguito a riabilitazione si osserva in funzione della durata della riabilitazione e del numero di sedute e tende a mantenersi almeno entro 1 anno dal termine del programma (Evidenza $B$ ).

L'effetto positivo dell'allenamento dei muscoli respiratori appare limitato a pazienti con forza inspiratoria maggiormente compromessa, ma può essere prolungato nel tempo (Evidenza B)

Lo stato nutrizionale espresso dal peso corporeo (BMI; Ideal Body Weight, IBW) è un fattore indipendente di influenza sulla sopravvivenza e su misure di outcome di trattamento (Evidenza $A$ ).

L'implementazione nutrizionale non appare una componente determinante per la sopravvivenza e il miglioramento funzionale del paziente (Evidenza $C$ ). 
Un programma di riabilitazione deve prevedere un numero di sessioni minime efficaci (per quanto noto a oggi non inferiore a 12) (Evidenza $B$ ); maggiore è la durata del trattamento, più esso risulterà efficace (Evidenza $B)$ [22].

\section{Terapia chirurgica}

- La bullectomia può migliorare sintomi e funzione respiratoria in casi altamente selezionati (Evidenza C).

- La riduzione chirurgica del volume polmonare è controindicata in pazienti ad alto rischio (VEMS $<20 \%$ e/o DLCO $<$ $20 \%$ del teorico) (Evidenza $B$ ). Tuttavia, è una terapia che può aumentare la sopravvivenza in pazienti selezionati (con predominanza di enfisema ai lobi superiori associata a ridotta tolleranza allo sforzo) (Evidenza B) [23].

- La riduzione volumetrica dell'enfisema per via broncoscopica si propone come scelta alternativa (Evidenza C) [24].

- Il trapianto polmonare per enfisema può migliorare la qualità di vita e la funzionalità in casi selezionati (Evidenza $C)$, ma non migliora la sopravvivenza a lungo termine (Evidenza C) [25].

\section{Ossigenoterapia a lungo termine}

L'ossigenoterapia a lungo termine ( $\geq 15$ ore/die) nei pazienti con insufficienza respiratoria cronica si è dimostrata efficace nell'aumentare la sopravvivenza (Evidenza A).

Si suggerisce un utilizzo più vicino possibile alle 24 ore/die (Evidenza A).

L'efficacia dell'ossigenoterapia a lungo termine in pazienti con ipossiemia intermittente (notturna, da sforzo) non è provata. L'ossigenoterapia a lungo termine consente di ridurre i giorni di ospedalizzazione del $43,5 \%$, le percentuali di ricovero del $23,8 \%$ e il numero di pazienti con almeno un'ospedalizzazione del 31,2\% [26].

\section{Ventilazione meccanica a lungo termine}

La ventilazione meccanica non invasiva a pressione positiva (NPPV) in aggiunta all'ossigenoterapia a lungo termine può migliorare gli scambi respiratori, i sintomi, la qualità di vita, ma non la sopravvivenza, in pazienti ipercapnici con BPCO stabile (Evidenza B) [27].

\section{Gestione delle riacutizzazioni}

\section{Definizione}

La riacutizzazione è definita come un peggioramento della sintomatologia tale da comportare una modificazione della terapia $[28,29]$.

Peggioramento dei sintomi:

- tosse;

- dispnea;

- variazioni qualitative e/o quantitative dell'espettorato.

Criteri accessori:

- variazione all'esame obiettivo polmonare;

- febbre;

- edemi declivi.

\section{Eziologia}

Parte delle riacutizzazioni della BPCO ha eziologia sconosciuta. Le infezioni sembrano tuttavia avere un ruolo significativo.
- Virus respiratori: fino al $50 \%$ dei casi nelle riacutizzazioni gravi.

- I batteri più frequentemente riscontrati sono $H$. influenzae, S. pneumoniae, M. catarrhalis.

- Nuovi ceppi dello stesso batterio aumentano il rischio di riacutizzazioni.

- L'inquinamento atmosferico (biossido di azoto, particolato - PM10, biossido di zolfo, ozono) può essere causa di riacutizzazione.

- Sono caratterizzate da aumento dell'infiammazione delle vie aeree.

- Sono più frequenti in presenza di colonizzazione batterica e nei pazienti con maggiore infiammazione bronchiale in fase di stabilità.

- Sono più gravi nei pazienti con rilevante ostruzione bronchiale e nei pazienti con frequenti riacutizzazioni.

- La mortalità nelle ospedalizzazioni può superare il $10 \%$.

\section{Trattamento domiciliare (a prescindere dallo stadio di malattia prima della riacutizzazione)}

I broncodilatatori a rapida insorgenza d'azione somministrati per via inalatoria (beta ${ }_{2}$-agonisti e/o anticolinergici) e i glucocorticoidi sistemici, preferibilmente quelli orali, sono i farmaci di scelta per il trattamento domiciliare delle riacutizzazioni della BPCO (Evidenza A).

I pazienti che presentano riacutizzazioni con segni clinici di infezione bronchiale (cioè aumento del volume e viraggio di colore dell'escreato e/o febbre) possono trarre beneficio da una terapia antibiotica (Evidenza $B$ ).

La scelta dell'antibiotico da utilizzare deve tener conto delle resistenze batteriche a livello locale.

In presenza di sintomi maggiori di riacutizzazione il dosaggio della proteina $C$-reattiva può essere utile per la diagnosi [30,31].

\section{Criteri per la richiesta di valutazione specialistica o di ospedalizzazione}

Le linee guida [1] indicano i seguenti criteri:

- marcato aumento dell'intensità dei sintomi, per esempio comparsa della dispnea a riposo;

- riacutizzazione nel paziente con BPCO classificata come grave;

- comparsa di nuovi segni obiettivi (cianosi, edemi periferici);

- mancata risposta al trattamento o impossibilità di rivalutazione;

- presenza di importanti patologie concomitanti;

- aritmie di nuova insorgenza;

- dubbio diagnostico;

- età avanzata;

- comparsa di disturbo del sensorio;

- non autosufficienza e/o mancato supporto familiare.

\section{Trattamento delle riacutizzazioni del paziente ospedalizzato}

Occorre valutare la gravità dei sintomi e i valori di $\mathrm{PaO}_{2} \mathrm{e}$ $\mathrm{PaCO}_{2}$, la radiografia del torace e l'elettrocardiogramma. 
- Somministrare l'ossigenoterapia fino a raggiungere $\mathrm{SaO}_{2}>$ $90 \%$ e $<96 \%$ (pulsossimetria) ed eseguire l'emogasanalisi dopo 30 minuti.

- Broncodilatatori: aumentare la dose o la frequenza di somministrazione; associare beta ${ }_{2}$-agonisti a rapida insorgenza d'azione e anticolinergici; utilizzare il distanziatore o il nebulizzatore; considerare l'aggiunta di aminofillina per via endovenosa.

- Considerare l'antibioticoterapia.

- Considerare la ventilazione meccanica non invasiva. In ogni caso:

- valutare la nutrizione e il bilancio idrico;

- considerare l'utilizzo di eparina a basso peso molecolare;

- identificare e trattare le possibili comorbilità (insufficienza di altri organi, aritmie);

- monitorare lo stato del paziente.

\section{Riacutizzazione di BPCO con insufficienza respiratoria acuta}

Quadro clinico di riacutizzazione grave (dispnea, tachipnea, respiro paradosso) $+\mathrm{PaO}_{2} / \mathrm{FiO}_{2}<300$ e/o $\mathrm{SaO}_{2}<90 \%$ in aria ambiente, con o senza acidosi respiratoria.

\section{Trattamento dell'insufficienza respiratoria acuta da riacutizzazione di BPCO}

- Terapia medica.

- Ossigenoterapia.

- Assistenza ventilatoria meccanica: non invasiva (NIMV): a pressione positiva (NPPV); a pressione negativa (NPV); invasiva.

\section{Ossigenoterapia}

Il target è mantenere una $\mathrm{PaO}_{2}>60 \mathrm{mmHg}$ senza contestualmente aumentare la $\mathrm{PaCO}_{2}$

- $\mathrm{PaO}_{2}$ e $\mathrm{PaCO}_{2}$ andrebbero nuovamente misurate 30 minuti dopo l'arrivo in reparto.

- La maschera di Venturi garantisce un più accurato controllo della $\mathrm{FiO}_{2}$, ma è meno tollerata delle cannule nasali.

Indicazione alla ventilazione meccanica non invasiva Dispnea a riposo con uso evidente dei muscoli respiratori accessori e/o paradosso addominale.

- Frequenza respiratoria > 25/min;

- Acidosi respiratoria: $\mathrm{pH}<7,36$;

- $\mathrm{PaCO}_{2}>45 \mathrm{mmHg}$ : dopo ottimizzazione della terapia medica e dell'ossigenoterapia.

\section{Ventilazione meccanica non invasiva} a pressione positiva

La NPPV [32,33] è la tecnica di assistenza ventilatoria più utilizzata nella modalità CPAP (Continous Positive Airway Pressure) + PS (Pressione di Supporto) nei pazienti con acidosi respiratoria.

- Migliora la $\mathrm{PaO}_{2}$ e la $\mathrm{PaCO}_{2}$ e il pH arteriosi (Evidenza A).

- Riduce la mortalità ospedaliera, la necessità di intubazione e la durata della degenza ospedaliera (Evidenza A).

- Favorisce lo svezzamento dal ventilatore (Evidenza A).

- Riduce la mortalità a 1 anno (Evidenza C).
Ventilazione meccanica a pressione negativa

La NPV in corso di riacutizzazione di BPCO [34]:

- migliora i livelli ematici di $\mathrm{PaO}_{2}$ e di $\mathrm{PaCO}_{2}$ e il pH (Evidenza $B)$;

- riduce il tasso di mortalità ospedaliera, la necessità di ventilazione meccanica invasiva e la degenza ospedaliera (Evidenza B);

- è stata proposta in caso di fallimento della NPPV prima di prendere in considerazione l'intubazione endotracheale (Evidenza C).

\section{Criteri di esclusione della ventilazione meccanica}

non invasiva a pressione positiva

Costituiscono criteri di esclusione della NPPV [33] (anche 1 solo criterio);

- arresto respiratorio;

- instabilità emodinamica (ipotensione, aritmie gravi, infarto miocardico);

- coma, paziente non collaborante;

- secrezioni vischiose e/o abbondanti, incapacità di proteggere le vie aeree;

- recente chirurgia facciale o addominale;

- trauma facciale, anormalità nasofaringea;

- insufficienza multiorgano.

Dove trattare il paziente con BPCO riacutizzata grave Il trattamento della BPCO riacutizzata grave in Unità di Terapia Intensiva Respiratoria (UTIR) può ridurre di circa la metà il costo-paziente senza peggiorare il risultato clinico rispetto al ricovero nelle terapie intensive generali (rianimazioni).

La migliore riuscita della NIMV dipende da fattori locali come il training e l'esperienza dello staff (Evidenza C), le risorse disponibili (numero di posti letto, personale, strumentazione) e il sistema di monitoraggio.

Esistono altresì criteri "predittivi" di possibile fallimento della NIMV (per esempio, mancato miglioramento del $\mathrm{pH}$ dopo 1-2 ore di ventilazione, presenza di comorbilità, scarsa tolleranza, stato funzionale respiratorio gravemente compromesso).

\section{Indicazioni per l'intubazione}

- Arresto respiratorio.

- Instabilità emodinamica (ipotensione, aritmie gravi, infarto miocardico).

- Coma, paziente non collaborante.

- Secrezioni vischiose e/o abbondanti, incapacità di proteggere le vie aeree.

- Recente chirurgia facciale o addominale.

- Trauma facciale, anormalità nasofaringea.

- Insufficienza multiorgano.

- Fallimento della NIMV (Evidenza B) (peggioramento clinico/gasanalitico entro 1-2 ore o mancato miglioramento dopo 4-6 ore).

\section{Bibliografia}

[1] Progetto Mondiale Broncopneumopatia Cronica Ostruttiva. Aggiornamento 2009 adattamento italiano. http: / / www.goldcopd.it

[2] Rabe KF, Hurd S, Anzueto A, Barnes PJ, Buist SA, Calverley P, et al., Global Initiative for Chronic Obstructive Lung Disease. 
Global strategy for the diagnosis, management, and prevention of chronic obstructive pulmonary disease: GOLD executive summary. Am J Respir Crit Care Med 2007;176(6):532-55.

[3] Celli BR, MacNee W, ATS/ERS Task Force. Standards for the diagnosis and treatment of patients with COPD: a summary of the ATS/ERS position paper. Eur Respir J 2004;23(6):932-46.

[4] Stoller JK, Aboussouan LS. Alpha1-antitrypsin deficiency. Lancet 2005;365(9478):2225-36.

[5] Rennard SI, Vestbo J. COPD: the dangerous underestimate of 15\%. Lancet 2006;367(9518):1216-9.

[6] Pellegrino R, Viegi G, Brusasco V, Crapo RO, Burgos F, Casaburi R, et al. Interpretative strategies for lung function tests. Eur Respir J 2005;26(5):948-68.

[7] Celli BR, Cote CG, Marin JM, Casanova C, Montes de Oca M, Mendez RA, et al. The body-mass index, airflow obstruction, dyspnea, and exercise capacity index in chronic obstructive pulmonary disease. N Engl J Med 2004;350(10):1005-12.

[8] Cote CG, Celli BR. Pulmonary rehabilitation and the BODE index in COPD. Eur Respir J 2005;26(4):630-6.

[9] Fishman A, Martinez F, Naunheim K, Piantadosi S, Wise R, Ries A, et al., National Emphysema Treatment Trial Research Group. A randomized trial comparing lung-volume-reduction surgery with medical therapy for severe emphysema. $N$ Engl J Med 2003;348(21):2059-73.

[10] Wilson DH, Wakefield MA, Steven ID, Rohrsheim RA, Esterman AJ, Graham NM. Sick of Smoking": evaluation of a targeted minimal smoking cessation intervention in general practice. Med J Aust 1990;152(10):518-21.

[11] Celli BR. Pulmonary rehabilitation in patients with COPD. Am J Respir Crit Care Med 1995;152(3):861-4.

[12] Tashkin DP, Celli B, Senn S, Burkhart D, Kesten S, Menjoge S, et al., UPLIFT Study Investigators. A 4-year trial of tiotropium in chronic obstructive pulmonary disease. $N$ Engl J Med 2008;359(15):1543-54.

[13] Calverley PM, Anderson JA, Celli B, Ferguson GT, Jenkins C, Jones PW, et al., TORCH investigators. Salmeterol and fluticasone propionate and survival in chronic obstructive pulmonary disease. N Engl J Med 2007;356(8):775-89.

[14] Oostenbrink JB, Rutten-van Mölken MP, Al MJ, Van Noord JA, Vincken W. One-year cost-effectiveness of tiotropium versus ipratropium to treat chronic obstructive pulmonary disease. Eur Respir J 2004;23(2):241-9.

[15] Calverley PM, Rabe KF, Goehring UM, Kristiansen S, Fabbri LM, Martinez FJ, M2-124 and M2-125 study groups. Roflumilast in symptomatic chronic obstructive pulmonary disease: two randomised clinical trials. Lancet 2009;374(9691):685-94.

[16] Fabbri LM, Calverley PM, Izquierdo-Alonso JL, Bundschuh DS, Brose M, Martinez FJ, et al., M2-127 and M2-128 study groups. Roflumilast in moderate-to-severe chronic obstructive pulmonary disease treated with longacting bronchodilators: two randomised clinical trials. Lancet 2009;374(9691):695-703.

[17] Nichol KL, Margolis KL, Wuorenma J, Von Sternberg T. The efficacy and cost effectiveness of vaccination against influenza among elderly persons living in the community. $\mathrm{N}$ Engl J Med 1994;331(12):778-84.

[18] Jackson LA, Neuzil KM, Yu O, Benson P, Barlow WE, Adams AL, et al., Vaccine Safety Datalink. Effectiveness of pneumococcal polysaccharide vaccine in older adults. N Engl J Med 2003; 348(18):1747-55.

[19] Allegra L, Cordaro Cl, Grassi C. Prevention of acute exacerbations of chronic obstructive bronchitis with carbocysteine lysine salt monohydrate: a multicenter, double-blind, placebo-controlled trial. Respiration 1996;63(3):174-80.

[20] Collet JP, Shapiro P, Ernst P, Renzi T, Ducruet T, Robinson A. Effects of an immunostimulating agent on acute exacerbations and hospitalizations in patients with chronic obstructive pulmonary disease. The PARI-IS Study Steering Committee and Research Group. Prevention of Acute Respiratory Infection by an Immunostimulant. Am J Respir Crit Care Med 1997;156(6): 1719-24.

[21] Woodcock AA, Gross ER, Gellert A, Shah S, Johnson M, Geddes DM. Effects of dihydrocodeine, alcohol, and caffeine on breathlessness and exercise tolerance in patients with chronic obstructive lung disease and normal blood gases. $N$ Engl J Med 1981;305(27):1611-6.

[22] Green RH, Singh SJ, Williams J, Morgan MD. A randomised controlled trial of four weeks versus seven weeks of pulmonary rehabilitation in chronic obstructive pulmonary disease. Thorax 2001;56(2):143-5.

[23] Naunheim KS, Wood DE, Mohsenifar Z, Sternberg AL, Criner GJ, DeCamp MM, et al., National Emphysema Treatment Trial Research Group. Long-term follow-up of patients receiving lung-volume-reduction surgery versus medical therapy for severe emphysema by the National Emphysema Treatment Trial Research Group. Ann Thorac Surg 2006;82(2):431-43.

[24] Sterman DH, Mehta AC, Wood DE, Mathur PN, McKenna Jr RJ, Ost DE, et al., IBV Valve US Pilot Trial Research Team. A multicenter pilot study of a bronchial valve for the treatment of severe emphysema. Respiration 2010;79(3):222-33.

[25] Hosenpud JD, Bennett LE, Keck BM, Edwards EB, Novick RJ. Effect of diagnosis on survival benefit of lung transplantation for end-stage lung disease. Lancet 1998;351(9095):24-7.

[26] Tarpy SP, Celli BR. Long-term oxygen therapy. N Engl J Med 1995;333(11):710-4.

[27] Clini E, Sturani C, Rossi A, Viaggi S, Corrado A, Donner CF, et al., Rehabilitation and Chronic Care Study Group, Italian Association of Hospital Pulmonologists (AIPO). The Italian multicentre study on noninvasive ventilation in chronic obstructive pulmonary disease patients. Eur Respir J 2002; 20(3):529-38.

[28] Rodriguez-Roisin R. Toward a consensus definition for COPD exacerbations. Chest 2000;117(5 Suppl 2):398-401S.

[29] Burge S, Wedzicha JA. COPD exacerbations: definitions and classifications. Eur Respir J Suppl 2003;41:46-53s.

[30] Woodhead M, Blasi F, Ewig S, Huchon G, leven M, Ortqvist A, et al., European Respiratory Society; European Society of Clinical Microbiology and Infectious Diseases. Guidelines for the management of adult lower respiratory tract infections. Eur Respir J 2005;26(6):1138-80.

[31] Sethi S, Evans N, Grant BJ, Murphy TF. New strains of bacteria and exacerbations of chronic obstructive pulmonary disease. $\mathrm{N}$ Engl J Med 2002;347(7):465-71.

[32] Meyer TJ, Hill NS. Noninvasive positive pressure ventilation to treat respiratory failure. Ann Intern Med 1994;120(9): 760-70.

[33] Brochard L, Mancebo J, Wysocki M, Lofaso F, Conti G, Rauss A, et al. Noninvasive ventilation for acute exacerbations of chronic obstructive pulmonary disease. N Engl J Med 1995;333(13):81722.

[34] Corrado A, Ginanni R, Villella G, Gorini M, Augustynen A, Tozzi $D$, et al. Iron lung versus conventional mechanical ventilation in acute exacerbation of COPD. Eur Respir J 2004;23(3):419-24. 


\section{BPCO e scompenso cardiaco}

\section{Carlo Nozzoli, Giovanni Mathieu, Gianfranco Gensini}

\section{Messaggi chiave}

- La broncopneumopatia cronica ostruttiva (BPCO) e lo scompenso cardiaco (SC) sono due malattie estremamente frequenti e diffuse nel mondo e sono entrambe gravate da un'elevata morbilità e mortalità.

- La prevalenza di BPCO in pazienti con SC varia dal 10 al $40 \%$.

- La prevalenza di SC in pazienti con BPCO è intorno al $20 \%$, mentre la prevalenza di cuore polmonare cronico è del $2 \%$; pertanto, i pazienti con BPCO e sospetto SC devono essere considerati portatori di insufficienza ventricolare sinistra fino a prova contraria.

- Lo SC cronico è spesso non riconosciuto, nonostante la prevalenza elevata.

- Valori elevati di peptide natriuretico B (BNP) dovrebbero allertare sulla presenza di SC nei pazienti con BPCO riacutizzata.

- La prevalenza del $20-30 \%$ di SC in pazienti con BPCO stabile indica in questi soggetti l'obbligo di una valutazione non invasiva della funzione ventricolare sinistra.

- La clinica è di scarso aiuto nella diagnosi di SC, per la sua mancanza di specificità e sensibilità,

- L'ecocardiografia transtoracica è limitata nei pazienti con BPCO per la cattiva finestra acustica, mentre la RMN cardiaca è raccomandata per valutare la funzione ventricolare sinistra in pazienti per i quali non è tecnicamente possibile acquisire immagini ecografiche.

- Il BNP Consensus Panel ha stabilito che il cuore polmonare è associato ad aumento di valori intermedi di BNP tra 100 e 500 pg/mL. Livelli di BNP $<100$ pg $/ \mathrm{mL}$ e $>500$ $\mathrm{pg} / \mathrm{mL}$ rappresentano valori predittivi altamente negativi e positivi, rispettivamente, per la diagnosi di SC in questi pazienti.
- La diagnosi di BPCO in pazienti con SC deve essere comprovata dalla spirometria. In condizioni di instabilità emodinamica il paziente può avere ostruzione al flusso transitoria per compressione delle vie aeree da parte dell'edema. Il paziente deve essere in condizioni di euvolemia, altrimenti si può avere una sovrastima.

- In condizioni di stabilità emodinamica il paziente con SC presenta un pattern restrittivo che può comunque mascherare un quadro di iperinsufflazione e quindi di BPCO.

- Tutti i pazienti affetti da BPCO e SC dovrebbero essere interrogati circa l'abitudine al fumo e i fumatori dovrebbero essere avviati a un programma strutturato di sospensione del fumo.

- L'esercizio fisico costituisce la principale componente di un programma di riabilitazione polmonare, ma esso è al tempo stesso di fondamentale importanza nella terapia dello SC.

- L'ossigenoterapia a lungo termine riduce la mortalità per tutte le cause nei pazienti con BPCO e ipossiemia, tuttavia l'ossigenoterapia non è prevista quale raccomandazione nelle attuali linee guida sulla terapia dello SC cronico, con l'eccezione del trattamento dello SC acuto e del cuore polmonare.

- Nella terapia della BPCO si preferisce utilizzare i beta ${ }_{2}$ agonisti long acting; questi farmaci sono rimossi più rapidamente dai beta-recettori cardiaci e renali, rendendo meno probabile la comparsa di effetti negativi a livello miocardico.

- I farmaci anticolinergici possono potenzialmente indurre la comparsa di eventi avversi cardiaci; ogni potenziale rischio cardiovascolare dovrebbe essere valutato confrontandolo con i vantaggi noti prodotti da questa classe di farmaci. 
- La teofillina ha una finestra terapeutica assai ristretta, con il rischio di comparsa di aritmie anche severe; non è indicata, quindi, nei pazienti affetti da cardiopatia ischemica.

- La modulazione del sistema renina-angiotensina con ACE-inibitori o ARB (Angiotensin II Receptor Blockers), in presenza di doppia patologia, esercita un duplice effetto favorevole mediato da una riduzione del rischio cardiovascolare e dalla prevenzione del danno polmonare. Gli ACE-inibitori sono in grado di prevenire l'atrofia della muscolatura scheletrica e la cachessia, migliorando la forza della muscolatura respiratoria.

- Le statine, somministrate insieme agli ACE-inibitori e agli ARB, possono esercitare un duplice effetto protettivo a livello cardiaco e polmonare (protezione cardiopolmonare) modificando sostanzialmente la prognosi dei pazienti con BPCO.

- Non vi è chiara evidenza a supporto dell'uso della digitale nel trattamento del cuore polmonare, a meno che non vi sia la concomitanza con un'insufficienza ventricolare sinistra o una fibrillazione atriale.

- Il trattamento diuretico dei pazienti con BPCO e SC destro prevede frequentemente il ricorso all'utilizzo dei diuretici dell'ansa; per questo motivo è obbligatoriamente richiesto un attento monitoraggio del quadro elettrolitico e, in presenza di un disequilibrio, può rendersi necessaria una correzione mediante supplementi di potassio e di magnesio, onde evitare la comparsa di aritmie minacciose. A dosaggi standard di diuretici, tuttavia, la funzione polmonare non viene abitualmente influenzata.
- A oggi i beta-bloccanti rimangono sottoprescritti nei pazienti con l'associazione delle due patologie, nonostante la raccolta di una considerevole mole di dati attestanti la sicurezza di impiego nei pazienti affetti da BPCO moderata o severa.

- I sintomi respiratori e il FEV1 non sono peggiorati in modo significativo dai beta-bloccati beta $a_{1}$-selettivi in corso di BPCO. I benefici indotti dai beta-bloccanti beta ${ }_{1}$-selettivi nei pazienti cardiopatici con associata BPCO sono di gran lunga superiori ai rischi.

- Le principali linee guida sullo SC raccomandano in tutti i pazienti con SC e associata BPCO l'uso dei beta-bloccanti, tenendo presente che tale terapia può essere implementata con successo e in regime di sicurezza seguendo un programma strutturato di controlli in regime ambulatoriale.

- L'implementazione di un modello dedicato alle malattie croniche è da considerare una strategia efficace nella terapia della BPCO (self-management, pianificazione delle dimissioni, riferimento alle linee guida, raccolta di dati informativi).

- Sono ancora presenti alcune perplessità circa la reale efficacia di un programma di disease management nel ridurre la mortalità per tutte le cause nei pazienti con SC e con BPCO, ferma restando l'efficacia nel migliorare la qualità di vita e la capacità di esercizio e nel ridurre le ospedalizzazioni.

- Si stanno affacciando nella pratica clinica modelli assistenziali basati sulla comunicazione e trasmissione di dati mediante apparecchiature telematiche; la validazione di questi modelli organizzativi e la loro estesa applicazione nella pratica clinica richiedono tuttora conferme e il completamento di studi più approfonditi ed estesi.

\section{Introduzione}

La broncopneumopatia cronica ostruttiva (BPCO) e lo scompenso cardiaco (SC) sono due malattie estremamente frequenti e diffuse nel mondo e sono entrambe gravate da un'elevata morbilità e mortalità [1-3]. La loro coesistenza non sempre è evidenziata in maniera chiara e questo comporta importanti problemi diagnostici e terapeutici. La mancata diagnosi di una delle due malattie può comportare una sottovalutazione dei problemi del paziente e, di conseguenza, a un sottotrattamento di sintomi erroneamente attribuiti esclusivamente a una delle due patologie.

\section{Dati epidemiologici}

\section{Prevalenza della BPCO in pazienti con SC}

La stima della prevalenza della BPCO varia molto in ragione della popolazione studiata, dei criteri diagnostici applicati, degli strumenti di misurazione e dei sistemi di sorveglianza [4]. Le variazioni geografiche correlano con le differenze nell'età della popolazione e nell'esposizione ai fattori di rischio, in particolare il fumo di sigaretta $[3,4]$.

Nel Cardiovascular Health Study la prevalenza di BPCO nei pazienti con SC era superiore a quella della popolazione generale $(20 \%$ vs $13 \% ; p=0,001)$ [5].
Non vi sono studi che abbiano esaminato sistematicamente la funzione polmonare nei pazienti con SC.

Nel Nord America la prevalenza varia dall'11\% al 52\%, in Europa dal 9\% al 41\% [6].

La prevalenza è più alta in studi più recenti e ciò può essere spiegato da una maggiore attenzione alla diagnosi di BPCO, all'allungamento della vita delle popolazioni e all'aumento dell'età di inizio dello SC.

La prevalenza aumenta con l'età fino a circa 75 anni, poi decresce, probabilmente perché la coesistenza di BPCO riduce la sopravvivenza oltre tale età 0 , in alternativa, un approccio diagnostico meno intensivo e sistematico negli anziani sottostima la comorbilità [7-10].

La BPCO è più frequente nei maschi con SC [10-15] e nelle aree urbane rispetto a quelle rurali.

La prevalenza è notevolmente più bassa nei pazienti gestiti dai cardiologi rispetto a quelli gestiti dagli internisti.

In pazienti con frazione di eiezione $(\mathrm{FE})$ preservata la prevalenza riportata è generalmente più alta $[16,17]$.

\section{Prevalenza di SC in pazienti con BPCO}

Il fumo di sigaretta, che è la causa più comune di BPCO, è associato a un rischio di comparsa di SC aumentato del $50 \%$. 
Il rischio di sviluppare uno SC è 4,5 volte superiore (IC 95\% 4,25-4,95) nei pazienti con BPCO rispetto ai controlli senza BPCO [18].

In una coorte altamente selezionata di pazienti con BPCO che si erano presentati a un Dipartimento di Emergenza per dispnea acuta la prevalenza di SC era del 20,9\% [19].

La prevalenza era simile $(20,5 \%)$ in uno studio di comunità su 405 pazienti anziani con BPCO stabile [20]. In tale gruppo nessuno aveva evidenza ecocardiografica di SC destro isolato. Questo studio conferma i dati che stimano la prevalenza di cuore polmonare nella BPCO intorno al 2\% [21].

Pertanto, i pazienti con BPCO e sospetto SC devono essere considerati portatori di insufficienza ventricolare sinistra fino a prova contraria.

Una recente review sistematica ha esaminato 18 studi in cui è stata misurata la FE del ventricolo sinistro nei pazienti con BPCO. La prevalenza di disfunzione ventricolare sinistra variava dal $10 \%$ al $46 \%$ in pazienti stabili [22].

Il programma medico Kaiser Permanente della California del Nord ha riportato una frequenza di ospedalizzazione per SC 5,55 volte superiore (IC $95 \%$ 4,71-5,73) e un odds ratio dello SC come comorbilità di 8,48 (IC 95\% 7,65-9,40) nei pazienti con BPCO rispetto ai controlli.

L'elevata prevalenza di SC in pazienti con BPCO non sorprende in quanto i pazienti con BPCO sono a più alto rischio di mortalità e morbilità cardiovascolare indipendentemente da altri fattori di rischio, tabacco incluso. Infatti la cardiopatia ischemica, e non l'insufficienza respiratoria, è la causa più importante di morte nei pazienti con BPCO [3].

Rimane incerta la relazione tra BPCO ed eventi cardiovascolari, ma l'infiammazione sistemica presente in questi pazienti potrebbe accelerare $\mathrm{i}$ processi di aterosclerosi coronarica che in ultimo determinano una cardiomiopatia ischemica.

\section{La diagnosi di SC in pazienti con BPCO}

\section{Elementi clinici}

La diagnosi di SC si basa su criteri clinici e sull'evidenza di disfunzione cardiaca. II problema, però, nasce dal fatto che la malattia polmonare può confondere ogni sintomo e segno definito dai criteri di Framingham [23].

La dispnea da sforzo, la tosse notturna e la dispnea parossistica notturna sono comuni a entrambe le condizioni. Infatti, nessuna delle caratteristiche di una dispnea è unica per lo SC.

Anche i segni di interessamento ventricolare destro possono essere confondenti, inclusi la distensione giugulare, gli edemi periferici e l'epatomegalia, potendo quest'ultima essere simulata dal posizionamento del fegato per l'iperinsufflazione del polmone.

La difficoltà di una diagnosi differenziale clinica tra le due entità nosologiche è comprovata dal confronto tra differenti sistemi di valutazione dei criteri diagnostici di SC. Confrontando un sistema meno specifico di valutazione come quello di Framingham [23] con uno più specifico utilizzato nel Cardiovascular Health Study [6], la prevalenza di concomitante BPCO è 2 volte superiore (13\% vs 6\%) [24].

\section{Diagnostica radiologica}

La diagnosi radiologica di SC è anch'essa limitata dalla presenza della BPCO. L'iperinsufflazione dei polmoni riduce falsamente il rapporto cardiotoracico [25]. Il rimaneggiamento vascolare polmonare e i campi polmonari radiolucenti mascherano il tipico aspetto radiologico alveolare in corso di edema polmonare [26]. Nella BPCO la distribuzione dell'edema assume spesso aspetti asimmetrici, regionali e con pattern reticolare $[25,26]$. La perdita di letto vascolare per l'enfisema crea una diversione del flusso venoso polmonare verso i lobi superiori, simulando la distribuzione della congestione tipica dello SC [27].

\section{Ecocardiografia}

L'ecocardiografia è uno degli esami fondamentali per la diagnosi di SC, in particolar modo per la forma con funzione sistolica ridotta. Nei pazienti con BPCO, però, tale esame è reso difficoltoso dalla presenza, in molti casi, di una finestra acustica non buona a causa della quale esso è inaffidabile in una quota variabile dal $10 \%$ al $50 \%$ dei soggetti, a seconda della gravità della patologia polmonare $[28,29]$. Ancora da definire è il ruolo dell'ecocardiografia con contrasto per la valutazione della FE in pazienti con BPCO.

\section{Risonanza magnetica nucleare}

La risonanza magnetica è in grado di fornire una stima precisa, affidabile e riproducibile dei volumi ventricolari e della $\mathrm{FE}$. Inoltre, la capacità di individuare aree di fibrosi può essere utile nel predire il rischio di aritmie [30]. Non risente, a differenza dell'ecocardiografia, delle modificazioni del parenchima polmonare che si realizzano nella BPCO.

\section{Peptidi natriuretici}

Gli esami generali di laboratorio sono necessari per l'inquadramento del paziente con SC e per la scelta delle terapie, ma non rivestono di per sé alcun valore diagnostico. Un grande aiuto nella pratica clinica è costituito dall'introduzione nella diagnostica di routine dei peptidi natriuretici. Essi si sono dimostrati il principale strumento di laboratorio per la diagnosi di SC e per la gestione dei pazienti con SC noto. Esiste in letteratura una messe di dati sul loro utilizzo per la diagnosi e la stadiazione dello scompenso e per la gestione dei pazienti ospedalizzati al fine di stabilire il timing più appropriato per la dimissione. Sono disponibili, inoltre, numerosi dati sul possibile ruolo dei peptidi natriuretici per l'aggiustamento delle terapie nello SC cronico, ma la loro validazione non è stata chiarita in maniera univoca.

I peptidi natriuretici sono sintetizzati a livello dei miociti atriali e ventricolari e rilasciati nel circolo ematico in seguito a un aumento dello "stress" miocardico dovuto a un sovraccarico di pressione e/o di volume sulle pareti miocardiche. Esistono tre tipi di peptidi natriuretici $(A, B, C)$, sintetizzati come precursori sotto forma di pre-pro peptidi che poi vengono clivati in propeptidi e quindi nelle molecole definitive dei peptidi natriuretici. Soltanto i peptidi natriuretici $A$ (ANP) e B (BNP) hanno azioni fisiologiche riconosciute sul bilancio idrosalino determinando natriuresi e diuresi a livello 
renale; l'ANP viene rilasciato in risposta prevalentemente a "stretch" atriale, mentre il BNP in risposta a incremento dello stress ventricolare. I livelli ematici sono influenzati non solo dal rilascio miocardico nel torrente circolatorio in seguito a sovraccarico delle camere cardiache, ma anche dall'età, dai livelli di pressione arteriosa, dall'introduzione salina, dalla riduzione della funzione renale, dalla presenza di cirrosi epatica e dalla sepsi, che possono determinare aumento dei valori; al contrario, l'obesità grave e il concomitante trattamento con farmaci per lo SC possono determinare riduzione dei valori. Questi fattori vanno tenuti in adeguata considerazione per l'interpretazione dei valori di laboratorio.

Nella pratica clinica sono utilizzati i dosaggi del BNP (biologicamente attivo) e del peptide di clivaggio in sede $\mathrm{N}$-terminale NT-proBNP biologicamente inattivo, ma più stabile e dotato di emivita più lunga rispetto all'analogo attivo.

Sia il peptide natriuretico di tipo B (BNP) sia il NT-proBNP sono utili per escludere uno SC nei pazienti con dispnea acuta [31].

Sono incerti, invece, il ruolo e l'accuratezza diagnostica nei pazienti con coesistente BPCO. In un sottogruppo dello studio "Breathing Not Properly" è riportata una differenza statisticamente significativa tra pazienti affetti da BPCO con e senza SC [19]. In un altro studio realizzato in California su 321 pazienti con dispnea acuta, i valori medi di BNP erano significativamente più elevati in pazienti con $\mathrm{SC}$ rispetto $\mathrm{a}$ quelli con BPCO [32].

Entrambi questi lavori presentano il limite della diagnosi retrospettiva di SC posta da cardiologi su dati clinici (solo il $29 \%$ disponeva di un ecocardiogramma); altro limite è costituito dal fatto che probabilmente vi era una sottodiagnosi di cuore polmonare cronico o che quest'ultimo veniva classificato come SC.

Il BNP risulta elevato sia nei pazienti con ipertensione polmonare primitiva sia nello scompenso destro da malattia respiratoria cronica. I valori del BNP correlano con la pressione in arteria polmonare e sono un predittore indipendente di mortalità [33].

Pochi studi hanno verificato il BNP specificamente in pazienti con BPCO [33]. Soltanto uno ha esaminato la capacità diagnostica in questi pazienti [34]. Duecento pazienti anziani stabili con BPCO erano stati sottoposti a quattro test di determinazione del BNP. Il valore predittivo negativo è risultato superiore a 0,85 . Tuttavia, il valore predittivo positivo era inferiore a quello osservato nei pazienti con dispnea acuta [31]. La minore accuratezza diagnostica può essere spiegata, da un lato, dal fatto che i pazienti stabili hanno valori più bassi di quelli con sovraccarico acuto e, dall'altro, dal fatto che in pazienti con BPCO i livelli di BNP sono aumentati.

Il BNP Consensus Panel ha stabilito che il cuore polmonare è associato $\mathrm{a}$ un aumento di valori intermedi di BNP tra $100 \mathrm{e}$ $500 \mathrm{pg} / \mathrm{mL}$ [31]. Livelli di BNP $<100 \mathrm{pg} / \mathrm{mL}$ e $>500 \mathrm{pg} / \mathrm{mL}$ rappresentano valori predittivi altamente negativi e positivi, rispettivamente, per la diagnosi di SC in questi pazienti.

\section{La diagnosi di BPCO in pazienti con SC}

Pazienti con SC presentano difetti di ventilazione in senso sia ostruttivo sia restrittivo compatibili con le caratteristiche limitazioni al flusso aereo proprie della BPCO.
L'ostruzione è definita dalla riduzione del rapporto FEV1 (Forced Expiratory Volume)/FVC (Forced Vital Capacity) < $70 \%$ [3]. Le forme restrittive sono caratterizzate da una riduzione dei volumi polmonari.

La diagnosi di BPCO deve essere confermata con la spirometria, anche se l'ostruzione polmonare può essere presente nel paziente con insufficienza cardiaca in fase di scompenso a causa dell'edema interstiziale e alveolare che determina compressione sulle vie aeree [35,36] e, pertanto, si può verificare una sovrastima di diagnosi di BPCO e della sua gravità. L'aumento della diuresi con la terapia può portare a un miglioramento fin del $35 \%$ del FEV1, spesso con ritorno alla normalità $[35,36]$. È quindi consigliabile eseguire i test di funzionalità respiratoria in condizioni di stabilità e di euvolemia del paziente.

In condizioni di stabilità emodinamica sono prevalenti i difetti in senso restrittivo. In uno studio multicentrico di 130 pazienti [37] FEV1 e FVC erano normali o proporzionalmente ridotti. A tali alterazioni concorrono la fibrosi interstiziale, il deficit dei muscoli respiratori, la cardiomegalia e la congestione polmonare $[38,39]$. La riduzione proporzionale di FEV1 e FVC può comunque verificarsi in pazienti con BPCO severa, ma in questi casi la diagnosi di ostruzione è definita sulla base della capacità polmonare totale e del volume residuo. Tuttavia, la riduzione dei volumi polmonari può mascherare l'iperinsufflazione e quindi la diagnosi di BPCO in pazienti con SC concomitante.

\section{Aspetti terapeutici}

La coesistenza nello stesso paziente di BPCO e SC - due patologie che abbiamo visto essere assai frequenti nella pratica clinica e con numerosi fattori di rischio in comune - oltre a causare difficoltà nell'iter diagnostico e a determinare in taluni casi ritardi nella diagnosi, contribuisce spesso a rendere più complesso e articolato l'approccio terapeutico; l'associazione tra le due patologie rappresenta inoltre una delle principali cause di non aderenza alle linee guida terapeutiche.

Nell'approccio terapeutico complessivo a questo tipo di pazienti con doppia patologia, si possono schematicamente distinguere due ordini di problemi:

- effetti favorevoli - o, al contrario, eventi avversi - indotti dai farmaci utilizzati nella terapia della BPCO in pazienti con SC associato, con una ricaduta (positiva o negativa) sulla morbilità e mortalità e/o sull'andamento clinico generale;

- effetti favorevoli - o, al contrario, eventi avversi - indotti dai farmaci utilizzati nella terapia dello SC in pazienti con BPCO associata, con una ricaduta sulla morbilità e mortalità e/o sull'andamento clinico generale.

\section{Terapia della BPCO in pazienti con SC}

\section{Abolizione del fumo}

L'abitudine al fumo rappresenta in assoluto la più rilevante causa di malattia e di morte prematura prevenibile. Negli Stati Uniti ogni anno muoiono circa 440.000 cittadini americani per malattie correlate al fumo attivo [40]. 
I dati della letteratura dimostrano che l'interruzione del fumo nei pazienti con BPCO, pur difficile da realizzare e mantenere nel tempo, riduce la mortalità per tutte le cause [41].

È noto che il principale effetto prodotto dall'interruzione del fumo è relativo alla riduzione della mortalità per infarto miocardico acuto e per cancro. Nelle persone che smettono di fumare il rischio di morte per malattie coronariche, dopo 1 anno di interruzione, diminuisce del $50 \%$ rispetto a chi continua a fumare [42]. In questo stesso studio, il fumo era associato a un incremento del rischio di SC pari al $47 \%$.

Negli studi SOLVD (Studies Of Left Ventricular Dysfunction) gli ex fumatori avevano una riduzione di mortalità pari al 30\% rispetto ai fumatori, beneficio che si evidenziava dopo 2 anni dalla sospensione [43]. Pertanto, tutti i pazienti affetti da SC (e non solo quelli con BPCO) dovrebbero essere interrogati circa l'abitudine al fumo e i fumatori dovrebbero essere avviati a un programma strutturato di sospensione del fumo [44].

\section{Riabilitazione}

Le tecniche di riabilitazione polmonare rappresentano una parte essenziale nel programma di management del paziente con BPCO [45]. L'esercizio fisico costituisce la principale componente di un programma di riabilitazione polmonare, ma al tempo stesso esso riveste fondamentale importanza nella terapia dello SC. Infatti, è stato dimostrato che l'inattività fisica è un fattore di rischio per SC e per le malattie cardiovascolari in generale. Studi epidemiologici di tipo prospettico hanno dimostrato che l'attività fisica di tipo occupazionale o nel tempo libero, nei soggetti più attivi (che svolgono cioè un'attività fisica di almeno 30 minuti al giorno per 5 giorni la settimana), riduce l'incidenza di cardiopatia ischemica, SC e stroke [46].

Più recentemente lo studio HF-ACTION [47] ha confermato l'importanza della promozione dell'esercizio fisico anaerobico nei pazienti ad alto rischio prognostico affetti da SC, evidenziando una seppur lieve riduzione (sotto il profilo della significatività statistica) di mortalità o ospedalizzazione per tutte le cause e di mortalità cardiovascolare o ospedalizzazione per SC.

\section{Ossigenoterapia a lungo termine}

L'ossigenoterapia a lungo termine reduce la mortalità per tutte le cause nei pazienti con BPCO e ipossiemia [48].

Al momento esistono solo prove indirette circa l'utilità di questa terapia nel ridurre mortalità e morbilità per SC. La documentata riduzione della policitemia, della pressione in arteria polmonare e dei parametri emodinamici relativi al circolo polmonare, delle aritmie notturne e dei disturbi del sonno, oltre all'incremento della tolleranza allo sforzo, induce a ritenere che gli effetti favorevoli dell'ossigenoterapia a lungo termine si estendano al di là della stretta patologia polmonare.

Tuttavia l'ossigenoterapia non è prevista quale raccomandazione nelle attuali linee guida sulla terapia dello SC cronico, con l'eccezione del trattamento dello SC acuto e del cuore polmonare [2].

\section{Beta 2 -stimolanti}

I farmaci beta ${ }_{2}$-agonisti, pur esercitando un'azione relativamente selettiva su recettori beta ${ }_{2}$-adrenergici, hanno generato alcune preoccupazioni per via di taluni effetti negativi che possono produrre, specialmente nei pazienti affetti da cardiopatia ischemica [49]:

- possibile induzione di aritmie, per la stimolazione dei betarecettori adrenergici cardiaci;

- attivazione riflessa di meccanismi adrenergici, successivi a una vasodilatazione periferica;

- down-regulation dei recettori beta ${ }_{2}$ a livello miocardico, con un conseguente accentuato consumo di ossigeno e un'aumentata produzione di catecolamine;

- potenziale peggioramento di uno SC, per induzione o accentuazione della disfunzione sistolica del ventricolo sinistro;

- induzione di ipopotassiemia;

- induzione di ipossia per mismatch ventilazione/perfusione. In un numero limitato di studi è stato dimostrato che gli agonisti dei recettori beta $a_{2}$, assunti per via orale o inalati nella formulazione "short acting", aumentano il rischio di mortalità e il numero di riacutizzazioni di SC nei pazienti con disfunzione del ventricolo sinistro [50].

I farmaci agonisti beta-adrenergici esercitano azioni opposte a quelle dei beta-bloccanti. Questi ultimi riducono la morbilità e la mortalità nei pazienti affetti da cardiopatia, mentre l'utilizzo di beta-agonisti nei pazienti con BPCO è stato associato a un aumentato rischio di infarto miocardico, SC, arresto cardiaco e morte cardiaca improvvisa. Una metanalisi di Salpeter et al. [51] circa l'uso dei beta-agonisti nei pazienti con BPCO ha valutato il loro effetto nel breve periodo sulla frequenza cardiaca e sulla potassiemia (13 studi clinici con somministrazione di una singola dose di farmaco) e nel lungo periodo sulla comparsa di alcuni eventi cardiovascolari (20 studi con più lungo periodo di somministrazione). Il farmaco beta-agonista in singola dose incrementava la frequenza cardiaca di 9,12 bpm (IC 95\% 5,32-12,92) e riduceva la concentrazione ematica di potassio di 0,36 mmol/L (IC 95\% 0,18-0,54); nei trial di durata superiore a 3 giorni e fino a 1 anno, il trattamento con farmaci beta-agonisti aumentava in modo significativo il rischio di eventi cardiovascolari (RR 2,54; IC 95\% 1,59-4,05).

In uno studio caso-controllo effettuato in un setting ambulatoriale (Ambulatory Care Quality Improvement Project, ACQUIP) [52] l'uso di beta-agonisti non risultava associato a un aumentata incidenza di SC; tuttavia, nei pazienti con precedente diagnosi di SC si riscontrava un'associazione con un aumento delle ospedalizzazioni per riacutizzazione di SC (associazione di tipo dose-risposta in base al numero di confezioni di farmaco consumate).

Al momento attuale, nella terapia della BPCO si preferisce utilizzare $i$ beta $a_{2}$-agonisti long acting; questi farmaci sono rimossi più rapidamente dai beta-recettori cardiaci e renali, rendendo meno probabile la comparsa di effetti negativi a livello miocardico [53].

Al fine di valutare la sicurezza d'impiego del salmeterolo nei pazienti affetti da BPCO è stata effettuata una metanalisi di 7 trial clinici che hanno confrontato il farmaco betaagonista (somministrato a 1.410 pazienti a un dosaggio di $50 \mu \mathrm{g}$ bid) con il placebo (somministrato a 1.443 pazienti). Il 
trattamento con salmeterolo, confrontato con il placebo, non incrementava il rischio di eventi avversi cardiovascolari (RR 1,03; IC 95\% 0,8-1,3; $p=0,838)$. Tra gli eventi avversi cardiovascolari fu anche presa in considerazione l'incidenza di SC, del tutto sovrapponibile nei due bracci di studio [54].

Nello studio TORCH [55] è stata valutato l'effetto di una terapia combinata salmeterolo/fluticasone sulla mortalità per tutte le cause nei pazienti con BPCO. Lo studio ha coinvolto 6.112 pazienti affetti da BPCO moderata-severa, con endpoint primario rappresentato dalla mortalità per tutte le cause a 3 anni. L'effetto sull'endpoint primario dell'associazione salmeterolo/fluticasone, rispetto al placebo, raggiungeva quasi la significatività (HR 0,825; IC 95\% $0,681-1,002 ; p=0,052)$. Di particolare interesse è stata l'analisi condotta da un panel di esperti sulle cause specifiche di morte in questa popolazione di pazienti: il $27 \%$ dei decessi era da correlare a cause cardiovascolari; gli effetti favorevoli della terapia di associazione salmeterolo/fluticasone risultavano equamente distribuiti tra le cause di morte polmonari e quelle non polmonari, suggerendo che il trattamento testato nello studio eserciti un effetto anche sulle patologie non polmonari [56].

\section{Anticolinergici}

I farmaci anticolinergici riducono per breve periodo il rilascio di acetilcolina; con questa modalità essi possono potenzialmente indurre la comparsa di eventi avversi cardiaci simili a quelli provocati dall'atropina [57].

In una recente metanalisi di 17 trial clinici randomizzati [58], che avevano arruolato circa 15.000 pazienti, l'utilizzo di ipratropio o tiotropio per un periodo superiore a 30 giorni aumentava in modo significativo il rischio di infarto miocardico (RR 1,53; IC 95\% 1,05-2,23) e di mortalità cardiovascolare (RR 1,80; IC 95\% 1,17-2,77); sebbene statisticamente non significativo, si osservava anche un trend di incremento della mortalità per tutte le cause (RR 1,26; IC 95\% 0,99$1,61)$.

Nello studio UPLIFT (Understanding Potential Long-term Impacts on Function with Tiotropium) [59] 5.993 pazienti sono stati randomizzati ad assumere tiotropio vs placebo, in aggiunta ad altri farmaci attivi sull'apparato respiratorio, per un periodo di 4 anni. Nel gruppo trattato con tiotropio si rilevava un tasso di eventi cardiovascolari significativamente inferiore ( $R R$ 0,84; IC 95\% 0,73-0,98); in questo gruppo si osservava, inoltre, un trend di riduzione della mortalità per tutte le cause che tuttavia non raggiungeva la significatività (RR 0,89; IC 95\% 0,79-1,02). Si potrebbe avanzare l'ipotesi che una metanalisi che includa anche la casistica dello studio UPLIFT non riuscirebbe a evidenziare gli effetti negativi indotti dalla terapia con anticolinergici per via inalatoria precedentemente segnalati. È auspicabile che vengano disegnati e realizzati trial clinici randomizzati in grado di testare gli effetti indotti da questi farmaci a lungo termine prendendo in considerazione endpoint cardiovascolari. Nel frattempo, ogni potenziale rischio cardiovascolare dovrebbe essere valutato confrontandolo con $i$ vantaggi noti prodotti da questa classe di farmaci (riduzione della frequenza delle riacutizzazioni della BPCO, riduzione delle ospedalizzazioni, miglioramento della dispnea) [60].

\section{Cortisone per via sistemica e per via inalatoria}

I farmaci cortisonici sono frequentemente prescritti nella terapia della BPCO, patologia di per sé associata a un aumentato rischio di mortalità e morbilità cardiovascolare per gli effetti sistemici che produce, indipendentemente dalla terapia praticata. A uno studio osservazionale caso-controllo (50.656 pazienti arruolati, di cui circa 1/3 affetti da BPCO), il trattamento continuativo con glicocorticoidi per via orale, ancor più rispetto a un pregresso trattamento recente 0 passato, è risultato essere associato in modo significativo a un aumentato rischio di SC (OR 2,66; IC 95\% 2,46-2,87). Un rischio più elevato si riscontrava nei pazienti in terapia continuativa (almeno 3 mesi) e a dosi più alte, anche se la curva dose-risposta non evidenziava una relazione di tipo continuo [61].

La ritenzione di liquidi in corso di trattamento corticosteroideo, indotta da un riassorbimento di sodio e da un'espansione dei liquidi extracellulari, sembra essere il meccanismo più importante nel determinare la comparsa di SC.

Alcuni studi clinici suggeriscono che gli steroidi per via inalatoria riducono le riacutizzazioni e migliorano lo stato di salute nei pazienti con BPCO. Una metanalisi dei dati relativi a 5.085 pazienti arruolati in 7 trial clinici randomizzati ha confrontato, in un follow-up di almeno 12 mesi, gli effetti degli steroidi vs placebo sulla mortalità per tutte le cause [62]. L'uso di steroidi per via inalatoria riduceva la mortalità per tutte le cause del $25 \%$ rispetto al placebo; i risultati erano sovrapponibili anche dopo un'analisi aggiustata per i fattori confondenti (HR 0,73; IC 95\% 0,55-0,96). Poiché il follow-up medio era di 26 mesi, sono necessari ulteriori studi per valutare la persistenza dell'effetto favorevole in un lasso di tempo più lungo.

\section{Teofillina}

La teofillina aumenta la frequenza cardiaca e l'automatismo atriale e accelera la conduzione intraventricolare; in questo modo induce la comparsa di battiti ectopici sopraventricolari, tachicardia sinusale e tachicardia atriale multifocale (MAT). Quest'ultima aritmia compare nell' $8 \%$ dei pazienti con teofillinemia compresa tra 10 e $20 \mathrm{mg} / \mathrm{L}$ e nel $16 \%$ per livelli sopraterapeutici (> $20 \mathrm{mg} / \mathrm{L}$ ) [63]. A una concentrazione ematica superiore a $30 \mathrm{mg} / \mathrm{L}$, la teofillina induce aritmie nell'85\% dei pazienti, specialmente se anziani [64].

La finestra terapeutica di questo farmaco è assai ristretta, con il rischio di comparsa di aritmie anche severe (MAT); non è quindi indicata nei pazienti affetti da cardiopatia ischemica.

L'efficacia broncodilatatrice è piuttosto limitata; è comunque un farmaco di terza linea nella terapia della BPCO, dopo i beta $a_{2}$-stimolanti e gli anticolinergici; il suo ruolo è dubbio nelle riacutizzazioni della BPCO [65].

La teofillina è metabolizzata a livello epatico attraverso una via metabolica mediata dal citocromo P450. Pertanto l'alcol, i chinolonici, i macrolidi, gli antagonisti dei recettori $\mathrm{H}_{2}$ e le benzodiazepine interferiscono con il suo metabolismo, contribuendo ad aumentarne la concentrazione ematica e quindi l'effetto farmacologico. Al contrario, l'aminoglutetimide e la carbamazepina ne riducono l'effetto [66]. 


\section{Terapia dello SC in pazienti con BPCO}

Le opzioni terapeutiche per lo SC includono i diuretici, i betabloccanti, gli ACE-inibitori, i sartanici, gli antagonisti dell'aldosterone, la digitale.

\section{ACE-inibitori}

Elemento in comune nella terapia delle due patologie è rappresentato dalla gestione delle alterazioni della muscolatura scheletrica, che sono principalmente caratterizzate dalla riduzione della forza e della massa muscolare e da uno shift delle fibre muscolari (atrofia delle fibre di tipo I ossidativo e incremento delle fibre di tipo lla e Ilb glicolitico). Di recente si è dimostrato che gli ACE-inibitori sono in grado di prevenire l'atrofia della muscolatura scheletrica e la cachessia, migliorando la forza della muscolatura respiratoria. L'effetto benefico esercitato dagli ACE-inibitori sui muscoli è mediato da una riduzione dei livelli di angiotensina II che a sua volta riduce $i$ livelli del fattore di crescita insulino-simile IGF-1 [67-71]. Tuttavia, in due studi distinti il losartan e l'irbesartan non sono risultati in grado di migliorare la funzione respiratoria o la forza della muscolatura striata nei pazienti con BPCO senza patologie cardiovascolari associate né la capacità di esercizio fisico o lo score di dispnea in pazienti con BPCO e ipertensione polmonare [72,73]. La modulazione del sistema renina-angiotensina con ACE-inibitori o ARB, in presenza di doppia patologia, produce comunque un duplice effetto favorevole mediato da una riduzione del rischio cardiovascolare e dalla prevenzione del danno polmonare [74,75].

Il sistema renina-angiotensina esercita la sua attività non solo a livello della circolazione sistemica, ma anche negli organi e nei tessuti periferici. L'angiotensina II è un potente broncocostrittore; pertanto gli ACE-inibitori e gli ARB svolgono un'azione favorevole nei pazienti con BPCO riducendo $i$ livelli di angiotensina II e di conseguenza la broncocostrizione. Gli ACE-inibitori, inoltre, sono in grado di ridurre l'infiammazione polmonare e la vasocostrizione polmonare e di migliorare gli scambi gassosi a livello della membrana alveolo-capillare [76].

\section{Statine}

La simvastatina, in un modello sperimentale animale, è risultata in grado di ridurre nel ratto l'ipertensione polmonare provocata dall'azione di sostanze tossiche sui vasi polmonari; è verosimile che ciò sia da attribuire agli effetti pleiotropici e antinfiammatori delle statine [77]. Uno studio caso-controllo di grandi dimensioni, effettuato in pazienti anziani, ha dimostrato che le statine, somministrate insieme agli ACE-inibitori e agli ARB, possono esercitare un duplice effetto protettivo a livello cardiaco e polmonare (protezione cardiopolmonare) modificando sostanzialmente la prognosi dei pazienti con BPCO [78]. La combinazione statine + ACEinibitori o ARB risultava associata a una riduzione delle ospedalizzazioni per BPCO e della mortalità totale nei pazienti con $\mathrm{BPCO}$, sia nel gruppo a più alto rischio cardiovascolare sia in quello a più basso rischio. In particolare, quest'associazione di farmaci si rivelava in grado di ridurre l'incidenza di infarto del miocardio nei pazienti con BPCO ad alto rischio cardiovascolare. Analoghi benefici si riscontravano nei pazienti in trattamento steroideo.

In uno studio retrospettivo di coorte, effettuato su 854 pazienti (età media 70,8 anni; $51,5 \%$ di sesso femminile; follow-up di 1,9 anni) dimessi dall'ospedale con diagnosi di BPCO riacutizzata, il trattamento con statine risultava associato a una ridotta mortalità (HR 0,57; IC 95\% 0,38-0,57), con un ulteriore miglioramento della sopravvivenza nei pazienti che assumevano steroidi per via inalatoria [79].

E ancora, in un altro recente studio retrospettivo di coorte effettuato sui dati amministrativi del Veterans Health Care System su 11.212 pazienti ospedalizzati per riacutizzazione di BPCO (età media 74 anni; 98\% di sesso maschile), l'uso di statine e di ACE-inibitori o ARB prima del ricovero risultava associato a una riduzione della mortalità a 90 giorni [80].

Le statine sono inoltre in grado di ridurre il declino della funzione polmonare, indipendentemente dal tipo di patologia polmonare presente [81]. Le proprietà antinfiammatorie delle statine potrebbero fornire la spiegazione di questi effetti favorevoli.

Nella BPCO indotta dal fumo di sigaretta compaiono alterazioni strutturali e funzionali caratterizzate da distruzione del parenchima e ipertensione polmonare. Le statine, in virtù delle loro proprietà antinfiammatorie, dell'effetto scavenger, del ripristino della funzione endoteliale e dell'azione antitrombogenetica, sono in grado di contrastare gli effetti dannosi del fumo. In animali da esperimento (ratti SpragueDowley), la simvastatina è stata infatti capace di inibire la distruzione del parenchima polmonare e lo sviluppo di ipertensione polmonare, così come l'infiltrazione peribronchiale e perivascolare di cellule infiammatorie e l'induzione dell'attività della metalloproteinasi polmonare. In questo modello sperimentale, inoltre, la simvastatina ha svolto un'azione preventiva nei confronti del rimodellamento vascolare polmonare e delle modificazioni della espressione della NO-sintasi a livello endoteliale [82].

Infine, in uno studio effettuato presso l'Oklahoma City VA Medical Center, l'uso delle statine in pazienti fumatori ed ex fumatori (circa la metà dei 418 pazienti complessivi studiati) risultava associato a un declino più lento della funzione polmonare (FEV1 e FVC) indipendentemente dalla malattia polmonare di base (di tipo ostruttivo o restrittivo) e dall'interruzione o prosecuzione del fumo di sigaretta [83].

\section{Cordarone}

L'amiodarone è un farmaco antiaritmico di classe III Vaughan Williams, utilizzato nel trattamento di aritmie ventricolari maligne e sopraventricolari. Il suo impiego, peraltro, può essere gravato da numerosi effetti avversi, quali per esempio la tossicità a livello polmonare e l'insufficienza respiratoria che si presentano con maggiore frequenza nei pazienti con BPCO [84].

Più recentemente sono stati valutati gli effetti sulla funzione polmonare prodotti dall'amiodarone nei pazienti con SC arruolati nel trial clinico randomizzato e controllato CHF-STAT (Congestive Heart Failure-Survival Trial of Antiarrhythmic Therapy) [85]. Non erano presenti differenze significative nei valori basali di DLCO (Diffuse Capacity of Carbon Monoxide) tra i 269 pazienti trattati con amiodarone e i 250 trattati con placebo. Dopo 1 e dopo 2 anni non si evidenziavano significative differenze di tale parametro nei 
due gruppi. Anche nei pazienti affetti da BPCO non emergevano differenze significative della DLCO nei due gruppi di pazienti al basale e dopo 1 e 2 anni. Veniva diagnosticata una fibrosi polmonare in 4 pazienti $(1,1 \%)$ trattati con amiodarone e in 3 pazienti $(0,8 \%)$ che assumevano il placebo. Questo studio ha permesso di valutare che l'amiodarone può essere utilizzato nei pazienti affetti da SC con ragionevole sicurezza e con un'accettabile tossicità a livello polmonare.

\section{Digitale}

La digitale è stata impiegata per molti anni nella terapia del cuore polmonare. Tuttavia non vi è chiara evidenza a supporto dell'uso della digitale nel trattamento del cuore polmonare, a meno che non sia concomitante un'insufficienza ventricolare sinistra [86] o una fibrillazione atriale [87].

A breve termine la digitale migliora la portata cardiaca e riduce le catecolamine in presenza di ipertensione polmonare primitiva. Inoltre, migliora la FE del ventricolo destro nell'insufficienza biventricolare, ma non nell'insufficienza isolata del ventricolo destro. Tuttavia, questo farmaco può provocare vasocostrizione polmonare e aumentare il rischio di aritmie, soprattutto in presenza di ipossiemia e ipercapnia, ovvero in corso di ipopotassiemia, per cui il suo uso è perlopiù limitato ai casi in cui sia compresente una fibrillazione atriale o un'insufficienza ventricolare sinistra [88].

\section{Diuretici}

I diuretici sono somministrati nella BPCO per ridurre gli edemi periferici e la ritenzione idrosodica (con una conseguente riduzione del precarico del ventricolo destro) quando coesista uno SC destro. Essi tuttavia possono indurre, in caso di alti dosaggi, la comparsa di alcalosi metabolica che - quando presente - può aggravare a sua volta l'ipercapnia attenuando il drive respiratorio [89]. Inoltre, un'eccessiva riduzione del volume intravascolare può compromettere un adeguato riempimento del ventricolo destro, peraltro già sottoposto a un incremento del postcarico per un'alterata emodinamica presente nel circolo polmonare. E ancora, i diuretici possono aggravare la viscosità ematica nei pazienti con BPCO quando a essa si associ una policitemia secondaria all'ipossia. Il trattamento diuretico dei pazienti con BPCO e SC destro prevede frequentemente il ricorso all'utilizzo dei diuretici dell'ansa; per questo motivo è obbligatoriamente richiesto un attento monitoraggio del quadro elettrolitico, e talora, in presenza di un disequilibrio, può rendersi necessaria una correzione mediante supplementi di potassio e di magnesio, onde evitare la comparsa di aritmie minacciose. A dosaggi standard dei diuretici, tuttavia, la funzione polmonare non viene abitualmente influenzata [90].

Gli antagonisti dell'aldosterone esercitano un effetto favorevole sulla diffusione dei gas a livello della membrana alveolo-capillare, riducendo il danno prodotto a questo livello dall'aldosterone [90].

\section{Calcio-antagonisti}

I calcio-antagonisti sono di rado utilizzati nella terapia dello SC. Tuttavia, i calcio-antagonisti di-idropiridinici possono essere usati per ottenere un miglior controllo dei valori pressori o per ottenere una più valida stabilizzazione del quadro clinico di una cardiopatia ischemica; quelli non diidropiridinici possono essere introdotti in terapia per ridurre la frequenza cardiaca in pazienti con SC con funzione sistolica conservata ed elevata frequenza cardiaca con/senza fibrillazione atriale. Nonostante una certa riduzione delle pressioni in arteria polmonare e un miglioramento della portata cardiaca, questa classe di farmaci è spesso associata a un peggioramento degli scambi gassosi per un'alterazione del rapporto ventilazione/perfusione con aumento del mismatch $\mathrm{V} / \mathrm{Q}$.

\section{Beta-bloccanti nei pazienti con BPCO e SC}

La terapia con beta-bloccanti nello SC rappresenta un'indicazione farmacologica basata sulle evidenze e riportata in tutte le principali linee guida dello SC; tuttavia essa è ampiamente sottoutilizzata nei pazienti con diagnosi di SC [91-93]. Il sottoutilizzo è in gran parte dovuto alla convinzione radicata che questa classe di farmaci possa determinare un deterioramento della capacità respiratoria in caso di coesistenza di SC e BPCO. Alcuni report che segnalavano la comparsa di broncospasmo acuto dopo l'inizio della terapia con beta-bloccanti hanno favorito l'esclusione dei pazienti con l'associazione di BPCO e SC dai principali trial clinici svolti per testare l'uso di tali farmaci nello SC. A oggi i betabloccanti rimangono sottoprescritti nei pazienti con l'associazione delle due patologie, nonostante la raccolta di una considerevole mole di dati attestanti la sicurezza di impiego nei pazienti affetti da BPCO moderata o severa [94,95].

\section{Beta-bloccanti beta1-selettivi}

I sintomi respiratori e il FEV1 non sono peggiorati in modo significativo dai beta-bloccati beta - $_{1}$-selettivi in corso di BPCO

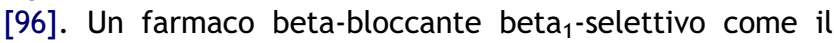
metoprololo tartrato o succinato è risultato ben tollerato per un periodo di 3 mesi in 50 pazienti affetti da cardiopatia ischemica e concomitante BPCO di grado lieve o severo [97]. In questa casistica, sia pure limitata per numero, i pazienti rimanevano privi di sintomi respiratori rilevanti e il FEV1 restava invariato. I beta-bloccanti beta ${ }_{1}$-selettivi non attenuano l'effetto di broncodilatazione indotto dai farmaci beta $_{2}$-agonisti [98]. L'evidenza cumulativa, ricavata da trial clinici e da metanalisi, suggerisce che i beta-bloccanti beta - $^{-}$ selettivi non dovrebbero essere sospesi o non prescritti in caso di coesistenza di BPCO e malattie cardiovascolari, per il fatto che i benefici da essi indotti nei pazienti cardiopatici con associata BPCO sono di gran lunga superiori ai rischi [99].

\section{Beta-bloccanti non selettivi con associato effetto alfa-bloccante}

Il profilo di sicurezza del carvedilolo e del labetalolo (betabloccanti non selettivi con associato effetto alfa-bloccante) in presenza di BPCO non è così ben dimostrato come per $i$ beta-bloccanti beta - $_{1}$-selettivi. Tuttavia il labetalolo a dosi massimali non modifica in modo significativo il FEV1 nei pazienti con BPCO [94] e il carvedilolo, utilizzato per 3 mesi in 89 pazienti con coesistenza di BPCO e SC, è risultato non 
ben tollerato da soli 13 pazienti [100]. In un altro studio, 31 pazienti con coesistenza di SC e BPCO senza evidenza di reversibilità di ostruzione delle vie aeree, trattati con una dose media di carvedilolo di $29 \pm 19 \mathrm{mg} / \mathrm{die}$, sono stato seguiti per una durata media di 2,4 anni: 1 solo paziente non tollerava il farmaco a causa della comparsa di esacerbazione della BPCO [101].

La riduzione delle dimensioni del cuore e il miglioramento della funzione cardiaca - dopo trattamento per 24 mesi con farmaci beta-bloccanti non selettivi e associato effetto alfabloccante - sono risultati essere di entità similare in pazienti con coesistenza di SC e BPCO o con SC isolato [102]. Non sono riscontrabili in letteratura dati riguardanti l'uso del carvedilolo in pazienti con BPCO e ostruzione reversibile delle vie aeree. Va sottolineato che, contrariamente ai beta-bloccanti

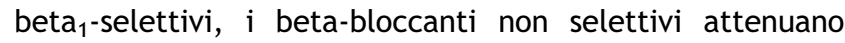
l'effetto broncodilatatore dei beta ${ }_{2}$-agonisti.

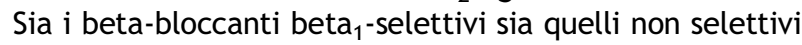
non modificano in modo significativo il tasso di ospedalizzazione per esacerbazione di BPCO in pazienti con recente storia clinica di infarto cardiaco, mentre esercitano un impatto favorevole sulla mortalità [103,104]. Anche in assenza di una recente storia clinica di infarto miocardico l'uso di beta-bloccanti beta ${ }_{1}$-selettivi o non selettivi non modifica il tasso di ospedalizzazione per riacutizzazione di BPCO, anche se alcuni case-report hanno documentato la comparsa di broncospasmo scatenato dall'utilizzo di beta-bloccanti non selettivi [105]. Sulla base di queste evidenze, le principali linee guida sullo SC raccomandano in tutti i pazienti con SC e associata BPCO l'uso dei beta-bloccanti (tabella 1), tenendo presente che tale terapia può essere implementata con successo e in regime di sicurezza seguendo un programma strutturato di controlli in regime ambulatoriale [106].

\section{Effetti polmonari tempo-dipendenti indotti dai beta-bloccanti}

I beta-bloccanti esercitano effetti opposti sui polmoni in acuto e nel lungo periodo. Un'ipersensibilità delle vie aeree (definita come una riduzione del FEV1 dopo metacolina $\geq$ $20 \%)$ è associata a un aumentato tasso di mortalità nei pazienti affetti da BPCO. La somministrazione in acuto di beta-bloccanti - selettivi o non selettivi - aumenta l'ipersensibilità bronchiale nei pazienti con BPCO [98], mentre in un modello murino la somministrazione di carvedilolo o di nadololo, dopo un iniziale incremento, riduce l'ipersensibilità bronchiale [107]. Non sono noti al momento dati riferiti all'ipersensibilità bronchiale con l'uso a lungo termine di beta-bloccanti nei pazienti con BPCO. Inoltre, la densità dei recettori dei beta-bloccanti, pur non essendo modificata in acuto dalla somministrazione di beta-bloccanti, aumenta dopo un uso prolungato. Un aumento della densità dei recettori per i beta-bloccanti può risultare di beneficio, in quanto una sovraespressione di recettori beta $a_{2}$ aumenta l'effetto della adenilciclasi sulla muscolatura liscia delle vie aeree e riduce l'ipersensibilità bronchiale [108].

In sintesi, gli effetti negativi dei beta-bloccanti sull'ipersensibilità bronchiale presenti quando essi sono somministrati in acuto possono nel lungo periodo trasformarsi in effetti benefici. Di conseguenza, un precoce e lieve peggioramento dei sintomi o del FEV1 nei pazienti con SC e BPCO associati non dovrebbe necessariamente comportare una sospensione dei beta-bloccanti. Ovviamente è raccomandabile una stretta sorveglianza clinica e, in caso di persistenza o peggioramento dei sintomi, dovrebbe essere consigliata la loro sospensione.

\section{Selettività dei beta-bloccanti per i recettori beta}

I beta-bloccanti beta ${ }_{1}$-selettivi hanno un'affinità per i recettori beta 20 volte superiore rispetto ai recettori beta . $_{1}$ Pertanto, è verosimile che $\mathrm{i}$ beta-bloccanti beta - $_{1}$-selettivi inducano meno broncocostrizione rispetto ai beta-bloccanti non selettivi [109].

La selettività per i beta-recettori varia in base a differenti condizioni.

- I recettori beta ${ }_{2}$ predominano a livello della muscolatura liscia dei bronchi, mentre i recettori beta ${ }_{1}$ costituiscono,

Tabella 1 Beta-bloccanti impiegati nello SC associato a BPCO.

\begin{tabular}{|c|c|c|c|c|c|c|}
\hline Farmaco & $\begin{array}{l}\text { Attività di } \\
\text { blocco dei } \\
\text { recettori } \\
\text { adrenergici }\end{array}$ & $\begin{array}{l}\text { Dosaggio } \\
\text { nello SC }\end{array}$ & $\begin{array}{l}\text { Dosi utilizzate } \\
\text { nei trial }\end{array}$ & $\begin{array}{l}\text { Effetto a lungo } \\
\text { termine sul FEV1 } \\
\text { (ostruzione } \\
\text { irreversibile) }\end{array}$ & $\begin{array}{l}\text { Effetto a lungo } \\
\text { termine sul FEV1 } \\
\text { (ostruzione } \\
\text { reversibile) }\end{array}$ & $\begin{array}{l}\text { Sintomi } \\
\text { respiratori }\end{array}$ \\
\hline Bisoprololo & Beta $_{1}$ & $1,25-10 \mathrm{mg} / \mathrm{die}$ & $20 \mathrm{mg} / \mathrm{die}$ & NA & NA & No \\
\hline Metoprololo & Beta $_{1}$ & $12,5-200 \mathrm{mg} / \mathrm{die}$ & $\begin{array}{c}200 \mathrm{mg} / \mathrm{die} \\
100 \mathrm{mg} \times 2100 \mathrm{mg} \times 2 \\
50 \mathrm{mg} \times 3 \\
100 \mathrm{mg} \times 2\end{array}$ & $\begin{array}{l}\text { NA } \\
\text { NA } \\
\text { NA } \\
\downarrow \\
\downarrow\end{array}$ & $\begin{array}{c}\text { NA } \\
\text { Escluso } \\
\text { Non specificato } \\
\text { Non specificato } \\
\text { Non specificato }\end{array}$ & 1/6 pazienti \\
\hline Carvedilolo & $\begin{array}{l}\text { Beta }_{1} \\
\text { Beta }_{2} \\
\text { Alfa }_{1} \\
\end{array}$ & $3,125-25 \mathrm{mg} \times 2$ & $\begin{array}{c}29 \pm 19 \mathrm{mg} / \mathrm{die} \\
12,5-25 \mathrm{mg} \times 2\end{array}$ & $\begin{array}{l}\text { NA } \\
\text { NA }\end{array}$ & $\begin{array}{c}\text { Escluso } \\
\text { Non specificato }\end{array}$ & $\begin{array}{l}\text { 1/31 pazienti } \\
13 / 89 \text { pazienti }\end{array}$ \\
\hline Nebivololo & $\begin{array}{c}\text { Beta }_{1} \\
\text { Vasodilazione } \\
\text { NON mediata }\end{array}$ & $1,25-10 \mathrm{mg} / \mathrm{die}$ & $10 \mathrm{mg} / \mathrm{die}$ & NA & NA & No \\
\hline
\end{tabular}

Legenda: $\mathrm{NA}=$ non disponibile. 
rispettivamente, il $10 \%$ e il $30 \%$ dei beta-recettori a livello delle ghiandole sottomucose e delle pareti degli alveoli [110].

- I beta-bloccanti beta ${ }_{1}$-selettivi tendono a perdere la loro selettività a un dosaggio ai limiti superiori del range terapeutico.

- È stato descritto un polimorfismo dei beta-recettori.

- Una precedente esposizione ai beta $a_{2}$-agonisti può modificare i recettori beta ${ }_{2}$, tanto da ridurre l'affinità del ligando fino a 10 volte [111]; di conseguenza, una precedente esposizione ai beta $a_{2}$-agonisti può ridurre il legame degli antagonisti ai recettori beta $a_{2}$. Ciò potrebbe spiegare la spiccata tollerabilità all'uso dei beta-bloccanti nei pazienti affetti da BPCO che seguono una terapia continuativa con beta $a_{2}$-agonisti per via inalatoria.

In sintesi, la selettività dei beta-bloccanti ai recettori è variabile, ma non è ancora chiarito quanto questa variabilità possa essere importante per l'approccio terapeutico ai pazienti con BPCO e SC.

\section{Uso concomitante di beta-bloccanti e beta ${ }_{2}$-agonisti inalatori}

In considerazione del rischio cardiovascolare associato all'uso dei farmaci beta ${ }_{2}$-agonisti per via inalatoria, i beta-bloccanti non selettivi potrebbero esercitare un effetto particolarmente benefico nei pazienti con SC e BPCO. Sono ben conosciuti gli effetti cardiovascolari negativi degli agonisti dei recettori beta $a_{2}$ per via inalatoria, che pure rappresentano una fondamentale opzione terapeutica nella BPCO. Una recente metanalisi - effettuata su 5 trial che hanno indagato gli effetti di una dose singola di beta $a_{2}$-agonisti e su 6 trial che hanno impiegato tali farmaci per un periodo più lungo - ha evidenziato inequivocabilmente gli effetti cardiovascolari negativi di questa classe di farmaci nei pazienti affetti da BPCO [51]. La terapia con beta $_{2}$-agonisti per via inalatoria è associata a un rischio aumentato di instabilizzazione di uno SC cronico (OR 3,42; IC 95\% 1,99-5,86) e di mortalità per tutte le cause in pazienti

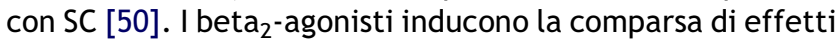
cardiaci avversi nei pazienti con malattie cardiovascolari preesistenti [53]. Si stima che gli effetti avversi indotti dai beta $a_{2}$-agonisti siano più evidenti nei pazienti con BPCO associata a SC. Non è ancora stato chiarito da trial clinici mirati quanto il concomitante utilizzo di beta-bloccanti sia in grado di contrastare questi effetti negativi.

\section{Considerazioni conclusive sui beta-bloccanti}

In tutti i pazienti affetti da SC in associazione con una BPCO stabilizzata, ma senza ostruzione reversibile delle vie aeree, dovrebbe essere introdotta una terapia con beta-bloccanti, utilizzando un farmaco beta ${ }_{1}$-selettivo ovvero un farmaco con azione combinata di blocco beta-adrenergico non selettivo e alfa-adrenergico.

Nei pazienti con SC e BPCO con ostruzione reversibile delle vie aeree è consigliato l'utilizzo di beta-bloccanti beta ${ }_{1}$ selettivi, mancando dati sulla sicurezza di impiego dei farmaci beta-bloccanti non selettivi con associata azione betaantagonista.

Durante le riacutizzazioni della BPCO è comunque prudente evitare l'uso dei farmaci beta-bloccanti in genere.

\section{Linee guida dello SC e della BPCO}

Com'è noto, le linee guida sono prevalentemente orientate alla gestione diagnostica e terapeutica di singole patologie, con limitati accenni alle modalità di comportamento in caso di malattie multiple associate. Tuttavia, l'adesione a multiple linee guida mirate alla cure delle singole patologie presenti nel medesimo paziente può esporre i soggetti più anziani, portatori di numerose comorbilità, al rischio di eventi avversi [112]. Infatti, non sempre il trattamento dedicato a una singola patologia costituisce la migliore opzione terapeutica per il paziente considerato nella sua globalità [113].

Nelle più recenti linee guida della Società Europea di Cardiologia sulla diagnosi e terapia dello SC acuto e cronico [2] sono riportati solo alcuni sintetici riferimenti alla terapia dello SC in concomitanza con BPCO.

- I farmaci con documentati effetti sulla morbilità e mortalità nei pazienti con SC (ACE-inibitori, beta-bloccanti, ARB) sono raccomandati nei pazienti con coesistenti patologie polmonari.

- La maggior parte dei pazienti con SC e BPCO è in grado di tollerare una terapia con beta-bloccanti; è raccomandabile iniziare con dosi basse e ottimizzare il dosaggio con gradualità; un lieve deterioramento della funzione polmonare e un peggioramento dei sintomi non deve di per sé portare alla decisione di sospendere il trattamento con beta-bloccanti; tuttavia se i sintomi peggiorano si rende necessaria una riduzione o sospensione del trattamento. I beta-bloccanti beta ${ }_{1}$-selettivi rappresentano comunque l'opzione preferibile.

- Una storia clinica di asma bronchiale dovrebbe essere considerata una controindicazione all'uso dei betabloccanti.

- I farmaci beta-agonisti devono essere somministrati come necessario nei pazienti con BPCO.

- La coesistenza di SC e BPCO riduce in modo rilevante la tolleranza allo sforzo fisico; l'attivazione di programmi riabilitativi appropriati può contribuire a migliorare la funzione dei muscoli scheletrici e l'affaticamento.

Nel recente aggiornamento delle linee guida dell'American College of Cardiology/American Heart Association sullo SC [1] sono molto vaghi e sintetici gli accenni relativi alla terapia dello SC nei pazienti con malattia polmonare associata.

- Alcuni farmaci utilizzati nella terapia dello SC possono generare o peggiorare sintomi polmonari. Gli ACE-inibitori possono provocare una tosse non produttiva persistente che può essere confusa con un'infezione respiratoria; la terapia con ACE-inibitori può in taluni casi essere interrotta in modo inappropriato; in tutti $i$ pazienti con SC che lamentano tosse, con o senza un trattamento in atto con ACE-inibitori, si dovrebbe ricercare una possibile causa polmonare di questo sintomo; la tosse dovrebbe essere attribuita all'ACE-inibitore solo dopo esclusione di patologie polmonari e se il sintomo scompare dopo la sospensione del farmaco e ricompare dopo la sua reintroduzione; poiché la tosse correlata all'uso di ACE-inibitori non rappresenta una malattia grave, molti pazienti potrebbero essere invitati a tollerare il sintomo in virtù degli effetti favorevoli connessi all'utilizzo degli ACE-inibitori. 
- I beta-bloccanti possono aggravare i sintomi collegati al broncospasmo nei pazienti affetti da asma bronchiale; tuttavia, molti pazienti con malattie delle vie aeree asintomatiche o di modesta entità tollerano bene i beta-bloccanti; inoltre la maggior parte dei pazienti con BPCO non ha una significativa componente broncospastica e rimane pertanto candidata al trattamento con beta-bloccanti. È da sottolineare che il bisoprololo e il metoprololo possono perdere la loro beta la $_{1}$-selettività quando sono impiegati alle dosi associate a una riduzione della mortalità nei pazienti con SC.

\section{Linee guida GOLD}

Nell'ambito del Progetto mondiale BPCO 2009 - GOLD [3] sono ripresi alcuni temi collegati alla presenza di comorbilità. Più nel dettaglio, vengono affrontati alcuni aspetti di seguito sinteticamente esposti.

- La BPCO si associa frequentemente ad altre malattie croniche, definite comorbilità, con elevata prevalenza e significativa importanza clinica.

- Le comorbilità possono essere classificate come

1) concausali: malattie che condividono fattori di rischio con la BPCO (malattie aterosclerotiche coronariche, cerebrali, periferiche; insufficienza renale; neoplasia polmonare; SC, aneurisma aortico);

2) complicanti: malattie accompagnate da effetti sistemici della BPCO (depressione; deficit cognitivo; osteoporosi; sarcopenia; aritmie; embolia polmonare);

3) concomitanti: malattie croniche coesistenti, senza relazione causale nota con la BPCO (glaucoma; sindrome delle apnee ostruttive del sonno; diabete mellito; anemia; patologia peptica).

- La distinzione fra le 3 categorie non sempre è agevole.

- Nel programmare la gestione del paziente è indispensabile tener conto di possibili condizioni morbose concomitanti, molto comuni nei pazienti di età $>65$ anni; per questi ultimi appare quindi opportuno uno screening delle principali comorbilità.

- Non è noto se l'applicazione contemporanea di linee guida rivolte a differenti patologie interferisca con il raggiungimento degli obiettivi terapeutici di ciascuna condizione.

- In futuro la formulazione e l'implementazione di specifiche linee guida dovranno avvalersi di un contributo multidisciplinare comprendente in particolare il medico di Medicina Generale.

\section{Disease management}

Il disease management può essere considerato come un approccio sistematico alla gestione globale e a lungo termine dei pazienti affetti da malattie croniche; sono patologie oggi sempre più frequenti in considerazione del progressivo invecchiamento della popolazione, tali da esercitare un rilevante impatto sul singolo individuo, sulla società nel suo complesso e sull'economia dei sistemi sanitari. Il disease management è definito come un approccio integrato alla malattia, teso al miglioramento dei risultati clinici e della qualità dei servizi offerti, nell'ottica di una razionalizzazione della spesa. Si tratta, in altri termini, di azioni coordinate, a valenza multidisciplinare e multiprofessionale, volte a migliorare il rapporto costo-efficacia nella cura di malattie ad andamento cronico ma passibili di periodiche riacutizzazioni.

Dal punto di vista metodologico, sono 8 i domini di cui si compone il disease management [114]:

- popolazione di riferimento: profilo demografico, stratificazione del rischio, livello di comorbilità presenti [115];

- destinatari dell'intervento: pazienti, familiari e care-giver, medici, operatori sanitari;

- contenuti dell'intervento sanitario: educazione sanitaria, gestione della terapia, supporti vari;

- personale sanitario coinvolto: rete di operatori, case manager, professionisti di varia competenza;

- modalità di comunicazione: diretta, cartacea, telefonica, telematica;

- intensità e complessità degli interventi;

- setting assistenziale: ospedaliero, territoriale;

- valutazione dell'outcome clinico.

Elementi chiave del disease management sono rappresentati da uno stretto coordinamento del processo di cura, da un'adeguata comunicazione, dalle azioni volte a favorire un'autogestione della malattia da parte del paziente (selfmanagement). Si tratta cioè di attivare forme collaborative di pratica clinica, verificando mediante opportuni indicatori i risultati raggiunti.

\section{Disease management dello SC}

La letteratura sul disease management dello SC è assai ricca, a partire dai primi studi storici che hanno aperto la strada a questa modalità di approccio gestionale [116] fino alle metanalisi degli anni 2004 e 2005 che hanno dimostrato la validità di tale approccio in termini di morbilità e qualità di vita, ma con alcuni dubbi circa l'efficacia in termini di mortalità [117-120].

\section{Disease management della BPCO}

Anche per il disease management della BPCO è presente nella letteratura medica un'ampia documentazione.

Elementi chiave di questo modello terapeutico sono rappresentati dalla promozione di programmi di self-management $[121,122]$ e dall'attivazione di interventi di riabilitazione polmonare [123].

Tuttavia, nel mondo reale sono ancora insufficienti - da parte dei pazienti affetti da BPCO - la conoscenza della propria malattia e l'adesione alle misure terapeutiche validate dalle linee guida [124].

L'implementazione di un modello dedicato alle malattie croniche è da considerarsi una strategia efficace nel trattamento della BPCO [125]; gli interventi più significativi di un modello organizzativo-gestionale mirato alla cura delle patologie croniche sono riconducibili a:

- self-management (educazione e motivazione dei pazienti); - pianificazione delle dimissioni (coordinamento delle cure);

- riferimento alle linee guida quale supporto alle decisioni cliniche;

- utilizzo di un sistema informativo (registri di patologia, reminder, feedback tra operatori).

Nonostante la grande mole di dati presenti in letteratura sul disease management dello SC e della BPCO, oggi 
sussistono ancora numerosi dubbi circa le migliori opzioni organizzative da attivare e le problematiche da chiarire [126]:

- definizione dei meccanismi in base ai quali si realizzano gli effetti benefici;

- omogeneità di efficacia nei vari approcci;

- durata della presa in carico;

- possibile dipendenza dei benefici dal singolo operatore;

- efficacia anche in caso di presenza di comorbilità.

In particolare, le modalità per valutare le prove di efficacia negli studi sui programmi di disease management sono ancora da perfezionare: la tipologia degli interventi spesso è descritta sommariamente (contenuti, componenti, operatori coinvolti, procedure), il confronto viene effettuato con le cure routinarie che peraltro variano da luogo a luogo, le modalità e i tempi di misurazione degli effetti non sono definiti nel dettaglio, vengono spesso a mancare valutazioni nel lungo periodo [127].

Due recenti metanalisi hanno sollevato perplessità circa la reale efficacia di un programma di disease management nel ridurre la mortalità per tutte le cause nei pazienti con SC [128] e in quelli con BPCO [129], ferma restando l'efficacia nel migliorare la qualità di vita e la capacità di esercizio e nel ridurre le ospedalizzazioni.

\section{Telemedicina}

Infine, si stanno affacciando nella pratica clinica modelli assistenziali basati sulla comunicazione e trasmissione di dati mediante apparecchiature telematiche. Questi modelli presuppongono la disponibilità di tecnologie avanzate e la realizzazione di un adeguato programma di educazione e addestramento dei pazienti e dei loro familiari [130,131]. La validazione di tali modelli organizzativi e una loro estesa applicazione nella pratica clinica richiedono tuttora conferme e soprattutto il completamento di studi più approfonditi ed estesi [132]; tuttavia, rappresentano strategie promettenti specialmente nella cura dei pazienti a maggior rischio.

\section{Bibliografia}

[1] Jessup M, Abraham WT, Casey DE, Feldman AM, Francis GS, Ganiats TG, et al. 2009 focused update: ACCF/AHA Guidelines for the Diagnosis and Management of Heart Failure in Adults: a report of the American College of Cardiology Foundation/ American Heart Association Task Force on Practice Guidelines: developed in collaboration with the International Society for Heart and Lung Transplantation. Circulation 2009;119(14): 1977-2016.

[2] Task Force for Diagnosis and Treatment of Acute and Chronic Heart Failure 2008 of European Society of Cardiology, Dickstein K, Cohen-Solal A, Filippatos G, McMurray JJ, Ponikowski P, Poole-Wilson PA, et al; ESC Committee for Practice Guidelines, Vahanian A, Camm J, De Caterina R, Dean V, Dickstein K, Filippatos G, et al. ESC Guidelines for the diagnosis and treatment of acute and chronic heart failure 2008: the Task Force for the Diagnosis and Treatment of Acute and Chronic Heart Failure 2008 of the European Society of Cardiology. Developed in collaboration with the Heart Failure Association of the ESC (HFA) and endorsed by the European Society of Intensive Care Medicine (ESICM). Eur Heart J 2008; 29(19):2388-442.
[3] The Global Initiative for Chronic Obstructive Lung Disease (GOLD). Global strategy for the diagnosis, management, and prevention of chronic obstructive pulmonary disease: NHLBI/ WHO workshop report 2006; updated 2009. http: / / www.goldcopd.com/

[4] Chapman KR, Mannino DM, Soriano JB, Vermeire PA, Buist AS, Thun MJ, et al. Epidemiology and costs of chronic obstructive pulmonary disease. Eur Respir J 2006;27(1):188-207.

[5] Kitzman DW, Gardin JM, Gottdiener JS, Arnold A, Boineau R, Aurigemma G, et al., Cardiovascular Health Study Research Group. Importance of heart failure with preserved systolic function in patients $>$ or $=65$ years of age. CHS Research Group. Cardiovascular Health Study. Am J Cardiol 2001;87(4): 413-9.

[6] Hawkins NM, Petrie MC, Jhund PS, Chalmers GW, Dunn FG, McMurray JJ. Heart failure and chronic obstructive pulmonary disease: diagnostic pitfalls and epidemiology. Eur J Heart Fail 2009;11(2):130-9.

[7] Gustafsson F, Torp-Pedersen C, Seibaek M, Burchardt H, Køber L, DIAMOND Study Group. Effect of age on short and long-term mortality in patients admitted to hospital with congestive heart failure. Eur Heart J 2004;25(19):1711-7.

[8] Gambassi G, Forman DE, Lapane KL, Mor V, Sgadari A, Lipsitz $\mathrm{LA}$, et al. Management of heart failure among very old persons living in long-term care: has the voice of trials spread? The 3 SAGE Study Group. Am Heart J 2000;139(1 Pt 1):85-93.

[9] Havranek EP, Masoudi FA, Westfall KA, Wolfe P, Ordin DL, Krumholz HM. Spectrum of heart failure in older patients: results from the National Heart Failure project. Am Heart $J$ 2002;143(3):412-7.

[10] van der Wel MC, Jansen RW, Bakx JC, Bor HH, Olderikkert MG, van Weel C. Non-cardiovascular co-morbidity in elderly patients with heart failure outnumbers cardiovascular comorbidity. Eur J Heart Fail 2007;9(6-7):709-15.

[11] Gustafsson F, Torp-Pedersen C, Burchardt H, Buch P, Seibaek M, Kjøller E, et al., DIAMOND Study Group. Female sex is associated with a better long-term survival in patients hospitalized with congestive heart failure. Eur Heart J 2004;25(2):129-35.

[12] Harjai KJ, Nunez E, Stewart Humphrey J, Turgut T, Shah M, Newman J. Does gender bias exist in the medical management of heart failure? Int J Cardiol 2000;75(1):65-9.

[13] Vaccarino V, Chen YT, Wang Y, Radford MJ, Krumholz HM. Sex differences in the clinical care and outcomes of congestive heart failure in the elderly. Am Heart J 1999;138(5 Pt 1): 835-42.

[14] Martínez-Sellés M, García Robles JA, Prieto L, Domínguez Muñoa M, Frades E, Díaz-Castro O, et al. Systolic dysfunction is a predictor of long term mortality in men but not in women with heart failure. Eur Heart J 2003;24(22):2046-53.

[15] Macchia A, Monte S, Romero M, D'Ettorre A, Tognoni G. The prognostic influence of chronic obstructive pulmonary disease in patients hospitalised for chronic heart failure. Eur $\mathrm{J}$ Heart Fail 2007;9(9):942-8.

[16] Bursi F, Weston SA, Redfield MM, Jacobsen SJ, Pakhomov S, Nkomo VT, et al. Systolic and diastolic heart failure in the community. JAMA 2006;296(18):2209-16.

[17] Bhatia RS, Tu JV, Lee DS, Austin PC, Fang J, Haouzi A, et al. Outcome of heart failure with preserved ejection fraction in a population-based study. N Engl J Med 2006;355(3):260-9.

[18] Curkendall SM, DeLuise C, Jones JK, Lanes S, Stang MR, Goehring Jr E, et al. Cardiovascular disease in patients with chronic obstructive pulmonary disease. Saskatchewan Canada cardiovascular disease in COPD patients. Ann Epidemiol 2006;16(1): 63-70.

[19] McCullough PA, Hollander JE, Nowak RM, Storrow AB, Duc P, Omland T, et al., BNP Multinational Study Investigators. Uncovering heart failure in patients with a history of pulmonary disease: rationale for the early use of B-type natriuretic 
peptide in the emergency department. Acad Emerg Med 2003;10(3):198-204.

[20] Rutten FH, Cramer MJ, Grobbee DE, Sachs AP, Kirkels JH, Lammers JW, et al. Unrecognized heart failure in elderly patients with stable chronic obstructive pulmonary disease. Eur Heart J 2005;26(18):1887-94.

[21] Naeije R. Pulmonary hypertension and right heart failure in chronic obstructive pulmonary disease. Proc Am Thorac Soc 2005;2(1):20-2.

[22] Rutten FH, Cramer MJ, Lammers JW, Grobbee DE, Hoes AW. Heart failure and chronic obstructive pulmonary disease: An ignored combination? Eur J Heart Fail 2006;8(7):706-11.

[23] McKee PA, Castelli WP, McNamara PM, Kannel WB. The natural history of congestive heart failure: the Framingham study. $\mathrm{N}$ Engl J Med 1971;285(26):1441-6.

[24] Schellenbaum GD, Rea TD, Heckbert SR, Smith NL, Lumley T, Roger VL, et al. Survival associated with two sets of diagnostic criteria for congestive heart failure. Am J Epidemiol 2004;160(7):628-35.

[25] Milne EN, Bass H. Roentgenologic and functional analysis of combined chronic obstructive pulmonary disease and congestive cardiac failure. Invest Radiol 1969;4(3):129-47.

[26] Gehlbach BK, Geppert E. The pulmonary manifestations of left heart failure. Chest 2004;125(2):669-82.

[27] Milne EN. Correlation of physiologic findings with chest roentgenology. Radiol Clin North Am 1973;11(1):17-47.

[28] Rutten FH, Moons KG, Cramer MJ, Grobbee DE, Zuithoff NP, Lammers JW, et al. Recognising heart failure in elderly patients with stable chronic obstructive pulmonary disease in primary care: cross sectional diagnostic study. BMJ 2005;331(7529):1379.

[29] Vizza CD, Lynch JP, Ochoa LL, Richardson G, Trulock EP. Right and left ventricular dysfunction in patients with severe pulmonary disease. Chest 1998;113(3):576-83.

[30] Pennell DJ, Sechtem UP, Higgins CB, Manning WJ, Pohost GM, Rademakers FE, et al., Society for Cardiovascular Magnetic Resonance; Working Group on Cardiovascular Magnetic Resonance of the European Society of Cardiology. Clinical indications for cardiovascular magnetic resonance (CMR): Consensus Panel report. Eur Heart J 2004;25(21):1940-65.

[31] Silver MA, Maisel A, Yancy CW, McCullough PA, Burnett Jr JC, Francis GS, et al., BNP Consensus Panel. BNP Consensus Panel 2004: A clinical approach for the diagnostic, prognostic, screening, treatment monitoring, and therapeutic roles of natriuretic peptides in cardiovascular diseases. Congest Heart Fail 2004;10(5 Suppl 3):1-30.

[32] Morrison LK, Harrison A, Krishnaswamy P, Kazanegra R, Clopton P, Maisel A. Utility of a rapid B-natriuretic peptide assay in differentiating congestive heart failure from lung disease in patients presenting with dyspnea. J Am Coll Cardiol 2002;39(2):202-9.

[33] Bozkanat E, Tozkoparan E, Baysan O, Deniz O, Ciftci F, Yokusoglu $M$. The significance of elevated brain natriuretic peptide levels in chronic obstructive pulmonary disease. J Int Med Res 2005;33(5):537-44.

[34] Rutten FH, Cramer MJ, Zuithoff NP, Lammers JW, Verweij W, Grobbee DE, et al. Comparison of B-type natriuretic peptide assays for identifying heart failure in stable elderly patients with a clinical diagnosis of chronic obstructive pulmonary disease. Eur J Heart Fail 2007;9(6-7):651-9.

[35] Light RW, George RB. Serial pulmonary function in patients with acute heart failure. Arch Intern Med 1983;143(3): 429-33.

[36] Peterman W, Barth J, Entzian P. Heart failure and airway obstruction. Int J Cardiol 1987;17:207-9.

[37] Wasserman K, Zhang YY, Gitt A, Belardinelli R, Koike A, Lubarsky $L$, et al. Lung function and exercise gas exchange in chronic heart failure. Circulation 1997;96(7):2221-7.
[38] Guazzi M. Alveolar-capillary membrane dysfunction in heart failure: evidence of a pathophysiologic role. Chest 2003;124(3):1090-102.

[39] Meyer FJ, Borst MM, Zugck C, Kirschke A, Schellberg D, Kübler $\mathrm{W}$, et al. Respiratory muscle dysfunction in congestive heart failure: clinical correlation and prognostic significance. Circulation 2001;103(17):2153-8.

[40] US Department of Health and Human Services. The health consequences of smoking: a report of the Surgeon General. Atlanta, Georgia: US Department of Health and Human Services, CDC, National Center for Chronic Disease Prevention and Health Promotion, Office on Smoking and Health, 2004.

[41] Anthonisen NR, Skeans MA, Wise RA, Manfreda J, Kanner RE, Connett JE, Lung Health Study Research Group. The effects of a smoking cessation intervention on 14.5-year mortality: a randomized clinical trial. Ann Intern Med 2005;142(4):233-9.

[42] Hoffman RM, Psaty BM, Kronmal RA. Modifiable risk factors for incident heart failure in the coronary artery surgery study. Arch Intern Med 1994;154(4):417-23.

[43] Suskin N, Sheth T, Negassa A, Yusuf S. Relationship of current and past smoking to mortality and morbidity in patients with left ventricular dysfunction. J Am Coll Cardiol 2001;37(6): 1677-82.

[44] Schocken DD, Benjamin EJ, Fonarow GC, Krumholz HM, Levy D, Mensah GA, et al., American Heart Association Council on Epidemiology and Prevention; American Heart Association Council on Clinical Cardiology; American Heart Association Council on Cardiovascular Nursing; American Heart Association Council on High Blood Pressure Research; Quality of Care and Outcomes Research Interdisciplinary Working Group; Functional Genomics and Translational Biology Interdisciplinary Working Group. Prevention of heart failure: a scientific statement from the American Heart Association Councils on Epidemiology and Prevention, Clinical Cardiology. Cardiovascular Nursing, and High Blood Pressure Research; Quality of Care and Outcomes Research Interdisciplinary Working Group; and Functional Genomics and Translational Biology Interdisciplinary Working Group. Circulation 2008;117(19):2544-65.

[45] Troosters T, Casaburi R, Gosselink R, Decramer M. Pulmonary rehabilitation in chronic obstructive pulmonary disease. Am J Respir Crit Care Med 2005;172(1):19-38.

[46] Eyre H, Kahn R, Robertson RM, Clark NG, Doyle C, Hong Y, et al., American Cancer Society; American Diabetes Association; American Heart Association. Preventing cancer, cardiovascular disease, and diabetes: a common agenda for the American Cancer Society, the American Diabetes Association, and the American Heart Association. Circulation 2004;109(25): 3244-55.

[47] O'Connor CM, Whellan DJ, Lee KL, Keteyian SJ, Cooper LS, Ellis SJ, et al., HF-ACTION Investigators. Efficacy and safety of exercise training in patients with chronic heart failure: HFACTION randomized controlled trial. JAMA 2009;301(14): 1439-50.

[48] Kim V, Benditt JO, Wise RA, Sharafkhaneh A. Oxygen therapy in chronic obstructive pulmonary disease. Proc Am Thorac Soc 2008;5(4):513-8.

[49] Sengstock DM, Obeidat O, Pasnoori V, Mehra P, Sandberg KR, McCullough PA. Asthma, beta-agonists, and development of congestive heart failure: results of the ABCHF study. J Card Fail 2002;8(4):232-8.

[50] Au DH, Udris EM, Fan VS, Curtis JR, McDonell MB, Finn SD. Risk of mortality and heart failure exacerbations associated with inhaled beta-adrenoceptor agonists among patients with known left ventricular systolic dysfunction. Chest 2003; 123(6):1964-9.

[51] Salpeter SR, Ormiston TM, Salpeter EE. Cardiovascular effects of beta-agonists in patients with asthma and COPD: a metaanalysis. Chest 2004;125(6):2309-21. 
[52] Au DH, Udris EM, Curtis JR, MCDonell MB, Fihn SD, ACQUIP Investigators. Association between chronic heart failure and inhaled beta-2-adrenoceptor agonists. Am Heart J 2004;148(5):915-20.

[53] Cazzola M, Imperatore F, Salzillo A, Di Perna F, Calderaro F, Imperatore A, et al. Cardiac effects of formoterol and salmeterol in patients suffering from COPD with preexisting cardiac arrhythmias and hypoxemia. Chest 1998;114(2):411-5.

[54] Ferguson GT, Funck-Brentano C, Fischer T, Darken P, Reisner C. Cardiovascular safety of salmeterol in COPD. Chest 2003;123(6):1817-24.

[55] Calverley PM, Anderson JA, Celli B, Ferguson GT, Jenkins C, Jones PW, et al., TORCH investigators. Salmeterol and fluticasone propionate and survival in chronic obstructive pulmonary disease. N Engl J Med 2007;356(8):775-89.

[56] McGarvey LP, John M, Anderson JA, Zvarich M, Wise RA, TORCH Clinical Endpoint Committee. Ascertainment of cause-specific mortality in COPD: operations of the TORCH Clinical Endpoint Committee. Thorax 2007;62(5):411-5.

[57] Casaburi R, Mahler DA, Jones PW, Wanner A, San PG, ZuWallack $\mathrm{RL}$, et al. A long-term evaluation of once-daily inhaled tiotropium in chronic obstructive pulmonary disease. Eur Respir J 2002;19(2):217-24.

[58] Singh S, Loke YK, Furberg CD. Inhaled anticholinergics and risk of major adverse cardiovascular events in patients with chronic obstructive pulmonary disease: a systematic review and meta-analysis. JAMA 2008;300(12):1439-50.

[59] Tashkin DP, Celli B, Senn S, Burkhart D, Kesten S, Menjoge S, et al., UPLIFT Study Investigators. A 4-year trial of tiotropium in chronic obstructive pulmonary disease. $\mathrm{N}$ Engl J Med 2008;359(15):1543-54.

[60] Lee TA, Wilke C, Joo M, Stroupe KT, Krishnan JA, Schumock GT, et al. Outcomes associated with tiotropium use in patients with chronic obstructive pulmonary disease. Arch Intern Med 2009;169(15):1403-10.

[61] Souverein PC, Berard A, Van Staa TP, Cooper C, Egberts AC, Leufkens HG, et al. Use of oral glucocorticoids and risk of cardiovascular and cerebrovascular disease in a population based case-control study. Heart 2004;90(8):859-65.

[62] Sin DD, Wu L, Anderson JA, Anthonisen NR, Buist AS, Burge PS, et al. Inhaled corticosteroids and mortality in chronic obstructive pulmonary disease. Thorax 2005;60(12):992-7.

[63] Bittar G, Friedman HS. The arrhythmogenicity of theophylline. A multivariate analysis of clinical determinants. Chest 1991;99(6):1415-20.

[64] Sessler CN, Cohen MD. Cardiac arrhythmias during theophylline toxicity. A prospective continuous electrocardiographic study. Chest 1990;98(3):672-8.

[65] Ram FS, Jones PW, Castro AA, De Brito JA, Atallah AN, Lacasse $\mathrm{Y}$, et al. Oral theophylline for chronic obstructive pulmonary disease. Cochrane Database Syst Rev 2002;(4):CD003902.

[66] Hendeles L, Jenkins J, Temple R. Revised FDA labeling guideline for theophylline oral dosage forms. Pharmacotherapy 1995;15(4):409-27.

[67] Jones A, Woods DR. Skeletal muscle RAS and exercise performance. Int J Biochem Cell Biol 2003;35(6):855-66.

[68] Anker SD, Negassa A, Coats AJ, Afzal R, Poole-Wilson PA, Cohn $\mathrm{JN}$, et al. Prognostic importance of weight loss in chronic heart failure and the effect of treatment with angiotensin-converting-enzyme inhibitors: an observational study. Lancet 2003;361(9363):1077-83.

[69] Coirault $C$, Hagège $A$, Chemla $D$, Fratacci $M D$, Guérot $C$, Lecarpentier $Y$. Angiotensin-converting enzyme inhibitor therapy improves respiratory muscle strength in patients with heart failure. Chest 2001;119(6):1755-60.

[70] Maggio M, Ceda GP, Lauretani F, Pahor M, Bandinelli S, Najjar SS, et al. Relation of angiotensin-converting enzyme inhibitor treatment to insulin-like growth factor-1 serum levels in subjects $>65$ years of age (the InCHIANTI study). Am J Cardiol 2006;97(10):1525-9.

[71] Andreas S, Anker SD, Scanlon PD, Somers VK. Neurohumoral activation as a link to systemic manifestations of chronic lung disease. Chest 2005;128(5):3618-24.

[72] Morrell NW, Higham MA, Phillips PG, Shakur BH, Robinson PJ, Beddoes RJ. Pilot study of losartan for pulmonary hypertension in chronic obstructive pulmonary disease. Respir Res 2005;6:88.

[73] Andreas S, Herrmann-Lingen C, Raupach T, Lüthje L, Fabricius JA, Hruska N, et al. Angiotensin II blockers in obstructive pulmonary disease: a randomised controlled trial. Eur Respir J 2006;27(5):972-9.

[74] Mancini GB. The "double dip" hypothesis: simultaneous prevention of cardiovascular and pulmonary morbidity and mortality using angiotensin II type 1 receptor blockers. Can J Cardiol 2005;21(6):519-23.

[75] Kuba K, Imai Y, Penninger JM. Angiotensin-converting enzyme 2 in lung diseases. Curr Opin Pharmacol 2006;6(3):271-6.

[76] Forth R, Montgomery H. ACE in COPD: a therapeutic target? Thorax 2003;58(7):556-8.

[77] Nishimura T, Vaszar LT, Faul JL, Zhao G, Berry GJ, Shi L, et al. Simvastatin rescues rats from fatal pulmonary hypertension by inducing apoptosis of neointimal smooth muscle cells. Circulation 2003;108(13):1640-5.

[78] Mancini GB, Etminan M, Zhang B, Levesque LE, Fitzgerald JM, Brophy JM. Reduction of morbidity and mortality by statins, angiotensin-converting enzyme inhibitors, and angiotensin receptor blockers in patients with chronic obstructive pulmonary disease. J Am Coll Cardiol 2006;47(12):2554-60.

[79] Søyseth V, Brekke PH, Smith P, Omland T. Statin use is associated with reduced mortality in COPD. Eur Respir J 2007;29(2):279-83.

[80] Mortensen EM, Copeland LA, Pugh MJ, Restrepo MI, de Molina RM, Nakashima B, et al. Impact of statins and ACE inhibitors on mortality after COPD exacerbations. Respir Res 2009;10:45.

[81] Alexeeff SE, Litonjua AA, Sparrow D, Vokonas PS, Schwartz J. Statin use reduces decline in lung function: VA Normative Aging Study. Am J Respir Crit Care Med 2007;176(8):742-7.

[82] Lee JH, Lee DS, Kim EK, Choe KH, Oh YM, Shim TS, et al. Simvastatin inhibits cigarette smoking-induced emphysema and pulmonary hypertension in rat lungs. Am J Respir Crit Care Med 2005;172(8):987-93.

[83] Keddissi JI, Younis WG, Chbeir EA, Daher NN, Dernaika TA, Kinasewitz GT. The use of statins and lung function in current and former smokers. Chest 2007;132(6):1764-71.

[84] Fraire AE, Guntupalli KK, Greenberg SD, Cartwright Jr J, Chasen MH. Amiodarone pulmonary toxicity: a multidisciplinary review of current status. South Med J 1993;86(1):67-77.

[85] Singh SN, Fisher SG, Deedwania PC, Rohatgi P, Singh BN, Fletcher RD. Pulmonary effect of amiodarone in patients with heart failure. The Congestive Heart Failure-Survival Trial of Antiarrhythmic Therapy (CHF-STAT) Investigators (Veterans Affairs Cooperative Study No. 320). J Am Coll Cardiol 1997;30(2):514-7.

[86] Mathur PN, Powles P, Pugsley SO, McEwan MP, Campbell EJ. Effect of digoxin on right ventricular function in severe chronic airflow obstruction. A controlled clinical trial. Ann Intern Med 1981;95(3):283-8.

[87] Polić S, Rumboldt Z, Dujić Z, Bagatin J, Deletis O, Rozga A. Role of digoxin in right ventricular failure due to chronic cor pulmonale. Int J Clin Pharmacol Res 1990;10(3):153-62.

[88] Lee-Chiong TL, Matthay RA. The heart in the stable COPD patient. In: Similowski T, Whitelaw WA, Derenne JP, editors. Clinical Management of Chronic Obstructive Pulmonary Disease. New York, NY: Marcel Dekker; 2002 p. 475-532.

[89] Brijker F, Heijdra YF, van den Elshout FJ, Folgering HT. Discontinuation of furosemide decreases $\mathrm{PaCO}(2)$ in patients with COPD. Chest 2002;121(2):377-82. 
[90] Aronow WS. Treatment of heart failure in older persons. Dilemmas with coexisting conditions: diabetes mellitus, chronic obstructive pulmonary disease, and arthritis. Congest Heart Fail 2003;9(3):142-7.

[91] Egred M, Shaw S, Mohammad B, Waitt P, Rodrigues E. Under-use of beta-blockers in patients with ischaemic heart disease and concomitant chronic obstructive pulmonary disease. QJM 2005;98(7):493-7.

[92] Bellotti P, Badano LP, Acquarone N, Griffo R, Lo Pinto G, Maggioni AP, et al., OSCUR Investigators. Specialty-related differences in the epidemiology, clinical profile, management and outcome of patients hospitalized for heart failure; the OSCUR study. Oucome dello Scompenso Cardiaco in relazione all'Utilizzo delle Risore. Eur Heart J 2001;22(7):596-604.

[93] Mascarenhas J, Lourenço P, Lopes R, Azevedo A, Bettencourt P. Chronic obstructive pulmonary disease in heart failure. Prevalence, therapeutic and prognostic implications. Am Heart J 2008;155(3):521-5.

[94] George RB, Manocha K, Burford JG, Conrad SA, Kinasewitz GT. Effects of labetalol in hypertensive patients with chronic obstructive pulmonary disease. Chest 1983;83(3):457-60.

[95] Salpeter S, Ormiston T, Salpeter E. Cardioselective beta-blockers for chronic obstructive pulmonary disease. Cochrane Database Syst Rev 2005;(4):CD003566.

[96] Dorow P, Bethge H, Tonnesmann U. Effects of single oral doses of bisoprolol and atenolol on airway function in nonasthmatic chronic obstructive lung disease and angina pectoris. Eur J Clin Pharmacol 1986;31(2):143-7.

[97] Camsari A, Arikan S, Avan C, Kaya D, Pekdemir H, Ciçek D, et al. Metoprolol, a beta-1 selective blocker, can be used safely in coronary artery disease patients with chronic obstructive pulmonary disease. Heart Vessels 2003;18(4):188-92.

[98] van der Woude HJ, Zaagsma J, Postma DS, Winter TH, van Hulst $M$, Aalbers R. Detrimental effects of beta-blockers in COPD: a concern for nonselective beta-blockers. Chest 2005;127(3): 818-24.

[99] Heart Failure Society of America. Executive summary: HFSA 2006 Comprehensive Heart Failure Practice Guideline. J Card Fail 2006;12(1):10-38.

[100] Kotlyar E, Keogh AM, MacDonald PS, Arnold RH, McCaffrey DJ, Glanville AR. Tolerability of carvedilol in patients with heart failure and concomitant chronic obstructive pulmonary disease or asthma. J Heart Lung Transplant 2002;21(12): 1290-5.

[101] Krum H, Ninio D, MacDonald P. Baseline predictors of tolerability to carvedilol in patients with chronic heart failure. Heart 2000;84(6):615-9.

[102] MacDonald PS, Keogh AM, Aboyoun CL, Lund M, Amor R, McCaffrey DJ. Tolerability and efficacy of carvedilol in patients with New York Heart Association class IV heart failure. J Am Coll Cardiol 1999;33(4):924-31.

[103] Chen J, Radford MJ, Wang Y, Marciniak TA, Krumholz HM. Effectiveness of beta-blocker therapy after acute myocardial infarction in elderly patients with chronic obstructive pulmonary disease or asthma. J Am Coll Cardiol 2001;37(7):1950-6.

[104] Gottlieb SS, McCarter RJ, Vogel RA. Effect of beta-blockade on mortality among high-risk and low-risk patients after myocardial infarction. N Engl J Med 1998;339(8):489-97.

[105] Barnett MJ, Milavetz G, Kaboli PJ. Beta-blocker therapy in veterans with asthma or chronic obstructive pulmonary disease. Pharmacotherapy 2005;25(11):1550-9.

[106] Shelton RJ, Rigby AS, Cleland JG, Clark AL. Effect of a community heart failure clinic on uptake of beta blockers by patients with obstructive airways disease and heart failure. Heart 2006;92(3):331-6.

[107] Callaerts-Vegh Z, Evans KL, Dudekula N, Cuba D, Knoll BJ, Callaerts PF, et al. Effects of acute and chronic administration of beta-adrenoceptor ligands on airway function in a murine model of asthma. Proc Natl Acad Sci U S A 2004;101(14):4948_53.

[108] McGraw DW, Fukuda N, James PF, Forbes SL, Woo AL, Lingrel $\mathrm{JB}$, et al. Targeted transgenic expression of beta(2)-adrenergic receptors to type II cells increases alveolar fluid clearance. Am J Physiol Lung Cell Mol Physiol 2001;281(4):L895-903.

[109] Wellstein A, Palm D, Belz GG, Butzer R, Polsak R, Pett B. Reduction of exercise tachycardia in man after propranolol, atenolol and bisoprolol in comparison to beta-adrenoceptor occupancy. Eur Heart J 1987;8(Suppl M):3-8.

[110] Carstairs JR, Nimmo AJ, Barnes PJ. Autoradiographic visualization of beta-adrenoceptor subtypes in human lung. Am Rev Respir Dis 1985;132(3):541-7.

[111] Baker JG, Hall IP, Hill SJ. Influence of agonist efficacy and receptor phosphorylation on antagonist affinity measurements: differences between second messenger and reporter gene responses. Mol Pharmacol 2003;64(3):679-88.

[112] Boyd CM, Darer J, Boult C, Fried LP, Boult L, Wu AW. Clinical practice guidelines and quality of care for older patients with multiple comorbid diseases: implications for pay for performance. JAMA 2005;294(6):716-24.

[113] Tinetti ME, Bogardus Jr ST, Agostini JV. Potential pitfalls of disease-specific guidelines for patients with multiple conditions. N Engl J Med 2004;351(27):2870-4.

[114] Faxon DP, Schwamm LH, Pasternak RC, Peterson ED, McNeil BJ, Bufalino V, et al., American Heart Association's Expert Panel on Disease Management. Improving quality of care through disease management: principles and recommendations from the American Heart Association's Expert Panel on Disease Management. Circulation 2004;109(21):2651-4.

[115] Krumholz HM, Currie PM, Riegel B, Phillips CO, Peterson ED, Smith R, et al., American Heart Association Disease Management Taxonomy Writing Group. A taxonomy for disease management: a scientific statement from the American Heart Association Disease Management Taxonomy Writing Group. Circulation 2006;114(13):1432-45.

[116] Rich MW, Beckham V, Wittenberg C, Leven CL, Freedland KE, Carney RM. A multidisciplinary intervention to prevent the readmission of elderly patients with congestive heart failure. N Engl J Med 1995;333(18):1190-5.

[117] Phillips CO, Wright SM, Kern DE, Singa RM, Shepperd S, Rubin HR. Comprehensive discharge planning with postdischarge support for older patients with congestive heart failure: a meta-analysis. JAMA 2004;291(11):1358-67.

[118] Gonseth J, Guallar-Castillón P, Banegas JR, Rodríguez-Artalejo F. The effectiveness of disease management programmes in reducing hospital re-admission in older patients with heart failure: a systematic review and meta-analysis of published reports. Eur Heart J 2004;25(18):1570-95.

[119] McAlister FA, Stewart S, Ferrua S, McMurray JJ. Multidisciplinary strategies for the management of heart failure patients at high risk for admission: a systematic review of randomized trials. J Am Coll Cardiol 2004;44(4):810-9.

[120] Roccaforte R, Demers C, Baldassarre F, Teo KK, Yusuf S. Effectiveness of comprehensive disease management programmes in improving clinical outcomes in heart failure patients. A meta-analysis. Eur J Heart Fail 2005;7(7):113344.

[121] Bourbeau J, van der Palen J. Promoting effective self-management programmes to improve COPD. Eur Respir J 2009; 33(3):461-3.

[122] Bourbeau J, Collet JP, Schwartzman K, Ducruet T, Nault D, Bradley $C$. Economic benefits of self-management education in COPD. Chest 2006;130(6):1704-11.

[123] Tiep BL. Disease management of COPD with pulmonary rehabilitation. Chest 1997;112(6):1630-56.

[124] Barr RG, Celli BR, Mannino DM, Petty T, Rennard SI, Sciurba FC, et al. Comorbidities, patient knowledge, and disease 
management in a national sample of patients with COPD. Am J Med 2009;122(4):348-55.

[125] Adams SG, Smith PK, Allan PF, Anzueto A, Pugh JA, Cornell JE. Systematic review of the chronic care model in chronic obstructive pulmonary disease prevention and management. Arch Intern Med 2007;167(6):551-61.

[126] Yu DS, Thompson DR, Lee DT. Disease management programmes for older people with heart failure: crucial characteristics which improve post-discharge outcomes. Eur Heart J 2006;27(5):596-612.

[127] Clark AM, Savard LA, Thompson DR. What is the strength of evidence for heart failure disease-management programs? J Am Coll Cardiol 2009;54(5):397-401.

[128] Jaarsma T, van der Wal MH, Lesman-Leegte I, Luttik ML, Hogenhuis J, Veeger NJ, et al., Coordinating Study Evaluating Outcomes of Advising and Counseling in Heart Failure (COACH) Investigators. Effect of moderate or intensive disease management program on outcome in patients with heart failure: Coordinating Study Evaluating Outcomes of Advising and
Counseling in Heart Failure $(\mathrm{COACH})$. Arch Intern Med 2008;168(3):316-24.

[129] Peytremann-Bridevaux I, Staeger P, Bridevaux PO, Ghali WA, Burnand B. Effectiveness of chronic obstructive pulmonary disease-management programs: systematic review and meta-analysis. Am J Med 2008;121(5):433e4-43e4.

[130] Cleland JG, Louis AA, Rigby AS, Janssens U, Balk AH, TEN-HMS Investigators. Noninvasive home telemonitoring for patients with heart failure at high risk of recurrent admission and death: the Trans-European Network-Home-Care Management System (TEN-HMS) study. J Am Coll Cardiol 2005;45(10):165464.

[131] Chaudhry SI, Phillips CO, Stewart SS, Riegel B, Mattera JA, Jerant $A F$, et al. Telemonitoring for patients with chronic heart failure: a systematic review. J Card Fail 2007;13(1): $56-62$.

[132] Jennett $P$, Yeo $M$, Pauls $M$, Graham J. Organizational readiness for telemedicine: implications for success and failure. J Telemed Telecare 2003;9(Suppl 2):S27-30. 


\section{BPCO e vasculopatie}

\section{Paolo Pauletto, Marcello Rattazzi}

\section{Messaggi chiave}

- Nell'ambito delle vasculopatie esiste un'associazione fra presenza di broncopneumopatia cronica ostruttiva (BPCO) e aumentata progressione della malattia aterosclerotica. Non vi sono invece evidenze di una particolare correlazione fra BPCO e altre forme di vasculopatia (come arteriti e vasculiti).

- Rispetto alla popolazione generale, nel paziente con BPCO è documentabile una maggiore incidenza di disfunzione endoteliale, incremento di rigidità vascolare e progressione delle lesioni aterosclerotiche.

- L'associazione fra BPCO e aterosclerosi non è spiegabile solo sulla base dei fattori di rischio "tradizionali" comuni alle due condizioni cliniche, come per esempio il fumo di sigaretta.

- Anche se i meccanismi fisiopatologici alla base della correlazione fra aterosclerosi e BPCO non sono chiariti, un ruolo rilevante potrebbe essere svolto dallo stato infiammatorio sistemico che caratterizza questi due quadri patologici.

\section{Introduzione}

Un'ampia serie di dati epidemiologici raccolti negli ultimi anni ha dimostrato l'esistenza di un'importante associazione fra la presenza di broncopneumopatia cronica ostruttiva (BPCO) e il rischio cardiovascolare [1]. In più occasioni, infatti, è stata osservata una correlazione fra la riduzione della funzione respiratoria e il rischio di andare incontro a eventi cerebro-cardiovascolari (come ictus e infarto del miocardio). Seppur di minore entità tale associazione si mantiene significativa anche dopo aver preso in considerazione il ruolo di fattori di rischio comuni, come per esempio il fumo di sigaretta. In questo contributo si espongono gli aspetti clinici e fisiopatologici che legano la presenza di BPCO con l'insorgenza di vasculopatie, in particolare l'aterosclerosi. Quest'ultima rappresenta il principale substrato fisiopatologico alla base dell'insorgenza delle malattie vascolari. Come vedremo, diversi studi clinici hanno mostrato la presenza di un'accelerazione del processo aterosclerotico, a carico di diversi distretti vascolari, nei pazienti con BPCO. Al contrario, a oggi, appare meno evidente un'associazione fra BPCO e la presenza di vasculopatie non aterosclerotiche (quali arteriti e vasculiti). Nella tabella 1 viene riproposta la tradizionale classificazione delle vasculopatie che saranno riassunte nel presente capitolo.

\section{Valutazione diagnostica non invasiva della vasculopatia aterosclerotica}

Lo studio delle patologie a carico del distretto arterioso è generalmente condotto mediante due metodiche: l'angiografia e l'esame ultrasonografico.

L'esame angiografico permette la visualizzazione dell'intero asse vascolare, rende evidente la superficie del vaso e l'eventuale presenza di placche aterosclerotiche. D'altra parte, si tratta di un esame invasivo e costoso che, a causa del rimodellamento arterioso, può sottostimare la presenza di lesioni aterosclerotiche iniziali.

L'ecografia invece, oltre a essere un esame sicuro e non invasivo, consente l'esecuzione di misurazioni multiple e la valutazione dell'intera parete del vaso arterioso. Depongono a suo sfavore la possibilità di valutare soltanto $i$ vasi più superficiali e la maggiore variabilità intrinseca se gli operatori non hanno avuto un training specifico e omogeneo. Non c'è dubbio, tuttavia, che la tecnica ultrasonografica sia il 
Tabella 1 Classificazione delle vasculopatie periferiche.

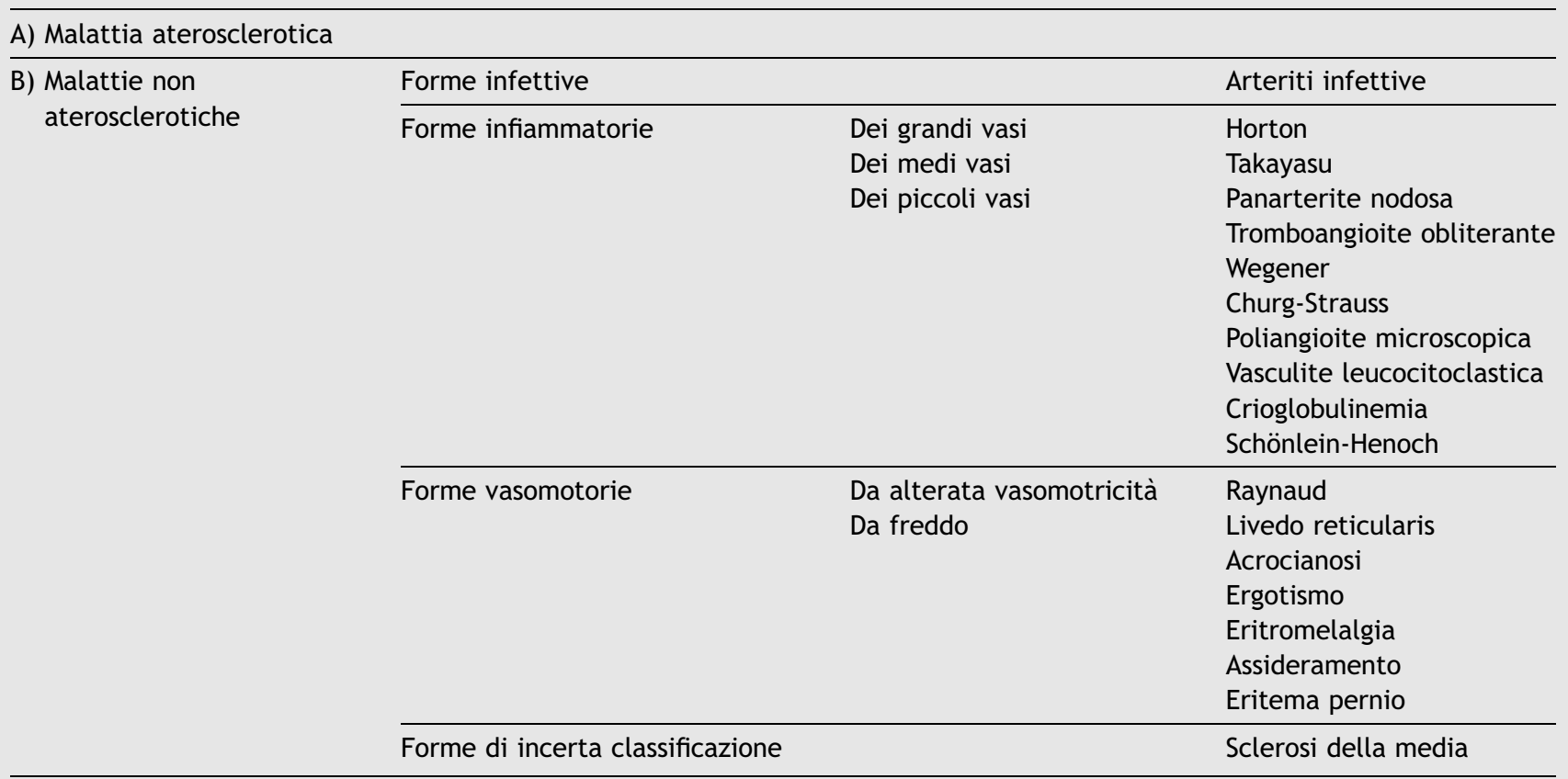

metodo più diffusamente utilizzato nella valutazione del flusso sanguigno, dello stato della parete arteriosa e dell'eventuale presenza di lesioni aterosclerotiche. L'ecografia vascolare arteriosa viene infatti comunemente utilizzata per la diagnostica della patologia aterosclerotica a carico dell'asse carotideo e dei vasi degli arti inferiori. In particolare l'esame eco-color-Doppler standard dei tronchi sovraortici rappresenta l'indagine diagnostica non invasiva che fornisce le informazioni più attendibili e specifiche sulla presenza di lesioni aterosclerotiche anche in fase precoce, consentendo di monitorare la loro evoluzione nel tempo a seguito di interventi di tipo preventivo e farmacologico. Le misure ecografiche finora validate e utilizzabili nello studio dell'asse carotideo sono il diametro del lume vascolare (misurato come distanza tra l'interfaccia lume-intima nel far-wall e quella media-avventizia nel near-wall) e l'ispessimento medio-intimale (IMT) misurato sul far-wall in telediastole. L'analisi Doppler, permette di rilevare parametri di velocità del flusso arterioso necessari per eseguire una stima accurata dell'entità della stenosi determinata da placche aterosclerotiche presenti nel vaso.

Lo studio ultrasonografico dei tronchi sovraortici ha consentito negli ultimi anni di raccogliere numerose informazioni per quanto riguarda l'associazione fra IMT e fattori di rischio cardiovascolari, come l'ipertensione [2]. Tale ispessimento rappresenta, infatti, una delle modificazioni strutturali più precoci che si possano analizzare e monitorare a livello dell'asse carotideo. Diversi trial prospettici, condotti negli anni Novanta, hanno dimostrato un'associazione fra l'incremento dell'IMT carotideo e il rischio di futuri eventi cerebro e cardiovascolari [3].

La misurazione dell'IMT, inoltre, è stata spesso utilizzata come endpoint intermedio per valutare l'efficacia di diversi trattamenti farmacologici, soprattutto antipertensivi e ipolipemizzanti, nel determinare un rallentamento nella progressione della malattia aterosclerotica [4].
Quali sono le categorie di pazienti per le quali è indicato eseguire un eco-color-Doppler standard dei tronchi sovraortici? Dopo una prima e accurata stratificazione in base ai "classici" fattori di rischio (età, sesso, fumo, ipertensione, ipercolesterolemia, intolleranza glucidica), il ricorso allo studio ultrasonografico si potrebbe rilevare utile nell'inquadramento dei pazienti clinicamente asintomatici ma con uno o più fattori di rischio cardiovascolare e ritenuti, quindi, a rischio coronarico intermedio. Per questi pazienti, è utile ottenere il maggior numero di informazioni possibili sullo stato di avanzamento e diffusione della malattia aterosclerotica prima di intraprendere strategie di tipo preventivo (soprattutto a carattere farmacologico). Vanno inoltre sottoposti a studio ultrasonografico tutti quei pazienti che, a prescindere dalla suddetta stratificazione, abbiano manifestato sintomi di tipo neurologico.

L'esecuzione di un esame eco-color-Doppler standard dovrebbe quindi prevedere: una valutazione delle lesioni aterosclerotiche eventualmente presenti e dei loro parametri di ecogenicità ed ecolucentezza; una valutazione delle modificazioni della velocità di picco in sistole e diastole in carotide comune e interna; la misurazione dell'IMT massimo in comune e interna. Nel caso siano riscontrate stenosi carotidee emodinamicamente significative, è necessario intraprendere da subito un adeguato trattamento antiaggregante accompagnato, per quanto possibile, dall'allontanamento/trattamento dei fattori di rischio modificabili.

È poi necessario, in base ai criteri NASCET (North American Symptomatic Carotid Endarterectomy Trial) [5] ed ECST (European Carotid Surgery Trial) [6] stabilire se il paziente possa o non possa trarre giovamento da un intervento di endoarterectomia. In questi studi è stato dimostrato come pazienti con stenosi sintomatica dell'arteria carotide interna $\geq 70 \%$ traggano beneficio dall'intervento di endoarterectomia rispetto al trattamento con sola terapia medica. Nei soggetti con stenosi sintomatica moderata (50-69\%) il 
beneficio dato dall'intervento chirurgico è marginale e diviene pressoché nullo nei pazienti con stenosi inferiore al 50\%. Sia nei pazienti con stenosi carotidea sintomatica, ma ancor più nei pazienti con stenosi asintomatica, è opportuno tenere conto del rischio chirurgico e dell'aspettativa di vita. Infatti, soggetti con stenosi carotidea asintomatica di almeno il $60 \%$, con rischio chirurgico inferiore al $3 \%$ e spettanza di vita di 5 anni possono trarre beneficio dall'intervento di endoarterectomia rispetto al solo trattamento medico. All'aumentare del rischio chirurgico aumenta il grado di stenosi carotidea per il quale l'indicazione chirurgica comporta un beneficio. Se si dovessero invece riscontrare lesioni aterosclerotiche che non soddisfano i criteri di eleggibilità per l'esecuzione dell'intervento chirurgico, è necessario impostare un adeguato follow-up di controllo, con ripetizione dell'esame a 6 mesi per le lesioni più importanti (stenosi 40-60\%) e a distanza di un anno se sono presenti lesioni di modesta entità (stenosi 20-30\%). Va precisato che non esistono, al momento attuale, linee guida che forniscano indicazioni precise in tal senso.

Negli ultimi anni si è reso disponibile l'utilizzo di stent carotidei per il trattamento di lesioni carotidee con stenosi emodinamicamente significativa. Tuttavia, molteplici trial clinici di confronto fra la procedura chirurgica e il trattamento endovascolare hanno mostrato una sostanziale equivalenza dei due approcci nella prevenzione di futuri eventi ischemici cerebrali, con l'aggravante però di un maggior rischio di eventi avversi periprocedurali e comparsa di restenosi nei pazienti trattati mediante stenting.

A oggi, quindi, l'intervento chirurgico rimane il gold standard per il trattamento in prevenzione primaria di lesioni carotidee emodinamicamente significative [7], mentre l'indicazione al trattamento endovascolare può essere prese in considerazione in pazienti con elevato rischio chirurgico. $\grave{E}$ importante sottolineare come l'esecuzione di uno studio ecografico più complesso, per quanto riguarda sia misurazioni ripetute dell'IMT sia un'analisi qualitativa delle lesioni aterosclerotiche, deve essere riservato a specifici programmi di ricerca svolti in centri ad alta specializzazione. Infatti, le differenze di IMT attese a un anno sono talmente minime che per valutare l'impatto dei fattori di rischio o di un trattamento sull'IMT si devono programmare studi della durata di almeno 4-5 anni.

L'eco-color-Doppler rappresenta, inoltre, un importante strumento di approfondimento diagnostico nei pazienti con arteriopatia ostruttiva degli arti inferiori. Il Doppler a onda continua permette di registrare il profilo velocimetrico del sangue nei diversi punti di repere arteriosi e di desumere le caratteristiche emodinamiche della circolazione distrettuale. Con questa metodica è possibile riconoscere le stenosi arteriose emodinamicamente significative che producono una riduzione del flusso o della pressione a valle. Come per il distretto carotideo, lo studio ecografico permette di individuare lesioni aterosclerotiche anche in fase iniziale. Si ricorda che in questo gruppo di pazienti la misurazione dell'indice di Windsor (detto anche Ankle-Brachial Index, $A B I$ ), cioè del rapporto tra il valore più elevato di pressione sistolica alla caviglia e il valore più elevato di pressione sistolica omerale, costituisce un importante mezzo di diagnosi precoce per la presenza di arteriopatia ostruttiva. La pressione alla caviglia normalmente è superiore a quella omerale e tende a calare proporzionalmente alla riduzione del flusso. Nei soggetti normali l'ABI è compreso fra 0,9 e 1,3, mentre diviene $<0,9$ nei pazienti con vasculopatia periferica conclamata.

Negli ultimi anni, fra le metodiche di studio non invasive della funzionalità vascolare, si è reso disponibile l'utilizzo della Flow-Mediated Dilatation (FMD), una tecnica che misura le variazioni del tono endoteliale in particolari distretti vascolari (arteria omerale e radiale). Tale procedura generalmente si applica all'arto superiore (arteria omerale) e prevede la misura, con metodica ultrasonografica, dell'aumento di calibro del vaso indotto dall'aumento del flusso arterioso, quindi dall'aumento di shear-stress, dopo ischemia dell'avambraccio; maggiore è la vasodilatazione indotta dall'ischemia, maggiore è la funzionalità endoteliale. Molti studi clinici, retrospettivi e prospettici, hanno evidenziato come la valutazione della funzione endoteliale mediante FMD sia in grado di identificare soggetti ad alto rischio per lo sviluppo di aterosclerosi e possa contribuire alla stratificazione del rischio cardiovascolare [8]. Appare comunque evidente come, allo stato attuale, la misurazione della FMD debba essere limitata a progetti di ricerca clinici in strutture specializzate.

\section{Vasculopatia aterosclerotica e associazione con la BPCO}

Come accennato in precedenza l'aterosclerosi rappresenta il principale, anche se non l'unico, substrato patogenetico alla base della cardiopatia ischemica e delle malattie cerebrovascolari. Le lesioni aterosclerotiche iniziano a svilupparsi durante le prime decadi di vita, ma la sintomatologia clinica compare dopo molto tempo, quando esse determinano una compromissione significativa del flusso arterioso oppure vanno incontro a complicanze di tipo trombotico. Come noto infatti, gli eventi clinici cardio-cerebrovascolari (infarto miocardico, ictus ecc.) che conseguono alla malattia aterosclerotica sono per lo più determinati dalle complicanze della placca, ovvero: la rottura del cappuccio fibroso, fenomeni trombotici ed emorragie all'interno della lesione $[9,10]$. I numerosi studi di popolazione e di intervento condotti negli ultimi anni hanno consentito di individuare una serie di ben noti, importanti fattori di rischio per la progressione dell'aterosclerosi, sia modificabili (come il fumo, l'ipertensione arteriosa, l'ipercolesterolemia, il diabete, la sedentarietà ecc.) sia non modificabili (come l'età, il sesso maschile, la familiarità). Tranne alcune condizioni cliniche in cui l'apporto di un singolo fattore di rischio appare predominante (come nel caso dell'ipercolesterolemia familiare), nella maggioranza dei casi l'insorgenza, la progressione e la complicanza dell'aterosclerosi possono essere spiegate solo come conseguenza di una complessa interazione fra predisposizione genetica (sia essa relativa all'assetto lipidico, emocoagulativo, metabolico o infiammatorio) e fattori ambientali (dieta, stile di vita, esposizione ad agenti inquinanti o infettivi).

Le fasi iniziali dell'aterosclerosi si caratterizzano per la comparsa di fenomeni di disfunzione/attivazione delle cellule endoteliali (EC) che può essere favorita da diversi tipi di "noxae" (quali l'ipercolesterolemia, il rilascio di radicali liberi dell'ossigeno, l'iperglicemia, l'ipertensione ecc.). La mancata rimozione di questi fattori nocivi porta allo sviluppo e al mantenimento di una risposta infiammatoria/riparativa 
all'interno della parete arteriosa che negli anni contribuisce alla formazione di lesioni aterosclerotiche complesse. Alcuni studi recenti hanno dimostrato come nei pazienti con BPCO siano più spesso osservabili tali alterazioni funzionali dell'endotelio che caratterizzano le fasi iniziali, nonché la progressione dell'aterosclerosi. Infatti, mediante l'utilizzo della FMD è stato osservato che i pazienti con BPCO mostrano un peggioramento della reattività vascolare sia endoteliomediata sia non endotelio-mediata $[11,12]$. In questi pazienti il peggioramento della funzione endoteliale correla con i livelli di infiammazione sistemica, ed è presente indipendentemente dall'utilizzo del fumo di sigaretta [11].

Oltre alla metodica della FMD, anche la misurazione della Pulse Wave Velocity (PWV) contribuisce in parte a valutare la funzionalità endoteliale, fornendo una stima della rigidità vascolare. In linea con le osservazioni raccolte utilizzando la FMD alcuni studi hanno dimostrato come nei pazienti con BPCO si possa riscontrare un incremento di rigidità vascolare misurata con la PWV $[13,14]$. L'aumento nei valori di PWV si accompagna a un incremento nei livelli di infiammazione sistemica, ed è più spiccato nei pazienti con BPCO che presentano un quadro concomitante di osteoporosi [13]. Un unico studio ha recentemente indagato la funzionalità vascolare nei pazienti con BPCO utilizzando sia la FMD sia la PWV. Questa ricerca ha confermato l'incremento di PWV nei pazienti con BPCO rispetto a una popolazione di controllo, senza però confermare l'associazione fra calo del FEV1 e la funzionalità vascolare sia endotelio che non endoteliomediata valutata mediante FMD. Pur prendendo in considerazione le diversità fra le popolazioni oggetto degli studi citati, quest'ultimo lavoro suggerisce che l'incremento di PWV osservato nei pazienti con BPCO possa essere imputato principalmente a modifiche strutturali a carico del vaso arterioso più che a modifiche nella funzionalità endoteliale [14], Nel complesso, comunque, emergono dalla letteratura dati significativi riguardo a un legame fra riduzione della funzionalità ventilatoria e disfunzione endoteliale.

Nella sua progressione il danno aterosclerotico si caratterizza per un accumulo di lipoproteine nello spazio sottoendoteliale. In questa sede le lipoproteine possono subire modificazioni soprattutto di tipo ossidativo e promuovere l'ulteriore attivazione infiammatoria dell'endotelio. Le EC, oltre a esprimere molecole di adesione come ICAM e VCAM, secernono chemochine e fattori di crescita che promuovono la migrazione di elementi infiammatori nello spazio neointimale. Come noto, i monociti migrati nel sottoendotelio si trasformano in macrofagi e, tramite l'espressione di "scavenger receptors" (SR), fagocitano le lipoproteine modificate dando origine alle cellule schiumose ("foam cells") [10]. Questo estremo tentativo di eliminare prodotti di derivazione lipidica si accompagna alla produzione, da parte delle cellule infiammatorie coinvolte e delle EC, di altre citochine (come TNF-alfa, IL-6, IL-1), chemochine (come MCP-1) e fattori di crescita che amplificano la risposta infiammatoria. Si ritiene sia proprio l'entità di questa risposta infiammatoria ad alimentare, poi, l'incremento dei livelli di infiammazione sistemica usualmente documentati mediante il dosaggio della proteina C-reattiva (PCR) $[10,15]$.

Con il progredire dell'aterogenesi si osservano fenomeni di necrosi/apoptosi e la formazione di detriti cellulari che vanno a costituire il "core" necrotico della placca aterosclerotica avanzata. A proteggere l'esposizione del "core" necrotico dal flusso sanguigno, prevenendo così la comparsa di complicanze trombotiche, partecipa un cappuccio fibroso prevalentemente costituito da cellule muscolari lisce (CML) immerse in una matrice extracellulare ricca di collagene. L'integrità e lo spessore di questo cappuccio fibroso sono fattori cruciali nel garantire la stabilità della placca aterosclerotica e prevenire la comparsa di eventi cardio-cerebrovascolari $[9,16,17]$. La migrazione delle CML, seppur presente in tutti gli stadi di progressione dell'aterosclerosi, gioca un ruolo importante soprattutto nelle fasi intermedie/ avanzate dello sviluppo della placca, completando un fenomeno fibroproliferativo assimilabile a un tentativo di riparazione del tessuto vascolare danneggiato dall'iniziale risposta infiammatoria [18].

Come descritto sopra, l'asse arterioso carotideo rappresenta una sede privilegiata per studiare il danno vascolare aterosclerotico, monitorare la sua progressione e aiutare nella stratificazione clinica del rischio cardiovascolare. È stato infatti ampiamente dimostrato che la presenza di IMT carotideo ha un importante valore predittivo riguardo al rischio di andare incontro a eventi cardio-cerebrovascolari [3]. Anche se non completamente assimilabile a una placca aterosclerotica "iniziale", l'IMT rappresenta un valido marcatore di danno vascolare; non stupisce, quindi, la sua associazione con la presenza di malattia aterosclerotica conclamata in altre sedi, come le coronarie.

Diversi autori hanno dimostrato come il peggioramento della funzione ventilatoria si associ a un'aumenta presenza di vasculopatia carotidea. Zureik et al. [19] hanno osservato in oltre 600 pazienti un'associazione fra la riduzione del picco di flusso espiratorio (PEF) e lo sviluppo di placche carotidee. In particolare, tale osservazione prospettica di 4 anni mostrava un'associazione fra il calo del PEF e la progressione del danno aterosclerotico, in misura indipendente rispetto all'esposizione a fattori di rischio tradizionali, incluso il fumo [19]. Altri studi, più spesso a carattere trasversale, hanno osservato un'associazione fra la riduzione di FEV1 e la presenza di IMT [20-23]. In particolare questi lavori mostrano come, a parità di esposizione al fumo di sigaretta, nei pazienti con riduzione del FEV1 si osservi un maggior incremento di IMT carotideo. Si tratta di dati che suggeriscono la presenza, nei pazienti con BPCO, di un'aumentata suscettibilità nei confronti della progressione del danno aterosclerotico carotideo. Inoltre, come è stato descritto nella popolazione generale, anche nei pazienti con BPCO l'incremento dell'IMT si rivela essere un importante predittore di mortalità cardiovascolare [23].

Un numero ridotto di studi ha invece indagato l'associazione fra funzionalità ventilatoria e coronaropatia. In questo ambito, pur con diversi limiti procedurali, uno studio recente ha mostrato la presenza angiografica di un maggior numero di lesioni coronariche critiche nei pazienti con BPCO rispetto a una popolazione di controllo [24].

Scarse sono anche le informazioni relative all'incidenza di vasculopatia agli arti inferiori nei pazienti con deficit ventilatorio, benché il ruolo preponderante del fumo di sigaretta nella genesi dell'arteriopatia obliterante lasci presupporre un'associazione fra BPCO e vasculopatia periferica. Questo dato è stato confermato in un unico studio che, tramite misurazione dell' $A B I$, ha dimostrato una maggiore incidenza di vasculopatia periferica nei pazienti con BPCO. Tale ricerca sottolinea come la presenza della patologia vascolare possa 
svolgere un ruolo importante nel determinare la tolleranza allo sforzo nei pazienti con BPCO [25].

Nel complesso, questi studi sull'uomo dimostrano come esista un legame significativo fra BPCO e progressione del danno aterosclerotico, anche se rimangono da chiarire $i$ meccanismi che guidano questa associazione. Si potrebbero in tal senso ipotizzare due teorie fisiopatologiche.

Una prima ipotesi tiene in considerazione la situazione di "infiammazione" sistemica che accomuna tali condizioni cliniche. Si tratta della cosiddetta teoria dello "spill-over", secondo cui l'incremento nei livelli circolanti delle diverse citochine infiammatorie (per esempio TNF-alfa, IL-6, IL-1) o altri mediatori, indipendentemente dalla sorgente primitiva (per esempio, il polmone del paziente con BPCO), può indurre fenomeni di danno in altri apparati/organi (per esempio, $i$ vasi arteriosi). Ad avvalorare tale ipotesi contribuisce una serie di lavori scientifici che dimostrano come l'incremento dei livelli circolanti di queste e altre citochine (ottenuti mediante studi di iniezione/infusione in modelli animali o la creazione di topi ingegnerizzati) possa contribuire alla genesi/progressione del danno vascolare. Evidenze in tal senso sono state raccolte soprattutto per il TNF-alfa e l'IL-6, mentre per la PCR, importante fattore predittivo di mortalità sia nei pazienti con BPCO sia nei pazienti vasculopatici, non esistono a tutt'oggi evidenze sufficienti che ne confermino un ruolo diretto nella progressione della patologia aterosclerotica.

Tuttavia, come detto sopra, la BPCO e l'aterosclerosi condividono alcuni fattori di rischio comuni, soprattutto il fumo di sigaretta. Recentemente altri fattori patogeni tipicamente presenti nella storia naturale del paziente con BPCO, quali agenti infettivi e inquinanti atmosferici, sono divenuti oggetto di studio per il loro possibile coinvolgimento nella progressione del danno aterosclerotico. In questo caso si tratterebbe di elementi patogeni per i quali, oltre a contribuire allo stato infiammatorio sistemico, è possibile individuare un'azione di danno diretta a carico sia del polmone sia delle strutture vascolari. Le nuove scoperte in merito al ruolo dell'attivazione dei meccanismi della risposta immunitaria durante lo sviluppo tanto della BPCO [26] quanto dell'aterosclerosi [10] potrebbero chiarire alcuni dei meccanismi fisiopatologici che legano queste due entità, e offrire l'occasione per la messa a punto di terapie ad azione combinata.

La dimostrazione della presenza nella placca di elementi cellulari coinvolti nella risposta immunitaria (macrofagi, linfociti, mastociti e cellule dendritiche) ha dato impulso a numerosi studi scientifici che hanno dimostrato come mediatori dell'immunità sia innata sia adattativa possano svolgere un ruolo patogenetico durante l'aterogenesi [15]. L'immunità innata si avvale di una serie di recettori (come i Toll-Like Receptors o TLR e gli SR), citochine/pentraxine (come interleuchine, PTX3, PCR) e alcuni elementi cellulari (come le cellule natural killer o NK, le cellule dendritiche) che hanno il compito di fungere da "prima" risposta immunitaria nei confronti degli agenti patogeni ed eventualmente partecipare allo sviluppo e all'amplificazione della risposta adattativa [27].

In questi anni si è osservato, nell'ambito della ricerca di base, un crescente interesse soprattutto nei confronti dei cosiddetti "pattern recognition receptors", un gruppo di recettori cui appartengono i TLR e gli SR. Si tratta di recettori, espressi su molti tipi cellulari (come le EC o CML), la cui attivazione determina una significativa risposta infiammatoria della cellula, con rilascio di mediatori infiammatori e modifiche del profilo fenotipico cellulare. In particolare, l'attivazione dei TLR, gruppo di recettori che riconoscono determinanti di superficie sia batterici sia virali, sembra svolgere un ruolo rilevante nell'aterogenesi. Numerosi studi hanno infatti dimostrato che l'inattivazione di questo gruppo di recettori, o dei pathway a essi correlati, riduce la progressione della placca aterosclerotica [15]. L'attivazione dei TLR potrebbe quindi svolgere un ruolo rilevante di mediatore fra l'esposizione ad agenti infettivi e l'attivazione infiammatoria degli elementi cellulari coinvolti nell'aterogenesi. Si potrebbero così spiegare molte delle evidenze epidemiologiche che hanno mostrato l'esistenza di una correlazione fra i livelli di anticorpi circolanti contro alcuni microorganismi (per esempio Chlamydia pneumoniae, Herpesvirus, Cytomegalovirus ed Helicobacter pylori), la progressione dell'aterosclerosi e l'insorgenza di eventi cardiovascolari [28].

Anche se nessuno di questi agenti infettivi è in grado di indurre per se la formazione di lesioni aterosclerotiche, ricerche più recenti hanno mostrato che l'infezione di animali da esperimento (come il topo ApoE-/-) con agenti infettivi, quali Chlamydia pneumoniae o virus (anche di tipo influenzale), può accelerare la progressione delle lesioni aterosclerotiche [29]. È quindi ipotizzabile che gli agenti infettivi possano contribuire ad aggravare il processo aterosclerotico una volta che questo sia già iniziato. Il ruolo di mediatore fra l'infezione e gli elementi cellulari coinvolti nell'aterogenesi potrebbe essere svolto proprio da molecole appartenenti alla risposta immunitaria innata, in particolare i TLR. Non è pertanto escludibile che la ripetuta esposizione ad agenti infettivi del paziente con BPCO possa avere, in seguito alla diffusione sistemica, ripercussioni dirette sulla parete vascolare. In questa sede l'interazione dei diversi agenti infettivi con gli elementi del sistema immunitario innato potrebbe portare a un'amplificazione della risposta infiammatoria, con effetti deleteri sulla progressione e sulla stabilità delle lesioni aterosclerotiche.

Ad avvalorare la possibile centralità della risposta immunitaria innata come "collante" fra BPCO e aterogenesi, contribuiscono dati più recenti che mostrano come anche il fumo di sigaretta o agenti inalatori nocivi possono mediare l'attivazione delle cellule infiammatorie attraverso i TLR [30]. L'azione deleteria di alcuni inquinanti atmosferici nella progressione del danno aterosclerotico è stata recentemente dimostrata in alcuni modelli animali di aterosclerosi come il topo ApoE-/ - [31]. È evidente che aspetti legati allo stress ossidativo che si genera con l'esposizione a questi agenti nocivi o l'amplificazione della risposta infiammatoria sistemica possano esercitare un ruolo diretto nel mediare il danno vascolare, sarà però d'interesse capire quanto l'attivazione dei mediatori della risposta innata all'interno della parete vascolare possa spiegare l'associazione fra il danno polmonare e l'accelerazione dell'aterosclerosi.

Un altro aspetto che merita di essere approfondito riguardo al legame fra aterosclerosi e danno polmonare è capire se lo stato infiammatorio sistemico indotto dalla patologia vascolare possa in qualche misura influire sul processo infiammatorio a livello polmonare. Recentemente è stato osservato che nel modello murino di aterosclerosi 
ApoE- / - è documentabile un significativo incremento della risposta infiammatoria polmonare, caratterizzata soprattutto dallo sviluppo di infiltrati perivascolari/peribronchiali e dall'attivazione delle metalloproteasi [32]. Lo stesso tipo di danno polmonare può essere ottenuto con iniezione endotracheale di TNF-alfanell'animale wild-type, suggerendo così che gli alti livelli sistemici di citochine infiammatorie riscontrati con lo sviluppo della vasculopatia aterosclerotica possano svolgere un'azione proinfiammatoria a livello del parenchima polmonare [32].

Nel complesso appare evidente come ulteriori studi sia clinici sia di ricerca di base su questi aspetti fisiopatologici siano più che mai necessari per chiarire i molti lati oscuri di tale comorbilità così clinicamente rilevante.

\section{Vasculopatie non aterosclerotiche}

Rispetto alla malattia aterosclerotica, le altre forme di vasculopatia sono meno frequenti nella popolazione generale. Si tratta prevalentemente di processi patologici a carattere infiammatorio (specie arteriti e vasculiti), ma per i quali non è stata a oggi dimostrata una particolare associazione con la presenza di BPCO. Di seguito vengono brevemente proposti alcuni aspetti patologici e clinici che caratterizzano queste forme di vasculopatia.

\section{Arteriti}

Le arteriti sono processi flogistici acuti, subacuti o cronici che colpiscono la parete arteriosa. Possono essere sia primitive sia secondarie, a eziologia nota o ignota. Il gruppo delle arteriti comprende patologie molto diverse tra loro, accomunate dalla sola natura infiammatoria e che più spesso vengono distinte in arteriti infettive e non infettive.

Le arteriti infettive sono prevalentemente causate da agenti patogeni che possono danneggiare il vaso primitivamente (angiotropismo primario, proprio delle arteriti virali o rickettsiosiche) o nel corso di malattie settiche (angiotropismo secondario). In questo secondo caso, l'arterite può essere sia la complicanza di una sepsi sistemica (per esempio, arterite tifosa o brucellare) sia la complicanza tardiva dell'infezione primaria (per esempio, nell'aortite luetica o in alcune rickettsiosi). Anche se ormai piuttosto rare, nelle arteriti batteriche i patogeni più spesso coinvolti sono le salmonelle, Escherichia coli e alcuni ceppi di stafilococchi. I germi possono raggiungere la parete arteriosa per impianto diretto sull'endotelio vasale, attraverso i "vasa vasorum", per contiguità da focolai suppurativi o attraverso ferite penetranti. Si verificano preferenzialmente in soggetti anziani e immunodepressi. Le manifestazioni cliniche comprendono sintomi sistemici (febbre e compromissione dello stato generale) e locali (segni di ischemia distrettuale). Sono costantemente presenti leucocitosi neutrofila e aumento della VES; le emoculture sono spesso positive. Bisogna sospettare un'arterite infettiva quando nel corso di malattie settiche compaiono manifestazioni ischemiche locali o aneurismi. La prognosi dipende dal letto vascolare interessato, mentre la terapia si basa sulla somministrazione di antibiotici. Altre forme di arterite, anch'esse oggigiorno più rare, sono l'arterite luetica e l'arterite tubercolare.
Alcune infezioni virali, specie sostenute da coxsackie A e $\mathrm{B}$, virus influenzali, Herpesvirus, Echovirus possono determinare arteriti acute, subacute o croniche, mono o polidistrettuali. Istologicamente è presente uno scarso infiltrato infiammatorio nella media e nell'avventizia associato a iperplasia intimale.

\section{Vasculiti}

Le vasculiti sono patologie infiammatorie della parete dei vasi che possono colpire i vasi di ogni tipo e di ogni organo. $\mathrm{Di}$ conseguenza, i processi vasculitici si caratterizzano per un'ampia varietà di segni e sintomi. Vengono classificate in base al calibro delle arterie colpite indipendentemente dalla loro collocazione.

Alcune vasculiti colpiscono i vasi di grosso calibro, come quelle di Horton e di Takayasu; altre, come la poliangioite microscopica, rimangono confinate nell'ambito dei piccoli vasi; altre ancora, come la malattia di Burger, procedono dai vasi di piccolo calibro a quelli di medio calibro con un decorso tipicamente centripeto.

Nonostante esista un'importante correlazione fra il fumo di sigaretta e la malattia di Burger, non è stata a oggi definita un'associazione significativa fra la presenza di questa vasculite e la BPCO. Tuttavia, proprio per la presenza di un fattore di rischio così rilevante per entrambi le condizioni cliniche, quale il fumo di sigaretta, non è inverosimile poter ipotizzare di riscontrare nei pazienti fumatori con malattia di Burger alterazioni della funzionalità respiratoria.

Le manifestazioni cliniche delle vasculiti sono spesso proteiformi e con scarsa specificità del quadro istologico, rendendo in alcuni casi difficoltosa la precisa identificazione del tipo di vasculite. Una dettagliata trattazione degli aspetti classificativi, fisiopatologici e clinici delle vasculiti esula dallo scopo del presente lavoro.

\section{Forme vasomotorie}

Esiste un gruppo di vasculopatie principalmente dovute ad alterazioni della motricità (acrosindromi vascolari distoniche) o alterazioni vasomotorie da freddo (acrosindromi vascolari distrofiche). Al primo gruppo appartiene una serie di malattie, non ben definite dal punto di vista nosologico, caratterizzate dalla presenza di turbe più o meno importanti dell'irrorazione cutanea e sottocutanea determinate dallo spasmo di vasi di piccolo calibro, piccole arterie, arteriole precapillari, capillari, venule, vene collettrici o muscolari. Sono dette "acrosindromi" perché le manifestazioni cliniche più evidenti riguardano la cute delle dita, della punta del naso, dei lobi auricolari e dei pomelli.

La forma più nota appartenente a questo gruppo è il fenomeno di Raynaud, che compare tipicamente a crisi, è localizzato alle estremità, specie alle mani, talora alle singole dita, più raramente a piedi, naso e orecchie ed è frequentemente bilaterale e simmetrico. La crisi è caratterizzata da successive variazioni di colore e temperatura della durata di qualche minuto con tipica successione temporale. Le estremità diventano dapprima pallide e fredde (per vasocostrizione delle piccole arterie), poi assumono un colorito cianotico (per ipossia tissutale), quindi rosso vivo (per iperemia reattiva), per poi tornare lentamente al colore e alla 
temperatura normali. La crisi è di solito scatenata dall'esposizione al freddo, talora da uno stimolo emozionale; a volte si manifesta senza ragione apparente. Tra una crisi e l'altra l'aspetto della cute può essere perfettamente normale. Il fenomeno di Raynaud può essere primitivo o rappresentare un sintomo secondario. Quando è primitivo viene definito malattia di Raynaud, quando è secondario fenomeno di Raynaud. La forma primitiva, che rappresenta il 60\% dei casi di fenomeno di Raynaud, colpisce prevalentemente le donne fra i 20 e i 40 anni. Il fenomeno di Raynaud secondario è invece presente in molte situazioni cliniche quali arteriopatie obliteranti, aterosclerosi, tromboangioite obliterante, embolia e trombosi arteriosa. Talora è legato all'assunzione di sostanze tossiche e farmaci (come alcaloidi della segale cornuta, beta-bloccanti, vincristina, cisplatino, bleomicina) oppure associato a malattie sistemiche come la sclerodermia, il lupus eritematoso sistemico, la panarterite nodosa, l'artrite reumatoide. Più raramente il fenomeno di Raynaud si associa a traumi prolungati, malattie del sistema nervoso centrale, compressione arteriosa o anomalie del sangue: crioglobulinemia, agglutinine da freddo. Si tratta di una manifestazione clinica che può precedere anche di molti anni l'insorgenza di una delle malattie sopraelencate.

La "livedo reticularis" è una malattia che si manifesta in seguito a esposizione al freddo, con marezzatura della cute a chiazze anulari o reticolari rosso-bluastre, non dolenti, generalizzate o localizzate alle estremità. La livedo può essere idiopatica a eziologia ignota o secondaria ad altre patologie, delle quali può rappresentare il primo segno, come: arteriopatie obliteranti, arteriti segmentarie, connettivopatie, malattie endocrine, malattie neurologiche, reazioni a farmaci, stati di iperviscosità e sindrome da anticorpi antifosfolipidi. La malattia di solito si manifesta in soggetti di età compresa fra 20 e 30 anni, e predilige il sesso femminile. $\grave{E}$ asintomatica o si manifesta con una sensazione di freddo alle estremità. Si ritiene che il meccanismo di base della livedo reticularis sia simile a quello dell'acrocianosi: costrizione delle arteriole seguita da stasi e dilatazione delle venule e dei capillari. L'aspetto reticolare della livedo riflette la struttura anatomica dei vasi colpiti. La diagnosi è esclusivamente clinica, basata sull'aspetto caratteristico della cute e sull'ipotermia delle zone colpite.

L'acrocianosi è, invece, un'alterazione funzionale assai frequente nelle giovani donne; insorge nell'adolescenza e tende a scomparire nell'età adulta. È caratterizzata da cianosi periferica permanente delle estremità, più spesso delle mani, con cute fredda e lievemente sudata. Il fenomeno si accentua con l'esposizione al freddo. A differenza del fenomeno di Raynaud, non compaiono mai pallore e rossore da iperemia reattiva e non vi sono lesioni trofiche della cute.

Altre condizioni vasomotorie più rare sono l'egotismo (legato all'intossicazione da ergotamina) e l'eritromelalgia (con sintomatologia caratterizzata da estremità rosse, congeste e brucianti), mentre nelle forme vasomotorie da freddo vanno considerati l'assideramento e l'eritema pernio o gelone.

Condizione a parte è invece la sclerosi della media di Monckeberg, malattia caratterizzata morfologicamente da una calcificazione più o meno completa della tonaca media delle arterie muscolari di medio e piccolo calibro e tipica dei pazienti diabetici. La media può venire completamente sostituita da materiale calcifico, mentre l'intima e l'avventizia sono, di solito, risparmiate. Il flusso ematico è generalmente conservato anche se la pulsatilità dei vasi è abolita.

\section{Terapia}

Le implicazioni terapeutiche relative alla gestione della vascolopatia aterosclerotica nel paziente con BPCO sono similari a quelle riportate in merito alla gestione della cardiopatia ischemica.

\section{Bibliografia}

[1] Maclay JD, McAllister DA, Macnee W. Cardiovascular risk in chronic obstructive pulmonary disease. Respirology 2007; 12(5):634-41.

[2] Pauletto P, Palatini P, Da Ros S, Pagliara V, Santipolo N, Baccillieri $S$, et al. Factors underlying the increase in carotid intima-media thickness in borderline hypertensives. Arterioscler Thromb Vasc Biol 1999;19(5):1231-7.

[3] Lorenz MW, Markus HS, Bots ML, Rosvall M, Sitzer M. Prediction of clinical cardiovascular events with carotid intima-media thickness: a systematic review and meta-analysis. Circulation 2007;115(4):459-67.

[4] de Groot E, van Leuven SI, Duivenvoorden R, Meuwese MC, Akdim F, Bots ML, et al. Measurement of carotid intima-media thickness to assess progression and regression of atherosclerosis. Nat Clin Pract Cardiovasc Med 2008;5(5):280-8.

[5] Barnett HJ, Taylor DW, Eliasziw M, Fox AJ, Ferguson GG, Haynes $\mathrm{RB}$, et al. Benefit of carotid endarterectomy in patients with symptomatic moderate or severe stenosis. North American Symptomatic Carotid Endarterectomy Trial Collaborators. N Engl J Med 1998;339(20):1415-25.

[6] European Carotid Surgery Trialists' Collaborative Group. MRC European Carotid Surgery Trial: interim results for symptomatic patients with severe $(70-99 \%)$ or with mild $(0-29 \%)$ carotid stenosis. Lancet 1991;337(8752):1235-43.

[7] van der Vaart MG, Meerwaldt R, Reijnen MM, Tio RA, Zeebregts CJ. Endarterectomy or carotid artery stenting: the quest continues. Am J Surg 2008;195(2):259-69.

[8] Brunner H, Cockcroft JR, Deanfield J, Donald A, Ferrannini E, Halcox J, et al., Working Group on Endothelins and Endothelial Factors of the European Society of Hypertension. Endothelial function and dysfunction. Part II: Association with cardiovascular risk factors and diseases. A statement by the Working Group on Endothelins and Endothelial Factors of the European Society of Hypertension. J Hypertens 2005;23(2):233-46.

[9] Libby P. Molecular bases of the acute coronary syndromes. Circulation 1995;91(11):2844-50.

[10] Hansson GK. Inflammation, atherosclerosis, and coronary artery disease. N Engl J Med 2005;352(16):1685-95.

[11] Eickhoff P, Valipour A, Kiss D, Schreder M, Cekici L, Geyer K, et al. Determinants of systemic vascular function in patients with stable chronic obstructive pulmonary disease. Am J Respir Crit Care Med 2008;178(12):1211-8.

[12] Moro L, Pedone C, Scarlata S, Malafarina V, Fimognari F, Antonelli Incalzi R. Endothelial dysfunction in chronic obstructive pulmonary disease. Angiology 2008;59(3):357-64.

[13] Sabit R, Bolton CE, Edwards PH, Pettit RJ, Evans WD, McEniery $C M$, et al. Arterial stiffness and osteoporosis in chronic obstructive pulmonary disease. Am J Respir Crit Care Med 2007; 175(12):1259-65.

[14] Maclay JD, McAllister DA, Mills NL, Paterson FP, Ludlam CA, Drost $E M$, et al. Vascular dysfunction in chronic obstructive pulmonary disease. Am J Respir Crit Care Med 2009; 180(6):513-20. 
[15] Hansson GK, Libby P, Schönbeck U, Yan ZQ. Innate and adaptive immunity in the pathogenesis of atherosclerosis. Circ Res 2002;91(4):281-91.

[16] Libby P, Ridker PM, Hansson GK, Leducq Transatlantic Network on Atherothrombosis. Inflammation in atherosclerosis: from pathophysiology to practice. J Am Coll Cardiol 2009;54(23): 2129-38.

[17] Libby P. Molecular and cellular mechanisms of the thrombotic complications of atherosclerosis. J Lipid Res 2009;50(Suppl): S352-7.

[18] Ross R. Atherosclerosis - An inflammatory disease. N Engl J Med 1999;340(2):115-26.

[19] Zureik M, Kauffmann F, Touboul PJ, Courbon D, Ducimetière P. Association between peak expiratory flow and the development of carotid atherosclerotic plaques. Arch Intern Med 2001; 161(13):1669-76.

[20] Ebrahim S, Papacosta O, Whincup P, Wannamethee G, Walker M, Nicolaides AN, et al. Carotid plaque, intima media thickness, cardiovascular risk factors, and prevalent cardiovascular disease in men and women: the British Regional Heart Study. Stroke 1999;30(4):841-50.

[21] Schroeder EB, Welch VL, Evans GW, Heiss G. Impaired lung function and subclinical atherosclerosis. The ARIC Study. Atherosclerosis 2005;180(2):367-73.

[22] Iwamoto H, Yokoyama A, Kitahara $Y$, Ishikawa N, Haruta $Y$, Yamane $\mathrm{K}$, et al. Airflow limitation in smokers is associated with subclinical atherosclerosis. Am J Respir Crit Care Med 2009;179(1):35-40.

[23] van Gestel YR, Flu WJ, van Kuijk JP, Hoeks SE, Bax JJ, Sin DD, et al. Association of COPD with carotid wall intimamedia thickness in vascular surgery patients. Respir Med 2010;104(5):712-6.
[24] Topsakal R, Kalay N, Ozdogru I, Cetinkaya Y, Oymak S, Kaya MG, et al. Effects of chronic obstructive pulmonary disease on coronary atherosclerosis. Heart Vessels 2009;24(3):164-8.

[25] Castagna O, Boussuges A, Nussbaum E, Marqueste L, Brisswalter J. Peripheral arterial disease: an underestimated aetiology of exercise intolerance in chronic obstructive pulmonary disease patients. Eur J Cardiovasc Prev Rehabil 2008;15(3):270-7.

[26] Cosio MG, Saetta M, Agusti A. Immunologic aspects of chronic obstructive pulmonary disease. N Engl J Med 2009;360(23): 2445-54.

[27] Rattazzi M, Faggin E, Bertipaglia B, Pauletto P. Innate immunity and atherogenesis. Lupus 2005;14(9):747-51.

[28] Ayada K, Yokota K, Kobayashi K, Shoenfeld Y, Matsuura E, Oguma K. Chronic infections and atherosclerosis. Ann N Y Acad Sci 2007;1108:594-602.

[29] Naghavi M, Wyde P, Litovsky S, Madjid M, Akhtar A, Naguib S, et al. Influenza infection exerts prominent inflammatory and thrombotic effects on the atherosclerotic plaques of apolipoprotein E-deficient mice. Circulation 2003;107(5): 762-8.

[30] Karimi K, Sarir H, Mortaz E, Smit JJ, Hosseini H, De Kimpe SJ, et al. Toll-like receptor-4 mediates cigarette smoke-induced cytokine production by human macrophages. Respir Res 2006;7:66.

[31] Araujo JA, Barajas B, Kleinman M, Wang X, Bennett BJ, Gong $\mathrm{KW}$, et al. Ambient particulate pollutants in the ultrafine range promote early atherosclerosis and systemic oxidative stress. Circ Res 2008;102(5):589-96.

[32] Naura AS, Hans CP, Zerfaoui M, Errami Y, Ju J, Kim H, et al. Highfat diet induces lung remodeling in ApoE-deficient mice: an association with an increase in circulatory and lung inflammatory factors. Lab Invest 2009;89(11):1243-51. 


\title{
BPCO e cardiopatia ischemica
}

\author{
Domenico Panuccio
}

\section{Messaggi chiave}

- Broncopneumopatia cronica ostruttiva (BPCO) e cardiopatia ischemica sono patologie frequentemente associate, avendo la seconda una prevalenza decisamente più alta nei pazienti con BPCO rispetto alla popolazione generale.

- La prognosi dei pazienti con queste due patologie è peggiore di quella di chi è affetto da una sola di esse.

- Il fumo è un fattore di rischio comune a entrambe e un processo di infiammazione cronica accomuna la fisiopatologia della malattia respiratoria e della lesione aterosclerotica coronarica.

- Non è indicato ricercare una cardiopatia ischemica occulta in pazienti con BPCO senza sintomi di coronaropatia.

- La BPCO può creare qualche problema per alcuni test diagnostici della cardiopatia ischemica, ma in genere non rappresenta una controindicazione né alla coronarografia né alle procedure di rivascolarizzazione.

- I farmaci necessari per la cardiopatia ischemica, compresi i beta-bloccanti cardioselettivi, non sono controindicati né pericolosi nei pazienti con BPCO, anzi alcuni di essi (per esempio le statine) possono avere benefici effetti sulla patologia respiratoria.

- Tra i farmaci della BPCO, i beta-stimolanti possono aumentare la frequenza cardiaca e/o indurre aritmie; gli anticolinergici sono verosimilmente privi di effetti cardiovascolari, ma la loro neutralità a questo livello è oggetto di dibattito.

\section{Introduzione}

La broncopneumopatia cronica ostruttiva (BPCO) è una della malattie croniche più diffuse in tutto il mondo; colpisce tra il $7 \%$ e il $10 \%$ della popolazione generale, la sua prevalenza è in continua crescita e rappresenta, già oggigiorno, la quarta causa di morte negli Stati Uniti e in Europa.

La cardiopatia ischemica, con le sue varie presentazioni cliniche che vanno dall'ischemia silente alla morte improvvisa passando per l'angina e l'infarto miocardico, è la prima causa di mortalità nei Paesi industrializzati e si prevede che presto lo sarà anche per quelli in via di sviluppo.

Stante questa grande prevalenza delle due patologie nella popolazione generale è comprensibile, anche semplicemente per un mero calcolo probabilistico, che esse possano riscontrarsi associate di frequente negli stessi pazienti. In effetti, circa un terzo dei pazienti con BPCO ha patologie cardiache associate [1] che nella metà dei casi sono rappresentate dalla cardiopatia ischemica [2], la quale arriva ad avere una prevalenza doppia rispetto a quella della popolazione generale [3]. E quanto più severa è la compromissione polmonare, tanto più frequente è l'associazione con le cardiopatie e con la mortalità a esse correlata [4].

Utilizzando l'ingente database del sistema sanitario privato Kaiser Permanente della California, è stato condotto uno studio caso-controllo nel quale 45.966 pazienti affetti da BPCO, esenti da cardiopatia ischemica, sono stati confrontati con altrettanti soggetti aventi caratteristiche cliniche simili, ma privi di patologia polmonare [5]; nel corso dei circa 3 anni di follow-up, i pazienti con BPCO hanno avuto un numero doppio di ricoveri ospedalieri per cardiopatia ischemica (angina e infarto miocardico acuto) rispetto a quelli senza BPCO.

Tra i pazienti ricoverati nel 1998 negli ospedali convenzionati con il Veterans Administration Medical System, la prevalenza della cardiopatia ischemica era pari al 33,6\% tra i soggetti affetti da BPCO rispetto al 27,1\% dei pazienti senza BPCO $(p<0,001)[6]$.

Il grande studio ARIC (Atherosclerosis Risk in Communities) [7] ha evidenziato una correlazione diretta tra la compromissione della funzione polmonare, valutata in termini di riduzione del FEV1, e l'incidenza di eventi coronarici in 14.480 soggetti senza precedenti malattie cardiovascolari. 
La stessa correlazione è stata dimostrata per quanto riguarda l'ictus nel Copenhagen City Heart Study [8].

Il deterioramento della funzione polmonare è un potente predittore di mortalità [9], che nella maggior parte dei casi è dovuta a malattie extrapolmonari [10] e in particolar modo cardiovascolari [11]. Queste, come dimostrato dallo studio TORCH (TOwards a Revolution in COPD Health) [12], sono la causa del decesso nel $27 \%$ dei pazienti affetti da BPCO.

Nel Lung Health Study [13], su circa 6.000 soggetti arruolati, è stato evidenziato che nei pazienti con BPCO il $50 \%$ dei ricoveri era motivato da cause cardiovascolari e che a una riduzione del FEV1 del $10 \%$ corrispondeva un aumento del $30 \%$ del rischio di morte cardiovascolare, rischio doppio rispetto alla popolazione generale [14].

Studi coronarografici dimostrano che, in caso di associazione di BPCO e cardiopatia ischemica, il numero di vasi interessati, l'estensione delle singole lesioni e le lesioni definite "critiche" sono più frequenti rispetto a quanto di solito riscontrato nella sola patologia coronarica [15].

In qualunque fase evolutiva della cardiopatia ischemica, la presenza di BPCO comporta un peggioramento della prognosi con aumento della mortalità nel medio-lungo periodo: ciò è stato dimostrato per i pazienti con infarto in fase acuta [16] come in quelli che abbiano superato l'evento [17] o che siano stati sottoposti a rivascolarizzazione coronarica, chirurgica o percutanea $(\mathrm{PCl})[18]$.

Peraltro è piuttosto frequente che, in pazienti ricoverati per riacutizzazione di BPCO, si verifichi una sottodiagnosi di eventi cardiaci ischemici come l'infarto miocardico acuto [19].

\section{Cenni di fisiopatologia}

I dati epidemiologici prima succintamente esposti documentano come la BPCO sia una condizione che predispone o almeno aumenta il rischio di sviluppare anche la cardiopatia ischemica. Ciò è ampiamente supportato anche da conoscenze di tipo fisiopatologico che accomunano la genesi della BPCO e quella del processo aterosclerotico che è alla base della cardiopatia ischemica e che vengono analizzate in dettaglio in un altro contributo della presente monografia. Qui ci limiteremo a ricordare come entrambe condividano il fumo quale importante fattore di rischio e come vari marker di infiammazione sistemica (proteina C-reattiva o PCR, IL-8, TNF-alfa, fibrinogeno) siano frequentemente elevati sia nell'una sia nell'altra patologia.

Sul piano clinico, la presenza di almeno tre variabili - fra età superiore a 40 anni, abitudine al fumo, BPCO, scompenso cardiaco, sindrome metabolica, alti valori di PCR - permette di individuare i pazienti con infiammazione sistemica cronica [20]. In linea con l'ipotesi "infiammatoria" sono i dati di uno studio caso-controllo che ha evidenziato, in 11.155 soggetti colpiti da processi infettivi delle vie respiratorie confrontati con altrettanti soggetti di pari età, sesso e condizioni cliniche ma senza tale patologia, una forte correlazione tra infezioni polmonari e incidenza di primo infarto miocardico entro 1-4 settimane dall'evento acuto [21].

Un ulteriore importante supporto a questa ipotesi fisiopatologica è rappresentato dai risultati di due recenti grandi studi randomizzati che hanno dimostrato come l'aggiunta alla terapia abituale della BPCO di un farmaco antinfiammatorio, il roflumilast, un inibitore della fosfodiesterasi-4, migliori la funzione polmonare dei pazienti [22] e possa ridurre le riacutizzazioni bronchitiche [23].

\section{Valutazione diagnostica}

I pazienti con BPCO che necessitino di una valutazione diagnostica cardiologia non invasiva possono presentare non pochi problemi, tanto più frequentemente quanto più compromessa è la funzionalità polmonare.

Il test ergometrico può risultare non diagnostico a causa della ridotta capacità fisica che la malattia respiratoria comporta e i test farmacologici con adenosina [24] e dipiridamolo [25] possono scatenare broncospasmo soprattutto nelle forme più gravi di BPCO. Va ricordato che la presenza di broncospasmo "severo" è una controindicazione assoluta a questi test provocativi [26].

L'ecocardiografia con stress farmacologico alla dobutamina, che risulta sicura nella popolazione generale [27], non è stata valutata in maniera specifica in pazienti con BPCO, nei quali comunque la tecnica ecografica risulta spesso limitata dalle modificazioni strutturali della parete toracica e del parenchima polmonare, che comportano, rispettivamente, difficoltà nel reperimento di un'adeguata finestra acustica e scarsa accuratezza nella valutazione della motilità delle pareti ventricolari.

Anche la TC multislice, che sembra avere un'accuratezza diagnostica vicina a quella della coronarografia [28], non è stata testata in pazienti con BPCO.

Tuttavia occorre sottolineare due concetti pratici molto importanti. In primo luogo, non è indicato ricercare una cardiopatia ischemica occulta in pazienti con BPCO che non presentino chiari segni e/o sintomi di coronaropatia. In secondo luogo, in caso di reale necessità clinica il ricorso alla coronarografia in tali pazienti non è controindicato né problematico, ma, come sempre, va inserito nella valutazione del rapporto rischio/beneficio del singolo paziente.

\section{Implicazioni terapeutiche}

Quando le due patologie coesistono nello stesso paziente vanno tenuti in debita considerazione $i$ vantaggi dei singoli farmaci per ciascuna delle malattie nonché le interferenze reciproche dei due trattamenti. Valuteremo di seguito il problema cercando di fornire risposta al seguente quesito: la terapia della cardiopatia ischemica interferisce positivamente o negativamente con la prognosi della BPCO, e viceversa?

\section{Terapia della cardiopatia ischemica in pazienti con BPCO}

\section{Beta-bloccanti}

I beta-bloccanti sono farmaci di estrema utilità per la cura dell'infarto miocardico acuto, poiché riducono la mortalità e la morbilità, ma altrettanto necessari per la prevenzione secondaria degli eventi nel lungo periodo. Inoltre, sono dotati di riconosciuta efficacia e pertanto largamente impiegati nella terapia dell'ipertensione arteriosa, dell'angina, 
delle tachiaritmie e dello scompenso cardiaco. Essi, però, sono stati a lungo ritenuti controindicati nei pazienti con BPCO con la motivazione che possono indurre broncospasmo; motivazione avvalorata dagli effetti farmacologici negativi sulla funzione polmonare dei beta-bloccanti non selettivi, confermati anche da trial clinici prospettici [29].

Differente è invece il caso dei beta-bloccanti cardioselettivi (metoprololo, atenololo, bisoprololo, nebivololo) e, tra i non selettivi, del carvedilolo, dotato di un'attività alfabloccante e beta-bloccante, per i quali una serie numerosa di dati conferma la sicurezza e la tollerabilità nei pazienti con BPCO.

Una metanalisi [30] ha evidenziato che, sul piano fisiopatologico, i beta-bloccanti cardioselettivi non interferiscono con la funzione polmonare di pazienti con BPCO, nel senso che non peggiorano il FEV1 né alterano la risposta bronchiale alla stimolazione beta-adrenergica. Anche nei soggetti anziani con BPCO lieve-moderata e cardiopatia ischemica questi farmaci non solo sono ben tollerati, ma riducono la mortalità soprattutto nei maschi, mentre per le donne i dati sono piuttosto limitati [31].

In un gruppo di 825 pazienti consecutivi ricoverati per riacutizzazione di BPCO è stata notata una riduzione della mortalità tra quanti erano trattamento cronico con betabloccanti, per vari motivi, al momento del ricovero rispetto ai soggetti non in terapia con questi farmaci anche se il profilo clinico complessivo dei primi era più grave (età più avanzata, maggiore prevalenza di malattie cardiovascolari e di altre comorbilità) [32].

Tra i 14.703 soggetti sopravvissuti a un infarto miocardico acuto arruolati nello studio VALIANT (Valsartan in Acute Myocardial Infarction Trial) ve ne erano 1.258 con BPCO; in tale sottogruppo si è verificata una significativa riduzione della mortalità tra coloro che assumevano i beta-bloccanti rispetto a quanti non li assumevano [17].

Tutti questi dati, che documentano la sicurezza dei betabloccanti nei pazienti con BPCO, hanno la limitazione di essere frutto di studi osservazionali o di analisi post hoc, quindi non consentono di trarre conclusioni definitive. Tuttavia, in assenza di studi clinici specificamente mirati sull'argomento, essi possono comunque fornire utili indicazioni per le scelte terapeutiche nella pratica clinica corrente, che dovrebbe essere improntata al principio di usare questi farmaci quando le condizioni cliniche dei singoli pazienti lo richiedono, non negandoli in maniera preconcetta a chi è affetto anche da BPCO [33] e non sospendendoli ai pazienti in trattamento qualora vengano ricoverati per un episodio di riacutizzazione della BPCO [32].

Nonostante tali evidenze, le reticenze all'uso dei betabloccanti nei pazienti con BPCO sono ancora molto forti, denunciate anche da dati recenti che evidenziano un ingiustificato e generalizzato sottoutilizzo [34].

In pazienti ricoverati per sindrome coronarica acuta (SCA) in 435 ospedali americani tra il 2000 e il 2006, l'uso dei betabloccanti era significativamente più basso tra i soggetti (12.967) con BPCO o asma rispetto ai pazienti (81.140) non affetti da tali patologie pneumologiche, sia all'ingresso (-42\%; $\mathrm{p}<0,0001)$ sia alla dimissione $(-55 \% ; \mathrm{p}<0,0001)$ [35].

$\mathrm{Se}$, da una parte, è necessario che i medici abbiano un atteggiamento meno rinunciatario nell'uso dei beta-bloccanti nei pazienti con BPCO, nella pratica clinica va comunque mantenuto un atteggiamento prudente con utilizzo esclusivamente delle molecole cardioselettive, iniziando il trattamento con bassi dosaggi e aumentandoli progressivamente fino al massimo dosaggio tollerato, per individuare quei pochi pazienti nei quali comunque un broncospasmo può manifestarsi, ma senza rinunciare a somministrarli ai numerosi pazienti che ne hanno bisogno a causa di comorbilità cardiovascolari [36].

\section{ACE-inibitori e inibitori recettoriali dell'angiotensina}

Il sistema renina-angiotensina-aldosterone (RAS), oltre ad avere un ruolo centrale nella regolazione dell'omeostasi dei liquidi e della pressione arteriosa dell'organismo, esplica numerose attività biologiche tra le quali la stimolazione della proliferazione cellulare a vari livelli, l'attività proinfiammatoria e quella protrombotica. I farmaci che antagonizzano il RAS, come gli ACE-inibitori e gli inibitori recettoriali dell'angiotensina II (ARB), sono ampiamente utilizzati nel trattamento dell'ipertensione arteriosa; sono farmaci indispensabili nella terapia dello scompenso cardiaco ed esercitano un ruolo molto importante anche nella prevenzione cardiovascolare, ruolo legato non solo alla loro attività antipertensiva, ma anche all'effetto antiaterosclerotico conseguente al blocco del RAS.

Il polmone è uno dei siti di maggiore espressione tissutale dell'enzima di conversione dell'angiotensina (ACE), pertanto è anche una delle sedi di maggiore produzione di angiotensina II.

A livello dell'apparato respiratorio il RAS è implicato nella patogenesi dell'ipertensione polmonare e della fibrosi polmonare, entrambe presenti molto spesso nelle malattie croniche polmonari, compresa la BPCO; inoltre, sembra che esso giochi un ruolo molto importante nella patogenesi della sindrome da distress respiratorio acuto (ADRS), sindrome per la quale è stata individuata una chiara correlazione con il polimorfismo genetico dell'ACE [37]. Tale polimorfismo è molto più frequentemente riscontrabile nei fumatori che sviluppano una BPCO e raddoppia la probabilità di andare incontro a questa malattia [38].

I farmaci ACE-inibitori e gli ARB hanno riconosciuti effetti antinfiammatori che si esplicano anche a livello dell'apparato respiratorio, con possibile azione sul rimodellamento bronchiale e vascolare, che nei pazienti con BPCO può comportare riduzione dell'ostruzione bronchiale, riduzione della pressione arteriosa polmonare, aumento della conduttanza della membrana alveolo-capillare e, di conseguenza, miglioramento degli scambi gassosi alveolari e dell'utilizzo periferico dell'ossigeno $[39,40]$; inoltre migliorano la funzione dei muscoli respiratori e riducono la capacità polmonare totale e l'ematocrito, tutti effetti positivi per questi pazienti [41].

In linea con tali premesse sono i pochi dati di due studi retrospettivi su ampie coorti che hanno valutato l'impatto dei farmaci che antagonizzano il RAS sugli eventi clinici in pazienti con BPCO e cardiopatie.

Il primo studio [42] ha selezionato pazienti con BPCO e cardiopatia ischemica e ha analizzato l'effetto di vari farmaci sulla prognosi, rispetto a pazienti di controllo che non li assumevano. L'uso di ACE-inibitori o ARB correlava con una minore incidenza di mortalità sia nei pazienti ad alto rischio (sottoposti a interventi di rivascolarizzazione coronarica) sia 
in quelli a basso rischio (con coronaropatia stabile); in quest'ultimo gruppo riduceva anche le riacutizzazioni della BPCO.

Nel secondo studio [43], 3.584 pazienti anziani (età $<65$ anni) ricoverati per riacutizzazione di BPCO e che assumevano cronicamente ACE-inibitori o ARB per vari motivi (pregresso infarto o stroke, scompenso cardiaco, diabete) sono stati confrontati con 7.628 soggetti con analoghe caratteristiche cliniche, ma non in terapia con tali farmaci. Nel gruppo di pazienti in trattamento con gli antagonisti del RAS si è verificata una significativa minore incidenza della mortalità nei 90 giorni successivi alla riacutizzazione della BPCO.

\section{Statine}

Le statine sono una pietra miliare nella prevenzione cardiovascolare, fortemente raccomandate dalle linee guida nei pazienti con cardiopatia ischemica, per la loro riconosciuta capacità di prevenire le recidive di eventi cardiovascolari. Numerosi studi, negli ultimi anni, stanno facendo emergere in maniera sempre più chiara un possibile ruolo delle statine anche nella terapia della BPCO. In animali da laboratorio le statine sono state in grado di prevenire lo sviluppo di enfisema polmonare indotto dal fumo [44]. In soggetti fumatori, con o senza BPCO, l'uso delle statine rallenta in maniera importante il declino annuale della funzione polmonare, valutata con il FEV1 $(-0,005 \pm 0,20$ L/anno vs $0,085 \pm 0,17$ L/anno; $p<0,0001$ ) [45]; analogo effetto è stato osservato in soggetti anziani, nei quali il declino del FEV1 è stato pari a $10,9 \mathrm{~mL} /$ anno in corso di terapia con statine rispetto a $23,9 \mathrm{~mL} /$ anno tra coloro che non le assumevano [46].

Sul piano clinico, in un'ampia casistica di popolazione (76.232 pazienti) l'uso di statine comportava una significativa minore incidenza di mortalità per BPCO e per influenza o polmonite [47]. Nello studio di Mancini et al. [42] questi farmaci riducevano non solo l'incidenza di infarto miocardico e di mortalità (effetti ampiamente attesi e documentati da numerosi studi di prevenzione cardiovascolare primaria e secondaria), ma anche le riacutizzazioni della BPCO; questo dato è stato confermato da successive ricerche [45-48] che hanno altresì documentato una minore necessità di ricorrere all'intubazione orotracheale per ventilazione assistita di tali pazienti.

Anche in corso di riacutizzazione di BPCO l'uso corrente delle statine ha comportato, in due studi retrospettivi, una significativa riduzione della mortalità, indipendentemente dal fatto che i pazienti fossero o non fossero affetti anche da una cardiopatia ischemica $[43,49]$.

L'uso delle statine è risultato associato a ridotta mortalità nel breve e nel lungo periodo anche in pazienti con BPCO e arteriopatia ostruttiva periferica [50], patologia non coronarica che però riconosce la stessa genesi aterosclerotica della cardiopatia ischemica. Una recente metanalisi [51] ha riconfermato che le statine potrebbero avere un ruolo, forse anche importante, nel trattamento della BPCO; tuttavia la natura osservazionale, retrospettiva o di coorte di queste ricerche non consente di trarre conclusioni definitive né di elaborare raccomandazioni al di fuori di quelle previste per la prevenzione cardiovascolare. Un solo studio randomizzato ha valutato una statina (pravastatina $40 \mathrm{mg}$ ) verso placebo in pazienti con BPCO e ha evidenziato un aumento del $54 \%$ della capacità di esercizio a 6 mesi, associato a riduzione della PCR; tale miglioramento rimaneva significativo anche dopo correzione per i parametri emodinamici e le variazioni dei lipidi [52].

I meccanismi attraverso i quali le statine possono migliorare la prognosi dei pazienti affetti da coronaropatia e BPCO non sono ben conosciuti, ma sono verosimilmente riconducibili ad alcuni di quelli ampiamente studiati sulle lesioni aterosclerotiche. Per la prevenzione degli eventi cardiovascolari, anche in questi pazienti le statine esplicano i propri effetti attraverso la riduzione del colesterolo plasmatico e alcune attività pleiotropiche sulle lesioni aterosclerotiche (azione antinfiammatoria, immunomodulatoria, stabilizzante della funzione endoteliale, antitrombogenica). Per quanto riguarda invece $i$ benefici delle statine sugli eventi respiratori (riduzione delle riacutizzazioni della BPCO, della mortalità per BPCO, polmoniti e influenza), è ipotizzabile che essi siano ascrivibili a loro effetti pleiotropici e in particolare all'attività antinfiammatoria e immunomodulatoria. È dimostrato che a livello vascolare tutte le componenti cellulari e biochimiche della flogosi si riducono dopo trattamento con statine, le quali riducono anche la risposta immunomediata, come evidenziato dalla riduzione dei linfociti T, dell'interferone-gamma, del TNF-alfa e della selectina P [53]. È verosimile supporre che queste stesse azioni vengano svolte anche a livello bronchiale, dove i processi fisiopatologici di tipo infiammatorio e immunologico della BPCO sono, almeno in parte, analoghi a quelli che avvengono, a livello vascolare, nella genesi delle lesioni aterosclerotiche.

\section{Procedure di rivascolarizzazione miocardica in pazienti con BPCO}

Nell'ambito della cardiopatia ischemica, il ricorso alle procedure di rivascolarizzazione miocardica, soprattutto quella non chirurgica, "percutanea" $(\mathrm{PCl})$, è diventato sempre più frequente e per alcune forme di SCA (infarto miocardico acuto con ST sopraslivellato) tale procedura rappresenta il gold standard di trattamento da eseguire in urgenza, mentre per altre forme (infarto miocardico acuto non ST sopraslivellato) è la terapia di elezione per i pazienti a più alto rischio. La rivascolarizzazione chirurgica è riservata ai casi di fallimento della $\mathrm{PCl}$ anche ripetuta più volte e/o ai casi di compromissione anatomica dei vasi coronarici non favorevole per la $\mathrm{PCl}$.

Nessuno studio prospettico, randomizzato ha specificamente valutato la sicurezza e l'efficacia di queste procedure nei pazienti con BPCO.

La BPCO non è considerata una controindicazione alla $\mathrm{PCl}$, ma i dati di letteratura, tutti di tipo osservazionale, sugli esiti in tali pazienti sono contrastanti. A parere di alcuni autori [54] essa sarebbe abbastanza sicura e non comporterebbe una maggiore incidenza di complicanze cardiocircolatorie o respiratorie né, soprattutto, di mortalità intraospedaliera; altri autori [55] hanno invece documentato una maggiore incidenza di mortalità intraospedaliera.

Anche per il by-pass aortocoronarico i dati reperibili in letteratura sono non numerosi, tutti di tipo osservazionale e spesso discordanti. In genere i pazienti con BPCO nelle casistiche di questo tipo di chirurgia sono sempre poco rappresentati: dal $4 \%$ al $27 \%$ [56,57]. Per quanto riguarda 
gli esiti nel breve periodo, alcuni autori non osservano differenze sostanziali nella mortalità intraospedaliera [58-60], soprattutto nei pazienti con BPCO di grado lieve o moderato [61]; dati di registro, invece, riportano una maggiore mortalità intraospedaliera tra i pazienti con BPCO rispetto a quelli senza BPCO $[62,63]$, soprattutto se la patologia respiratoria è di grado severo [64]. Nel complesso, quindi, sembra che $i$ pazienti con BPCO possano trarre beneficio dalle procedure di rivascolarizzazione rispetto al non intervento [64]. Tuttavia, occorre prestare attenzione nella selezione dei pazienti con maggiore compromissione respiratoria, nei quali il ricorso a tecniche chirurgiche meno invasive può migliorare gli esiti [65].

Infine, va tenuto conto che comunque la prognosi a lungo termine dei pazienti con BPCO sottoposti a procedure di rivascolarizzazione, sia percutanea $[54,55]$ sia chirurgica $[60,66]$, è gravata da una mortalità quasi doppia rispetto ai pazienti senza tale comorbilità, come del resto è prevedibile in base agli studi di epidemiologia generale citati in precedenza.

\section{Trattamento farmacologico della bpco in pazienti con cardiopatia ischemica}

Il trattamento cronico della BPCO si basa fondamentalmente su due categorie di farmaci, i cortisonici e i broncodilatatori, con una somministrazione preferenziale per via inalatoria, ove possibile, al fine di minimizzare gli effetti negativi sistemici. I broncodilatatori più utilizzati sono i beta-stimolanti e gli anticolinergici, mentre le metilxantine, molto usate in passato, sono oggi poco raccomandate. In questo paragrafo non verranno valutati gli aspetti di efficacia di tali farmaci sulla patologia respiratoria (per i quali si rimanda ad altro contributo della presente monografia), ma ci si limiterà a verificare se il trattamento farmacologico cronico della BPCO influenzi positivamente o negativamente una cardiopatia ischemica eventualmente associata.

\section{Beta-stimolanti}

I beta-stimolanti più utilizzati nella terapia della BPCO sono fondamentalmente beta ${ }_{2}$-agonisti, tuttavia due presupposti motivano ampiamente i potenziali effetti cardiaci negativi di questi farmaci. In primo luogo la distribuzione dei recettori beta $_{2}$, che sono prevalentemente concentrati a livello bronchiale e nella muscolatura liscia vascolare; la loro stimolazione provoca bronco e vasodilatazione. Tuttavia essi sono presenti anche a livello del muscolo cardiaco, ove possono rappresentare fino al $20 \%$ dei recettori beta. La seconda motivazione è che $i$ farmaci beta $a_{2}$-stimolanti non sono totalmente selettivi e possono stimolare anche i recettori beta ${ }_{1}$ cardiaci. La stimolazione dei recettori beta cardiaci, com'è noto, ha effetti cronotropo, dromotropo, inotropo e lusitropo positivi; tali effetti comportano aumento del consumo di ossigeno ed espongono a una maggiore suscettibilità all'insorgenza di aritmie ipercinetiche, rendendo questi farmaci potenzialmente pericolosi, soprattutto in un cuore non più sano com'è quello colpito da cardiopatia ischemica. In effetti una metanalisi non recentissima [67], che ha esaminato 18 studi nei quali erano stati utilizzati beta-stimolanti prevalentemente long acting, ha dimostrato che l'uso di tali farmaci aumenta in maniera significativa la frequenza cardiaca e l'incidenza di aritmie e, in maniera non statisticamente significativa, l'incidenza di eventi cardiovascolari maggiori tra cui infarto miocardico acuto e morte cardiovascolare.

Di differente sentore sono i dati dello studio TORCH [68]. Oltre 6.000 pazienti affetti da BPCO sono stati randomizzati al trattamento con salmeterolo (beta-stimolante long acting), fluticasone, l'associazione di questi due farmaci o placebo. Dopo un follow-up di circa 3 anni, nel gruppo salmeterolo l'incidenza di mortalità totale è stata analoga a quella del gruppo placebo; la mortalità cardiovascolare è stata invece tendenzialmente più bassa ( $3 \%$ vs $5 \%)$ pur senza significatività statistica, dimostrando quindi una sostanziale assenza di effetti negativi del farmaco a livello cardiovascolare.

Uno studio osservazionale retrospettivo caso-controllo più recente [69] ha confrontato gli effetti cardiovascolari dei beta-agonisti assunti per via inalatoria per asma o BPCO in una coorte di 26.728 pazienti ipertesi. Nell'intera casistica non è emerso un significativo aumento di rischio di infarto miocardico acuto, ma restringendo l'analisi ai 4.817 pazienti con storia di cardiopatia ischemica è stato constatato che, tra gli 860 utilizzatori di beta-agonisti (casi) rispetto ai 3.957 (controlli) che non assumevano tali farmaci, l'incidenza di infarto era quasi doppia e si manifestava soprattutto per esposizione complessiva al farmaco bassa, come per esempio nelle fasi iniziali del trattamento.

\section{Cortisonici}

I cortisonici per via inalatoria sono parte integrante del trattamento cronico della BPCO, nell'ambito della quale possono ridurre l'infiammazione sistemica cronica [70]. Nella pratica clinica, tuttavia, questi farmaci vengono più frequentemente utilizzati in associazione con i beta-agonisti long acting e questo si riflette anche nei contenuti della letteratura, dove i dati sulla loro sicurezza cardiovascolare sono molto scarsi e tutti indiretti, derivanti cioè da analisi di sottogruppi, da analisi post hoc, da studi osservazionali o da metanalisi di studi di piccole dimensioni.

Il ruolo dei cortisonici per via inalatoria in monoterapia nel trattamento cronico della BPCO è oggetto di ampia discussione, essendo ritenuti utili da alcuni autori, ma non da altri.

Nello studio osservazionale di Soriano et al. [71] la sopravvivenza a 3 anni in 1.045 pazienti con BPCO, trattati con fluticasone da solo o in associazione con salmeterolo per via inalatoria, è stata più elevata rispetto a un gruppo di 3.620 pazienti confrontabili che utilizzavano altri broncodilatatori (78,6\% vs $63,6 \%)$; non sono riportati dati relativi alla mortalità cardiovascolare o all'incidenza di patologia coronarica.

La metanalisi di Sin et al. [72] ha utilizzato i dati di 7 studi randomizzati coinvolgenti complessivamente 5.085 pazienti con un follow-up medio di 26 mesi, evidenziando una riduzione del $25 \%$ della mortalità rispetto al placebo. Questo beneficio era sostenuto dalla riduzione dei decessi per cause respiratorie e neoplastiche, ma non di quelle per cause cardiovascolari.

Un'altra metanalisi più recente [73] di 9 studi e 14.426 pazienti complessivi non ha riscontrato differenze di mortalità a un anno tra chi utilizzava gli steroidi inalatori rispetto a chi non li utilizzava. Anche in questo caso non vengono riferiti dati sulla tipologia dei decessi. 
Nello studio TORCH la mortalità a 3 anni nel gruppo di pazienti trattati con il solo fluticasone è stata pressoché uguale a quella del gruppo placebo (16\% vs $15,2 \%)$ e significativamente più elevata rispetto al gruppo di trattamento combinato $(12,6 \% ; p=0,007)$. Anche la mortalità per cause cardiovascolari è stata solo lievemente più bassa tra $i$ pazienti trattati con il cortisonico inalatorio rispetto al placebo (4\% vs $5 \%$ ), ma la scarsa numerosità dei casi non consente di riconoscere peso statistico al dato [68].

Un'analisi post hoc dello studio EUROSCOP (European Respiratory Society's study on Chronic Obstructive Pulmonary Disease) ha dimostrato che il trattamento con budesonide $800 \mu \mathrm{g} /$ die per via inalatoria in pazienti con BPCO lieve-moderata all'incirca dimezzava l'incidenza di eventi ischemici coronarici rispetto al placebo (3\% vs 5,3\%) [74].

Selezionando le informazioni derivanti da studi osservazionali e dai trial randomizzati è stato osservato che nei primi gli steroidi inalatori erano associati a una significativa riduzione della mortalità cardiovascolare $(p<0,0001)$ e totale ( $p<0,001)$; nei secondi, invece, i dati cumulativi non confermano tale beneficio né evidenziano una minore incidenza di infarto miocardico [75], anche se in via teorica questi farmaci potrebbero ridurre l'infiammazione sistemica cronica e le sue conseguenze [76].

\section{Anticolinergici}

Tutte le linee guida concordano sull'utilità dei broncodilatatori nella terapia dei pazienti con BPCO e tra essi un posto di rilievo è occupato dagli anticolinergici. Per questi farmaci, tuttavia, accanto a un'accertata efficacia nel ridurre le riacutizzazioni, esistono non rare perplessità relativamente alla loro sicurezza, soprattutto a livello cardiovascolare.

Una delle prime segnalazioni di un incremento di eventi cardiovascolari legato all'uso degli anticolinergici inalatori è quella dello Lung Health Study, uno studio randomizzato in doppio cieco condotto su 5.887 soggetti con modesta riduzione della funzionalità polmonare, seguiti per circa 5 anni. Tra i pazienti che smettevano di fumare, quelli che utilizzavano l'ipatropio, rispetto al placebo, avevano una maggiore incidenza di mortalità cardiovascolare $(p=0,027)$, anche se gli eventi cardiovascolari considerati complessivamente avevano incidenza analoga nei due gruppi [77].

Nel 2008 la Food and Drug Administration, sulla base di una metanalisi di 29 trial, ha lanciato un "early warning" sul potenziale aumento di incidenza dell'ictus indotto dal tiotropio: 8 casi/1.000 pazienti trattati rispetto a 6 casi/ 1.000 pazienti in placebo [78].

Poco dopo un'altra metanalisi di 17 studi, con 14.783 pazienti seguiti per un periodo variabile da 6 settimane a 5 anni, concludeva che l'uso degli anticolinergici inalatori si associava a un significativo aumento del rischio di morte cardiovascolare, infarto miocardico e stroke considerati cumulativamente come endpoint principale $(1,8 \%$ vs $1,2 \%$ rispetto ai controlli; $\mathrm{p}<0,001)$, mentre non modificava la mortalità totale [79].

Due studi caso-controllo condotti su dati amministrativi di sistemi sanitari nordamericani hanno evidenziato un aumento delle ospedalizzazioni per cause cardiache [80] e della mortalità totale e cardiovascolare tra gli utilizzatori di ipatropio [81].
Lo studio INSPIRE (Investigating New Standards for Prophylaxis in Reducing Exacerbations), randomizzato e in doppio cieco, ha confrontato il trattamento con l'associazione salmeterolo/fluticasone vs tiotropio in 1.323 pazienti, con un follow-up di 2 anni, evidenziando una riduzione dell'endpoint secondario, mortalità totale $(3 \%$ vs $6 \%$; $\mathrm{p}=0,032$ ) e cardiaca (1\% vs $3 \%$ ), nel primo gruppo [82].

Non tutti i dati, però, concordano nell'evidenziare effetti negativi degli anticolinergici a livello cardiaco. Per esempio, in una coorte di 10.603 pazienti con BPCO seguiti per 18 mesi, l'uso del tiotropio rispetto al non uso è stato associato a una significativa riduzione della mortalità totale senza alcuna differenza nell'incidenza di eventi cardiaci [83]. I dati di sicurezza del tiotropio relativi a 19 studi analizzati cumulativamente [84] hanno evidenziato, rispetto al placebo, una riduzione del rischio di mortalità totale, cardiovascolare e respiratoria.

Nello studio UPLIFT (Understanding Potential Long-term Impacts on Function with Tiotropium) il tiotropio rispetto al placebo ha comportato una riduzione non significativa della mortalità totale $(H R \quad 0,89 ; p=0,09)$, che tuttavia era un endpoint secondario, senza alcuna interferenza sull'infarto miocardico e sullo stroke [85]. Quando i dati di questo studio sono stati messi insieme con quelli della metanalisi di Singh et al. [79] la significativa maggiore incidenza di eventi cardiovascolari legata all'uso del tiotropio non veniva più evidenziata (RR 1,00; IC 95\% 0,88-1,1; $p=0,96$ ) e anche $i$ singoli eventi (infarto miocardico, stroke e morte cardiovascolare) non si manifestavano più di frequente che nel gruppo placebo [86]. Va tenuto comunque conto che circa i due terzi dei pazienti dello studio UPLIFT erano anche in terapia con cortisonici e beta-stimolanti per via inalatoria, pertanto è difficile estrapolare gli effetti del solo tiotropio da quelli della triplice terapia.

Al momento attuale, quindi, in base alle evidenze di letteratura, il problema della sicurezza cardiovascolare degli anticolinergici è lungi dall'essere risolto e sarebbero necessari ulteriori ampi studi appositamente disegnati per fare definitiva chiarezza sull'argomento.

\section{Terapia non farmacologica}

Le modificazioni dello stile di vita rappresentano uno dei cardini più importanti dei programmi di intervento di prevenzione primaria e secondaria di varie patologie. Due di queste modificazioni sono particolarmente indicate e favorevoli sia per la cardiopatia ischemica sia la BPCO: si tratta della cessazione del fumo e dell'attività fisica.

In ambito cardiovascolare è ormai ampiamente accertato che il fumo è uno dei fattori di rischio maggiori e che la sua cessazione è in grado di ridurre drasticamente il rischio di eventi cardiovascolari già dopo 2 anni e di annullarlo nell'arco di 5-10 anni [87]. Questa riduzione del rischio clinico verosimilmente trova le sue motivazioni nel rallentamento dei processi biologici dell'infiammazione cronica che sostengono l'evoluzione delle lesioni aterosclerotiche, come sembrano indicare recenti dati che evidenziano, già dopo poche settimane, una riduzione dei tassi plasmatici di marker di infiammazione, come PCR, TNF, IL-6 e molecole di adesione (VCAM) [88]. In ambito pneumologico, la cessazione dell'abitudine tabagica è considerata dalle linee guida GOLD la 
singola misura più efficace ed economicamente vantaggiosa per ridurre il rischio di sviluppare BPCO e per rallentarne la progressione [89].

Per quanto riguarda l'attività fisica, senza entrare nei dettagli, ci limiteremo a sottolineare come le linee guida pneumologiche e cardiologiche, rispettivamente per i pazienti con BPCO e cardiopatia ischemica, raccomandino fortemente i programmi di riabilitazione e di allenamento all'esercizio fisico poiché migliorano la qualità di vita: aumentano la tolleranza allo sforzo, riducono la dispnea, l'affaticabilità e la depressione, che spesso accompagna queste patologie; migliorano altresì la prognosi di tali patologie grazie alla riduzione delle riacutizzazioni della BPCO e delle recidive di eventi ischemici coronarici.

Non esistono molte evidenze sull'effetto dell'attività fisica in pazienti affetti contemporaneamente da BPCO e cardiopatia ischemica, ma, come sarebbe prevedibile, in studi osservazionali su pazienti con BPCO sottoposti a riabilitazione fisica è stato notato che l'associazione con la cardiopatia ischemica è un predittore di miglioramento degli indicatori di performance fisica e di qualità di vita [90].

\section{Bibliografia}

[1] Freeborne N, Lynn J, Desbiens NA. Insights about dying from the SUPPORT project. The Study to Understand Prognoses and Preferences for Outcomes and Risks of Treatments. J Am Geriatr Soc 2000;48(5 Suppl):S199-205.

[2] Holguin F, Folch E, Redd SC, Mannino DM. Comorbidity and mortality in COPD-related hospitalizations in the United States, 1979 to 2001. Chest 2005;128(4):2005-11.

[3] Huiart L, Ernst P, Suissa S. Cardiovascular morbidity and mortality in COPD. Chest 2005;128(4):2640-6.

[4] Curkendall SM, Lanes S, de Luise C, Stang MR, Jones JK, She D, et al. Chronic obstructive pulmonary disease severity and cardiovascular outcomes. Eur J Epidemiol 2006;21(11):803-13.

[5] Sidney S, Sorel M, Quesenberry Jr CP, DeLuise C, Lanes S, Eisner $M D$. COPD and incident cardiovascular disease hospitalizations and mortality: Kaiser Permanente Medical Care Program. Chest 2005;128(4):2068-75.

[6] Mapel DW, Dedrick D, Davis K. Trends and cardiovascular comorbidities of COPD patients in the Veterans Administration Medical System, 1991-1999. COPD 2005;2(1):35-41.

[7] Schroeder EB, Welch VL, Couper D, Nieto FJ, Liao D, Rosamond WD, et al. Lung function and incident coronary heart disease: the Atherosclerosis Risk in Communities Study. Am J Epidemiol 2003;158(12):1171-81.

[8] Truelsen T, Prescott E, Lange P, Schnohr P, Boysen G. Lung function and risk of fatal and non-fatal stroke. The Copenhagen City Heart Study. Int J Epidemiol 2001;30(1):145-51.

[9] Mannino DM, Buist AS. Global burden of COPD: risk factors, prevalence, and future trends. Lancet 2007;370(9589):765-73.

[10] Mannino DM, Brown C, Giovino GA. Obstructive lung disease deaths in the United States from 1979 through 1993. An analysis using multiple-cause mortality data. Am J Respir Crit Care Med 1997;156(3 Pt 1):814-8.

[11] Mannino DM, Doherty DE, Sonia Buist A. Global Initiative on Obstructive Lung Disease (GOLD) classification of lung disease and mortality: findings from the Atherosclerosis Risk in Communities (ARIC) study. Respir Med 2006;100(1):115-22.

[12] McGarvey LP, John M, Anderson JA, Zvarich M, Wise RA, TORCH Clinical Endpoint Committee. Ascertainment of cause-specific mortality in COPD: operations of the TORCH Clinical Endpoint Committee. Thorax 2007;62(5):411-5.
[13] Anthonisen NR, Connett JE, Kiley JP, Altose MD, Bailey WC, Buist AS, et al. Effects of smoking intervention and the use of an inhaled anticholinergic bronchodilator on the rate of decline of FEV1. The Lung Health Study. JAMA 1994;272(19):1497-505.

[14] Curkendall SM, DeLuise C, Jones JK, Lanes S, Stang MR, Goehring Jr E, et al. Cardiovascular disease in patients with chronic obstructive pulmonary disease. Saskatchewan Canada cardiovascular disease in COPD patients. Ann Epidemiol 2006;16(1): 63-70.

[15] Topsakal R, Kalay N, Ozdogru I, Cetinkaya Y, Oymak S, Kaya MG, et al. Effects of chronic obstructive pulmonary disease on coronary atherosclerosis. Heart Vessels 2009;24(3):164-8.

[16] Gottlieb SS, McCarter RJ, Vogel RA. Effect of beta-blockade on mortality among high-risk and low-risk patients after myocardial infarction. N Engl J Med 1998;339(8):489-97.

[17] Hawkins NM, Huang Z, Pieper KS, Solomon SD, Kober L, Velazquez EJ, et al., Valsartan in Acute Myocardial Infarction Trial Investigators. Chronic obstructive pulmonary disease is an independent predictor of death but not atherosclerotic events in patients with myocardial infarction: analysis of the Valsartan in Acute Myocardial Infarction Trial (VALIANT). Eur J Heart Fail 2009;11(3):292-8.

[18] Nishiyama K, Morimoto T, Furukawa Y, Nakagawa Y, Ehara N, Taniguchi R, et al. Chronic obstructive pulmonary disease - An independent risk factor for long-term cardiac and cardiovascular mortality in patients with ischemic heart disease. Int $\mathrm{J}$ Cardiol 2010;143(2):178-83.

[19] Brekke PH, Omland T, Smith P, Søyseth V. Underdiagnosis of myocardial infarction in COPD - Cardiac Infarction Injury Score (CIIS) in patients hospitalised for COPD exacerbation. Respir Med 2008;102(9):1243-7.

[20] Fabbri LM, Rabe KF. From COPD to chronic systemic inflammatory syndrome? Lancet 2007;370(9589):797-9.

[21] Clayton TC, Thompson M, Meade TW. Recent respiratory infection and risk of cardiovascular disease: case-control study through a general practice database. Eur Heart J 2008;29(1): 96-103.

[22] Fabbri LM, Calverley PM, Izquierdo-Alonso JL, Bundschuh DS, Brose M, Martinez FJ, et al., M2-127 and M2-128 study groups. Roflumilast in moderate-to-severe chronic obstructive pulmonary disease treated with longacting bronchodilators: two randomised clinical trials. Lancet 2009;374(9691):695-703.

[23] Calverley PM, Rabe KF, Goehring UM, Kristiansen S, Fabbri LM, Martinez FJ, M2-124 and M2-125 study groups. Roflumilast in symptomatic chronic obstructive pulmonary disease: two randomised clinical trials. Lancet 2009;374(9691):685-94.

[24] Balan KK, Critchley M. Is the dyspnea during adenosine cardiac stress test caused by bronchospasm? Am Heart J 2001;142(1): $142-5$.

[25] Thurnheer R, Laube I, Kaufmann PA, Stumpe KD, Stammberger $\mathrm{U}$, Bloch KE, et al. Practicability and safety of dipyridamole cardiac imaging in patients with severe chronic obstructive pulmonary disease. Eur J Nucl Med 1999;26(8):812-7.

[26] Hesse B, Tägil K, Cuocolo A, Anagnostopoulos C, Bardiés M, Bax J, et al., EANM/ESC Group. EANM/ESC procedural guidelines for myocardial perfusion imaging in nuclear cardiology. Eur $\mathrm{J} \mathrm{Nucl}$ Med Mol Imaging 2005;32(7):855-97.

[27] Geleijnse ML, Fioretti PM, Roelandt JR. Methodology, feasibility, safety and diagnostic accuracy of dobutamine stress echocardiography. J Am Coll Cardiol 1997;30(3):595-606.

[28] Nikolaou K, Knez A, Rist C, Wintersperger BJ, Leber A, Johnson $T$, et al. Accuracy of 64-MDCT in the diagnosis of ischemic heart disease. AJR Am J Roentgenol 2006;187(1):111-7.

[29] van der Woude HJ, Zaagsma J, Postma DS, Winter TH, van Hulst $M$, Aalbers R. Detrimental effects of beta-blockers in COPD: a concern for nonselective beta-blockers. Chest 2005;127(3): 818-24. 
[30] Salpeter SR, Ormiston TM, Salpeter EE, Poole PJ, Cates CJ. Cardioselective beta-blockers for chronic obstructive pulmonary disease: a meta-analysis. Respir Med 2003;97(10):1094101.

[31] Andrus MR, Loyed JV. Use of beta-adrenoceptor antagonists in older patients with chronic obstructive pulmonary disease and cardiovascular co-morbidity: safety issues. Drugs Aging 2008;25(2):131-44.

[32] Dransfield MT, Rowe SM, Johnson JE, Bailey WC, Gerald LB. Use of beta blockers and the risk of death in hospitalised patients with acute exacerbations of COPD. Thorax 2008;63(4):301-5.

[33] Salpeter S, Ormiston T, Salpeter E. Cardioselective beta-blockers for chronic obstructive pulmonary disease. Cochrane Database Syst Rev 2005;(4):CD003566.

[34] Ollivier R, Donal E, Delaval P, Daubert JC, Mabo P. Beta-blocker prescription and chronic obstructive pulmonary disease. Ann Cardiol Angeiol (Paris) 2007;56(5):231-6.

[35] Olenchock BA, Fonarow GG, Pan W, Hernandez A, Cannon CP, Get With The Guidelines Steering Committee. Current use of beta blockers in patients with reactive airway disease who are hospitalized with acute coronary syndromes. Am J Cardiol 2009;103(3):295-300.

[36] Albouaini K, Andron M, Alahmar A, Egred M. Beta-blockers use in patients with chronic obstructive pulmonary disease and concomitant cardiovascular conditions. Int J Chron Obstruct Pulmon Dis 2007;2(4):535-40.

[37] Kuba K, Imai Y, Penninger JM. Angiotensin-converting enzyme 2 in lung diseases. Curr Opin Pharmacol 2006;6(3):271-6.

[38] Busquets X, MacFarlane NG, Heine-Suñer D, Morlá $M$, Torres-Juan L, Iglesias A, et al. Angiotensin-converting-enzyme gene polymorphisms, smoking and chronic obstructive pulmonary disease. Int J Chron Obstruct Pulmon Dis 2007;2(3):329-34.

[39] Kanazawa H, Hirata K, Yoshikawa J. Effects of captopril administration on pulmonary haemodynamics and tissue oxygenation during exercise in ACE gene subtypes in patients with COPD: a preliminary study. Thorax 2003;58(7):629-31.

[40] Forth R, Montgomery H. ACE in COPD: a therapeutic target? Thorax 2003;58(7):556-8.

[41] Andreas S, Herrmann-Lingen C, Raupach T, Lüthje L, Fabricius $\mathrm{JA}$, Hruska N, et al. Angiotensin II blockers in obstructive pulmonary disease: a randomised controlled trial. Eur Respir J 2006;27(5):972-9.

[42] Mancini GB, Etminan M, Zhang B, Levesque LE, Fitzgerald JM, Brophy JM. Reduction of morbidity and mortality by statins, angiotensin-converting enzyme inhibitors, and angiotensin receptor blockers in patients with chronic obstructive pulmonary disease. J Am Coll Cardiol 2006;47(12):2554-60.

[43] Mortensen EM, Copeland LA, Pugh MJ, Restrepo MI, de Molina RM, Nakashima B, et al. Impact of statins and ACE inhibitors on mortality after COPD exacerbations. Respir Res 2009;10:45.

[44] Lee JH, Lee DS, Kim EK, Choe KH, Oh YM, Shim TS, et al. Simvastatin inhibits cigarette smoking-induced emphysema and pulmonary hypertension in rat lungs. Am J Respir Crit Care Med 2005;172(8):987-93.

[45] Keddissi JI, Younis WG, Chbeir EA, Daher NN, Dernaika TA, Kinasewitz GT. The use of statins and lung function in current and former smokers. Chest 2007;132(6):1764-71.

[46] Alexeeff SE, Litonjua AA, Sparrow D, Vokonas PS, Schwartz J. Statin use reduces decline in lung function: VA Normative Aging Study. Am J Respir Crit Care Med 2007;176(8):742-7.

[47] Frost FJ, Petersen H, Tollestrup K, Skipper B. Influenza and COPD mortality protection as pleiotropic, dose-dependent effects of statins. Chest 2007;131(4):1006-12.

[48] Blamoun Al, Batty GN, DeBari VA, Rashid AO, Sheikh M, Khan MA. Statins may reduce episodes of exacerbation and the requirement for intubation in patients with COPD: evidence from a retrospective cohort study. Int $\mathrm{J}$ Clin Pract 2008;62(9):1373-8.
[49] Søyseth V, Brekke PH, Smith P, Omland T. Statin use is associated with reduced mortality in COPD. Eur Respir J 2007;29(2): 279-83.

[50] van Gestel YR, Hoeks SE, Sin DD, Simsek C, Welten GM, Schouten $O$, et al. Effect of statin therapy on mortality in patients with peripheral arterial disease and comparison of those with versus without associated chronic obstructive pulmonary disease. Am J Cardiol 2008;102(2):192-6.

[51] Janda S, Park K, Fitzgerald JM, Etminan M, Swiston J. Statins in COPD: a systematic review. Chest 2009;136(3):734-43.

[52] Lee TM, Lin MS, Chang NC. Usefulness of C-reactive protein and interleukin- 6 as predictors of outcomes in patients with chronic obstructive pulmonary disease receiving pravastatin. Am J Cardiol 2008;101(4):530-5.

[53] Blum A, Shamburek R. The pleiotropic effects of statins on endothelial function, vascular inflammation, immunomodulation and thrombogenesis. Atherosclerosis 2009;203(2):325-30.

[54] Berger JS, Sanborn TA, Sherman W, Brown DL. Effect of chronic obstructive pulmonary disease on survival of patients with coronary heart disease having percutaneous coronary intervention. Am J Cardiol 2004;94(5):649-51.

[55] Selvaraj CL, Gurm HS, Gupta R, Ellis SG, Bhatt DL. Chronic obstructive pulmonary disease as a predictor of mortality in patients undergoing percutaneous coronary intervention. Am J Cardiol 2005;96(6):756-9.

[56] Roques F, Nashef SA, Michel P, Gauducheau E, de Vincentiis C, Baudet E, et al. Risk factors and outcome in European cardiac surgery: analysis of the EuroSCORE multinational database of 19030 patients. Eur J Cardiothorac Surg 1999;15(6):816-22.

[57] Gardner SC, Grunwald GK, Rumsfeld JS, Mackenzie T, Gao D, Perlin JB, et al. Risk factors for intermediate-term survival after coronary artery bypass grafting. Ann Thorac Surg $2001 ; 72(6): 2033-7$.

[58] Samuels LE, Kaufman MS, Morris RJ, Promisloff R, Brockman SK. Coronary artery bypass grafting in patients with COPD. Chest 1998;113(4):878-82.

[59] Canver CC, Nichols RD, Kroncke GM. Influence of age-specific lung function on survival after coronary bypass. Ann Thorac Surg 1998;66(1):144-7.

[60] Gao D, Grunwald GK, Rumsfeld JS, Mackenzie T, Grover FL, Perlin JB, et al. Variation in mortality risk factors with time after coronary artery bypass graft operation. Ann Thorac Surg 2003;75(1):74-81.

[61] Michalopoulos A, Geroulanos S, Papadimitriou L, Papadakis E, Triantafillou K, Papadopoulos K, et al. Mild or moderate chronic obstructive pulmonary disease risk in elective coronary artery bypass grafting surgery. World J Surg 2001;25(12):1507-11.

[62] Clough RA, Leavitt BJ, Morton JR, Plume SK, Hernandez F, Nugent $\mathrm{W}$, et al. The effect of comorbid illness on mortality outcomes in cardiac surgery. Arch Surg 2002;137(4):428-32.

[63] Rosenthal GE, Vaughan Sarrazin M, Hannan EL. In-hospital mortality following coronary artery bypass graft surgery in Veterans Health Administration and private sector hospitals. Med Care 2003;41(4):522-35.

[64] Medalion B, Katz MG, Cohen AJ, Hauptman E, Sasson L, Schachner A. Long-term beneficial effect of coronary artery bypass grafting in patients with COPD. Chest 2004;125(1):56-62.

[65] Güler M, Kirali K, Toker ME, Bozbuğa N, Omeroğlu SN, Akinci E, et al. Different CABG methods in patients with chronic obstructive pulmonary disease. Ann Thorac Surg 2001;71(1):152-7.

[66] Leavitt BJ, Ross CS, Spence B, Surgenor SD, Olmstead EM, Clough RA, et al., Northern New England Cardiovascular Disease Study Group. Long-term survival of patients with chronic obstructive pulmonary disease undergoing coronary artery bypass surgery. Circulation 2006;114(1 Suppl):1430-4.

[67] Salpeter SR, Ormiston TM, Salpeter EE. Cardiovascular effects of beta-agonists in patients with asthma and COPD: a metaanalysis. Chest 2004;125(6):2309-21. 
[68] Calverley PM, Anderson JA, Celli B, Ferguson GT, Jenkins C, Jones PW, et al., TORCH investigators. Salmeterol and fluticasone propionate and survival in chronic obstructive pulmonary disease. N Engl J Med 2007;356(8):775-89.

[69] de Vries F, Pouwels S, Bracke M, Lammers JW, Klungel O, Leufkens $\mathrm{H}$, et al. Use of beta2 agonists and risk of acute myocardial infarction in patients with hypertension. $\mathrm{Br} \mathrm{J}$ Clin Pharmacol 2008;65(4):580-6.

[70] Sin DD, Man SF. Do chronic inhaled steroids alone or in combination with a bronchodilator prolong life in chronic obstructive pulmonary disease patients? Curr Opin Pulm Med 2007;13(2): 90-7.

[71] Soriano JB, Vestbo J, Pride NB, Kiri V, Maden C, Maier WC. Survival in COPD patients after regular use of fluticasone propionate and salmeterol in general practice. Eur Respir $\mathrm{J}$ 2002;20(4):819-25.

[72] Sin DD, Wu L, Anderson JA, Anthonisen NR, Buist AS, Burge PS, et al. Inhaled corticosteroids and mortality in chronic obstructive pulmonary disease. Thorax 2005;60(12):992-7.

[73] Drummond MB, Dasenbrook EC, Pitz MW, Murphy DJ, Fan E. Inhaled corticosteroids in patients with stable chronic obstructive pulmonary disease: a systematic review and meta-analysis. JAMA 2008;300(20):2407-16.

[74] Löfdahl CG, Postma DS, Pride NB, Boe J, Thorén A. Possible protection by inhaled budesonide against ischaemic cardiac events in mild COPD. Eur Respir J 2007;29(6):1115-9.

[75] Loke YK, Kwok CS, Singh S. Risk of myocardial infarction and cardiovascular death associated with inhaled corticosteroids in COPD. Eur Respir J 2010;35(5):1003-21.

[76] Huiart L, Ernst P, Ranouil X, Suissa S. Low-dose inhaled corticosteroids and the risk of acute myocardial infarction in COPD. Eur Respir J 2005;25(4):634-9.

[77] Anthonisen NR, Connett JE, Enright PL, Manfreda J, Lung Health Study Research Group. Hospitalizations and mortality in the Lung Health Study. Am J Respir Crit Care Med 2002;166(3):333-9.

[78] US Food and Drug Administration. Early communication about an ongoing safety review of tiotropium (marketed as Spiriva Handihaler) http://www.fda.gov/cder/drug/early_comm/tiotropium.htm (Accessed August 5, 2008).

[79] Singh S, Loke YK, Furberg CD. Inhaled anticholinergics and risk of major adverse cardiovascular events in patients with chronic obstructive pulmonary disease: a systematic review and metaanalysis. JAMA 2008;300(12):1439-50.

[80] Macie C, Wooldrage K, Manfreda J, Anthonisen N. Cardiovascular morbidity and the use of inhaled bronchodilators. Int J Chron Obstruct Pulmon Dis 2008;3(1):163-9.

[81] Lee TA, Pickard AS, Au DH, Bartle B, Weiss KB. Risk for death associated with medications for recently diagnosed chronic obstructive pulmonary disease. Ann Intern Med 2008;149(6): 380-90.

[82] Wedzicha JA, Calverley PM, Seemungal TA, Hagan G, Ansari Z, Stockley RA, INSPIRE Investigators. The prevention of chronic obstructive pulmonary disease exacerbations by salmeterol/ fluticasone propionate or tiotropium bromide. Am J Respir Crit Care Med 2008;177(1):19-26.

[83] de Luise C, Lanes SF, Jacobsen J, Pedersen L, Sørensen HT. Cardiovascular and respiratory hospitalizations and mortality among users of tiotropium in Denmark. Eur J Epidemiol 2007;22(4):267-72.

[84] Kesten S, Jara M, Wentworth C, Lanes S. Pooled clinical trial analysis of tiotropium safety. Chest 2006;130(6):1695-703.

[85] Tashkin DP, Celli B, Senn S, Burkhart D, Kesten S, Menjoge S, et al., UPLIFT Study Investigators. A 4-year trial of tiotropium in chronic obstructive pulmonary disease. $\mathrm{N}$ Engl J Med 2008;359(15):1543-54.

[86] Oba Y, Zaza T, Thameem DM. Safety, tolerability and risk benefit analysis of tiotropium in COPD. Int J Chron Obstruct Pulmon Dis 2008;3(4):575-84.

[87] Iso H, Date C, Yamamoto A, Toyoshima H, Watanabe Y, Kikuchi S, et al., JACC Study Group. Smoking cessation and mortality from cardiovascular disease among Japanese men and women: the JACC Study. Am J Epidemiol 2005;161(2):170-9.

[88] Reichert V, Xue X, Bartscherer D, Jacobsen D, Fardellone C, Folan $\mathrm{P}$, et al. A pilot study to examine the effects of smoking cessation on serum markers of inflammation in women at risk for cardiovascular disease. Chest 2009;136(1):212-9.

[89] Global Strategy for Diagnosis, Management, and Prevention of COPD. Executive summary updated 2009. www.goldcopd.org

[90] Crisafulli E, Costi S, Luppi F, Cirelli G, Cilione C, Coletti O, et al. Role of comorbidities in a cohort of patients with COPD undergoing pulmonary rehabilitation. Thorax 2008;63(6): 487-92. 


\section{BPCO e ipertensione arteriosa}

\section{Fabrizio Colombo}

\section{Messaggi chiave}

- La broncopneumopatia cronica ostruttiva (BPCO) negli stadi GOLD 3 e 4 si associa a un maggior rischio di ipertensione arteriosa $(O R$ 1,6) rispetto alla popolazione generale.

- Un fattore eziopatogenetico comune a entrambe le patologie è il fumo.

- Il vero nesso fra le due condizioni va ricercato nell'infiammazione sistemica.

- Un ruolo chiave nell'infiammazione è svolto dall'angiotensina II. L'attivazione del sistema nervoso simpatico, in particolare del sistema renina-angiotensina (RAS), soprattutto quello tissutale, è presente sia nella BPCO, in cui l'attivazione è determinata dall'eritrocitosi e dall'ipossiemia, sia nell'ipertensione arteriosa.

\section{Introduzione}

La broncopneumopatia cronica ostruttiva (BPCO) si associa a numerose comorbilità; tra queste sono frequenti l'ictus, la cardiopatia ischemica, lo scompenso cardiaco e l'ipertensione arteriosa.

Si calcola che il decesso entro le 24 ore successive al ricovero per BPCO agli stadi lieve e moderato avvenga per complicanze cardiovascolari.

L'ipertensione può essere una primissima manifestazione di eventi cardiovascolari più importanti, che si sviluppano lungo il "continuum fisiopatologico" [1,2].

La BPCO negli stadi GOLD 3 e 4 si associa a un maggior rischio di ipertensione arteriosa (OR 1,6) rispetto alla popolazione generale. D'altra parte si calcola che il $5 \%$ degli ipertesi sia affetto da BPCO e che la prevalenza di BPCO negli ipertesi sia simile a quella della popolazione generale, attestandosi sul $7,4 \%$.

Un fattore eziopatogenetico comune a entrambe le patologie è il fumo. Il fumo è presente nel $25-43 \%$ degli ipertesi. La patologia polmonare, come la BPCO, indotta dal fumo costituisce un fattore di rischio indipendente per lo sviluppo di eventi cardiovascolari.

Il vero nesso fra le due condizioni va ricercato nell'infiammazione sistemica; d'altronde il fumo aumenta la suscettibilità alle infezioni e, più in generale, è in grado di attivare meccanismi infiammatori.

Un ruolo chiave nell'infiammazione è svolto, oltre che dal fumo, dall'angiotensina II. L'attivazione del sistema nervoso simpatico e in particolare del sistema renina-angiotensina (RAS), soprattutto quello tissutale, è presente sia nella BPCO, in cui l'attivazione è determinata dall'eritrocitosi e dall'ipossiemia, sia, com'è ormai noto, nell'ipertensione arteriosa.

Il ruolo chiave del RAS nella fisiopatologia cardiovascolare e nell'ipertensione arteriosa è ben documentato.

L'azione dell'angiotensina II è mediata dai recettori $\mathrm{AT}_{1}$. Questi recettori esercitano attività non solo vasocostrittiva, ma anche proinfiammatoria e protrombotica, e sono presenti a livello vascolare cardiaco, neuronale e polmonare $[3,4]$.

Un ruolo chiave è rappresentato dalla formazione di specie reattive dell'ossigeno (ROS), il cui aumento è mediato dall'angiotensina II.

L'angiotensina II, mediante l'attivazione della NAPH-ossidasi, porta alla formazione dell'anione superossido e di radicali liberi dell'ossigeno con successiva iperespressione di ICAM, VCAM, MCP-1, metalloproteinasi e citochine proinfiammatorie (TNF-alfa, IL-1, IL-6) [5,6].

Anche l'aumentata resistenza all'insulina, condizione peraltro presente sia nella BPCO sia nell'ipertensione arteriosa, può attivare il RAS e di conseguenza scatenare una risposta proinfiammatoria e protrombotica. 
Numerosi studi clinici, a questo proposito, hanno dimostrato come il blocco del RAS riduca lo stress ossidativo e più in generale moduli l'infiammazione sistemica.

\section{Trattamento farmacologico}

Negli ipertesi, studi con farmaci bloccanti i recettori dell'angiotensina (ARB) hanno dimostrato la diminuzione dell'espressione di citochine proinfiammatorie.

I livelli plasmatici di MCP-1, TNF-alfa e PAl-1 vengono ridotti, tuttavia questi cambiamenti dei mediatori dell'infiammazione non sembrano correlare con la riduzione dei valori pressori.

Tale meccanismo fisiopatologico è presente anche quando si usino ACE-inibitori, benché la risposta sia parziale in quanto gli $A R B$ bloccano solo il recettore $A T_{1}$, non il recettore $A T_{2}$, la cui attivazione è in grado di produrre una risposta antinfiammatoria e vasodilatatrice [7].

Presentano inoltre un vantaggio, rispetto agli ACE-inibitori, nei pazienti con tosse, poiché non interferiscono con il sistema della bradichinina e dalla sostanza $P$ [8].

\section{Altri farmaci in uso nei pazienti affetti da BPCO e ipertensione arteriosa}

Altri farmaci utilizzati nei pazienti affetti da BPCO e ipertensione arteriosa sono [9]:

- i diuretici: l'uso dei diuretici nei pazienti ipertesi affetti da BPCO è stato testato in pochi trial;

- i calcio-antagonisti: gli studi sono insufficienti, alcuni sono favorevoli all'impiego dei calcio-antagonisti diidropiridinici a lunga durata d'azione;
- i beta-boccanti: questi farmaci non dovrebbero essere usati nei pazienti con compromissione della funzione polmonare;

- gli alfa-bloccanti: non vi sono controindicazioni.

\section{Bibliografia}

[1] Mannino DM, Thorn D, Swensen A, Holguin F. Prevalence and outcomes of diabetes, hypertension and cardiovascular disease in COPD. Eur Respir J 2008;32(4):962-9.

[2] Sin DD, Anthonisen NR, Soriano JB, Agusti AG. Mortality in COPD: Role of comorbidities. Eur Respir J 2006;28(6):1245-57.

[3] Verma S, Li SH, Badiwala MV, Weisel RD, Fedak PW, Li RK, et al. Endothelin antagonism and interleukin- 6 inhibition attenuate the proatherogenic effects of $\mathrm{C}$-reactive protein. Circulation 2002;105(16):1890-6.

[4] Dandona P, Dhindsa S, Ghanim H, Chaudhuri A. Angiotensin II and inflammation: the effect of angiotensin-converting enzyme inhibition and angiotensin II receptor blockade. J Hum Hypertens 2007;21(1):20-7.

[5] Zahradka P, Werner JP, Buhay S, Litchie B, Helwer G, Thomas S. NF-kappaB activation is essential for angiotensin II-dependent proliferation and migration of vascular smooth muscle cells. J Mol Cell Cardiol 2002;34(12):1609-21.

[6] Dzau VJ. Theodore Cooper Lecture: Tissue angiotensin and pathobiology of vascular disease: a unifying hypothesis. Hypertension 2001;37(4):1047-52.

[7] Burnier M. Angiotensin II type 1 receptor blockers. Circulation 2001;103(6):904-12.

[8] Andreas S, Herrmann-Lingen C, Raupach T, Lüthje L, Fabricius JA, Hruska N, et al. Angiotensin II blockers in obstructive pulmonary disease: a randomised controlled trial. Eur Respir J 2006;27(5): 972-9.

[9] Dart RA, Gollub S, Lazar J, Nair C, Schroeder D, Woolf SH. Treatment of systemic hypertension in patients with pulmonary disease: COPD and asthma. Chest 2003;123(1):222-43. 


\title{
BPCO e tromboembolismo venoso
}

\author{
Pietro Roversi, Mauro Campanini
}

\section{Messaggi chiave}

- La broncopneumopatia cronica ostruttiva (BPCO) è uno dei fattori di rischio per tromboembolia polmonare (TEP).

- La TEP deve essere considerata tra le cause di riacutizzazione di BPCO e la sua frequenza varia in funzione della casistica studiata e del setting clinico, potendo arrivare fino al $25 \%$ dei casi.

- La diagnosi è resa difficile dall'aspecificità dei sintomi e dalla possibile sovrapposizione con quelli di una riacutizzazione e la formulazione di uno score clinico di probabilità è utile sia per porre il sospetto sia per l'accuratezza diagnostica.

- La performance clinica delle indagini diagnostiche, con l'eccezione della scintigrafia polmonare perfusionale/ventilatoria, non è influenzata in modo significativo dalla presenza di BPCO.

- Lo studio del circolo polmonare arterioso con tomografia computerizzata (angioTC polmonare) è l'indagine di riferimento; un eccessivo impiego di esami TC con mezzo di contrasto può essere evitato escludendo $i$ soggetti con score di probabilità medio-basso associato a D-dimero negativo.

- La valutazione del rischio di morte (stratificazione del rischio con ricerca dei segni di disfunzione ventricolare destra) è utile a fini prognostici e terapeutici.

\section{Introduzione}

I pazienti con broncopneumopatia cronica ostruttiva (BPCO) che si presentano con dispnea acuta costituiscono un problema diagnostico e terapeutico rilevante, sia nella pratica ambulatoriale sia nella degenza ospedaliera. Le cause di riacutizzazione di BPCO sono spesso di difficile riconoscimento e in una percentuale significativa di casi non ne viene evidenziata alcuna [1]: la tromboembolia polmonare (TEP) è una delle possibili cause di peggioramento della dispnea, in particolare quando non è evidente una causa infettiva.

La TEP nella BPCO è di difficile diagnosi per l'aspecificità del quadro clinico, pertanto la probabilità di ometterne la diagnosi è molto elevata, come attestato dall'elevata incidenza di TEP non diagnosticate in vita in casistiche autoptiche.

Una TEP non trattata (perché non diagnosticata) comporta una probabilità di morte elevata che aumenta ulteriormente nei soggetti con copatologie, tra cui la BPCO, pertanto la formulazione del sospetto diagnostico, basato sui fattori di rischio e sui dati clinici di probabilità, diventa fondamentale per ridurre il numero di mancate diagnosi che comportano conseguenze potenzialmente devastanti.

\section{Tromboembolismo venoso nella BPCO: alcuni dati epidemiologici}

L'incidenza di tromboembolismo venoso (TEV) nella popolazione generale è compresa tra 1 e 3 casi per 1.000 abitanti e si manifesta essenzialmente come trombosi venosa profonda (TVP) degli arti inferiori o superiori e come tromboembolia polmonare (TEP). Incidenze 2-5 volte superiori si osservano in pazienti con specifici fattori predisponenti [2,3].

La TVP localizzata agli arti inferiori è la forma più comune e può interessare le sole vene della gamba (TVP distale) o estendersi sopra il livello del ginocchio (TVP prossimale). Questa distinzione topografica ha rilevanza clinica in quanto le forme prossimali tendono a embolizzare nel circolo arterioso polmonare molto più frequentemente (fino a $50 \%$ dei casi) di quelle distali (circa 10-15\%), e queste ultime embolizzano nella maggior parte dei casi solo dopo essersi propagate spontaneamente sopra al livello del ginocchio (20-25\% dei casi, per lo più entro 7 giorni dalla comparsa dei primi sintomi) [4]. 
La mortalità globale a 3 mesi dalla diagnosi di TEV raggiunge il $17 \%$, ma dipende in gran parte dalle comorbilità associate (soprattutto cancro o gravi cardiopatie), piuttosto che direttamente dalle complicanze tromboemboliche. La quota attribuibile alla TEV in senso stretto dipende quasi interamente dall'EP ed è complessivamente molto inferiore, aggirandosi intorno al 2,5\% nei 12 mesi dalla diagnosi.

Va comunque considerato che la diagnosi di EP è spesso misconosciuta in quanto le manifestazioni cliniche di presentazione possono essere modeste e poco specifiche. A fronte di embolie massive con riduzione del flusso polmonare maggiore del $50 \%$, caratterizzate da shock cardiogeno e morte improvvisa, si osservano embolie di minore entità caratterizzate da infarto polmonare o semplice tachicardia e/o polipnea da sforzo.

La BPCO è unanimemente riconosciuta come uno dei fattori di rischio per TEP [5]. Soggetti con BPCO hanno un rischio aumentato di sviluppare malattie cardiovascolari; nella fattispecie, il rischio di morte o di ricovero per TEP è più che doppio rispetto alla popolazione generale [6].

In alcune casistiche selezionate 0 in particolari setting clinici la frequenza di TEP in riacutizzazione di BPCO può arrivare a 1 caso ogni 4 o 5 , mentre nel complesso dei soggetti BPCO si stima una prevalenza del 3\% di EP e del 10\% di TVP [7].

Studi autoptici hanno dimostrato un'incidenza significativa di TEP nella popolazione generale: Nordström et al. [8] hanno riscontrato, su 2.356 autopsie di soggetti deceduti in ospedale, 308 casi TEP $(13,1 \%$ del totale) di cui solo il $2 \%$ era stato diagnosticato in vita. Altri studi autoptici condotti in soggetti con BPCO riportano il riscontro di manifestazioni tromboemboliche nel $28-51 \%$ dei casi considerati $[9,10]$.

Una recente metanalisi [11] sull'incidenza di TEP in pazienti con BPCO riacutizzata evidenzia un'elevata prevalenza di TEP nei pazienti ospedalizzati, pari al 24,7\% (IC 95\% 17,9-31,4\%; $p=0,001)$, con una prevalenza di TEP del 19,9\% (IC 95\% 6,7-33,0\%; $p=0,014$ ) nella globalità dei soggetti considerati, senza distinzione tra pazienti ospedalizzati o trattati a domicilio

Dati differenti sono riportati in uno studio [12] che ha arruolato pazienti con BPCO riacutizzata valutati sequenzialmente con tomografia computerizzata presso il Dipartimento di Emergenza, nei quali si è riscontrata una bassa incidenza di TEP, pari al 3,3\%.

Altri studi che hanno considerato soggetti con BPCO riacutizzata evidenziano una percentuale di TEP del $25,5 \%$ in pazienti ricoverati $[13,14]$ e del $23,6 \%$ in casistiche di pazienti sia ricoverati sia domiciliari $[15,16]$.

La maggior parte degli studi, come già è stato sottolineato, sono retrospettivi, mentre particolare considerazione merita il lavoro di Tillie-Leblond et al. [14], studio prospettico che documenta, in pazienti con BPCO riacutizzata esclusi quelli con chiara genesi infettiva, una prevalenza di TEP del $25 \%$.

In letteratura, quindi, sono riportati dati molto discordanti, probabilmente in rapporto a vari fattori quali:

- il differente metodo utilizzato per la diagnosi di TEP. Infatti, mentre la specificità e sensibilità della scintigrafia polmonare ventilatoria/perfusoria è condizionata dalla presenza della BPCO, l'angioTC non ne è influenzata [15]; - la maggior parte degli studi è di tipo retrospettivo e presenta limitazioni per quanto riguarda sia l'accuratezza della diagnosi di BPCO sia la determinazione dello stadio di gravità;

- la casistica esaminata è molto eterogenea, sia per la differente gravità sia per i criteri di selezione delle popolazioni considerate. Per esempio, in alcuni studi vengono esclusi i pazienti con valori di D-dimero normale [15], in altri la frequenza di neoplasie maligne è assai diversa: il 29\% nello studio di Tillie-Leblond et al. [14], il 5\% nella casistica di Rutschmann [12].

Dall'insieme dei dati si evince che la TEP nel paziente BPCO può essere una condizione molto frequente in determinati setting clinici o in particolari popolazioni selezionate, rappresentando comunque, in ogni caso, un problema epidemiologico rilevante.

Per quanto riguarda la prevalenza di TVP, essa è inferiore rispetto a quella dell'EP e pari al 12,4\% (IC 95\% 2,2-27,1\%; $p=0,074)$. La prevalenza è maggiore se si considerano solo $i$ pazienti ricoverati (16,6\%; IC 95\% 1,1-32,1\%; $p=0,044)$ [11]. La metodica utilizzata per indagare la presenza di TVP ne influenza la prevalenza.

Prescott et al. [17], utilizzando la flebografia e il fibrinogeno-I125 entro 7 giorni dal ricovero in ospedale in 45 pazienti allettati e non sottoposti a profilassi, dimostrano un'incidenza del 9\%. Con l'impiego dell'ultrasonografia (US) la prevalenza di TVP varia tra lo 0\% [18] e il 10\% [19]. Quando la TVP è ricercata nei pazienti ricoverati presso un reparto di Terapia Intensiva, si dimostra una prevalenza del 10,7\%. È importante sottolineare che nella maggior parte dei casi la TVP era asintomatica (86\%) e nessuna delle principali variabili cliniche (età, peso, severità della dispnea e valori dell'emogasanalisi) era predittiva per lo sviluppo di TVP [20].

Lo studio di Schönhofer et al. [20] pare di particolare interesse anche perché ha dimostrato in 196 pazienti con $\mathrm{BPCO}$, ricoverati in un reparto di Terapia Intensiva, una prevalenza di TVP con esame ultrasonografico del $10,7 \%$. Questo studio osservazionale ha escluso i pazienti con BPCO affetti da cancro, insufficienza cardiaca o storia di precedente TEV, indicando pertanto che la relativa elevata frequenza di TVP in tali pazienti, senza altri fattori di rischio concomitanti, può dipendere dalla sola malattia respiratoria cronica o dalla sua riacutizzazione.

\section{Fattori di rischio}

La BPCO, come si è già ricordato, rappresenta di per sé una condizione a rischio di TEP [5]. All'interno di popolazioni di soggetti con BPCO i fattori di rischio correlati allo sviluppo di TEP sono diversi: nello studio di Tillie-Leblond et al. [14], utilizzando lo score di Ginevra [21], ne vengono evidenziati tre:

- presenza di neoplasia maligna (RR 1,82; IC 95\% 1,3-2,92\%); - storia di pregressa TVP o EP (RR 2,43; IC 95\% 1,49-3,49\%); - riduzione dei valori di $\mathrm{PaCO}_{2}>5 \mathrm{mmHg}$.

In generale la storia di cancro e lo scompenso cardiaco congestizio paiono essere le comorbilità più frequenti nei pazienti con BPCO e TVP [22]. Questo dato è coerente con il riscontro di una più elevata incidenza di TEP in soggetti ospedalizzati: la presenza di precedenti di TEV, di interventi chirurgici e di neoplasie è pari rispettivamente al 3\%, 2\%, 5\% nei pazienti che si recano al Dipartimento di Emergenza e Accettazione [12] e al 14\%, 13\% e 10\% nei soggetti ricoverati 
[15]. Inoltre i pazienti ricoverati sono generalmente più fragili e hanno un numero maggiore di comorbilità alle quali si associa spesso una prolungata immobilizzazione, che costituisce un ulteriore fattore di rischio trombotico [23].

I pazienti con TEP e BPCO sono inoltre spesso più anziani e fumatori rispetto ai pazienti con BPCO senza TEP [17]. Il fumo infatti è in grado di aumentare in modo indipendente il rischio tromboembolico. Uomini che fumano 15 o più sigarette al giorno presentano un rischio relativo di TEV di 2,82 (IC 95\% 1,30-6,13\%; $p=0,009$ ) rispetto ai non fumatori [24]. Durante le riacutizzazioni della BPCO è spesso presente un aumento del fibrinogeno correlato con la presenza di sputo purulento, frequenza e intensità della tosse ed età dei pazienti [25]. Nella BPCO riacutizzata si determina un aumento dell'interleuchina-6, correlato in modo stretto con l'aumento del fibrinogeno e con lo sviluppo di eventi tromboembolici [25].

Il fumo è il fattore ambientale più importante nel condizionare le concentrazioni di fibrinogeno e può stimolare il rilascio di catecolamine [26]. L'epinefrina a sua volta può aumentare la sintesi di fibrinogeno dal fegato sia direttamente sia attraverso la sintesi di mRNA [27]. I livelli di fattore tissutale (TF) sono influenzati dal fumo di sigaretta ed è nota l'importanza del TF nell'innescare la cascata emocoagulativa attraverso l'attivazione del fattore VII. È dimostrato che 2 ore dopo aver fumato 2 sigarette il TF aumenta ( $217 \pm 72$ vs $283 \pm 106 \mathrm{pmol} / \mathrm{L} ; \mathrm{p}=0,003)$ suggerendo pertanto un altro importante legame tra fumo e TEV [28]. Il fumo, inoltre, può influenzare anche la fibrinolisi. Una fibrinolisi efficace richiede un rapido rilascio di attivatore tissutale del plasminogeno (tPA) da parte dell'endotelio. Il fumo è in grado di inibire acutamente il rilascio di tPA indotto dall'endotelio attraverso un'inibizione della nitrossido-sintetasi [29].

I fumatori di sigarette presentano altresì un aumentato livello di omocisteina (OR 2,10; IC 95\% 1,62-27,4\%; $\mathrm{p}<0,001)$, che costituisce un fattore di rischio per la patologia trombotica venosa e arteriosa [30].

\section{Diagnosi clinico-strumentale}

\section{Valutazione clinica}

La diagnosi di TEP, come è già stato ricordato, presenta molte insidie; nel soggetto con BPCO esiste una difficoltà particolare in quanto le due condizioni patologiche condividono segni e sintomi aspecifici, tanto che spesso non sono clinicamente distinguibili [16].

Le differenze più significative tra pazienti con riacutizzazione di BPCO con e senza EP sono descritte nella recente metanalisi di Rizkallah et al. [11]: nei soggetti con riacutizzazione di BPCO ed EP si riscontrano una più elevata percentuale di pregresso TEV, di neoplasie maligne, una minore $\mathrm{PaCO}_{2}$ [14], una più severa ipossia, una maggiore probabilità di dolore toracico, di sincope e assenza di sputo purulento $[12,13]$. Nello studio PIOPED [16], in 108 soggetti con BPCO riacutizzata di cui 19 con EP documentata angiograficamente, non vi erano differenze significative tra i due gruppi, né cliniche né nelle alterazioni emogasanalitiche.

La presenza/assenza di BPCO non influenza l'accuratezza diagnostica del $D$-dimero [15] che, vale la pena ricordare, è un test con impiego elettivo in senso predittivo negativo (ossia di esclusione della TEP) e trova applicazione preferenziale in particolari setting clinici (sospetti casi di TEP in Pronto Soccorso) e in pazienti non affetti da altre patologie che ne condizionino significativamente la specificità.

La combinazione del D-dimero con un test clinico di probabilità a punteggio o "clinical prediction rule" (CPR) è utile nella strategia diagnostica della TEP anche nei pazienti con comorbilità, in particolare con BPCO, in quanto un basso CPR associato a un normale D-dimero esclude la TEP con ampio margine di sicurezza [31].

Occorre comunque precisare che gli score maggiormente usati in clinica, come quelli di Ginevra (tabella 1) e di Wells $[21,32]$, sono stati validati in popolazioni indifferenziate e non in popolazioni selezionate come quella dei soggetti con BPCO, che differisce, per esempio, per la maggior frequenza di neoplasie.

\section{Diagnosi strumentale}

La radiografia standard del torace del soggetto con EP può evidenziare anomalie parenchimali aspecifiche, come atelettasie o versamenti pleurici di modeste dimensioni [33] e, più raramente, immagini radiologiche associate classicamente alla diagnosi di EP (segno di Westermark, segno di Hampton). Nel soggetto con BPCO tali segni hanno sensibilità ulteriormente ridotta, per cui la radiografia standard del torace ha utilità prevalente nell'escludere diagnosi alternative alla TEP.

L'ecografia compressiva e il Doppler venoso degli arti inferiori costituiscono uno strumento diagnostico di grande utilità nel sospetto di TEV in soggetti con BPCO grazie

Tabella 1 Score di Ginevra (rivisto).

\begin{tabular}{lc}
\hline Variabile & Punteggio \\
\hline Età $>65$ anni & 1 \\
\hline Pregressa trombosi venosa profonda & 3 \\
\hline o embolia polmonare & 2 \\
\hline Intervento chirurgico o frattura & 2 \\
\hline di arto nella settimana precedente & 3 \\
\hline Cancro in atto & 2 \\
\hline Dolore unilaterale di gamba & 3 \\
\hline Emottisi & 5 \\
\hline Frequenza cardiaca 75-94 bpm & 4 \\
\hline Frequenza cardiaca $\geq 95$ bpm & Punteggio \\
\hline Dolore alla palpazione o edema & totale \\
\hline unilaterale di gamba & $<3$ \\
\hline Probabilità & $4-11$ \\
\hline Bassa & $>11$ \\
\hline Moderata & \\
\hline Alta & \\
\hline 52. & \\
\hline
\end{tabular}


all'assenza di invasività e alla relativa semplicità di esecuzione, anche se la resa diagnostica è condizionata dall'esperienza dell'operatore. $\grave{E}$ noto che la TVP è presente nel 30-50\% dei casi di EP, pertanto la dimostrazione di TVP costituisce un elemento sufficiente per iniziare il trattamento, il quale non si discosta da quello dell'EP [34].

In alcuni studi l'eco-Doppler venoso veniva raccomandato come indagine da associare alla TC "single slice" [35,36] per aumentarne la sensibilità: indicazione ora meno attuale con la diffusione di apparecchi TC multistrato che hanno una sensibilità diagnostica più elevata (si veda oltre).

Per quanto riguarda l'angiografia polmonare con tomografia computerizzata (angioTC) del torace, anche se in studi non recenti si ipotizza una sua minore sensibilità nei pazienti con BPCO rispetto a quelli senza BPCO, va precisato che con l'introduzione sul mercato di apparecchi TC multistrato (MDCT) in grado di offrire maggiore potere di risoluzione e tempi di esecuzione più brevi, essa costituisce lo strumento diagnostico di riferimento nella pratica clinica.

In pazienti con un livello di probabilità clinica pre-test medio o basso, una MDCT negativa ha un potere predittivo negativo molto soddisfacente, rispettivamente dell' $89 \%$ e del $96 \%$ e un altrettanto elevato valore predittivo positivo in casi con probabilità pre-test intermedia o alta (rispettivamente 92\% e 96\%) [37].

Nelle principali linee guida non vi sono indicazioni specifiche riferite alla diagnostica di TEP nel paziente con BPCO: nei lavori di Hartmann et al. e di Remy-Jardin et al. $[15,38]$ la diagnosi radiologica di TEP con angioTC non è influenzata dalla presenza di BPCO o altre condizioni patologiche croniche, e gli autori concludono che l'impiego di questo esame non debba discostarsi da quanto previsto per la popolazione generale.

Anche nello studio di Sohne et al. [32] la performance diagnostica della TC (valore predittivo negativo) in una popolazione di pazienti con BPCO era simile a quella di altri gruppi di pazienti con cardiopatia cronica o neoplasia maligna; va comunque notato che in questo studio l'intervallo di confidenza dei falsi negativi era relativamente alto a causa della bassa numerosità della popolazione $(0,6-4 \%$ di eventi tromboembolici a 3 mesi dalla dimissione) per cui si impone cautela nell'esclusione della TEP.

Con il diffondersi della disponibilità di apparecchiature $M D C T$, si è presentato il problema dell'eccesso di richieste con elevati tassi di in appropriatezza e, di conseguenza, con la necessità di contenere le richieste affinandone le indicazioni, sia per problemi economici sia per evitare al paziente il carico di radiazioni e gli effetti collaterali dei mezzi di contrasto. Una procedura diagnostica metodologicamente corretta può aiutare ad aumentare la resa diagnostica e a ridurre gli esami inutili (fino al 30\% dei casi) escludendo, come detto, i pazienti con basso score di probabilità pre-test e D-dimero negativo.

In definitiva una MDCT polmonare negativa è un esame relativamente sicuro per escludere l'EP in soggetti con BPCO se il test preclinico di probabilità non è elevato e ha una buona performance diagnostica (un caso positivo ogni 4-5 casi esaminati) in casistiche in cui siano stati esclusi soggetti con basso livello di probabilità.

La resa diagnostica della scintigrafia polmonare è meno soddisfacente in soggetti con BPCO rispetto a soggetti senza BPCO, a causa delle alterazioni ventilatorie/perfusionali proprie di questa malattia. Infatti gli esami risultati a elevata probabilità avevano una percentuale di TEP confermata angiograficamente nel 79\% (IC 95\% 54-94\%) nei soggetti con BPCO e del 90\% (IC 95\% 84-95\%) nei soggetti senza BPCO [15]. Occorre tuttavia ricordare che la scintigrafia polmonare perfusionale (associata alla scintigrafia ventilatoria o alla radiografia del torace come surrogato della scintigrafia) è un esame che perde progressivamente terreno nella diagnostica della TEP sia per la ridotta disponibilità di questa tecnologia in molti ospedali, specie in quelli periferici, sia per le limitazioni intrinseche della metodica. Essa infatti è operatore-dipendente e condizionata da sensibilità e specificità modeste. Nello studio di Hartmann et al. [15], condotto in una popolazione di pazienti con BPCO, gli esami risultati utili ai fini diagnostici, in senso sia di conferma sia di esclusione di TEP, erano una minoranza (39\% del totale); anche in questo caso, l'associazione con uno score di probabilità aumenta il potere diagnostico in senso predittivo positivo e negativo.

\section{Metodologia diagnostica}

L'approccio al paziente con BPCO e sospetta TEP varia in base alla disponibilità locale degli strumenti diagnostici, al setting clinico in cui si opera (Dipartimento di Emergenza, reparti di degenza ordinaria, ambulatori ecc.) e alla gravità della presentazione clinica.

In presenza di shock o ipotensione la diagnosi differenziale si pone innanzitutto verso patologie con elevato rischio di morte, quali shock cardiogeno, tamponamento cardiaco, dissezione aortica, disfunzione valvolare acuta. In queste circostanze assume importanza determinante l'esame ecocardiografico in urgenza con possibilità di accesso alla sala di emodinamica per la terapia in emergenza (trombolisi ed embolectomia: si veda oltre).

Nella situazione caratterizzata da stabilità emodinamica, fortunatamente più frequente nella pratica clinica, la valutazione in elezione consente di seguire una procedura diagnostica che tenga presente la specificità del paziente con BPCO, eventualmente con l'ausilio di algoritmi decisionali.

Un esempio di algoritmo diagnostico ( fig. 1) è proposto da Moua et al. [39]. Innanzitutto è necessario che sia posto il sospetto clinico: come si diceva, la maggior parte delle EP non è diagnosticata in vita, pertanto il primo passo consiste nel comprendere l'EP nello spettro delle possibili diagnosi differenziali e, dopo un attento esame clinico anamnestico, nel formulare uno score di probabilità clinica pre-test basato su dati obiettivi e anamnestici, utile sia in termini di aiuto diagnostico sia per definire il valore predittivo delle successive indagini strumentali [21,32].

L'assenza di sintomatologia tipica per riacutizzazione infettiva di BPCO oppure una riacutizzazione che non risponde al trattamento medico convenzionale deve indurre a considerare con maggiore attenzione la possibilità di TEP; al contrario, un D-dimero normale, associato a un basso score predittivo di EP tende a escludere L'EP con ragionevole certezza e consente di risparmiare ulteriori indagini. Elevati valori di peptide natriuretico B (BNP) e troponina possono orientare verso una diagnosi alternativa di scompenso o ischemia cardiaca. 


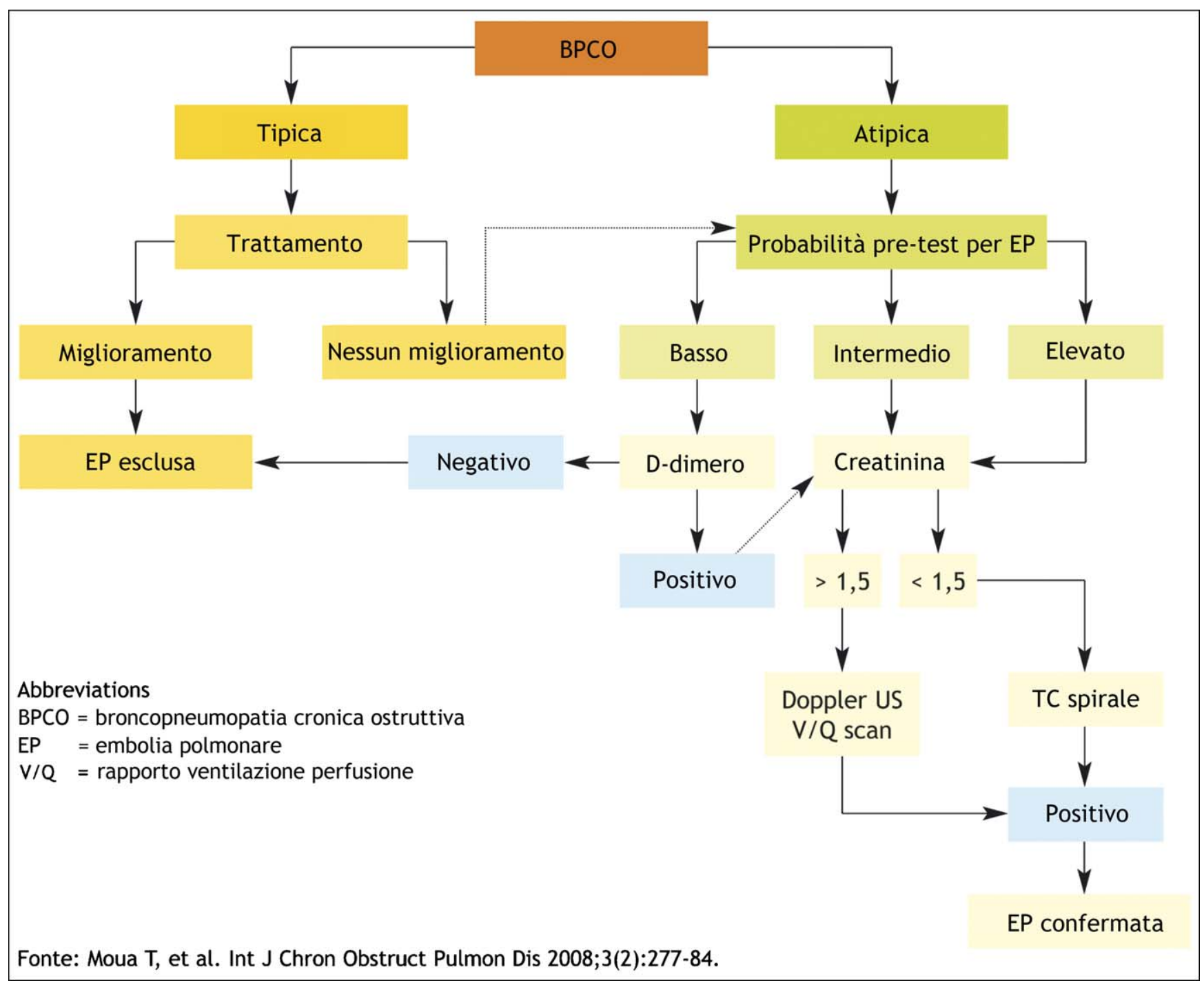

Figura 1 Algoritmo decisionale per sospetta tromboembolia polmonare nella BPCO.

Essendo l'angioTC polmonare l'esame di riferimento, diventa discriminante selezionare i soggetti con una normale funzione renale per la somministrazione del mezzo di contrasto radiologico. In caso di insufficienza renale ci si orienta verso l'eco-Doppler venoso o la scintigrafia V/Q o la risonanza magnetica (RMN), sebbene manchino evidenze solide su questa metodica diagnostica nel BPCO; solo nei casi di probabilità elevata di TEP, in presenza di scintigrafia ed ecoDoppler venoso negativo, si può considerare di forzare l'indicazione all'angioTC cercando di proteggere il rene dalla somministrazione del mezzo di contrasto.

\section{Valutazione di gravità e prognosi}

La prognosi nel soggetto con BPCO e TEP dipende dalle condizioni cliniche preesistenti, in particolare dal grado di severità della BPCO e dalla presenza di associate copatologie. La presenza di TEP aumenta la probabilità di morte $a$ un anno in soggetti con BPCO [40].

Le linee guida ESC (European Society of Cardiology) [37] pongono l'accento sulla possibilità che una percentuale di soggetti con TEP emodinamicamente stabile possa avere segni di disfunzione ventricolare destra rilevabili ecograficamente o con l'aumento dei marcatori di sofferenza miocardica (troponina e BNP). Il dato è rilevante perché identifica un sottogruppo di pazienti che, seppur non impegnativi alla presentazione, hanno una prognosi peggiore in quanto a rischio di evoluzione verso il cuore polmonare acuto, con aumentata probabilità di morte.

Anche se non sono disponibili dati riferiti esclusivamente a popolazioni di soggetti con BPCO, è consigliabile considerare questa condizione nella fase di gestione dei pazienti con TEP e BPCO in acuto.

Un tema dibattuto riguarda la mortalità nel lungo periodo per le conseguenze emodinamiche sul ventricolo destro con comparsa di ipertensione polmonare e cuore polmonare cronico secondario a TEP, in quanto un evento embolico non risolto o ripetuti episodi submassivi con interessamento dei rami distali dell'albero vascolare polmonare possono essere causa di ipertensione polmonare cronica. L'entità del fenomeno è oggetto di studi recenti [41,42].

Nella maggior parte di soggetti con BPCO, quando è presente ipertensione polmonare, essa è di solito di entità 
lieve-moderata, correla con lo stadio di gravità e si associa a una prognosi peggiore [41]. Nei casi in cui si riscontrano valori di pressione arteriosa polmonare (PAP) severi (cosiddetti "out-of-proportion") deve essere considerata la presenza di ipertensione polmonare primitiva, secondaria a scompenso cardiaco con insufficienza ventricolare sinistra oppure associata a sindrome delle apnee del sonno o a tromboembolismo cronico. Quest'ultima evenienza è risultata poco frequente [41]: su 998 soggetti con BPCO esaminati con cateterismo cardiaco, 27 (5\% del totale) avevano valori di PAP media superiori a $40 \mathrm{mmHg}$; tra questi, solo 2 casi venivano riconosciuti come secondari a tromboembolismo cronico.

In conclusione, lo sviluppo di ipertensione polmonare severa e cuore polmonare cronico nel paziente con BPCO appare riconducibile a cause diverse dal TEV cronico nella maggior parte dei casi.

\section{Terapia della tromboembolia polmonare}

Il trattamento anticoagulante è in grado di ridurre la frequenza di recidiva, di estensione e di embolizzazione polmonare delle TVP prossimali dal 15-50\% al 5-8\% e la frequenza di morte per EP dal 30\% al 2-8\% (tabella 2).

La terapia dei pazienti con EP si prefigge i seguenti obiettivi fondamentali:

- evitare la progressione del trombo nella sua sede primitiva di insorgenza, limitando quindi il pericolo di frammentazione ed embolizzazione;

- favorirne la regressione ed eventualmente l'organizzazione;

- prevenire lo sviluppo di ulteriori trombi in sedi differenti (nei pazienti con fattori predisponenti specifici) [43].

Tutti questi obiettivi vengono raggiunti attraverso l'istituzione di un trattamento anticoagulante per un periodo di almeno 3 mesi (Grado A) [4,44].

La consistente latenza di effetto degli anticoagulanti cumarinici (alcuni giorni) e la loro attitudine a determinare un transitorio stato trombofilico durante le prime somministrazioni hanno indotto tradizionalmente a raccomandare l'associazione di questi farmaci a un'eparina (non frazionata - ENF - o a basso peso molecolare - EBPM) per almeno 4-5 giorni, sospendendo l'eparina appena il valore di PT INR si attesta intorno a 2,5. Tuttavia, almeno nel breve termine (3-6 mesi), un trattamento continuativo con le sole EBPM, a dosi inferiori rispetto a quelle impiegate in fase iniziale (per esempio: enoxaparina $40 \mathrm{mg} / \mathrm{die}$; dalteparina $5.000 \mathrm{UI} / \mathrm{die}$ ), è almeno altrettanto efficace e significativamente più sicuro rispetto alla terapia cumarinica nel prevenire una TVP dopo un episodio di TVP sintomatica (Grado A) [44,45]. Non è comunque ancora dimostrato che questi vantaggi persistano a più lungo termine, soprattutto in considerazione delle possibili complicanze del trattamento eparinico prolungato, quali la trombocitopenia e soprattutto l'osteoporosi. Allo stato attuale, pertanto, i cumarinici sono ancora considerati i farmaci di prima scelta per il trattamento anticoagulante di lungo termine nella maggior parte dei pazienti con TEV, benché il trattamento prolungato con EBPM possa essere preso in considerazione per particolari categorie di soggetti, quali i residenti in località rurali con scarsa accessibilità ai laboratori che eseguono i controlli del PT INR e quelli che non tollerano i cumarinici o presentano controindicazioni alla loro assunzione e per i pazienti con cancro [46]. Questa raccomandazione potrebbe cambiare se verrà confermata l'efficacia e la sicurezza degli inibitori diretti della trombina e del fattore $\mathrm{Xa}$, attivi per via orale e in grado di inibire la coagulazione a livelli terapeutici entro un'ora dalla prima dose senza effetti trombofilici iniziali e senza la necessità di un controllo seriato dei valori di INR.

Nei pazienti con EP, le EBPM hanno efficacia uguale o superiore all'ENF nel prevenire le recidive tromboemboliche (Grado A) e nel ridurre la mortalità per ogni causa (Grado A) senza significative differenze nella frequenza di complicanze emorragiche maggiori (Grado A) [44,47,48]. Non esistono sufficienti evidenze dirette per definire l'eventuale superiorità di efficacia e sicurezza di una EBPM rispetto ad altre; $i$

Tabella 2 Dosaggi standard delle eparine per pazienti con TVP o TEP.

\begin{tabular}{|c|c|}
\hline Eparina sodica non frazionata & $\begin{array}{l}60-80 \mathrm{UI} / \mathrm{kg} \text { endovena in bolo, seguiti da } 18 \mathrm{UI} / \mathrm{kg} / \mathrm{h} \text { in infusione endover } \\
\text { modificando la dose in modo da mantenere il tempo di tromboplastina } \\
\text { parziale attivata (PTTa) tra } 1,5 \text { e } 2,5 \text { volte il valore normale }\end{array}$ \\
\hline Eparina calcica non frazionata & $\begin{array}{l}\text { Iniziare con } 5.000-10.000 \mathrm{UI} / 8 \mathrm{~h} \text { (secondo il peso corporeo), modificare } \\
\text { la dose in modo da mantenere il valore di PTTa tra } 1,5 \text { e } 2,5 \text { volte } \\
\text { il valore normale }\end{array}$ \\
\hline Dalteparina & $\begin{array}{l}100 \mathrm{UI} / \mathrm{kg} / 12 \mathrm{~h} \text {, oppure } 200 \mathrm{UI} / \mathrm{kg} / 24 \mathrm{~h} \text { sottocute } \\
\text { (dose massima totale } 18.000 \mathrm{UI} / \mathrm{die} \text { ) }\end{array}$ \\
\hline Enoxaparina & $\begin{array}{l}100 \mathrm{UI} / \mathrm{kg} / 12 \mathrm{~h} \text {, oppure } 150 \mathrm{UI} / \mathrm{kg} / 24 \mathrm{~h} \text { sottocute } \\
\text { (dose massima totale } 18.000 \mathrm{UI} / \mathrm{die} \text { ) }\end{array}$ \\
\hline Nadroparina & $\begin{array}{l}171 \mathrm{UI} / \mathrm{kg} / 24 \mathrm{~h} \text {, oppure } 86 \mathrm{UI} / \mathrm{kg} / 12 \mathrm{~h} \text { sottocute } \\
\text { (dose massima totale } 17.100 \mathrm{UI} / \mathrm{die} \text { ) }\end{array}$ \\
\hline Reviparina & $87,5 \mathrm{UI} / \mathrm{kg} / 12 \mathrm{~h}$ sottocute \\
\hline Tinzaparina & $\begin{array}{l}175 \mathrm{UI} / \mathrm{kg} / 24 \mathrm{~h} \text {, oppure } 87,5 \mathrm{UI} / \mathrm{kg} / 12 \mathrm{~h} \text { sottocute } \\
\text { (dose massima totale } 18.000 \mathrm{UI} / \mathrm{die} \text { ) }\end{array}$ \\
\hline Fondaparinux & $\begin{array}{l}7,5 \mathrm{mg} / 24 \mathrm{~h}(5 \mathrm{mg} / 24 \mathrm{~h} \text { se peso corporeo }<50 \mathrm{~kg} \text {, } \\
10 \mathrm{mg} / 24 \mathrm{~h} \text { se peso corporeo }>100 \mathrm{~kg})\end{array}$ \\
\hline
\end{tabular}


risultati ottenuti dal confronto tra dalteparina, enoxaparina, nadroparina, reviparina e tinzaparina con un comune termine di paragone, rappresentato dall'ENF, non hanno consentito di evidenziare differenze significative tra queste molecole [49]. La possibile eccezione è costituita dalla dalteparina che, alle dosi studiate, ha mostrato minore capacità di prevenire la recidiva embolica, ma anche una minore attitudine a determinare complicanze emorragiche maggiori [49].

Sia per i pazienti con TVP sia per quelli con EP, gli schemi di trattamento basati su 2 somministrazioni giornaliere paiono sostanzialmente equivalenti, in termini di recidiva trombotica e mortalità a breve termine, rispetto a quelli basati su un'unica somministrazione (Grado A) [44].

Analoghi vantaggi sembra offrire il fondaparinux, un pentasaccaride sintetico attivo sul fattore Xa. I dati degli studi Rembrandt [50] e Matisse-EP [51] dimostrano che il fondaparinux, utilizzato a dose fissa in monosomministrazione per via sottocutanea, è almeno altrettanto efficace e sicuro, rispettivamente, della dalteparina e dell'ENF a dose aggiustata, somministrate in infusione continua nel trattamento dei pazienti con EP sintomatica senza impegno emodinamico [52].

In pazienti con severa insufficienza renale è suggerito l'uso dell'ENF rispetto all'EBPM (Grado 2C) [44].

Nei pazienti con EP asintomatica, scoperta occasionalmente, è consigliato un trattamento analogo a quello dell'EP sintomatica (Grado 1C).

Nelle linee guida ACCP (American College of Chest Physicians) del 2008 [44], a conferma dell'estrema utilità clinica, nel breve e nel lungo termine, di iniziare il più precocemente possibile il trattamento farmacologico nei pazienti con EP, viene introdotto il concetto di avviare la terapia anticoagulante, se il sospetto clinico di EP è elevato, senza attendere la conferma diagnostica.

\section{Raccomandazioni ACCP del 2008 [44]}

4.1.1. Per i pazienti con EP non massiva si raccomanda il trattamento a breve termine con EBPM sottocute (Grado 1A), ENF infusione venosa (Grado 1A), fondaparinux sottocute (Grado 1A).

4.1.2. Per i pazienti con elevato sospetto di EP, si raccomanda il trattamento con anticoagulanti in attesa di completare i test diagnostici (Grado 1C+).

4.1.3. Nei pazienti con EP acuta non massiva si raccomanda EBPM o ENF (Grado 1A).

4.1.4. Nell'EP acuta non massiva si raccomanda un trattamento iniziale con EBPM o ENF o fondaparinux per almeno 5 giorni con un valore di INR pari a 2 o maggiore di 2 da almeno 24 ore (Grado 1C).

4.1.5. Nei pazienti con EP acuta non massiva, trattata con EBPM, si raccomanda di non effettuare il monitoraggio di routine dei livelli di anti-fattore Xa (Grado 1A).

4.1.6. Nei pazienti con insufficienza renale severa si suggerisce ENF infusione venosa piuttosto che EBPM (Grado 2C).

4.1.1. Nei pazienti che richiedono elevate dosi di ENF senza raggiungere un range terapeutico di PTTa si raccomanda la misurazione dei livelli di anti-Xa per guidare il dosaggio (Grado 1B).
Tabella 3 Dosi standard di alcuni farmaci trombolitici per adulti con TVP massiva o TEP.

\begin{tabular}{ll}
\hline Alteplasi & $\begin{array}{l}10 \mathrm{mg} \text { endovena in 1-2', quindi } 90 \mathrm{mg} \\
\text { infusione endovenosa in } 2 \mathrm{~h}, \text { oppure } \\
0,6 \mathrm{mg} / \mathrm{kg} \text { endovena in 2-15' } \\
\text { (massimo } 50 \mathrm{mg} \text { ) }\end{array}$ \\
Anistreplasi & $30 \mathrm{U}$ infusione endovenosa in almeno 5' \\
Streptochinasi & $\begin{array}{l}250.000 \mathrm{U} \text { infusione endovenosa in 30', } \\
\text { quindi } 100.000 \mathrm{U} / \mathrm{h} \text { infusione endovenosa }\end{array}$ \\
& $\begin{array}{l}\text { per } 24 \mathrm{~h}, \text { oppure } 1,5 \mathrm{MU} \text { infusione } \\
\text { endovenosa in 120' }\end{array}$ \\
& $\begin{array}{l}4.400 \mathrm{U} / \mathrm{kg} \text { endovena in 10', } \\
\text { poi } 4.400 \mathrm{U} / \mathrm{kg} / \mathrm{h} \text { infusione endovenosa }\end{array}$ \\
& $\begin{array}{l}\text { per } 12-24 \mathrm{~h}, \text { oppure } 1 \mathrm{MU} \text { endovena in 10', } \\
\text { poi } 2 \mathrm{MU} \text { infusione endovenosa in 110', } \\
\text { oppure } 15.000 \mathrm{UI} / \mathrm{kg} \text { endovena in 10' }\end{array}$ \\
\hline
\end{tabular}

In caso di grave compromissione emodinamica, il trattamento anticoagulante deve prefiggersi di ottenere una disostruzione rapida dei vasi polmonari interessati al fine di evitare il collasso cardiocircolatorio. Per quest'ultimo scopo vengono impiegati gli agenti trombolitici (tabella 3 ).

Rispetto alla semplice terapia eparinica, il trattamento trombolitico sistemico determina una più rapida regressione dell'ostruzione del circolo polmonare e delle alterazioni emodinamiche associate all'EP [52], a prezzo però di un rischio quasi doppio di complicanze emorragiche maggiori (Grado A), incluse le emorragie endocraniche (Grado B), e senza consistente miglioramento della morbilità, della mortalità e della frequenza di recidiva embolica a breve termine (Grado A), con la possibile eccezione dell'EP massiva condizionante shock cardiogeno (Grado B) [53,54].

Il bilancio rischio/beneficio della terapia trombolitica sistemica nel breve termine pare quindi probabilmente favorevole per le embolie polmonari associate a segni di ipoperfusione sistemica (Grado B), ma non per gli emboli di minore entità (Grado A) [53]. Non è noto al momento se queste conclusioni siano valide anche nel lungo termine [54]. Rimane inoltre da definire quale sia il trattamento ottimale del sottogruppo di pazienti emodinamicamente instabili con diagnosi di EP non sicura, ma molto sospetta, e del sottogruppo di pazienti emodinamicamente stabili con trombi di grandi dimensioni e/o disfunzione del cuore destro evidente all'ecocardiogramma. In entrambi i casi la trombolisi sistemica potrebbe garantire qualche vantaggio in termini di mortalità totale e di rischio di recidiva embolica (Grado C) $[52,53]$.

In un recente trial [54] randomizzato nei pazienti con EP a rischio intermedio, secondo la classificazione dell'ESC e quindi in pazienti stabili dal punto di vista emodinamico ma senza evidenza di disfunzione ventricolare destra e/o sofferenza miocardica, il trattamento trombolitico con rtPA rispetto all'eparina riduceva la mortalità intraospedaliera e il ricorso a nuovi trattamenti trombolitici, senza influenzare la mortalità totale. Pertanto la decisione di utilizzare la terapia trombolitica dipende dalla valutazione clinica della severità della TEP, dalla prognosi e dal rischio di sanguinamento. 


\begin{tabular}{lc} 
Tabella 4 Controindicazioni alla trombolisi. \\
\hline Assolute & - Ictus emorragico o ictus di origine \\
indeterminata "at any time" \\
- Ictus ischemico nei precedenti 6 mesi \\
- Neoplasia cerebrale e danno \\
del sistema nervoso centrale \\
- Emorragia gastroenterica \\
nel mese precedente \\
- Sanguinamento noto \\
- Attacco ischemico transitorio \\
nei precedenti 6 mesi \\
- Terapia anticoagulante orale \\
- Gravidanza o prima settimana dal parto \\
- Ipertensione refrattaria (pressione \\
arteriosa sistolica > 180 mmHg) \\
- Malattia epatica in stato avanzato \\
- Endocardite infettiva \\
- Ulcera peptica attiva
\end{tabular}

Per la maggior parte dei pazienti con TEP, le linee guida ACCP del 2008 [44] raccomandano di non usare la terapia trombolitica (Grado 1B). Parimenti, non è definitivamente chiarito il ruolo della trombolisi intrapolmonare, che allo stato attuale non pare comunque offrire significativi vantaggi in termini di efficacia e sicurezza (Grado B) [52].

4.1.1. Per la maggior parte dei pazienti con TEP, si raccomanda ai clinici di non usare la terapia trombolitica (Grado 1A). In pazienti selezionati si suggerisce la somministrazione sistemica di terapia trombolitica (Grado 2B). Per i pazienti che sono emodinamicamente instabili sii suggerisce l'uso della terapia trombolitica (Grado 2B).

4.1.2. Si suggerisce ai clinici di non ricorrere alla somministrazione locale di trombolitico attraverso il catetere (Grado 1C).

4.1.3. Per i pazienti con EP che devono ricevere un trattamento trombolitico, si suggerisce l'uso di trombolitici con un tempo di infusione breve rispetto a quelli con un tempo di infusione prolungato (Grado $2 \mathrm{C}$ ).

È importante ricordare le controindicazioni alla terapia trombolitica (tabella 4).

I benefici terapeutici della trombolisi sistemica si riducono progressivamente col trascorrere del tempo dall'evento embolico, divenendo trascurabili a distanza di 14 giorni [55]. Il trattamento andrebbe quindi iniziato quanto più precocemente possibile dopo la diagnosi definitiva di TEP.

Nel breve termine non esistono probabilmente significative differenze di efficacia e sicurezza tra i diversi agenti trombolitici (rtPA, streptochinasi, urochinasi) quando essi vengono impiegati alle dosi convenzionali (Grado B) (tabella 3 ), benché lo schema usuale di somministrazione di rtPA (infusione in 2 ore) determini una più rapida lisi del trombo rispetto alle infusioni prolungate (12-24 ore) di streptochinasi e urochinasi (Grado B) [55].

L'embolectomia polmonare viene eseguita in situazioni di emergenza quando trattamenti più conservativi abbiano fallito. Il candidato a una terapia di questo tipo presenta:

- EP massiva documentata angiograficamente;

- stato di shock nonostante l'eparina;
- insuccesso della terapia trombolitica o controindicazione al suo uso.

Le raccomandazioni ACCP del 2008 [44] per questo tipo di trattamento sono:

4.4.1. per la maggior parte dei pazienti con TEP non si raccomanda l'embolectomia polmonare (Grado $1 \mathrm{C}$ ). In casi selezionati con marcata compromissione e ove non sia possibile la terapia trombolitica o ove le condizioni generali non rendano possibile la somministrazione del trombolitico si suggerisce l'embolectomia polmonare (Grado $2 \mathrm{C}$ ).

Il razionale per l'impianto di filtri cavali in pazienti con TVP ed EP è costituito principalmente dalla presenza di controindicazioni o complicanze della terapia anticoagulante nel soggetto ad alto rischio di embolizzazioni ricorrenti. La terapia anticoagulante deve essere ripresa il più presto possibile in quanto il filtro, da solo, non è efficace nel trattamento del TEV.

4.5.1. Nei pazienti con EP con controindicazioni al trattamento anticoagulante per una complicanza, così come per coloro che presentano episodi di tromboembolismo ricorrente nonostante una terapia anticoagulante adeguata, si suggerisce l'impianto di un filtro cavale (Grado 2C).

Le linee guida ACCP del 2008 [44] forniscono indicazioni sulla durata della terapia anticoagulante orale nei pazienti con TEP.

- Per i pazienti con un primo episodio di EP indeterminata e con rischio emorragico assente e con facilità nel controllare la terapia anticoagulante si raccomanda un trattamento a lungo termine (Grado 1A).

- Per i pazienti con un secondo episodio di EP non determinata si raccomanda il trattamento a lungo termine (Grado 1A).

- Per i pazienti con EP e cancro si raccomanda EBPM per 3-6 mesi (Grado 1A).

- Nei pazienti che ricevono un trattamento anticoagulante a lungo termine si raccomanda di rivalutare il rapporto rischio/beneficio a intervalli periodici.

- Nei pazienti con diagnosi di EP occasionale e asintomatica si raccomanda lo stesso trattamento iniziale e a lungo termine con terapia anticoagulante come nei pazienti con EP sintomatica (Grado 1C).

\section{Tromboembolia polmonare nella BPCO: considerazioni finali}

La maggior parte della casistica esaminata negli studi riportati si riferisce agli anni antecedenti il 2001 (quindi non valutati le secondo linee guida GOLD), pertanto con accuratezza non ottimale in termini diagnostici e di definizione dello stadio di gravità (bassa percentuale di diagnosi supportate da spirometria).

Molte delle raccomandazioni contenute nelle principali linee guida sul TEV si riferiscono a studi condotti su casistica non selezionata. Ciò costituisce una limitazione oggettiva e rende auspicabile che in futuro siano condotti ulteriori studi per valutare le indicazioni diagnostiche e terapeutiche in popolazioni selezionate di pazienti con BPCO. 


\section{Bibliografia}

[1] Sapey E, Stockley RA. COPD exacerbations. 2: aetiology. Thorax 2006;61(3):250-8.

[2] Nordström M, Lindblad B, Bergqvist D, Kjellström T. A prospective study of the incidence of deep-vein thrombosis within a defined urban population. J Intern Med 1992;232(2):155-60.

[3] Hansson PO, Welin L, Tibblin G, Eriksson H. Deep vein thrombosis and pulmonary embolism in the general population. 'The Study of Men Born in 1913'. Arch Intern Med 1997;157(15): 1665-70.

[4] Segal JB, Eng J, Jenckes MW, Tamariz LJ, Bolger DT, Krishnan JA, et al. Diagnosis and treatment of deep venous thrombosis and pulmonary embolism. Evid Rep Technol Assess (Summ) 2003;(68):1-6.

[5] Poulsen SH, Noer I, Møller JE, Knudsen TE, Frandsen JL. Clinical outcome of patients with suspected pulmonary embolism. A follow-up study of 588 consecutive patients. J Intern Med 2001;250(2):137-43.

[6] Sidney S, Sorel M, Quesenberry Jr CP, DeLuise C, Lanes S, Eisner $M D$. COPD and incident cardiovascular disease hospitalizations and mortality: Kaiser Permanente Medical Care Program. Chest 2005;128(4):2068-75.

[7] Ambrosetti M, Ageno W, Spanevello A, Salerno M, Pedretti RF. Prevalence and prevention of venous thromboembolism in patients with acute exacerbations of COPD. Thromb Res 2003;112(4):203-7.

[8] Nordström M, Lindblad B. Autopsy-verified venous thromboembolism within a defined urban population - The city of Malmö, Sweden. APMIS 1998;106(3):378-84.

[9] Baum GL, Fisher FD. The relationship of fatal pulmonary insufficiency with cor pulmonale, rightsided mural thrombi and pulmonary emboli: a preliminary report. Am J Med Sci 1960;240:609-12.

[10] Mitchell RS, Silvers GW, Dart GA, Petty TL, Vincent TN, Ryan SF, et al. Clinical and morphologic correlations in chronic airway obstruction. Aspen Emphysema Conf 1968;9:109-23.

[11] Rizkallah J, Man SF, Sin DD. Prevalence of pulmonary embolism in acute exacerbations of COPD: a systematic review and metaanalysis. Chest 2009;135(3):786-93.

[12] Rutschmann OT, Cornuz J, Poletti PA, Bridevaux PO, Hugli OW, Qanadli SD, et al. Should pulmonary embolism be suspected in exacerbation of chronic obstructive pulmonary disease? Thorax 2007;62(2):121-5.

[13] Mispelaere D, Glerant JC, Audebert M, Remond A, SevestrePietri MA, Jounieaux V. Pulmonary embolism and sibilant types of chronic obstructive pulmonary disease decompensations. Rev Mal Respir 2002;19(4):415-23.

[14] Tillie-Leblond I, Marquette CH, Perez T, Scherpereel A, Zanetti $C$, Tonnel $A B$, et al. Pulmonary embolism in patients with unexplained exacerbation of chronic obstructive pulmonary disease: prevalence and risk factors. Ann Intern Med 2006; 144(6):390-6.

[15] Hartmann IJ, Hagen PJ, Melissant CF, Postmus PE, Prins MH. Diagnosing acute pulmonary embolism: effect of chronic obstructive pulmonary disease on the performance of D-dimer testing, ventilation/perfusion scintigraphy, spiral computed tomographic angiography, and conventional angiography. ANTELOPE Study Group. Advances in New Technologies Evaluating the Localization of Pulmonary Embolism. Am J Respir Crit Care Med 2000;162(6):2232-7.

[16] Lesser BA, Leeper Jr KV, Stein PD, Saltzman HA, Chen J, Thompson BT, et al. The diagnosis of acute pulmonary embolism in patients with chronic obstructive pulmonary disease. Chest 1992;102(1):17-22.

[17] Prescott SM, Richards KL, Tikoff G, Armstrong Jr JD, Shigeoka JW. Venous thromboembolism in decompensated chronic obstructive pulmonary disease. A prospective study. Am Rev Respir Dis 1981;123(1):32-6.

[18] Pek WY, Johan A, Stan S, Lee P, Chee CB, Wang YT. Deep vein thrombosis in patients admitted for exacerbation of chronic obstructive pulmonary disease. Singapore Med J 2001;42(7): 308-11.

[19] Erelel M, Cuhadaroğlu C, Ece T, Arseven O. The frequency of deep venous thrombosis and pulmonary embolus in acute exacerbation of chronic obstructive pulmonary disease. Respir Med 2002;96(7):515-8.

[20] Schönhofer B, Köhler D. Prevalence of deep-vein thrombosis of the leg in patients with acute exacerbation of chronic obstructive pulmonary disease. Respiration 1998;65(3):173-7.

[21] Wicki J, Perneger TV, Junod AF, Bounameaux H, Perrier A. Assessing clinical probability of pulmonary embolism in the emergency ward: a simple score. Arch Intern Med 2001; 161(1):92-7.

[22] Shetty R, Seddighzadeh A, Piazza G, Goldhaber SZ. Chronic obstructive pulmonary disease and deep vein thrombosis: a prevalent combination. J Thromb Thrombolysis 2008;26(1): $35-40$.

[23] Soler JJ, Sánchez L, Román P, Martínez MA, Perpiñá M. Risk factors of emergency care and admissions in COPD patients with high consumption of health resources. Respir Med 2004;98(4): 318-29.

[24] Hansson PO, Eriksson H, Welin L, Svärdsudd K, Wilhelmsen L. Smoking and abdominal obesity: risk factors for venous thromboembolism among middle-aged men'The Study of Men Born in 1913'. Arch Intern Med 1999;159(16):1886-90.

[25] Wedzicha JA, Seemungal TA, MacCallum PK, Paul EA, Donaldson GC, Bhowmik A, et al. Acute exacerbations of chronic obstructive pulmonary disease are accompanied by elevations of plasma fibrinogen and serum IL-6 levels. Thromb Haemost 2000;84(2):210-5.

[26] Cryer PE, Haymond MW, Santiago JV, Shah SD. Norepinephrine and epinephrine release and adrenergic mediation of smokingassociated hemodynamic and metabolic events. N Engl J Med 1976;295(11):573-7.

[27] Roy AK, Sarkar J, Bhadra R, Datta AG. Effect of amines on fibrinogen synthesis. Arch Biochem Biophys 1985;239(2):364-7.

[28] Sambola A, Osende J, Hathcock J, Degen M, Nemerson Y, Fuster $\mathrm{V}$, et al. Role of risk factors in the modulation of tissue factor activity and blood thrombogenicity. Circulation 2003;107(7): 973-7.

[29] Newby DE, Wright RA, Labinjoh C, Ludlam CA, Fox KA, Boon NA, et al. Endothelial dysfunction, impaired endogenous fibrinolysis, and cigarette smoking: a mechanism for arterial thrombosis and myocardial infarction. Circulation 1999;99(11): 1411-5.

[30] Bazzano LA, He J, Muntner P, Vupputuri S, Whelton PK. Relationship between cigarette smoking and novel risk factors for cardiovascular disease in the United States. Ann Intern Med 2003;138(11):891-7.

[31] Sohne M, Kruip MJ, Nijkeuter M, Tick L, Kwakkel H, Halkes SJ, et al., Christoper Study Group. Accuracy of clinical decision rule, D-dimer and spiral computed tomography in patients with malignancy, previous venous thromboembolism, COPD or heart failure and in older patients with suspected pulmonary embolism. J Thromb Haemost 2006;4(5):1042-6.

[32] Wells PS, Anderson DR, Rodger M, Stiell I, Dreyer JF, Barnes D, et al. Excluding pulmonary embolism at the bedside without diagnostic imaging: management of patients with suspected pulmonary embolism presenting to the emergency department by using a simple clinical model and D-dimer. Ann Intern Med 2001;135(2):98-107.

[33] Stein PD, Terrin ML, Hales CA, Palevsky HI, Saltzman HA, Thompson BT, et al. Clinical, laboratory, roentgenographic, and electrocardiographic findings in patients with acute 
pulmonary embolism and no pre-existing cardiac or pulmonary disease. Chest 1991;100(3):598-603.

[34] Sharma GV, Sasahara AA. Diagnosis of pulmonary embolism in patients with chronic obstructive pulmonary disease. J Chronic Dis 1975;28(5-6):253-7.

[35] Musset D, Parent F, Meyer G, Maître S, Girard P, Leroyer C, et al., Evaluation du Scanner Spiralé dans l'Embolie Pulmonaire study group. Diagnostic strategy for patients with suspected pulmonary embolism: a prospective multicentre outcome study. Lancet 2002;360(9349):1914-20.

[36] Perrier A, Roy PM, Aujesky D, Chagnon I, Howarth N, Gourdier $\mathrm{AL}$, et al. Diagnosing pulmonary embolism in outpatients with clinical assessment. D-dimer measurement, venous ultrasound, and helical computed tomography: a multicenter management study. Am J Med 2004;116(5):291-9.

[37] Torbicki A, Perrier A, Konstantinides S, Agnelli G, Galiè N, Pruszczyk P, et al., ESC Committee for Practice Guidelines (CPG). Guidelines on the diagnosis and management of acute pulmonary embolism: the Task Force for the Diagnosis and Management of Acute Pulmonary Embolism of the European Society of Cardiology (ESC). Eur Heart J 2008;29(18):2276-315.

[38] Remy-Jardin M, Tillie-Leblond I, Szapiro D, Ghaye B, Cotte L, Mastora I, et al. CT angiography of pulmonary embolism in patients with underlying respiratory disease: impact of multislice CT on image quality and negative predictive value. Eur Radiol 2002;12(8):1971-8.

[39] Moua T, Wood K. COPD and PE: a clinical dilemma. Int J Chron Obstruct Pulmon Dis 2008;3(2):277-84.

[40] Carson JL, Terrin ML, Duff A, Kelley MA. Pulmonary embolism and mortality in patients with COPD. Chest 1996;110(5):1212-9.

[41] Chaouat A, Bugnet AS, Kadaoui N, Schott R, Enache I, Ducoloné $A$, et al. Severe pulmonary hypertension and chronic obstructive pulmonary disease. Am J Respir Crit Care Med 2005;172(2): 189-94.

[42] Chaouat A, Naeije R, Weitzenblum E. Pulmonary hypertension in COPD. Eur Respir J 2008;32(5):1371-85.

[43] Campanini M, Airoldi G. Terapia della tromboembolia polmonare. Ital J Medicine 2009;3(1 Suppl 2):43-6.

[44] Kearon C, Kahn SR, Agnelli G, Goldhaber S, Raskob GE, Comerota AJ, American College of Chest Physicians. Antithrombotic therapy for venous thromboembolic disease: American College of Chest Physicians Evidence-Based Clinical Practice Guidelines (8th Edition). Chest 2008;133(6 Suppl):454-545S.

[45] Meyer G, Marjanovic Z, Valcke J, Lorcerie B, Gruel Y, SolalCeligny $\mathrm{P}$, et al. Comparison of low-molecular-weight heparin and warfarin for the secondary prevention of venous thromboembolism in patients with cancer: a randomized controlled study. Arch Intern Med 2002;162(15):1729-35.

[46] van der Heijden JF, Hutten BA, Büller HR, Prins MH. Vitamin K antagonists or low-molecular-weight heparin for the long term treatment of symptomatic venous thromboembolism. Cochrane Database Syst Rev 2002;(1):CD002001.

[47] Hull RD, Raskob GE, Brant RF, Pineo GF, Elliott G, Stein PD, et al. Low-molecular-weight heparin vs heparin in the treatment of patients with pulmonary embolism. American-Canadian Thrombosis Study Group. Arch Intern Med 2000;160(2):229-36.

[48] Simonneau G, Sors H, Charbonnier B, Page Y, Laaban JP, Azarian $\mathrm{R}$, et al. A comparison of low-molecular-weight heparin with unfractionated heparin for acute pulmonary embolism. The THESEE Study Group. Tinzaparine ou Heparine Standard: Evaluations dans l'Embolie Pulmonaire. N Engl J Med 1997;337(10):663-9.

[49] van der Heijden JF, Prins MH, Büller HR. For the initial treatment of venous thromboembolism: are all low-molecular-weight heparin compounds the same? Thromb Res 2000;100(2): V121-30.

[50] The Rembrandt Investigators. Treatment of proximal deep vein thrombosis with a novel synthetic compound (SR90107A/ ORG31540) with pure anti-factor Xa activity: A phase II evaluation. Circulation 2000;102(22):2726-31.

[51] Büller HR, Davidson BL, Decousus H, Gallus A, Gent M, Piovella F, et al., Matisse Investigators. Subcutaneous fondaparinux versus intravenous unfractionated heparin in the initial treatment of pulmonary embolism. N Engl J Med 2003;349(18):1695-702.

[52] NHS Centre for Reviews and Dissemination. Thrombolytic therapy of pulmonary embolism. [Miscellaneous] Database Abstracts Rev Effectiveness 2003; 3.

[53] American College of Emergency Physicians Clinical Policies Committee; Clinical Policies Committee Subcommittee on Suspected Pulmonary Embolism. Clinical policy: critical issues in the evaluation and management of adult patients presenting with suspected pulmonary embolism. Ann Emerg Med 2003; $41(2): 257-70$.

[54] Konstantinides S, Geibel A, Heusel G, Heinrich F, Kasper W, Management Strategies and Prognosis of Pulmonary Embolism-3 Trial Investigators. Heparin plus alteplase compared with heparin alone in patients with submassive pulmonary embolism. $\mathrm{N}$ Engl J Med 2002;347(15):1143-50.

[55] Dong B, Pineo G, Mulrooney T. Thrombolytic therapy for pulmonary embolism. Cochrane Database Syst Rev 2003; 3. 


\section{BPCO e nefropatie croniche}

\section{Filippo Salvati, Antonio Santoro, Claudio Pedone}

\section{Messaggi chiave}

- Broncopneumopatia cronica ostruttiva (BPCO) e insufficienza renale (IR) sono spesso associate.

- La creatinina normale nasconde IR inapparente.

- Si devono utilizzare sempre le formule (Cockroft o MDRD - Modification of Diet in Renal Disease).

- L'IR comporta aumento del rischio cardiovascolare.

- L'IR comporta spesso anemia in presenza di BPCO.

- IR e BPCO causano quadri misti emogasanalitici.

- L'IR comporta variazioni nel dosaggio di vari farmaci.

\section{Introduzione}

Le nefropatie croniche e l'insufficienza renale cronica (IRC) rappresentano una comorbilità poco considerata, addirittura "negletta", della broncopneumopatia cronica ostruttiva (BPCO) [1]. Una delle ragioni che portano a non identificare in un paziente con BPCO la presenza di un deficit renale è la valutazione di questo solo attraverso i livelli della creatinina sierica. Come è noto la creatinina è strettamente dipendente dalle masse muscolari e in presenza di malnutrizione è scarsamente rappresentativa del filtrato glomerulare.

Il paziente affetto da BPCO presenta frequentemente un'alterazione dello stato nutrizionale causata da un aumento della spesa energetica a riposo dovuto all'aumento del lavoro dei muscoli respiratori, alla terapia farmacologia (per esempio, beta ${ }_{2}$-agonisti) e allo stato infiammatorio sistemico.

La malnutrizione del paziente con BPCO è strettamente correlata alla prognosi e il Body Mass Index (BMI) è parte integrante della valutazione clinica di questi soggetti, tanto da essere inserito in score prognostici importanti come il BODE Index.

La conseguente riduzione della massa magra (legata anche all'invecchiamento dei pazienti) comporta una minore concentrazione di creatinina sierica a parità di velocità di filtrazione glomerulare. Questi pazienti spesso presentano, pertanto, creatinina sierica nella norma anche per valori di filtrato glomerulare $<60 \mathrm{~mL} / \mathrm{min}$ : è la cosiddetta insufficienza renale inapparente.

Tra le conseguenze del mancato riconoscimento di un'alterata funzione renale in corso di BPCO vi è il maggiore rischio di reazioni avverse a farmaci a eliminazione prevalentemente renale (tra cui ACE-inibitori, digossina, glibenclamide, metformina, molti antibiotici) e il cui dosaggio nella pratica clinica quotidiana viene modificato e ridotto spesso solo in presenza di aumento dei valori della creatinina sierica. Il riconoscimento, invece, di una coesistenza di patologia renale e di una BPCO è estremamente importante dal punto di vista sia terapeutico sia prognostico.

L'IRC è un importante fattore di rischio cardiovascolare indipendente; nei pazienti con IRC sono presenti fattori di rischio cardiovascolare aggiuntivi ai fattori classici: l'iperparatiroidismo secondario, l'anemia precoce, la ritenzione di dimetil-arginina asimmetrica (ADMA) potente inibitore dell'ossido nitrico, l'infiammazione cronica e l'aumento dello stress ossidativo, l'iperattivazione del sistema simpatico. Tutti questi fattori determinano, sin dalle prime fasi dell'insufficienza renale, un aumento sensibile del rischio cardiovascolare. Quest'ultimo aumenta esponenzialmente con la caduta del filtrato glomerulare sino a raggiungere valori di mortalità cardiovascolare per i pazienti con IRC terminale in emodialisi anche decine di volte superiori rispetto alla popolazione senza IRC [2].

L'associazione di BPCO e IRC comporta, pertanto, un rischio cardiovascolare e di mortalità aggiuntivo che si sovrappone al rischio di mortalità già elevato nei pazienti con BPCO. 
Sul piano metabolico e biochimico, l'insufficienza renale determina, specie negli stati avanzati, importanti alterazioni. Si accresce il rischio di acidosi metabolica a gap anionico aumentato, con quadri emogasanalitici misti, talora di non facile interpretazione e che pongono ampi dubbi sull'atteggiamento terapeutico. Per esempio: infondere o non infondere bicarbonato in presenza di un'acidosi mista e con un rene già impegnato a compensare l'acidosi respiratoria con il riassorbimento compensatorio di bicarbonati. Inoltre, le alterazioni dell'equilibrio acido-base di rilevante entità possono comportare secondarie alterazioni degli elettroliti plasmatici (come l'iperpotassiemia in seguito a una grave acidosi con aumento della concentrazione idrogenionica) che, a loro volta, possono indurre pericolose aritmie cardiache.

Da tutto ciò si evince la necessità nei pazienti con BPCO di considerare sempre la funzione renale per tener conto di vari aspetti come l'aumentato rischio cardiovascolare, che richiede terapie specifiche, le modificazioni posologiche dei farmaci e infine l'eventuale correzione dei disturbi dell'equilibrio acido-base ed elettrolitici che si sviluppano nell'insufficienza combinata dei due organi. A tal riguardo potrebbe essere utile misurare, oltre la creatinina sierica, anche la clearance o far ricorso alle formule di Cockroft o MDRD (Modification of Diet in Renal Disease) che tengono conto del peso, dell'età e del sesso del paziente.

\section{Epidemiologia}

La BPCO è ormai riconosciuta come una tra le patologie più frequenti nella popolazione ed è destinata a diventare una delle prime cause di mortalità nei prossimi anni [3]. Per l'insufficienza renale vi è invece spesso una sottostima in termini sia di prevalenza sia di incidenza.

In realtà dati del National Health and Nutrition Examination Survey (NHANES) dimostrano un'ampia diffusione della malattia renale cronica. Nella popolazione americana ben 50 milioni di individui presentano valori di filtrato glomerulare $<60 \mathrm{~mL} / \mathrm{min}$ e circa 1 milione di soggetti presenta IRC con valori di filtrato $<30 \mathrm{~mL} / \mathrm{min}$. Con questi dati non si può non parlare di una sorta di epidemia di IRC. Non deve meravigliare, perciò, che l'aggregazione delle due patologie (BPCO e IRC) sia più frequente di quanto si pensi.

Già alcuni anni fa Antonelli Incalzi et al. [3] hanno pubblicato dati significativi sul contributo della comorbilità nel predire la mortalità dei pazienti con IRC: in tale rassegna lo score di predittività assegnato alla stessa IRC in pazienti con BPCO è stato quello di maggior peso e con un'alta significatività statistica $(\mathrm{p}<0,002)$.

Sempre lo stesso gruppo, inoltre, ha valutato in un numero di pazienti molto più elevato e significativo l'associazione tra BPCO e insufficienza renale utilizzando con il calcolo del filtrato glomerulare usando la formula MDRD [1].

In 356 pazienti con BPCO la prevalenza di IRC sia inapparente (con filtrato $<60 \mathrm{~mL} / \mathrm{min}$ ma creatinina normale) sia conclamata era rispettivamente del $20,8 \%$ e del $22,2 \%$. BPCO ed età avanzata erano anch'esse associate significativamente a IRC inapparente (BPCO: OR = 2,19; IC 95\% U 1,17$4,12$; età: $O R=1,06 ;$ IC $95 \%=1,04-1,10)$ e conclamata
(BPCO: $O R=1,94 ; \quad I C \quad 95 \%=1,01-4,66$; età $O R=1,06 ; \quad I C$ $95 \%=1,04-110)$.

Il diabete $(O R=1,96$; IC $95 \%=1,02-3,76)$, l'ipoalbuminemia (OR $=2,83$; IC $95 \%=1,70-4,73$ ) e le malattie muscoloscheletriche $(O R=1,78$; IC $95 \%=1,01-3,16)$ erano correlate con IRC inapparente, mentre erano correlate con IRC conclamata BMI $(O R=1,05 ;$ IC $95 \%=1,01-1,10)$ e diabete $(\mathrm{OR}=2,25 ; \mathrm{IC} 95 \%=1,26-4,03)$.

Gli autori concludevano che la comorbilità BPCO-IRC poteva contribuire a spiegare peculiarità cliniche di alcuni pazienti con BPCO come per esempio la presenza, in alcuni, di anemia normocromica.

Altri autori hanno evidenziato come anche la mancanza da parte dei pazienti di consapevolezza della propria condizione comorbile (come attestato da self-reporting) fosse fortemente correlata con il rischio di morte e per la BPCO tale rischio era: $H R=1,36 ; \mathrm{IC} 95 \%=1,11-1.66 ; \mathrm{p}<0,001$ [4-7].

Uno studio statunitense ha inoltre riportato come negli afroamericani, rispetto alla popolazione bianca, la comorbilità, compresa quella BPCO-IRC, comportasse un rischio relativo di IRC severa del $3,52 \%$ (IC $95 \%=1,94-2,30)$ [8]. Ciò era dovuto alla minore fruibilità da parte della popolazione di colore, per motivi socioeconomici, dei servizi di prevenzione dei fattori che possono portare all'insorgenza di una condizione di comorbilità.

Un altro studio (CHOICE) ha confermato i dati di comorbilità della popolazione in emodialisi utilizzando per la raccolta dei dati, dal database di 80 centri dialisi, lo score ICED, basato su 116 item validati, e il form 2728 della John Hopkins School of Medicine [9].

\section{Fisiopatologia dell'interessamento renale in corso di BPCO}

Il polmone è l'organo che gestisce la più ampia rete capillare dell'organismo e nello stesso tempo riceve in un minuto l'intera portata cardiaca. La sua posizione centrale, dal punto di vista dell'emocircolazione, lo porta necessariamente a interagire con gli altri organi e in particolare con il rene, che è uno dei suoi principali interlocutori. D'altronde il rene riceve circa un quarto della portata cardiaca e partecipa insieme con il polmone alla regolazione dell'equilibrio acido-base e del sistema renina-angiotensina (SRA). Il polmone è deputato alla produzione di ACE e il rene a quella della renina, due fattori indispensabili alla generazione dell'angiotensina II.

Oltre che in fisiologia, anche in patologia il legame tra $i$ due organi resta sempre estremamente saldo. Sostanze rilasciate dal polmone lesionato possono generare una patologia renale e, nello stesso tempo, in presenza di un danno renale può verificarsi un danno polmonare mediato da mediatori umorali o connesso a un sovraccarico idrico ed elettrolitico secondario alla disfunzione renale. Questo è particolarmente vero in una patologia cronica come la BPCO contraddistinta da fasi di riaccensione con episodi di flogosi e rilascio di metaboliti dell'infiammazione e dello stress ossidativo. Nello stesso tempo gli scompensi respiratori comportano alterazioni dei gas del sangue con ovvie ripercussioni sulla fisiopatologia renale. 


\section{Il polmone danneggia il rene}

Nelle patologie croniche come la BPCO il polmone può danneggiare il rene attraverso tre differenti meccanismi ( fig. 1):

- attraverso le alterazioni dei gas del sangue;

- attraverso una serie di effetti emodinamici a livello sistemico e renale innescati dalla produzione abnorme di ormoni e sostanze vasoattive;

- attraverso il rilascio di mediatori dell'infiammazione prodotti primitivamente a livello polmonare.

L'esempio più classico di danno polmonare che genera un danno renale è quello della ventilazione polmonare assistita [10]. La ventilazione meccanica è seguita da una sovraespressione a livello renale di enzimi che partecipano alla sintesi dell'ossido nitrico e da un'aumentata produzione di endotelina [11]. Ventilazioni meccaniche ad alti volumi correnti inducono un danno renale acuto sia negli animali da esperimento sia in pazienti con pneumopatie. L'instillazione di liposaccaridi a livello intratracheale genera un contemporaneo danno infiammatorio a livello del polmone e del rene [12].

\section{Alterazione della $\mathrm{PaO}_{2}$ e della $\mathrm{PaCO}_{2}$}

L'ipossiemia di grado lieve-moderato non sembra indurre modificazioni sostanziali della circolazione intrarenale, mentre se è di entità severa con $\mathrm{PaO}_{2}<40 \mathrm{mmHg}$ o si accompagna a ipercapnia genera un aumento delle resistenze intrarenali, un'iperperfusione renale e una riduzione del filtrato glomerulare [13]. Modificazioni della sintesi locale di ossido nitrico, dell'angiotensina II e dell'endotelina sono alla base delle alterazioni intrarenali. L'ipercapnia [14] invece è in grado da sola di causare vasocostrizione intrarenale con riduzione del flusso plasmatico renale e liberazione di noradrenalina attraverso una stimolazione adrenergica.
Effetti emodinamici ormono-mediati

I pazienti con BPCO spesso presentano uno stato di ritenzione idrica e sodica con iponatremia ed edemi. Se si studia il SRA in questi pazienti si trova un aumento dell'attività reninica con elevati livelli di aldosterone [15]. Anche i livelli di vasopressina sono spesso abnormemente elevati. Il meccanismo fisiopatologico che porta a un aumento della vasopressina è poco noto, ma è molto probabile che sia legato a una riduzione della volemia "efficace" e sia quindi di tipo volemico e non osmotico [16]. Sul piano clinico sia l'aumento della vasopressina sia l'attivazione del SRA determinano una ritenzione di acqua sproporzionata rispetto alla ritenzione sodica. Ne consegue uno stato di iperidratazione ipotonica con iposodiemia relativa. Lo stato di iperidratazione persiste nella BPCO nonostante vi sia un aumento del fattore natriuretico atriale (ANP) che dovrebbe favorire la natriuresi. I livelli di ANP risultano inversamente correlati con $\mathrm{la}_{\mathrm{PaO}_{2}}$ e possono risultare particolarmente elevati in condizioni di grave ipossiemia [8]. Tuttavia, nonostante l'incremento dei livelli di ANP, non vi è una soddisfacente sodiuria perché si sviluppa contemporaneamente un'aumentata resistenza del tubulo renale all'ormone antidiuretico.

\section{Interazioni polmone-rene mediate \\ da fattori infiammatori}

Un grande numero di mediatori infiammatori viene rilasciato nella circolazione sistemica dal polmone affetto da BPCO. L'interleuchina 6 (IL-6) è la più nota tra le sostanze che, prodotte nel polmone, passano nella circolazione sistemica e raggiungono altri organi dove esercitano un effetto infiammatorio. Tuttavia, oltre all'IL-6, in corso di BPCO risultano aumentati i livelli ematici di altre citochine pro e antiinfiammatorie come IL-1beta, IL-8, IL-10, e TNF-alfa [17].

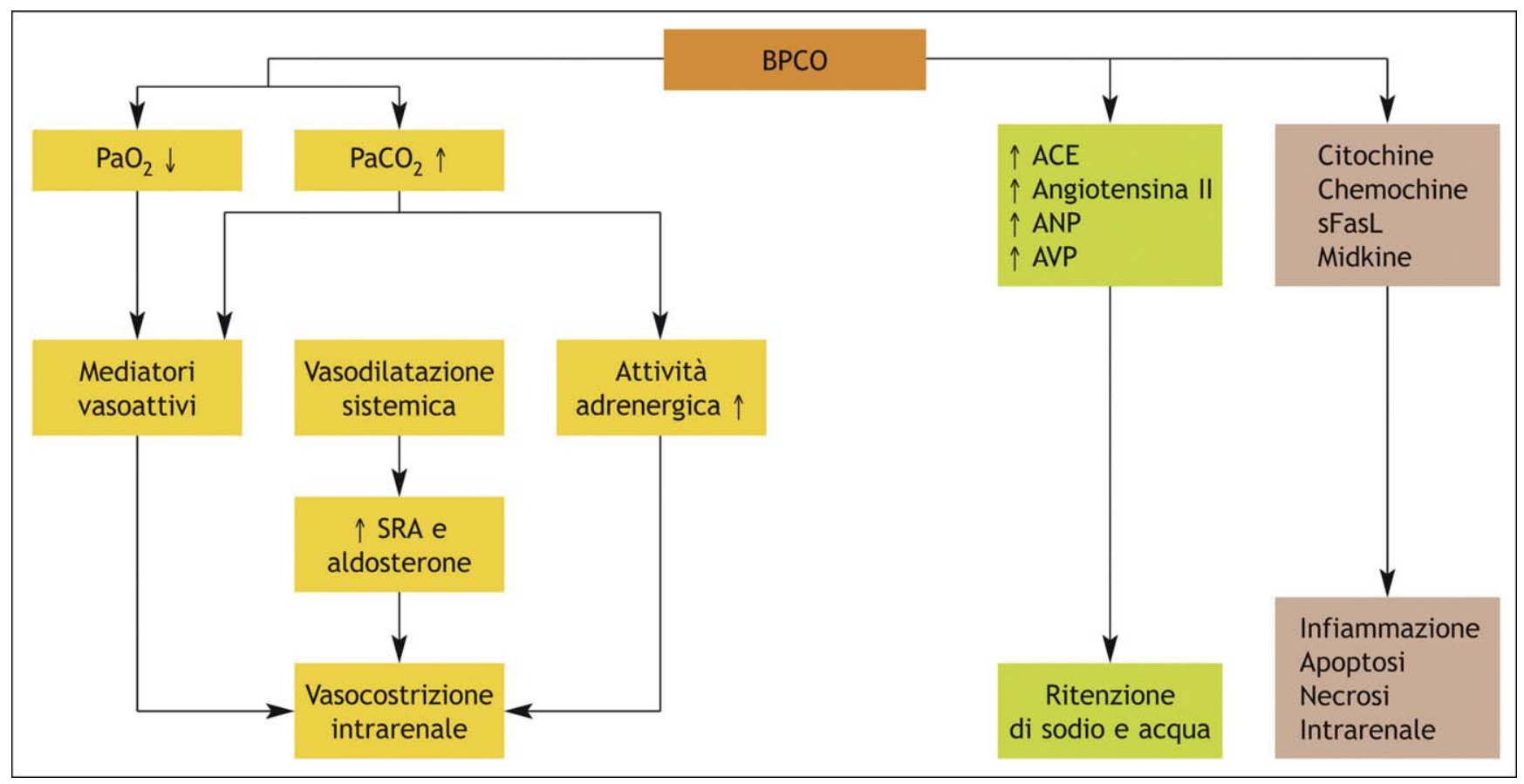

Figura 1 Alterazioni renali in corso di BPCO indotte da 1) alterazioni dei gas del sangue (ipossiemia e ipercapnia), 2) aumentata sintesi di ACE da parte del polmone, di angiotensina II, peptidi natriuretici atriali (ANP), vasopressina (AVP) e 3) rilascio di mediatori della flogosi e di danno cellulare. 
IL-6, IL-1, TNF-alfa e MCP1 sono tutti mediatori della flogosi in grado di indurre un danno tubulare renale di carattere infiammatorio attraverso il reclutamento di macrofagi e monociti e attraverso un'attivazione del PAF. Recentemente è stata prospettata, nel danno renale in presenza di BPCO e di altre patologie polmonari [18], una responsabilità del legante Fas (sFasL). Nell'animale da esperimento questa sostanza esalta i processi apoptotici a livello glomerulare e genera un danno renale acuto con veri e propri episodi di insufficienza renale acuta.

\section{Il rene che danneggia il polmone}

Se è vero che in corso di BPCO può esserci un danno renale, è altrettanto vero, come si diceva in precedenza, il contrario, e quindi un danno renale primitivo può dar luogo a un danno polmonare secondario o accrescere una patologia preesistente, come la BPCO. L'ischemia renale e la nefrectomia 5/6 alterano immediatamente l'espressione del gene dell'ACE [19]. L'ischemia renale può accrescere la permeabilità vascolare polmonare e determinare una down-regulation dei canali ionici deputati al riassorbimento dei fluidi a livello degli alveoli polmonari. Queste alterazioni generano infiammazione polmonare, emorragie, edema dei setti e apoptosi a livello alveolare.

Recentemente è stato prospettato come fattore di comunicazione tra rene e polmone, ma anche tra polmone e rene, la midkine [20]. La midkine [21] è un fattore di crescita legante l'eparina e inducibile dall'acido retinoico che è connesso ai processi di sviluppo cellulare, di rigenerazione e di vasculogenesi, ma anche ai processi infiammatori (fibrinolisi, produzione di chemochine, migrazione di leucociti ecc.). Hobo et al. [20] hanno dimostrato che nei ratti 5/6 vi è un'up-regulation dell'enzima ACE con un aumento di attività di questo enzima a livello polmonare ( fig. 2). Topi con deficit genetico di midkine non presentano un'up-regulation del gene dell'ACE e sono protetti dall'ipertensione e dal severo danno renale [22].

La somministrazione di midikine a questi topi $\mathrm{MK}^{-1-} \mathrm{li}$ rende ipertesi e fa aumentare l'espressione polmonare di ACE. Non vi sono ancora chiare dimostrazioni che tutto questo possa avvenire, oltre che nel ratto, anche nell'uomo. Tuttavia la midkine potrebbe essere l'agente che permette una maggiore comunicazione tra rene e polmone e viceversa. Nell'uomo è stato dimostrato che in corso di BPCO con ipossiemia vi è un'esaltata produzione di midkine. Ciò si verifica perché la liberazione di midkine è regolata da un gene HIF che è redox-sensibile.

Questa è un'ulteriore dimostrazione di come un organo, apparentemente lontano dal rene, come il polmone, sia in grado di indurre un danno renale attraverso il rilascio di sostanze che servono da interfono tra i due organi.

\section{Diagnosi e valutazione}

\section{Identificazione dei pazienti a rischio}

L'identificazione dei soggetti a rischio per insufficienza renale è un passo importante per una diagnosi quanto più possibile precoce della malattia. II Kidney Disease Outcome Quality Initiative (K/DOQI), gruppo della National Kidney

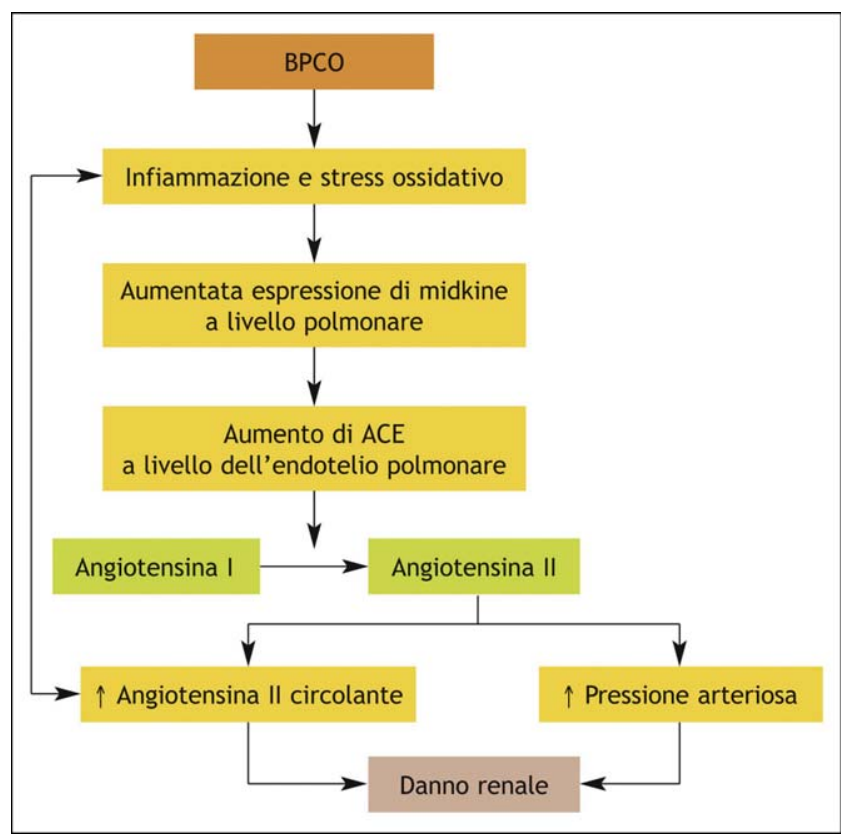

Figura 2 Sequenza di eventi che possono portare da una situazione di BPCO con infiammazione e stress ossidativo al danno renale conclamato.

Foundation statunitense, differenzia tra i fattori di rischio che incrementano la suscettibilità al danno renale (età, familiarità, riduzione della massa renale, bassa scolarità, stato socioeconomico disagiato) quelli che danneggiano direttamente il rene (diabete mellito, ipertensione, patologie autoimmuni, infezioni sistemiche e del tratto urinario, calcolosi urinaria, stenosi del tratto urinario inferiore, danno da farmaci) [23].

Come accennato precedentemente, la prevalenza di insufficienza renale nei pazienti con BPCO è circa doppia rispetto a quella dei soggetti di pari età senza questa patologia [1], che deve essere dunque considerata anch'essa un fattore di rischio. L'associazione tra BPCO e danno renale potrebbe essere mediata dalla presenza di coronaropatia, che è frequente nei pazienti con BPCO [24], e si associa a danno renale [25]. Inoltre, i fumatori mostrano livelli di cadmio e piombo ematici superiori del $30-50 \%$ rispetto ai non fumatori, e ambedue i metalli sono nefrotossici [26].

\section{Diagnosi e stadiazione}

La diagnosi di danno renale si basa sostanzialmente sulla valutazione dell'escrezione renale di albumina (rapporto albumina/creatinina urinaria) [27]. Altri indicatori di danno renale sono le anomalie del sedimento urinario, anormalità degli esami ematici e anomalie nelle indagini di imaging [23]. Il principale indicatore globale della funzione renale è la velocità di filtrazione glomerulare (VFG). I metodi diretti di valutazione della VFG (clearance dell'inulina o del ${ }^{131 / \text { iota- }}$ lamato) sono utilizzati praticamente solo in ambito di ricerca, mentre in clinica vengono più frequentemente utilizzate le tecniche di medicina nucleare (scintigrafia con $99 \mathrm{~m}$ tecnezio-DTPA) oppure la misurazione della clearance dello iohexolo. Anche questi metodi, tuttavia, hanno una 
complessità e un costo notevole, per cui vengono impiegati sono in situazioni particolari. In clinica le metodiche più comunemente applicate sono la misurazione della clearance della creatinina, che però richiede almeno 24 ore e la collaborazione da parte del paziente, oppure l'utilizzo di formule predittive.

Sfortunatamente, è pratica comune quella di utilizzare la sola creatinina sierica come indicatore di funzione renale. Nei pazienti con BPCO ciò può portare a non diagnosticare la presenza di insufficienza renale in un numero consistente di casi ( $\sim 50 \%$ dei pazienti con VFG stimata $<60 \mathrm{~mL} / \mathrm{min}$ ) [22]. In questi pazienti, l'elevata prevalenza di insufficienza renale in presenza di normale creatinina sierica è verosimilmente dovuta allo stato di ipercatabolismo, che provoca una riduzione della massa magra con conseguente calo della produzione di creatinina, che quindi mantiene una concentrazione relativamente bassa anche a fronte di una riduzione della VFG.

In realtà, anche le diverse equazioni predittive non hanno mostrato una particolare affidabilità nel predire la VFG in confronto con le metodiche più raffinate e tra di loro mostrano una scarsa concordanza [28]; purtuttavia il loro utilizzo permette di identificare i pazienti a rischio di reazioni avverse a farmaci con escrezione renale [29] e con prognosi peggiore [30]. L'uso di queste formule, pertanto, è da raccomandare nei pazienti con BPCO, anche in considerazione del fatto che i farmaci anticolinergici hanno escrezione renale.

\section{Clinica dell'associazione tra BPCO e insufficienza renale cronica}

Il quadro clinico dei pazienti con BPCO e concomitante insufficienza renale si caratterizza per il complesso rapporto che lega i due organi, con effetti della patologia polmonare sul rene ed effetti della patologia renale sul polmone. È inoltre da tener presente che i pazienti con BPCO e insufficienza renale hanno un peculiare profilo delle altre comorbilità.

\section{Effetti della patologia polmonare sul rene e alterazioni dell'equilibrio acido-base}

I pazienti con BPCO e insufficienza respiratoria possono presentare un ridotto flusso plasmatico renale, anche se la VFG tende a ridursi meno rapidamente del flusso [31]. Questi pazienti hanno ovviamente un aumentato rischio di alterazioni dell'equilibrio acido-base, soprattutto a causa della ridotta capacità del rene di ritenere $\mathrm{HCO}_{3}{ }^{-}$. Da questo punto di vista, è importante ricordare che la fisiologica risposta renale ad alterazioni del $\mathrm{pH}$ è piuttosto lenta e si instaura nell'arco di giorni. Di conseguenza, la disfunzione renale non peggiora sostanzialmente le alterazioni dell'equilibrio acidobase che si verificano acutamente nel corso di esacerbazioni della BPCO, ma ostacola il ripristino dell'equilibrio nella fase cronica [32].

\section{Effetti della patologia renale sul polmone}

Le complicazioni polmonari dell'insufficienza renale includono l'edema polmonare, la pleurite fibrinosa, le calcificazioni polmonari e un aumentato rischio di infezione tubercolare. La pleurite fibrinosa è tipicamente essudativa, ma si possono avere anche versamenti emorragici, e frequentemente è monolaterale [33]. È una complicazione tardiva dell'uremia e tende a evolvere in fibrosi pleurica [34]. L'aumentato rischio di infezione tubercolare è da collegarsi allo stato di immunodepressione che si sviluppa nella malattia renale cronica, peggiorato nella BPCO dalla frequente necessità di utilizzo di corticosteroidi per via sistemica. In una casistica di 900 pazienti con insufficienza renale, la prevalenza di infezione tubercolare era del $4 \%$, anche se prevaleva la localizzazione extrapolmonare [35]. A prescindere da queste complicazioni, nei pazienti con insufficienza renale, al disturbo ventilatorio ostruttivo si può aggiungere anche un disturbo restrittivo con associata riduzione della capacità di diffusione del monossido di carbonio (DLCO) dovuta al sovraccarico del circolo polmonare [36]. L'alterazione degli scambi è ulteriormente peggiorata nei pazienti in emodialisi con membrane non biocompatibili, verosimilmente a causa dell'instaurarsi di una fibrosi polmonare sostenuta dall'attivazione del complemento [37].

\section{Peculiare profilo di comorbilità}

La popolazione con BPCO e insufficienza renale si caratterizza per un'elevata prevalenza di diabete mellito e, limitatamente ai pazienti con insufficienza renale inapparente, di malattie muscoloscheletriche [1]. L'elevata prevalenza di diabete in questo gruppo, peraltro attesa data l'associazione tra diabete e danno renale, è di particolare importanza in considerazione della già citata elevata frequenza di insufficienza renale inapparente. In questa condizione, infatti, spesso il dosaggio dei farmaci ipoglicemizzanti orali o dell'insulina (che viene metabolizzata più lentamente a causa del deficit di insulinasi renale) non viene adeguatamente ridotto, con importante aumento del rischio di ipoglicemia [30].

La nefropatia diabetica è inoltre importante per spiegare la frequente presenza di anemia. Nonostante la BPCO sia tradizionalmente associata a policitemia, l'anemia è un'importante complicanza in questi pazienti, e la sua prevalenza in tale popolazione varia dal $10 \%$ al $23 \%$ a seconda dei criteri diagnostici usati e della gravità dell'ostruzione bronchiale [38-40]. In genere questa condizione viene imputata allo stato infiammatorio cronico [41], ma nei pazienti con BPCO è anche frequente la malnutrizione, che può portare ad anemie carenziali. Quando si associa anche nefropatia diabetica, si può instaurare una carenza di eritropoietina già per una VFG $<60 \mathrm{~mL} / \mathrm{min}$ [42]. Inoltre, come l'albuminuria, la riduzione dell'eritropoietina è una manifestazione precoce della nefropatia diabetica e, spesso, addirittura precede il declino della VFG $[43,44]$.

I pazienti con BPCO sono a elevato rischio di osteoporosi a causa dell'esposizione al fumo e ai corticosteroidi, ma anche a causa della frequente malnutrizione e dei ridotti livelli di deidroepiandrosterone solfato che questa si associano [45]. La contemporanea presenza di insufficienza renale ovviamente rende questo rischio ancora più elevato: è da sottolineare, in proposito, che livelli ridotti di funzione dell'alfa $a_{1}$-idrossilasi sono stati riscontrati anche in pazienti con insufficienza renale lieve, e il gruppo K/DOQI suggerisce 
Tabella 1 Comorbilità nell'associazione di BPCO e insufficienza renale.

\begin{tabular}{|c|c|}
\hline Profilo di comorbilità & $\begin{array}{l}\text { Aumentata prevalenza di patologie cardiovascolari, diabete mellito (specie } \\
\text { per l'insufficienza renale conclamata) e di malattie muscoloscheletriche } \\
\text { (specie per l'insufficienza renale inapparente) }\end{array}$ \\
\hline Rischio di sovradosaggio farmaci & $\begin{array}{l}\text { Limitato a farmaci idrosolubili (per esempio digitale) e liposolubili con metaboliti } \\
\text { idrosolubili Farmaci comunemente considerati sicuri, come le eparine a basso peso } \\
\text { molecolare, possono essere sovradosati in corso di insufficienza renale. Nelle nefropatie } \\
\text { gravi (VFG }<30 \mathrm{~mL} / \mathrm{min} \text { ) il deficit di attività insulinasica può causare ipoglicemie } \\
\text { in pazienti diabetici in trattamento insulinico }\end{array}$ \\
\hline Anemia & $\begin{array}{l}\text { Peggioramento dell'ipossia tissutale Nei pazienti diabetici, frequente deficit funzionale } \\
\text { di eritropoietina anche in presenza di VFG moderatamente ridotta. Oltre alla disfunzione } \\
\text { renale, vari fattori (perdita gastrointestinale, malnutrizione, flogosi) possono concorrervi }\end{array}$ \\
\hline Osteoporosi & $\begin{array}{l}\text { Rischio molto elevato, data la ridotta attività alfa }{ }_{1} \text {-idrossilasica, ma multifattoriale } \\
\text { (malnutrizione, ipomobilità, ridotta fotoesposizione, steroidi). In pazienti con fratture } \\
\text { vertebrali, possibile riduzione della capacità vitale e conseguente quadro disfunzionale } \\
\text { misto Inoltre anoressia e sazietà precoce da bulging addominale, instabilità posturale } \\
\text { e rischio di cadute, depressione in presenza di cifosi dorsale }\end{array}$ \\
\hline Immunodepressione & $\begin{array}{l}\text { Effetto sinergico dell'insufficienza renale e della terapia corticosteroidea. } \\
\text { Aumento del rischio di infezione da micobatterio }\end{array}$ \\
\hline Ipertensione & $\begin{array}{l}\text { Vari meccanismi (attivazione sistema renina-angiotensina, deficit di renalasi); } \\
\text { tra questi, il deficit di renalasi può comportare ipertono simpatico }\end{array}$ \\
\hline Astenia & Depressione ATPasi di membrana in presenza di insufficienza renale \\
\hline Miopatia prossimale & $\begin{array}{l}\text { Carenza di vitamina D attiva (danno prevalente a carico di ileo-psoas } \\
\text { e quadricipite femorale: instabilità posturale, cadute) }\end{array}$ \\
\hline Neoplasia uroteliale o renale & Rischio aumentato in rapporto al tabagismo o alla nefropatia \\
\hline $\begin{array}{l}\text { Maggiore rischio disidratazione } \\
\text { o anasarca }\end{array}$ & Ridotta regolazione renale dell'equilibrio idroelettrolitico \\
\hline
\end{tabular}

una supplementazione orale anche in pazienti selezionati con VFG $<90 \mathrm{~mL} / \mathrm{min}$.

Infine, l'associazione di BPCO e insufficienza renale è sinergica nel peggiorare sintomi, come l'astenia, che sono propri delle due patologie, e inoltre in questi pazienti è sostanzialmente aumentato il rischio di neoplasia uroteliale in rapporto all'abitudine tabagica (tabella 1). Nella tabella 2 vengono riportate le alterazioni degli esami di laboratorio.

Tabella 2 Alterazioni degli esami di laboratorio.

\begin{tabular}{|c|c|}
\hline Esame & Risultato \\
\hline Emocromo & $\begin{array}{l}\text { Frequente riscontro di anemia normocromica normocitica } \\
\text { Possibile riduzione o mancato aumento dell'eritropoietina }\end{array}$ \\
\hline Equilibrio acido-base & $\begin{array}{l}\text { Acidosi prevalentemente mista, ma dipendente dal grado } \\
\text { di severità relativa delle due patologie }\end{array}$ \\
\hline Esame delle urine & $\begin{array}{l}\text { Microalbuminuria in presenza di coesistente diabete } \\
\text { o di grave ipossiemia }\end{array}$ \\
\hline VES & L'insufficienza renale causa ipersedimetria \\
\hline Omocisteina & Aumentata per stato ossidativo da insufficienza renale \\
\hline Vitamina D & $\begin{array}{l}\text { Ridotta per diminuita fotoesposizione, deficit nutrizionali } \\
\text { e carente attività alfa } a_{1} \text {-idrossilasica renale }\end{array}$ \\
\hline Paratormone & Aumentato ( $>40 \mathrm{pg} / \mathrm{mL}$ per $25 \mathrm{OH}$ vitamina $\mathrm{D}<15 \mathrm{ng} / \mathrm{mL}$ ) \\
\hline Attività del sistema renina-angiotensina & Aumentata \\
\hline Catecolamine & Possono aumentare per ridotta attività renalasica \\
\hline Assetto lipidico & $\begin{array}{l}\text { Effetti non prevedibili: la BPCO, a differenza dell'insufficienza } \\
\text { renale, di per sé si associa a profilo lipidico non aterogeno }\end{array}$ \\
\hline
\end{tabular}




\section{Trattamento}

Il trattamento dei pazienti con comorbilità BPCO-IRC deve prima di tutto tenere conto delle modificazioni posologiche dei farmaci legate alla diminuita escrezione renale secondo la farmacocinetica specifica di ogni singola molecola (per esempio, dosaggio degli antibiotici in corso di riacutizzazione di BPCO).

L'accelerata aterosclerosi che si accompagna all'IRC impone in questi pazienti un rigoroso approccio di prevenzione del rischio cardiovascolare secondo le linee guida specifiche dei pazienti con IRC.

L'eventuale alterato equilibrio acido-base deve essere trattato tenendo conto dei frequenti quadri misti (acidosi respiratoria-acidosi metabolica uremica a gap anionico aumentato).

La malnutrizione va assolutamente evitata, dal momento che incide sfavorevolmente in entrambe le patologie.

L'anemia che si associa all'IRC va trattata con eritropoietina umana ricombinante con un target di emoglobina da raggiungere compreso tra 11 e $12 \mathrm{~g} \%$ (ematocrito 33-36), nei diabetici non in emodialisi tra 9 e $10 \mathrm{~g} \%$ secondo i dati dello studio TREAT.

Per le altre eventuali patologie che si aggiungono alla BPCO in corso di IRC, come l'iperparatiroidismo secondario, occorre seguire lo stesso approccio terapeutico validato per $i$ pazienti con IRC.

La ventilazione non invasiva, quando necessaria, non è controindicata in presenza di IRC.

\section{Bibliografia}

[1] Antonelli-Incalzi R, Corsonello A, Pedone C, Battaglia S, Paglino $\mathrm{G}$, Bellia $\mathrm{V}$, on behalf of the Extrapulmonary Consequences of COPD in the Elderly (ECCE) study investigators. Chronic renal failure: a neglected comorbidity of COPD. Chest 2009 Nov 10 [Epub ahead of print].

[2] Campbell RC, Sui X, Filippatos G, Love TE, Wahle C, Sanders PW, et al. Association of chronic kidney disease with outcomes in chronic heart failure: a propensity-matched study. Nephrol Dial Transplant 2009;24(1):186-93.

[3] Antonelli Incalzi R, Fuso L, De Rosa M, Forastiere F, Rapiti E, Nardecchia B, et al. Co-morbidity contributes to predict mortality of patients with chronic obstructive pulmonary disease. Eur Respir J 1997;10(12):2794-800.

[4] Fernandez Lucas M, Teruel JL, Zamora J, Lopez Mateos M, Rivera $M$, Ortuno J. A Mediterranean age-comorbidity prognostic index for survival in dialysis populations. J Nephrol 2007;20(6):696702.

[5] Cavanaugh KL, Merkin SS, Plantinga LC, Fink NE, Sadler JH, Powe NR. Accuracy of patients' reports of comorbid disease and their association with mortality in ESRD. Am J Kidney Dis 2008;52(1):118-27.

[6] Merkin SS, Cavanaugh K, Longenecker JC, Fink NE, Levey AS, Powe NR. Agreement of self-reported comorbid conditions with medical and physician reports varied by disease among endstage renal disease patients. J Clin Epidemiol 2007;60(6):63442.

[7] Abramson R, Garg M, Angell J. Living dangerously-the effect of chronic pulmonary and renal failure on self-image. Psychother Psychosom 1975;26(5):303-11.

[8] Li S, McAlpine DD, Liu J, Li S, Collins AJ. Differences between blacks and whites in the incidence of end-stage renal disease and associated risk factors. Adv Ren Replace Ther 2004;11(1): 5-13.

[9] Longenecker JC, Coresh J, Klag MJ, Levey AS, Martin AA, Fink $\mathrm{NE}$, et al. Validation of comorbid conditions on the end-stage renal disease medical evidence report: the CHOICE study. Choices for Healthy Outcomes in Caring for ESRD. J Am Soc Nephrol 2000;11(3):520-9.

[10] Kuiper JW, Groeneveid J, Slutsky AS, Plotz FB. Mechanical ventilation and acute failure. Crit Care Med 2005;33(6):1408-15.

[11] Choi WI, Quint DA, Park KM, et al. Systemic microvascular leak in vitro and in vivo rat model of ventilator-induced lung injury. Am J Respir Crit Care Med 2003;167:1627-32.

[12] Peng X, Hassoun PM, Summani S, et al. Protective effects of sphingosine 1-phophate in murine endotoxin-induced inflammatory lung injury. Am J Respir Crit Care Med 2004;169:1251-4.

[13] Guignard JP, Torrado A, Mazouni SM, et al. Renal function in respiratory distress syndrome. J pediatr 1976;88:845-50.

[14] Kilburn KH, Dowell AR. Renal function in respiratory failure. Effects of hypoxia, hyperoxia and hypercapnia. Arch intern med 1971;127:754-62.

[15] Palange P. Renal and hormonal abonormalities in chronic obstructive pulmonary disease (COPD). Thorax 1998;53:58991.

[16] Farbert $M D$, Robert $L R$, Weinberger $M H$, et al. Abnormalities in sodium and $\mathrm{H}_{2} \mathrm{O}$ handling in chronic obstructive lung disease. Arch intern Med 1982;142:1326-30.

[17] Winter RJ, Davidson AC, Treacher DF, et al. Atrial natriuretic peptide concentration in hypoxic secondary pulmonary hypertension: relation to haemodynamic and blood gas variables and response to supplemental oxygen. Thorax 1989;44:58-62.

[18] Krzystek-Korpacka M, Matusiewicz M, Diakowska D, et al. Respiratory insufficiency related to COPD accelerates systemic inflammation, under-nutrition, and angiogenesis in esophageal malignancies. Exp Oncol 2008;30:75-80.

[19] Imai Y, parodo J, Kajikawa $O$, et al. Injurious mechanical ventilation and end-organ epithelial cell apoptosis and organ dysfunction in an experimental model of acute respiratory distress sybdrome. JAMA 2003;289:2104-12.

[20] Hobo A, Yuzawa Y, Kosugi. et al. The growth factor midkine regulates the rennin-angiotensin system in mice. J Clin Invest 2009;119:1616-25.

[21] Sato W, Kadomatsu K, Yuzawa Y, et al. Midkine is involved in neutrophil infiltration into tubularinterstitium in ischemic renal injury. J immunol 2001;167:3463-9.

[22] Horiba M, Kadomatsu K, Nakamura E, et al. Neointim A Formation in restenosis model is suppressed in midkine-deficient mice J clin invest 2000;105:489-95.

[23] Levey AS, Coresh J, Balk E, Kausz AT, Levin A, Steffes MW, et al., National Kidney Foundation. National Kidney Foundation practice guidelines for chronic kidney disease: evaluation, classification, and stratification. Ann Intern Med 2003;139(2):137-47.

[24] Soriano JB, Visick GT, Muellerova H, Payvandi N, Hansell AL. Patterns of comorbidities in newly diagnosed COPD and asthma in primary care. Chest 2005;128(4):2099-107.

[25] Preston RA, Epstein M. Ischemic renal disease: an emerging cause of chronic renal failure and end-stage renal disease. $J$ Hypertens 1997;15(12 Pt 1):1365-77.

[26] Cooper RG. Effect of tobacco smoking on renal function. Indian J Med Res 2006;124(3):261-8.

[27] Keane WF, Eknoyan G. Proteinuria, albuminuria, risk, assessment, detection, elimination (PARADE): a position paper of the National Kidney Foundation. Am J Kidney Dis 1999;33(5): 1004-10.

[28] Pedone C, Corsonello A, Incalzi RA, GIFA Investigators. Estimating renal function in older people: a comparison of three formulas. Age Ageing 2006;35(2):121-6.

[29] Corsonello A, Pedone C, Corica F, Mussi C, Carbonin P, Antonelli Incalzi R, Gruppo Italiano di Farmacovigilanza nell’Anziano 
(GIFA) Investigators. Concealed renal insufficiency and adverse drug reactions in elderly hospitalized patients. Arch Intern Med 2005;165(7):790-5.

[30] Go AS, Chertow GM, Fan D, McCulloch CE, Hsu CY. Chronic kidney disease and the risks of death, cardiovascular events, and hospitalization. N Engl J Med 2004;351(13):1296-305.

[31] Anand IS, Chandrashekhar Y, Ferrari R, Sarma R, Guleria R, Jindal SK, et al. Pathogenesis of congestive state in chronic obstructive pulmonary disease. Studies of body water and sodium, renal function, hemodynamics, and plasma hormones during edema and after recovery. Circulation 1992;86(1): 12-21.

[32] Pierson DJ. Respiratory considerations in the patient with renal failure. Respir Care 2006;51(4):413-22.

[33] Maher JF. Uremic pleuritis. Am J Kidney Dis 1987;10(1):19-22.

[34] Huggins JT, Sahn SA. Causes and management of pleural fibrosis. Respirology 2004;9(4):441-7.

[35] Venkata RK, Kumar S, Krishna RP, Kumar SB, Padmanabhan S, Kumar S. Tuberculosis in chronic kidney disease. Clin Nephrol 2007;67(4):217-20.

[36] Lee HY, Stretton TB, Barnes AM. The lungs in renal failure. Thorax 1975;30(1):46-53.

[37] Moinard J, Guenard H. Membrane diffusion of the lungs in patients with chronic renal failure. Eur Respir J 1993;6(2):225-30.
[38] Cote C, Zilberberg MD, Mody SH, Dordelly LJ, Celli B. Haemoglobin level and its clinical impact in a cohort of patients with COPD. Eur Respir J 2007;29(5):923-9.

[39] John M, Lange A, Hoernig S, Witt C, Anker SD. Prevalence of anemia in chronic obstructive pulmonary disease: comparison to other chronic diseases. Int J Cardiol 2006;111(3):365-70.

[40] John M, Hoernig S, Doehner W, Okonko DD, Witt C, Anker SD. Anemia and inflammation in COPD. Chest 2005;127(3):825-9.

[41] Similowski T, Agustí A, MacNee W, Schönhofer B. The potential impact of anaemia of chronic disease in COPD. Eur Respir $\mathrm{J}$ 2006;27(2):390-6.

[42] Ble A, Fink JC, Woodman RC, Klausner MA, Windham BG, Guralnik JM, et al. Renal function, erythropoietin, and anemia of older persons: the InCHIANTI study. Arch Intern Med 2005;165(19):2222-7.

[43] Bosman DR, Winkler AS, Marsden JT, MacDougall IC, Watkins PJ. Anemia with erythropoietin deficiency occurs early in diabetic nephropathy. Diabetes Care 2001;24(3):495-9.

[44] Thomas MC, Tsalamandris C, Macisaac R, Jerums G. Functional erythropoietin deficiency in patients with type 2 diabetes and anaemia. Diabet Med 2006;23(5):502-9.

[45] Debigaré R, Marquis K, Côté CH, Tremblay RR, Michaud A, LeBlanc $P$, et al. Catabolic/anabolic balance and muscle wasting in patients with COPD. Chest 2003;124(1):83-9. 


\section{BPCO, obesità, sindrome metabolica e diabete}

\section{Giovanni Gulli, Valerio Miselli}

\section{Messaggi chiave}

- La prevalenza e l'incidenza di broncopneumopatia cronica ostruttiva (BPCO), obesità, sindrome metabolica e diabete mellito di tipo 2 sono globalmente in aumento e concorrono alla determinazione della mortalità cardiovascolare.

- BPCO, obesità, sindrome metabolica e diabete mellito di tipo 2 si manifestano in uno stesso individuo con una frequenza superiore di quanto atteso dal caso.

- BPCO, obesità, sindrome metabolica e diabete mellito di tipo 2 sono caratterizzati da una condizione di flogosi sistemica e da un pattern citochinico comune.

- La presenza di una di queste condizioni mediche richiede un adeguato studio per la diagnosi precoce delle altre.

- La terapia di ognuna di queste condizioni è necessaria per modificare in senso favorevole la storia naturale di ciascuna di esse.

- Il paziente affetto da BPCO è un paziente complesso e richiede un approccio olistico.

\section{BPCO}

La broncopneumopatia cronica ostruttiva (BPCO) è una malattia prevenibile e trattabile caratterizzata da una limitazione del flusso aereo generalmente progressivo e non completamente reversibile, la cui cifra spirometrica è data da un ridotto rapporto FEV1/FVC ( $<70 \%)$, associata a effetti extrapolmonari che possono contribuire alla severità della malattia nel singolo paziente. La BPCO è una delle principali cause di mortalità e morbilità/disabilità nel mondo. Secondo le stime della World Health Organization (WHO) [1], 80 milioni di persone soffrono di BPCO e nel 2005 più di 3 milioni

di individui sono morti per BPCO (il 3\% di tutte le morti). In assenza di interventi contro il fumo di sigaretta e la combustione di biomasse in ambienti confinati, la WHO ritiene che le morti per BPCO aumenteranno di oltre il 30\% nei prossimi 10 anni. Secondo le proiezioni 2002-2030 [2] la BPCO, guadagnando tre posizioni rispetto al 1990, sarà la quarta causa di morte nel mondo, preceduta da cardiopatia ischemica, malattia cerebrovascolare (ictus), HIV/AIDS. Sebbene la maggior parte delle informazioni sulla BPCO provenga da Paesi ad alto reddito, circa il $90 \%$ delle morti avviene in nazioni a reddito medio-basso. La principale causa di morte nei pazienti con BPCO è la malattia cardiovascolare, e l'infiammazione cronica non autolimitante è alla base della malattia delle piccole vie aeree (infiammazione e rimodellamento) e della distruzione parenchimale (perdita dei setti alveolari, riduzione del ritorno elastico) che conducono alla limitazione non reversibile del flusso aereo [3].

\section{Obesità}

L'epidemia globale di obesità, la "globesity" della WHO, è ormai diventata un problema di sanità pubblica nei Paesi industrializzati e, paradossalmente, nei Paesi in via di sviluppo, dove coesiste con la malnutrizione, soprattutto nelle aree urbane dove l'iponutrizione prenatale, infantile e adolescenziale è seguita dall'esposizione a cibi ipercalorici, poveri in micronutrienti, e dalla mancanza di attività fisica. Nel 2005, circa 1.600.000.000 individui di età superiore a 15 anni erano in sovrappeso e almeno 400.000 .000 erano obesi; per il 2015 la WHO stima che 2.300.000.000 individui di età superiore a 15 anni saranno in sovrappeso e almeno 400.000.000 saranno obesi. L'obesità e il sovrappeso costituiscono un fattore di rischio maggiore per malattia cardiovascolare, soprattutto sindromi coronariche e ictus, attualmente prima causa di morte, responsabile di 17.000.000 di decessi l'anno, diabete, patologia che sta assumendo dimensioni epidemiche, gravato da una mortalità 
che aumenterà del 50\% nei prossimi 10 anni, disturbi muscoloscheletrici, soprattutto artrosi, e, infine, cancro dell'endometrio, del colon e della mammella [4].

Il sovrappeso e il grado di obesità sono definiti dal Body Mass Index (BMI), ritenuto il gold standard antropometrico. Si tratta di un semplice indice peso-altezza, definito dal peso espresso in kilogrammi diviso per il quadrato dell'altezza espressa in metri.

Sempre la WHO definisce sovrappeso un BMI uguale o superiore a 25 e obesità un BMI uguale o superiore a 30 . Sebbene questi limiti (cut-off) forniscano un indice per la valutazione individuale, esiste evidenza che il rischio per le malattie croniche precedentemente elencate aumenti progressivamente, nella popolazione, a partire da un BMI di 21 [5]. Per quanto utile negli studi di popolazione, il BMI deve essere considerato un indice grossolano, giacché, in differenti individui, lo stesso BMI non corrisponde necessariamente allo stesso grado di adiposità [6] né fornisce informazioni sulla distribuzione dell'adiposità stessa. Questa considerazione ha indotto a rivalutare l'uso della circonferenza addominale (misurata immediatamente al di sopra della cresta iliaca), favorito dalla crescente evidenza epidemiologica e sperimentale dell'associazione fra obesità addominale, insulinoresistenza e malattia cardiovascolare [7].

\section{Sindrome metabolica}

L'obesità addominale - e il suo ruolo nell'indurre uno stato cronico di infiammazione di basso grado [8] - costituisce il requisito necessario per la diagnosi di sindrome metabolica (SM) [9], diagnosi posta quando a essa si associno almeno altri due fattori di rischio fra ipertrigliceridemia ( $\geq 150 \mathrm{mg} / \mathrm{dL}$ ), ridotta concentrazione di colesterolo HDL ( $<40 \mathrm{mg} / \mathrm{dL}$ nel maschio, $<50 \mathrm{mg} / \mathrm{dL}$ nella femmina), elevati valori di pressione arteriosa (sistolica $\geq 130 \mathrm{mmHg}$ e/o diastolica $\geq 85 \mathrm{mmHg}$ ), elevata glicemia a digiuno $(\geq 100 \mathrm{mg} / \mathrm{dL})$.

La SM non è un indice di rischio assoluto, giacché non comprende numerosi fattori (età, sesso, fumo di sigaretta, colesterolo LDL) che determinano il rischio assoluto; inoltre, costituisce, per definizione, una condizione prepatologica, piuttosto che una diagnosi clinica, e, pertanto, dovrebbe escludere individui con diabete franco o malattia cardiovascolare nota [10]. Pur con questi limiti, pazienti che soddisfano i criteri per SM manifestano uno stato protrombotico e proinfiammatorio sistemico e hanno un rischio doppio di sviluppare malattia cardiovascolare nei 10 anni successivi rispetto a individui senza sindrome [10]. In un campione rappresentativo di adulti nordamericani, la prevalenza complessiva di SM è risultata pari al $40 \%$ circa e interessa, pertanto, circa 54 milioni di individui [11].

\section{Diabete mellito di tipo 2}

Obesità e SM costituiscono formidabili fattori di rischio per il diabete mellito di tipo 2 (DMT2). Circa 194 milioni di persone, in tutto il mondo, sono affette da diabete [12]. Urbanizzazione, errori alimentari, riduzione dell'attività fisica e stress danno ragione di tale incremento. Questa prevalenza globale fa del diabete una delle malattie non trasmissibili più frequenti. Nel 2002 il diabete è stato la quinta causa di morte negli Stati Uniti e ha determinato una spesa di 132 miliardi di dollari [13]. Il diabete sta assumendo caratteristiche di epidemia in Paesi in via di sviluppo e in nazioni da poco industrializzate, e le proiezioni depongono per il raddoppio del numero mondiale di casi entro il 2030 [12]. I determinanti patogenetici del DMT2 sono, semplificando, l'insulinoresistenza e la ridotta secrezione insulinica associata a una conservata secrezione di glucagone [14]. Le sequele sistemiche macroangiopatiche e microangiopatiche del diabete, ovvero coronaropatia, vasculopatia cerebrale e periferica, neuropatia, nefropatia, retinopatia e le loro complicanze, infarto miocardio e scompenso cardiaco, ictus e disabilità, amputazioni, insufficienza renale terminale e cecità, riducono la spettanza di vita e aumentano la spesa sanitaria e sociale in ogni nazione. Oltre alle citochine proinfiammatorie correlate alla condizione di obesità e alla SM (il blocco di IL-1 determina una riduzione della flogosi sistemica e un sostenuto miglioramento della secrezione e dell'azione insulinica nei pazienti diabetici di tipo 2) [15], iperglicemia, glicazione proteica non enzimatica e stress ossidativo sono i determinanti patogenetici del DMT2 [16] che, con la BPCO, condivide una delle principali cause di morte, ovvero la cardiopatia ischemica.

Sebbene uno stretto controllo dei valori glicemici e una contestuale riduzione del biomarker della glicemia media, l'emoglobina glicata [17], abbiano determinato la significativa riduzione del danno microangiopatico, l'effetto della riduzione dell'A1C sulla progressione della macroangiopatia e, quindi, sulla mortalità cardiovascolare, è ancora controverso [18]; questo dato determina un ulteriore, scoraggiante parallelismo fra DMT2 e BPCO, patologia per la quale, a oggi, ancora manca una terapia "disease modifying", in grado, cioè, di modificarne in senso favorevole (mortalità) la prognosi [19].

\section{La comorbilità}

In considerazione delle elevate prevalenze, non sorprende che BPCO, obesità, SM e DMT2 possano coesistere nello stesso individuo e amplificare il rischio cardiovascolare che ciascuna condizione comporta.

\section{Obesità e BPCO}

I dati disponibili suggeriscono che la prevalenza dell'obesità sia maggiore nei pazienti con BPCO rispetto alla popolazione generale, in funzione della severità del grado di ostruzione. In uno studio europeo [20] la prevalenza complessiva di obesità nei soggetti con BPCO era il 18\%, contro una prevalenza media dell'11\% nella popolazione generale, con prevalenze maggiori negli stadi GOLD [21] 1 e 2 (16 e $24 \%$, rispettivamente) e minore nello stadio GOLD 4 (6\%). Una prevalenza di obesità assai più elevata (54\%) è stata riportata in una coorte nordamericana di pazienti con BPCO [22] in paragone alla popolazione generale di riferimento (24\%).

Può essere di interesse fisiopatologico ricordare che la prevalenza dell'obesità della BPCO può differire nei diversi fenotipi della malattia, schematicamente distinti in "pink 
puffers", generalmente magri e con storia di perdita di peso, e "blue bloaters", tendenzialmente in sovrappeso [23] e che, come per altre patologie croniche, particolarmente nello scompenso cardiaco, il sovrappeso e l'obesità possono costituire un vantaggio relativamente agli outcome cardiovascolari, fenomeno conosciuto come "obesity paradox" [24]. In un ampio studio epidemiologico [25], il rischio di morte era inferiore nei pazienti affetti da BPCO obesi e in sovrappeso, e il recupero del peso corporeo è associato a una riduzione del rischio di mortalità nei pazienti con BPCO severa (stadi 3-4 di GOLD) [26]. L'identificazione di una perdita di massa magra con conservazione del peso (fenotipo sarcopenico), ovvero con peso corporeo inferiore alla norma (cachessia polmonare, fenotipo cachettico) nei pazienti con progressione di malattia, correlata a un'aumentata mortalità, rende ragione di questo apparente paradosso. Pur in assenza di dati pubblicati, i risultati del $4^{\text {th }}$ Examination of The Copenhagen City Heart Study suggeriscono che la prevalenza della BPCO negli individui obesi sia significativamente inferiore a quella della popolazione generale $(11,2 \%$ vs $18,6 \%)$. Sebbene questa osservazione, limitata a una sola città, non consenta di inferire un effetto protettivo dell'obesità verso il rischio di contrarre $\mathrm{BPCO}$, certamente permette di ipotizzare che obesità e BPCO siano sottese da percorsi patogenetici distinti. Di fatto, pur essendo l'obesità un fattore predisponente per dispnea a causa dell'aumentata richiesta di ossigeno che la mobilizzazione di un eccesso di peso comporta, un ridotto rapporto FEV1/FVC non ne costituisce un aspetto caratterizzante. La presenza di tessuto adiposo nelle cavità addominale e toracica e nella stessa parete toracica riduce il volume espiratorio di riserva e la capacità funzionale residua senza, tuttavia, alterare le resistenze delle vie aeree e $\mathrm{i}$ flussi espiratori quando $\mathrm{i}$ dati spirometrici sono normalizzati per $i$ volumi polmonari $[27,28]$.

\section{Sindrome metabolica e BPCO}

Più speculativi e contraddittori appaiono, invece, i rapporti fra BPCO e SM che, in Europa, secondo i dati dell'ESC, nella popolazione adulta ha una prevalenza complessiva del $38 \%$, non dissimile da quella documentata negli Stati Uniti (40\%). Non altrettanto univoca è la valutazione della prevalenza della SM nella popolazione affetta da BPCO. Una delle principali cause di questa indeterminatezza è da ricercarsi nelle differenti definizioni di SM che sono state formulate, in modo subentrante, dalle numerose organizzazioni e società scientifiche (WHO, NCEP-ATP III, AHA/NHLBI, ACE/AACE, IDF) che, dalla pubblicazione del lavoro staminale di Reaven [29], hanno cercato di acquisire la leadership scientifica (ed economica?) sulla sindrome, proponendo l'insulinoresistenza (WHO, AHA/NHLBI, ACE/AACE) o l'obesità addominale (NCEP-ATP III, IDF) quale determinante della sindrome stessa. Secondo l'ultima definizione IDF, si attesta la presenza della sindrome se sono presenti almeno tre criteri fra obesità, identificata dalla misura della circonferenza addominale $(>94 \mathrm{~cm}$ per i maschi, $>80 \mathrm{~cm}$ per le femmine "europidi"), ipertrigliceridemia $(\geq 150 \mathrm{mg} / \mathrm{dL})$, ridotta concentrazione di colesterolo HDL ( $<40 \mathrm{mg} / \mathrm{dL}$ per i maschi, $<50 \mathrm{mg} / \mathrm{dL}$ per le femmine), ipertensione arteriosa (sistolica $\geq 130 \mathrm{mmHg}$ e/o diastolica $\geq 85 \mathrm{mmHg}$ ), valori di glicemia a digiuno $\geq 100 \mathrm{mg} / \mathrm{dL}$ [10]. La non più necessaria centralità dell'obesità tronculare nella definizione della SM e la possibilità di formularne la diagnosi con 10 differenti combinazioni, per ciascuna delle quali non sono ancora disponibili dati relativi al peso sia dei singoli componenti, sia della combinazione in sé sugli outcome cardiovascolari, ha reso più vago e disomogeneo il contesto fisiopatologico e clinico della SM. In questo modo, una stessa diagnosi identifica differenti popolazioni a rischio [30], rendendo complessa la ricerca, l'individuazione e l'interpretazione delle relazioni fra BPCO e SM.

Date queste premesse, non stupisce l'eterogeneità dei risultati degli studi pubblicati su questo argomento. Una significativa prevalenza di SM nei pazienti con BPCO è stata rilevata dalla maggior parte degli studi pubblicati [31-35], ma non da tutti [36-38]. Fra gli studi che hanno concluso per una significativa correlazione fra SM e BPCO, tre erano caratterizzati da una numerosità del campione troppo esigua per poterne generalizzare i risultati [31,32,35], uno [33], pur interessando una popolazione numericamente adeguata, non utilizzava il rapporto FEV1/FVC per caratterizzare la presenza e lo stadio della BPCO e un altro ancora [34], altrettanto adeguato in termini di numerosità del campione, analizzava una popolazione asiatica, con prevalenze di SM $(20 \%)$ e BPCO $(6,7 \%)$ affatto dissimili da quelle riscontrate nei Paesi occidentali. Ė interessante osservare come, fra gli studi negativi, uno [37], rilevante per numerosità del campione, fosse condotto in una popolazione asiatica.

\section{Diabete mellito di tipo 2 e BPCO}

L'associazione fra ridotta funzionalità polmonare e DMT2 è stata descritta già da molti anni [39] e, tuttavia, il significato clinico di quest'associazione non è ancora noto. Se considerare il polmone un altro organo bersaglio dell'iperglicemia può essere intuibile sulla scorta delle conoscenze relative all'effetto dell'iperglicemia sul microcircolo, assai più stimolante è speculare sulla riduzione della funzione polmonare documentata prima dell'insorgenza del diabete [40] e sul ruolo che questa può avere nella patogenesi della malattia. L'incidenza del DMT2 è stata indagata nel Nurses' Health Study, uno studio di coorte prospettico che ha interessato 97.618 donne per 8 anni [41]. Il RR per DMT2, nella coorte affetta da BPCO, era 1,8. In una coorte numericamente simile di soggetti affetti da asma bronchiale, l'incidenza di DMT2 non risultava aumentata $(R R=1,1)$. Questo dato, correlato al differente pattern citochinico presente nell'asma (IL-4, IL-5, IL-13) rispetto al DMT2 (TNF-alfa, IL-6, IL-8), consentiva agli autori di speculare sull'attività permissiva della flogosi sullo sviluppo dell'insulinoresistenza e sulla patogenesi del DMT2 e di escludere il ruolo della terapia steroidea, assunta in modo identico da pazienti con asma o BPCO, nell'indurre diabete. Questi risultati sono stati confermati da altri studi nei quali una ridotta funzione polmonare è stata predittore indipendente di DMT2 incidente [40,42].

Studi trasversali e prospettici hanno evidenziato che la funzione polmonare in pazienti con DMT2 è compromessa rispetto a controlli non diabetici e declina con maggiore celerità quanto più cattivo è il controllo glicemico $[43,44]$. Infine, il rischio di sviluppare BPCO in individui affetti da DMT2 è stato valutato in un recente studio di coorte retrospettivo 
condotto su 1.811.886 individui, 77.637 dei quali affetti da DMT2 [45]. I risultati di questo studio hanno dimostrato che, in pazienti affetti da DMT2, il rischio di sviluppare BPCO era significativamente aumentato $(H R=1,57)$ e che il rischio aumentava con l'aumento del valore di A1C rilevato all'inizio dello studio.

Di considerevole rilevanza clinica è l'osservazione che l'iperglicemia è associata a una povera prognosi delle esacerbazioni della BPCO e che la presenza di iperglicemia al momento del ricovero è predittiva del fallimento della ventilazione non invasiva e di complicanze polmonari infettive in pazienti in terapia intensiva per insufficienza respiratoria acuta [46].

\section{Discussione}

L'analisi retrospettiva di un ampio campione della popolazione italiana, derivato dal registro della Società Italiana di Medicina Generale, ha evidenziato una prevalenza complessiva di BPCO pari al 4,4\%. La presenza di BPCO aumentava del $197 \%$ la prevalenza di cardiopatia ischemica $(6,9 \%$ nella popolazione generale, $15,9 \%$ nei pazienti BPCO) e del $178 \%$ la prevalenza di DMT2 $(10,5 \%$ vs $18,7 \%)$ [47]. Esiste oggi crescente consenso circa la complessità della BPCO e delle numerose comorbilità a essa associate.

Se il termine "comorbilità" è convenzionalmente definito come "condizione medica che esiste simultaneamente ma indipendentemente da un'altra nello stesso paziente", definire obesità, SM o diabete "comorbilità" quando si accompagnano alla BPCO può costituire un errore concettuale, giacché è documentato che queste patologie si associano alla BPCO più frequentemente di quanto ci si aspetterebbe dal caso. L'interesse clinico circa l'interazione fra BPCO, obesità, SM e DMT2 origina dall'osservazione epidemiologica dell'eccesso di mortalità cardiovascolare e degli aumentati livelli di molecole proinfiammatorie circolanti (TNF-alfa, IL1, IL-6, IL-8, IFN-gamma) comuni alle quattro condizioni. Nel 2007 è stata proposta la definizione sindrome infiammatoria sistemica cronica [48] nella quale gli aspetti squisitamente polmonari sono solamente uno dei fattori che possono dare ragione della mortalità correlata alla BPCO, raramente determinata dall'insufficienza respiratoria di per sé.

Obesità, ipertensione, dislipidemia, insulinoresistenza, scompenso cardiaco, sarcopenia/cachessia sono condizioni patologiche che, con differente espressività clinica, possono raggrupparsi nel paziente affetto da BPCO con maggiore frequenza rispetto alla popolazione generale. Queste patologie extrapolmonari potrebbero essere interpretate, quindi, come parte della diagnosi e non come singole comorbilità associate alla BPCO e, come tali, ricercate e trattate, al fine di individuare una terapia, oggi inesistente [19], in grado di modificare la mortalità associata con la BPCO. La riduzione di mortalità nei pazienti con BPCO trattati con statina [49], il miglioramento del FEV nei pazienti affetti da BPCO e DMT2 trattati con insulinosensibilizzanti [50] e il ruolo dei mediatori di flogosi interessati nella fisiopatologia e nella patogenesi della BPCO [51] suggeriscono il razionale degli studi che indagano una piattaforma eziologica comune dalla quale BPCO, obesità, SM e diabete mellito si sviluppano. I dati epidemiologici, oggi ancora insufficienti e contraddittori, se confermeranno l'aggregazione (clustering) di queste patologie, porranno l'indicazione a studi di intervento. In ogni caso, qualora il destino della sindrome infiammatoria sistemica cronica dovesse seguire la stessa parabola della SM, oggi "derubricata" a "useful concept" [52], rimarrebbe il formidabile messaggio agli operatori sanitari della necessità di valutare tutti i fattori di rischio quando uno di essi sia presente, ovvero di realizzare "what many clinicians want and patients need-a holistic approach to the management of this disabling condition" [53].

\section{Considerazioni cliniche}

Al di fuori degli ambiti specialistici, la diagnosi di BPCO è frequentemente malposta, la sua stadiazione non adeguatamente effettuata, l'efficacia della terapia raramente verificata, la prevenzione delle complicanze non sistematicamente perseguita. Nell'affrontare il paziente con BPCO l'inerzia di molti medici di fronte alle patologie croniche è amplificata dalla compresenza di altre affezioni quali l'obesità, l'ipertensione, la dislipidemia, il diabete mellito. Tuttavia, il bronchitico cronico con queste comorbilità è, paradossalmente, un paziente privilegiato. Infatti, in considerazione sia dei determinanti fisiopatologici condivisi fra tali patologie, sia dell'obiettivo terapeutico comune di riduzione della mortalità cardiovascolare, piccoli interventi comportano considerevoli vantaggi. Per questi pazienti sarà necessario eseguire una valutazione spirometrica con valutazione del rapporto FEV1/FVC per confermare la diagnosi o individuare precocemente l'instaurarsi di una disfunzione ostruttiva, seguire nel tempo l'andamento del FEV1, compiere periodicamente la valutazione multidimensionale secondo i criteri dell'indice BODE [54] (tabella 1). Pregiudiziale a ogni intervento sarà perseguire la sospensione del fumo di sigaretta, anche avvantaggiandosi dei preparati transdermici di nicotina e della somministrazione di bupropione o vareniclina quando non controindicata. Particolare attenzione dovrà essere posta all'alimentazione per ridurre la componente viscerale dell'obesità, attenuare l'intensità della flogosi a essa associata e prevenire la sovrapposizione della componente restrittiva, frequente nella SM, al deficit ventilatorio ostruttivo della BPCO. Un'alimentazione ipercalorica sarà, per contro, indicata negli stadi GOLD più avanzati, per contrastare l'eventuale presenza di sarcopenia.

Per tutte le condizioni qui trattate sarà necessario prescrivere un'attività fisica aerobica moderata e costante, giacché esiste evidenza che la ridotta attività fisica si associa a una condizione di flogosi sistemica [55].

Particolare attenzione andrà posta alla correzione dell' $i$ possia per il peggioramento dell'insulinoresistenza e della flogosi nel tessuto adiposo viscerale che la ridotta saturazione di ossigeno induce. In presenza di insufficienza respiratoria, sarcopenia o riacutizzazioni che richiedano la somministrazione sistemica di steroidi, andrà sospeso l'uso della metformina e degli ipoglicemizzanti orali e introdotta la terapia sostitutiva insulinica con l'obiettivo di mantenere la glicemia costantemente $<180 \mathrm{mg} / \mathrm{dL}$.

Pur in assenza di un'evidenza definitiva, attenzione andrà riposta alla profilassi vaccinale contro il virus dell'influenza stagionale e contro lo pneumococco. La dislipidemia andrà aggressivamente trattata anche nella BPCO, il cui peso come fattore di rischio per mortalità cardiaca andrebbe rivalutato 
Tabella 1 Indice BODE (Body mass index, airways Obstruction, Dyspnea, Exercise performance).

\begin{tabular}{lllll}
\hline & \multicolumn{1}{c}{0} & 1 & 2 & 3 \\
\hline Body mass index & $>21$ & $<21$ & & $36-49$ \\
\hline FEV1 (\% teorico) & $>65$ & $50-64$ & 3 & 435 \\
\hline Grado di dispnea & $0-1$ & 2 & $150-249$ & $<149$ \\
\hline Distanza percorsa in 6 min $(\mathrm{m})$ & $>350$ & $250-349$ & & \\
\hline
\end{tabular}

- Body Mass Index (BMI): peso $(\mathrm{kg})$ diviso altezza al quadrato $\left(\mathrm{m}^{2}\right)$.

- FEV1 (\% teorico).

- Grado di dispnea cronica (scala del Medical Research Council).

0 Dispnea per esercizio intenso

1 Dispnea camminando a passo svelto in pianura o in leggera salita

2 Impossibilità di mantenere il passo dei coetanei o necessità di fermarsi per la dispnea camminando al proprio passo in pianura

3 Necessità di fermarsi per la dispnea dopo $100 \mathrm{~m}$ o dopo pochi minuti in pianura

4 Impossibilità di uscire di casa a causa della dispnea

- Test del cammino (6 min): distanza percorsa camminando alla massima velocità per 6 min

di fronte al Regolatore per un allargamento della nota 13, soprattutto se le statine si confermeranno, a differenza di ogni altro farmaco attualmente approvato per la BPCO, in grado di ridurre la progressione della caduta del FEV1.

\section{Bibliografia}

[1] www.who.int/respiratory/copd/burden/en/index.html

[2] Mathers CD, Loncar D. Projections of global mortality and burden of disease from 2002 to 2030. PLoS Med 2006;3(11): e442.

[3] Global Strategy for Diagnosis, Management, and Prevention of COPD (Updated 2009). www.goldcopd.com

[4] http://apps.who.int/bmi/index.jsp

[5] Manson JE, Willett WC, Stampfer MJ, Colditz GA, Hunter DJ, Hankinson SE, et al. Body weight and mortality among women. $\mathrm{N}$ Engl J Med 1995;333(11):677-85.

[6] Canoy D, Boekholdt SM, Wareham N, Luben R, Welch A, Bingham $S$, et al. Body fat distribution and risk of coronary heart disease in men and women in the European Prospective Investigation Into Cancer and Nutrition in Norfolk cohort: a population-based prospective study. Circulation 2007;116(25): 2933-43.

[7] Grundy SM, Brewer Jr HB, Cleeman JI, Smith Jr SC, Lenfant C, American Heart Association; National Heart, Lung, and Blood Institute. Definition of metabolic syndrome: Report of the National Heart, Lung, and Blood Institute/American Heart Association conference on scientific issues related to definition. Circulation 2004;109(3):433-8.

[8] Yudkin JS. Adipose tissue, insulin action and vascular disease: inflammatory signals. Int J Obes Relat Metab Disord 2003; 27(Suppl 3):S25-8.

[9] Alberti KG, Zimmet P, Shaw J, IDF Epidemiology Task Force Consensus Group. The metabolic syndrome-a new worldwide definition. Lancet 2005;366(9491):1059-62.

[10] Alberti KG, Eckel RH, Grundy SM, Zimmet PZ, Cleeman JI, Donato KA, et al. International Diabetes Federation Task Force on Epidemiology and Prevention; Hational Heart, Lung, and Blood Institute; American Heart Association; World Heart Federation; International Atherosclerosis Society; International Association for the Study of Obesity. Harmonizing the metabolic syndrome: a joint interim statement of the International Diabetes Federation Task Force on Epidemiology and Prevention;
National Heart, Lung, and Blood Institute; American Heart Association; World Heart Federation; International Atherosclerosis Society; and International Association for the Study of Obesity. Circulation 2009;120(16):1640-5.

[11] Ford ES, Giles WH, Dietz WH. Prevalence of the metabolic syndrome among US adults: findings from the third National Health and Nutrition Examination Survey. JAMA 2002;287(3): 356-9.

[12] Wild S, Roglic G, Green A, Sicree R, King H. Global prevalence of diabetes: estimates for the year 2000 and projections for 2030. Diabetes Care 2004;27(5):1047-53.

[13] Hogan P, Dall T, Nikolov P. American Diabetes Association. Economic costs of diabetes in the US in 2002. Diabetes Care 2003;26(3):917-32.

[14] DeFronzo RA. Lilly lecture 1987. The triumvirate: beta-cell, muscle, liver. A collusion responsible for NIDDM. Diabetes 1988;37(6):667-87.

[15] Larsen CM, Faulenbach M, Vaag A, Ehses JA, Donath MY, Mandrup-Poulsen T. Sustained effects of interleukin-1 receptor antagonist treatment in type 2 diabetes. Diabetes Care 2009;32(9):1663-8.

[16] Brownlee M. The pathobiology of diabetic complications: a unifying mechanism. Diabetes 2005;54(6):1615-25.

[17] Little RR, Sacks DB. HbA1c: how do we measure it and what does it mean? Curr Opin Endocrinol Diabetes Obes 2009;16(2): 113-8.

[18] Del Prato S. Megatrials in type 2 diabetes. From excitement to frustration? Diabetologia 2009;52(7):1219-26.

[19] Calverley PM, Anderson JA, Celli B, Ferguson GT, Jenkins C, Jones PW, et al., TORCH investigators. Salmeterol and fluticasone propionate and survival in chronic obstructive pulmonary disease. N Engl J Med 2007;356(8):775-89.

[20] Steuten LM, Creutzberg EC, Vrijhoef HJ, Wouters EF. COPD as a multicomponent disease: inventory of dyspnoea, underweight, obesity and fat free mass depletion in primary care. Prim Care Respir J 2006;15(2):84-91.

[21] Pauwels RA, Buist AS, Calverley PM, Jenkins CR, Hurd SS, GOLD Scientific Committee. Global strategy for the diagnosis, management, and prevention of chronic obstructive pulmonary disease. NHLBI/WHO Global Initiative for Chronic Obstructive Lung Disease (GOLD) Workshop summary. Am J Respir Crit Care Med 2001;163(5):1256-76.

[22] Eisner MD, Blanc PD, Sidney S, Yelin EH, Lathon PV, Katz PP, et al. Body composition and functional limitation in COPD. Respir Res 2007;8:7. 
[23] Guerra S, Sherrill DL, Bobadilla A, Martinez FD, Barbee RA. The relation of body mass index to asthma, chronic bronchitis, and emphysema. Chest 2002;122(4):1256-63.

[24] Curtis JP, Selter JG, Wang Y, Rathore SS, Jovin IS, Jadbabaie F, et al. The obesity paradox: body mass index and outcomes in patients with heart failure. Arch Intern Med 2005;165(1): 55-61.

[25] Vestbo J, Prescott E, Almdal T, Dahl M, Nordestgaard BG, Andersen $\mathrm{T}$, et al. Body mass, fat-free body mass, and prognosis in patients with chronic obstructive pulmonary disease from a random population sample: findings from the Copenhagen City Heart Study. Am J Respir Crit Care Med 2006;173(1):79-83.

[26] Schols AM, Slangen J, Volovics L, Wouters EF. Weight loss is a reversible factor in the prognosis of chronic obstructive pulmonary disease. Am J Respir Crit Care Med 1998;157(6 Pt 1): $1791-7$.

[27] Sin DD, Jones RL, Man SF. Obesity is a risk factor for dyspnea but not for airflow obstruction. Arch Intern Med 2002;162(13): 1477-81.

[28] Salome CM, King GG, Berend N. Physiology of obesity and effects on lung function. J Appl Physiol 2010;108(1):206-11.

[29] Reaven GM. Banting lecture 1988. Role of insulin resistance in human disease. Diabetes 1988;37(12):1595-607.

[30] Lee CM, Huxley RR, Woodward M, Zimmet P, Shaw J, Cho NH, et al., DETECT-2 Collaboration. The metabolic syndrome identifies a heterogeneous group of metabolic component combinations in the Asia-Pacific region. Diabetes Res Clin Pract 2008;81(3):377-80.

[31] Marquis K, Maltais F, Duguay V, Bezeau AM, LeBlanc P, Jobin J, et al. The metabolic syndrome in patients with chronic obstruc tive pulmonary disease. J Cardiopulm Rehabil 2005;25(4): 226-32.

[32] Poulain M, Doucet M, Drapeau V, Fournier G, Tremblay A, Poirier $P$, et al. Metabolic and inflammatory profile in obese patients with chronic obstructive pulmonary disease. Chron Respir Dis 2008;5(1):35-41.

[33] Leone N, Courbon D, Thomas F, Bean K, Jégo B, Leynaert B, et al. Lung function impairment and metabolic syndrome: the critical role of abdominal obesity. Am J Respir Crit Care Med 2009;179(6):509-16.

[34] Lam KB, Jordan RE, Jiang CQ, Thomas GN, Miller MR, Zhang WS, et al. Airflow obstruction and metabolic syndrome: the Guangzhou Biobank Cohort Study. Eur Respir J 2010;35(2):317-23.

[35] Watz H, Waschki B, Kirsten A, Müller KC, Kretschmar G, Meyer T, et al. The metabolic syndrome in patients with chronic bronchitis and COPD: frequency and associated consequences for systemic inflammation and physical inactivity. Chest 2009;136(4):1039-46.

[36] Fimognari FL, Pasqualetti P, Moro L, Franco A, Piccirillo G, Pastorelli R, et al. The association between metabolic syndrome and restrictive ventilatory dysfunction in older persons. J Gerontol A Biol Sci Med Sci 2007;62(7):760-5.

[37] Paek YJ, Jung KS, Hwang YI, Lee KS, Lee DR, Lee JU. Association between low pulmonary function and metabolic risk factors in Korean adults: the Korean National Health and Nutrition Survey. Metabolism 2010 Sep;59(9):1300-6.

[38] Rogliani P, Curradi G, Mura M, Lauro D, Federici M, Galli A, et al. Metabolic syndrome and risk of pulmonary involvement. Respir Med 2010;104(1):47-51.
[39] Goldman MD. Lung dysfunction in diabetes. Diabetes Care 2003;26(6):1915-8.

[40] Engström G, Janzon L. Risk of developing diabetes is inversely related to lung function: a population-based cohort study. Diabet Med 2002;19(2):167-70.

[41] Rana JS, Mittleman MA, Sheikh J, Hu FB, Manson JE, Colditz GA, et al. Chronic obstructive pulmonary disease, asthma, and risk of type 2 diabetes in women. Diabetes Care 2004;27(10): 2478-84.

[42] Yeh HC, Punjabi NM, Wang NY, Pankow JS, Duncan BB, Brancati FL. Vital capacity as a predictor of incident type 2 diabetes: the Atherosclerosis Risk in Communities study. Diabetes Care 2005;28(6):1472-9.

[43] Yeh HC, Punjabi NM, Wang NY, Pankow JS, Duncan BB, Cox CE, et al. Cross-sectional and prospective study of lung function in adults with type 2 diabetes: the Atherosclerosis Risk in Communities (ARIC) study. Diabetes Care 2008;31(4):741-6.

[44] Davis WA, Knuiman M, Kendall P, Grange V, Davis TM, Fremantle Diabetes Study. Glycemic exposure is associated with reduced pulmonary function in type 2 diabetes: the Fremantle Diabetes Study. Diabetes Care 2004;27(3):752-7.

[45] Ehrlich SF, Quesenberry Jr CP, Van Den Eeden SK, Shan J, Ferrara A. Patients diagnosed with diabetes are at increased risk for asthma, chronic obstructive pulmonary disease, pulmonary fibrosis, and pneumonia but not lung cancer. Diabetes Care 2010;33(1):55-60.

[46] Baker EH, Janaway CH, Philips BJ, Brennan AL, Baines DL, Wood DM, et al. Hyperglycaemia is associated with poor outcomes in patients admitted to hospital with acute exacerbations of chronic obstructive pulmonary disease. Thorax 2006;61(4): 284-9.

[47] Cazzola M, Bettoncelli G, Sessa E, Cricelli C, Biscione G. Prevalence of comorbidities in patients with chronic obstructive pulmonary disease. Respiration 2010;80(2):112-9.

[48] Fabbri LM, Rabe KF. From COPD to chronic systemic inflammatory syndrome? Lancet 2007;370(9589):797-9.

[49] Young RP, Hopkins R, Eaton TE. Potential benefits of statins on morbidity and mortality in chronic obstructive pulmonary disease: a review of the evidence. Postgrad Med J 2009; 85(1006):414-21.

[50] Kim HJ, Lee JY, Jung HS, Kim DK, Lee SM, Yim JJ, et al. The impact of insulin sensitisers on lung function in patients with chronic obstructive pulmonary disease and diabetes. Int $\mathrm{J}$ Tuberc Lung Dis 2010;14(3):362-7.

[51] Barnes PJ. The cytokine network in chronic obstructive pulmonary disease. Am J Respir Cell Mol Biol 2009;41(6):631-8.

[52] Simmons RK, Alberti KG, Gale EA, Colagiuri S, Tuomilehto J, Qiao Q, et al. The metabolic syndrome: useful concept or clinical tool? Report of a WHO Expert Consultation. Diabetologia 2010;53(4):600-5.

[53] Beyond the lungs-a new view of COPD. Lancet 2007; 370(9589):713.

[54] Celli BR, Cote CG, Marin JM, Casanova C, Montes de Oca M, Mendez RA, et al. The body-mass index, airflow obstruction, dyspnea, and exercise capacity index in chronic obstructive pulmonary disease. N Engl J Med 2004;350(10):1005-12.

[55] ten Hacken NH. Physical inactivity and obesity: relation to asthma and chronic obstructive pulmonary disease? Proc Am Thorac Soc 2009;6(8):663-7. 


\section{BPCO e depressione/ansia}

\section{Fabrizio Boni, Andrea Corsonello, Domenico Panuccio}

\section{Messaggi chiave}

- Depressione e ansia sono due comorbilità psichiatriche assai frequenti in pazienti con broncopneumopatia cronica ostruttiva (BPCO). Si tratta peraltro di problemi che spesso restano misco nosciuti per molto tempo.

- I soggetti con BPCO possono avere uno spettro di severità diversa di depressione che va da sintomi depressivi minori di breve durata e/o sintomi di lungo termine che però non sono disabilitanti (distimia) a depressione clinica maggiore (episodio e disturbo depressivo maggiore). Molto frequentemente, le riacutizzazioni di BPCO si associano a un'esacerbazione di sintomi depressivo-ansiosi di entità lievemoderata.

- Ansia e depressione esercitano un impatto negativo sulle capacità fisiche nello svolgimento delle attività della vita quotidiana, sul sonno e sui contatti sociali, con inevitabile peggioramento della qualità di vita complessiva.

- La depressione è predittore di riospedalizzazioni e uso di risorse sanitarie, persistenza dell'abitudine al fumo e mortalità in pazienti con BPCO.

- Sertralina, paroxetina e buspirone si sono mostrati di qualche utilità nei pazienti con BPCO e depressione.

- La riabilitazione respiratoria ha effetti positivi sulla sintomatologia depressivo-ansiosa. Riguardo agli interventi cognitivo-comportamentali, le informazioni disponibili non sono sufficienti a fornire indicazioni definitive sulla loro efficacia.

\section{Introduzione}

Tra le manifestazioni sistemiche della BPCO vanno certamente annoverate anche le comorbilità psichiatriche. Tra queste rientrano non solo i disturbi della funzione cognitiva, di cui è essenziale tener conto per l'importante impatto sulla compliance alla terapia, ma anche depressione e ansia.

I meccanismi fisiopatologici coinvolti nella patogenesi di depressione e ansia sono numerosi: alterazione dell'asse ipotalamo-ipofisi-surrene [1,2], modificazioni nei sistemi neurotrasmetittoriali noradrenergico e serotoninergico [3], infiammazione [4], nonché tutti i vari fattori di rischio per lo sviluppo di depressione e ansia nelle patologie organiche croniche (severità della malattia organica, ridotta attività fisica, eventi di perdita, anamnesi psichiatrica positiva, compromissione cognitiva, fattori iatrogeni. Nei pazienti con BPCO, oltre a questi meccanismi fisiopatologici, sono da considerare fattori "chimici" (per esempio la nicotina), fattori "ipossico-ischemici" o fattori "infiammatori" legati specificamente alla patologia.

Depressione e ansia sono frequentemente osservabili in soggetti con BPCO e si associano a una prognosi generalmente peggiore, sia in termini di qualità di vita sia in termini di aspettativa di vita. Per tale motivo la letteratura scientifica ha riservato particolare attenzione, nel corso degli ultimi anni, allo studio dell'impatto esercitato dalla BPCO sulla sfera dell'umore [5,6], come è possibile rilevare dalla crescita esponenziale nell'ultimo decennio del numero di pubblicazioni scientifiche ottenibili su Medline utilizzando le parole chiave "depressione", "ansia" e "BPCO". Bisogna comunque considerare che, sebbene l'associazione tra BPCO e depressione/ansia sia nota da molti anni [7-9], tali comorbilità continuano a restare per molto tempo misconosciute e sottotrattate nei pazienti con BPCO [10]. In questo contributo vengono analizzati gli aspetti clinico-epidemiologici dell'associazione tra BPCO e depressione/ansia, nonché 
l'impatto che tali comorbilità esercitano sulla prognosi e sull'approccio terapeutico al paziente con BPCO.

\section{Aspetti epidemiologici}

La BPCO e la depressione/ansia sono patologie ad alta prevalenza nella popolazione generale, ed entrambe sono più frequenti in pazienti anziani. Data l'elevata prevalenza di entrambe le condizioni in età avanzata, la coesistenza di BPCO e depressione/ansia potrebbe essere spiegata da una semplice "coincidenza" o "concomitanza". Tuttavia, bisogna considerare che la depressione risulta essere circa 4 volte più frequente nei pazienti con BPCO rispetto ai coetanei che non ne sono affetti [11]. Inoltre, i pazienti con BPCO e depressione presentano molto frequentemente sintomatologia ansiosa [9] e in presenza di ansia gli episodi depressivi tendono a essere più severi, più duraturi e più resistenti alla terapia [12].

I dati di prevalenza per depressione/ansia nei pazienti con BPCO sono estremamente variabili. Diversi fattori contribuiscono a determinare tale variabilità, tra cui la numerosità dei soggetti arruolati nei vari studi, la differenza degli strumenti diagnostici utilizzati, la rappresentatività dei diversi stadi di severità della BPCO, la stabilità/instabilità clinica della BPCO nei pazienti arruolati. Inoltre, alcuni sintomi della BPCO sono simili a quelli della depressione (difficoltà di concentrazione, astenia, facile affaticamento, turbe del sonno e dell'appetito) rendendo ancora più difficile la diagnosi. Infine, la depressione può avere un impatto negativo sulla performance cognitiva dei pazienti con BPCO, potendo sia simulare un disturbo della funzione cognitiva sia peggiorarne l'evoluzione $[13,14]$.

In pazienti ambulatoriali con BPCO stabile la prevalenza della depressione oscilla tra il $10 \%$ e il $42 \%$, mentre quella dell'ansia tra il $10 \%$ e il 19\% [9-12,15-27]. Il rischio di sviluppare la depressione è più alto nei pazienti che hanno un grado più avanzato di BPCO [16]. I pazienti con BPCO in issigenoterapia a lungo termine (OLT) possono raggiungere il $62 \%$ di depressione associata [18]. Nei pazienti con BPCO riacutizzata la prevalenza di depressione è più alta e oscilla tra il $19,5 \%$ e il $50 \%$, mentre la prevalenza di ansia varia tra il $9,3 \%$ e il 58\% [6]. In pazienti con BPCO severa la prevalenza della depressione arriva a valori del $37-71 \%$ e quella dell'ansia al 50-75\% [6].

I dati di incidenza non sono meno impressionanti. In un recente studio di popolazione l'incidenza di depressione dopo la diagnosi di BPCO è pari a 16,2/1.000 persone-anno, mentre in pazienti non affetti da BPCO è pari a 9,4/1.000 persone-anno (OR 2,01; IC 95\% 1,45-2,78) [28].

Pur con i limiti sopra citati, legati all'estrema variabilità delle popolazioni studiate e dei metodi utilizzati, l'insieme di tali dati rende conto di un fenomeno tanto frequente da non poter essere in alcun modo sottovalutato nella valutazione clinica e nell'approccio terapeutico al paziente con BPCO e comorbilità. Peraltro, è importante sottolineare come la prevalenza di depressione/ansia in pazienti con BPCO sia simile, o a seconda delle casistiche addirittura superiore, a quella rilevabile in altre patologie croniche, quali la malattia di Alzheimer (20-30\%), le neoplasie (20-45\%), il dolore cronico (33-35\%), il diabete mellito (22-50\%), l'infarto del miocardio (33\%), l'ictus (20-50\%) e l'insufficienza renale cronica (20-40\%) [29]. Infine, tra gli aspetti epidemiologici che contribuiscono a definire il profilo del paziente con BPCO e depressione rientrano alcuni fattori sociodemografici, nonché alcuni indici di severità della malattia e/o di complessità clinica complessiva del paziente (tabella 1).

\section{Diagnosi e diagnosi differenziale}

Anche se i dati epidemiologici sopra riportati indicano una prevalenza di depressione/ansia molto elevata in pazienti con BPCO, il problema resta spesso misconosciuto e la diagnosi è frequentemente tardiva [10,11,20-27]. D'altro canto la stessa diagnosi di BPCO è spesso posta tardivamente, quando invece l'identificazione precoce della patologia respiratoria e un tempestivo e appropriato trattamento potrebbero contribuire a ridurre la frequenza di disturbi dell'umore in pazienti con BPCO.

La metodologia diagnostica per l'individuazione della depressione/ansia nei pazienti con BPCO non è diversa da

Tabella 1 Fattori sociodemografici e clinici associati a depressione/ansia in pazienti con BPCO.

\begin{tabular}{|c|c|}
\hline $\begin{array}{l}\text { Fattori sociodemografici } \\
\text { e clinici }\end{array}$ & Studi \\
\hline Disabilità fisica & Kunik ME et al., 2005 [17] \\
\hline $\begin{array}{l}\text { Ossigenoterapia a } \\
\text { lungo termine }\end{array}$ & Lacasse Y et al., 2001 [18] \\
\hline Basso Body Mass Index & Kunik ME et al., 2005 [17] \\
\hline Dispnea severa & Di Marco F et al., 2006 [19] \\
\hline FEV1 $<50 \%$ del predetto & van Manen JG et al., 2002 [20] \\
\hline $\begin{array}{l}\text { Alta frequenza } \\
\text { di riacutizzazioni } \\
\text { di BPCO }\end{array}$ & Xu W et al., 2008 [27] \\
\hline $\begin{array}{l}\text { Concomitante disturbo } \\
\text { del sonno (sindrome } \\
\text { delle apnee ostruttive) }\end{array}$ & Peppard PE et al., 2006 [22] \\
\hline Scarsa qualità di vita & $\begin{array}{l}\text { Cully JA et al., } 2006 \text { [10] } \\
\text { Di Marco F et al., } 2006 \text { [19] } \\
\text { Gudmundsson G et al., } 2006 \\
\text { [21] }\end{array}$ \\
\hline Presenza di comorbilità & van Manen JG et al., 2002 [20] \\
\hline Vivere da solo & van Manen JG et al., 2002 [20] \\
\hline Sesso femminile & $\begin{array}{l}\text { Kunik ME et al., } 2005 \text { [17] } \\
\text { Lacasse Y et al., } 2001 \text { [18] } \\
\text { Di Marco F et al., } 2006 \text { [19] }\end{array}$ \\
\hline Stato di fumatore & $\begin{array}{l}\text { Cully JA et al., } 2006 \text { [10] } \\
\text { Kunik ME et al., } 2005 \text { [17] } \\
\text { Lacasse Y et al., } 2001 \text { [18] } \\
\text { Di Marco F et al., } 2006 \text { [19] } \\
\text { Gudmundsson G et al., 2006 } \\
\text { [21] }\end{array}$ \\
\hline $\begin{array}{l}\text { Bassa scolarità } \\
\text { e basso stato sociale }\end{array}$ & Kunik ME et al., 2005 [17] \\
\hline
\end{tabular}


quella applicata nella popolazione generale, e si basa sui criteri DSM-IV [30] (tabelle 2 e 3).

Tuttavia, trattandosi di un problema molto frequente con impatto significativo sulla qualità di vita e sulla prognosi, l'uso di sistemi di screening per l'individuazione di pazienti meritevoli di un approfondimento diagnostico può risultare utile. Bisogna anche considerare che in realtà molti pazienti con BPCO presentano sintomi depressivi o di ansia durante una riacutizzazione dello loro malattia che però si risolvono al miglioramento della sintomatologia clinica della riacutizzazione. Al contrario dell'episodio depressivo maggiore che richiede sicuramente un'adeguata e tempestiva terapia, non c'è evidenza che questi episodi depressivi minori e di breve durata richiedano di uno specifico trattamento. Tuttavia, sebbene uno screening di massa con strumenti che richiedano esperienza e tempi adeguati per la loro corretta utilizzazione non sia proponibile, l'utilizzazione su larga scala di strumenti semplici per l'individuazione del paziente da sottoporre a uno screening mirato che individui i pazienti meritevoli di un approfondimento specialistico appare invece auspicabile. D'altronde, le stesse linee guida GOLD raccomandano che ogni soggetto affetto da BPCO sia sottoposto a una dettagliata raccolta della storia medica che includa anche una valutazione del suo tono dell'umore per quanto riguarda l'ansia e la depressione [31]. Allo stesso modo, le linee guida di "primary care" raccomandano la sistematica esecuzione dello screening per problemi di salute mentale [32]. Tutti gli operatori sanitari interessati alla gestione della BPCO dovrebbero pertanto familiarizzare con i questionari per lo screening di base. D'altronde, dati molto recenti dimostrano l'efficacia dell'applicazione della Geriatric Depression Scale a 15 item nell'individuazione dei pazienti con BPCO e disturbo depressivo maggiore con un buon mix di sensibilità e specificità (rispettivamente $81 \%$ e $87 \%$ ) [33].

In tabella 4 sono riportati i questionari per lo screening di depressione/ansia in pazienti con BPCO [34-44]. In tabella 5 è riportato il questionario breve per la depressione/ansia applicabile nel setting delle cure primarie per lo screening di massa [34].

\section{Valutazione di gravità}

I soggetti con BPCO possono avere uno spettro di severità diversa di depressione che va da sintomi depressivi minori di breve durata e/o sintomi di lungo termine che però non sono disabilitanti (distimia) a depressione clinica maggiore (episodio e disturbo depressivo maggiore). Alcuni studi hanno riportato che approssimativamente $i$ due terzi dei pazienti BPCO con depressione hanno una forma moderata/severa di malattia $[45,46]$. Le manifestazioni più severe non devono in alcun modo essere sottovalutate, in particolare nei pazienti

Tabella 2 Criteri diagnostici per l'episodio depressivo maggiore.

\begin{tabular}{|c|c|}
\hline \multirow[t]{10}{*}{ A } & $\begin{array}{l}\text { Cinque (o più) dei seguenti sintomi sono stati contemporaneamente presenti durante un periodo di } 2 \text { settimane } \\
\text { e rappresentano un cambiamento rispetto al precedente livello di funzionamento; almeno uno dei sintomi } \\
\text { è costituito da } 1 \text { ) umore depresso o } 2 \text { ) perdita di interesse o piacere }\end{array}$ \\
\hline & $\begin{array}{l}\text { Umore depresso per la maggior parte del giorno, quasi ogni giorno, come riportato dal soggetto } \\
\text { (per esempio, si sente triste o vuoto) o come osservato dagli altri (per esempio, appare lamentoso) }\end{array}$ \\
\hline & $\begin{array}{l}\text { Marcata diminuzione di interesse o piacere per tutte, o quasi tutte, le attività per la maggior parte del giorno, } \\
\text { quasi ogni giorno (come riportato dal soggetto o come osservato dagli altri) }\end{array}$ \\
\hline & $\begin{array}{l}\text { Significativa perdita di peso, senza essere a dieta, o aumento di peso (per esempio, un cambiamento superiore } \\
\text { al } 5 \% \text { del peso corporeo in un mese) oppure diminuzione o aumento dell'appetito quasi ogni giorno }\end{array}$ \\
\hline & Insonnia o ipersonnia quasi ogni giorno \\
\hline & $\begin{array}{l}\text { Agitazione o rallentamento psicomotorio quasi ogni giorno (osservabile dagli altri, non semplicemente } \\
\text { sentimenti soggettivi di essere irrequieto o rallentato) }\end{array}$ \\
\hline & Faticabilità o mancanza di energia quasi ogni giorno \\
\hline & $\begin{array}{l}\text { Sentimenti di autosvalutazione o di colpa eccessivi o inappropriati (che possono essere deliranti), } \\
\text { quasi ogni giorno (non semplicemente autoaccusa o sentimenti di colpa per essere ammalato) }\end{array}$ \\
\hline & $\begin{array}{l}\text { Ridotta capacità di pensare o di concentrarsi, o indecisione, quasi ogni giorno (come impressione soggettiva } \\
\text { o osservata dagli altri) }\end{array}$ \\
\hline & $\begin{array}{l}\text { Pensieri ricorrenti di morte (non solo paura di morire), ricorrente ideazione suicidaria senza un piano specifico, } \\
\text { o un tentativo di suicidio, o l'ideazione di un piano specifico per commettere suicidio }\end{array}$ \\
\hline B & I sintomi non soddisfano i criteri per un episodio misto \\
\hline $\mathrm{C}$ & $\begin{array}{l}\text { I sintomi causano disagio clinicamente significativo o compromissione del funzionamento sociale, } \\
\text { lavorativo o di altre aree importanti }\end{array}$ \\
\hline $\mathrm{D}$ & $\begin{array}{l}\text { I sintomi non sono dovuti agli effetti fisiologici diretti di una sostanza (per esempio una droga di abuso, } \\
\text { un medicamento) o di una condizione medica generale (per esempio, ipotiroidismo) }\end{array}$ \\
\hline $\mathrm{E}$ & $\begin{array}{l}\text { I sintomi non sono meglio giustificati da lutto, cioè, dopo la perdita di una persona amata, i sintomi persistono } \\
\text { per più di } 2 \text { mesi o sono caratterizzati da compromissione funzionale marcata, autosvalutazione patologica, } \\
\text { ideazione suicidaria, sintomi psicotici o rallentamento psicomotorio }\end{array}$ \\
\hline
\end{tabular}


Tabella 3 Criteri diagnostici per i disturbi d'ansia. Disturbo di panico con o senza agorafobia

Attacchi di panico inaspettati con o senza comportamento agorafobico

Agorafobia senza anamnesi di disturbo di panico

Agorafobia e sintomi tipo panico senza anamnesi di attacchi di panico inaspettati

\section{Fobia specifica}

Ansia clinicamente significativa provocata dall'esposizione a un oggetto o a una situazione temuti, che spesso determina condotte di evitamento

\section{Fobia sociale}

Ansia clinicamente significativa provocata dall'esposizione a certi tipi di situazioni o di prestazioni sociali, che spesso determina condotte di evitamento

Disturbo ossessivo-compulsivo

Ossessioni (che causano ansia o disagio marcati) e/o compulsioni (che servono a neutralizzare l'ansia)

Disturbo post-traumatico da stress

Rivivere un evento estremamente traumatico accompagnato da sintomi di aumento dell'arousal e da evitamento di stimoli associati al trauma

Disturbo acuto da stress

Sintomi simili a quelli del disturbo post-traumatico da stress che si verificano immediatamente a seguito di un evento estremamente traumatico

\begin{tabular}{l}
\hline Disturbo d'ansia generalizzato \\
\hline Almeno 6 mesi di ansia e preoccupazione persistenti \\
ed eccessive \\
\hline Disturbo d'ansia dovuto a una condizione medica generale \\
\hline Sintomi rilevanti di ansia ritenuti conseguenza fisiologica \\
diretta di una condizione medica generale \\
\hline Disturbo d'ansia indotto da sostanze \\
\hline Sintomi rilevanti di ansia ritenuti conseguenza fisiologica \\
diretta di una droga di abuso, di un farmaco \\
o dell'esposizione a una tossina \\
\hline Disturbo d'ansia non altrimenti specificato \\
\hline Disturbi con ansia o evitamento fobico rilevanti che non \\
soddisfano i criteri per alcuno specifico disturbo d'ansia \\
\hline
\end{tabular}

anziani: in uno studio condotto su 95 pazienti di età compresa tra 60 e 90 anni che avevano tentato il suicidio, la depressione maggiore era la diagnosi psichiatrica più spesso rilevabile, mentre la BPCO e lo scompenso cardiaco erano le comorbilità non psichiatriche più frequenti [47]. Ciò non riduce l'importanza di individuare anche i pazienti con forme più lievi di depressione/ansia che comunque presentano un alto rischio di sviluppare nel tempo sia una disabilità fisica sproporzionata rispetto al loro grado di malattia respiratoria sia una depressione maggiore [48].
Tabella 4 Questionari per lo screening di depressione/ansia in pazienti con BPCO.

Strumenti per lo screening di massa

Patient Health Questionnaire-2 (PHQ2):

Depression screening [34]

Patient Health Questionnaire-3 (PHQ3):

Anxiety screening [34]

Strumenti per lo screening mirato

Depressione

1. Patient Health Questionnaire-9 (PHQ-9) [35]

2. Center for Epidemiologic Studies - Depression (CES-D) scale [36]

3. Geriatric Depression Scale (GDS-30 o GDS-15) [37]

4. Zung Self-Rating Depression Scale [38]

5. Beck Depression Inventory [39]

6. Hamilton Depression Scale [40]

Ansia

1. Hospital Anxiety and Depression Scale (HADS) [41]

2. Depression Anxiety Stress Scale [42]

3. Beck Anxiety Inventory [39]

4. Hamilton Anxiety Rating Scale [43]

5. Spielberg State Trait Anxiety Inventory [44]

\section{Prognosi}

Ansia e depressione determinano una limitazione aggiuntiva delle capacità fisiche già variamente compromesse dalla malattia respiratoria nei pazienti con BPCO. Inoltre, ansia e depressione predicono il declino funzionale meglio della misurazione della riserva respiratoria. Le limitate capacità fisiche riducono anche il ruolo del paziente con BPCO all'interno della famiglia, contribuendo a determinare isolamento e inattività fisica che, a loro volta, accentuano ansia e depressione in un fatale circolo vizioso, responsabile di un costante peggioramento della qualità di vita. Infatti, la depressione è un predittore del declino funzionale nello svolgimento delle attività della vita quotidiana più sensibile della stessa riduzione del FEV1 [48].

Tabella 5 Questionario breve per la depressione/ansia applicabile nel setting delle cure primarie per lo screening di massa.

Patient Health Questionnaire-2 (PHQ2): Depression screening Nel mese precedente:

ha provato persistentemente scarso interesse o scarso piacere nello svolgimento delle attività quotidiane? si è sentito abbattuto, depresso o senza speranza?

Patient Health Questionnaire-3 (PHQ3): Anxiety screening

Nel mese precedente ha provato persistentemente: stato nervoso, ansioso, si è sentito "sulle spine"? preoccupazione per tanti problemi?

Nel mese precedente: ha presentato attacchi acuti di ansia (ha provato improvvisi attacchi di paura o di panico)?

Fonte: Spitzer RL, et al. JAMA 1994;272(22):1749-56. 
Altro problema di grande rilievo nella gestione del paziente pneumopatico con depressione/ansia è la tendenza ad avere una minore aderenza alle prescrizioni terapeutiche [49]. Tale fenomeno favorisce le riacutizzazioni con necessità di ricovero ospedaliero e aumenta la durata delle ospedalizzazioni causate da esacerbazione della BPCO a parità di stadio di malattia e di altri fattori di rischio [24], aumentando anche $i$ costi di gestione [6].

Disturbi del sonno sono frequenti nei pazienti con BPCO e, nei soggetti in cui coesiste depressione, questo disturbo è ancora più frequente [50].

Tabella 6 Studi clinici sul trattamento farmacologico antidepressivo nei pazienti con BPCO.

\begin{tabular}{|c|c|c|c|}
\hline Studi & Pazienti (N) & Tipo di studio e intervento & Risultati \\
\hline $\begin{array}{l}\text { Borson S et al., } \\
1992 \text { [69] }\end{array}$ & $\begin{array}{l}\mathrm{N}=30 ; \mathrm{BPCO} \\
\text { moderata/ } \\
\text { severa e } \\
\text { depressione }\end{array}$ & $\begin{array}{l}\text { Trial randomizzato controllato; } \\
\text { nortriptilina } 12 \text { settimane }\end{array}$ & $\begin{array}{l}\text { Marcato miglioramento di } \\
\text { depressione, ansia e alcuni } \\
\text { sintomi respiratori e della } \\
\text { performance fisica generale }\end{array}$ \\
\hline $\begin{array}{l}\text { Argyropoulou P et al., } \\
1993 \text { [70] }\end{array}$ & $N=16$ & $\begin{array}{l}\text { Studio in doppio cieco, } \\
\text { crossover, randomizzato; } \\
\text { buspirone } 14 \text { giorni } \\
\text { ( } 20 \mathrm{mg} / \mathrm{die})\end{array}$ & $\begin{array}{l}\text { Miglioramento significativo } \\
\text { dell'ansia, della depressione e } \\
\text { dei sintomi ossessivo-compulsivi; } \\
\text { miglioramento della tolleranza } \\
\text { all'esercizio e della sensazione } \\
\text { di dispnea }\end{array}$ \\
\hline $\begin{array}{l}\text { Singh NP et al., } \\
1993 \text { [71] }\end{array}$ & $\begin{array}{l}\mathrm{N}=11 ; \text { ansia } \\
\text { lieve-moderata } \\
\text { e BPCO }\end{array}$ & $\begin{array}{l}\text { Studio in doppio cieco, crossover, } \\
\text { randomizzato, controllato vs } \\
\text { placebo; buspirone } \\
10-20 \mathrm{mg} \times 3 / \text { die per } \\
6 \text { settimane }\end{array}$ & $\begin{array}{l}\text { Nessun effetto significativo su } \\
\text { ansia o parametri fisici, inclusa } \\
\text { la dispnea }\end{array}$ \\
\hline $\begin{array}{l}\text { Papp LA et al., } \\
1995 \text { [72] }\end{array}$ & $N=6$ & $\begin{array}{l}\text { Studio descrittivo; sertraline } \\
12,5 \mathrm{mg} / \text { die titolata fino a } \\
100 \mathrm{mg} / \text { die in } 2 \text { settimane } \\
\text { e mantenuta in terapia } \\
\text { per } 6 \text { settimane }\end{array}$ & $\begin{array}{l}\text { Trattamento ben tollerato; al termine } \\
\text { del periodo di osservazione } 5 \text { dei } \\
6 \text { pazienti miglioravano nello } \\
\text { svolgimento delle attività della } \\
\text { vita quotidiana; miglioramento } \\
\text { soggettivo dei sintomi psichiatrici } \\
\text { nella metà dei casi; nessun } \\
\text { cambiamento nei parametri } \\
\text { respiratori strumentali }\end{array}$ \\
\hline $\begin{array}{l}\text { Evans } M \text { et al., } \\
1997[73]\end{array}$ & $\begin{array}{l}\mathrm{N}=82 ; 42 \text { pazienti } \\
\text { completavano } \\
\text { il trial }\end{array}$ & $\begin{array}{l}\text { Studio in doppio cieco, } \\
\text { randomizzato, per gruppi } \\
\text { paralleli; fluoxetina } \\
20 \mathrm{mg} / \text { die per } 8 \text { settimane }\end{array}$ & $\begin{array}{l}\text { Non significative differenze di } \\
\text { risposta tra i gruppi; nei pazienti } \\
\text { in terapia per più di } 5 \text { settimane } \\
\text { l'umore migliorava }\end{array}$ \\
\hline $\begin{array}{l}\text { Smoller JW et al., } \\
1998 \text { [59] }\end{array}$ & $N=7$ & $\begin{array}{l}\text { Serie di casi; sertralina } \\
25-100 \mathrm{mg} / \text { die per } 2-12 \text { mesi }\end{array}$ & $\begin{array}{l}\text { Riduzione dei sintomi respiratori } \\
\text { e in alcuni casi della tolleranza } \\
\text { all'esercizio }\end{array}$ \\
\hline $\begin{array}{l}\text { Yohannes AM et al., } \\
2001 \text { [74] }\end{array}$ & $\begin{array}{l}\mathrm{N}=57 ; \mathrm{BPCO} \\
\text { moderata/ } \\
\text { severa e } \\
\text { depressione }\end{array}$ & $\begin{array}{l}\text { Studio in singolo-cieco, in aperto; } \\
\text { fluoxetina } 20 \mathrm{mg} / \text { die per } 6 \text { mesi }\end{array}$ & $\begin{array}{l}\text { Scarsa accettazione del trattamento; } \\
\text { solo } 7 \text { pazienti completavano lo studio; } \\
4 \text { dei } 7 \text { pazienti miglioravano; } \\
\text { i sintomi depressivi persistevano } \\
\text { invariati nell' } 86 \% \text { dei pazienti } \\
\text { non trattati }\end{array}$ \\
\hline $\begin{array}{l}\text { Lacasse Y et al., } \\
2004 \text { [75] }\end{array}$ & $\begin{array}{l}\mathrm{N}=23 ; \mathrm{BPCO} \\
\text { end-stage; } \\
15 \text { pazienti } \\
\text { completavano } \\
\text { lo studio }\end{array}$ & $\begin{array}{l}\text { Studio in doppio cieco, randomizzato, } \\
\text { controllato vs placebo; paroxetina } \\
\text { (dosaggio non specificato) } \\
\text { per } 12 \text { settimane }\end{array}$ & $\begin{array}{l}\text { Miglioramento dell'umore e della } \\
\text { qualità di vita; lieve miglioramento } \\
\text { (non statisticamente significativo) } \\
\text { della dispnea }\end{array}$ \\
\hline $\begin{array}{l}\text { Eiser } \mathrm{N} \text { et al., } \\
2005[76]\end{array}$ & $N=28$ & $\begin{array}{l}\text { Studio in doppio-cieco, randomizzato, } \\
\text { controllato vs placebo; paroxetina } \\
20 \mathrm{mg} / \text { die per } 6 \text { settimane; } \\
\text { unblinded paroxetina per } 3 \text { mesi }\end{array}$ & $\begin{array}{l}\text { Nessuna differenza significativa per } \\
\text { quanto riguarda depressione, qualità } \\
\text { di vita e performance fisica. } \\
\text { Il trattamento unblinded per } 3 \text { mesi } \\
\text { migliorava i sintomi depressivi }\end{array}$ \\
\hline
\end{tabular}

Fonte: Putman-Casdorph H, et al. Heart Lung 2009;38(1):34-47. 
Nei pazienti con BPCO in OLT la presenza di depressione riduce la volontà di accettare manovre di rianimazione, mentre non sembra avere effetto sull'accettazione della ventilazione meccanica [51].

Per quanto riguarda la mortalità, bisogna infine considerare che depressione e ansia sono fattori prognostici negativi nei pazienti con BPCO. Dopo un ricovero ospedaliero per riacutizzazione di BPCO la depressione è un predittore indipendente di ulteriori riospedalizzazioni, della persistenza dell'abitudine al fumo [52,53] e soprattutto di mortalità a un anno. Studi recenti indicano che depressione e ansia possono avere non solo un impatto negativo sull'utilizzazione di risorse sanitarie e sulla qualità di vita [54], ma anche sulla mortalità $[55,56]$.

\section{Trattamento farmacologico}

Il trattamento farmacologico della depressione/ansia in pazienti con BPCO non differisce da quello indicato nella popolazione generale. Bisogna a tal proposito considerare che dati recenti dimostrano come l'efficacia reale degli antidepressivi sia piuttosto limitata nei casi di depressione lieve e aumenti all'aumentare della severità della sintomatologia depressiva. Tale evidenza sembra quindi indicare che un trattamento farmacologico sia in generale da riservare a pazienti con sintomatologia depressivo-ansiosa di grado moderato-severo [57].

Per quanto riguarda il trattamento farmacologico di depressione e ansia in pazienti con BPCO, numerosi trial hanno valutato l'efficacia di alcuni farmaci, tra cui nortriptilina, buspirone, sertralina, paroxetina e fluoxetina.

Sertralina, paroxetina e buspirone sembrano essere ben tollerati nei pazienti con BPCO e sembrano avere, almeno a breve termine, effetti positivi sui sintomi ansioso-depressivi. In aggiunta, tali farmaci possono ridurre anche altri sintomi associati a BPCO, quali il craving per il fumo di sigaretta (in particolare durante il trattamento con bupropione) [58], la sensazione soggettiva di dispnea [59], la perdita di appetito e di peso e l'ansia [60,61]. Tuttavia, riguardo al trattamento farmacologico dei pazienti con BPCO e depressione non è possibile trarre alcuna informazione conclusiva. Resta infatti

Tabella 7 Studi clinici sul trattamento cognitivo-comportamentale dei disturbi dell'umore nei pazienti con BPCO

\begin{tabular}{llll}
\hline Studi & Pazienti $(\mathrm{N})$ & \multicolumn{1}{c}{ Tipo di studio e intervento } & \multicolumn{1}{c}{ Risultati } \\
\hline $\begin{array}{l}\text { Gift AG et al., } \\
1992 \text { [80] }\end{array}$ & $\mathrm{N}=26$ & $\begin{array}{l}\text { Convenience sampling; assegnazione } \\
\text { randomizzata al gruppo di intervento } \\
\text { o di controllo; } 4 \text { sessioni di rilassamento } \\
\text { per 4 settimane }\end{array}$ & $\begin{array}{l}\text { Dispnea, ansia e sintomi respiratori } \\
\text { miglioravano nel gruppo di intervento; } \\
\text { nel gruppo di controllo le condizioni } \\
\text { rimanevano invariate o peggioravano }\end{array}$ \\
\hline $\begin{array}{lll}\text { Lisansky DP et al., } \\
1996 \text { [81] }\end{array}$ & $\mathrm{N}=8$ & $\begin{array}{l}\text { Studio descrittivo; convenience sampling; } \\
\text { programma educativo } \\
\text { cognitivo-comportamentale } \\
\text { per } 8 \text { settimane }\end{array}$ & $\begin{array}{l}\text { Significativa riduzione della disabilità } \\
\text { ai punteggi psicosociale e totale } \\
\text { della scala Sickness Impact Profile; } \\
\text { miglioramento della performance } \\
\text { cognitiva; nessun effetto su } \\
\text { depressione e ansia }\end{array}$
\end{tabular}

\begin{tabular}{|c|c|c|c|}
\hline $\begin{array}{l}\text { Eiser } \mathrm{N} \text { et al., } \\
1997 \text { [82] }\end{array}$ & $\begin{array}{l}\mathrm{N}=10 ; \mathrm{BPCO} \\
\text { moderata/ } \\
\text { severa }\end{array}$ & $\begin{array}{l}\text { Studio descrittivo; sessioni di } 90 \text { minuti } \\
\text { di psicoterapia cognitivo-comportamentale } \\
\text { per } 6 \text { settimane }\end{array}$ & $\begin{array}{l}\text { Miglioramento della tolleranza } \\
\text { all'esercizio fisico; nessun effetto } \\
\text { sull'ansia }\end{array}$ \\
\hline $\begin{array}{l}\text { Emery CF et al., } \\
1998 \text { [83] }\end{array}$ & $N=79$ & $\begin{array}{l}\text { Studio pre-test e post-test, assegnazione } \\
\text { randomizzata a } 3 \text { gruppi (esercizio, } \\
\text { gestione dell stress ed educazione; } \\
\text { gestione dello stress ed educazione; } \\
\text { controllo); } 10 \text { settimane }\end{array}$ & $\begin{array}{l}\text { Esercizio e gestione dello stress } \\
\text { miglioravano la capacità di esercizio, } \\
\text { l'ansia e la performance cognitiva; } \\
\text { esercizio, gestione dello stress ed } \\
\text { educazione miglioravano la depressione }\end{array}$ \\
\hline $\begin{array}{l}\text { Kunik ME et al., } \\
2001 \text { [84] }\end{array}$ & $N=56$ & $\begin{array}{l}\text { Studio in singolo cieco, randomizzato, } \\
\text { controllato; sessione di } 2 \text { ore di terapia } \\
\text { cognitivo-comportamentale seguita da } \\
\text { contatti settimanali per } 6 \text { settimane vs } \\
\text { sessione di } 2 \text { ore di educazione sulla } \\
\text { BPCO e contatti settimanali }\end{array}$ & $\begin{array}{l}\text { L'intervento cognitivo-comportamentale } \\
\text { riduceva depressione e ansia, ma non } \\
\text { aveva effetti sulla performance fisica }\end{array}$ \\
\hline $\begin{array}{l}\text { de Godoy DV et al., } \\
2003 \text { [85] }\end{array}$ & $N=33$ & $\begin{array}{l}\text { Studio in singolo cieco, randomizzato, } \\
\text { controllato; gruppo 1, } 24 \text { sessioni di esercizio } \\
\text { fisico e fisioterapia, } 12 \text { sessioni di intervento } \\
\text { psicologico e } 3 \text { sessioni educative; gruppo 2, } \\
\text { nessun intervento di psicoterapia }\end{array}$ & $\begin{array}{l}\text { L'intervento psicoterapico riduceva ansia } \\
\text { e depressione, ma non migliorava } \\
\text { la performance fisica }\end{array}$ \\
\hline $\begin{array}{l}\text { McGeoch GR et al., } \\
2006[86]\end{array}$ & $N=159$ & $\begin{array}{l}\text { Gruppo intervento: piano d'azione per la } \\
\text { gestione della BPCO; gruppo controllo: } \\
\text { trattamento usuale }\end{array}$ & $\begin{array}{l}\text { Nessuna differenza significativa } \\
\text { tra i due gruppi }\end{array}$ \\
\hline
\end{tabular}

Fonte: Putman-Casdorph H, et al. Heart Lung 2009;38(1):34-47. 
da colmare la lacuna di informazione sugli effetti a lungo termine del trattamento antidepressivo sul benessere generale e sulla sopravvivenza [62]. Inoltre, la maggior parte degli studi è stata condotta su casistiche numericamente limitate e la generalizzabilità dei risultati all'intera popolazione dei pazienti con BPCO non è pertanto possibile allo stato attuale delle conoscenze. Infine, la possibilità che alcuni farmaci antidepressivi di prima generazione possano avere effetti negativi sul controllo della ventilazione in pazienti con BPCO è stata descritta in letteratura [63], così come l'incremento del rischio di iponatremia da inappropriata secrezione di vasopressina in pazienti depressi trattati con inibitori del reuptake della serotonina [64-68].

Nella tabella 6 [6] sono riportati gli studi clinici sul trattamento farmacologico antidepressivo nei pazienti con BPCO [59,69-76].

\section{Trattamento non farmacologico (educazione, interventi comportamentali, riabilitazione ecc.)}

Fra i possibili trattamenti non farmacologici, gli interventi cognitivo-comportamentali e la riabilitazione respiratoria sono stati studiati riguardo alla possibile applicazione terapeutica in pazienti con BPCO e depressione/ansia.

Alcuni interventi di tipo cognitivo-comportamentale basati sul rilassamento muscolare o l'esercizio fisico associato a educazione sulla gestione dello stress hanno mostrato effetti benefici sull'ansia, sui sintomi depressivi e sulla performance cognitiva. Tuttavia, altri studi non hanno confermato tali risultati. Resta pertanto la necessità di trial randomizzati e controllati su popolazioni più ampie di

Tabella 8 Studi clinici sugli effetti esercitati dalla riabilitazione respiratoria sui disturbi dell'umore nei pazienti con BPCO

\begin{tabular}{|c|c|c|c|}
\hline Studi & Pazienti (N) & Tipo di studio e intervento & Risultati \\
\hline $\begin{array}{l}\text { Sassi-Dambron DE } \\
\text { et al., } 1995 \text { [87] }\end{array}$ & $N=89$ & $\begin{array}{l}\text { Trial randomizzato, controllato; } \\
\text { rilassamento muscolare, esercizi } \\
\text { respiratori, controllo del panico } \\
\text { o educazione alla salute }\end{array}$ & $\begin{array}{l}\text { Nessun effetto su parametri fisici, qualità } \\
\text { di vita, ansia o depressione }\end{array}$ \\
\hline $\begin{array}{l}\text { Ries AL et al., } \\
1995[88]\end{array}$ & $\begin{array}{l}\mathrm{N}=119 ; \text { pazienti } \\
\text { con BPCO stabile }\end{array}$ & Trial randomizzato, controllato & $\begin{array}{l}\text { Il gruppo in trattamento riabilitativo mostrava } \\
\text { un miglioramento significativo della tolleranza } \\
\text { all'esercizio, della dispnea e dell'autonomia. } \\
\text { Funzione respiratoria, depressione e qualità } \\
\text { di vita non si modificavano }\end{array}$ \\
\hline $\begin{array}{l}\text { Withers NJ et al., } \\
1999 \text { [89] }\end{array}$ & $\begin{array}{l}\mathrm{N}=95 ; \text { pazienti } \\
\text { con BPCO severa }\end{array}$ & $\begin{array}{l}\text { Studio longitudinale pre-test } \\
\text { e post-test }\end{array}$ & $\begin{array}{l}\text { Riduzione dei sintomi depressivi e ansiosi. } \\
\text { Il miglioramento dell'ansia contribuiva } \\
\text { a migliorare la capacità di esercizio }\end{array}$ \\
\hline $\begin{array}{l}\text { Kozora E et al., } \\
2002 \text { [90] }\end{array}$ & $\begin{array}{l}\mathrm{N}=80 ; 59 \text { con } \\
\text { BPCO e } 21 \\
\text { controlli }\end{array}$ & $\begin{array}{l}\text { Studio longitudinale pre-test } \\
\text { e post-test }\end{array}$ & $\begin{array}{l}\text { Il gruppo riabilitazione presentava un } \\
\text { miglioramento della sintomatologia depressiva } \\
\text { e della capacità di esercizio fisico. Evidente } \\
\text { miglioramento di alcune funzioni cognitive } \\
\text { (attenzione visiva, capacità verbale, abilità } \\
\text { visuo-spaziali) nei pazienti cognitivamente } \\
\text { compromessi afferenti al gruppo riabilitazione }\end{array}$ \\
\hline $\begin{array}{l}\text { Nguyen HQ et al., } \\
2005 \text { [91] }\end{array}$ & $\begin{array}{l}\mathrm{N}=100 ; \mathrm{BPCO} \\
\text { moderata/severa }\end{array}$ & $\begin{array}{l}\text { Trial randomizzato, controllato; } \\
\text { confronto fra } 3 \text { diverse modalità } \\
\text { di gestione della dispnea }\end{array}$ & $\begin{array}{l}\text { Miglioramento dei sintomi depressivi in tutti } \\
\text { e } 3 \text { i gruppi }\end{array}$ \\
\hline $\begin{array}{l}\text { Kayahan B et al., } \\
2006 \text { [92] }\end{array}$ & $\begin{array}{l}\mathrm{N}=45,26 \\
\text { pazienti in } \\
\text { riabilitazione } \\
\text { e } 19 \text { controlli }\end{array}$ & Trial clinico randomizzato & $\begin{array}{l}\text { Significativo miglioramento dell'ansia, della } \\
\text { dispnea, dello stato di salute generale nel } \\
\text { gruppo riabilitazione. Nessun effetto sui } \\
\text { sintomi depressivi }\end{array}$ \\
\hline $\begin{array}{l}\text { Guell R et al., } \\
2006 \text { [93] }\end{array}$ & $N=40$ & Trial randomizzato, controllato & $\begin{array}{l}\text { La riabilitazione polmonare può ridurre la } \\
\text { morbilità psicologica anche in assenza di } \\
\text { un intervento psicologico specifico }\end{array}$ \\
\hline $\begin{array}{l}\text { Alexopoulos GS } \\
\text { et al., } 2006 \text { [94] }\end{array}$ & $N=63$ & $\begin{array}{l}\text { Convenience sample di pazienti } \\
\text { consecutivamente ricoverati } \\
\text { in riabilitazione respiratoria }\end{array}$ & $\begin{array}{l}\text { Miglioramento dei sintomi depressivi nel } 51 \% \\
\text { dei casi e remissione nel } 39 \% \text { dei casi. } \\
\text { Miglioramento del grado di disabilità }\end{array}$ \\
\hline $\begin{array}{l}\text { Paz-Diaz H et al., } \\
2007 \text { [95] }\end{array}$ & $\begin{array}{l}\mathrm{N}=24 \text {; pazienti } \\
\text { con BPCO } \\
\text { severa }\end{array}$ & Trial randomizzato, controllato & $\begin{array}{l}\text { Miglioramento della severità della depressione, } \\
\text { dei sintomi depressivi, della dispnea e della } \\
\text { performance nelle attività della vita quotidiana }\end{array}$ \\
\hline
\end{tabular}

Fonte: Putman-Casdorph H, et al. Heart Lung 2009;38(1):34-47. 
pazienti con BPCO per valutare in maniera definitiva l'efficacia di questo tipo di interventi.

La riabilitazione respiratoria sembra invece esercitare effetti positivi anche sui sintomi depressivi e ansiosi, fornendo spesso un contributo importante al miglioramento dei sintomi respiratori e della performance fisica. I meccanismi attraverso cui l'esercizio contribuisce a migliorare i sintomi ansiosi e depressivi sono legati a fattori biologici (incremento di endorfine ed encefaline, aumento della disponibilità di neurotrasmettitori quali serotonina, dopamina, norepinefrina, riduzione dell'infiammazione) e comportamentali (partecipazione ad attività di gruppo piacevoli, aumento dei contatti sociali, miglior controllo della dispnea) [77].

Bisogna tenere presente che in studi precedenti la presenza di depressione favoriva l'interruzione precoce dei trattamenti riabilitativi peggiorando significativamente la costo-efficacia dell'intervento di riabilitazione respiratoria [78]. Tuttavia, proprio in virtù degli effetti positivi che la riabilitazione può esercitare anche sul tono dell'umore, oltre che sulla capacità di esercizio, la presenza di depressione non dovrebbe scoraggiare dall'intraprendere il percorso riabilitativo. Peraltro, è importante sottolineare come gli effetti dell'intervento riabilitativo su ansia, depressione e qualità di vita siano persistenti e ancora evidenziabili 24 mesi dopo il trattamento [79], suggerendo che, almeno allo stato attuale delle conoscenze, il trattamento riabilitativo possa rappresentare la migliore strategia terapeutica per il controllo dell'ansia e della depressione nei pazienti con BPCO.

Nella tabella 7 sono riportati gli studi clinici sul trattamento cognitivo-comportamentale dei disturbi dell'umore nei pazienti con BPCO [80-86]; nella tabella 8 sono riportati gli studi clinici sugli effetti esercitati dalla riabilitazione respiratoria sui disturbi dell'umore nei pazienti con BPCO [87-95].

\section{Bibliografia}

[1] Müller MB, Wurst W. Getting closer to affective disorders: the role of CRH receptor systems. Trends Mol Med 2004;10(8): $409-15$.

[2] Erhardt A, Ising M, Unschuld PG, Kern N, Lucae S, Pütz B, et al. Regulation of the hypothalamic-pituitary-adrenocortical system in patients with panic disorder. Neuropsychopharmacology 2006;31(11):2515-22.

[3] Elhwuegi AS. Central monoamines and their role in major depression. Prog Neuropsychopharmacol Biol Psychiatry 2004;28(3):435-51.

[4] Keller MB, Krystal JH, Hen R, Neumeister A, Simon NM. Untangling depression and anxiety: clinical challenges. J Clin Psychiatry 2005;66(11):1477-84.

[5] Barnes PJ, Celli BR. Systemic manifestations and comorbidities of COPD. Eur Respir J 2009;33(5):1165-85.

[6] Putman-Casdorph H, McCrone S. Chronic obstructive pulmonary disease, anxiety, and depression: state of the science. Heart Lung 2009;38(1):34-47.

[7] Cassem EH. Depression and anxiety secondary to medical illness. Psychiatr Clin North Am 1990;13(4):597-612.

[8] Smoller JW, Pollack MH, Otto MW, Rosenbaum JF, Kradin RL. Panic anxiety, dyspnea, and respiratory disease. Theoretical and clinical considerations. Am J Respir Crit Care Med 1996;154(1):6-17.

[9] van Ede L, Yzermans CJ, Brouwer HJ. Prevalence of depression in patients with chronic obstructive pulmonary disease: a systematic review. Thorax 1999;54(8):688-92.
[10] Cully JA, Graham DP, Stanley MA, Ferguson CJ, Sharafkhaneh A, Souchek J, et al. Quality of life in patients with chronic obstructive pulmonary disease and comorbid anxiety or depression. Psychosomatics 2006;47(4):312-9.

[11] Maurer J, Rebbapragada V, Borson S, Goldstein R, Kunik ME, Yohannes AM, et al., ACCP Workshop Panel on Anxiety and Depression in COPD. Anxiety and depression in COPD: current understanding, unanswered questions, and research needs. Chest 2008;134(4 Suppl):43S-56S.

[12] Levine J, Cole DP, Chengappa KN, Gershon S. Anxiety disorders and major depression, together or apart. Depress Anxiety 2001;14(2):94-104.

[13] Wells CE. Pseudodementia. Am J Psychiatry 1979;136(7): 895-900.

[14] Incalzi RA, Chiappini F, Fuso L, Torrice MP, Gemma A, Pistelli R. Predicting cognitive decline in patients with hypoxaemic COPD. Respir Med 1998;92(3):527-33.

[15] de Marco R, Accordini S, Cerveri I, Corsico A, Sunyer J, Neukirch F, et al., European Community Respiratory Health Survey Study Group. An international survey of chronic obstructive pulmonary disease in young adults according to GOLD stages. Thorax 2004;59(2):120-5.

[16] Norwood R. Prevalence and impact of depression in chronic obstructive pulmonary disease patients. Curr Opin Pulm Med 2006;12(2):113-7.

[17] Kunik ME, Roundy K, Veazey C, Souchek J, Richardson P, Wray NP, et al. Surprisingly high prevalence of anxiety and depression in chronic breathing disorders. Chest 2005;127(4):1205-11.

[18] Lacasse Y, Rousseau L, Maltais F. Prevalence of depressive symptoms and depression in patients with severe oxygendependent chronic obstructive pulmonary disease. J Cardiopulm Rehabil 2001;21(2):80-6.

[19] Di Marco F, Verga M, Reggente M, Maria Casanova F, Santus P, Blasi F, et al. Anxiety and depression in COPD patients: The roles of gender and disease severity. Respir Med 2006;100(10): $1767-74$

[20] van Manen JG, Bindels PJ, Dekker FW, IJzermans CJ, van der Zee JS, Schadé E. Risk of depression in patients with chronic obstructive pulmonary disease and its determinants. Thorax 2002;57(5):412-6.

[21] Gudmundsson G, Gislason T, Janson C, Lindberg E, Suppli Ulrik C, Brøndum E, et al. Depression, anxiety and health status after hospitalisation for COPD: a multicentre study in the Nordic countries. Respir Med 2006;100(1):87-93.

[22] Peppard PE, Szklo-Coxe M, Hla KM, Young T. Longitudinal association of sleep-related breathing disorder and depression. Arch Intern Med 2006;166(16):1709-15.

[23] Wagena EJ, Arrindell WA, Wouters EF, van Schayck CP. Are patients with COPD psychologically distressed? Eur Respir J 2005;26(2):242-8.

[24] Mikkelsen RL, Middelboe T, Pisinger C, Stage KB. Anxiety and depression in patients with chronic obstructive pulmonary disease (COPD). A review. Nord J Psychiatry 2004;58(1): 65-70.

[25] Wamboldt FS. Anxiety and depression in COPD: a call (and need) for further research. COPD 2005;2(2):199-201.

[26] van den Bemt L, Schermer T, Bor H, Smink R, van WeelBaumgarten $E$, Lucassen $P$, et al. The risk for depression comorbidity in patients with COPD. Chest 2009;135(1):108-14.

[27] Xu W, Collet JP, Shapiro S, Lin Y, Yang T, Platt RW, et al. Independent effect of depression and anxiety on chronic obstructive pulmonary disease exacerbations and hospitalizations. Am J Respir Crit Care Med 2008;178(9):913-20.

[28] Schneider C, Jick SS, Bothner U, Meier CR. COPD and the risk of depression. Chest 2010;137(2):341-7.

[29] Egede LE. Effect of comorbid chronic diseases on prevalence and odds of depression in adults with diabetes. Psychosom Med 2005;67(1):46-51. 
[30] American Psychiatric Association. DSM-IV-TR Diagnostic and Statistical Manual of Mental Disorders, Fourth Edition, Text Revision. Edizione Italiana. Milano: Masson, 2000.

[31] Rabe KF, Hurd S, Anzueto A, Barnes PJ, Buist SA, Calverley P, et al., Global Initiative for Chronic Obstructive Lung Disease. Global strategy for the diagnosis, management, and prevention of chronic obstructive pulmonary disease: GOLD executive summary. Am J Respir Crit Care Med 2007;176(6):532-55.

[32] Celli BR, MacNee W, ATS/ERS Task Force. Standards for the diagnosis and treatment of patients with COPD: a summary of the ATS/ERS position paper. Eur Respir J 2004;23(6):932-46.

[33] Julian LJ, Gregorich SE, Earnest G, Eisner MD, Chen H, Blanc PD, et al. Screening for depression in chronic obstructive pulmonary disease. COPD 2009;6(6):452-8.

[34] Spitzer RL, Williams JB, Kroenke K, Linzer M, deGruy 3rd FV, Hahn SR, et al. Utility of a new procedure for diagnosing mental disorders in primary care. The PRIME-MD 1000 study. JAMA 1994;272(22):1749-56.

[35] Kroenke K, Spitzer RL, Williams JB. The PHQ-9: validity of a brief depression severity measure. J Gen Intern Med 2001;16(9): 606-13.

[36] Weissman MM, Sholomskas D, Pottenger M, Prusoff BA, Locke BZ. Assessing depressive symptoms in five psychiatric populations: a validation study. Am J Epidemiol 1977;106(3):203-14.

[37] Yesavage JA, Brink TL, Rose TL, Lum O, Huang V, Adey M, et al. Development and validation of a geriatric depression screening scale: a preliminary report. J Psychiatr Res 1982-1983;17(1): 37-49.

[38] Zung WW. A Self-Rating Depression Scale. Arch Gen Psychiatry 1965;12:63-70.

[39] Beck AT, Ward CH, Mendelson M, Mock J, Erbaugh J. An inventory for measuring depression. Arch Gen Psychiatry 1961;4:561-71.

[40] Hamilton $M$. The Hamilton rating scale for depression. J Operat Psychiatry 1979;10(2):149-65.

[41] Zigmond AS, Snaith RP. The hospital anxiety and depression scale. Acta Psychiatr Scand 1983;67(6):361-70.

[42] Lovibond PF, Lovibond SH. The structure of negative emotional states: comparison of the Depression Anxiety Stress Scales (DASS) with the Beck Depression and Anxiety Inventories. Behav Res Ther 1995;33(3):335-43.

[43] Hamilton $M$. The assessment of anxiety states by rating. $\mathrm{Br} \mathrm{J}$ Med Psychol 1959;32(1):50-5.

[44] Spielberger CD, Gorsuch RL, Lushene RE. Manual for the StateTrait Anxiety Inventory. Palo Alto, CA: Consulting Psychologists Press; 1970.

[45] Yohannes AM, Baldwin RC, Connolly MJ. Depression and anxiety in elderly outpatients with chronic obstructive pulmonary disease: prevalence, and validation of the BASDEC screening questionnaire. Int J Geriatr Psychiatry 2000;15(12):1090-6.

[46] Jones PW, Baveystock CM, Littlejohns P. Relationships between general health measured with the sickness impact profile and respiratory symptoms, physiological measures, and mood in patients with chronic airflow limitation. Am Rev Respir Dis 1989;140(6):1538-43.

[47] Frierson RL. Suicide attempts by the old and the very old. Arch Intern Med 1991;151(1):141-4.

[48] Yohannes AM, Baldwin RC, Connolly MJ. Prevalence of subthreshold depression in elderly patients with chronic obstructive pulmonary disease. Int J Geriatr Psychiatry 2003;18(5): 412-6.

[49] Cluley S, Cochrane GM. Psychological disorder in asthma is associated with poor control and poor adherence to inhaled steroids. Respir Med 2001;95(1):37-9.

[50] Bellia V, Catalano F, Scichilone N, Incalzi RA, Spatafora M, Vergani $C$, et al. Sleep disorders in the elderly with and without chronic airflow obstruction: the SARA study. Sleep 2003;26(3): 318-23.
[51] Stapleton RD, Nielsen EL, Engelberg RA, Patrick DL, Curtis JR. Association of depression and life-sustaining treatment preferences in patients with COPD. Chest 2005;127(1):328-34.

[52] Wagena EJ, van der Meer RM, Ostelo RJ, Jacobs JE, van Schayck CP. The efficacy of smoking cessation strategies in people with chronic obstructive pulmonary disease: results from a systematic review. Respir Med 2004;98(9):805-15.

[53] Wagena EJ, Kant I, van Amelsvoort LG, Wouters EF, van Schayck CP, Swaen GM. Risk of depression and anxiety in employees with chronic bronchitis: the modifying effect of cigarette smoking. Psychosom Med 2004;66(5):729-34.

[54] Omachi TA, Katz PP, Yelin EH, Gregorich SE, Iribarren C, Blanc PD, et al. Depression and health-related quality of life in chronic obstructive pulmonary disease. Am J Med 2009;122(8). p. 778.e9-e15.

[55] Yohannes AM, Willgoss TG, Baldwin RC, Connolly MJ. Depression and anxiety in chronic heart failure and chronic obstructive pulmonary disease: prevalence, relevance, clinical implications and management principles. Int J Geriatr Psychiatry 2010; 25(12):1209-21.

[56] Ng TP, Niti M, Tan WC, Cao Z, Ong KC, Eng P. Depressive symptoms and chronic obstructive pulmonary disease: effect on mortality, hospital readmission, symptom burden, functional status, and quality of life. Arch Intern Med 2007;167(1):60-7.

[57] Fournier JC, DeRubeis RJ, Hollon SD, Dimidjian S, Amsterdam JD, Shelton RC, et al. Antidepressant drug effects and depression severity: a patient-level meta-analysis. JAMA 2010;303(1): 47-53.

[58] Tashkin D, Kanner R, Bailey W, Buist S, Anderson P, Nides M, et al. Smoking cessation in patients with chronic obstructive pulmonary disease: a double-blind, placebo-controlled, randomised trial. Lancet 2001;357(9268):1571-5.

[59] Smoller JW, Pollack MH, Systrom D, Kradin RL. Sertraline effects on dyspnea in patients with obstructive airways disease. Psychosomatics 1998;39(1):24-9.

[60] Roundy K, Cully JA, Stanley MA, Veazey C, Souchek J, Wray NP, et al. Are Anxiety and Depression Addressed in Primary Care Patients With Chronic Obstructive Pulmonary Disease? A Chart Review. Prim Care Companion J Clin Psychiatry 2005;7(5): 213-8.

[61] Versiani M, Moreno R, Ramakers-van Moorsel CJ, Schutte AJ, Comparative Efficacy Antidepressants Study Group. Comparison of the effects of mirtazapine and fluoxetine in severely depressed patients. CNS Drugs 2005;19(2):137-46.

[62] Raji MA. On depression, antidepressant medications, and resuscitation preferences in COPD patients. Chest 2006;129(1):211.

[63] Greenberg HE, Scharf SM, Green H. Nortriptyline-induced depression of ventilatory control in a patient with chronic obstructive pulmonary disease. Am Rev Respir Dis 1993; 147(5):1303-5.

[64] Koelkebeck K, Domschke K, Zwanzger P, Hetzel G, Lang D, Arolt $\mathrm{V}$. A case of non-SIADH-induced hyponatremia in depression after treatment with reboxetine. World J Biol Psychiatry 2009;10(4 Pt 2):609-11.

[65] Ishii T, Ohtake T, Yasu T, Kadotani Y, Hayashi S, Oka M, et al. A rare case of combined syndrome of inappropriate antidiuretic hormone secretion and Fanconi syndrome in an elderly woman. Am J Kidney Dis 2006;48(1):155-8.

[66] Twardowschy CA, Bertolucci CB, Gracia Cde M, Brandão MA. Severe hyponatremia and the syndrome of inappropriate secretion of antidiuretic hormone (SIADH) associated with fluoxetine: case report. Arq Neuropsiquiatr 2006;64(1):142-5.

[67] Bouman WP, Pinner G, Johnson H. Incidence of selective serotonin reuptake inhibitor (SSRI) induced hyponatraemia due to the syndrome of inappropriate antidiuretic hormone (SIADH) secretion in the elderly. Int J Geriatr Psychiatry 1998;13(1): $12-5$. 
[68] Liu BA, Mittmann N, Knowles SR, Shear NH. Hyponatremia and the syndrome of inappropriate secretion of antidiuretic hormone associated with the use of selective serotonin reuptake inhibitors: a review of spontaneous reports. CMAJ 1996;155(5): 519-27.

[69] Borson S, McDonald GJ, Gayle T, Deffebach M, Lakshminarayan $S$, VanTuinen C. Improvement in mood, physical symptoms, and function with nortriptyline for depression in patients with chronic obstructive pulmonary disease. Psychosomatics 1992;33(2):190-201.

[70] Argyropoulou P, Patakas D, Koukou A, Vasiliadis P, Georgopoulos D. Buspirone effect on breathlessness and exercise performance in patients with chronic obstructive pulmonary disease. Respiration 1993;60(4):216-20.

[71] Singh NP, Despars JA, Stansbury DW, Avalos K, Light RW. Effects of buspirone on anxiety levels and exercise tolerance in patients with chronic airflow obstruction and mild anxiety. Chest 1993;103(3):800-4.

[72] Papp LA, Weiss JR, Greenberg HE, Rifkin A, Scharf SM, Gorman $J M$, et al. Sertraline for chronic obstructive pulmonary disease and comorbid anxiety and mood disorders. Am J Psychiatry 1995;152(10):1531.

[73] Evans M, Hammond M, Wilson K, Lye M, Copeland J. Placebocontrolled treatment trial of depression in elderly physically ill patients. Int J Geriatr Psychiatry 1997;12(8):817-24.

[74] Yohannes AM, Connolly MJ, Baldwin RC. A feasibility study of antidepressant drug therapy in depressed elderly patients with chronic obstructive pulmonary disease. Int J Geriatr Psychiatry 2001;16(5):451-4.

[75] Lacasse Y, Beaudoin L, Rousseau L, Maltais F. Randomized trial of paroxetine in end-stage COPD. Monaldi Arch Chest Dis 2004;61(3):140-7.

[76] Eiser N, Harte R, Spiros K, Phillips C, Isaac MT. Effect of treating depression on quality-of-life and exercise tolerance in severe COPD. COPD 2005;2(2):233-41.

[77] Emery CF, Green MR, Suh S. Neuropsychiatric function in chronic lung disease: the role of pulmonary rehabilitation. Respir Care 2008;53(9):1208-16.

[78] Garrod R, Marshall J, Barley E, Jones PW. Predictors of success and failure in pulmonary rehabilitation. Eur Respir J 2006; 27(4):788-94.

[79] Godoy RF, Teixeira PJ, Becker Júnior B, Michelli M, Godoy DV. Long-term repercussions of a pulmonary rehabilitation program on the indices of anxiety, depression, quality of life and physical performance in patients with COPD. J Bras Pneumol 2009;35(2): $129-36$.

[80] Gift AG, Moore T, Soeken K. Relaxation to reduce dyspnea and anxiety in COPD patients. Nurs Res 1992;41(4):242-6.

[81] Lisansky DP, Clough DH. A cognitive-behavioral self-help educational program for patients with COPD. A pilot study. Psychother Psychosom 1996;65(2):97-101.
[82] Eiser N, West C, Evans S, Jeffers A, Quirk F. Effects of psychotherapy in moderately severe COPD: a pilot study. Eur Respir J 1997;10(7):1581-4.

[83] Emery CF, Schein RL, Hauck ER, MacIntyre NR. Psychological and cognitive outcomes of a randomized trial of exercise among patients with chronic obstructive pulmonary disease. Health Psychol 1998;17(3):232-40.

[84] Kunik ME, Braun U, Stanley MA, Wristers K, Molinari V, Stoebner $D$, et al. One session cognitive behavioural therapy for elderly patients with chronic obstructive pulmonary disease. Psychol Med 2001;31(4):717-23.

[85] de Godoy DV, de Godoy RF. A randomized controlled trial of the effect of psychotherapy on anxiety and depression in chronic obstructive pulmonary disease. Arch Phys Med Rehabil 2003; 84(8):1154-7.

[86] McGeoch GR, Willsman KJ, Dowson CA, Town GI, Frampton CM, McCartin FJ, et al. Self-management plans in the primary care of patients with chronic obstructive pulmonary disease. Respirology 2006;11(5):611-8.

[87] Sassi-Dambron DE, Eakin EG, Ries AL, Kaplan RM. Treatment of dyspnea in COPD. A controlled clinical trial of dyspnea management strategies. Chest 1995;107(3):724-9.

[88] Ries AL, Kaplan RM, Limberg TM, Prewitt LM. Effects of pulmonary rehabilitation on physiologic and psychosocial outcomes in patients with chronic obstructive pulmonary disease. Ann Intern Med 1995;122(11):823-32.

[89] Withers NJ, Rudkin ST, White RJ. Anxiety and depression in severe chronic obstructive pulmonary disease: the effects of pulmonary rehabilitation. J Cardiopulm Rehabil 1999;19(6):362-5.

[90] Kozora E, Tran ZV, Make B. Neurobehavioral improvement after brief rehabilitation in patients with chronic obstructive pulmonary disease. J Cardiopulm Rehabil 2002;22(6):426-30.

[91] Nguyen HQ, Carrieri-Kohlman V. Dyspnea self-management in patients with chronic obstructive pulmonary disease: moderating effects of depressed mood. Psychosomatics 2005;46(5): 402-10.

[92] Kayahan B, Karapolat H, Atýntoprak E, Atasever A, Oztürk O. Psychological outcomes of an outpatient pulmonary rehabilitation program in patients with chronic obstructive pulmonary disease. Respir Med 2006;100(6):1050-7.

[93] Güell R, Resqueti V, Sangenis M, Morante F, Martorell B, Casan P, et al. Impact of pulmonary rehabilitation on psychosocial morbidity in patients with severe COPD. Chest 2006;129(4):899-904.

[94] Alexopoulos GS, Sirey JA, Raue PJ, Kanellopoulos D, Clark TE, Novitch RS. Outcomes of depressed patients undergoing inpatient pulmonary rehabilitation. Am J Geriatr Psychiatry 2006; 14(5):466-75.

[95] Paz-Díaz H, Montes de Oca M, López JM, Celli BR. Pulmonary rehabilitation improves depression, anxiety, dyspnea and health status in patients with COPD. Am J Phys Med Rehabil 2007;86(1): 30-6. 


\section{BPCO e deficit cognitivo}

\section{Fabrizio Boni, Andrea Corsonello, Domenico Panuccio}

\section{Messaggi chiave}

- La presenza di deficit cognitivo è un problema molto frequente nei pazienti con BPCO, in particolare nei pazienti ipossiemici in cui la prevalenza supera il $40 \%$.

- Il deficit cognitivo dei pazienti con BPCO può interessare numerose aree neuropsicologiche (abilità costruttive, funzione esecutiva, memoria verbale, abilità visuo-spaziali, produzione verbale, ragionamento logico-deduttivo).

- Sul piano clinico, il deficit cognitivo può determinare in pazienti con BPCO una limitazione significativa dell'indipendenza nelle attività della vita quotidiana, difficoltà nell'uso degli inhaler, ridotta aderenza alla terapia e conseguente incremento del rischio di riacutizzazioni, limitazione della comunicazione e dei contatti sociali, isolamento e, di conseguenza, maggiore rapidità di declino cognitivo.
- Il deficit della funzione costruttivo-esecutiva può avere significato prognostico in pazienti anziani con BPCO ipossiemica.

- La terapia farmacologica del deficit cognitivo nei pazienti con BPCO si basa sostanzialmente sul trattamento corretto della patologia di base e delle comorbilità che possono favorirla. Per i pazienti con BPCO particolare rilevanza può avere il miglioramento della qualità dell'ossigenoterapia, con particolare attenzione alla prevenzione di episodi di desaturazione notturna.

- Gli inhaler dovrebbero sempre essere scelti tenendo in consideraizone l'eventuale presenza di deficit cognitivo. Pazienti e caregiver dovrebbero sempre essere attentamente istruiti sul loro utilizzo corretto.

- Il training cognitivo non sembra in grado di modificare la performance cognitiva in pazienti con BPCO ipossiemica. Tuttavia, un'approccio multidisciplinare comprendente riabilitazione respiratoria, counseling nutrizionale, educazione, ottimizzazione dell'ossigenoterapia può contribuire a ridurre la progressione del deficit cognitivo.

\section{Introduzione}

Sebbene sia stata considerata per molto tempo una malattia respiratoria, la BPCO è oggi considerata a tutti gli effetti una malattia sistemica per i suoi forti legami fisiopatologici e clinici con numerose altre patologie, quali le malattie cardiovascolari, la malnutrizione, l'osteoporosi, la depressione, il deterioramento cognitivo e altre manifestazioni sistemiche [1-4]. Infiammazione sistemica, ipercatabolismo e ipercoagulabilità rappresentano i principali meccanismi fisiopatologici che sottendono gran parte degli effetti non respiratori della
BPCO [1-7]. Tra questi effetti, particolare considerazione va riservata al deficit cognitivo, sia come indicatore di severità della BPCO sia come marcatore prognostico.

L'associazione tra BPCO e deficit cognitivo è nota da oltre 30 anni $[8,9]$, ma le sue implicazioni cliniche sono state per molto tempo sottostimate; solo negli ultimi 15 anni sono stati chiaramente individuati i domini cognitivi più frequentemente alterati in pazienti con BPCO e il significato prognostico di tali deficit. In tabella 1 sono riportate le tappe principali dell'evoluzione delle conoscenze sul tema [8-14]. 
Tabella 1 Evoluzione delle evidenze scientifiche sul deficit cognitivo nei pazienti con BPCO.

\begin{tabular}{|c|c|}
\hline Studio & Evidenza \\
\hline Krop HD et al., 1973 [8] & $\begin{array}{l}\text { Molti domini della funzione cognitiva possono essere alterati nei pazienti con BPCO. } \\
\text { Dopo } 4 \text { settimane di ossigenoterapia continuativa si verifica un cospicuo miglioramento } \\
\text { delle capacità percettive e dei tempi di reazione, ma non della performance intellettiva } \\
\text { generale, del ragionamento deduttivo e della memoria verbale }\end{array}$ \\
\hline Grant I et al., 1982 [9] & $\begin{array}{l}\text { Il } 42 \% \text { dei pazienti arruolati nel trial "Nocturnal Oxygen Therapy" presentavano un deficit } \\
\text { cognitivo riguardante il pensiero astratto e le capacità motorie semplici e complesse }\end{array}$ \\
\hline $\begin{array}{l}\text { Antonelli Incalzi R et al., } \\
1993 \text { [10] }\end{array}$ & $\begin{array}{l}\text { Il deficit cognitivo dei pazienti con BPCO riguarda prevalentemente la memoria } \\
\text { e la produzione verbale. Tale deficit differisce in maniera significativa da quello } \\
\text { osservabile nelle demenze degenerative o vascolari }\end{array}$ \\
\hline $\begin{array}{l}\text { Antonelli Incalzi R et al., } \\
1998 \text { [11] }\end{array}$ & La depressione può predire la comparsa di deficit cognitivo in pazienti con BPCO \\
\hline $\begin{array}{l}\text { Antonelli Incalzi R et al., } \\
2003 \text { [12] }\end{array}$ & $\begin{array}{l}\text { L'ipossiemia in assenza di ipercapnia è associata a una moderata alterazione delle funzioni } \\
\text { cognitive non evidenziabile nei pazienti con BPCO ipossiemica. Tuttavia, i dati SPECT } \\
\text { indicano un'evidente alterazione del metabolismo cerebrale anche in assenza di ipossiemia }\end{array}$ \\
\hline $\begin{array}{l}\text { Antonelli Incalzi R et al., } \\
2004 \text { [13] }\end{array}$ & $\begin{array}{l}\text { Il deficit cognitivo dei pazienti con BPCO è in qualche misura simile a quello osservabile } \\
\text { nei pazienti con sindrome delle apnee ostruttive (deficit del pensiero deduttivo e induttivo } \\
\text { e della funzione verbale) }\end{array}$ \\
\hline $\begin{array}{l}\text { Antonelli Incalzi R et al., } \\
2006 \text { [14] }\end{array}$ & $\begin{array}{l}\text { Circa un terzo dei pazienti con BPCO ipossiemica presenta un'alterazione della performance } \\
\text { nella copia di disegno e nei test di memoria verbale. Un deficit nella copia di disegno } \\
\text { con punti di riferimento predice la mortalità in tali pazienti }\end{array}$ \\
\hline
\end{tabular}

Fonte: Corsonello A, et al. Curr Respir Med Rev 2007;3:107-15.

\section{Aspetti epidemiologici}

La prevalenza di deficit cognitivo in pazienti con BPCO varia in relazione al setting e alla metodologia di selezione delle casistiche. Per esempio, in pazienti anziani ospedalizzati per riacutizzazione di BPCO la prevalenza di deficit cognitivo è pari al $25,8 \%$, simile quindi a quella osservata in pazienti con diagnosi principale di scompenso cardiaco (28\%) o diabete (23\%) [15], patologie molto più frequentemente studiate riguardo ai loro effetti neuropsicologici. In pazienti con BPCO ipossiemica la prevalenza è del 42\% [9] e il deficit cognitivo riguarda prevalentemente la funzione costruttiva (per esempio la destrezza manuale) e la memoria verbale secondaria [14]. La durata di malattia e la presenza di ipercapnia sono associate a una più severa compromissione della memoria e della produzione verbale [10]. Inoltre, numerose altre comorbilità, quali ipertensione arteriosa, sindrome delle apnee ostruttive, diabete, depressione, fibrillazione atriale e malnutrizione possono peggiorare la performance cognitiva in pazienti con BPCO [13,16-20]. Tra le comorbilità in grado di influenzare la performance cognitiva dei pazienti con BPCO, la depressione sembra giocare un ruolo particolarmente rilevante, potendo sia simulare un disturbo della funzione cognitiva sia peggiorarne l'evoluzione $[11,21]$.

\section{Diagnosi e diagnosi differenziale}

Il problema diagnostico più importante riguardo al deficit cognitivo dei pazienti con BPCO è la diagnosi differenziale con la demenza. In generale, quest'ultima si caratterizza per un disturbo della memoria associato a deficit di almeno un altro dominio cognitivo in grado di limitare l'indipendenza funzionale nelle attività quotidiane [22]. Tale condizione non è facile da individuare in pazienti con BPCO, dal momento che la stessa sintomatologia respiratoria tipica della malattia è in grado di per sé di limitare le capacità fisiche rendendo di difficile interpretazione il legame tra deficit cognitivo e performance fisica.

Il deficit cognitivo può essere definito come una performance subnormale in uno o più domini cognitivi. In generale, tale disturbo è molto frequente nei pazienti anziani, ma anche in questo caso esistono fattori che possono rendere difficile la diagnosi: la depressione e la limitazione dei contatti sociali possono contribuire a complicarne l'identificazione favorendo espressioni cliniche estremamente variabili e prevenendone la percezione da parte di familiari e/o caregiver [23,24]. Nei pazienti con BPCO, il deficit riguarda classicamente la memoria verbale secondaria e la produzione verbale $[10,25]$, potendo tuttavia interessare anche l'attenzione, l'apprendimento e il ragionamento logico [26]. Sul piano clinico, il deficit della memoria e della produzione verbale riveste particolare rilevanza per il fatto che un difetto nell'immagazinamento delle informazioni e nel riconoscimento e richiamo delle stesse si associa a una ridotta aderenza alle terapie prescritte e, di conseguenza, può determinare un maggior rischio di riacutizzazione e ospedalizzazione in pazienti con BPCO [25]. Tuttavia, anche altri disturbi cognitivi ben definiti possono avere un significato clinico estremamente importante in questo tipo di pazienti (tabella 2): tra questi, il deficit della funzione esecutiva è associato a una maggiore difficoltà nell'uso degli inhaler per il trattamento a lungo termine della BPCO [27].

Il pattern neuropsicologico della BPCO può essere ulteriormente complicato dalla contemporanea presenza di 
Tabella 2 Implicazioni cliniche dei deficit cognitivi in pazienti con BPCO.

\begin{tabular}{|c|c|c|}
\hline Deficit & Definizione & Significato clinico \\
\hline Abilità costruttive & $\begin{array}{l}\text { Ridotta capacità di costruire figure bi e tridimensionali } \\
\text { a partire da elementi mono e bidimensionali }\end{array}$ & $\begin{array}{l}\text { La perdita di destrezza può limitare } \\
\text { in maniera significativa l'indipendenza } \\
\text { nelle attività della vita quotidiana }\end{array}$ \\
\hline Funzione esecutiva & $\begin{array}{l}\text { Deficit in alcune capacità cognitive (abilità nell'iniziare } \\
\text { e fermare un'azione, controllare e modificare } \\
\text { il comportamento quando necessario, } \\
\text { adattamento alle situazioni) che controllano } \\
\text { e regolano altre abilità e comportamenti }\end{array}$ & Difficoltà nell'uso degli inhaler \\
\hline Memoria verbale & $\begin{array}{l}\text { Deficit della capacità di immagazzinare nuove } \\
\text { informazioni verbali, di riconoscere e rievocare } \\
\text { informazioni acquisite }\end{array}$ & $\begin{array}{l}\text { Ridotta aderenza alla terapia } \\
\text { e conseguente incremento } \\
\text { del rischio di riacutizzazioni }\end{array}$ \\
\hline Abilità visuo-spaziali & $\begin{array}{l}\text { Deficit delle capacità visive (identificazione } \\
\text { di figure incomplete, riconoscimento di oggetti } \\
\text { uniti tra loro, organizzazione di blocchi in disegni) }\end{array}$ & $\begin{array}{l}\text { Ridotta capacità di eseguire compiti } \\
\text { complessi che presuppongono una forte } \\
\text { integrazione delle funzioni visiva } \\
\text { e motoria }\end{array}$ \\
\hline Produzione verbale & Ridotto patrimonio di lessico e concetti verbali & $\begin{array}{l}\text { Limitazione della comunicazione e dei } \\
\text { contatti sociali, isolamento, maggiore } \\
\text { rapidità di declino cognitivo }\end{array}$ \\
\hline $\begin{array}{l}\text { Ragionamento } \\
\text { deduttivo }\end{array}$ & $\begin{array}{l}\text { Ridotta capacità di trarre una conclusione } \\
\text { sulla base di una premessa }\end{array}$ & $\begin{array}{l}\text { Riduzione delle capacita di ragionamento } \\
\text { e conseguente perdita di indipendenza } \\
\text { nelle attività strumentali della vita } \\
\text { quotidiana che presuppongono integrità } \\
\text { cognitiva (per esempio gestione } \\
\text { del denaro) }\end{array}$ \\
\hline
\end{tabular}

Fonte: Corsonello A, et al. Curr Respir Med Rev 2007;3:107-15.

una sindrome delle apnee ostruttive (OSAS), combinazione piuttosto frequente nell'anziano [28]. Le OSAS determinano un disturbo cognitivo di tipo frontale con una componente comportamentale piuttosto marcata (alterata manipolazione delle informazioni e pianificazione, perdita di flessibilità, difficoltà nel mantenere attenzione e motivazione, instabilità emotiva) [29]. Sul piano cognitivo, le OSAS si caratterizzano per una compromissione sia del ragionamento deduttivo sia di quello induttivo, nonché delle abilità costruttive [13]. Per tale motivo, la presenza di un deficit della funzione costruttiva in pazienti con BPCO dovrebbe sempre spingere a escludere la presenza concomitante di una OSAS. Quest'ultimo aspetto di diagnostica differenziale non è privo di implicazioni, anche sul piano terapeutico. Infatti, i deficit cognitivi associati a OSAS generalmente rispondono al trattamento con C-PAP (Continous Positive Airway Pressure), mentre il deficit cognitivo dei pazienti con BPCO risponde solo parzialmente a un'ossigenoterapia ottimale [11].

Sul piano diagnostico, occorre sottolineare come non siano attualmente disponibili ottimali strumenti di screening per il deficit cognitivo nei pazienti con BPCO. Infatti, gli strumenti attualmente disponibili sono stati sviluppati e validati con lo scopo di identificare i pazienti con demenza, il cui pattern neuropsicologico differisce in maniera significativa, come sopra descritto, da quello dei pazienti con BPCO. Per tale motivo, anche il più diffuso strumento di screening per i disturbi cognitivi, il Mini Mental State Examination (MMSE) [30], non ha sensibilità e specificità sufficienti per individuare i pazienti con BPCO e deficit cognitivo [31]. La presenza di un deficit cognitivo andrebbe sospettata anche in presenza di compromissione di alcune funzioni esplorate dalla scala di valutazione per le attività strumentali della vita quotidiana (IADL) [31] fortemente dipendenti dall'integrità cognitiva (quali, per esempio, la perdita di autonomia nella gestione del denaro e/o dei farmaci). Tuttavia, mentre la combinazione di MMSE e IADL è in grado di escludere con discreta precisione la presenza di un deficit cognitivo, la contemporanea presenza di deficit cognitivo al MMSE e compromissione in almeno una IADL non consente di porre con certezza la diagnosi di disturbo cognitivo in pazienti con BPCO. In questo caso andrebbe eseguito un approfondimento specialistico neuropsicologico attraverso strumenti più complessi (per esempio la Mental Deterioration Battery) [31].

\section{Valutazione di gravità}

Allo stato attuale, non sono disponibili informazioni specifiche riguardo alla valutazione della severità del deficit cognitivo per i pazienti con BPCO. Tuttavia, dati recenti indicano che la severità delle alterazioni della funzione attentiva, dell'apprendimento e del ragionamento logico aumenti in funzione dell'età e della severità della patologia respiratoria [26], mentre la severità della compromissione della memoria e della produzione verbale aumenta in funzione della durata di malattia e della presenza di ipercapnia [10]. Inoltre, è verosimile che un deficit interessante alcune aree neuropsicologiche specifiche piuttosto che altre possa essere considerato un indicatore indiretto di severità. È il caso del deficit 
della funzione prassico-esecutiva per il quale sono stati dimostrati un ruolo prognostico negativo e una correlazione con la ridotta modulazione del sistema simpatico in pazienti con BPCO ipossiemica [14,32,33]. Infine, vista la relazione esistente tra deficit cognitivo e disabilità in pazienti con BPCO [34], una valutazione complessiva dell'impatto clinico determinato dal deficit cognitivo dovrebbe comunque sempre essere completata con una valutazione dell'autonomia nello svolgimento delle attività della vita quotidiana.

\section{Prognosi}

Allo stato attuale le informazioni sul significato prognostico del deficit cognitivo nei pazienti con BPCO sono limitate. Tuttavia, come già accennato, un deficit della funzione costruttivo-esecutiva può avere significato prognostico in pazienti anziani con BPCO ipossiemica. Infatti, il deficit nella copia di disegno con punti di riferimento (test nel quale al paziente viene richiesto di completare un disegno a partire da alcuni elementi di riferimento e che può essere considerato un sistema di valutazione sia della funzione costruttiva ssia di quella esecutiva) è risultato essere un fattore di rischio indipendente per mortalità in pazienti con BPCO ipossiemica [14]. Se questo deficit rappresenti un marcatore di severità della BPCO o influisca sulla prognosi in maniera indipendente rimane da stabilire. Tuttavia, un deficit di questo tipo può essere legato ad alterazioni funzionali di alcune aree cerebrali sottocorticali e, in particolare, dell'insula destra che è sede del controllo neuroautonomico del bilancio simpatovagale [33]. In questo senso, la recente dimostrazione che la modulazione simpatica si riduce all'aumentare della severità della patologia e che la performance alla copia di disegno con punti di riferimento correla con la ridotta modulazione simpatica in pazienti con BPCO, suggerisce che entrambi gli elementi possano essere considerati veri e propri indicatori di severità della malattia [32]. In ogni caso, l'alterazione di aree subcorticali spesso si associa a bradicinesia in diverse condizioni cliniche [35] e in tal modo accelera l'evoluzione verso la disabilità, che rappresenta un fattore prognostico negativo universale [36]. Infine, nel paziente anziano la disfunzione esecutiva predice la perdita di indipendenza fisica e contribuisce a spiegare gli effetti negativi della perdita di memoria verbale sullo stato funzionale [37]. Per tale motivo, il deficit nella copia di disegno con punti di riferimento potrebbe essere molto più che un indicatore della severità della BPCO, potendo rappresentare anche un marcatore di funzione cognitiva in grado di predire la prognosi indipendentemente dalla patologia di base [14,38].

\section{Trattamento farmacologico}

La terapia farmacologica del deficit cognitivo nei pazienti con BPCO si basa sostanzialmente sul trattamento corretto della patologia di base. Nello specifico, l'identificazione di un deficit cognitivo dovrebbe innanzitutto spingere alla ricerca di possibili fattori patogenetici, specie le comorbilità più frequentemente responsabili di disturbi della funzione cognitiva, allo scopo di ottimizzarne il trattamento. Per i pazienti con BPCO particolare rilevanza può avere il miglioramento della qualità dell'ossigenoterapia, con attenzione soprattutto alla prevenzione di episodi di desaturazione notturna. Inoltre, proprio per l'impatto negativo esercitato dal deficit cognitivo, è molto importante una rivalutazione periodica dell'aderenza alla terapia farmacologica per la BPCO, così come un'attenta selezione delle misure terapeutiche adottate in base alle abilità residue del paziente. Gli inhaler dovrebbero sempre essere scelti considerando questo problema e i pazienti dovrebbero sempre essere attentamente istruiti sul loro utilizzo corretto [36].

\section{Trattamento non farmacologico (educazione, interventi comportamentali, riabilitazione ecc.)}

Un obiettivo terapeutico ambizioso potrebbe essere rappresentato da interventi non farmacologici in grado di bloccare o invertire la progressione del deterioramento cognitivo in pazienti con BPCO. Tra questi, il training cognitivo ha dimostrato di essere in grado di migliorare la memoria e lo stato psicosociale in soggetti con declino cognitivo età-correlato [39], nonché lo stato funzionale in pazienti con malattia di Alzheimer [39]. Inoltre, un intervento di terapia occupazionale è in grado di migliorare lo stato funzionale in pazienti con demenza, riducendo anche lo stress dei caregiver [40].

Il training cognitivo è stato recentemente valutato in un trial clinico randomizzato in cui i pazienti arruolati ricevevano un trattamento standardizzato multidimensionale (comprendente terapia farmacologica, educazione sanitaria, selezione degli inhaler in base alle capacità del paziente, riabilitazione respiratoria, counseling nutrizionale, ossigenoterapia e visite periodiche di controllo) con o senza training cognitivo (stimolazione dell'attenzione, dell'apprendimento e del ragionamento logico-deduttivo). Sebbene non sia stato possibile dimostrare alcun significativo beneficio del training cognitivo rispetto al solo percorso standardizzato multidimensionale, è stato possibile osservare come lo stato cognitivo non si modificasse in maniera significativa nei 6 mesi di osservazione. Tale risultato andrebbe interpretato positivamente, suggerendo che un approccio terapeutico standardizzato multidisciplinare sia in grado almeno di rallentare la progressione del deterioramento cognitivo in pazienti con BPCO [41].

\section{Bibliografia}

[1] Gan WQ, Man SF, Senthilselvan A, Sin DD. Association between chronic obstructive pulmonary disease and systemic inflammation: a systematic review and a meta-analysis. Thorax 2004; 59(7):574-80.

[2] Andreassen $\mathrm{H}$, Vestbo J. Chronic obstructive pulmonary disease as a systemic disease: an epidemiological perspective. Eur Respir J Suppl 2003;46:2s-4s.

[3] Agustí AG, Noguera A, Sauleda J, Sala E, Pons J, Busquets X. Systemic effects of chronic obstructive pulmonary disease. Eur Respir J 2003;21(2):347-60.

[4] Wouters EF, Creutzberg EC, Schols AM. Systemic effects in COPD. Chest 2002;121(5 Suppl):127S-30S.

[5] Sevenoaks MJ, Stockley RA. Chronic Obstructive Pulmonary Disease, inflammation and co-morbidity-a common inflammatory phenotype? Respir Res 2006;7:70.

[6] Alessandri C, Basili S, Violi F, Ferroni P, Gazzaniga PP, Cordova C. Hypercoagulability state in patients with chronic obstructive 
pulmonary disease. Chronic Obstructive Bronchitis and Haemostasis Group. Thromb Haemost 1994;72(3):343-6.

[7] Ashitani J, Mukae H, Arimura Y, Matsukura S. Elevated plasma procoagulant and fibrinolytic markers in patients with chronic obstructive pulmonary disease. Intern Med 2002;41(3):181-5.

[8] Krop HD, Block AJ, Cohen E. Neuropsychologic effects of continuous oxygen therapy in chronic obstructive pulmonary disease. Chest 1973;64(3):317-22.

[9] Grant I, Heaton RK, McSweeny AJ, Adams KM, Timms RM. Neuropsychologic findings in hypoxemic chronic obstructive pulmonary disease. Arch Intern Med 1982;142(8):1470-6.

[10] Incalzi RA, Gemma A, Marra C, Muzzolon R, Capparella O, Carbonin P. Chronic obstructive pulmonary disease. An original model of cognitive decline. Am Rev Respir Dis 1993;148(2): 418-24.

[11] Incalzi RA, Chiappini F, Fuso L, Torrice MP, Gemma A, Pistelli R. Predicting cognitive decline in patients with hypoxaemic COPD. Respir Med 1998;92(3):527-33.

[12] Antonelli Incalzi R, Marra C, Giordano A, Calcagni ML, Cappa A, Basso $S$, et al. Cognitive impairment in chronic obstructive pulmonary disease-a neuropsychological and spect study. J Neurol 2003;250(3):325-32.

[13] Antonelli Incalzi R, Marra C, Salvigni BL, Petrone A, Gemma A, Selvaggio $D$, et al. Does cognitive dysfunction conform to a distinctive pattern in obstructive sleep apnea syndrome? J Sleep Res 2004;13(1):79-86.

[14] Antonelli-Incalzi R, Corsonello A, Pedone C, Trojano L, Acanfora $D$, Spada A, et al. Drawing impairment predicts mortality in severe COPD. Chest 2006;130(6):1687-94.

[15] Corsonello A, Pedone C, Carosella L, Corica F, Mazzei B, Incalzi RA, Gruppo Italiano di Farmacovigilanza nell'Anziano Investigators. Health status in older hospitalized patients with cancer or non-neoplastic chronic diseases. BMC Geriatr 2005;5:10.

[16] Qiu C, Winblad B, Fratiglioni L. The age-dependent relation of blood pressure to cognitive function and dementia. Lancet Neurol 2005;4(8):487-99.

[17] Cukierman T, Gerstein HC, Williamson JD. Cognitive decline and dementia in diabetes-systematic overview of prospective observational studies. Diabetologia 2005;48(12):2460-9.

[18] Alexopoulos GS. Depression in the elderly. Lancet 2005; 365(9475):1961-70.

[19] Chatap G, Giraud K, Vincent JP. Atrial fibrillation in the elderly: facts and management. Drugs Aging 2002;19(11):819-46.

[20] Salerno-Kennedy $R$, Cashman KD. The role of nutrition in dementia: an overview. J Br Menopause Soc 2006;12(2):44-8.

[21] Wells CE. Pseudodementia. Am J Psychiatry 1979;136(7): 895-900.

[22] American Psychiatric Association. Diagnostic and Statistical Manual of Mental Disorders, $4^{\text {th }}$ Ed., Washington, DC: American Psychiatric Association; 1994.

[23] Bartolini M, Coccia M, Luzzi S, Provinciali L, Ceravolo MG. Motivational symptoms of depression mask preclinical Alzheimer's disease in elderly subjects. Dement Geriatr Cogn Disord 2005;19(1):31-6.

[24] Trouton A, Stewart R, Prince M. Does social activity influence the accuracy of subjective memory deficit? Findings from a British community survey. J Am Geriatr Soc 2006;54(7):1108-13.
[25] Incalzi RA, Gemma A, Marra C, Capparella O, Fuso L, Carbonin P. Verbal memory impairment in COPD: its mechanisms and clinical relevance. Chest 1997;112(6):1506-13.

[26] Klein M, Gauggel S, Sachs G, Pohl W. Impact of chronic obstructive pulmonary disease (COPD) on attention functions. Respir Med 2010;104(1):52-60.

[27] Allen SC, Jain M, Ragab S, Malik N. Acquisition and short-term retention of inhaler techniques require intact executive function in elderly subjects. Age Ageing 2003;32(3):299-302.

[28] Durán J, Esnaola S, Rubio R, Iztueta A. Obstructive sleep apneahypopnea and related clinical features in a population-based sample of subjects aged 30 to 70 yr. Am J Respir Crit Care Med 2001;163(3 Pt 1):685-9.

[29] Beebe DW, Gozal D. Obstructive sleep apnea and the prefrontal cortex: towards a comprehensive model linking nocturnal upper airway obstruction to daytime cognitive and behavioral deficits. J Sleep Res 2002;11(1):1-16.

[30] Folstein MF, Folstein SE, McHugh PR. "Mini-mental state". A practical method for grading the cognitive state of patients for the clinician. J Psychiatr Res 1975;12(3):189-98.

[31] Antonelli-Incalzi R, Corsonello A, Trojano L, Pedone C, Acanfora D, Spada A, et al. Screening of cognitive impairment in chronic obstructive pulmonary disease. Dement Geriatr Cogn Disord 2007;23(4):264-70.

[32] Antonelli Incalzi R, Corsonello A, Trojano L, Pedone C, Acanfora D, Spada A, et al. Heart rate variability and drawing impairment in hypoxemic COPD. Brain Cogn 2009;70(1): 163-70.

[33] Royall DR. Double jeopardy. Chest 2006;130(6):1636-8.

[34] Antonelli-Incalzi R, Corsonello A, Trojano L, Acanfora D, Spada $\mathrm{A}$, Izzo 0 , et al. Correlation between cognitive impairment and dependence in hypoxemic COPD. J Clin Exp Neuropsychol 2008;30(2):141-50.

[35] Zadikoff C, Lang AE. Apraxia in movement disorders. Brain 2005;128(Pt 7):1480-97.

[36] Rockwood K, Mitnitski A, Song X, Steen B, Skoog I. Long-term risks of death and institutionalization of elderly people in relation to deficit accumulation at age 70 . J Am Geriatr Soc 2006;54(6):975-9.

[37] Royall DR, Chiodo LK, Polk MJ. Executive dyscontrol in normal aging: normative data, factor structure, and clinical correlates. Curr Neurol Neurosci Rep 2003;3(6):487-93.

[38] Corsonello A, Pedone C, Antonelli Incalzi R. Clinical and prognostic implications of cognitive dysfunction and depression in COPD. Curr Respir Med Rev 2007;3:107-15.

[39] Willis SL, Tennstedt SL, Marsiske M, Ball K, Elias J, Koepke KM, et al., ACTIVE Study Group. Long-term effects of cognitive training on everyday functional outcomes in older adults. JAMA 2006;296(23):2805-14.

[40] Graff MJ, Vernooij-Dassen MJ, Thijssen M, Dekker J, Hoefnagels WH, Rikkert MG. Community based occupational therapy for patients with dementia and their care givers: randomised controlled trial. BMJ 2006;333(7580):1196.

[41] Incalzi RA, Corsonello A, Trojano L, Pedone C, Acanfora D, Spada $A$, et al. Cognitive training is ineffective in hypoxemic COPD: a six-month randomized controlled trial. Rejuvenation Res 2008;11(1):239-50. 


\section{BPCO e osteoporosi}

\section{Marco Grandi, Carla Sacchetti, Paolo Montanari, Giovanni Scanelli}

Messaggi chiave

- Molti fattori di rischio per l'insorgenza dell'osteoporosi e delle sue complicanze fratturative sono comuni con la broncopneumopatia cronica ostruttiva (BPCO), specie se grave.

- La prevalenza dell'osteoporosi nella BPCO è elevata, fino al $30 \%$ dei pazienti, ma sottostimata da molti clinici.

- La gravità dell'insufficienza respiratoria e, quindi, gli stadi GOLD più avanzati correlano con un aumentato rischio di fratture osteoporotiche.

- Il trattamento steroideo sistemico, anche a posologie minimali, aumenta significativamente il rischio di fratture osteoporotiche.

- Il trattamento steroideo inalatorio può avere un ruolo di aumento del rischio solo per posologie giornaliere molto elevate.

- Soprattutto nei pazienti con BPCO occorre incentivare le misure di prevenzione dell'osteoporosi, fra queste un'adeguata supplementazione di calcio e di vitamina D.

- I bisfosfonati rappresentano la terapia di scelta dell'osteoporosi BPCO-correlata.

\section{Introduzione}

L'osteoporosi è una malattia sistemica a eziologia multifattoriale caratterizzata da una ridotta massa ossea, con deterioramento della microarchitettura del tessuto osseo che conduce a un'aumentata fragilità con conseguente aumento del rischio di frattura [1].
L'Organizzazione Mondiale della Sanità (OMS) e la National Osteoporosis Foundation [2], così come i National Institutes of Health $(\mathrm{NIH})$ [3], hanno definito i criteri densitometrici per la diagnosi di osteoporosi mediante l'uso del t-score, vale a dire la differenza, espressa in deviazioni standard (DS), tra valore osservato e valore medio dei giovani adulti. Si fondano sulla valutazione della densità minerale ossea eseguita a livello del rachide lombare e del femore con un densitometro a doppio raggio $X$. Poiché è stato osservato che il rischio di frattura inizia ad aumentare in maniera esponenziale per valori densitometrici di t-score $\leq 2,5 \mathrm{DS}$, questo limite rappresenta la soglia per diagnosticare la presenza di osteoporosi. Secondo l'OMS, nell'interpretare i risultati della densità minerale ossea (BMD) si conviene di adottare le definizioni seguenti:

- la $B M D$ normale è definita per un t-score compreso fra $+2,5$ e $-1,0$ (la BMD del paziente è, cioè, fra 2,5 DS sopra la media di un giovane adulto e 1 DS sotto la media di un giovane adulto);

- l'osteopenia (bassa BMD) è associata a un t-score compreso tra $-1,0$ e $-2,5$ DS;

- l'osteoporosi è caratterizzata da un t-score inferiore a 2,5 DS;

- per osteoporosi conclamata si intende un valore di t-score inferiore a -2,5 DS con la contemporanea presenza di una o più fratture da fragilità.

Questa nosografia, pur essendo stata pensata per le donne in menopausa, è tuttavia ancora accettata per tutte le altre condizioni etiologiche.

L'osteoporosi primitiva comprende la forma postmenopausale, quella senile e l'idiopatica giovanile.

L'osteoporosi secondaria riconosce un'eziologia multifattoriale e può essere la conseguenza di condizioni patologiche o di trattamenti farmacologici, dettagliatamente sintetizzati in tabella 1. Fra le condizioni patologiche, benché ancora sottovalutata, vi è la broncopneumopatia cronica ostruttiva (BPCO), la cui negativa interferenza con il metabolismo osseo 
Tabella 1 Patologie e farmaci che posso associarsi a osteoporosi.

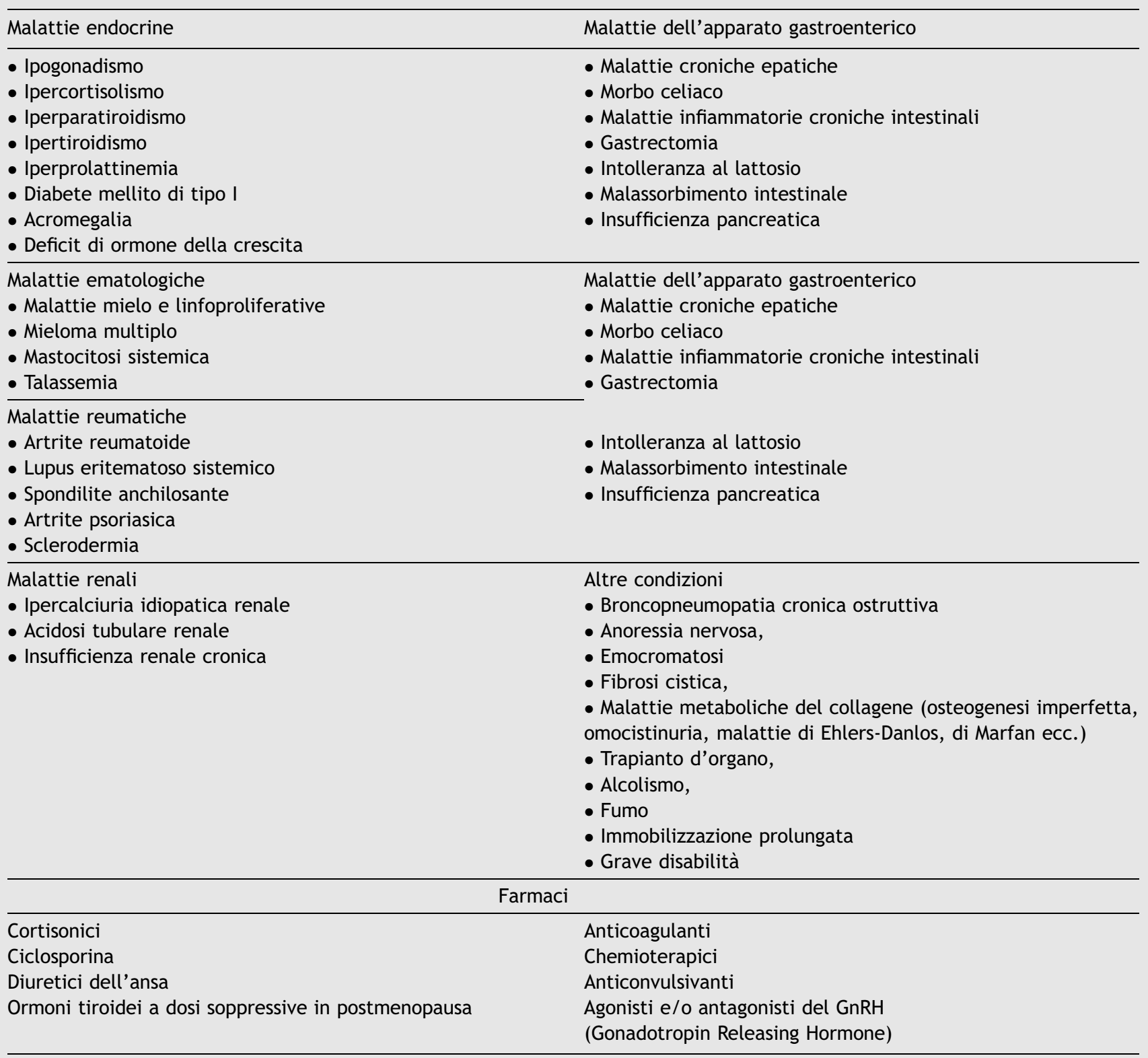

si esplica di per sé e anche attraverso gli effetti negativi di un eventuale trattamento farmacologico.

Tra i fattori di rischio per osteoporosi, molti sono comuni ai pazienti affetti da BPCO, in particolare se grave. I fattori di rischio per osteoporosi non modificabili sono:

- età;

- sesso femminile;

- anamnesi familiare positiva.

I fattori di rischio per osteoporosi potenzialmente modificabili sono:

- nutrizione (scarso apporto di calcio e vitamina D; peso corporeo e indice di massa corporea molto ridotti);

- stile di vita (fumo: > 20 sigarette al giorno; abuso di alcol; scarsa attività fisica, immobilizzazione);

- fattori endocrini (menopausa precoce; amenorrea);
- farmaci (corticosteroidi, levotiroxina, anticonvulsivanti, eparina; farmaci antiretrovirali; farmaci che inducono ipogonadismo)

\section{Aspetti epidemiologici ed eziopatogenetici}

Numerosi studi hanno valutato la prevalenza dell'osteopenia e dell'osteoporosi nella BPCO [4-7]. Se ci si limita alla sola osteoporosi, i dati della letteratura la stimano presente nel 20-32\% dei pazienti con BPCO rispetto al 3-12\% dei soggetti "sani", mentre per quanto riguarda l'osteopenia la percentuale supera il $60 \%$.

La prevalenza della patologia ossea è elevata anche nei maschi e tale condizione aggrava, ovviamente, anche la capacità respiratoria dei pazienti, limitandone la compliance 
BPCO

Gravità dell' ipossia/ipercapnia
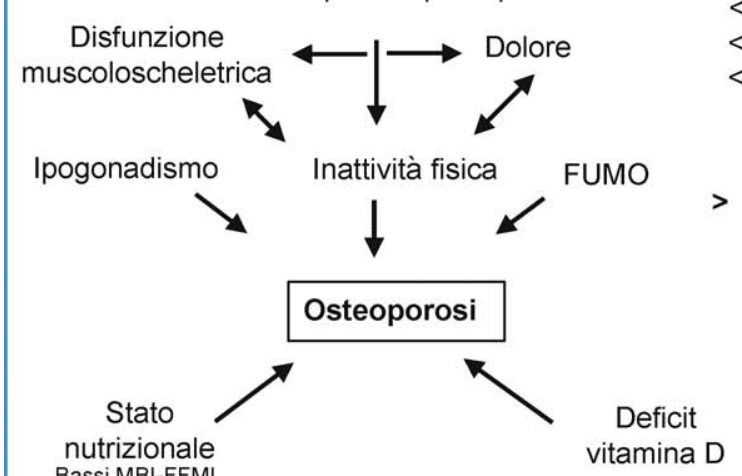

Bassi MBI-FFMI

vitamina D
STEROIDE

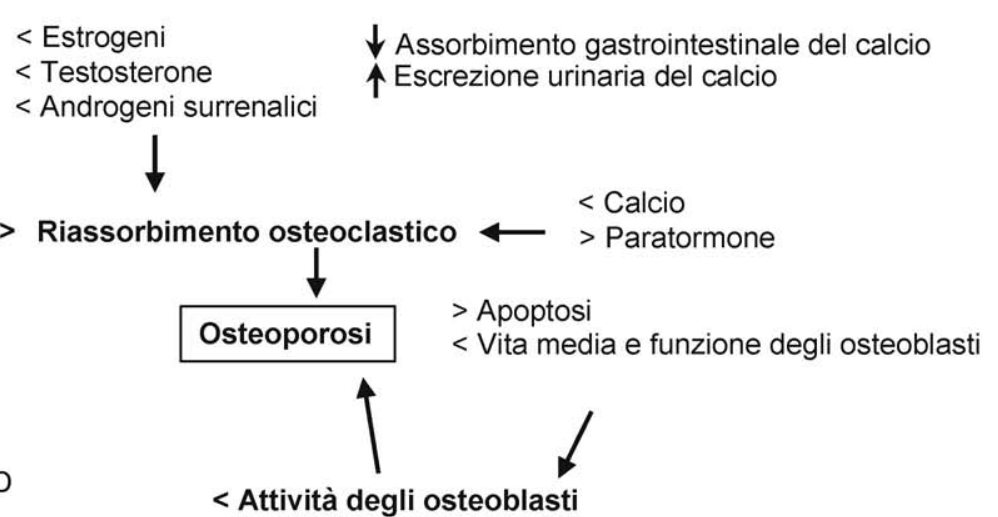

Legenda: $\mathrm{BMI}=$ Body Mass Index; FFMI = Fat Free Mass Index .

Figura 1 Aspetti fisiopatologici associabili all'osteoporosi BPCO-correlata e al trattamento steroideo. Legenda: $\mathrm{BMI}=$ Body Mass Index; FFMI = Fat Free Mass Index.

toracica. Un recente studio collaborativo italiano, lo studio EOLO [8], ha valutato in oltre 3.000 pazienti ambulatoriali la presenza di fratture vertebrali correlandola con la gravità della BPCO. Una o più fratture vertebrali sono state riscontrate in oltre 1.200 di questi pazienti, 724 uomini $(41,7 \%)$ e 512 donne $(41,2 \%)$, correlabili in termini statistici con le seguenti variabili cliniche:

- precedenti fratture dopo i 50 anni (OR 1,83; IC 95\% 1,3592,464);

- indice di massa corporea $(\mathrm{BMI})<26,7 \mathrm{~kg} / \mathrm{m}^{2}$ (OR 1, 323; IC 95\% 1,137-1,540);

- gravità della BPCO:

o lieve (OR 1,00),

- moderata (OR 1,123; IC 95\% 0,920-1,370),

- grave (OR 1,333; IC 95\% 1,063-1,671),

- molto grave (OR 1,934; IC 95\% 1,342-2,787);

- terapia:

o con glucocorticoidi orali (OR 1,590; IC 95\% 1,042-2,426),

o con steroidi inalatori (OR 1,352: IC 95\% 1,085-1,685),

di associazione (OR 1,525, IC 95\% 1,110-2,094).

Il dato dell'elevato rischio di fratture osteoporotiche nei pazienti con BPCO è stato recentemente confermato da un altro contributo non italiano [9] i cui risultati evidenziano in questi soggetti un rischio di frattura che può essere, a seconda della loro situazione clinica, 6 volte maggiore nel range di età 55-65 anni e addirittura di 11 volte più elevato in età superiore a 65 anni. Tali rilevi meritano un opportuno approfondimento dei principali aspetti fisiopatologici correlabili all'osteoporosi nella BPCO e al suo trattamento (fig. 1).

\section{Fumo}

L'esatto meccanismo attraverso il quale il fumo interagisce negativamente sull'equilibrio osseo non è ancora del tutto elucidato. Per quanto riguarda la nicotina, lavori ormai datati [10-13], prospettano un suo effetto tossico diretto sugli osteoblasti con conseguente riduzione dell'attività osteoblastica, cui si aggiunge una possibile riduzione dell'assorbimento intestinale del calcio ulteriormente aggravante le alterazioni ossee.

\section{Gravità del deficit respiratorio}

Sono numerosi i contributi che correlano la gravità dell'insufficienza respiratoria, misurata o no con l'utilizzo degli stadi GOLD [14], con la gravità dell'osteoporosi e il conseguente rischio fratturativo [5,15-17]. A titolo di esempio si riportano $i$ dati estremamente esemplificativi di un gruppo olandese [9] che, oltre a confermare il dato sulla correlazione fra gravità del deficit respiratorio e rischio di fratture osteoporotiche significativamente aumentato, specifica anche che l'età deve considerarsi fattore di rischio indipendente. In questo studio, l'odds ratio per rischio di frattura è così riportato in base all'età e allo stadio GOLD:

- stadio GOLD I e II

o età 55-65 anni, OR 2,53; IC 95\% 0,398-13,900

o età > 65 anni, OR 5,50, IC 9\% 1,047-28,879

- stadio GOLD III

o età 55-65 anni, OR 2,17; IC 95\% 0,514-9,183

o età > 65 anni, OR 5,73; IC 95\% 1,481-22,245

- stadio GOLD IV

o età 55-65 anni, OR 3,78; IC 95\% 1,173-12,247

o età > 65 anni, OR 3,16; IC 95\% 1,009-9,951.

$\grave{E}$ intuitivo che con il progressivo deterioramento della funzione respiratoria compaiano anche tutti gli altri danni multiorgano che contribuiscono nel loro insieme al peggioramento del trofismo osseo.

\section{Stato nutrizionale}

Similmente a quanto avviene per l'osteoporosi non BPCOcorrelata $[18,19]$, anche nei pazienti con BPCO il sovrappeso e l'obesità esercitano un ruolo protettivo per l'insorgenza del danno osseo [9], al pari di quanto avviene, almeno negli stadi avanzati ma non in quelli precoci [20], per la funzione respiratoria e per la mortalità ("the obesity paradox"). Al 
contrario, i pazienti con cachessia, valutati sia con il classico indice di massa corporea (BMI) sia con il Fat Free Mass Index (FFMI), così come presentano outcome peggiori in ambito respiratorio [21], hanno anche un rischio significativamente maggiore per la comparsa di osteoporosi [21,22]; in uno studio [9] tale rischio risulta essere addirittura 12 volte superiore rispetto ai coetanei "sani". Si ipotizza che uno dei maggiori meccanismi patogenetici coinvolti sia l'aumentata produzione di citochine, quali l'IL-6 e il TNF-alfa [22], induttrici dell'atrofia muscoloscheletrica e del breakdown proteico $[23,24]$. Tale condizione sarebbe quindi una delle espressioni dello stato di "infiammazione cronica" che caratterizza la BPCO [22].

\section{Ipogonadismo}

Plurime osservazioni segnalano l'aumentata incidenza di un deficit funzionale gonadico nei pazienti con BPCO [25-28]. Ne deriva una riduzione dello stimolo anabolico possibile sia nel sesso femminile (aggravando l'osteoporosi postmenopausale) sia nel maschio, ovviamente predisponente all'osteoporosi. In aggiuntiva, l'ipogonadismo è condizione favorente il deficit dell'efficienza muscolare [26,27] considerato di per sé influente sull'insorgenza di fratture.

\section{Deficit di vitamina D}

Ove la si indaghi, tale situazione risulta presente in oltre il $90 \%$ dei pazienti con BPCO e, così come per altri parametri, questo deficit e il conseguente iperparatiroidismo secondario non correlato all'assunzione di steroidi (potenzialmente in grado di determinarli) sono correlabili al degrado funzionale respiratorio [29] e risultano essere tra i fattori maggiormente predisponenti all'insorgenza dell'osteopenia/osteoporosi.

\section{Trattamento steroideo}

Com'è noto, la somministrazione prolungata dei glucocorticoidi, deprimendo l'attività osteoblastica a favore di quella osteoclastica, induce osteoporosi con meccanismi quali:

- l'inibizione della replicazione della linea osteoblastica e la diminuzione della genesi di nuove cellule osteoblastiche [30];

- l'induzione della morte e/o apoptosi delle medesime [31]. Si aggiungono:

- l'inibizione della sintesi di matrice ossea per un'azione negativa sul collagene [32];

- l'attivazione di molteplici fattori di crescita locale che ne amplificano l'effetto [33].

In associazione a ciò i glucocorticoidi determinano:

- una riduzione dell'assorbimento intestinale del calcio e una sua maggior eliminazione renale [34];

- una negativa interferenza con l'ormone della crescita e con la funzione dell'asse ipotalamo-ipofiso-gonadale che, unitamente alle alterazioni del metabolismo della vitamina D e all'attivazione secondaria dell'ormone paratiroideo (PTH), giustifica ampiamente la loro azione osteopenizzante specie a livello dell'osso trabecolare [35].

Il danno osseo inizia molto precocemente e raggiunge il suo massimo entro i primi 6-12 mesi dall'inizio del trattamento. Il rischio di frattura è dose-dipendente e durata-dipendente essendo possibile per posologie di $2,5 \mathrm{mg}$ di prednisone o equivalenti [36]. Dosi di 7,5 mg/die e oltre aumentano di 4 volte il rischio di fratture vertebrali e di 2 volte quello di fratture del femore [37].

Argomento assai controverso è quello relativo al supposto danno osseo dei glucocorticoidi inalatori. Per quanto riguarda il loro uso nei pazienti con asma, la più completa revisione dell'argomento è stata compiuta pochi anni orsono dall'American College of Chest Physicians e dall'American College of Allergy, Asthma, and Immunology, che concludono per una sostanziale non interferenza. E ciò vale tanto nei bambini, dei quali non influenzano negativamente la crescita, quanto negli adulti, nei quali solo posologie giornaliere particolarmente elevate possono alterare la BMD.

Molto minori le certezze quando si affronti il medesimo argomento nei pazienti con BPCO. L'eterogeneità clinica dei pazienti, i numerosi fattori influenti (il fumo in primis), le casistiche spesso statisticamente insufficienti, i differenti preparati e le diverse posologie utilizzati sono tutti elementi che impediscono di trarre conclusioni definitive.

Anche se vi sono evidenze circa i potenziali rischi ossei di questi preparati inalatori, va sottolineato che la maggior parte di queste fanno riferimento a end-point derivati quali le alterazioni dei marcatori del metabolismo osseo o la BMD e non all'incidenza di fratture.

L'unica revisione Cochrane che ha affrontato l'argomento - seppur limitandolo, per quanto riguarda la BPCO, ai soli pazienti con BPCO lieve, conclude così: "At conventional doses of inhaled steroid there appears to be no significant effect on bone metabolism as measured by osteocalcin, bone mineral density, or clinical fracture rate [...] The evidence available for this review suggest that inhaled steroids in currently recommended doses incur little risk of osteoporosis and fractures over the medium term (months to a few years)" [38]. Posizione, questa, poi confermata da altri contributi [39] anche più recenti [40] che sottolineano un rischio aumentato solo per dosi di steroidi inalatori significativamente superiori a $1.000 \mu \mathrm{g} /$ die di beclometasone o equivalenti (fig. 2).

Per quanto attiene a eventuali differenze fra i vari preparati a disposizione, i dati della letteratura non sono sufficienti a dirimere il quesito, in quanto non vi sono studi di confronto che li comprendano tutti. Per quelli disponibili, emerge ancora una volta l'importanza della posologia più che del tipo di preparato utilizzato $[41,42]$.

Si può quindi concludere con la certezza che il trattamento steroideo sistemico, anche a posologie minimali, può significativamente aumentare il rischio di fratture osteoporotiche, mentre per quanto riguarda i preparati inalatori tale rischio, seppur notevolmente inferiore a quello indotto dalla somministrazione per via generale, è correlato alla posologia $(>1.000 \mu \mathrm{g} /$ die) più che al tipo di preparato impiegato.

\section{Diagnosi}

L'interesse di tale problematica non riguarda tanto la già documentata e specificata rassegna degli accertamenti utili e necessari per la diagnosi di osteoporosi, facilmente ricavabili dalle numerose e qualificate segnalazioni della letteratura $[2,3,43,44]$, quanto piuttosto quando e con quale frequenza eseguirli in pazienti con BPCO. 


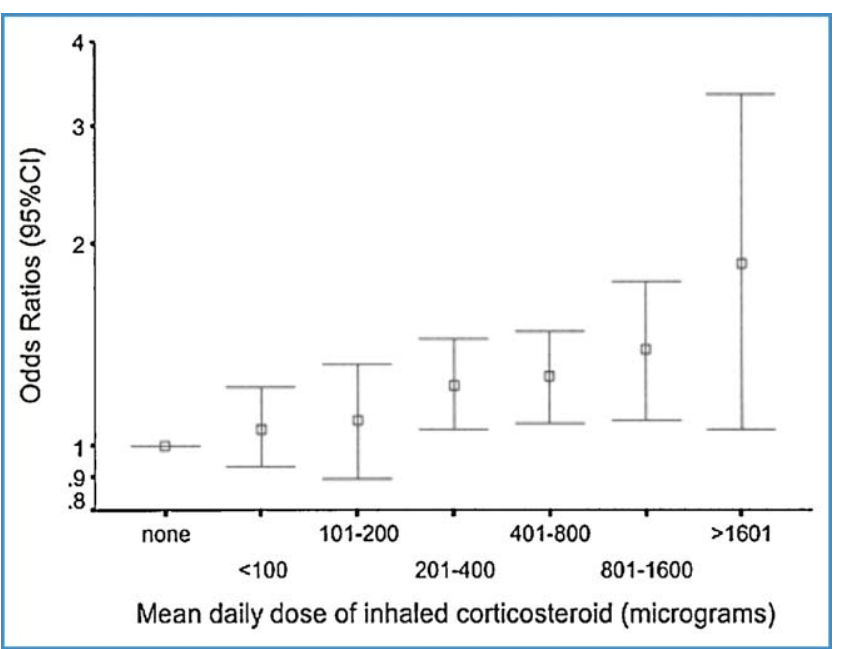

Figura 2 Odds ratio per fratture del femore in relazione alla posologia degli steroidi inalatori.

Fonte: Weatherall M, et al. Clin Exp Allergy 2008;38(9):1451-8.

A parere di chi scrive, ove si assumesse la politica del trattamento "comunque", seppure graduato nei suoi interventi a seconda della gravità e delle circostanze cliniche della patologia respiratoria, la valutazione diagnostica dell'osteoporosi potrebbe essere limitata ai soli casi nei quali emergessero segni o sintomi compatibili con il sospetto di una complicanza della malattia ossea e questo perché tale comparsa richiederebbe una variazione terapeutica.

Ove invece si volessero seguire pedissequamente le linee guida, poiché la BPCO rappresenta un documentato fattore di rischio per l'insorgenza dell'osteoporosi, potrebbe essere giustificato che nelle donne in menopausa (che dovrebbero comunque seguire il consigliato iter diagnostico), ma soprattutto negli uomini di età superiore a 55 anni, specie se in stadio GOLD superiore al II, fosse verificata la BMD a livello del rachide lombare e del femore con densitometro a doppio raggio $\mathrm{X}$ o a livello calcaneare con le metodiche ultrasonografiche.

Un suggerimento per la pratica clinica quotidiana potrebbe essere quello della richiesta della valutazione morfometrica delle vertebre dorso-lombari, aggiuntiva a quella del parenchima polmonare, nella prima occasione nella quale il paziente con BPCO necessiti di un'indagine radiografica del polmone.

Negativa per costo/beneficio, a meno che non la si voglia utilizzare a scopo di ricerca, la valutazione dei marcatori di formazione o riassorbimento osseo, che non aggiungerebbe nulla alle decisioni terapeutiche.

\section{Aspetti di prevenzione, farmacologica e non farmacologica, e di terapia}

La prevenzione dell'osteoporosi consiste nell'applicazione delle misure atte a impedirne o rallentarne la comparsa e si attua mediante la correzione dei fattori di rischio.

Interventi non farmacologici (dieta, attività fisica) ed eliminazione di fattori di rischio modificabili (fumo, igiene di vita) devono essere consigliati a tutti.
Una dieta adeguata con giusto apporto di vitamina $D$, ma anche equilibrata con corretto apporto di proteine, carboidrati e lipidi, è utile per ottimizzare il picco di massa ossea in età giovanile.

Così come specificato nelle ultime linee guida italiane [44], l'introito medio giornaliero di calcio nella popolazione è insufficiente, specie in età senile. A queste carenze alimentari è ascritto un largo eccesso di osteoporosi, fratture osteoporotiche e morbilità generale. Nel caso in cui l'apporto di calcio e vitamina D sia insufficiente, supplementi sono in grado di ridurre significativamente il rischio di frattura. Le dosi consigliabili di supplementi di calcio vanno commisurate al grado di carenza alimentare (in generale tra 500 e $1.000 \mathrm{mg} / \mathrm{die}$ ). La supplementazione con calcio (specie se si superano i $1.000 \mathrm{mg} / \mathrm{die}$ ) è controindicata in presenza di condizioni associate a rischio di ipercalcemia.

La vitamina $D$ può essere somministrata a dosi giornaliere di 400-800 U/die o a dosi settimanali di 2.800-6.000 U o a dosi di 100.000-300.000 U ogni 4-6 mesi, oppure a dosi uniche di 400.000-600.000 U/anno. L'uso dei metaboliti attivi della vitamina $D$ non è indicato per la prevenzione dell'ipovitaminosi D, presenta maggiori rischi di ipercalcemia e ipercalciuria ed è oggi giustificato solo in casi selezionati (grave insufficienza renale o epatica, grave malassorbimento intestinale, ipoparatiroidismo).

Per quanto attiene all'attività fisica, la raccomandazione di praticarla "al minimo" (camminare per più di 30 minuti al di), ove ciò sia consentito dalle condizioni respiratorie, appare condivisibile per l'effetto sul rischio di caduta e per quello indiretto sui livelli di vitamina D, malgrado l'inadeguatezza della documentazione di efficacia sulla massa ossea.

L'utilizzo precoce di farmaci antiriassorbitivi a scopo preventivo non è quasi mai giustificata. A partire dal 2000 si sono succedute numerose linee guida e/o raccomandazioni delle più autorevoli società scientifiche internazionali che hanno messo a punto la condotta da seguire per la prevenzione primaria e secondaria dei danni ossei da glucocorticoidi [45] ed è a queste, oltre che a contributi importanti anche di autori italiani [46], a cui ci rifaremo.

Tutte le linee guida raccomandano misure generali da adottare in tutti i pazienti che necessitano di una terapia con glucocorticoidi, indipendentemente dalla dose e dalla durata di questa ( $>3$ mesi), particolarmente per le donne in menopausa o con $\mathrm{BMI}<20$, per i pazienti di età $>65$ anni, per quelli che necessitano di dosaggi $>7 \mathrm{mg} /$ die di prednisone 0 equivalenti e per quelli con familiarità per fratture da fragilità. Queste raccomandazioni possono essere così riassunte: - sensibilizzare i pazienti nei confronti del rischio di osteoporosi;

- correggerne i fattori di rischio modificabili quali il fumo, l'alcol, la sedentarietà, il deficit di ormoni sessuali, il basso BMI $\left(<19 \mathrm{~kg} / \mathrm{m}^{2}\right)$ e l'uso concomitante di altri farmaci osteopenizzanti;

- assumere una quantità di calcio pari ad almeno 1,2-1,5 g/die, preferibilmente per via alimentare;

- correggere un'eventuale ipovitaminosi D (dosare 25-OH- $\mathrm{D}_{3}$ ) con supplementazione farmacologica $(400-800 \mathrm{UI} /$ die di vitamina $D_{3}$ );

- ridurre l'apporto giornaliero di sodio ( $\leq 2 \mathrm{~g} / \mathrm{die})$;

- utilizzare la dose minima efficace di glucocorticoidi, preferibilmente in unica somministrazione mattutina e, se 
possibile, ricorrere a vie alternative di somministrazione (topica, intrarticolare, inalatoria).

Per quanto attiene al trattamento, riportiamo quanto riportato nelle più recenti linee guida italiane, condivise da tutte le società scientifiche che si interessano di osteoporosi [44].

\section{Terapie con evidenza di efficacia}

\section{Calcio e vitamina $D$}

La supplementazione con $1.000 \mathrm{mg} /$ die di calcio e $500 \mathrm{UI} \mathrm{di}$ vitamina $D$ è in grado di prevenire la perdita di densità minerale ossea, anche secondaria a trattamento steroideo (Livello 1B). L'assunzione di metaboliti idrossilati non sembra fornire vantaggi aggiuntivi rispetto alla vitamina $D$. Poiché negli studi con evidenza di efficacia antifratturativa dei bisfosfonati, i pazienti assumevano supplementi di calcio e vitamina $D$, questo trattamento deve essere raccomandato a tutti i pazienti in trattamento o in procinto di essere trattati con tali farmaci (raccomandazione di Grado A).

\section{Terapia ormonale sostitutiva}

In numerosi studi clinici di piccole dimensioni è emerso che la terapia ormonale sostitutiva è in grado di prevenire la perdita d'osso in donne in postmenopausa, anche in terapia con steroidi (Livello 1B). Pur in mancanza di studi controllati sull'incidenza di fratture appare ragionevole prendere in considerazione la terapia ormonale sostitutiva sia nella donna sia nell'uomo con ipogonadismo (raccomandazione di Grado A).

\section{Bisfosfonati}

I risultati di studi randomizzati e controllati indicano che alendronato e risedronato sono efficaci sia nella prevenzione sia nel trattamento dell'osteoporosi, anche indotta da glucocorticoidi (Livello 1A). In questo caso, per la maggior parte delle linee guida la dose soglia di intervento è pari a $7,5 \mathrm{mg} /$ die di prednisone. Tuttavia, come precedentemente ricordato, anche dosi comprese tra 2,5 e $7,5 \mathrm{mg} / \mathrm{die} \mathrm{di}$ prednisone o equivalenti si associano a un aumento significativo del rischio di frattura. Per tale motivo, la totalità delle società scientifiche italiane che si interessano di osteoporosi raccomandano il trattamento farmacologico di prevenzione dell'osteoporosi in tutti i soggetti di età superiore a 50 anni, a prescindere dai valori densitometrici, per dosi di prednisone o equivalenti $>5 \mathrm{mg} /$ die. Per l'osteoporosi non associata a terapia steroidea, pur in mancanza di studi dimensionati per evidenziare un effetto di prevenzione delle fratture attuata da tali preparati, questo tipo di efficacia si può evincere da analisi o metanalisi post-hoc (Livello 2). In casi selezionati, la terapia con bisfosfonati è quindi sicuramente da raccomandare (raccomandazione di Grado A).

\section{Altre terapie}

Esistono studi clinici di piccole dimensioni per calcitonina e steroidi anabolizzanti. I livelli di evidenza di efficacia sono insufficienti anche per la prevenzione della perdita di massa ossea. Gli steroidi anabolizzanti sono talora utilizzati per l'effetto anche sulla massa muscolare.

Tali raccomandazioni, tuttavia, se non pongono nessun dubbio sul modo in cui ci si debba e possa comportare nei confronti dei pazienti che abbiano la necessità di terapia steroidea per via sistemica, non indicano invece quale debba essere il momento di inizio della terapia antiriassorbitiva nei pazienti con BPCO che non la utilizzano, né incidono sulla sua prescrivibilità gratuita.

Se infatti si fa riferimento alle note dell'Agenzia Italiana del Farmaco, anche per i pazienti con BPCO l'acido alendronico, associato o no alla vitamina $D$, l'acido risedronico, l'acido ibandronico, il raloxifene e il ranelato di stronzio possono essere prescritti a carico del Sistema Sanitario Nazionale solo per le seguenti categorie di pazienti:

- soggetti con pregresse fratture osteoporotiche vertebrali o di femore;

- soggetti di età superiore a 50 anni con valori di t-score della BMD femorale o ultrasonografica del calcagno $\leq 4$ ( $0 \leq 5$ per ultrasuoni falangi);

- soggetti di età superiore a 50 anni con valori di t-score della BMD femorale o ultrasonografica del calcagno $\leq 3$ ( $0 \leq 4$ per ultrasuoni falangi) e con almeno uno dei seguenti fattori di rischio aggiuntivi

- storia familiare di fratture vertebrali,

- artrite reumatoide e altre connettiviti,

- pregressa frattura osteoporotica al polso,

- menopausa prima dei 45 anni di età,

- terapia cortisonica cronica.

Il teriparatide è riservato ai soggetti che incorrono in una nuova frattura vertebrale moderata-severa o in una frattura di femore in corso di trattamento da almeno un anno con uno dei farmaci sopraccitati per una pregressa frattura vertebrale moderata-severa; oppure ai soggetti che presentano 30 più fratture vertebrali severe (diminuzione di una delle altezze dei corpi vertebrali $>50 \%$ rispetto alle equivalenti altezze di corpi vertebrali adiacenti integri) o 2 fratture vertebrali severe e una frattura femorale prossimale, anche se in precedenza mai trattati con gli altri farmaci.

Sulla scorta dei precedenti rilievi della letteratura, a tutti i pazienti con BPCO si dovrebbe consigliare di utiliz zare, fin dall'inizio della loro storia clinica respiratoria, preparati di calcio e vitamina $\mathrm{D}$, lasciando la terapia antiriassorbitiva ai soli pazienti in stadio GOLD III e IV. Da valutare, con studi clinici ad hoc, se tale terapia debba essere consigliata $a b$ initio anche ai pazienti in stadio GOLD I e II con fattori di rischio aggiuntivi per l'osteoporosi indipendenti dalla BPCO.

\section{Bibliografia}

[1] Consensus Development Conference V, 1993. Osteoporosis Int 1997;7:1-6.

[2] National Osteoporosis Foundation. NOF Physician's Guidelines. September 2005. www.nof.org/professionals/clinical.htm. [Accessed 20 June 2007].

[3] NIH Consensus Development Panel on Osteoporosis Prevention, Diagnosis, and Therapy. Osteoporosis prevention, diagnosis, and therapy. JAMA 2001;285(6):785-95.

[4] Jørgensen NR, Schwarz P. Osteoporosis in chronic obstructive pulmonary disease patients. Curr Opin Pulm Med 2008;14(2): $122-7$.

[5] Vrieze A, de Greef MH, Wijkstra PJ, Wempe JB. Low bone mineral density in COPD patients related to worse lung function, low weight and decreased fat-free mass. Osteoporos Int 2007;18(9):1197-202. 
[6] Jørgensen NR, Schwarz P, Holme I, Henriksen BM, Petersen LJ, Backer V. The prevalence of osteoporosis in patients with chronic obstructive pulmonary disease: a cross sectional study. Respir Med 2007;101(1):177-85.

[7] Barnes PJ, Celli BR. Systemic manifestations and comorbidities of COPD. Eur Respir J 2009;33(5):1165-85.

[8] Nuti R, Siviero P, Maggi S, Guglielmi G, Caffarelli C, Crepaldi G, et al. Vertebral fractures in patients with chronic obstructive pulmonary disease: the EOLO Study. Osteoporos Int 2009;20(6): 989-98.

[9] Graat-Verboom L, Spruit MA, van den Borne BE, Smeenk FW, Martens EJ, Lunde R, et al., CIRO Network. Correlates of osteoporosis in chronic obstructive pulmonary disease: An underestimated systemic component. Respir Med 2009;103(8):1143-51.

[10] de Vernejoul MC, Bielakoff J, Herve $M$, Gueris J, Hott $M$, Modrowski D, et al. Evidence for defective osteoblastic function. A role for alcohol and tobacco consumption in osteoporosis in middle-aged men. Clin Orthop Relat Res 1983;(179):107-15.

[11] Fang MA, Frost PJ, lida-Klein A, Hahn TJ. Effects of nicotine on cellular function in UMR 106-01 osteoblast-like cells. Bone 1991;12(4):283-6.

[12] Krall EA, Dawson-Hughes B. Smoking and bone loss among postmenopausal women. J Bone Miner Res 1991;6(4):331-8.

[13] Law MR, Hackshaw AK. A meta-analysis of cigarette smoking, bone mineral density and risk of hip fracture: recognition of a major effect. BMJ 1997;315(7112):841-6.

[14] Rabe KF, Hurd S, Anzueto A, Barnes PJ, Buist SA, Calverley P, et al., Global Initiative for Chronic Obstructive Lung Disease. Global strategy for the diagnosis, management, and prevention of chronic obstructive pulmonary disease: GOLD executive summary. Am J Respir Crit Care Med 2007;176(6):532-55.

[15] Leech JA, Dulberg C, Kellie S, Pattee L, Gay J. Relationship of lung function to severity of osteoporosis in women. Am Rev Respir Dis 1990;141(1):68-71.

[16] Dimai HP, Domej W, Leb G, Lau KH. Bone loss in patients with untreated chronic obstructive pulmonary disease is mediated by an increase in bone resorption associated with hypercapnia. $J$ Bone Miner Res 2001;16(11):2132-41.

[17] Kjensli A, Mowinckel P, Ryg MS, Falch JA. Low bone mineral density is related to severity of chronic obstructive pulmonary disease. Bone 2007;40(2):493-7.

[18] Reid IR. Obesity and osteoporosis. Ann Endocrinol (Paris) 2006;67(2):125-9.

[19] Looker AC, Flegal KM, Melton 3rd LJ. Impact of increased overweight on the projected prevalence of osteoporosis in older women. Osteoporos Int 2007;18(3):307-13.

[20] Franssen FM, O’Donnell DE, Goossens GH, Blaak EE, Schols AM. Obesity and the lung: 5 . Obesity and COPD. Thorax 2008;63(12): 1110-7.

[21] Vestbo J, Prescott E, Almdal T, Dahl M, Nordestgaard BG, Andersen T, et al. Body mass, fat-free body mass, and prognosis in patients with chronic obstructive pulmonary disease from a random population sample: findings from the Copenhagen City Heart Study. Am J Respir Crit Care Med 2006;173(1):79-83.

[22] Bolton CE, lonescu AA, Shiels KM, Pettit RJ, Edwards PH, Stone $M D$, et al. Associated loss of fat-free mass and bone mineral density in chronic obstructive pulmonary disease. Am J Respir Crit Care Med 2004;170(12):1286-93.

[23] Tsujinaka T, Ebisui C, Fujita J, Kishibuchi M, Morimoto T, Ogawa $A$, et al. Muscle undergoes atrophy in association with increase of lysosomal cathepsin activity in interleukin-6 transgenic mouse. Biochem Biophys Res Commun 1995;207(1):168-74.

[24] Kosmidou I, Vassilakopoulos T, Xagorari A, Zakynthinos S, Papapetropoulos A, Roussos C. Production of interleukin-6 by skeletal myotubes: role of reactive oxygen species. Am J Respir Cell Mol Biol 2002;26(5):587-93.

[25] Kamischke A, Kemper DE, Castel MA, Lüthke M, Rolf C, Behre $\mathrm{HM}$, et al. Testosterone levels in men with chronic obstructive pulmonary disease with or without glucocorticoid therapy. Eur Respir J 1998;11(1):41-5.

[26] Debigaré R, Marquis K, Côté CH, Tremblay RR, Michaud A, LeBlanc $P$, et al. Catabolic/anabolic balance and muscle wasting in patients with COPD. Chest 2003;124(1):83-9.

[27] Van Vliet M, Spruit MA, Verleden G, Kasran A, Van Herck E, Pitta $F$, et al. Hypogonadism, quadriceps weakness, and exercise intolerance in chronic obstructive pulmonary disease. Am J Respir Crit Care Med 2005;172(9):1105-11.

[28] Mellström D, Johnell O, Ljunggren O, Eriksson AL, Lorentzon M, Mallmin $\mathrm{H}$, et al. Free testosterone is an independent predictor of BMD and prevalent fractures in elderly men: MrOS Sweden. J Bone Miner Res 2006;21(4):529-35.

[29] Franco CB, Paz-Filho G, Gomes PE, Nascimento VB, Kulak CA, Boguszewski CL, et al. Chronic obstructive pulmonary disease is associated with osteoporosis and low levels of vitamin D. Osteoporos Int 2009;20(11):1881-7.

[30] Lian JB, Stein GS. Regulatory networks in the control of osteoblast cell fate are influenced by glucocorticoids. Bone 2009;45(Suppl 3):S121.

[31] Manolagas SC. Oxidative stress, cell apoptosis, glucocorticoids and osteoporosis. Bone 2009;45(Suppl 3):S120.

[32] Lane NE, Lukert B. The science and therapy of glucocorticoidinduced bone loss. Endocrinol Metab Clin North Am 1998;27(2): 465-83.

[33] Canalis E. Role of Notch signaling in osteoblast differentiation and bone remodeling. Bone 2009;45(Suppl 3):S120-1.

[34] Canalis E. Clinical review 83: Mechanisms of glucocorticoid action in bone: implications to glucocorticoid-induced osteoporosis. J Clin Endocrinol Metab 1996;81(10):3441-7.

[35] Baylink DJ. Glucocorticoid-induced osteoporosis. N Engl J Med 1983;309(5):306-8.

[36] Gennari C. Glucocorticoid and bone. In: Peck WA, editor. Bone and Mineral Research. 3.. Amsterdam: Elsevier; 1985. p. 213323.

[37] Grandi M, Trischitta C. La terapia corticosteroidea. In: Atti IX Congresso Nazionale FADOI. Torino: Centro Scientifico Editore; 2004.

[38] Jones A, Fay JK, Burr M, Stone M, Hood K, Roberts G. Inhaled corticosteroid effects on bone metabolism in asthma and mild chronic obstructive pulmonary disease. Cochrane Database Syst Rev 2002;(1):CD003537.

[39] Hubbard RB, Smith CJ, Smeeth L, Harrison TW, Tattersfield AE. Inhaled corticosteroids and hip fracture: a population-based case-control study. Am J Respir Crit Care Med 2002;166(12 Pt 1): 1563-6.

[40] Weatherall M, James K, Clay J, Perrin K, Masoli M, Wijesinghe M, et al. Dose-response relationship for risk of non-vertebral fracture with inhaled corticosteroids. Clin Exp Allergy 2008;38(9):1451-8.

[41] Medici TC, Grebski E, Häcki M, Rüegsegger P, Maden C, Efthimiou J. Effect of one year treatment with inhaled fluticasone propionate or beclomethasone dipropionate on bone density and bone metabolism: a randomised parallel group study in adult asthmatic subjects. Thorax 2000;55(5):375-82.

[42] Johnell O, Pauwels R, Löfdahl CG, Laitinen LA, Postma DS, Pride $\mathrm{NB}$, et al. Bone mineral density in patients with chronic obstructive pulmonary disease treated with budesonide Turbuhaler. Eur Respir J 2002;19(6):1058-63.

[43] U.S. Preventive Services Task Force. Screening for osteoporosis in postmenopausal women: recommendations and rationale. Ann Intern Med 2002;137(6):526-8.

[44] Linee guida per la diagnosi, prevenzione e terapia dell'osteoporosi approvate dalle seguenti Società Scientifiche: Collegio dei Reumatologi Ospedalieri (CROI); Società Italiana dell'Osteoporosi e delle Malattie del Metabolismo Minerale e Scheletrico (SIOMMMS); Società Italiana di Medicina Fisica e Riabilitativa (SIMFER); Società Italiana di Medicina Interna (SIMI); Società 
Italiana di Ortopedia e Traumatologia (SIOT); Società Italiana di Radiologia Medica (SIRM); Società Italiana di Reumatologia (SIR). Pavia: EDIMES, 2006.

[45] Recommendations for the prevention and treatment of glucocorticoid-induced osteoporosis: 2001 update. American College of Rheumatology Ad Hoc Committee on Glucocorticoid-Induced Osteoporosis. Arthritis Rheum 2001;44(7):1496-503.

[46] Di Munno O, Delle Sedie A. Glucocorticoid-induced osteoporosis and rheumatic diseases. Pathogenesis, prevention and treatment. Reumatismo 2006;58(1):11-21. 


\title{
BPCO e malattie reumatiche
}

\author{
Alba Sciascera, Antonino Mazzone
}

\section{Messaggi chiave}

- Nelle malattie reumatiche, quali le connettiviti, l'artrite reumatoide e le vasculiti, il possibile coinvolgimento polmonare può essere confuso con i quadri di broncopneumopatia cronica ostruttiva (BPCO). Spesso i quadri si presentano di difficile diagnosi, anche dal punto di vista fisiopatologico (sindromi ostruttive) e dal punto di vista clinico, soprattutto nei pazienti fumatori, nonché dal punto di vista radiologico e della tomografia computerizzata ad alta risoluzione (HRCT).

- Poiché il trattamento di queste forme è diverso, la diagnosi differenziale, pur non facile, è fondamentale.

- La compresenza di malattie reumatiche e BPCO con insufficienza respiratoria ipercapnica, frequentementente riacutizzata da agenti patogeni "difficili" da eradicare, può essere un limite per eventuali trattamenti con immunosoppressori o con farmaci biologici: questi ultimi, infatti, predispongono alle infezioni e non sono indicati nelle cardiopatie e nel cuore polmonare cronico.

- La discussione è aperta in quanto nel meccanismo patogenetico della BPCO è coinvolto il sistema delle citochine e in particolare si ha un'elevata produzione di TNF-alfa. Si sta, quindi, ancora valutando la sicurezza d'impiego dell'anti-TNF nei pazienti affetti da patologie reumatiche che presentino quadri di BPCO.

- Il fumo di sigaretta è un fattore prognostico negativo anche nelle malattie reumatiche. Infatti, mutazioni o alterazioni di p53 (un gene soppressore che regola il fattore di crescita) sono presenti sia nei pazienti fumatori sia nei pazienti con malattie croniche quali l'artrite reumatoide

\section{Introduzione}

La correlazione diretta tra broncopneumopatia cronica ostruttiva (BPCO) e malattie reumatiche presenta qualche difficoltà: vi sono, infatti, in letteratura, scarsi dati sull'argomento. Riteniamo pertanto importante, da un punto di vista diagnostico, terapeutico e prognostico, che i clinici possano disporre degli elementi necessari a differenziare le due patologie.

Le malattie reumatiche, tra cui le connettiviti, l'artrite reumatoide e alcune vasculiti, possono avere un interessamento polmonare che può coinvolgere vari distretti tra i quali le alte e basse vie aeree, l'interstizio, la pleura e i vasi. Si possono quindi osservare pazienti affetti da patologie reumatiche che presentano sindromi ostruttive, anche se non fumatori, per quadri di bronchiolite costrittiva o follicolare determinati dalla malattia autoimune. La difficoltà della diagnosi differenziale da parte del clinico aumenta quando i pazienti sono anche fumatori. Bisogna tenere presente, infatti, che il fumo di sigaretta è un fattore prognostico negativo anche per i portatori di malattie autoimmunitarie e che facilita l'insorgenza di vasculiti secondarie e il coinvolgimento extrarticolare di malattia. Elemento cardine dell'evoluzione della BPCO sono le continue riacutizzazioni che condizionano un peggioramento dell'evoluzione e della prognosi di malattia. I farmaci utilizzati per le cure delle malattie reumatiche sono steroidi, immunoppressori e farmaci biologici. Nel caso di coesistenza di BPCO (soprattutto se al III-IV stadio) e di connettivite, per il rischio di ulteriori riacutizzazioni, l'utilizzo di questi ultimi è controindicato. La presenza di sola malattia reumatica con interessamento polmonare induce, invece, a scelte terapeutiche ben precise e con dosaggi "pieni". La presenza di malattia reumatica, senza interessamento polmonare secondario ma con BPCO, a seconda del grado di questa, richiederà un trattamento in base alle linee guida GOLD. La presenza di malattia reumatica in questo caso non limita il trattamento della broncopenumopatia. 


\section{Aspetti epidemiologici}

Non esistono in letteratura evidenza e dati sulla coesistenza di BPCO e malattie reumatiche, come non esistono informazioni sulla loro possibile interdipendenza. Il fumo di sigaretta modifica l'incidenza e la severità dell'artrite reumatoide, soprattutto quella sieropositiva nel sesso maschile. Studi epidemiologici (caso controllo) hanno evidenziato un maggiore interessamento extrarticolare e una maggiore insorgenza di vasculiti secondarie ad artrite reumatoide nei fumatori. Pare, infatti, che mutazioni o alterazioni di p53 (un gene soppressore che regola il fattore di crescita) siano presenti sia nei pazienti fumatori sia nei pazienti con malattie croniche quali l'artrite reumatoide.

\section{Caratteristiche radiologiche dell'interessamento polmonare}

L'interessamento polmonare nelle malattie reumatiche varia da caso a caso: da diversi anni l'attenzione si è concentrata sull'interessamento delle vie aeree e dell'interstizio, confrontando le immagini della tomografia computerizzata ad alta risoluzione (HRCT) che evidenziano key pattern ben precisi, con pattern istologici.

Tale confronto può fornire informazioni sul quadro infiammatorio o fibrotico (sempre irreversibile) e sulla possibile reversibilità del primo.
Lo studio dell'interstizio polmonare alla HRCT e la suddivisione in key pattern in base al lobulo secondario polmonare interessato ha portato alla classificazione dei quadri radiologici (come riassunto in tabella 1) e alle varie correlazioni con malattie polmonari.

Per i pazienti con BPCO si deve distinguere distinguere l'enfisema acinare prossimale o centrolobulare da quello panlobolulare o panacinare e da quello acinare distale o parasettale. Il primo è correlato alla distruzione del tessuto parenchimale nella regione dei bronchioli prossimali e, poiché ogni lobulo secondario contiene acini multipli, la malattia è plurifocale. L'enfisema centrolobulare è il quadro più comune nei fumatori. Tra i key pattern è rappresentato il pattern cistico con cisti a distribuzione random.

L'enfisema acinare distale (parasettale) coinvolge selettivamente i dotti e i sacchi alveolari nella porzione periferica dell'acino; di solito è periferico e subpleurico e ha un pattern cistico con cisti a collana di perle.

Esiste, poi, l'enfisema panacinare o panlobulare, definito anche non selettivo perché l'acino e i lobuli secondari sono coinvolti in modo diffuso e non selettivo come avviene nella malattia cistico-prossimale e distale. Di solito si associa a un deficit di inibitori della alfa ${ }_{1}$-antitripsina. Interessa soprattutto i lobi inferiori e le zone anteriori, con presenza di bolle basali. Ha un key pattern alveolare con mosaico diffuso e air trapping.

Dalla tabella 1 possiamo evincere come malattie reumatiche con interessamento polmonare e BPCO (enfisema) abbiano quadri radiologici simili ma non uguali: stesso pattern cistico nell'enfisema centrolobulare e nella fibrosi

Tabella 1 Dai key pattern HRCT alle malattie polmonari.

\begin{tabular}{|c|c|c|}
\hline $\begin{array}{l}\text { Quadro } \\
\text { radiologico }\end{array}$ & Pattern & Correlazioni con malattie polmonari \\
\hline $\begin{array}{l}\text { Malattia } \\
\text { reticolare }\end{array}$ & $\begin{array}{l}\text { - Liscia } \\
\text { - Nodulare } \\
\text { - Irregolare }\end{array}$ & $\begin{array}{l}\text { - Linfangite, edema polmonare acuto interstiziale, amiloidosi interstiziale } \\
\text { - Linfangite, amiloidosi interstiziale, asbestosi iniziale } \\
\text { - Sarcoidosi fibrosante, alveolite allergica estrinseca cronica, farmaci, } \\
\text { connettiviti iniziali, polmonite interstiziale non specifica, } \\
\text { polmonite interstiziale usuale iniziale, asbestosi iniziale }\end{array}$ \\
\hline $\begin{array}{l}\text { Malattia } \\
\text { nodulare }\end{array}$ & $\begin{array}{l}\text { - Noduli pavidi } \\
\text { di pleura } \\
\text { - Noduli avidi di pleura } \\
\text { - Noduli indifferenti } \\
\text { alla pleura }\end{array}$ & $\begin{array}{l}\text { - RB-ILD ((Respiratory Bronchiolitis Interstizial Lung Diseases), istiocitosi X iniziale, } \\
\text { polmonite linfocitaria interstiziale, alveolite allergica subacuta } \\
\text { - Sarcoidosi granulomatosa, polmonite interstiziale linfocitaria } \\
\text { - Silicosi, tubercolosi miliare, metastasi }\end{array}$ \\
\hline $\begin{array}{l}\text { Malattia } \\
\text { alveolare }\end{array}$ & $\begin{array}{l}\text { - Addensativo } \\
\text { misto acuto } \\
\text { - Addensativo misto } \\
\text { cronico } \\
\text { - Oligoemica a mosaico } \\
\text { con air trapping } \\
\text { - Tree-in-bud }\end{array}$ & $\begin{array}{l}\text { - Vasculite emorragica, alveolite allergica estrinseca acuta, adult respiratory } \\
\text { distress syndrome, edema polmonare acuto alveolare, polmonite interstiziale } \\
\text { acuta, polmonite da Pneumocystis carinii } \\
\text { - Farmaci, maltoma, carcinoma bronchiolo-alveolare, proteinosi alveolare, } \\
\text { polmonite cronica eosinofila, polmonite desquamativa, organizing pneumonia } \\
\text { - Bronchiolite costrittiva } \\
\text { - Infezioni endobronchiali }\end{array}$ \\
\hline $\begin{array}{l}\text { Malattia } \\
\text { cistica }\end{array}$ & $\begin{array}{l}\text { - Cisti a grappolo } \\
\text { - Cisti a collana di perle } \\
\text { - Honeycombing } \\
\text { - Cisti con distribuzione } \\
\text { random }\end{array}$ & $\begin{array}{l}\text { - Bronchiectasie cistiche, fibrosi cistica } \\
\text { - Enfisema parasettale } \\
\text { - Polmonite interstiziale usuale, connettiviti evolute, asbestosi evoluta } \\
\text { - Enfisema centrolobulare, istiocitosi X evoluta, linfangioleiomiomatosi }\end{array}$ \\
\hline
\end{tabular}

Fonte: modificata da Cancellieri A, et al. Pneumopatie infiltrative diffuse: clinica, anatomia patologica, HRCT. Milano: Springer, 2004. 
polmonare delle connettiviti, ma sottogruppo diverso; cisti con distribuzione random nel primo e honeycombing nel secondo.

La bronchiolite costrittiva, molto frequente nell'artrite reumatoide, ha un pattern alveolare, e anche in questo caso può essere simile ma assolutamente non uguale all'enfisema panlobulare.

Il paziente reumatologico può quindi avere un BPCO che complica il quadro radiologico, fisiopatologico e clinico. Se ha malattia reumatica senza interessamento polmonare secondario, ma con BPCO, avrà un quadro fisiopatologico di sindrome ostruttiva di diversa gravità a seconda della riduzione del FEV1, con quadri HRCT che possono essere espressione di enfisema panlobulare, centrolobulare o parasettale ed essere espressi con pattern alveolare con oligoemia diffusa e con air trapping, nel primo caso, o con pattern cistico con cisti a distribuzione random, nel secondo, o con cisti a collana di perle, nel terzo.

Se il paziente, oltre ad avere malattia reumatica, ha anche pneumopatia secondaria e BPCO, i quadri radiologici e fisiopatologici saranno diversi a seconda del tipo di malattia reumatica e del diverso interessamento polmonare e si evidenzieranno forme ostruttive o miste a seconda che la malattia reumatica di base induca una forma restrittiva o anch'essa una forma ostruttiva. L'HRCT potrà mostrare un insieme: l'esperienza e la professionalità del clinico e del radiologo permetteranno un giusto inquadramento nosologico.

\section{Diagnosi, valutazione di gravità e prognosi}

La diagnosi di BPCO è clinica, ma si avvale anche delle prove di funzionalità respiratoria che evidenziano una riduzione del FEV1, con FEV1/CVF $<0,70$.

Nella sindrome di Sjögren (SS), anche in pazienti non fumatori si può avere, alle prove spirometriche, una riduzione del MEF 25 (ostruzione delle piccole vie aeree non sforzo dipendente). Il MEF è il massimo flusso espiratorio che viene calcolato sulla pendenza della retta che interseca la curva di espirazione forzata nei punti $25 \%$, 50\% e 75\% della capacità vitale. Altri autori hanno eseguito dei test alla metacolina, sempre nei pazienti con SS, e hanno evidenziato che nel $50 \%$ dei casi si aveva iperreattività bronchiale, contro il $6,5 \%$ della popolazione di controllo. In questo caso la broncoreattività non è responsiva ai comuni trattamenti

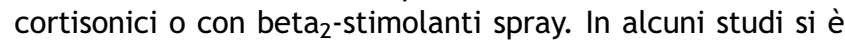
evidenziato una riduzione del FEV1 e del MEF 25 con segni di iperinflazione radiologica. Questi pazienti, con beta -micro- $^{-}$ globulina incrementata hanno una maggiore probabilità di avere una malattia linfoproliferativa. In essi la biopsia polmonare evidenziava un'infiltrazione di cellule mononucleate nelle piccole vie aeree con restringimento delle stesse (bronchioliti follicolari linfocitarie). Alla HRCT si evidenziavano bronchiectasie, ispessimenti bronchiolari o quadri di air trapping. I quadri a mosaico e l'air trapping alla HRCT espiratoria non correlano sempre con le prove di funzionalità respiratoria (sindrome ostruttiva). Ciò indica che la TC evidenzia precocemente ciò che le prove fisiopatologiche mostreranno più tardivamente.

Tutti questi elementi - sindrome ostruttiva, quadri HRCT, broncoreattività - possono confondere le idee al clinico e se il paziente con SS ha anche una storia di fumatore si possono erroneamente attribuire alla sola BPCO e trattarli come tale. In questo caso, però, il paziente non trae alcun beneficio dalla terapia broncodilatatrice. Necessita, invece, di un attento monitoraggio per la possibile evoluzione verso malattie linfoproliferative.

L'artrite reumatoide si accompagna spesso a malattie delle vie aeree di tipo ostruttivo. In uno studio condotto su 200 pazienti non selezionati, metà dei quali con artrite reumatoide, la dispnea sibilante fu riscontrata soprattutto tra i pazienti affetti da artrite reumatoide ( $18 \%$ vs $4 \%$ ). Questi pazienti, inoltre, avevano una maggiore ostruzione delle vie aeree e una maggiore iperreattività rispetto alla popolazione di controllo. Le complicanze a carico delle vie aeree sono le bronchioliti, le beonchiectasie, la bronchiolite follicolare (soprattutto se è presente anche una SS secondaria). Si devono tenere presenti anche le ostruzioni delle vie aeree superiori, come nell'anchilosi delle articolazioni cricoaritenoidee e cricotiroidee e nella sleep apnea.

L'artrite reumatoide (soprattutto) e altre connettiviti quali il lupus eritematoso sistemico si accompagnano spesso a bronchiolite costrittiva, cioè a un'infiammazione delle piccole vie aeree. L'associazione tra bronchiolite obliterante e artrite reumatoide fu dimostrata per la prima volta in 6 donne affette da artrite reumatoide che presentavano una pneumopatia ostruttiva progressiva. Molti studi di screening hanno evidenziato un'associazione tra malattia reumatica e bronchiolite in pazienti con HLA-DR4. Le prove di funzionalità respiratoria evidenziano una sindrome ostruttiva severa, non reversibile come nella BPCO, accompagnata da una riduzione della DLCO. Clinicamente il paziente ha tosse con un reperto di sibili all'auscultazione. L'ostruzione dei bronchioli fino alla completa obliterazione è però dovuta alla fibrosi. In questo caso alla HRCT si evidenziano chiazze di iperdiafania, povertà delle strutture vascolari senza distorsione dell'architettura lobulare (pattern a mosaico), air trapping. In 1/3 dei casi queste immagini si valutano solo nelle scansioni espiratorie. Le zone oligoemiche sono dovute a vasocostrizione riflessa in corrispondenza di aree polmonari meno ventilate per la stenosi bronchiolare. La distribuzione è a chiazze e asimmetrica, però solo nei casi più gravi può avere un'estensione omogenea similenfisematosa. Tra le varie diagnosi differenziali, si deve pensare all'enfisema panlobulare: nell'enfisema l'interessamento è diffuso e non a chiazze, è bilaterale e simmetrico con prevalenza ai lobi inferiori; il pattern è alveolare, ma con una distribuzione diversa rispetto al sottogruppo dell'oligoemia a mosaico con air trapping.

La sclerodermia, più frequentemente, ma tutte le connettiviti in genere, nella forma più evoluta hanno un quadro di fibrosi, che all'HRCT si estrinseca con un key pattern cistico. Anche l'enfisema ha un pattern cistico, ma le connettiviti con fibrosi hanno un quadro cistico honeycombing, mentre l'enfisema parasettale ha un quadro di cisti a collana di perle, e l'enfisema centrolobulare ha un quadro di cisti con distribuzione random. Se poi si osservano cisti a grappolo, si deve pensare alle bronchiectasie cistiche.

Nella fibrosi con honecombig, quindi, pur essendo sempre in presenza di pattern cistico, si hanno elementi che possono essere di aiuto nella diagnosi differenziale. Anche la clinica è differente rispetto alla BPCO, perché in questo caso si hanno tosse secca, dispnea inizialmente da sforzo e poi anche a riposo. All'auscultazione non vi è segno di brocospasmo, ma 
sono presenti crepitazioni "a velcro". Le prove spirometriche evidenziano una sindrome restrittiva con una riduzione della DLCO. Segni di ipertensione polmonare e anche di cuore polmonare cronico possono essere presenti. È proprio in questo caso che, nei pazienti con connettivi e fumatori, non si deve commettere l'errore di interpretare il quadro come una BPCO.

\section{Terapia}

Si possono avere le seguenti situazioni:

- paziente con malattia reumatica e interessamento polmonare secondario, non fumatore e senza BPCO;

- paziente con malattia reumatica senza interessamento polmonare secondario, fumatore con BPCO;

- paziente con malattia reumatica con interessamento polmonare secondario, fumatore e con BPCO.

Nel primo caso, come si è detto, a livello radiologico e fisiopatologico si possono evidenziare quadri ostruttivi o restrittivi, ma nella diagnosi differenziale con BPCO si prendono in considerazione solo quelli ostruttivi e quest'ultimi sono poco responsivi alle terapie broncodilatatrici. Di solito si utilizzano immunosoppressori o alti dosaggi di steroidi a seconda del tipo di malattia reumatica.

Nel secondo caso, esistono una malattia reumatica e una BPCO. Quest'ultima è trattata in base alle linee guida GOLD. La compresenza di malattie reumatiche e BPCO, soprattutto se quest'ultima è in stadio avanzato con insufficienza respiratoria ipercapnica, frequenti riacutizzazioni, nonché infezioni da agenti patogeni "difficili" da eradicare, può però costituire un limite per eventuali trattamenti con immunosoppressori o farmaci biologici. Questi, infatti, predispongono alle infezioni e non sono indicati nelle cardiopatie e nel cuore polmonare cronico. La discussione, tuttavia, è aperta in quanto nel meccanismo patogenetico della BPCO si ha un'elevata produzione di TNF-alfa. Si sta, valutando, quindi, la sicurezza d'impiego degli anti-TNF. I dati in letteratura attualmente non sono sufficienti e soddisfacenti per indicare un trattamento con questi ultimi, per cui si ha un atteggiamento di prudenza nell'utilizzo degli stessi.

Se il paziente ha, oltre alla BPCO, anche un interessamento polmonare legato alla malattia reumatica i problemi sono seri. Per la BPCO ci si attiene alle linee guida GOLD, ma per la malattia reumatica si utilizza prevalentemente la terapia steroidea; la prognosi del paziente è, ovviamente, peggiore.

\section{Bibliografia consigliata}

Albano SA, Santana-Sahagun E, Weisman MH. Cigarette smoking and rheumatoid arthritis. Semin Arthritis Rheum 2001;31(3):146-59.

Antoniu SA, Mihaltan F, Ulmeanu R. Anti-TNF-alpha therapies in chronic obstructive pulmonary diseases. Expert Opin Investig Drugs 2008;17(8):1203-11.

American Thoracic Society/European Respiratory Society International Multidisciplinary Consensus. Classification of the idiopathic Interstitial Pneumonias. Am J Respir Crit Care Med 2002;165:277-304.
Bergin C, Roggli V, Coblentz C, Chiles C. The secondary pulmonary lobule: normal and abnormal CT appearances. AJR Am J Roentgenol 1988;151(1):21-5.

Cancellieri A, Dalpiaz G, Maffessanti M, Pesci A, Polverosi R, Zompatori M. Pneumopatie infiltrative diffuse: clinica, anatomia patologica, HRCT. Milano: Springer, 2004.

Chung MH, Lee HG, Kwon SS, Park SH, Kim KJ, Jung JI, et al. Airway obstruction in rheumatoid arthritis: CT manifestations, correlated with pulmonary function testing. Yonsei Med J 2004;45(3):443-52.

Colby TV. Bronchiolitis. Pathologic considerations. Am J Clin Pathol 1998;109(1):101-9.

Colby TV, Swensen SJ. Anatomic distribution and histopathologic patterns in diffuse lung disease: correlation with HRCT. J Thorac Imaging 1996;11(1):1-26.

Copley SJ, Wells AU, Müller NL, Rubens MB, Hollings NP, Cleverley JR, et al. Thin-section CT in obstructive pulmonary disease: discriminatory value. Radiology 2002;223(3): 812-9.

Costenbader KH, Feskanich D, Mandl LA, Karlson EW. Smoking intensity, duration, and cessation, and the risk of rheumatoid arthritis in women. Am J Med 2006;119(6):503.e1-9.

Devouassoux G, Cottin V, Lioté H, Marchand E, Frachon I, Schuller A, et al; Groupe d'Etudes et de Recherche sur les Maladies "Orphelines" Pulmonaires (GERM"O"P). Characterisation of severe obliterative bronchiolitis in rheumatoid arthritis. Eur Respir J 2009;33(5):1053-61.

Dorinsky PM, Davis WB, Lucas JG, Weiland JE, Gadek JE. Adult bronchiolitis. Evaluation by bronchoalveolar lavage and response to prednisone therapy. Chest 1985;88(1):58-63.

Franquet T, Díaz C, Domingo P, Giménez A, Geli C. Air trapping in primary Sjögren syndrome: correlation of expiratory CT with pulmonary function tests. J Comput Assist Tomogr 1999;23(2):169-73.

Fraser RS, Paré PD, Muller NL, Colman N. Diagnosi delle malattie del torace. Roma: Verduci, 2001.

Geddes DM, Corrin B, Brewerton DA, Davies RJ, TurnerWarwick $M$. Progressive airway obliteration in adults and its association with rheumatoid disease. Q J Med 1977; 46(184):427-44.

Hayakawa H, Sato A, Imokawa S, Toyoshima M, Chida K, Iwata $M$. Bronchiolar disease in rheumatoid arthritis. Am J Respir Crit Care Med 1996;154(5):1531-6.

Hansell DM. HRCT of obliterative bronchiolitis and other small airways diseases. Semin Roentgenol 2001;36(1):51-65.

Hassan WU, Keaney NP, Holland CD, Kelly CA. Bronchial reactivity and airflow obstruction in rheumatoid arthritis. Ann Rheum Dis 1994;53(8):511-4.

Hunninghake GW, Fauci AS. Pulmonary involvement in the collagen vascular diseases. Am Rev Respir Dis 1979;119(3): 471-503. 
Inanc N, Direskeneli H. Serious infections under treatment with TNF-alpha antagonists compared to traditional DMARDs in patients with rheumatoid arthritis. Rheumatol Int 2006; 27(1):67-71.

Kim J, Remick DG. Tumor necrosis factor inhibitors for the treatment of asthma. Curr Allergy Asthma Rep 2007;7(2): 151-6.

Kraft M, Mortenson RL, Colby TV, Newman L, Waldron JA Jr, King TE Jr. Cryptogenic constrictive bronchiolitis. A clinicopathologic study. Am Rev Respir Dis 1993;148(4 Pt 1): 1093-101.

La Corte R, Bajocchi G, Potena A, Govoni M, Trotta F. Bronchial hyperreactivity in systemic sclerosis patients: influence of associated Sjögren's syndrome. Ann Rheum Dis 1995;54(8):636-9.

La Corte R, Potena A, Bajocchi G, Fabbri L, Trotta F. Increased bronchial responsiveness in primary Sjögren's syndrome. A sign of tracheobronchial involvement. Clin Exp Rheumatol 1991;9(2):125-30.

Lamblin C, Bergoin C, Saelens T, Wallaert B. Interstitial lung diseases in collagen vascular diseases. Eur Respir J Suppl 2001;32:69-80s.

Lee HS, Irigoyen P, Kern M, Lee A, Batliwalla F, Khalili H, et al. Interaction between smoking, the shared epitope, and anticyclic citrullinated peptide: a mixed picture in three large North American rheumatoid arthritis cohorts. Arthritis Rheum 2007;56(6):1745-53.

Linstow, Kriegboum NJ, Broker V, et al. A follow up study of pulmonary finding in patients in the primary Sjögren's syndrome. Rheumatol Intr 1990;10:47.

Miller KL, Sawitzke AD, Doane J. Abatacept and serious respiratory infections in patients with previous lung disease. Clin Rheumatol 2008;27(12):1569-71.

Poletti V, Cancellieri A. Aspetti istopatologici nell'interessamento polmonare in corso di malattie reumatiche autoimmuni. Progressi Reumatologia 2003;IV(4):334-44.
Raghu G. Interstitial lung disease: a diagnostic approach. Are CT scan and lung biopsy indicated in every patient? Am J Respir Crit Care Med 1995;151(3 Pt 1):909-14.

Ryu JH, Olson EJ, Midthun DE, Swensen SJ. Diagnostic approach to the patient with diffuse lung disease. Mayo Clin Proc 2002;77(11):1221-7.

Schwarz M, King TE, Raghu G. Approach to the evaluation and diagnosis of interstitial lung disease. In: Schwarz MI, King Jr TE (eds). Interstitial Lung Disease. $4^{\text {th }}$ Ed. Hamilton, ON: BC Decker, 2003.

Stern EJ, Frank MS. Small-airway diseases of the lungs: findings at expiratory CT. AJR Am J Roentgenol 1994; 163(1):37-41.

Stolt P, Bengtsson C, Nordmark B, Lindblad S, Lundberg I, Klareskog L, et al; EIRA study group. Quantification of the influence of cigarette smoking on rheumatoid arthritis: results from a population based case-control study, using incident cases. Ann Rheum Dis 2003;62(9):835-41.

Suissa S, Ernst P, Hudson M. TNF-alpha antagonists and the prevention of hospitalisation for chronic obstructive pulmonary disease. Pulm Pharmacol Ther 2008;21(1):234-8.

Waitches GM, Stern EJ. High-resolution CT of peripheral airways diseases. Radiol Clin North Am 2002;40(1):21-9.

Weibel ER, Crystal RG. Structural organization of the pulmonary interstitium. In: Crystal RG, West JB (eds). The Lung. New York, NY: Raven Press, 1991, pp. 369-80.

Weisman MH, Paulus HE, Burch FX, Kivitz AJ, Fierer J, Dunn M, et al. A placebo-controlled, randomized, double-blinded study evaluating the safety of etanercept in patients with rheumatoid arthritis and concomitant comorbid diseases. Rheumatology (Oxford) 2007 Jul;46(7):1122-5.

Worthy SA, Müller NL, Hartman TE, Swensen SJ, Padley SP, Hansell DM. Mosaic attenuation pattern on thin-section CT scans of the lung: differentiation among infiltrative lung, airway, and vascular diseases as a cause. Radiology 1997;205(2):465-70. 


\section{BPCO e malattie dell'apparato digerente}

\section{Francesco Cipollini}

\section{Messaggi chiave}

Malattia da reflusso gastroesofageo

- La broncopneumopatia cronica ostruttiva (BPCO) è fattore di rischio per la malattia da reflusso gastroesofageo (MRGE), ma non viceversa.

- Gli episodi di reflusso gastroesofageo possono avere un ruolo causale nelle riacutizzazioni della BPCO.

- Gli inibitori di pompa protonica (PPI) possono avere un ruolo nei pazienti con BPCO e MRGE nel prevenire le riesacerbazioni reflusso-indotte.

- Nei pazienti con BPCO e MRGE i beta ${ }_{2}$-agonisti per via inalatoria e le metilxantine non sono controindicati.

\section{Ulcera peptica}

- L'ulcera peptica, e in particolare quella gastrica, ha un'incidenza maggiore nei soggetti con BPCO rispetto alla popolazione generale.

- Nei pazienti con BPCO vi è una sieroprevalenza per gli anticorpi anti-Helicobacter pylori superiore a quella della popolazione generale.

- Nei pazienti con BPCO trattati con steroidi per via sistemica è più elevata l'incidenza di complicanze di ulcera peptica (perforazione ed emorragia). In questi soggetti la mortalità è più elevata rispetto ai controlli.

- Gli steroidi per via inalatoria dovrebbero essere assunti correttamente, eventualmente utilizzando device distanziatori per prevenire eventuali sintomi digestivi.

Malattie infiammatorie croniche intestinali e funzionali

- Nei pazienti con BPCO l'incidenza di sindrome del colon irritabile è superiore rispetto alla popolazione generale.

- Nei pazienti con morbo di Crohn, ma non in quelli con colite ulcerosa, l'associazione con BPCO aumenta il rischio di mortalità di oltre 3 volte.

Epatite cronica, cirrosi

- L'epatite cronica HCV si associa a un deterioramento della funzionalità respiratoria nei soggetti con BPCO.

- Nella cirrosi epatica il rilievo di un'ipossiemia è frequente.

- Nella cirrosi epatica associata alla BPCO, l'alterazione meccanica legata all'ascite, la sindrome epatopolmonare e l'ipertensione polmonare sono le condizioni che inducono il deterioramento della funzione respiratoria.

\section{BPCO e malattie gastrointestinali}

Se si tiene conto della comune embriogenesi e della contiguità anatomica, si comprende come la malattia da reflusso gastroesofageo (MRGE) possa coinvolgere diversi segmenti delle vie respiratorie. Anzi, in uno studio di el-Serag et al. [1], è stato osservato che i pazienti con reflusso gastroesofageo, documentato dalla presenza di erosioni all'esame endoscopico, presentavano un rischio significativamente superiore ( $p<0,0001$ ) rispetto ai controlli di ammalarsi di malattie polmonari quali asma, bronchite cronica, bronchiectasie, polmoniti, fibrosi polmonare e broncopneumopatia cronica ostruttiva (BPCO).

\section{Malattia da reflusso gastroesofageo}

La MRGE è una patologia molto frequente: in un'indagine eseguita nella contea di Olmsted (Minnesota) [2], la 
prevalenza di reflusso gastroesofageo variava, in base al numero degli episodi di reflusso, dal $44 \%$ (un episodio mensile) al 20\% (1-2 episodi settimanali) sino al 10\% (episodi giornalieri). Negli ultimi trent'anni è stato osservato un notevole aumento dei casi di MRGE: un'analisi dei registri di oltre 179 Veteran's Hospitals statunitensi, relativa al periodo 1970-1995, ha dimostrato un incremento di casi di 7 volte tra gli uomini e di 4 volte tra le donne [3]. La MRGE ha una prevalenza simile nei due sessi, anche se l'esofagite è più frequente nel maschio (rapporto M/F 2-3:1).

Il reflusso gastroesofageo è comune nei pazienti adulti asmatici ed è considerato un potenziale "trigger" di asma. La prevalenza varia dal 30 all' $80 \%$ dei casi sulla base delle varie casistiche pubblicate [4,5]. La laringite posteriore - "laringite da reflusso" - rappresenta la condizione più comune, anche se non esclusiva [6], di patologia laringea correlata al reflusso gastroesofageo. Si associa a sintomi quali secchezza, disfonia, necessità di frequenti deglutizioni, ipersecrezione mucosa, tosse, disfagia e sensazione di globo. Da sottolineare, inoltre, che il reflusso gastroesofageo è causa di tosse cronica in una percentuale ( $20 \%$ circa) non trascurabile di soggetti [7] e rappresenta la terza causa di tosse cronica dopo la sindrome da Post-Nasal Drip (PND) e l'asma bronchiale.

Anche per la BPCO è stata dimostrata un'associazione con la MRGE. Si tratta di un'associazione casuale oppure vi è un nesso causale tra le due patologie? Gli studi epidemiologici disponibili riguardo all'associazione delle due patologie, seppur concordanti, non risultano omogenei né per numero di casi osservati né - e soprattutto - per i criteri di definizione di reflusso gastroesofageo. Il reflusso può essere definito dalla sola presenza di sintomatologia specifica seppur soggettiva quale "bruciore retrosternale" oppure dalla presenza di erosioni all'esame endoscopico [8] oppure - e questo rappresenta il gold standard - dalla positività della $\mathrm{pH}$-metria esofagea delle 24 ore $[9,10]$. In uno studio casocontrollo [11] eseguito in 100 pazienti portatori di BPCO mediante somministrazione di questionario (presenza di pirosi/rigurgito una o più volte/settimana), sintomi da reflusso sono risultati presenti nel $19 \%$ dei casi contro nessun caso osservato tra i 51 controlli ( $p<0,001)$. Nel gruppo di pazienti con BPCO i sintomi da reflusso risultavano avere una frequenza maggiore nei soggetti con $\mathrm{FEV} 1<50 \%$ rispetto a quelli con $\mathrm{FEV} 1>50 \%$ (50\% vs $27 \%$, rispettivamente; $p=0,08)$. Dal questionario risultava inoltre un maggiore utilizzo, statisticamente significativo $(p=0,008)$, di farmaci antireflusso tra i soggetti con BPCO rispetto ai controlli. In un altro studio [12] condotto in 41 pazienti con BPCO di grado severo e con un valore di FEV1 pari al 24\% del teorico, e nel quale la valutazione del reflusso gastroesofageo è stata eseguita mediante monitoraggio $\mathrm{pH}$-metrico delle 24 ore, la prevalenza di reflusso è stata evidenziata addirittura nel $57 \%$ dei casi.

Uno studio longitudinale eseguito in un numero considerevole di soggetti (4.391 pazienti affetti da MRGE e 1.628 da BPCO) seguiti per 5 anni ha dimostrato che nei soggetti con BPCO il rischio di sviluppare una malattia da reflusso è risultato significativamente superiore $(R R=1,46)$ rispetto ai soggetti di controllo. Peraltro non è stato dimostrato un aumento significativo del rischio di incidenza di BPCO nei pazienti con MRGE [13]. Rispetto agli studi precedenti, quest'ultimo lavoro, oltre a essere stato eseguito su una popolazione ampiamente rappresentativa, aggiunge un dato temporale che permette di documentare la relazione tra le due patologie: il follow-up a 5 anni, infatti, ha dimostrato come, nel tempo, la BPCO sembri predisporre i soggetti alla MRGE, ma non viceversa.

Per quanto riguarda i meccanismi patogenetici di questa interazione, non vi sono comunque interpretazioni univoche. Nell'asma bronchiale è stato ipotizzato un meccanismo reflusso-correlato per mezzo di riflesso esofago-bronchiale vago-mediato $[14,15]$ Un secondo meccanismo chiamato in causa è l'iperreattività bronchiale reflusso-indotta [16,17]: è stato dimostrato che l'instillazione di $\mathrm{HCl}$ in esofago aumenta la risposta broncomotoria indotta da vari stimoli Un terzo meccanismo ipotizzato è la microaspirazione di reflussato acido nell'albero tracheobronchiale $[18,19]$. Nei soggetti con BPCO la perfusione acida dell'esofago non aumenta la broncocostrizione [20]. Pertanto, anche se l'associazione tra le due patologie è stata osservata, non sono chiari i meccanismi patogenetici di interazione. Sicuramente i pazienti con BPCO sono particolarmente vulnerabili al reflusso acido gastroesofageo e ciò è dovuto ai notevoli mutamenti della pressione intratoracica, all'aumentata frequenza di tosse, all'appiattimento del diaframma [21].

La diagnosi di MRGE [22] si basa sopratutto sull'esame clinico: è infatti ampiamente dimostrato che il rilievo di una sintomatologia tipica (bruciore retrosternale) rappresenta un elemento altamente predittivo. Il sintomo "pirosi" ha dimostrato un'alta sensibilità e specificità anche se non vi è correlazione tra il danno mucoso e la frequenza e l'intensità degli episodi di reflusso: è pertanto possibile che pazienti senza esofagite riferiscano una sintomatologia severa, mentre soggetti con esofagite erosiva accusino, al contrario, sintomi lievi.

Le indagini diagnostiche hanno l'obiettivo di documentare la presenza del reflusso specialmente in quei soggetti con presentazione atipica o con sintomatologia perdurante e non responsiva alla terapia, nonché l'eventuale presenza di danno indotto dal reflusso alla mucosa esofagea.

L'esame radiologico con pasto baritato delle prime vie digestive appartiene ormai alla storia della medicina, essendo stato sostituito da indagini più specifiche e sensibili.

L'esofagoscopia è indicata nei pazienti in cui si sospettino un danno mucoso, come l'esofagite, e le eventuali complicanze, quali l'esofago di Barrett, l'ulcera peptica e la stenosi. A fronte di un'elevatissima specificità (quasi $100 \%$ ), l'indagine ha dimostrato una sensibilità non superiore al $40-45 \%$ [23]. Ciò dipende dal fatto che meno della metà dei pazienti con malattia sintomatica presenta lesioni specifiche reflusso-indotte, ovvero le erosioni ( fig. 1).

Sono state proposti numerosi schemi di classificazione dell'esofagite: negli ultimi due decenni del secolo scorso il sistema sicuramente più seguito è stato quello proposto da Savary. Da qualche anno la classificazione che ha ottenuto i maggiori consensi è il cosiddetto sistema Los Angeles (LA), proposto proprio per ridurre al minimo la variabilità interosservatore e per ottenere un maggior grado di riproducibilità $[24,25]$. Il sistema LA definisce i diversi gradi di esofagite - da A a D - in base alla presenza e all'estensione della lesione della mucosa, intesa come area di interruzione o eritema nettamente demarcata rispetto alla mucosa adiacente. A differenza di altre classificazioni, le complicanze della malattia da reflusso quali l'ulcera, la stenosi e l'esofago di Barrett, sono descritte separatamente. I risultati delle 

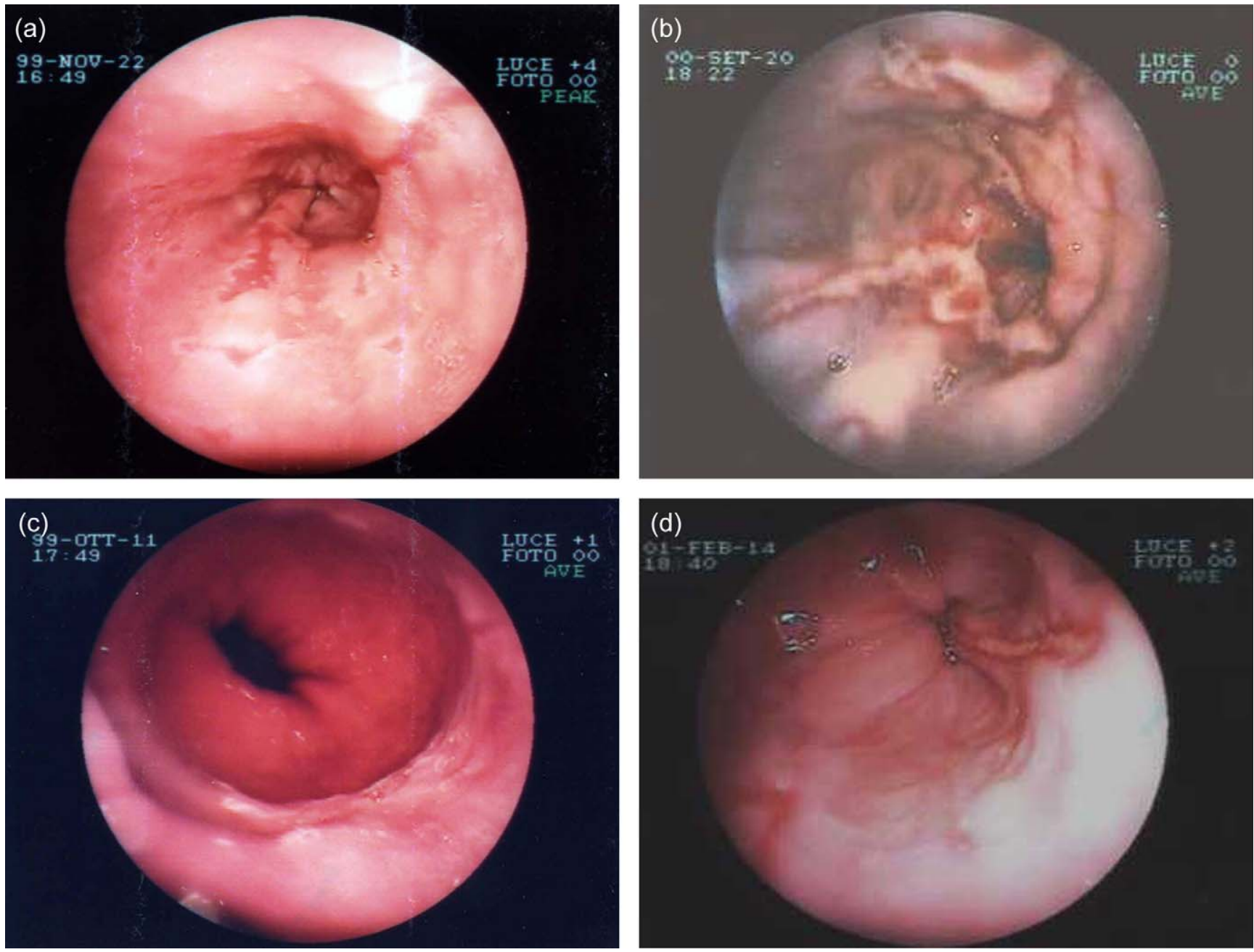

Figura 1 Quadri endoscopici di esofagite da reflusso gastroesofageo.

indagini endoscopiche riportate in letteratura indicano che oltre i due terzi dei pazienti con esofagite presentano lesioni di grado lieve o moderato equivalenti ai gradi A e B della classificazione LA.

Proprio a causa della non elevata sensibilità dell'esame endoscopico, soprattutto nella valutazione delle cosiddette manifestazioni atipiche e in quei soggetti nei quali si vuole dimostrare se la sintomatologia riferita è veramente secondaria al reflusso, sono state proposte diverse indagini. Una di queste è il test di Bernstein, ideato per riprodurre in laboratorio i sintomi del reflusso acido gastroesofageo. Il test consiste nella perfusione dell'esofago con $\mathrm{HCl} 0.1 \mathrm{~N}$. Se si verificano sintomi durante l'infusione acida, e non durante quella con soluzione fisiologica, il test è considerato positivo. Purtroppo il test ha una sensibilità molto variabile (dal 40 all' $80 \%$ nelle manifestazioni tipiche e nel $10-30 \%$ in quelle atipiche); come l'endoscopia, questo test è abbastanza affidabile in caso di risultato positivo, anche se un esito negativo non esclude la malattia da reflusso.

Un'altra indagine proposta per la diagnosi di reflusso gastroesofageo è la scintigrafia con pasto marcato con 99Tc colloidale. È un test non invasivo ma dotato di bassa sensibilità (50-60\%), costoso e non facilmente ripetibile a causa dell'impiego di radioisotopi.
Il monitoraggio ambulatoriale del $\mathrm{pH}$ nelle 24 ore rappresenta il gold standard per definire l'entità del reflusso e per correlare temporalmente i sintomi evocati con il reflusso medesimo. Il test viene eseguito posizionando per via transnasale un sottile catetere, provvisto di elettrodo all'estremità, $5 \mathrm{~cm}$ a monte della giunzione esofago-gastrica. Le rilevazioni vengono registrate su memoria solida e quindi analizzate con un software dedicato. Durante tutto il periodo della registrazione il paziente esegue le normali attività quotidiane e "marca" con un tasto sul recorder la comparsa di sintomi. L'esposizione acida viene definita come la percentuale di tempo in cui il pH è $<4$ : valori $>4 \%$ del tempo totale sono considerati patologici ( fig. 2). Il test è dotata di alta sensibilità (88\%) e specificità $(96 \%)$ e trova la principale applicazione nella malattia da reflusso senza esofagite, nella valutazione della terapia medica o nell'indicazione a un intervento di chirurgia antireflusso [9]. Benché il monitoraggio del $\mathrm{pH}$ nelle 24 ore rappresenti indubbiamente il gold standard, l'esecuzione dell'indagine richiede un impegno di personale e una dotazione strumentale tale da rendere il costo dell'esame non trascurabile. È proprio per queste sue caratteristiche che la $\mathrm{pH}$-metria prolungata non può essere proposta come test di primo livello. Non solo, ma si deve altresì sottolineare che tale indagine, in caso di positività, 


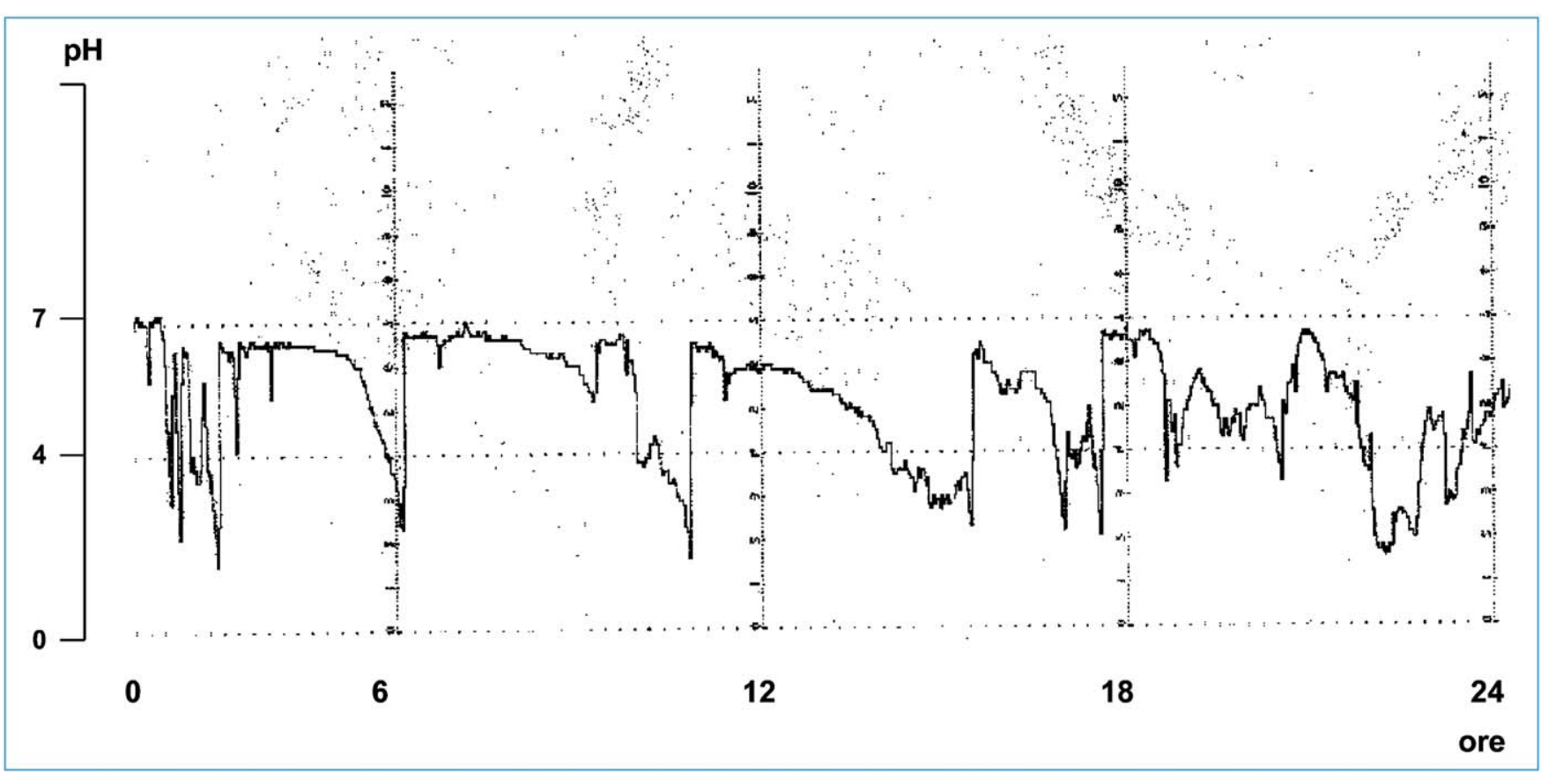

Figura 2 pH-metria delle 24 ore in soggetto con reflusso gastroesofageo patologico.

conferma il sospetto diagnostico di reflusso ma non conferma se sia il reflusso a evocare la sintomatologia riferita dal paziente. Sicuramente una relazione causa/effetto può essere documentata se la sintomatologia recede o migliora significativamente dopo un trattamento ex iuvantibus di terapia antisecretiva.

Infatti, proprio per definire correttamente il rapporto tra reflusso gastroesofageo e i sintomi correlati è stato proposto un approccio diagnostico che consiste in un trial empirico di terapia antisecretiva a dosi massimali con inibitori di pompa protonica (test PPI). Questo tipo di approccio diagnostico è sicuramente semplice, economico e bene accettato dal paziente [26]. Certamente non può sostituire indagini validate, ma può sicuramente costituire un'efficace alternativa, quantomeno in fase diagnostica iniziale, a indagini più complesse e costose. In studi recenti ha inoltre dimostrato una sensibilità e specificità comparabile a quella della $\mathrm{pH}$-metria nelle 24 ore [27]. Nella tabella 1 sono riportati i diversi livelli di predittività diagnostica delle indagini proposte nella diagnosi di MRGE.

Se la BPCO è un fattore favorente il reflusso gastroesofageo - ma non viceversa! - è stato altresì osservato che il reflusso può aumentare gli episodi di esacerbazione della BPCO. In uno studio prospettico [28], 82 soggetti con BPCO sono stati seguiti per 6 mesi e la frequenza delle riesacerbazioni era significativamente associata agli episodi di reflusso, valutati sulla base della frequenza dei sintomi. Il rischio relativo di incidenza di riacutizzazioni della BPCO in corso di reflusso risultava di 6,5 volte. In un altro studio [29], il tasso di esacerbazioni della BPCO correlato a episodi di reflusso gastroesofageo era doppio rispetto ai pazienti con BPCO senza MRGE (3,2 vs 1,6 episodi di riacutizzazione per anno; $p=0,02$ ).

Inoltre, è stato osservato che i pazienti con BPCO assumono farmaci antireflusso in percentuali (50\%) significativamente superiori rispetto ai controlli [11] e l'associazione delle due patologie - BPCO con MRGE - peggiora la qualità di vita rispetto ai pazienti con BPCO senza MRGE.

I dati disponibili in letteratura sembrerebbero quindi dimostrare come in questi pazienti si innesti un circolo vizioso: la BPCO predispone alla comparsa di episodi di reflusso gastroesofageo i quali, a loro volta, favorirebbero le riacutizzazioni della BPCO.

A questo punto sorge spontaneo il quesito se si debba o non si debba associare alla terapia antinfiammatoria e broncodilatatrice anche un trattamento con farmaci antireflusso. In uno studio [30] a singolo cieco non controllato, condotto in 100 pazienti anziani (età media 74,9 anni) con BPCO e seguiti per 12 mesi, i pazienti trattati, oltre alla terapia convenzionale, con il PPI lansoprazolo hanno avuto un numero di esacerbazioni significativamente ridotto $(O R=0,23)$ rispetto ai pazienti trattati con la sola terapia convenzionale $(0,34$ vs $1,18 ; p>0,001)$. Se il trattamento è in grado di prevenire la

\begin{tabular}{|c|c|c|}
\hline & $\begin{array}{c}\text { Sensibilità } \\
(\%)\end{array}$ & $\begin{array}{c}\text { Specificità } \\
(\%)\end{array}$ \\
\hline Esofago baritato & 40 & 85 \\
\hline Esofagoscopia & 55 & 96 \\
\hline Biopsia & 77 & 92 \\
\hline Scintigrafia con 99Tc & 61 & 95 \\
\hline Test di Bernstein & 45 & 80 \\
\hline Monitoraggio del $\mathrm{pH}$ nelle 24 ore & 88 & 96 \\
\hline $\begin{array}{l}\text { Test PPI (inibitori di pompa } \\
\text { protonica) }\end{array}$ & 85 & 95 \\
\hline
\end{tabular}


comparsa dei sintomi correlati al reflusso, non è stato analogamente dimostrato che il trattamento con PPI comporti un miglioramento della funzione respiratoria. Infatti, in uno studio randomizzato in doppio cieco contro placebo in 36 pazienti con broncopneumopatia ostruttiva trattati per 3 mesi con dosi massimali di omeprazolo, la terapia antisecretiva non ha avuto effetti benefici sui parametri di funzionalità respiratoria [31]. Purtroppo i due sopraccitati studi di intervento prendono in esame un numero non elevato di casi e ciò impedisce di trarre conclusioni solide. I dati sinora disponibili indicherebbero che la BPCO è una condizione predisponente alla MRGE cosi come questa, a sua volta, sembrerebbe avere un ruolo causale nelle riesacerbazioni della BPCO. In considerazione degli effetti positivi della terapia con PPI nel ridurre gli episodi di riacutizzazione, la presenza/assenza di un'associazione con MRGE deve essere valutata nei pazienti con BPCO così come deve essere valutata, qualora risulti una sequenzialità tra episodi di reflusso e riacutizzazioni dei sintomi respiratori, l'indicazione a una terapia antisecretiva.

Per quanto riguarda il versante terapeutico $e$ in particolare gli eventuali effetti del trattamento della broncopneumopatia sul reflusso gastroesofageo, quantunque teoricamente possibile per l'effetto potenzialmente ipotensivo sulla muscolatura dello sfintere esofageo inferiore, in letteratura non vi sono dati relativi al peggioramento dei sintomi da reflusso gastroesofageo in seguito a terapia con beta $2^{-}$ agonisti, così come non ve ne sono per gli steroidi inalatori. Per quanto riguarda l'impiego delle metilxantine, sono stati documentati in laboratorio un aumento della secrezione gastrica e una riduzione del tono dello sfintere esofageo inferiore. Questi dati suggerirebbero precauzione nell'utilizzo di tali sostanze nei pazienti con MRGE, anche se non vi sono studi clinici a sostegno. In uno studio in doppio cieco randomizzato contro placebo [32] è stato comparato l'effetto della teofillina per una settimana in pazienti adulti asmatici; al termine del trattamento non sono stati dimostrati incrementi significativi degli episodi di reflusso tra i due gruppi (teofillina vs placebo) valutati mediante $\mathrm{pH}$-metria prolungata nelle ore notturne. Gli autori concludevano che non esistono controindicazioni assolute all'uso di teofillina nei pazienti con MRGE.

Per quanto riguarda, dall'altro lato, gli effetti dei PPI sulla BPCO è stato ipotizzato che, a causa dell'aumento del $\mathrm{pH}$ gastrico, questi farmaci potrebbero aumentare la colonizzazione batterica dello stomaco e predisporre $i$ pazienti a un aumentato rischio di infezioni respiratorie [33]. In una metanalisi [34] basata su sette trial clinici controllati, seppur sia risultato evidente un trend a favore di un'associazione tra uso di PPI e infezioni respiratorie, non è stata raggiunta la significatività statistica dell'associazione (OR 1,42; $p=0,17)$. Sulla base di questi dati, anche se è d'obbligo raccomandare la massima attenzione e appropriatezza nell'utilizzo dei PPI, non sembrerebbero esservi indicazioni circa le limitazioni d'uso per i PPI nei pazienti con BPCO.

\section{Ulcera peptica}

L'ulcera peptica, diversamente dalla MRGE, è una patologia in costante e significativo decremento negli ultimi anni. Due sono i principali agenti eziologici correlati alla malattia: l'infezione da Helicobacter pylori e l'uso di farmaci antinfiammatori non steroidei; una quota di ulcere, sicuramente minoritaria, tuttavia non riconosce questi due agenti causali.

L'incidenza di ulcera peptica è significativamente più elevata (30\%) nei pazienti con BPCO rispetto alla popolazione generale [35]; in particolare, l'ulcera gastrica risulta maggiormente rappresentata rispetto all'ulcera duodenale. Sono diversi i fattori chiamati in causa a giustificare quest'aumentata associazione. Probabilmente il fumo e l'utilizzo di farmaci steroidei - condizioni, queste, presenti nei pazienti con BPCO - rappresentano due fattori di rischio ben noti per l'insorgenza di ulcera gastrica e duodenale [36]. In passato si era ipotizzato un ruolo delle alterazioni dell'equilibrio acidobase indotte dalla patologia polmonare, ma negli anni successivi è stato osservato che l'incidenza di ulcera non correla né con la gravità della malattia né con i livelli di $\mathrm{pCO}_{2}$ [37]. Nei pazienti con BPCO è stata segnalata una sieroprevalenza dell'infezione da Helicobacter pylori rispetto a un gruppo di controllo [38] e i livelli di anticorpi IgG anti-Helicobacter pylori erano correlati alla severità della broncopneumopatia. Un'aumentata esposizione all'Helicobacter pylori è stata segnalata anche in un altro studio nel quale, peraltro, si è osservato che non vi era una riduzione significativa di FEV1 e FVC in soggetti con BPCO in un follow-up di 9 anni [39]. Entrambi gli studi, basati sulla sieroprevalenza dell'infezione, hanno sicuramente fornito un contributo dal punto di vista epidemiologico, dimostrando un'associazione tra il microrganismo e la broncopneumopatia. Sulla base di questi dati si può ipotizzare che l'aumentata incidenza di ulcera peptica possa essere correlata all'infezione da Helicobacter pylori anche se, è importante sottolineare, gli studi citati non hanno dimostrato direttamente la presenza di patologia gastroduodenale con l'esame endoscopico.

La diagnosi di ulcera peptica si basa sull'esame endoscopico delle vie digestive superiori (fig. 3) che permette di visualizzare direttamente la lesione localizzata a livello dello stomaco e del duodeno. La valutazione dell'infezione da Helicobacter pylori può essere eseguita nel corso dell'esame endoscopico mediante test rapido all'ureasi, l'esame morfologico della mucosa prelevata con biopsia oppure mediante indagini non invasive (tabella 2): $13 \mathrm{C}$ urea breath test, ricerca degli anticorpi nel siero o nelle feci del paziente [40].

Il trattamento dell'ulcera peptica si basa sulla terapia antisecretoria con PPI, che garantisce una guarigione nell' 80 $100 \%$ dei casi dopo 4-8 settimane di assunzione del farmaco. Nell'ulcera peptica Helicobacter pylori-relata la terapia eradicante prevede un trattamento combinato con claritromicina associata ad amoxicillina o metronidazolo per una durata variabile da 7 a 14 giorni. La triplice terapia (i due antibiotici associati a un PPI) comporta un'eradicazione del microrganismo in una percentuale non superiore all' $80 \%$ dei casi [41].

Nei pazienti con BPCO è stata osservata un'aumentata mortalità dovuta a complicanze maggiori dell'ulcera peptica rispetto ai controlli. In uno studio retrospettivo danese nel quale venivano presi in considerazione oltre 7.500 pazienti ospedalizzati nel periodo 1991-2004 per la comparsa di emorragia o perforazione da ulcera peptica, la mortalità a 30 giorni dal ricovero risultava significativamente superiore (44\% vs $25,5 \%$ negli ospedalizzati per perforazione; $16,5 \%$ vs $10,8 \%$ negli ospedalizzati per emorragia) nei soggetti in cui l'ulcera peptica era associata a BPCO rispetto ai pazienti 

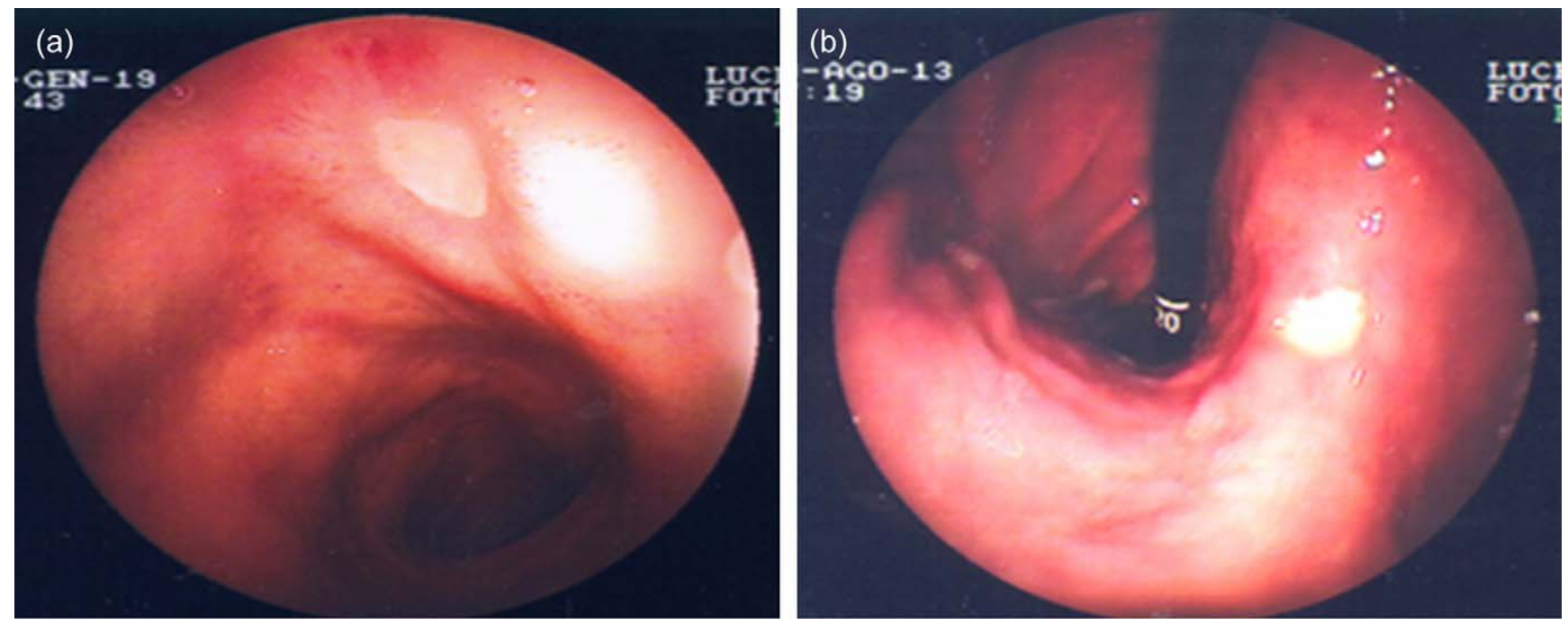

Figura 3 Quadri endoscopici di ulcera duodenale (a) e gastrica (b).

senza questa comorbilità [42]. Nelle complicanze maggiori dell'ulcera peptica un ruolo importante è svolto dal trattamento corticosteroideo. Infatti nei pazienti con ulcera perforata [43] il trattamento con cortisonici per via orale nei giorni precedenti il ricovero era associato a un aumento di circa 2 volte della mortalità a 30 giorni nei pazienti con $\mathrm{BPCO}$ $(39,4 \%)$ rispetto a quelli non steroido-trattati $(25,2 \%)$. Questi dati confermano conoscenze ormai consolidate: nei soggetti trattati con corticosteroidei l'incidenza di ulcera peptica, emorragia digestiva, perforazione è significativamente superiore ai non trattati [44].

Per quanto riguarda invece gli steroidi per inalazione, $i$ dati in letteratura non sono altrettanto concordanti $[45,46]$ circa eventuali effetti sistemici secondari. In uno studio retrospettivo condotto su una coorte di pazienti affetti da patologia respiratoria osservati tra il 1977 e il 2002 e trattati con steroidi inalatori o albuterolo sono stati valutati gli effetti collaterali gastrointestinali. I soggetti trattati con steroidi inalatori presentavano un minimo rischio di eventi gastrolesivi (prevalentemente gastrite); il rischio veniva significativamente ridotto se la somministrazione del farmaco avveniva per mezzo di apposito device distanziatore [47]. Infatti è stato documentato da studi scintigrafici [48]

Tabella 2 Test diagnostici per infezione da Helicobacter pylori.

\begin{tabular}{lcc}
\hline Test diagnostici & $\begin{array}{c}\text { Sensibilità } \\
(\%)\end{array}$ & $\begin{array}{c}\text { Specificità } \\
(\%)\end{array}$ \\
\hline Non invasivi & & \\
- Rapid Office Test (ROT) & 90 & 70 \\
- IgG ELISA (siero) & 95 & 70 \\
- 13C urea breath test & 98 & 97 \\
- HpSA EIA (feci) & 94 & 92 \\
Invasivi & & \\
- Test rapido dell'ureasi & 90 & 95 \\
- Istologia & 98 & 98 \\
- Esame colturale & 90 & 99 \\
\hline
\end{tabular}

come parti considerevoli del farmaco radiomarcato raggiungano l'esofago e quindi il tratto gastrointestinale. D'altra parte, se si applica il device distanziatore, solo una piccola quantità di farmaco si ritrova nel tratto digestivo superiore. $\grave{E}$ proprio la quantità di farmaco che raggiunge, attraverso la deglutizione, la mucosa gastrointestinale e che può essere significativamente ridotta per mezzo di idonei distanziatori la causa di effetti collaterali a livello gastroduodenale.

\section{Malattie intestinali}

Diversamente dalle patologie tratto digestivo superiore, per le quali vi sono dati relativi alla comorbilità con la BPCO, per quanto riguarda le malattie intestinali, siano esse organiche o funzionali, sono veramente molto scarse le informazioni disponibili circa l'insorgenza di sintomi gastrointestinali.

In uno studio svedese [49] condotto si 113 pazienti con BPCO è stato somministrato un questionario per l'autovalutazione del Gastrointestinal Symptom-Rating Score (GSRS), dei criteri Rome II per la sindrome del colon irritabile e il Psychological General Well-Being index (PGWB). Lo score del GSRS è risultato significativamente superiore nei soggetti con BPCO rispetto ai controlli, così come significativamente ridotto è risultato lo score PGWB con una correlazione negativa significativa tra quest'ultimo e i sintomi digestivi ( $p<0,001$ ). In questo studio, inoltre, ben il $14 \%$ dei pazienti con BPCO soddisfacevano i criteri Rome II per la sindrome del colon irritabile.

Anche per quanto riguarda le malattie croniche infiammatorie intestinali (colite ulcerosa e morbo di Crohn) sono disponibili scarse segnalazioni su un eventuale rapporto tra le due patologie, inteso sia come ipotetici fattori di rischio comuni sia come interazioni della terapia dell'una patologia sull'altra e viceversa. Dai dati della letteratura risulta per esempio che il fumo, il cui ruolo causale nella BPCO è dimostrato, è un fattore di rischio per il morbo di Crohn mentre non lo è per la colite ulcerosa [50].

Per quanto riguarda, invece, il ruolo della comorbilità tra le due patologie sugli outcome, uno studio prospettico [51] 
eseguito su una coorte di 692 pazienti affetti da malattie infiammatorie croniche intestinali nella contea do Olmsted (Minnesota), finalizzato alla valutazione della sopravvivenza a lungo termine e delle cause di mortalità, ha dimostrato che nei pazienti con morbo di Crohn, ma non in quelli con colite ulcerosa, la coesistenza di una BPCO aumentava il rischio di mortalità (rapporto morti osservate/morti attese $=3,5$ ).

\section{BPCO e malattie del fegato}

Molte pneumopatie possono essere associate a malattie croniche del fegato: patologie epatiche quali la cirrosi biliare primitiva e l'epatite cronica autoimmune possono essere associate a patologie polmonari immuno-mediate, così come alcune patologie sistemiche che colpiscono sia il polmone sia il fegato, la fibrosi cistica, il deficit di alfa ${ }_{1}$-antitripsina, la sarcoidosi ecc.

L'alcol e l'infezione da virus epatitici B e C sono gli agenti eziologici maggiormente responsabili delle malattie croniche del fegato e della cirrosi in particolare. L'infezione da virus dell'epatite C (HCV) rappresenta la causa più frequente di persistenza, cronicizzazione dell'epatite e sviluppo di cirrosi. L'interferone e farmaci antivirali quali la ribavirina costituiscono la terapia di elezione in questi casi, per bloccare l'infezione o comunque per rallentare la progressione della malattia.

\section{Epatite cronica da HCV}

È stato ipotizzato per le malattie virali croniche un aumento del rischio di danno polmonare mediato dai T-linfociti citotossici virus-relati. In uno studio giapponese [52] sono stati valutati 30 pazienti con BPCO con associata epatite cronica da HCV (15 fumatori e 15 non o ex fumatori) seguiti per 5 anni e confrontati con 25 pazienti con BPCO senza infezione da HCV. Lo studio ha messo in evidenza una riduzione significativa ( $p<0,001$ ) della funzione respiratoria (FEV1 e DLCO) nel gruppo HCV positivi vs HCV negativi indipendentemente dal fatto di essere fumatori, ex fumatori o non fumatori. Al termine del follow-up 21 soggetti HCV postivi sono stata trattati con interferone-alfa per 24 settimane. Al termine del trattamento i soggetti responder all'interferone (ovvero con HCV-RNA non rilevabile nel siero) mostravano un miglioramento significativo ( $\mathrm{p}<0,01$ ) del FEV1 rispetto ai trattati e non responder. Questo studio, pur con i limiti di un numero di pazienti trattati non elevato, sembrerebbe suggerire, qualora confermato da casistiche più ampie, che l'infezione da $\mathrm{HCV}$ può accelerare il declino della funzione respiratoria nei pazienti con BPCO. Declino che può essere rallentato dalla terapia antivirale con interferone.

\section{Cirrosi epatica}

I pazienti con cirrosi epatica hanno un aumentato rischio di alterazioni respiratorie che possono influenzare negativamente sia la qualità sia la durata di vita. Con la progressione della malattia la dispnea può insorgere anche a riposo e l'ipossiemia è un reperto frequente nei pazienti cirrotici, variabile dal 20 al $40 \%$. Le manifestazioni polmonari che possono associarsi alle malattie croniche epatiche in fase avanzata sono:

- l'alterazione della meccanica polmonare causata dall'ascite;

- la sindrome epatopolmonare (HPS);

- l'ipertensione portopolmonare (POPH).

Le ultime due manifestazioni restano molto spesso misconosciute o comunque sottostimate anche se rappresentano condizioni che hanno un notevole impatto sulla sopravvivenza di questi pazienti e richiedono un trattamento specifico [53].

L'accumulo di versamento ascitico può portare ad anomalie significative della meccanica polmonare e della pressione intraddominale e intratoracica, spesso aggravate dal concomitante versamento pleurico (equivalente ascitico sovradiaframmatico). Queste alterazioni provocano una riduzione dei volumi polmonari, compresa la capacità polmonare totale. La progressiva riduzione dei volumi polmonari e della superficie alveolare funzionale comporta ipossiemia. Di solito i sintomi respiratori migliorano dopo paracentesi evacuative di almeno 4-5 L o comunque dopo terapia diuretica combinata efficace (fig. 4) con associazione di spironolattone $100 \mathrm{mg}$ + furosemide $40 \mathrm{mg}$ come dosaggio basale e restrizione alimentare di cloruro di sodio a $2 \mathrm{~g} /$ die [54].

Nei pazienti con BPCO associata a epatopatia cronica ascitica la funzionalità respiratoria e l'ipossiemia in particolare risultano maggiormente compromesse anche per volumi di ascite non elevati; pertanto in questi pazienti, in caso di peggioramento della dispnea, prima di attribuirlo a una riacutizzazione o comunque a una causa polmonare, dovrebbe essere esclusa una riduzione volumetrica indotta da versamento ascitico e/o pleurico.

La HPS è più complessa: il determinante fisiopatologico specifico è dato dall'abnorme dilatazione vascolare intrapolmonare secondaria alla riduzione delle resistenze vascolari polmonari con conseguente shunt arterioso polmonare dagli alveoli funzionali, alterata ossigenazione e ipossiemia secondaria all'alterato scambio gassoso. La sindrome non è correlata alla gravita dell'epatopatia e può svilupparsi non solo nelle fasi avanzate della malattia ma anche in assenza di ascite. L'esercizio peggiora ulteriormente il grado di shunting intrapolmonare [55]. Non è stata ancora definita la patogenesi delle alterazioni circolatorie polmonari, anche se è verosimile un concorso multifattoriale legato a inadeguata sintesi o alterato metabolismo di sostanze vasoattive polmonari.

La diagnosi di HPS si basa sui seguenti criteri:

- epatopatia cronica;

- assenza di malattia cardiaca o polmonare intrinseca;

- anomalie degli scambi gassosi polmonari con aumentato gradiente alveolo-arterioso di ossigeno e ipossiemia; - evidenza di shunt intrapolmonare.

Per la valutazione di quest'ultimo elemento, che rappresenta peraltro il momento fisiopatologico più importante, sono state proposte diverse indagini diagnostiche; l'ecocardiografia con mezzo di contrasto è attualmente la metodica dotata di maggiore sensibilità in quanto capace di rilevare dilatazioni del letto vascolare polmonare [56]. Giova comunque ricordare che l'ipossiemia non è dovuta solo allo shunt intrapolmonare; altri meccanismi quali l'alterazione del rapporto ventilazione/per fusione, l'alterata diffusione dell'ossigeno e le variazioni emodinamiche sistemiche 


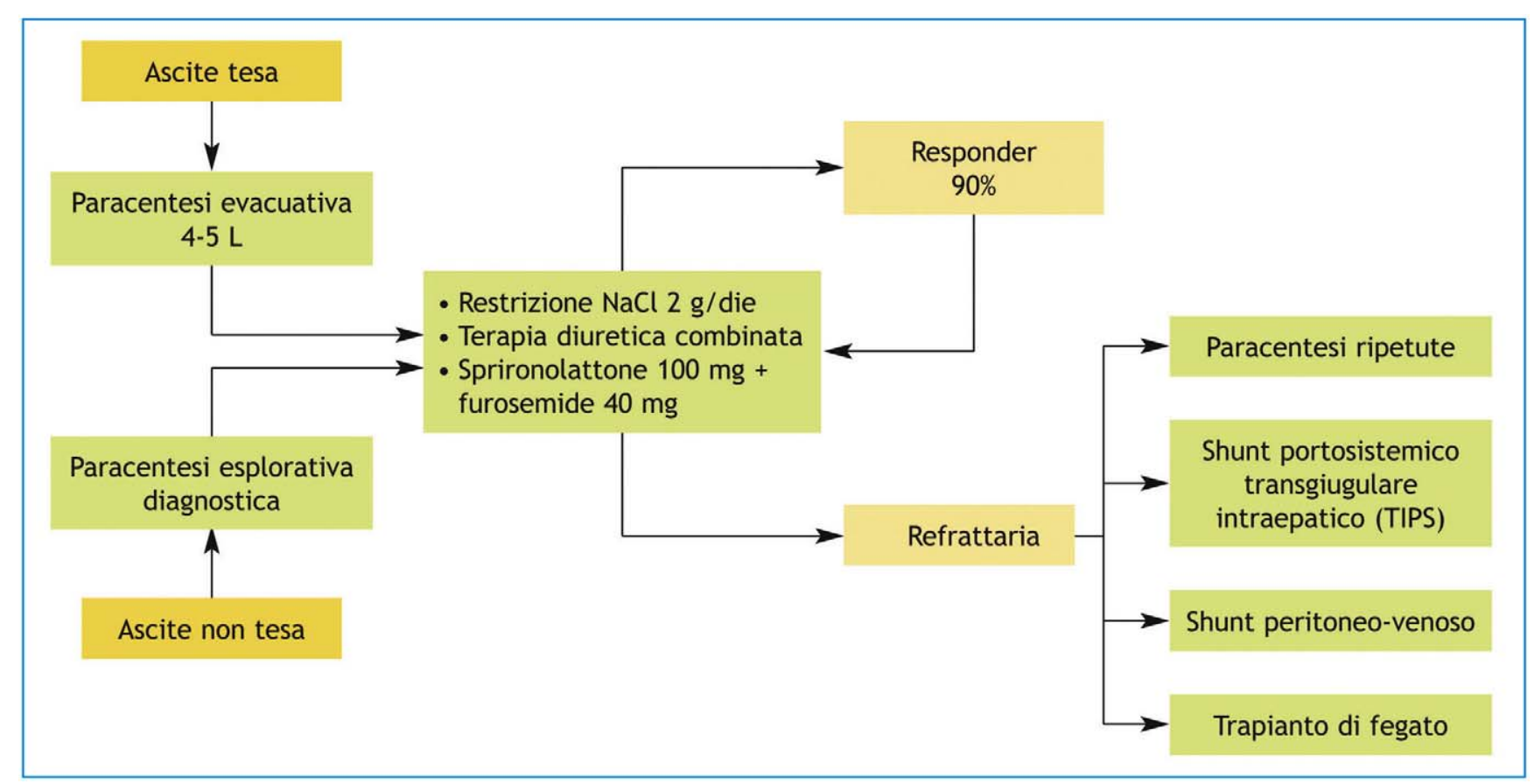

Figura 4 Terapia dell'ascite cirrotica.

possono svolgere un ruolo più o meno rilevante nel determinare la riduzione della $\mathrm{PaO}_{2}$.

La POPH invece è caratterizzata da un'eccessiva vasocostrizione arteriolare polmonare e da un rimodellamento vascolare e può essere causa di scompenso destro. Poco si conosce sulla patogenesi per la mancanza di studi che abbiano valutato la prevalenza dell'ipertensione polmonare nei pazienti cirrotici, e probabilmente questa condizione è sottostimata. È stato ipotizzato che in alcuni soggetti l'ipertensione polmonare si sviluppi a causa dello shunt portosistemico di alcune sostanze vasoattive. La diagnosi di ipertensione polmonare complicante una cirrosi epatica dovrebbe essere sospettata in presenza di una forte componente polmonare del secondo tono e confermata con un esame ecocardiografico, che permette di dimostrare una dilatazione delle cavità cardiache destre, un'ipertrofia ventricolare destra e una pressione arteriosa polmonare $>40$ $\mathrm{mmHg}$ [57].

La terapia farmacologica dell'HPS e della POPH appare alquanto deludente, anche perché ancora poco note sono le cause determinanti il quadro patologico. La sola terapia di supporto basata sull'ossigenoterapia e, se coesistente, il trattamento intensivo dell'ascite non migliorano complessivamente la prognosi del paziente. Solo il trapianto ortotopico del fegato può risolvere con successo lo shunt intrapolmonare e l'ipertensione arteriosa polmonare e correggere l'insufficienza respiratoria [58].

Sia l'HPS sia la POPH possono complicare una cirrosi epatica - indipendentemente da eziologia, età e sesso nelle fasi avanzate della malattia ma possono, d'altra parte, porre problemi di diagnostica differenziale con altre patologie croniche polmonari - BPCO in primis - così come possono coesistere con esse.

Nei pazienti con malattia cronica epatica la BPCO ha una prevalenza superiore rispetto alla popolazione generale, verosimilmente per la coesistenza a livello socioambientale di condizioni di rischio (fumo, alcol) per entrambe le patologie. L'insorgenza di HPS e/o POPH nei soggetti in cui coesistono sia l'epatopatia cronica sia la BPCO è 2-3 volte superiore rispetto ai cirrotici senza BPCO e determina un ulteriore peggioramento della qualità di vita e della prognosi [59]. In questi soggetti, infatti, anche minime riduzioni della funzionalità respiratoria comportanti una riduzione anche lieve-moderata della $\mathrm{PaO}_{2}$ si sommano alle alterazioni respiratorie proprie della broncopneumopatia. Pertanto, identificare precocemente la comparsa di queste condizioni e inviarle a un centro trapiantologico rappresenta l'unica soluzione terapeutica adeguata anche se, in tali soggetti, il rischio della procedura è sicuramente aumentato.

\section{Bibliografia}

[1] el-Serag HB, Sonnenberg A. Comorbid occurrence of laryngeal or pulmonary disease with esophagitis in United States military veterans. Gastroenterology 1997;113(3):755-60.

[2] Locke 3rd GR, Talley NJ, Fett SL, Zinsmeister AR, Melton 3rd LJ. Prevalence and clinical spectrum of gastroesophageal reflux: a population-based study in Olmsted County, Minnesota. Gastroenterology 1997;112(5):1448-56.

[3] el-Serag HB, Sonnenberg A. Opposing time trends of peptic ulcer and reflux disease. Gut 1998;43(3):327-33.

[4] Harding SM. Gastroesophageal reflux and asthma: insight into the association. J Allergy Clin Immunol 1999;104(2 Pt 1):251-9.

[5] Harding SM, Richter JE, Guzzo MR, Schan CA, Alexander RW, Bradley LA. Asthma and gastroesophageal reflux: acid suppressive therapy improves asthma outcome. Am J Med 1996; 100(4):395-405.

[6] Shaker R, Milbrath M, Ren J, Toohill R, Hogan WJ, Li Q, et al. Esophagopharyngeal distribution of refluxed gastric acid in patients with reflux laryngitis. Gastroenterology 1995;109(5): 1575-82. 
[7] Irwin RS, Curley FJ, French CL. Chronic cough. The spectrum and frequency of causes, key components of the diagnostic evaluation, and outcome of specific therapy. Am Rev Respir Dis 1990;141(3):640-7.

[8] Ronkainen J, Aro P, Storskrubb T. Prevalence of esophagitis and endoscopy-negative reflux disease in a population. A report of Kalixanda Study. Gastroenterology 2002;122(Suppl): 213.

[9] Franzén T, Grahn LT. Reliability of 24-hour oesophageal pH monitoring under standardized conditions. Scand J Gastroenterol 2002;37(1):6-8.

[10] Vaezi MF, Schroeder PL, Richter JE. Reproducibility of proximal probe $\mathrm{pH}$ parameters in 24-hour ambulatory esophageal $\mathrm{pH}$ monitoring. Am J Gastroenterol 1997;92(5):825-9.

[11] Mokhlesi B, Morris AL, Huang CF, Curcio AJ, Barrett TA, Kamp DW. Increased prevalence of gastroesophageal reflux symptoms in patients with COPD. Chest 2001;119(4):1043-8.

[12] Kempainen RR, Savik K, Whelan TP, Dunitz JM, Herrington CS, Billings JL. High prevalence of proximal and distal gastroesophageal reflux disease in advanced COPD. Chest 2007;131(6): 1666-71.

[13] García Rodríguez LA, Ruigómez A, Martín-Merino E, Johansson S, Wallander MA. Relationship between gastroesophageal reflux disease and COPD in UK primary care. Chest 2008;134(6): 1223-30.

[14] Wright RA, Miller SA, Corsello BF. Acid-induced esophagobronchial-cardiac reflexes in humans. Gastroenterology 1990;99(1): 71-3.

[15] Schan CA, Harding SM, Haile JM, Bradley LA, Richter JE. Gastroesophageal reflux-induced bronchoconstriction. An intraesophageal acid infusion study using state-of-the-art technology. Chest 1994;106(3):731-7.

[16] Herve P, Denjean A, Jian R, Simonneau G, Duroux P. Intraesophageal perfusion of acid increases the bronchomotor response to methacholine and to isocapnic hyperventilation in asthmatic subjects. Am Rev Respir Dis 1986;134(5):986-9.

[17] Vincent D, Cohen-Jonathan AM, Leport J, Merrouche $M$, Geronimi A, Pradalier A, et al. Gastro-oesophageal reflux prevalence and relationship with bronchial reactivity in asthma. Eur Respir J 1997;10(10):2255-9.

[18] Jack CI, Calverley PM, Donnelly RJ, Tran J, Russell G, Hind CR, et al. Simultaneous tracheal and oesophageal $\mathrm{pH}$ measurements in asthmatic patients with gastro-oesophageal reflux. Thorax 1995;50(2):201-4.

[19] Tuchman DN, Boyle JT, Pack Al, Scwartz J, Kokonos M, Spitzer $A R$, et al. Comparison of airway responses following tracheal or esophageal acidification in the cat. Gastroenterology 1984;87(4):872-81.

[20] Orr WC, Shamma-Othman Z, Allen M, Robinson MG. Esophageal function and gastroesophageal reflux during sleep and waking in patients with chronic obstructive pulmonary disease. Chest 1992;101(6):1521-5.

[21] Crowell MD, Zayat EN, Lacy BE, Schettler-Duncan A, Liu MC. The effects of an inhaled beta(2)-adrenergic agonist on lower esophageal function: a dose-response study. Chest 2001;120(4): 1184-9.

[22] Richter JE, Castell DO. Gastroesophageal reflux. Pathogenesis, diagnosis, and therapy. Ann Intern Med 1982;97(1):93-103.

[23] Ollyo J, Fontolliet C, Brossard E. La nouvelle classification de Savary des oesophagites de reflux. Acta Endosc 1992;22: 307-20.

[24] Lundell LR, Dent J, Bennett JR, Blum AL, Armstrong D, Galmiche $J P$, et al. Endoscopic assessment of oesophagitis: clinical and functional correlates and further validation of the Los Angeles classification. Gut 1999;45(2):172-80.

[25] Tam W, Edebo A, Bruno M. Endoscopy negative reflux disease (ENRD): high resolution endoscopic and histological signs. Gastroenterology 2002;122(Suppl):A74.
[26] Schenk BE, Kuipers EJ, Klinkenberg-Knol EC, Festen HP, Jansen $\mathrm{EH}$, Tuynman HA, et al. Omeprazole as a diagnostic tool in gastroesophageal reflux disease. Am J Gastroenterol 1997;92(11):1997-2000.

[27] Johnsson F, Hatlebakk JG, Klintenberg AC, Román J, Toth E, Stubberöd A, et al. One-week esomeprazole treatment: an effective confirmatory test in patients with suspected gastroesophageal reflux disease. Scand J Gastroenterol 2003;38(4): 354-9.

[28] Terada K, Muro S, Sato S, Ohara T, Haruna A, Marumo S, et al. Impact of gastro-oesophageal reflux disease symptoms on COPD exacerbation. Thorax 2008;63(11):951-5.

[29] Rascon-Aguilar IE, Pamer M, Wludyka P, Cury J, Coultas D, Lambiase LR, et al. Role of gastroesophageal reflux symptoms in exacerbations of COPD. Chest 2006;130(4):1096-101.

[30] Sasaki T, Katsutoshi N, Hiroyasu Y, Takaaki A, Takashi O, Hiroyuki A, Jun A, Kazuyoshi K, Mutuo Y, Sasaki T, Nakayama K, Yasuda H, Yoshida M, Asamura T, Ohrui T, et al. A randomized, single-blind study of lansoprazole for the prevention of exacerbations of chronic obstructive pulmonary disease in older patients. J Am Geriatr Soc 2009;57(8):1453-7.

[31] Langman MJ, Cooke AR. Gastric and duodenal ulcer and associated diseases. Lancet 1976;1:680-3.

[32] Hubert D, Gaudric M, Guerre J, Lockhart A, Marsac J. Effect of theophylline on gastroesophageal reflux in patients with asthma. J Allergy Clin Immunol 1988;81(6):1168-74.

[33] Sarkar M, Hennessy S, Yang YX. Proton-pump inhibitor use and the risk for community-acquired pneumonia. Ann Intern Med 2008;149(6):391-8.

[34] Sultan N, Nazareno J, Gregor J. Association between proton pump inhibitors and respiratory infections: a systematic review and meta-analysis of clinical trials. Can J Gastroenterol 2008;22(9):761-6.

[35] Boeree MJ, Peters FT, Postma DS, Kleibeuker JH. No effects of high-dose omeprazole in patients with severe airway hyperresponsiveness and (a)symptomatic gastro-oesophageal reflux. Eur Respir J 1998;11(5):1070-4.

[36] Stemmermann GN, Marcus EB, Buist AS, MacLean CJ. Relative impact of smoking and reduced pulmonary function on peptic ulcer risk. prospective study of Japanese men in Hawaii. Gastroenterology 1989;96(6):1419-24.

[37] Kellow JE, Tao Z, Piper DW. Ventilatory function in chronic peptic ulcer. A controlled study of ventilatory function in patients with gastric and duodenal ulcer. Gastroenterology 1986;91(3):590-5.

[38] Gencer M, Ceylan E, Yildiz Zeyrek F, Aksoy N. Helicobacter pylori seroprevalence in patients with chronic obstructive pulmonary disease and its relation to pulmonary function tests. Respiration 2007;74(2):170-5.

[39] Fullerton D, Britton JR, Lewis SA, Pavord ID, McKeever TM, Fogarty AW. Helicobacter pylori and lung function, asthma, atopy and allergic disease-a population-based cross-sectional study in adults. Int J Epidemiol 2009;38(2):419-26.

[40] Vaira D, Malfertheiner P, Mégraud F, Axon AT, Deltenre M, Hirschl AM, et al. Diagnosis of Helicobacter pylori infection with a new non-invasive antigen-based assay. HpSA European study group. Lancet 1999;354(9172):30-3.

[41] Gisbert JP, González L, Calvet X, García N, López T, Roqué M, et al. Proton pump inhibitor, clarithromycin and either amoxycillin or nitroimidazole: a meta-analysis of eradication of Helicobacter pylori. Aliment Pharmacol Ther 2000;14(10):1319-28.

[42] Christensen S, Thomsen RW, Tørring ML, Riis A, Nørgaard M, Sørensen HT. Impact of COPD on outcome among patients with complicated peptic ulcer. Chest 2008;133(6):1360-6.

[43] Christensen S, Riis A, Nørgaard M, Thomsen RW, Tønnesen EM, Larsson A, et al. Perforated peptic ulcer: use of pre-admission oral glucocorticoids and 30-day mortality. Aliment Pharmacol Ther 2006;23(1):45-52. 
[44] Messer J, Reitman D, Sacks HS, Smith Jr H, Chalmers TC. Association of adrenocorticosteroid therapy and peptic-ulcer disease. N Engl J Med 1983;309(1):21-4.

[45] Tashkin DP, Murray HE, Skeans M, Murray RP. Skin manifestations of inhaled corticosteroids in COPD patients: results from Lung Health Study II. Chest 2004;126(4):1123-33.

[46] Barnes NC. Safety of high-dose inhaled corticosteroids. Respir Med 1993;87(Suppl A):27-31.

[47] Hansen RA, Tu W, Wang J, Ambuehl R, McDonald CJ, Murray MD. Risk of adverse gastrointestinal events from inhaled corticosteroids. Pharmacotherapy 2008;28(11):1325-34.

[48] Trescoli C, Ward MJ. Systemic activity of inhaled and swallowed beclomethasone dipropionate and the effect of different inhaler devices. Postgrad Med J 1998;74(877):675-7.

[49] Niklasson A, Strid $H$, Simrén $M$, Engström CP, Björnsson E. Prevalence of gastrointestinal symptoms in patients with chronic obstructive pulmonary disease. Eur J Gastroenterol Hepatol 2008;20(4):335-41.

[50] García Rodríguez LA, González-Pérez A, Johansson S, Wallander MA. Risk factors for inflammatory bowel disease in the general population. Aliment Pharmacol Ther 2005;22(4):309-15.

[51] Jess T, Loftus Jr EV, Harmsen WS, Zinsmeister AR, Tremaine WJ, Melton 3rd LJ, et al. Survival and cause specific mortality in patients with inflammatory bowel disease: a long term outcome study in Olmsted County, Minnesota, 1940-2004. Gut 2006;55(9):1248-54.
[52] Kanazawa H, Hirata K, Yoshikawa J. Accelerated decline of lung function in COPD patients with chronic hepatitis $C$ virus infection: a preliminary study based on small numbers of patients. Chest 2003;123(2):596-9.

[53] Rodríguez-Roisin R, Agustí AG, Roca J. The hepatopulmonary syndrome: new name, old complexities. Thorax 1992;47(11): 897-902.

[54] Angueira CE, Kadakia SC. Effects of large-volume paracentesis on pulmonary function in patients with tense cirrhotic ascites. Hepatology 1994;20(4 Pt 1):825-8.

[55] Fallon MB, Abrams GA. Hepatopulmonary syndrome. Curr Gastroenterol Rep 2000;2(1):40-5.

[56] Abrams GA, Jaffe CC, Hoffer PB, Binder HJ, Fallon MB. Diagnostic utility of contrast echocardiography and lung perfusion scan in patients with hepatopulmonary syndrome. Gastroenterology 1995;109(4):1283-8.

[57] Hoeper MM, Krowka MJ, Strassburg CP. Portopulmonary hypertension and hepatopulmonary syndrome. Lancet 2004; 363(9419):1461-8.

[58] Koneru B, Ahmed S, Weisse AB, Grant GP, McKim KA. Resolution of pulmonary hypertension of cirrhosis after liver transplantation. Transplantation 1994;58(10):1133-5.

[59] Nevzorova VA, Pestrikova TL, Kochetkova EA, Osvald $M$, Doutreleau S, Massard G. Hepatopulmonary syndrome characteristics in hepatic cirrhosis associated with COPD. Ter Arkh 2009;81(3):15-9. 


\section{BPCO ed emopatie}

\section{Giuseppe Chesi, Attilio Grechi, Eleonora Spaggiari, Giorgio Bonardi, Maria Sole Simonini, Enrico Rottoli, Antonino Mazzone}

\section{Messaggi chiave}

- Contrariamente a quanto comunemente si pensa la broncopneumopatia cronica ostruttiva (BPCO) si associa più frequentemente ad anemia anziché a policitemia.

- La prevalenza dell'anemia in coorti di soggetti con BPCO si aggira intorno al 13\%, mentre la prevalenza della policitemia è stimata in intervalli compresi tra il 4,5\% e l' $8,4 \%$ e in diminuzione, probabilmente a seguito dell'aumento delle pratiche di ossigenoterapia domiciliare.

- L'anemia in corso di BPCO presenta aspetti compatibili con il quadro dell'anemia da malattia cronica, anche se, specie nei soggetti più anziani, può presentare elementi di polifattorialità.

- La presenza di anemia nel paziente con BPCO correla bene con un aumentato rischio di morte, anche se non esistono studi che abbiano dimostrato un incremento della sopravvivenza associato alla sua correzione.
- La correzione dell'anemia si è dimostrata efficace nel miglioramento della capacità di esercizio del paziente con BPCO ed è quindi indicata per migliorare i sintomi e la qualità di vita.

- La correzione dell'anemia, oltre alla correzione degli eventuali fattori causali, prevede l'impiego di emotrasfusioni. Altre forme di trattamento, quali eritropoietina e supplementazione di ferro in soggetti non sideropenici, non si sono rivelate efficaci.

- La policitemia va corretta quando l'ematocrito è particolarmente elevato (> 55-60\%) per ridurne gli effetti reologicamente sfavorevoli; il target attualmente considerato ottimale è valutato intorno al $50 \%$.

- Alcuni farmaci come gli ACE-inibitori, gli inibitori dell'angiotensina II e i teofillinici possono avere effetti di inibizione sull'eritropoiesi ed essere quindi impiegati anche per sfruttarne questo effetto al fine di ridurre $i$ livelli di policitemia nei soggetti che la presentano.

\section{Introduzione}

La broncopneumopatia cronica ostruttiva (BPCO) è caratterizzata da una progressiva limitazione del flusso aereo, che risulta solo in parte reversibile ed è in genere dovuta a un'abnorme risposta del polmone a irritanti ambientali, in particolare al fumo di sigaretta. Numerosi studi hanno evidenziato che la BPCO è spesso associata a molteplici manifestazioni extrapolmonari, definite anche "effetti sistemici della BPCO". Questi effetti sono dovuti in massima parte all'aumentato rilascio di citochine proinfiammatorie, come IL-1, IL-6 e il TNF-alfa che raggiungono i massimi livelli durante le riacutizzazioni di malattia.
Tradizionalmente la BPCO è stata associata a poliglobulia, che rappresenta, infatti, un meccanismo compensatorio all'ipossia cronica; negli ultimi anni, però, si è osservata una sua minore incidenza tra i pazienti affetti da BPCO, in relazione alla più diffusa correzione dell'ipossia cronica mediante ossigenoterapia domiciliare. Recenti studi hanno invece rilevato una maggiore prevalenza dell'anemia in questo gruppo di pazienti, che può essere in gran parte correlata allo stato di infiammazione sistemica [1].

La risposta infiammatoria sistemica può divenire inoltre responsabile di alterazioni a carico della linea leucocitaria, in grado di favorire la comparsa di infezioni, e può attivare $i$ sistemi emocoagulativi in maniera tale da favorire, 
unitamente all'iperviscosità ematica della poliglobulia, all'ipomobilizzazione e al ridotto tono muscolare di questi soggetti, la comparsa clinica di fenomeni trombotici.

Nella presente trattazione si analizzano in maniera separata l'associazione di BPCO e anemia e l'associazione di BPCO e poliglobulia, facendo poi cenno alle problematiche cliniche connesse alla BPCO in presenza di altre malattie acute o croniche del sistema emopoietico.

\section{BPCO e anemia}

\section{Epidemiologia}

La World Health Organization (WHO) definisce l'anemia come una condizione caratterizzata da livelli di emoglobina $<13 \mathrm{~g} / \mathrm{dL}$ nella popolazione di sesso maschile $\mathrm{e}<12 \mathrm{~g} / \mathrm{dL}$ in quella femminile [2].

In letteratura non ci sono molti dati riguardo alla prevalenza dell'anemia nella BPCO (tabella 1) e il suo impatto nella pratica clinica. Uno studio condotto da John et al. [3] ha rilevato una prevalenza dell'anemia in pazienti con BPCO pari al 13\%. Lo studio è stato condotto in 101 pazienti (età media 60,8 $\pm 1,2$ anni; 66 maschi e 35 femmine) affetti da BPCO, diagnosticata secondo le linee guida dell'American Thoracic Society. In questa popolazione, 21 pazienti risultavano fumatori, 75 ex fumatori e 5 non fumatori ( $>5$ anni dalla cessazione del fumo). In relazione al grado di severità della malattia, definito sulla base delle linee guida GOLD, 23 pazienti avevano una forma lieve di BPCO, 36 moderata e 42 severa. Al momento dell'indagine tutti i pazienti risultavano clinicamente stabili, senza segni di riacutizzazione. Un altro studio condotto da Chambellan et al. [4] in un'ampia coorte di 2.524 pazienti, affetti da BPCO severa in ossigenoterapia a lungo termine, ha evidenziato che l'anemia (in accordo con i criteri WHO) ha una prevalenza del 12,6\% negli uomini e dell' $8,2 \%$ nelle donne, mentre un valore di ematocrito $>55 \%$ è stato riscontrato nell' $8,4 \%$ dei pazienti. $\mathrm{Si}$ tratta di uno studio retrospettivo osservazionale, condotto nell'arco di oltre 20 anni, attingendo a un vasto database nazionale francese raccolto dall'Associazione Nazionale per il Trattamento a Domicilio dell'Insufficienza Respiratoria

Tabella 1 Prevalenza e caratteristiche dell'anemia nei soggetti con BPCO.

\begin{tabular}{ll}
\hline Prevalenza & Maggiore nei maschi \\
- Maggiore negli stadi più lievi & di malattia \\
- Sostanzialmente sovrapponibile & a quella dei pazienti con scompenso \\
& cardiaco cronico \\
- Superiore a quella riscontrata & negli asmatici \\
- Inferiore a quella dei soggetti \\
affetti da insufficienza renale \\
cronica e neoplasie \\
\hline Caratteristiche & Solitamente normocromica \\
& normocitica \\
\hline
\end{tabular}

(ANTADIR). Un altro studio retrospettivo condotto da Halpern et al. [5] in una coorte di 132.424 pazienti, ottenuti da un ampio database americano (US Medicare) mediante l'impiego dei codici ICD-9 corrispondenti alla diagnosi di BPCO e di anemia (venivano esclusi i pazienti con anemia secondaria ad altre malattie croniche, a deficit nutrizionali o malattie ereditarie), ha rilevato che l'anemia era presente nel 21\% dei pazienti con BPCO. La maggiore prevalenza riscontrata in questo studio rispetto ai precedenti può riflettere differenze relative ad alcuni parametri: nello studio di John et al. [3] i valori di emoglobina corrispondono a quelli del momento dell'arruolamento, mentre nello studio di Halpern et al. [5] la presenza di anemia è ricavata in base ai codici specifici ICD-9. Inoltre in questo studio l'età media dei pazienti risulta essere superiore a quella dei pazienti del primo studio citato e ciò può influire, poiché la prevalenza dell'anemia aumenta all'aumentare dell'età.

Infine, uno studio più recente condotto sempre da John et al. [6] in 312 pazienti ospedalizzati affetti da BPCO ha mostrato una prevalenza dell'anemia del 23,1 $\pm 2,4 \%$. Questo studio, di tipo retrospettivo osservazionale, ha inoltre paragonato la prevalenza dell'anemia nei pazienti affetti da BPCO con altre malattie croniche, rilevando che nella BPCO la prevalenza dell'anemia è sovrapponibile a quella riscontrata nello scompenso cardiaco cronico, maggiore di quella dei pazienti con asma e inferiore a quella dei pazienti affetti da insufficienza renale cronica e neoplasie.

La maggiore prevalenza riscontrata in quest'ultimo studio può dipendere dalla tipologia dei pazienti reclutati: si tratta, infatti, di soggetti ricoverati in ambiente ospedaliero per riacutizzazione di BPCO, evidenziando anche che l'anemia è un'importante comorbilità nella BPCO.

\section{Meccanismi patogenetici dell'anemia associata a BPCO}

L'anemia correlata alla BPCO risulta di tipo normocitico, normocromico (tabella 1) e viene considerata, nei vari studi, come anemia da malattia cronica (ACD) correlata allo stato di flogosi sistemica che caratterizza tale patologia [1]. L'ACD è un disordine immunologico che si osserva in diverse malattie croniche e che dipende dall'aumentato rilascio di citochine e chemochine proinfiammatorie. Da un punto di vista fisiopatologico i principali meccanismi che portano allo sviluppo di ACD sono rappresentati da (tabella 2):

- ridotta sopravvivenza degli eritrociti, come risultato dell'aumentato rilascio di IL-1 e TNF- alfache riducono la disponibilità di eritropoietina (EPO) e portano a un'emolisi degli eritrociti nascenti;

- alterazione dell'omeostasi del ferro, con ridotti mobilizzazione e utilizzo del ferro presente nei depositi dell'organismo, come conseguenza di un'upregulation dell'mRNA codificante per la ferritina (mediata da IL-1 e da INFgammae parallelamente di una downregulation e internalizzazione dei recettori della transferrina a opera di TNFalfae IL-1;

- inadeguata risposta del midollo osseo all'EPO, conseguente principalmente a ridotta risposta dei precursori eritroidi all'EPO, apoptosi dei precursori eritroidi e downregulation dell'espressione dei recettori per l'EPO a livello midollare. È stato ampiamente dimostrato che la BPCO è una 
Tabella 2 Meccanismi fisiopatologici concorrenti al determinismo dell'anemia in soggetti con BPCO.

Meccanismi riconducibili all'anemia nelle malattie croniche

Altri meccanismi
Ridotta disponibilità di eritrociti

- Aumentato rilascio di citochine (IL-1 e TNF-alfa)

- Minore disponibilità di eritropoietina

Emolisi intramidollare

- Alterata omeostasi del ferro

- Mobilizzazione e utilizzo del ferro ridotti Inadeguata risposta midollare all'eritropoietina

Fumo sia con effetto diretto sia come amplificatore dei precedenti meccanismi

Farmaci

- ACE-inibitori

- Antagonisti dell'angiotensina II

- Teofillina e derivati malattia infiammatoria sistemica e non confinata al polmone ed è pertanto caratterizzata dal rilascio di molti dei mediatori che concorrono allo sviluppo dell'ACD. Nei pazienti affetti da BPCO si osservano infatti:

- elevati indici di flogosi (aumento della proteina C-reattiva - PCR, dei leucociti, del fibrinogeno, delle citochine come IL-1, IL-6, TNF-alfa delle chemochine come IL-8 e della proteina chemiotattica dei monociti MCP-a;

- modificazioni qualitative e quantitative a carico dei neutrofili (modificazioni della funzione e della deformabilità, aumentato rilascio da parte del midollo osseo) e aumentata espressione delle molecole di adesione ai neutrofili.

Nei fumatori e nelle fasi di riacutizzazione della BPCO tali meccanismi sono ulteriormente amplificati [1].

Queste osservazioni, pur rendendo plausibile l'ipotesi di un'associazione tra le due condizioni, non sembrano provare che la BPCO inibisca l'eritropoiesi. Un mancata risposta poliglobulica all'ipossia in corso di BPCO fu descritta già in studi ormai datati $[7,8]$ e l'esatta correlazione tra anemia e BPCO fino a pochi anni fa era ancora poco studiata. Recentemente, come è stato detto sopra, John et al. [3] hanno rilevato, nell'ambito di una coorte di 101 pazienti affetti da BPCO severa, una prevalenza di anemia correlata a BPCO pari al $13 \%$. In tutti i pazienti esaminati si è visto che i livelli sierici di PCR e IL-6 risultano significativamente aumentati rispetto al gruppo di controllo. Inoltre la PCR risulta aumentata in maniera significativa nei pazienti anemici affetti da BPCO rispetto ai non anemici. Questa correlazione non è stata osservata per IL-6, IL-8 o IL-10. I pazienti anemici con BPCO presentano, inoltre, livelli sierici significativamente aumentati di EPO rispetto ai non anemici: si è osservata una correlazione inversa tra livelli di emoglobina vs EPO, indicando la presenza di resistenza all'EPO, analogamente a quanto accade anche in altre condizioni di insufficienza respiratoria ipossiemica [9]. La presenza di infiammazione sistemica e di resistenza all'EPO è tipica dell'ACD e pertanto tale studio dimostra la relazione causale tra BPCO e ACD. Nello stesso studio, non viene rilevata la correlazione tra anemia e perdita di peso o cachessia, suggerendo che lo sviluppo dell'anemia è indipendente da fattori nutrizionali.

Occorre altresì precisare che altri fattori, oltre all'aumentato rilascio di citochine proinfiammatorie, possono essere responsabili dell'anemia in pazienti con BPCO. Oltre ovviamente alle comorbilità che possono risultare coesistenti, specie nei soggetti più anziani (sanguinamenti gastrointestinali, deficit di folati e vitamina B12, sindromi mielodisplastiche), la malnutrizione (che sembra essere correlata all'incremento di TNF-alfapuò svolgere un ruolo importante e creare un circolo vizioso con l'infiammazione. Anche il fumo di sigaretta di per sé, probabilmente attraverso un aumentato stress ossidativo, interferisce con la produzione dei globuli rossi e con gli effetti dell'ossigenoterapia a lungo termine sull'eritropoiesi [1]. Alcuni farmaci possono interferire con la produzione dei globuli rossi: in particolare gli ACE-inibitori, che determinano riduzione dei livelli di EPO, e la teofillina, che agisce attraverso un meccanismo complesso che si esplica principalmente attraverso un'induzione dell'apoptosi senza alterare la produzione di EPO. Inoltre bassi livelli di androgeni (in particolare di testosterone) sono stati riscontrati negli uomini affetti da BPCO [10]. Infine, l'ossigenoterapia può teoricamente ridurre lo stimolo all'eritropoiesi indotto dall'ipossia cronica, tuttavia il reale impatto clinico richiederebbe maggiori approfondimenti [1].

È stato, infine, osservato che l'anemia in corso di BPCO è più frequente nei pazienti con minor grado di severità rispetto ai pazienti con stadio avanzato della malattia. Generalmente l'ipossia è più frequente nei pazienti con BPCO severa e l'ipossia rappresenta un forte stimolo per l'eritropoiesi, con conseguente aumento dei livelli di emoglobina [6].

\section{Significato clinico dell'anemia in corso di BPCO}

\section{Anemia e mortalità}

La più importante evidenza di un'associazione (causale o di altro tipo) tra bassi livelli di emoglobina e mortalità in pazienti affetti da BPCO deriva dallo studio ANTADIR condotto da Chambellan et al. [4]. In questo studio l'ematocrito risulta essere inversamente correlato con l'età (un reperto piuttosto comune in geriatria) e con il FEV1/VC. Al contrario, l'ematocrito risulta correlato positivamente, seppur in maniera meno forte, con il Body Mass Index (BMI) e la $\mathrm{pCO}_{2}$. L'età e il sesso maschile sono considerati come fattori prognostici sfavorevoli in base al modello Cox (valuta il rischio relativo di morte correlato ad alcuni fattori prognostici). Questo stesso modello indica che l'aumento dei valori di $\mathrm{pO}_{2}, \mathrm{BMI}$ e della percentuale di FEV1 sono associati in maniera significativa a una prognosi migliore. Le analisi statistiche hanno dimostrato che l'ematocrito rappresenta 
un importante fattore predittivo indipendente di sopravvivenza, dopo l'età. La sopravvivenza a 3 anni è risultata essere del 24\% (IC 95\% 16-33\%) quando l'ematocrito era < 35\% e del $70 \%$ (dal 63\% al 76\%) quando l'ematocrito risultava $>55 \%$. In questo studio i fattori predittivi di sopravvivenza sono risultati, in ordine decrescente: età, ematocrito, $\mathrm{BMI}, \mathrm{pO}_{2}$, sesso e FEV1. In particolare, tra i vari fattori, l'ipercapnia risulta essere correlata positivamente con l'ematocrito: dal momento che l'ipercapnia si osserva negli stadi più avanzati della malattia, la correlazione inversa tra ematocrito e sopravvivenza può sembrare un paradosso. Invece, può dipendere dal fatto che bassi livelli di emoglobina stimolano la ventilazione e ciò potrebbe essere responsabile di bassi valori "artificiali" di $\mathrm{pCO}_{2}$ [4].

Altri due studi hanno valutato l'impatto prognostico dell'anemia cronica nei pazienti affetti da BPCO sulla sopravvivenza. In uno di essi, condotto da Cappell et al. [11], la mortalità in seguito a sanguinamento gastrointestinale risulta essere maggiore in una coorte di 53 pazienti affetti da BPCO, rispetto a un gruppo di controllo con emorragie digestive senza BPCO (32\% vs $10 \%$, rispettivamente) e rispetto a un gruppo di controllo con BPCO senza sanguinamenti gastrointestinali $(32 \%$ vs $11 \%$, rispettivamente) [1]. Upchurch et al. [12], in uno studio che ha preso in esame 158 pazienti affetti da BPCO, sottoposti a intervento chirurgico elettivo per aneurisma dell'aorta addominale, hanno evidenziato che la presenza di un basso valore di ematocrito prima dell'intervento si associa a una prognosi sfavorevole.

Infine, in una coorte di 207 pazienti, considerata da Celli et al. [13] per descrivere l'indice prognostico denominato BODE (Body mass index, air flow Obstruction, Dyspnea and Exercise capacity index), l'ematocrito è risultato significativamente maggiore nei pazienti sopravvissuti ( $\mathrm{N}=182$; ematocrito $=42 \pm 5 \%$ ) rispetto a quelli che sono andati incontro a morte $(N=25$; ematocrito $=39 \pm 5 \%)$.

Da tutto ciò si può dedurre che, complessivamente, l'impatto negativo dell'anemia nei soggetti con BPCO su outcome maggiori, quali la mortalità, è decisamente più significativo rispetto a quanto avviene per la policitemia secondaria.

\section{Sintomi e morbilità}

Lo studio ANTADIR [4] suggerisce altresì che bassi livelli di ematocrito siano associati a un incremento della morbilità. Infatti, in questo studio si è osservata una correlazione inversa tra ematocrito e quota di ospedalizzazioni, così come tra ematocrito e durata della degenza ospedaliera. Sarebbero necessarie ulteriori indagini per determinare se bassi valori di ematocrito rappresentino un fattore favorente l'ospedalizzazione o se, al contrario, frequenti ricoveri ospedalieri contribuiscano a determinare anemia [1]. L'ematocrito risulta pertanto un fattore predittivo negativo di ospedalizzazione e della durata dell'ospedalizzazione stessa [4].

È stato poi osservato, in termini di costi, che la presenza di anemia si associa a un importante onere economico e a un maggior impiego di risorse. Anche se i pazienti con BPCO e anemia sono maggiormente compromessi rispetto ai pazienti con BPCO senza anemia, l'associazione di anemia e maggiori costi è indipendente da altri potenziali fattori confondenti. Inoltre, la maggiore spesa sanitaria per i pazienti anemici con
BPCO non è direttamente correlata al trattamento dell'anemia stessa [5].

\section{Emodinamica e scambi gassosi}

L'efficienza degli scambi gassosi a livello polmonare è correlata ai livelli di emoglobina: aumentando i livelli di emoglobina, migliora l'emodinamica. Di conseguenza, livelli di ematocrito e di emoglobina superiori e più vicini possibile agli intervalli di normalità dovrebbero comportare un miglioramento del compenso cardiorespiratorio e, conseguentemente, della tolleranza all'esercizio fisico e della qualità di vita nei pazienti affetti da BPCO [1].

\section{Funzione dei muscoli scheletrici}

La disfunzione muscoloscheletrica (MSD) contribuisce a limitare la capacità di svolgere attività fisica provocando, di conseguenza, disabilità nei pazienti affetti da BPCO. I pazienti affetti da BPCO hanno svariate ragioni per sviluppare una MSD, tra cui periodi di relativa inattività fisica, trattamento steroideo più o meno prolungato, malnutrizione e stato di flogosi sistemica. Si è ipotizzato che l'anemia possa ulteriormente peggiorare la MSD nei pazienti con BPCO. L'ipotesi scaturisce indirettamente dall'osservazione che in pazienti con insufficienza renale cronica la somministrazione di EPO comporta un più efficiente trasporto di ossigeno durante l'esercizio fisico, con un incremento effettivo della quota di ossigeno in proporzione all'aumento dell'irrorazione sanguigna ai muscoli stessi. La correlazione fra trasporto di ossigeno ai tessuti, flusso ematico e livelli di emoglobina è molto complessa e al momento non esistono studi che valutino tale rapporto nei pazienti con BPCO [1].

\section{Diagnostica differenziale dell'anemia in corso di BPCO}

L'anemia in corso di BPCO, come già detto, mostra meccanismi eziopatogenetici e aspetti morfologici ben compatibili con l'anemia delle malattie croniche. È solitamente un'anemia normocromica normocitica di moderata entità. In presenza di un'anemia di questo tipo è presumibile che il trattamento dell'anemia possa coincidere con il miglior trattamento della malattia di base, la BPCO, e delle eventuali altre comorbilità. Specialmente nel caso di un'anemia lieve (emoglobina $>10 \mathrm{~g} / \mathrm{dL}$ ) probabilmente non è necessario eseguire altri esami bioumorali per un suo più corretto inquadramento, a meno che, per esempio, non coesista un'insufficienza renale e vi siano le condizioni a motivo di questa patologia per poter prospettare l'impiego di EPO. Quando invece l'anemia è più severa (emoglobina $<10 \mathrm{~g} / \mathrm{dL}$ ) o presenta caratteristiche morfologiche tali da far presupporre la coesistenza di altri e diversi meccanismi fisiopatologici alla sua radice, è opportuno svolgere le opportune indagini per chiarire tale eziologia ed eventualmente, qualora possibile, correggerla.

Così, in presenza di anemia microcitica sarà mandatorio, una volta esclusa una preesistente talassemia minore, dosare la ferritina, alla ricerca di una ferrodeplezione e, una volta accertatala, tentare di individuarne le eventuali cause sottese (fonti di sanguinamento, dieta incongrua, malassorbimento). Viceversa, in presenza di un quadro di macrocitosi sarà opportuna la determinazione dei reticolociti, quale 
primo step per valutare la funzionalità midollare ed eventualmente, nel caso vi sia evidenza di eritropoiesi inefficace in associazione a segni bioumorali di emolisi quali incremento di bilirubina e di LDH, ricercare una carenza di vitamina B12 o folati.

Specie nei soggetti più anziani, andrà considerata la possibilità di una coesistente sindrome mielodisplastica che potrebbe essere confermata da opportune analisi citogenetiche.

Infine, soprattutto in presenza di alterazioni delle altre serie emopoietiche e specie qualora vi sia la documentazione di una splenomegalia, l'anemia potrebbe essere inquadrabile nell'ambito di una sindrome mieloproliferativa cronica.

Ovviamente tutta questa tensione diagnostica andrà dispiegata qualora l'anemia sia quantomeno moderatosevera e qualora una diagnosi più precisa possa permetterne un più appropriato ed efficace trattamento, che, si ricorda, potrà apportare benefici clinici e in termini di qualità di vita al paziente con BPCO.

\section{Trattamento}

Parrebbe abbastanza intuitiva la considerazione che una correzione dell'anemia, qualora presente, possa determinare, tramite un miglioramento del trasporto di ossigeno e conseguentemente dell'ossigenazione periferica, un miglioramento della sintomatologia nel paziente con BPCO. Tuttavia dalla scarsa letteratura disponibile emerge che, in realtà, l'anemia è maggiormente presente in gradi di malattia meno avanzati, in quanto un'ipossiemia più persistente e severa sarebbe in grado di ripristinare uno stimolo adeguato alla secrezione di EPO e probabilmente superare la soglia di una resistenza periferica alla sua azione.

È noto che l'anemia è causa di dispnea e contribuisce alla limitazione funzionale dei pazienti anemici. Non esistono al momento studi prospettici che correlino l'anemia con parametri come la dispnea, la tolleranza all'esercizio fisico o in generale che valutino il suo impatto sulla qualità di vita dei pazienti con BPCO [10]. Due studi, svolti da Schönhofer et al. [14,15], suggeriscono come la correzione dell'anemia nei pazienti con BPCO possa migliorare le loro condizioni fisiche e cliniche. Nel primo di tali studi [14] sono stati presi in considerazione 20 pazienti affetti da BPCO, ricoverati in reparto di Terapia Intensiva, i quali sono stati sottoposti a emotrasfusioni per la correzione dell'anemia. In base ai risultati ottenuti gli autori hanno concluso che tale trattamento comporta una significativa riduzione sia del consumo di ossigeno sia del lavoro respiratorio. In questi pazienti le trasfusioni possono essere associate a minor lavoro ("unloading") dei muscoli respiratori, ma anche a una lieve ipoventilazione (all'emogasanalisi la $\mathrm{pO}_{2}$ scendeva da $56,9 \pm 8,9$ prima delle trasfusioni a 52,8 \pm 7 dopo il trattamento). Nel secondo studio di Schönhofer et al. [15] viene presa in esame una serie di 5 pazienti con BPCO, sottoposti a ventilazione meccanica non invasiva e affetti da anemia moderata al momento dell'ammissione. Dopo aver sottoposto ognuno di loro a emotrasfusioni, raggiungendo livelli di emoglobina pari a $12 \mathrm{~g} / \mathrm{dL}$, gli autori hanno osservato un miglioramento delle manifestazioni cliniche, giungendo allo svezzamento dal ventilatore in 1-4 giorni dopo le trasfusioni.
Non esistono studi, anche per l'obiettiva difficoltà di un disegno di questo tipo, che abbiamo correlato strategie di intervento con emotrasfusioni in soggetti anemici con BPCO con un incremento della sopravvivenza. Tantomeno esistono dati di interventi farmacologici finalizzati al trattamento dell'anemia.

Per quanto riguarda l'EPO mancano i presupposti razionali, in quanto nel paziente con BPCO esiste già uno stimolo alla produzione che è tanto più marcato quanto più è severo lo stadio della malattia stessa, e uno dei meccanismi invocati per spiegare situazioni di anemia in questi pazienti è invece una ridotta risposta periferica all'EPO stessa $[9,16]$.

A differenza di quanto ormai abbastanza studiato e consolidato nell'ambito dello scompenso cardiaco [17], per i pazienti con BPCO non esistono studi specifici che abbiano testato l'utilizzo di supplementazioni di ferro o di vitamine coinvolte nei processi dell'eritropoiesi e pertanto tali supplementazioni andrebbero riservate solamente ai soggetti nei quali la polifattorialità dell'anemia coinvolge anche alcune delle sostanze in questione.

Infine, considerato il loro effetto parzialmente inibitorio sull'eritropoiesi, nei soggetti con anemia e BPCO farmaci come gli ACE-inibitori, i teofillinici e, forse, anche gli inibitori dell'angiotensina II [18] andrebbero usati con particolare cautela e, qualora possibile, sostituiti con altre classi di farmaci.

\section{BPCO e poliglobulia}

\section{Epidemiologia}

Contrariamente a quanto comunemente si può pensare, nella BPCO la poliglobulia "secondaria" è presente in una quota di pazienti non particolarmente elevata e decisamente inferiore rispetto alla prevalenza dell'anemia. Il dato riportato in un recente studio prospettico svolto da Cote et al. in una coorte di 683 pazienti non ospedalizzati, nei quali il cut-off di emoglobinemia per la diagnosi di poliglobulia era fissato in $17 \mathrm{~g} / \mathrm{dL}$ per i maschi e $15 \mathrm{~g} / \mathrm{dL}$ per le femmine, era del $6 \%$ [13].

Uno dei motivi per i quali attualmente vi è evidenza di una prevalenza di poliglobulia decisamente meno frequente rispetto al passato è probabilmente il miglioramento delle cure e in particolare la maggiore attenzione a ottenere livelli di ossigenazione adeguati nei soggetti affetti da BPCO in fase di insufficienza respiratoria. Dati europei [19] relativi a una casistica numericamente inferiore confermano la prevalenza piuttosto bassa e pari al $4,5 \%$, calcolata in questa coorte di soggetti, che, a differenza del gruppo precedente, erano soggetti ospedalizzati afferenti a un ospedale di riferimento e quindi verosimilmente con BPCO di maggiore severità rispetto ai pazienti del gruppo di Cote.

Infine nell'ampio studio retrospettivo condotto da Chambellan et al. [4] la prevalenza riportata era leggermente più elevata $(8,4 \%)$, ma in relazione al diverso criterio identificativo, meno restrittivo, posto da questi autori (ematocrito $>55 \%$ ) [20].

\section{Fisiopatologia}

La risposta eritropoietica all'ipossiemia nel paziente con BPCO deriva dal fatto che la riduzione della pressione 
parziale di ossigeno tissutale a livello delle cellule della macula densa del rene stimola - da parte del rene medesimo e, in minor misura (15\%), da parte del fegato - la produzione di EPO, che a sua volta induce la proliferazione e la differenziazione delle cellule eritroidi progenitrici $[21,22]$. La risposta normale all'ipossia si esplica in un aumento della massa eritrocitaria e dell'ematocrito. Anche altri sistemi omeostatici dell'organismo possono interagire e modulare la risposta eritropoietica.

In particolare, numerosi studi hanno confermato una correlazione positiva tra il sistema renina-angiotensina (RAS) e la stimolazione di EPO: l'attivazione di tale sistema può svolgere un ruolo significativo nello sviluppo dell'eritrocitosi secondaria alla malattie croniche ostruttive polmonari. Nonostante non sia ancora del tutto noto il meccanismo d'azione, sembrerebbe che l'enzima angiotensina II stimoli direttamente i progenitori eritroidi in vitro [23].

Farmaci modulanti o bloccanti tale sistema, come gli ACEinibitori, agirebbero sia inibendo la sintesi dell'EPO sia stimolando l'apoptosi dei precursori eritroidi a livello midollare. Pertanto, un inibitore dell'enzima di conversione dell'angiotensina II, riducendo indirettamente l'eritrocitosi secondaria nella BPCO, potrebbe procrastinare la necessità del salasso terapeutico. Il trattamento con ACE-inibitori, in virtù di questo meccanismo, secondo alcuni, potrebbe apportare benefici non trascurabili con una riduzione significativa delle esacerbazioni della BPCO e della mortalità [24].

La risposta poliglobulica all'ipossiemia cronica si realizza in maniera diversa ed esistono almeno due sottopopolazioni di pazienti: il primo sottogruppo, più numeroso, presenta una risposta attenuata, mentre un secondo sottogruppo presenta una risposta accentuata.

Numerosi e variabili nel tempo sono $i$ fattori in grado di influenzare questa risposta [25] (tabella 3).

La risposta poliglobulica è accentuata in presenza di:

- livello di 2,3-disfosfoglicerato - pazienti con BPCO e con acidosi respiratoria hanno ridotti livelli di 2,3-disfosfoglicerato. Ciò comporta per ogni $\mathrm{PaO}_{2}$ uno spostamento a destra della curva di dissociazione dell' $\mathrm{HbO}_{2}$ con conseguente riduzione della $\mathrm{SaO}_{2}$;

- fumatori attivi con livelli aumentati di carbossiemoglobina - pur in presenza di valori simili di $\mathrm{SaO}_{2}$, i fumatori hanno più elevati valori di ematocrito a motivo della sovrapposta aumentata desaturazione condizionata da livelli aumentati di carbossiemoglobina;

Tabella 3 Fattori modulanti la risposta emopoietica in presenza di ipossiemia cronica.

\begin{tabular}{ll}
\hline Fattori & - Riduzione dei livelli \\
amplificanti & di 2,3-disfosfoglicerato \\
& Incremento dei valori di \\
& carbossiemoglobina nei \\
& soggetti fumatori \\
- Desaturazioni prolungate & notturne \\
\hline Fattori & - Infezioni e stati infiammatori \\
riducenti & acuti e cronici \\
& - Carenza di ferro \\
& - Ridotti livelli di ormoni \\
& androgenici \\
\hline
\end{tabular}

- ipossiemia durante il sonno - l'ipossiemia nei pazienti BPCO si aggrava nel sonno, soprattutto durante la fase REM. I pazienti con BPCO e con più significativi gradi di poliglobulia secondaria sono quelli che solitamente presentano periodi più prolungati di desaturazione notturna.

Al contrario, si osserva una risposta poliglobulica attenuata in presenza di:

- infezioni e stati infiammatori acuti, e, in maggior misura, cronici - è noto da tempo che una quota di pazienti BPCO presentano valori di ematocrito inappropriatamente bassi in rapporto alla loro ipossiemia. In questi casi è verosimile la concomitanza di un'anemia da malattia cronica. Anche i processi infettivi ricorrenti possono alterare la risposta eritropoietica;

- carenza marziale - nei pazienti con BPCO è abbastanza frequente una riduzione della concentrazione emoglobinica corpuscolare media $(\mathrm{MCHC})$, che può essere presente quando coesista una carenza marziale, in grado di alterare e ridurre i processi eritropoietici;

- secrezione androgenica - l'ipossiemia riduce l'attività endocrina testicolare e la riduzione dell'entità di testosterone compromette la risposta midollare all'ipossia.

\section{Significato clinico della poliglobulia nei soggetti con BPCO}

La poliglobulia nel paziente BPCO origina come meccanismo compensatorio finalizzato ad aumentare la capacità di trasporto di ossigeno da parte del sangue e migliorare, quindi, in maniera indiretta l'apporto tissutale di ossigeno, in presenza di una complessiva riduzione percentuale dei suoi livelli nel sangue. Tuttavia, come molti meccanismi di compenso, i suoi effetti non sempre risultano globalmente favorevoli al paziente. Infatti, oltre certi livelli la poliglobulia e il contestuale aumento dell'ematocrito determinano un effetto reologicamente sfavorevole sulla circolazione ematica. Quando questa risposta è eccessiva possono quindi insorgere problemi, i più importanti dei quali a carico dell'attività cerebrale e cardiaca.

In un piccolo gruppo di pazienti con BPCO è stato misurato il flusso ematico cerebrale prima e dopo salasso $(500 \mathrm{~mL})$ [26]: a fronte di una riduzione dell'ematocrito dal $60 \%$ al $44 \%$ (e della viscosità ematica del $35 \%$ ) si è registrato un importante incremento del flusso ematico cerebrale a livello sopratentoriale (di circa l' $80 \%$ ), oltre a un miglioramento soggettivo riferito dal paziente (acufeni, cefalea). Questi effetti sfavorevoli circolatori della poliglobulia a livello cerebrale possono in parte concorrere, insieme all'ateromasia favorita dal fumo di sigaretta, al deterioramento cerebrale che non di rado può precocemente essere osservato in soggetti con BPCO. Analogamente, l'aumentata viscosità ematica prodotta da alti livelli di ematocrito può realizzare un aumento delle resistenze vascolari polmonari, che insieme a una riduzione del flusso coronarico e alla ridotta saturazione arteriosa in $\mathrm{O}_{2}$ può concorrere a un peggioramento della funzionalità cardiaca, favorendo l'insorgenza di scompenso prevalentemente di tipo destro, ma anche di tipo sinistro [27].

Controprova è che numerosi studi hanno dimostrato come, nei pazienti policitemici, una moderata riduzione dell'ematocrito diminuisca la pressione sistemica e dell'arteria 
polmonare, migliori l'output cardiaco e la disponibilità di ossigeno e aumenti la tolleranza all'esercizio fisico [28].

Il meccanismo alla base dell'aumento delle resistenze periferiche è da ricercare nell'aumento della viscosità ematica e del fenomeno di vasocostrizione determinato dallo stress esercitato sulla parete dei vasi arteriosi [29]. Lo stiramento della parete muscolare è stimolata dal rilascio dell'ossido nitrico endoteliale prodotto dalla NOS (ossido nitrico-sintetasi). Se, da un lato, la viscosità ematica aumenta l'attivazione dell'enzima, dall'altro, la concentrazione emoglobinica sembra determinarne la sua inattivazione [30], causando un effetto netto di vasocostrizione periferica.

Nonostante la supplementazione con ossigenoterapia domiciliare subcontinua abbia diminuito la severità della policitemia nei pazienti con malattia polmonare cronica ipossiemica, l'aumento dei livelli di ematocrito rimane un reperto piuttosto comune in questi pazienti, specialmente quando si associa alla sindrome delle apnee notturne (OSAS) $[31,32]$.

Infine, un aumento eccessivo dei valori di emoglobina e di ematocrito da un punto di vista teorico potrebbe favorire l'insorgenza di fenomeni tromboembolici di tipo sia venoso sia arterioso [33,34] tramite un rallentamento del flusso ematico più periferico. Tuttavia non esistono in letteratura chiare evidenze a questo riguardo. Nei diversi lavori che hanno studiato la prevalenza della tromboembolia polmonare nei pazienti con BPCO, specie durante riacutizzazioni, $i$ parametri di emoglobina ed ematocrito non venivano analizzati anzi, paradossalmente, emergeva una maggiore prevalenza di tromboembolia nei soggetti con BPCO meno severa [35]. Tuttavia, il dato evidente è che la policitemia secondaria non è forse stata sufficientemente valutata quale fattore di rischio tromboembolico nei lavori riguardanti coorti di soggetti con BPCO.

\section{Diagnosi}

Per policitemia si intende un incremento del numero di globuli rossi circolanti. Per eritrocitosi si intende invece un incremento globale della massa eritrocitaria. Per porre la diagnosi si può considerare sia il livello dei valori di emoglobina sia il livello di valori di ematocrito. I livelli di emoglobina necessari per porre la diagnosi sono stati fissati in $17 \mathrm{~g} / \mathrm{dL}$ per i maschi e $15 \mathrm{~g} / \mathrm{dL}$ per le femmine [36]. Seppure anche i livelli di emoglobina circolanti possano essere parzialmente influenzati da modificazioni della quota plasmatica circolante, tuttavia lo sono in misura inferiore rispetto ai livelli di ematocrito, al punto che pur essendo considerati già anormali livelli di ematocrito $>50 \%$ nel maschio e $>45 \%$ nella femmina, si assumono francamente patologici per policitemia valori di ematocrito $>60 \%$ nel maschio e $>55 \%$ nella donna.

Una policitemia può essere spuria, e dovuta a riduzioni significative del volume plasmatico circolante, primitiva o secondaria. La policitemia del soggetto con BPCO appartiene al gruppo delle policitemie secondarie ed è dovuta a un'inappropriata secrezione di EPO stimolata dall'ipossiemia di questi soggetti. Nella maggioranza dei casi potrà bastare l'anamnesi, che in un soggetto con BPCO diventa orientativa verso una policitemia secondaria. La presenza di policitemia poi può indurre il clinico a valutare attentamente il compenso clinico e la presenza di un'insufficienza respiratoria ipossiemica già a riposo o in condizioni particolari, quali fasi di apnee notturne e/o durante attività o sforzi fisici. Ovviamente tale ricerca, se fosse confermato il dato dell'ipossiemia, sarebbe finalizzata a intraprendere la più appropriata ossigenoterapia cronica, che, se opportunamente e precocemente instaurata, potrebbe essere l'unico presidio in grado di ripristinare una condizione di normoglobulia.

Tuttavia, in altre situazioni, in presenza per esempio di un soggetto senza insufficienza respiratoria significativa o ben compensato con un'ossigenoterapia domiciliare cronica, la diagnosi di secondarietà, specie in soggetti anziani e quindi predisposti a sviluppare anche comorbilità di tipo ematologico, dovrebbe essere verificata con maggiore accuratezza. Il primo step di tali verifiche consiste nella determinazione dell'EPO sierica, che nel soggetto con policitemia secondaria a BPCO dovrebbe essere inappropriatamente elevata. In presenza di tale riscontro, se il paziente policitemico presenta una condizione di ossigenazione a riposo discretamente compensata, è necessario ricercare le situazioni nelle quali potrebbero verificarsi significative desaturazioni arteriose. In particolare, è opportuno eseguire un test del cammino con valutazione della saturimetria da sforzo e una saturimetria notturna. Se venisse confermata la presenza di fasi di desaturazione notturna, occorrerà poi eseguire anche una polisonnografia per confermare l'eventuale presenza di un'eventuale OSAS. In presenza, invece, di ipossiemia durante attività fisica, per controllare la poliglobulia potrebbe essere sufficiente un appropriato regime di ossigenoterapia durante la medesima attività; se fosse confermata la presenza di OSAS potrebbe essere necessario impostare un trattamento con C-PAP notturna.

Seppure veramente molto rara, è stata descritta l'associazione tra BPCO e policitemia vera [37]. In questi casi la diagnosi può risultare difficoltosa e più tardiva, a motivo del fatto che il primo sospetto è quello di una forma secondaria alla cronica ipossiemia del soggetto con BPCO. Il sospetto deve però essere posto qualora si riscontri un'evidente discrepanza tra i livelli di ipossiemia e i valori di emoglobina ed ematocrito. In tal caso un approfondimento diagnostico, sia rivolto all'esatta determinazione scintigrafica della massa eritrocitaria (più elevata in presenza di policitemia vera) sia tramite la determinazione dell'EPO sierica (non soppressa, ma tendenzialmente elevata nella policitemia vera) - potrà orientare correttamente e, nel caso vi sia una policitemia vera, eventualmente indurre a procedere a trattamenti farmacologici specifici per la riduzione della massa eritrocitaria.

\section{Trattamento}

Qualora l'ematocrito risulti costantemente elevato (> 55$60 \%$ ), salassi ripetuti di circa $250-300$ cc di sangue con reinfusione di fisiologica hanno effetti favorevoli in quanto riducono le resistenze periferiche vascolari polmonari con modesta riduzione della PAP media, aumentano il flusso ematico cerebrale, specie nelle regioni sopratentoriali, e aumentano la performance allo sforzo fisico [38,39]. Il valore di ematocrito ideale è quello che minimizza i problemi reologici e massimizza il trasporto di ossigeno. Sulla base 
dei dati della letteratura sembra ragionevole indicarlo in un valore intorno, ma non superiore, al 50\% [28]. L'indicazione a una salassoterapia periodica finalizzata al mantenimento, nel soggetto con BPCO, del target cui accennato sopra rimane, tuttavia, soltanto qualora tale stato policitemico permanga nonostante l'ottimizzazione della terapia medica e della supplementazione di ossigeno. Soggetti con policitemia significativa e assenza di desaturazione arteriosa in ossigeno a riposo dovrebbero essere studiati adeguatamente per verificare l'eventuale presenza di una desaturazione da sforzo e/o di una desaturazione arteriosa notturna, sia essa dovuta o non dovuta alla coesistenza di una OSAS. In questi soggetti, pertanto, vi è l'indicazione a eseguire test del cammino e monitoraggio della saturimetria notturna per mettere in atto correttivi specifici nel caso tali test diano esiti positivi (nella fattispecie, ossigenoterapia da sforzo con i migliori dispositivi portatili e C-PAP notturna nei pazienti con OSAS).

In assenza di controindicazioni legate a ipotensione, intolleranza al farmaco o altro e specie se coesistono comorbilità per le quali siano indicati i farmaci bloccanti a vari livelli il sistema renina angiotensina - quali gli ACE-inibitori [23] e gli inibitori dell'angiotensina II e in particolare il losartan [18] potrebbero essere utilmente impiegati nell'intento di inibire, almeno parzialmente, l'eritropoiesi e mantenere così un ematocrito più vicino al valore auspicabile di circa il $50 \%$. Infatti, diversi lavori, seppure non con casistiche numericamente rilevanti, riportano evidenze in tale direzione, anche se al momento non vi è alcuno studio che dimostri benefici in termini sia di mortalità sia di morbilità derivanti dall'impiego di tali farmaci in queste coorti di pazienti.

Concettualmente, in un soggetto con BPCO, a prescindere dai costi parrebbe più opportuno scegliere un inibitore dell'angiotensina II onde evitare il problema della tosse, che in questi pazienti potrebbe diventare confondente ai fini dell'evidenziazione di un'eventuale riacutizzazione.

Tra i farmaci già impiegati, anche se con sempre meno spazio nei soggetti con BPCO, la teofillina [40,41] è stata segnalata come potenzialmente in grado di ridurre la produzione di globuli rossi, seppur con un meccanismo non ancora del tutto chiarito e più probabilmente legato a un'azione diretta sull'eritropoiesi e non tramite una modulazione della produzione di EPO. Anche questo aspetto dovrebbe essere tenuto presente nella considerazione dell'eventuale rapporto costo/beneficio dell'impiego cronico di un teofillinico in un soggetto con BPCO.

\section{Bibliografia}

[1] Similowski T, Agustí A, MacNee W, Schönhofer B. The potential impact of anaemia of chronic disease in COPD. Eur Respir $J$ 2006;27(2):390-6.

[2] World Health Organization. Nutritional anemias: report of a WHO scientific group. In: WHO Technical Report Series 405. Geneva: World Health Organization; 1968. p. 1-37.

[3] John M, Hoernig S, Doehner W, Okonko DD, Witt C, Anker SD. Anemia and inflammation in COPD. Chest 2005;127(3): 825-9.

[4] Chambellan A, Chailleux E, Similowski T, ANTADIR Observatory Group. Prognostic value of the hematocrit in patients with severe COPD receiving long-term oxygen therapy. Chest 2005;128(3):1201-8.
[5] Halpern MT, Zilberberg MD, Schmier JK, Lau EC, Shorr AF. Anemia, costs and mortality in chronic obstructive pulmonary disease. Cost Eff Resour Alloc 2006;4:17.

[6] John M, Lange A, Hoernig S, Witt C, Anker SD. Prevalence of anemia in chronic obstructive pulmonary disease: comparison to other chronic diseases. Int J Cardiol 2006;111(3):365-70.

[7] Baldwin EF, Cournand A, Richard DW. Pulmonary insufficiency. III. A study of 122 cases of chronic pulmonary emphysema. Medicine 1949;28:201-10.

[8] Wilson RH, Borden CW, Ebert RV. Adaptation to anoxia in chronic pulmonary emphysema. AMA Arch Intern Med 1951;88(5):58190.

[9] Tsantes A, Tassiopoulos S, Papadhimitriou SI, Bonovas S, Kavalierou L, Vaiopoulos G, et al. Suboptimal erythropoietic response to hypoxemia in idiopathic pulmonary fibrosis. Chest 2003;124(2):548-53.

[10] Carroz KP. Anemia in COPD: should it be taken into consideration? Arch Bronconeumol 2007;43(7):392-8.

[11] Cappell MS, Nadler SC. Increased mortality of acute upper gastrointestinal bleeding in patients with chronic obstructive pulmonary disease. A case controlled, multiyear study of 53 consecutive patients. Dig Dis Sci 1995;40(2):256-62.

[12] Upchurch Jr GR, Proctor MC, Henke PK, Zajkowski P, Riles EM, Ascher MS, et al. Predictors of severe morbidity and death after elective abdominal aortic aneurysmectomy in patients with chronic obstructive pulmonary disease. J Vasc Surg 2003; 37(3):594-9.

[13] Celli BR, Cote CG, Marin JM, Casanova C, Montes de Oca M, Mendez RA, et al. The body-mass index, airflow obstruction, dyspnea, and exercise capacity index in chronic obstructive pulmonary disease. N Engl J Med 2004;350(10):1005-12.

[14] Schönhofer B, Wenzel M, Geibel M, Köhler D. Blood transfusion and lung function in chronically anemic patients with severe chronic obstructive pulmonary disease. Crit Care Med 1998; 26(11):1824-8.

[15] Schönhofer B, Böhrer H, Köhler D. Importance of blood transfusion in anemic patients with COPD and unsuccessful weaning from respirator. Med Klin (Munich) 1999;94(1 Spec No):70-2.

[16] Pavlisa G, Vrbanic V, Kusec V, Jaksic B. Erythropoietin response after correction of severe hypoxaemia due to acute respiratory failure in chronic obstructive pulmonary disease patients. Clin Sci (Lond) 2004;106(1):43-51.

[17] Anker SD, Colet JC, Filippatos G, Willenheimer R, Dickstein K, Drexler $\mathrm{H}$, et al., FAIR-HF committees and investigators. Rationale and design of Ferinject assessment in patients with IRon deficiency and chronic Heart Failure (FAIR-HF) study: a randomized, placebo-controlled study of intravenous iron supplementation in patients with and without anaemia. Eur J Heart Fail 2009;11(11):1084-91.

[18] Vlahakos DV, Marathias KP, Kosmas EN. Losartan reduces hematocrit in patients with chronic obstructive pulmonary disease and secondary erythrocytosis. Ann Intern Med 2001;134(5): $426-7$.

[19] Portillo K, Belda J, Antón P, Casan P. High frequency of anemia in COPD patients admitted in a tertiary hospital. Rev Clin Esp 2007;207(8):383-7.

[20] Zieliński J. Effects of long-term oxygen therapy in patients with chronic obstructive pulmonary disease. Curr Opin Pulm Med 1999;5(2):81-7.

[21] Hurtado A, Merino C, Delgrado E. Influence of anoxemia on the hemopoietic response. Arch Intern Med 1945;75:284-9.

[22] Weil JV, Jamieson G, Brown DW, Grover RF. The red cell massarterial oxygen relationship in normal man. Application to patients with chronic obstructive airway disease. J Clin Invest 1968;47(7):1627-39.

[23] Vlahakos DV, Kosmas EN, Dimopoulou I, Ikonomou E, Jullien G, Vassilakos $\mathrm{P}$, et al. Association between activation of the reninangiotensin system and secondary erythrocytosis in patients 
with chronic obstructive pulmonary disease. Am J Med 1999; 106(2):158-64.

[24] Mancini GB, Etminan M, Zhang B, Levesque LE, Fitzgerald JM, Brophy JM. Reduction of morbidity and mortality by statins, angiotensin-converting enzyme inhibitors, and angiotensin receptor blockers in patients with chronic obstructive pulmonary disease. J Am Coll Cardiol 2006;47(12):2554-60.

[25] Cahan C, Strohl K. Hematologic manifestation of COPD. In: Cherniack NS, editor. Chronic Obstructive Pulmonary Disease. Philadelphia, PE: WB Saunders; 1991.

[26] York EL, Jones RL, Menon D, Sproule BJ. Effects of secondary polycythemia on cerebral blood flow in chronic obstructive pulmonary disease. Am Rev Respir Dis 1980;121(5):813-8.

[27] Nakamura A, Kasamatsu N, Hashizume I, Shirai T, Hanzawa S, Momiki S, et al. Effects of hemoglobin on pulmonary arterial pressure and pulmonary vascular resistance in patients with chronic emphysema. Respiration 2000;67(5):502-6.

[28] Chetty KG, Brown SE, Light RW. Improved exercise tolerance of the polycythemic lung patient following phlebotomy. Am J Med 1983;74(3):415-20.

[29] Buga GM, Gold ME, Fukuto JM, Ignarro LJ. Shear stress-induced release of nitric oxide from endothelial cells grown on beads. Hypertension 1991;17(2):187-93.

[30] Rimar S, Gillis CN. Selective pulmonary vasodilation by inhaled nitric oxide is due to hemoglobin inactivation. Circulation 1993;88(6):2884-7.

[31] Casale R, Pasqualetti P. Diurnal rhythm of serum erythropoietin circulating levels in chronic obstructive pulmonary disease. Panminerva Med 1997;39(3):183-5.

[32] Fitzpatrick MF, Mackay T, Whyte KF, Allen M, Tam RC, Dore CJ, et al. Nocturnal desaturation and serum erythropoietin: a study in patients with chronic obstructive pulmonary disease and in normal subjects. Clin Sci (Lond) 1993;84(3):319-24.
[33] Shetty R, Seddighzadeh A, Piazza G, Goldhaber SZ. Chronic obstructive pulmonary disease and deep vein thrombosis: a prevalent combination. J Thromb Thrombolysis 2008;26(1): $35-40$.

[34] Alessandri C, Basili S, Violi F, Ferroni P, Gazzaniga PP, Cordova C. Hypercoagulability state in patients with chronic obstructive pulmonary disease. Chronic Obstructive Bronchitis and Haemostasis Group. Thromb Haemost 1994;72(3):343-6.

[35] Tillie-Leblond I, Marquette CH, Perez T, Scherpereel A, Zanetti C, Tonnel $A B$, et al. Pulmonary embolism in patients with unexplained exacerbation of chronic obstructive pulmonary disease: prevalence and risk factors. Ann Intern Med 2006;144(6):390-6.

[36] Harrison's Principles of Internal Medicine. 17 Ed. Chapt 58. Anemia and Polycythemia. New York: McGraw-Hill; 2008.

[37] Vicari AM, Ponzoni M, Alberetto M, Martani C, Pontiroli AE, Folli F. Erythrocytosis in a patient with chronic obstructive pulmonary disease. Haematologica 1998;83(2):183-6.

[38] Martinez JA, Guerra CC, Nery LE, Jardim JR. Iron stores and coagulation parameters in patients with hypoxemic polycythemia secondary to chronic obstructive pulmonary disease: the effect of phlebotomies. Sao Paulo Med J 1997;115(2):1395-402.

[39] Erickson AD, Golden WA, Claunch BC, Donat WE, Kaemmerlen JT. Acute effects of phlebotomy on right ventricular size and performance in polycythemic patients with chronic obstructive pulmonary disease. Am J Cardiol 1983;52(1):163-6.

[40] Tsantes AE, Tassiopoulos ST, Papadhimitriou SI, Bonovas S, Poulakis N, Vlachou A, et al. Theophylline treatment may adversely affect the anoxia-induced erythropoietic response without suppressing erythropoietin production. Eur J Clin Pharmacol 2003;59(5-6):379-83.

[41] Trivedi H, Lal SM. A prospective, randomized, open labeled crossover trial of fosinopril and theophylline in post renal transplant erythrocytosis. Ren Fail 2003;25(1):77-86. 


\section{BPCO e tumori}

\section{Roberto Biasioli, Luca Pavan, Attilio Grechi}

\section{Messaggi chiave}

- Il cancro polmonare rappresenta una delle principali cause di mortalità nei paesi industrializzati.

- Lo screening del tumore polmonare non è attualmente raccomandabile.

- Utile, per pazienti a rischio, partecipare a studi randomizzati controllati di screening.

- Esiste uno stretto rapporto tra BPCO e tumore polmonare.

- La presenza di BPCO non pregiudica l'effettuazione di chemioterapia e radioterapia nei pazienti affetti da cancro.

- Il paziente con tumore polmonare e BPCO deve essere valutato attentamente prima dell'intervento, per quantificare il rischio di complicanze cardiorespiratorie immediate e disabilità a lungo termine.

\section{Epidemiologia e fattori di rischio del tumore polmonare}

Il cancro polmonare rappresenta una delle principali cause di morbilità e mortalità nei paesi industrializzati, in quanto costituisce circa il 12\% dei tumori: è legato ad alti tassi di letalità, con livelli di sopravvivenza bassi, intorno al 10-15\% a 5 anni dalla diagnosi.

I trend di incidenza evidenziano, nei paesi occidentali, un andamento decrescente negli uomini ma, per contro, una tendenza all'aumento nelle donne, quale conseguenza dell'incrementata diffusione dell'abitudine al fumo. Anche $i$ dati di mortalità rispecchiano questo scenario, con una diminuzione negli uomini e un aumento nelle donne, tanto che negli Stati Uniti il carcinoma polmonare ha sopravanzato nelle donne l'incidenza del carcinoma mammario, diventando la prima causa di morte. In Italia si stimano circa 35-40.000 nuovi casi all'anno, con una sopravvivenza globale a 5 anni dalla diagnosi del $13 \%$, percentuale che è rimasta immutata nel corso degli ultimi 20 anni con solo una lievissima tendenza all'aumento; il cancro polmonare costituisce globalmente la prima causa di morte per neoplasia $e$, più precisamente, la prima causa di morte negli uomini e la terza nelle donne. Esiste una variabilità geografica nell'incidenza del tumore del polmone nel nostro paese, con un rapporto di circa 2:1 tra le aree a maggior incidenza e quelle $a$ incidenza più bassa: in generale i tassi più elevati si riscontrano al Nord e i più bassi nel Meridione. Inoltre i dati ISTAT evidenziano in Italia una riduzione della mortalità per tumore di circa il $2 \%$; più precisamente per il tumore polmonare la diminuzione dell'1,8\% riguarda il sesso maschile mentre nelle donne i decessi sono aumentati dell'1,5\%.

Il fumo di tabacco è la principale causa del carcinoma polmonare: si stima che circa il $70-80 \%$ dei tumori sia dovuto al tabagismo attivo. Negli ultimi anni dai dati analizzati emergono due aspetti importanti; la percentuale dei forti fumatori diminuisce tra i maschi ma aumenta tra le donne e, nella fascia tra i 15 e i 24 anni, vi è un aumento globale del consumo di tabacco, più marcato per le femmine anche in questo setting. L'Italia si distingue per aver adottato, con l'applicazione della Legge 3/2003, una politica contro il fumo che viene considerata la più avanzata in Europa.

Esiste una chiara correlazione dose-risposta tra il rischio di insorgenza di tumori polmonari e quantità di esposizione al fumo, inteso sia come numero di sigarette fumate sia come numero di anni di abitudine al fumo: rischio quantificabile in circa 20-30 volte quello di un non fumatore. Anche l'inalazione del fumo passivo produce effetti deleteri che si riflettono in un aumentato rischio di ammalarsi.

Un altro fattore di rischio è rappresentato dall'esposizione occupazionale all'asbesto (causa di circa il 5-10\% dei tumori polmonari), fibra minerale di piccole dimensioni che ha la capacità di potenziare l'effetto cancerogeno del fumo. Altri elementi cancerogeni conosciuti sono il nickel, 
l'arsenico e il cadmio. Un terzo fattore di rischio conosciuto è l'esposizione al radon, gas nobile radioattivo, che si forma in maniera naturale nel suolo e che si diffonde nell'ambiente. Anche l'esposizione a lungo termine ad alte concentrazioni ambientali di polveri sottili, la cui fonte principale è il traffico motorizzato, può portare a un aumento del rischio di tumore polmonare, anche se i dati attualmente presenti in letteratura e derivanti da studi epidemiologici sono contraddittori, per la difficoltà a separare l'effetto delle polveri da altri fattori di rischio. Infine è stata dimostrata una stretta relazione tra la cicatrice polmonare e il cancro, relazione limitata al polmone ipsilaterale ed estesa nel tempo; tale riscontro è stato spiegato con il fatto che un processo infiammatorio localizzato con cicatrizzazione può favorire la cancerogenesi.

\section{Screening del tumore polmonare}

Nessuno degli studi sullo screening del tumore polmonare con radiografia standard del torace, eseguiti negli anni SessantaOttanta, ha rilevato una diminuzione di mortalità: i motivi erano soprattutto legati alla difficoltà di evidenziare lesioni di diametro inferiore a $10 \mathrm{~mm}$ e quindi potenzialmente guaribili chirurgicamente, alla scarsa definizione dei tumori periferici e all'elevato indice di accrescimento dei tumori centrali. Anche gli screening centrati sull'analisi citologica dell'espettorato non hanno portato a una diminuzione della mortalità, per la mancanza di adeguatezza nell'indagare i tumori periferici e per l'incapacità di diagnosticare i tumori centrali se non a uno stadio troppo avanzato. L'avvento della tomografia assiale computerizzata (TAC) a basso dosaggio ne ha indotto la sperimentazione nello screening; lo studio ELCAP, pubblicato nel 1999 su Lancet, concludeva che questa metodica incrementava la sensibilità diagnostica dei tumori polmonari in stadio operabile nelle popolazioni a rischio, ma presentava un'elevata frequenza di falsi positivi. Il limite degli studi è legato alla presenza di bias: la diagnosi di tumore, in corso di screening, è anticipata rispetto ai controlli, per cui risulta un apparente aumento della sopravvivenza anche se il momento della morte è lo stesso in entrambi i bracci (lead-time bias); inoltre, la probabilità di diagnosi di un tumore è connessa all'indice di accrescimento: tumori aggressivi hanno un breve periodo di screening e per tale motivo questi pazienti, anche se studiati frequentemente, hanno più probabilità di essere sintomatici; al contrario i pazienti con tumori indolenti hanno maggiore probabilità di essere indagati quando sono asintomatici: ne risulta che una maggior percentuale di tumori asintomatici è riscontrata nei pazienti sottoposti a screening, determinando un apparente aumento della sopravvivenza (length-time bias); infine, il riscontro di tumori asintomatici nei gruppi sottoposti a screening aumenta apparentemente il numero di casi di tumore polmonare e ne aumenta la sopravvivenza, perché i soggetti sottoposti a screening potrebbero giungere all'exitus per altre cause, senza che il tumore si manifesti (overdiagnosis bias)

Dall'analisi delle linee guida prodotte dall'American College of Chest Physicians (ACCP), dal National Cancer Institute $(\mathrm{NCl})$, dal National Comprehensive Cancer Network (NCCN), dall'American Cancer Society (ACS), dall'Australian Cancer Network (ACN/AUS) e dallo UK National Screening
Committee (NSC/UK) risulta una generale concordanza nel non raccomandare alcuna procedura per lo screening del tumore al polmone nella popolazione generale e nello stabilire che lo screening del tumore polmonare debba essere studiato nell'ambito di persone adulte a rischio: peraltro l'identificazione di tale rischio è poco chiara e non omogenea tra le varie linee guida.

Tutte le linee guida sopracitate, a esclusione della NCCN che non prevede lo screening con radiografia del torace, esprimono parere negativo riguardo allo screening con radiografia del torace associato o meno a esame citologico dell'espettorato, in quanto sono presenti in letteratura sufficienti dati di non efficacia. Vi è quindi molta aspettativa per studi randomizzati controllati ancora in corso.

Tre linee guida (ACS, ACN/AUS e NSC/UK) non raccomandano lo screening con TAC spirale, basando questa posizione sulla mancanza di prove convincenti a favore dell'intervento; le linee guida di ACCP, ACN/AUS e NCCN, pur esprimendo lo stesso parere per quanto riguarda la popolazione generale, raccomandano alle persone ad alto rischio di partecipare a studi randomizzati controllati che valutino l'impatto, in questo setting, della TAC spirale. Tutte queste linee guida sono state valutate con lo strumento AGREE, risultando complessivamente soddisfacenti: AGREE è uno strumento composto da una check list per la valutazione di una linea guida, che esplora non solo il terreno scientifico ma anche quello metodologico e la presenza o meno di conflitti di interesse.

\section{Relazione tra BPCO e cancro polmonare}

Carcinoma del polmone e BPCO rappresentano due emergenze sanitarie nel mondo occidentale, in quanto costituiscono la prima e la quarta causa di morte. Inoltre, le due condizioni cliniche sono spesso associate, e ciò rappresenta una comorbilità importante per entrambe le patologie, poiché sono variamente combinate in circa il $40 \%$ dei casi.

Da sempre l'associazione tra BPCO e aumentato rischio di carcinoma del polmone è stato messo in relazione con il fumo di sigaretta, essendo quest'ultimo fattore importante ma non unico in entrambe le patologie (dal momento che non tutti i fumatori sviluppano le due malattie). Il carcinoma del polmone è una delle più importanti e delicate comorbilità della BPCO, ma recenti evidenze suggeriscono che l'associazione possa essere indipendente dall'esposizione al tabacco. Un'ipotesi ragionevole è che entrambe le condizioni siano geneticamente determinate e che fattori di rischio personali e ambientali scatenino la manifestazione clinica delle due malattie. Il fumo e l'inquinamento ambientale possono portare a una serie di mutazioni, a loro volta responsabili dell'infiammazione e della distruzione alveolare, nonché ad alterazioni displastiche: possiamo quindi considerare le due condizioni quali due manifestazioni di una medesima malattia, come scritto qualche anno fa in un editoriale su Chest?

Complesse e non sempre chiarite sono le relazioni tra BPCO e cancro del polmone, anche se un recente articolo ha cercato di fare il punto della situazione: la riduzione modesta nella mortalità per cancro del polmone e BPCO negli ultimi anni (da 156,1 a 149,9 per 100.000 per il primo e da 123,9 a 
112,8 per il secondo) è correlata alla riduzione del consumo di tabacco; vi è comunque da tenere presente che il rischio di malattia per i fumatori rimane più elevato per alcuni anni, se comparato con i non fumatori.

BPCO e cancro occorrono più frequentemente tra le persone con più basso reddito e minore istruzione; basse performance polmonari sono un fattore di rischio per lo sviluppo di cancro polmonare, e tra i fumatori l'ostruzione delle vie aeree rappresenta un ulteriore fattore di rischio.

Inoltre, molti studi hanno evidenziato che il rischio di sviluppare un cancro al polmone aumenta con la presenza di BPCO e che il carcinoma del polmone è causa di morte nel $33 \%$ dei pazienti con BPCO negli stadi intermedi, mentre rappresenta il $14 \%$ delle cause di morte nei pazienti con BPCO severa. $\mathrm{E}$, per sottolineare ulteriormente le connessioni tra malattie croniche del polmone e cancro, una recente pubblicazione ha dimostrato che la presenza di enfisema si accompagna con una prognosi peggiore nei pazienti con tumore polmonare.

Il tumore polmonare viene schematicamente diviso in carcinoma a piccole cellule (SCLC) e carcinoma non a piccole cellule (NSCLC) che, a sua volta, raggruppa l'adenocarcinoma, il carcinoma epiteliale e il carcinoma a grandi cellule: questi tre sottogruppi rappresentano circa l' $80 \%$ dei tumori polmonari, mentre il SCLC è presente nel restante $20 \%$.

Esiste una relazione più stretta tra sottotipi di cancro polmonare e BPCO? O, per meglio dire, la relazione tra BPCO e cancro è sottotipo-specifica? Un piccolo studio ha mostrato che esiste una relazione tra ostruzione delle vie aeree e carcinoma epiteliale, che sintomi di bronchite cronica senza $\mathrm{BPCO}$ si accompagnano con un'incidenza più elevata di adenocarcinoma e, inoltre, che la contemporanea presenza di sintomi da bronchite cronica e BPCO aumentava fortemente il rischio che si sviluppasse un carcinoma epiteliale. Sembra peraltro evincersi da altri studi una relazione molto più stretta tra cancro polmonare ed enfisema, rispetto alla presenza di ostruzione delle vie aeree. Come già detto, si deve sottolineare che processi cicatriziali metapneumonici in pazienti affetti da BPCO sono localmente un importante fattore di rischio per la cancerogenesi.

Molti dei meccanismi patogenetici sono similari nelle due malattie, a riprova dell'enunciato che cancro polmonare e BPCO sono due facce della stessa medaglia: molte sostanze contribuiscono alla transizione epiteliale mesenchimale (EMT), processo nel quale le cellule subiscono un cambiamento dal fenotipo epiteliale al fenotipo mesenchimale. Tale processo sembra svolgere un ruolo importante sia nel cancro polmonare che nello sviluppo e nella progressione della BPCO: inoltre studi recenti hanno dimostrato che l'infiammazione contribuisce a promuovere l'EMT e l'infiammazione è connessa sia alla BPCO sia al tumore polmonare.

Ma esistono anche differenze sostanziali tra i due processi: il cancro è un processo antiapoptoico, è caratterizzato da proliferazione cellulare e invasione dei tessuti e da marcata angiogenesi; al contrario, la BPCO è caratterizzata da marcata apoptosi, degradazione della matrice cellulare, inefficace riparazione tissutale e limitata angiogenesi. E queste differenze potrebbero spiegare il perché una malattia diventa preminente rispetto all'altra.

\section{Trattamento del cancro nei pazienti con BPCO}

Posso trattare un paziente con il cancro in maniera aggressiva se presenta contemporaneamente un quadro di BPCO? La domanda pone diversi problemi e si presta a diverse interpretazioni, dal momento che gli studi condotti su pazienti con cancro e comorbilità non sono molti, per cui il clinico è lasciato solo di fronte a una decisione e segue più spesso il buon senso, senza il supporto di linee guida. Vi è inoltre da sottolineare che, con il generale invecchiamento della popolazione, sempre più frequentemente ci si trova a programmare un piano terapeutico in pazienti con una 0 più comorbilità, che rendono ancora più complesse scelte già difficili quando si tratta di pianificare un trattamento oncologico chirurgico, chemioterapico e radioterapico in pazienti anziani che presentano solo il cancro come malattia. Recenti studi hanno evidenziato che oltre il $60 \%$ dei pazienti con cancro ed età superiore a 65 anni soffrivano di una o più malattie croniche; in questo setting di pazienti la BPCO era la causa più frequente di comorbilità. In più, gli studi clinici tendono di norma a selezionare i pazienti escludendo quelli appartenenti alle fasce più anziane e con importanti comorbilità, per cui poco sappiamo sul trattamento e sulla sopravvivenza di questi pazienti.

Nello specifico della BPCO come comorbilità del cancro, affronteremo il problema del trattamento del carcinoma polmonare in presenza di BPCO, ma, anche, come debba comportarsi l'oncologo quando è chiamato a pianificare un trattamento chemioradioterapico per un tumore, in presenza di comorbilità.

Nella maggioranza dei casi la presenza di BPCO non sembra modificare le scelte terapeutiche degli oncologi: un importante e recente studio europeo ha valutato l'influenza della BPCO sulla diagnosi, sulle strategie terapeutiche e sulla sopravvivenza di pazienti non selezionati affetti da cancro con età superiore ai 35 anni; il $12 \%$ di tutti i pazienti presentava un quadro di BPCO al momento della diagnosi di cancro, con una percentuale che saliva al $15 \%$ nei pazienti over 65; nel sottogruppo del carcinoma polmonare la percentuale di BPCO saliva a più del $30 \%$.

La presenza di BPCO non sembra influenzare lo stadio della diagnosi se si eccettua, come prevedibile, il tumore polmonare, che viene diagnosticato più precocemente nei pazienti con BPCO. Sostanzialmente la presenza di BPCO non modifica il trattamento, se si esclude il NSCLC, che riceve un numero inferiore di trattamenti chirurgici e chemioterapici a fronte di un maggior numero di trattamenti radioterapici, il carcinoma esofageo nelle donne, che con minore frequenza viene trattato chirurgicamente, e i tumori della testa e del collo dove, quando possibile, la radioterapia diviene il trattamento di scelta. Sicuramente, invece, la presenza di BPCO peggiora la prognosi per la maggior parte dei tumori, specialmente nella fascia più anziana.

Un altro problema aperto è l'uso della chemioterapia adiuvante nel trattamento dei tumori in presenza di malattie croniche: quanto la loro presenza influenza l'uso ed eventualmente l'efficacia del trattamento? Un recente studio apparso nel 2007 ha investigato l'impatto della chemioterapia adiuvante nel carcinoma del colon, in presenza di insufficienza cardiaca, diabete e BPCO: l'evidenza dai trial clinici ci dice che la chemioterapia adiuvante nello stadio III del 
colon riduce la mortalità del 34\%, e che questo beneficio si mantiene con l'aumento dell'età; tali dati sono in contrasto con quanto avviene nel mondo reale, dove l'utilizzo della chemioterapia si riduce con l'aumento di età dei pazienti, con un decremento di circa il 35\% nei pazienti over 80 . Anche se gli studi in proposito non sono sufficienti, è possibile che le malattie croniche aumentino il rischio di ospedalizzazione legato alla tossicità chemioindotta e che, d'altro canto, la chemioterapia possa produrre un'aumentata ospedalizzazione dovuta all'esacerbarsi della malattia cronica sottostante. Lo studio, che ha arruolato circa 5.300 pazienti, ha evidenziato solo una modesta riduzione dell'utilizzo della chemioterapia nei pazienti con BPCO, mentre la riduzione era più consistente nel gruppo con insufficienza cardiaca. Un importante dato è la non riduzione del numero di pazienti che completa il ciclo di chemioterapia nel gruppo con malattie croniche. Il beneficio in termini di sopravvivenza a 5 anni, nel sottogruppo di pazienti con BPCO, è stato del 46,2\% dei trattati vs 34,1 dei non trattati: questo dato indica che la presenza di BPCO non altera il beneficio del trattamento adiuvante. Importante anche il dato di mortalità correlata alla chemioterapia, che è dello 0,67 nel gruppo senza malattie croniche vs 0,70 in quello con comorbilità. Anche il tasso di ospedalizzazione nell'anno seguente al trattamento è uguale nei due gruppi. Vi è da segnalare che questi dati si riferiscono all'utilizzo del fluorouracile, che rappresentava il gold standard del trattamento adiuvante per il carcinoma del colon al momento della raccolta dati: attualmente vengono utilizzati altri farmaci, come capecitabina e oxaliplatino, dotati di maggior efficacia ma anche con tossicità superiore.

Un problema importante e non ben definito per la complessità della situazione e per la variabilità dei dati è il trattamento chirurgico del carcinoma polmonare nei pazienti con BPCO.

\section{La terapia chirurgica del tumore polmonare nel paziente affetto da BPCO}

L'intervento chirurgico rappresenta ancora oggi la principale possibilità di successo nei pazienti con tumore squamocellulare, adenocarcinoma e tumore a grandi cellule.

Resta confermato che proprio la resezione chirurgica è il trattamento di scelta per gli stadi I e II, mentre ancora dibattuti sono i risultati per lo stadio III, o meglio IIIA e IIIB.

La tecnica usata dipende dalle caratteristiche della massa (dimensioni, sede, estensione locale e linfonodale ecc.); la tipologia comprende:

- pneumonectomia;

- lobectomia o bilobectomia;

- segmentectomia;

- resezione a cuneo (wedge resection);

- lobectomia con resezione bronchiale a manicotto (sleeve lobectomy).

Mentre in passato si privilegiava la pneumonectomia, per una supposta maggiore radicalità oncologica, oggi si pensa che tale tecnica non aumenti le probabilità di guarigione. Infatti spesso la malattia è disseminata al momento della diagnosi, e la progressione solitamente avviene per metastasi a distanza più che per recidiva locoregionale.

Oggi l'intervento più frequente è la lobectomia, che presenta una mortalità intraospedaliera 3 volte minore di quella secondaria alla pneumonectomia. La segmentectomia dovrebbe essere considerata in pazienti con SCLC CT1N0, con un volume espiratorio forzato in un secondo (FEV1) predetto postoperatorio normale ( $>80 \%$ ); se è $<70 \%$, la segmentectomia non offre vantaggi funzionali rispetto alla lobectomia.

La valutazione preoperatoria delle condizioni del paziente è di notevole importanza, poiché spesso la neoplasia insorge in soggetti di età avanzata e con altre patologie, specialmente secondarie al tabagismo, quali BPCO, coronaropatie e ipertensione arteriosa.

In questa sede si tratterà in particolare del paziente affetto da BPCO.

Non è raro che il paziente addirittura non sia trattato, ed è stato evidenziato che una corretta preparazione farmacologica può essere efficace nell'ottica di un programma chirurgico.

Il rischio operatorio è duplice:

- complicanze cardiorespiratorie immediate;

- disabilità respiratorie a lungo termine.

Tale rischio viene misurato nella pratica clinica corrente mediante indagini non invasive, di basso costo e facilmente disponibili, da affrontare in una situazione di stabilità clinica:

- spirometria globale;

- emogasanalisi;

- diffusione alveolo-capillare del CO;

- valutazione della funzione polmonare residua postoperatoria;

- test cardiopolmonare.

\section{Spirometria globale}

La spirometria evidenzia il FEV1, che deve essere maggiore di $2 \mathrm{~L}$ in caso di pneumonectomia, di 1,5 $\mathrm{L}$ in caso di lobectomia e, infine, maggiore dell' $80 \%$ del predetto in caso di anziani, donne e persone di bassa statura; il rispetto di tale raccomandazione ha permesso di mantenere la mortalità al di sotto del $5 \%$ in più di 2.000 casi. Un FEV1 inferiore a $0,8 \mathrm{~L} \mathrm{o}$ al $30 \%$ del predetto indica un rischio molto aumentato, mentre, se è compreso tra il 30 e il 40\%, raccomanda di approfondire la valutazione.

\section{Emogasanalisi}

L'emogasanalisi mostra la $\mathrm{PaCO}_{2}$ che, se superiore a 45 $\mathrm{mmHg}$, aumenta di molto la probabilità di una qualsiasi complicazione (fino all' $87 \%$ in alcune casistiche).

\section{Diffusione alveolo-capillare del CO}

La diffusione alveolo-capillare del CO (DLCO) è un esame centrale nella valutazione del paziente; già dal 1988 era noto che la DLCO costituisce il più importante indice di mortalità $(p<0,01)$ e l'unico "predittore" di complicazioni polmonari postoperatorie $(p<0,005)$. Successivamente si è arrivati a precisare che:

- DLCO $<60 \%$ del teorico, aumenta il rischio di mortalità;

- DLCO $<80 \%$ del teorico, aumenta di tre volte il rischio di complicanze polmonari postoperatorie.

Da ciò discende che:

- DLCO $>80 \%$ del teorico = paziente idoneo;

- DLCO $<80 \%$ del teorico = consigliabili altri accertamenti; 
- $\mathrm{DLCO}<60 \%$ del teorico = obbligatori altri accertamenti.

Si deve sottolineare che tale parametro mantiene la propria importanza anche nel caso di spirometria del tutto normale.

\section{Valutazione della funzione polmonare residua postoperatoria}

La valutazione della funzione polmonare residua postoperatoria avviene dapprima misurando gli indici di funzionalità respiratoria e poi calcolando il probabile peggioramento degli stessi in seguito alla rimozione di tessuto polmonare. Il calcolo avviene mediante una semplice formula matematica (Kearney et al., Chest,1994):

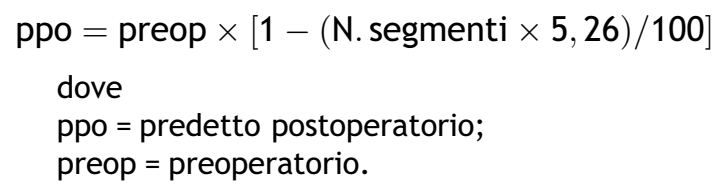
segmento può non essere perfuso (e quindi non funzionante) prima dell'intervento. Infatti sembra che la resezione chirurgica possa essere effettuata anche in pazienti selezionati con FEV1 ridotto e BPCO di stadio II senza significativa riduzione nella funzionalità polmonare. Inoltre, tale errore è minimo negli interventi di lobectomia, mentre può essere importante in quelli di pneumonectomia. È stato inoltre dimostrato che i pazienti affetti da BPCO moderata e severa presentano dopo lobectomia una riduzione del FEV1 (come del massimo consumo di ossigeno, $\mathrm{VO}_{2}$ max) minore di quella dei pazienti con BPCO lieve o senza tale patologia. Analogamente, i pazienti affetti da BPCO presentano dopo pneumonectomia riduzioni funzionali minori dei soggetti sani, verosimilmente per la riduzione di volume connessa alla resezione. L'esperienza di vari autori ha dimostrato pertanto come pazienti che dovrebbero essere considerati inoperabili possano superare l'intervento in tutta sicurezza.

Può comunque risultare necessario lo studio perfusionale, che si effettua mediante scintigrafia polmonare perfusoria; nella pratica clinica corrente tale esame non si effettua se FEV1 ppo > 40\% del teorico.

Il contributo di quest'ultimo accertamento è esplicato dalla seguente formula:

$$
\begin{gathered}
\text { ppo }=\text { preop } \times(1-\text { contributo frazionario delle } \\
\text { aree perfuse })
\end{gathered}
$$

Più recentemente è stato studiato il possibile contributo della TAC polmonare. La formula è la seguente:

$$
\begin{array}{r}
\text { ppo }=\text { preop } \times[1-(\text { volume polmonare da rimuovere } / \\
\text { volume polmonare funzionale totale })]
\end{array}
$$

Nella valutazione del FEV1 postoperatorio, è necessario considerare un margine di sicurezza (almeno del 15-20\%), dal momento che nel periodo postoperatorio possono fare la loro comparsa condizioni che possono ridurre il valore teorico molto al di sotto del valore soglia, a causa di:

- resezioni chirurgiche maggiori del previsto;
Tabella 1 Segmenti polmonari.

\begin{tabular}{lccc}
\hline & N & $\%$ & Funzione residua (\%) \\
\hline Polmone destro & 22 & 52 & 48 \\
- Lobo superiore & 6 & 14 & 86 \\
- Lobo medio & 4 & 9 & 91 \\
- Lobo inferiore & 12 & 29 & 71 \\
\hline Polmone sinistro & 20 & 48 & 52 \\
- Lobo superiore & 10 & 24 & 76 \\
- Lobo inferiore & 10 & 24 & 76 \\
\hline
\end{tabular}

- insorgenza nel postoperatorio di atelettasia, flogosi, edema polmonare o versamento pleurico;

- peggioramento della funzionalità del polmone controlaterale per analoghi motivi.

\section{Test da sforzo cardiopolmonare}

Il test da sforzo cardiopolmonare permette di misurare molti parametri, tra cui il $\mathrm{VO}_{2}$ max. Nel caso in cui l' $\mathrm{O}_{2}$ disponibile non sia sufficiente al bisogno dei tessuti, si determina una sofferenza metabolica con conseguente aumento della mortalità e morbilità postoperatoria. Secondo vari autori, un $\mathrm{VO}_{2}$ $\max <10 \mathrm{~mL} / \mathrm{kg} / \mathrm{min}$ è indice di un grosso incremento di mortalità, mentre se è $>20 \mathrm{~mL} / \mathrm{kg} / \mathrm{min}$ segnala che non vi è alcun aumento di rischio, né di mortalità né di complicanze. Grande incertezza sussiste per un $\mathrm{VO}_{2}$ max compreso tra 10 e $20 \mathrm{~mL} / \mathrm{kg} / \mathrm{min}$.

Le alternative a tale esame sono limitate: finora è indicata solo la salita delle scale, che non è però un esame standardizzato.

In caso di rischio operatorio troppo elevato, nella pratica clinica avviene che il chirurgo e/o l'anestesista possano esprimere un giudizio di inoperabilità. Tuttavia, qualora il paziente (correttamente informato sia sul rischio legato alla storia naturale della malattia, sia su quelli di mortalità e/o disabilità connessi all'eventuale intervento chirurgico) insista per l'intervento, si ritiene etico rivalutare la richiesta alla luce delle preferenze espresse.

\section{Bibliografia consigliata}

Bach PB, Silvestri GA, Hanger M, Jett JR; American College of Chest Physicians. Screening for lung cancer: ACCP evidencebased clinical practice guidelines (2nd edition). Chest 2007;132(3 Suppl):69-77S.

Beckles MA, Spiro SG, Colice GL, Rudd RM; American College of Chest Physicians. The physiologic evaluation of patients with lung cancer being considered for resectional surgery. Chest 2003;123(1 Suppl):105-14S.

Bolliger CT, Perruchoud AP. Functional evaluation of the lung resection candidate. Eur Respir J 1998;11(1):198-212.

British Thoracic Society; Society of Cardiothoracic Surgeons of Great Britain and Ireland Working Party. BTS guidelines: guidelines on the selection of patients with lung cancer for surgery. Thorax 2001;56(2):89-108. 
Coburn MC, Pricolo VE, Soderberg CH. Factors affecting prognosis and management of carcinoma of the colon and rectum in patients more than eighty years of age. J Am Coll Surg 1994;179(1):65-9.

Colice GL, Shafazand S, Griffin JP, Keenan R, Bolliger CT; American College of Chest Physicians. Physiologic evaluation of the patient with lung cancer being considered for resectional surgery: ACCP evidenced-based clinical practice guidelines (2nd edition). Chest 2007;132(3 Suppl):161-77S.

Ferguson MK, Little L, Rizzo L, Popovich KJ, Glonek GF, Leff A, et al. Diffusing capacity predicts morbidity and mortality after pulmonary resection. J Thorac Cardiovasc Surg 1988; 96(6):894-900.

Ferguson MK, Vigneswaran WT. Diffusing capacity predicts morbidity after lung resection in patients without obstructive lung disease. Ann Thorac Surg 2008;85(4):1158-64.

Fiorani CM, Fiorucci F. Trattato di medicina respiratoria. Vol 2. Roma: Verduci, 1994, pp. 946-8.

Gill S, Loprinzi CL, Sargent DJ, Thomé SD, Alberts SR, Haller DG, et al. Pooled analysis of fluorouracil-based adjuvant therapy for stage II and III colon cancer: who benefits and by how much? J Clin Oncol 2004;22(10):1797-806.

Gross CP, McAvay GJ, Guo Z, Tinetti ME. The impact of chronic illnesses on the use and effectiveness of adjuvant chemotherapy for colon cancer. Cancer 2007;109(12):2410-9.

Holden DA, Rice TW, Stelmach K, Meeker DP. Exercise testing, 6-min walk, and stair climb in the evaluation of patients at high risk for pulmonary resection. Chest 1992;102(6): 1774-9.

Houghton AM, Mouded M, Shapiro SD. Common origins of lung cancer and COPD. Nat Med 2008;14(10):1023-4.

Jemal A, Clegg LX, Ward E, Ries LA, Wu X, Jamison PM, et al. Annual report to the nation on the status of cancer, 19752001, with a special feature regarding survival. Cancer 2004; 101(1):3-27.

Kashiwabara K, Sasaki J, Mori T, Nomori H, Fujii K, Kohrogi H. Relationship between functional preservation after segmentectomy and volume-reduction effects after lobectomy in stage I non-small cell lung cancer patients with emphysema. J Thorac Oncol 2009;4(9):1111-6.

Kearney DJ, Lee TH, Reilly JJ, DeCamp MM, Sugarbaker DJ. Assessment of operative risk in patients undergoing lung resection. Importance of predicted pulmonary function. Chest 1994;105(3):753-9.

Kobayashi S, Suzuki S, Niikawa H, Sugawara T, Yanai M. Preoperative use of inhaled tiotropium in lung cancer patients with untreated COPD. Respirology 2009;14(5): 675-9.

Kushibe K, Kawaguchi T, Kimura M, Takahama M, Tojo T, Taniguchi S. Exercise capacity after lobectomy in patients with chronic obstructive pulmonary disease. Interact Cardiovasc Thorac Surg 2008;7(3):398-401.
Luzzi L, Tenconi S, Voltolini L, Paladini P, Ghiribelli C, Di Bisceglie $M$, et al. Long-term respiratory functional results after pneumonectomy. Eur J Cardiothorac Surg 2008;34(1): 164-8.

Mannino DM. COPD and lung cancer among women: an equal opportunity risk? J Thorac Oncol 2009;4(3):275-6.

Mannino DM. COPD and lung cancer have come a long way. baby. Am J Respir Crit Care Med 2007;176(2):108-9.

Markos J, Mullan BP, Hillman DR, Musk AW, Antico VF, Lovegrove FT, et al. Preoperative assessment as a predictor of mortality and morbidity after lung resection. Am Rev Respir Dis 1989;139(4):902-10.

Martin J. Lung resection in the pulmonary-compromised patient. Thorac Surg Clin 2004;14(2):157-62.

Morice RC, Peters EJ, Ryan MB, Putnam JB, Ali MK, Roth JA. Exercise testing in the evaluation of patients at high risk for complications from lung resection. Chest 1992;101(2): 356-61.

Nordquist LT, Simon GR, Cantor A, Alberts WM, Bepler G. Improved survival in never-smokers vs current smokers with primary adenocarcinoma of the lung. Chest 2004;126(2): $347-51$.

Olsen GN, Weiman DS, Bolton JW, Gass GD, McLain WC, Schoonover GA, et al. Submaximal invasive exercise testing and quantitative lung scanning in the evaluation for tolerance of lung resection. Chest 1989;95(2):267-73.

Pate P, Tenholder MF, Griffin JP, Eastridge CE, Weiman DS. Preoperative assessment of the high-risk patient for lung resection. Ann Thorac Surg 1996;61(5):1494-500.

Perrone F, Gallo C, Daniele B. Chemotherapy in the elderly. N Engl J Med 2002;346(8):622-3.

Petty TL. Are COPD and lung cancer two manifestations of the same disease? Chest 2005;128(4):1895-7.

Punturieri A, Szabo E, Croxton TL, Shapiro SD, Dubinett SM. Lung cancer and chronic obstructive pulmonary disease: needs and opportunities for integrated research. J Natl Cancer Inst 2009;101(8):554-9.

Schattenberg T, Muley T, Dienemann H, Pfannschmidt J. Impact on pulmonary function after lobectomy in patients with chronic obstructive pulmonary disease. Thorac Cardiovasc Surg 2007;55(8):500-4.

Smith RA, Cokkinides V, Brawley OW. Cancer screening in the United States, 2009: a review of current American Cancer Society guidelines and issues in cancer screening. CA Cancer J Clin 2009;59(1):27-41.

Sundararajan V, Mitra N, Jacobson JS, Grann VR, Heitjan DF, Neugut Al. Survival associated with 5-fluorouracil-based adjuvant chemotherapy among elderly patients with nodepositive colon cancer. Ann Intern Med 2002;136(5):349-57.

Tammemagi CM, Neslund-Dudas C, Simoff M, Kvale P. Impact of comorbidity on lung cancer survival. Int $\mathrm{J}$ Cancer 2003;103(6):792-802. 
van de Schans SA, Janssen-Heijnen ML, Biesma B, Smeenk FW, van de Poll-Franse LV, Seynaeve C, et al. COPD in cancer patients: higher prevalence in the elderly, a different treatment strategy in case of primary tumours above the diaphragm, and a worse overall survival in the elderly patient. Eur J Cancer 2007;43(15):2194-202.

Wetstein L, Bechard D. Assessment of exercise oxygen consumption: reply. Ann Thorac Surg 1989;47(4):639.

Wu MT, Pan HB, Chiang AA, Hsu HK, Chang HC, Peng NJ, et al. Prediction of postoperative lung function in patients with lung cancer: comparison of quantitative CT with perfusion scintigraphy. AJR Am J Roentgenol 2002;178(3): $667-72$.
Wyser C, Stulz P, Solèr M, Tamm M, Müller-Brand J, Habicht J, et al. Prospective evaluation of an algorithm for the functional assessment of lung resection candidates. Am J Respir Crit Care Med 1999;159(5 Pt 1):1450-6.

Yancik R, Wesley MN, Ries LA, Havlik RJ, Long S, Edwards BK, et al. Comorbidity and age as predictors of risk for early mortality of male and female colon carcinoma patients: a population-based study. Cancer 1998;82(11):2123-34.

Yu YY, Pinsky PF, Caporaso NE, Chatterjee N, Baumgarten M, Langenberg $\mathrm{P}$, et al. Lung cancer risk following detection of pulmonary scarring by chest radiography in the prostate, lung, colorectal, and ovarian cancer screening trial. Arch Intern Med 2008;168(21):2326-32. 


\section{Le infezioni come comorbilità della BPCO}

\section{Fabrizio Luppi, Bianca Beghè, Pietro Roversi}

\section{Messaggi chiave}

- Il polmone normale presenta diversi meccanismi di difesa nei confronti dei microrganismi che colonizzano le vie aeree. In assenza di patologie broncopolmonari, le infezioni delle basse vie aeree sono piuttosto rare rispetto alla frequenza con la quale insorgono a carico delle alte vie aeree.

- Nei pazienti affetti da broncopneumopatia cronica ostruttiva (BPCO), le infezioni sia acute sia croniche delle basse vie aeree insorgono con aumentata frequenza rispetto ai soggetti sani.

- Poiché la comparsa di infezioni in pazienti affetti da BPCO contribuisce in modo significativo al decorso clinico della malattia, esse costituiscono un'importante comorbilità della BPCO.

- Si ritiene che le infezioni acute causate da patogeni batterici e/o virali siano correlate alla comparsa di episodi di riacutizzazione della malattia.

- L'insorgenza di polmoniti in pazienti affetti da BPCO è a tutt'oggi motivo di dibattito, poiché potrebbe essere favorita dall'assunzione di steroidi inalatori.

- Il ruolo delle infezioni croniche nella patogenesi della BPCO costituisce un'importante area di ricerca, con diversi patogeni potenzialmente implicati.

\section{Ruolo dell'infezione acuta e cronica}

In condizioni normali, l'albero tracheobronchiale e il parenchima polmonare dei soggetti sani sono in grado di mantenere - nonostante la comunicazione con l'esterno che, attraverso la microaspirazione e l'inalazione, comporta la presenza di microbi - una condizione di sterilità. Tuttavia, nei pazienti affetti da broncopneumopatia cronica ostruttiva (BPCO) l'immunità innata del polmone risulta deficitaria, quale conseguenza dell'esposizione al fumo di sigaretta e ad altri irritanti ambientali. Il deficit dell'immunità innata comporta due diversi tipi di infezione, l'acuta e la cronica, che potrebbero contribuire alla progressiva perdita funzionale dei pazienti affetti da BPCO (fig. 1).

L'infezione acuta è caratterizzata dal fatto che il polmone dei pazienti affetti da BPCO diviene suscettibile a ripetute infezioni acute della mucosa bronchiale, a opera sia di virus sia di batteri patogeni, che determinano un'episodica accentuazione dell'infiammazione a livello della mucosa bronchiale e un conseguente peggioramento dei sintomi: tali episodi vengono clinicamente diagnosticati come riacutizzazioni della malattia.

L'infezione cronica si associa, viceversa, a colonizzazione microbica, che determina quindi una persistente infiammazione cronica e la distruzione del parenchima polmonare. Questa ipotesi si fonda sul principio che il fumo di sigaretta determini un deficit dell'immunità innata, con conseguente persistente colonizzazione delle vie aeree da parte di diversi agenti patogeni, i quali determinano un ulteriore deficit della clearance mucociliare e delle difese polmonari, causato dall'aumentata secrezione mucosa, dall'inefficiente attività delle ciglia vibratili presenti a livello bronchiale e dal danno arrecato alla componente epiteliale della mucosa bronchiale. Pertanto, la colonizzazione microbica delle basse vie aeree in pazienti con BPCO può automantenersi e la cronica presenza di batteri a tale livello non può essere considerata innocua, in quanto induce un'infiammazione che può contribuire alla progressiva ostruzione bronchiale e al danno polmonare caratteristici della malattia.

\section{Ruolo delle infezioni nelle riacutizzazioni della BPCO}

Le riacutizzazioni della BPCO secondarie a infezioni batteriche e/o virali insorgono in quasi tutti i pazienti affetti da BPCO. Sono ormai disponibili molteplici evidenze che dimostrano l'importanza delle riacutizzazioni nel determinare la qualità di vita, la progressione della malattia e la sopravvivenza dei pazienti affetti da BPCO. Inoltre, gli episodi di 


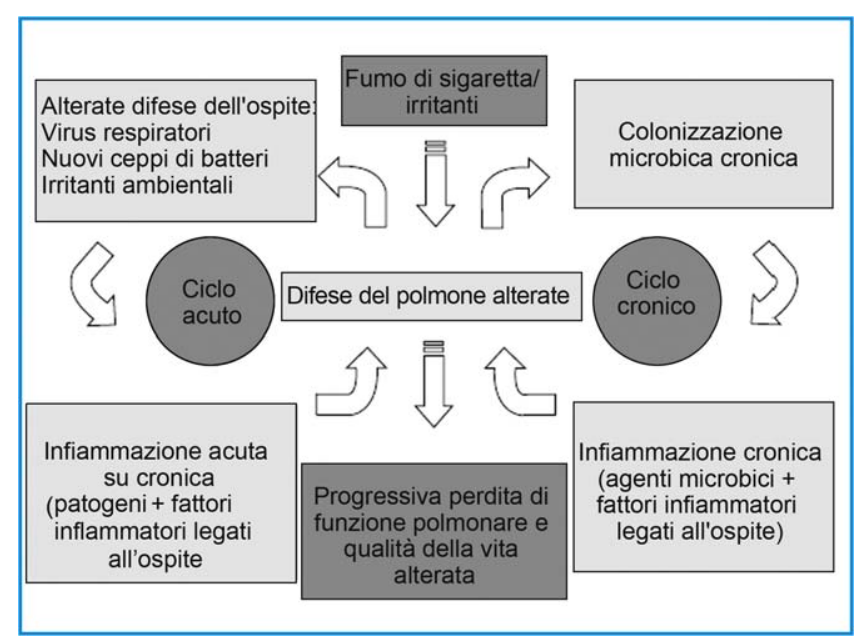

Figura 1 Infezione acuta e cronica in pazienti affetti da BPCO.

riacutizzazione assorbono il 35-45\% delle risorse sanitarie destinate alla BPCO.

Per decenni, è stato studiato il ruolo delle infezioni batteriche in pazienti affetti da BPCO senza raggiungere un consenso. Studi condotti in passato, basati sulla coltura delle secrezioni respiratorie e sui test sierologici, hanno dimostrato che circa un terzo delle riacutizzazioni era determinato da infezioni batteriche. Tuttavia, nei restanti casi, l'eziologia rimaneva incerta; in particolare risultava oscuro il significato dell'isolamento di batteri nell'espettorato [1]. L'esecuzione di studi longitudinali, che mostravano tassi simili di isolamento di Streptococcus pneumoniae e di Haemophilus influenzae nell'espettorato di pazienti riacutizzati e di quelli in fase di stabilizzazione clinica, aveva portato a ridimensionare la relazione causale fra crescita di batteri nell'espettorato ed episodi di riacutizzazione [1-3]. Un'importante limitazione di questi studi era tuttavia da ricercarsi - data l'assenza della tecnologia necessaria - nel fatto che in essi non si differenziavano i diversi ceppi nell'ambito di una medesima specie batterica [1], con la conseguente impossibilità di rilevare la presenza di diversi ceppi batterici nel corso del tempo. Più recentemente, in particolare grazie alla fruibilità della biologia molecolare, sono state introdotti nella pratica clinica nuovi metodi di tipizzazione delle specie batteriche, che hanno rivalutato l'interesse dei batteri quali potenziali agenti causali delle riacutizzazioni della BPCO.

\section{Ruolo patogenetico delle infezioni batteriche nella BPCO}

Nonostante gli isolati batterici siano del tutto sovrapponibili nei pazienti affetti da BPCO in fase di stabilizzazione clinica, rispetto a quelli che presentano una riacutizzazione della malattia, è noto che le infezioni batteriche possono avere un importante ruolo nella patogenesi delle riacutizzazioni della malattia. In passato si riteneva che le riacutizzazioni indotte da batteri fossero da riferirsi all'aumentata carica batterica durante la riacutizzazione della malattia. Questa ipotesi non è stata tuttavia confermata dai dati empirici e oggigiorno si ritiene che il contributo dell'aumentata carica batterica alle riacutizzazioni della BPCO sia discutibile; questo meccanismo potrebbe forse essere operante solo per alcune specie batteriche (quali Enterobacteriaceae, Pseudomonas aeruginosa e Staphylococcus aureus). Si è tuttavia osservato che la carica batterica è anche un importante determinante di infiammazione bronchiale, in particolare di un aumentato reclutamento di neutrofili [4].

Un modello alternativo, oggigiorno molto più accreditato, si basa sull'acquisizione di nuovi ceppi batterici che risultano poi essere responsabili dell'episodio di riacutizzazione. In questo modello, l'acquisizione di nuovi ceppi batterici determina un nuovo equilibrio fra l'incrementata virulenza del batterio e le difese immunitarie polmonari, che porta all'aumento dell'infiammazione a livello sia polmonare sia sistemico. L'aumentato grado di infiammazione a sua volta provoca un aggravamento dei sintomi, che si rendono pertanto responsabili dell'episodio di riacutizzazione. $\mathrm{Si}$ instaura quindi una risposta immune di tipo adattativo nei confronti del nuovo ceppo batterico, la quale - possibilmente favorita dalla terapia antibiotica - controlla ed eventualmente elimina il ceppo batterico responsabile dell'infezione. Tuttavia, poiché la risposta immune è specifica per il determinato ceppo batterico che ha causato la riacutizzazione, altri ceppi della stessa specie che presentino un diverso profilo antigenico e, a maggior ragione, diverse specie batteriche possono causare ulteriori episodi di riacutizzazione [5].

Se l'isolamento di un nuovo ceppo batterico risulta essere causa di una riacutizzazione della malattia, si dovrebbe apprezzare un diverso profilo infiammatorio, nel corso di tale riacutizzazione, rispetto a episodi di riacutizzazione che non si accompagnano all'acquisizione di nuovi ceppi batterici: nel caso dell'acquisizione di nuovi ceppi batterici in corso di riacutizzazione si osserva un'infiammazione neutrofila sia bronchiale sia sistemica [6]. Inoltre, White et al. hanno osservato che 10 giorni di trattamento antibiotico, somministrato in pazienti affetti da BPCO in cui si osservava la purulenza dell'espettorato, determinava un'attenuazione dell'infiammazione neutrofila; la persistenza dei batteri si associava invece a una persistenza dell'intensità dell'infiammazione neutrofila [7].

Un altro possibile approccio che si può utilizzare per valutare il ruolo dei batteri quali agenti causali delle riacutizzazioni di BPCO consiste nello studiare lo sviluppo di una specifica risposta immune nei confronti di batteri patogeni che seguono una riacutizzazione. Sono state dimostrate - in particolare quando il ceppo batterico è di nuova acquisizione - specifiche risposte immuni nei confronti di ceppi di Haemophilus influenzae, S. pneumoniae e $M$. catarrhalis, a livello sistemico (immunoglobuline sieriche, IgG) e/o a livello della mucosa (IgA nell'espettorato). Inoltre, per quanto riguarda Haemophilus influenzae, tale risposta immune presenta una notevole specificità per ciascun ceppo, con potenziali, molteplici episodi di riacutizzazione derivanti da diversi ceppi di una stessa specie che presentino un diverso assetto antigenico. Studi recenti hanno inoltre dimostrato che si osserva la coinfezione di virus e batteri in circa un quarto degli episodi di riacutizzazione; tale condizione conferisce maggiore gravità, sia clinica sia dal punto di vista della funzionalità respiratoria. 


\section{Trattamento antibiotico delle riacutizzazioni}

Le metanalisi eseguite avvalendosi degli studi clinici randomizzati e controllati contro placebo, unitamente al risultato di recenti studi epidemiologici, supportano l'utilizzo degli antibiotici per il trattamento di alcune riacutizzazioni di BPCO [8,9]. Le attuali linee guida, infatti, raccomandano l'uso di antibiotici in caso di riacutizzazioni moderate o severe, cioè quelle che richiedono l'ospedalizzazione o che si caratterizzano per la presenza di almeno due dei criteri di Anthonisen: peggioramento della dispnea, aumento di volume dell'espettorato e/o purulenza dello stesso [10]. Daniels et al. [11] hanno recentemente pubblicato i risultati di uno studio clinico randomizzato, controllato contro placebo, che valuta la somministrazione di antibiotici (doxiciclina) in associazione a steroidi per via sistemica in pazienti affetti da riacutizzazione di BPCO che presentavano i criteri di Anthonisen. Tale studio ha dimostrato la sostanziale mancanza di efficacia della terapia antibiotica in questi pazienti, che costituiscono il sottogruppo per i quali le linee guida raccomandano anche la somministrazione di antibiotici nel trattamento degli episodi di riacutizzazione. Lo studio permetterebbe quindi di ipotizzare un ruolo delle infezioni batteriche nel determinare un'infiammazione broncopolmonare, che verrebbe tuttavia dominata dalla somministrazione di steroidi per via sistemica [12].

I pazienti che presentano una riacutizzazione di BPCO possono essere distinti in pazienti "complicati", che presentano cioè uno o più fattori di rischio (fra cui l'età avanzata, l'ostruzione bronchiale grave, le frequenti riacutizzazioni, la presenza di comorbilità extrapolmonari), e "non complicati", che non presentano tali fattori di rischio. I pazienti "complicati" dovrebbero essere trattati con fluorochinoloni o amoxicillina/clavulanato, mentre per i pazienti "non complicati" viene considerata appropriata una terapia antibiotica con macrolidi, cefalosporine, tetracicline o trimetoprim/sulfametossazolo. La risposta alla terapia dovrebbe essere valutata a distanza di 48-72 ore dal suo inizio.

\section{Polmonite acquisita in comunità in pazienti affetti da BPCO}

Una delle più importanti cause di ospedalizzazione e una delle più comuni cause di morte in pazienti fumatori e/o affetti da BPCO è rappresentata dall'insorgenza di polmoniti acquisite in comunità (CAP) [13]. È comunque oggetto di discussione se la prognosi delle CAP sia peggiore in pazienti affetti da BPCO rispetto ai pazienti che non presentano ostruzione bronchiale. Uno studio caso-controllo ha dimostrato un elevato rischio di contrarre la polmonite da parte dei fumatori; tale rischio si riduce considerevolmente dopo 5 anni dalla sospensione dell'abitudine tabagica e ritorna del tutto analogo rispetto ai non fumatori dopo 10 anni [14].

Anche la terapia steroidea per via inalatoria, che viene praticata in pazienti affetti da BPCO, in genere di grado severo, può aumentare il rischio di contrarre una CAP. Tale dato è risultato particolarmente evidente dai risultati dello studio TORCH (TOwards a Revolution in COPD Health), che ha evidenziato un significativo aumento nel tasso di polmoniti insorto nei due bracci dello studio, nei quali i pazienti assumevano steroidi inalatori, rispetto al gruppo che assumeva placebo (19,6 e 18,3\% vs $12,3 \%$, rispettivamente; $p=0,001)$. L'aumentato rischio di contrarre la polmonite non si è tuttavia associato a un incremento del tasso di mortalità [15].

Una recente metanalisi [16] ha valutato gli studi eseguiti con sufficiente rigore metodologico che riportavano i risultati relativi all'insorgenza di polmoniti in pazienti affetti da BPCO in terapia con steroidi inalatori: 7 sono stati gli studi - per un totale di 10.776 pazienti - che hanno valutato l'insorgenza di polmoniti in questi pazienti. Tali studi hanno compreso 777 eventi fra 5.405 pazienti che erano in trattamento con steroidi inalatori e 561 eventi fra 5.371 pazienti in trattamento con placebo. I pazienti in terapia con steroidi inalatori hanno presentato una più elevata incidenza di polmonite (RR 1,34; IC 95\% 1,03-1,75; $p=0,03$ ). In quest'analisi, si è osservato un moderato grado di eterogeneità $(p<0,001$; $1^{2}=72 \%$ ): tre singoli studi, che hanno riportato un'incidenza significativamente più elevata di polmoniti, costituivano il $61,9 \%$ del peso complessivo della metanalisi. Ciascuno di questi studi è stato pubblicato dopo il 2006 (fig. 2).

Un'ulteriore recente metanalisi [17] ha compreso 18 studi randomizzati e controllati (per un totale di 16.996 pazienti) con un follow-up che oscillava fra 24 e 156 settimane. Anche in questa ulteriore metanalisi l'assunzione di steroidi inalatori è risultata associata a un significativo aumento del rischio di contrarre sia una polmonite indipendentemente dalla sua gravità (RR 1,60; IC 95\% 1,33-1,92; $\mathrm{p}<0,001 ; \mathrm{I}^{2}=16 \%$ ) sia una polmonite grave (RR 1,71; IC 95\% 1,46-1,99; $p<0,001$; $\mathrm{I}^{2}=0 \%$ ), ma senza un aumentato rischio di morte, legato sia alla polmonite stessa (RR 1,27; IC 95\% 0,80-2,03; $p=0,31$; $\mathrm{I}^{2}=0 \%$ ) sia alla mortalità globale (RR 0,96 ; IC 95\% 0,86-1,08; $\left.p=0,51 ; 1^{2}=0 \%\right)$. Gli steroidi inalatori sono inoltre risultati associati, per i pazienti che li assumevano, a un significativo rischio di contrarre una polmonite grave, rispetto ai pazienti che assumevano il placebo (RR, 1,81; IC 95\% 1,44-2,29; $\mathrm{p}<0,001$ ); tale rischio è risultato altresì aumentato in quei pazienti che assumevano la combinazione di steroidi inalatori e beta $a_{2}$-agonisti a lunga durata d'azione rispetto ai pazienti in terapia solo con beta ${ }_{2}$-agonisti a lunga durata d'azione (RR 1,68; IC 95\%,20-2,34; $p=0,002$ ). In conclusione, quindi, la somministrazione di steroidi inalatori per almeno 24 settimane in pazienti affetti da BPCO è risultata associata a un significativo aumento del rischio di contrarre una polmonite, in assenza di un significativo aumento del rischio di morte.

Le due metanalisi sopraccitate hanno tuttavia importanti limitazioni, dovute al fatto che gli studi inclusi presentavano una notevole eterogeneità in relazione sia al farmaco utilizzato sia alla durata del trattamento; tali differenze hanno probabilmente contribuito a determinare una notevole variabilità nei risultati ottenuti.

In proposito, Sin et al. [18] hanno esaminato i risultati ottenuti da 7 studi clinici di vaste dimensioni, nei quali pazienti affetti da BPCO in fase di stabilizzazione clinica venivano trattati con un solo steroide inalatorio, la budesonide (320-1.280 $\mu \mathrm{g} / \mathrm{die})$, in associazione o no a un broncodilatatore a lunga durata d'azione, il formoterolo (in totale 7.042 pazienti, 3.801 dei quali in trattamento con budesonide e 3.241 in trattamento con placebo o formoterolo); tali pazienti venivano confrontati con pazienti che costituivano la popolazione di controllo (in trattamento con placebo o formoterolo) per almeno 6 mesi. Non si sono osservate significative differenze fra i due gruppi in termini di insorgenza di polmoniti $(3 \%, \mathrm{~N}=122$ pazienti vs $3 \%, \mathrm{~N}=103$; 


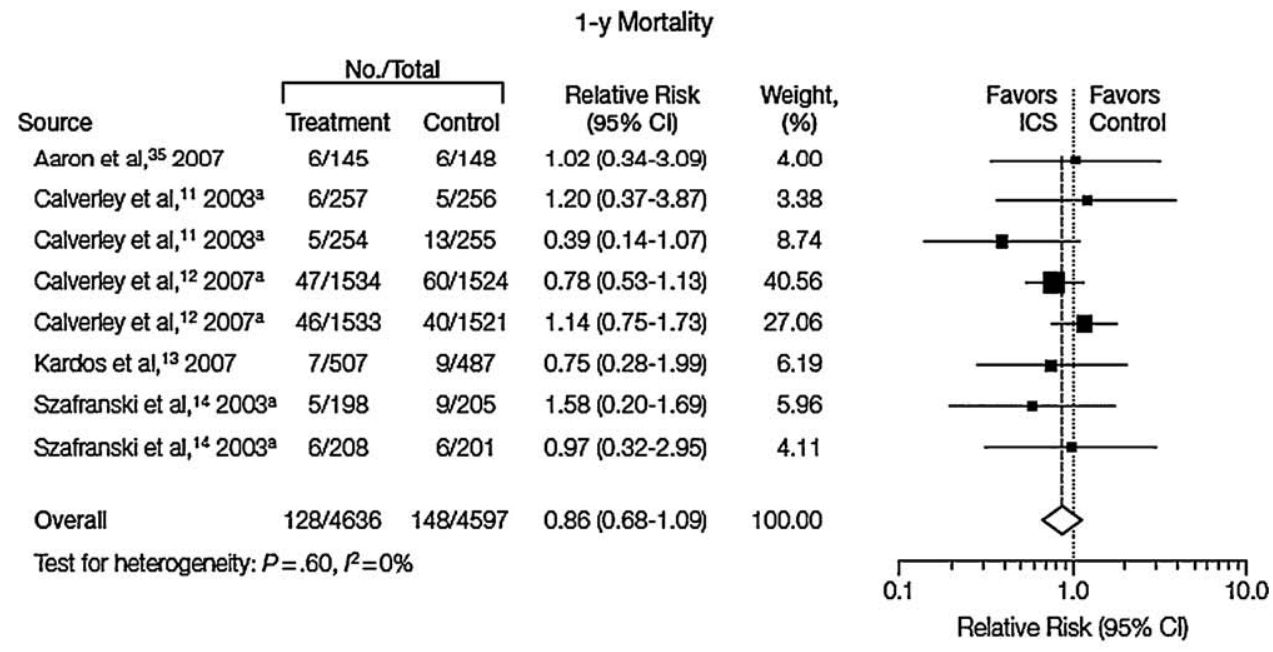

Pneumonia Risk

\begin{tabular}{|c|c|c|c|c|}
\hline \multirow[b]{2}{*}{ Source } & & \multirow[b]{2}{*}{$\begin{array}{l}\text { Odds Ratio } \\
(95 \% \mathrm{Cl})\end{array}$} & \multirow{2}{*}{$\begin{array}{l}\text { Weigh } \\
(\%)\end{array}$} \\
\hline & Treatment & Control & & \\
\hline Aaron et al, ${ }^{35} 2007$ & $1 / 145$ & $1 / 148$ & $1.02(0.06-16.16)$ & 0.86 \\
\hline Durge et al, ${ }^{10} 2000$ & $87 / 372$ & $101 / 370$ & $0.86(0.67-1.10)$ & 19.02 \\
\hline Calverley et al, ${ }^{11} 2003^{a}$ & $5 / 257$ & $2 / 256$ & $2.49(0.49-12.72)$ & 2.31 \\
\hline Calverley et al, ${ }^{11} 2003^{a}$ & $8 / 254$ & $7 / 255$ & $1.15(0.42-3.12)$ & 5.28 \\
\hline Calverley et al, ${ }^{12} 2007^{\mathrm{a}}$ & $284 / 1534$ & $190 / 1524$ & $1.48(1.25-1.76)$ & 20.93 \\
\hline Calverley et al, ${ }^{12} 2007^{a}$ & $303 / 1533$ & $205 / 1521$ & $1.47(1.25-1.73)$ & 21.08 \\
\hline Kardos et al, ${ }^{13} 2007$ & $23 / 507$ & $7 / 487$ & $3.16(1.37-7.29)$ & 6.85 \\
\hline Vestbo et al, ${ }^{37} 1999$ & $16 / 145$ & $24 / 145$ & $0.67(0.37-1.20)$ & 10.60 \\
\hline Wectzicha et al, ${ }^{15} 2008$ & $50 / 658$ & $24 / 665$ & $2.11(1.31-3.38)$ & 13.07 \\
\hline verall & $777 / 5405$ & $561 / 5371$ & $1.34(1.03-1.75)$ & 100.00 \\
\hline
\end{tabular}

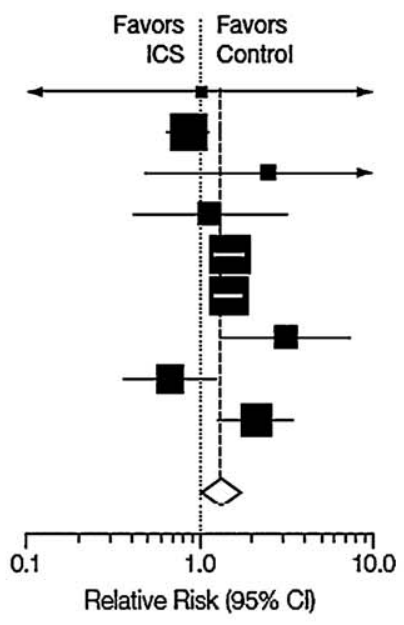

Figura 2 Effetto degli steroidi inalatori sulla mortalità, indipendentemente dalla causa che l'ha determinata, dopo un anno di follow-up, e rischio di contrarre una polmonite in pazienti affetti da BPCO [16].

adjusted hazard ratio 1,05; IC 95\% 0,81-1,37) o come evento avverso grave ( $1 \%, \mathrm{~N}=53$ vs $2 \%, \mathrm{~N}=50$; adjusted hazard ratio 0,92; IC 95\% 0,62-1,35). Solo l'età avanzata e un basso volume espiratorio massimo nel primo secondo (VEMS) sono risultati variabili associate in modo significativo all'insorgenza di polmonite.

In pazienti affetti da BPCO, i microrganismi responsabili di polmonite appaiono diversi rispetto a quelli presenti nei pazienti affetti da polmonite nei quali non è preesistente una patologia cronica ostruttiva respiratoria. Nonostante Streptococcus pneumoniae rimanga la specie batterica predominante, si è osservata un'aumentata incidenza di Haemophilus influenzae e, occasionalmente, di Moraxella catarrhalis. La presenza di una BPCO molto grave (stadio GOLD IV) associata alla presenza di bronchiectasie, con la conseguente necessità di somministrare al paziente ripetuti cicli di terapia antibiotica, lo predispone alla polmonite causata da Pseudomonas aeruginosa [19]. Tuttavia la diagnosi eziologica di polmonite - che presuppone l'isolamento della specie patogena responsabile della polmonite stessa - risulta più difficile nei pazienti che presentano $\mathrm{BPCO}$, poiché la colonizzazione cronica da parte dei germi costituisce un elemento che confonde l'interpretazione dell'esame microbiologico dell'espettorato. La BPCO e il fumo di sigaretta aumentano inoltre i titoli anticorpali sierici di Chlamydia pneumoniae, rendendo la diagnosi sierologica di questa infezione difficile da interpretare, in particolare quando si esegue a scopo diagnostico una sola titolazione anticorpale [13].

\section{Infezione cronica in pazienti affetti da BPCO}

La presenza di microrganismi patogeni nelle vie aeree dei pazienti affetti da BPCO viene di solito definita come "colonizzazione", principalmente perché la presenza di tali patogeni non si associa a sintomi acuti di infezione. La definizione 
più appropriata di "colonizzazione" si riferisce tuttavia alla presenza di un patogeno che non danneggi direttamente l'ospite, o che non possa sollecitare in lui una reazione che a sua volta sia in grado di determinare un danno tissutale. In realtà, diversi studi recenti sembrano dimostrare che tali patogeni si associno con una risposta infiammatoria e immunitaria nei pazienti affetti da BPCO in fase di stabilizzazione clinica [13]. Questa definizione suggerisce che l'applicazione del termine "colonizzazione" alle basse vie respiratorie dei pazienti affetti da BPCO sia impropria, poiché si ritiene molto probabile che tale infezione cronica, a bassa carica, determini significative conseguenze in termini fisiopatologici. Svariati batteri patogeni sono stati coinvolti nell'infezione cronica dei pazienti affetti da BPCO, fra cui Haemophilus influenzae e Pseudomonas aeruginosa, i batteri atipici, quali Chlamydia pneumoniae, i virus, quali l'adenovirus e il virus respiratorio sinciziale, e recentemente anche un fungo, Pneumocystis jiroveci.

L'ipotesi del circolo vizioso rappresenta un utile modello che dimostra come le infezioni croniche possano contribuire alla progressione della malattia (fig. 1), determinando l'infiammazione broncopolmonare nei pazienti affetti da BPCO secondo due meccanismi: come stimolo infiammatorio diretto e, indirettamente, influenzando la risposta immunitaria dell'ospite al fumo di tabacco.

\section{La colonizzazione batterica quale stimolo infiammatorio in pazienti affetti da BPCO in fase di stabilizzazione clinica}

Molteplici studi hanno dimostrato che la colonizzazione batterica dell'albero tracheobronchiale può rappresentare uno stimolo infiammatorio a livello bronchiale e, potenzialmente, anche contribuire alla progressione clinica della malattia [20]. Uno studio osservazionale che arruolava 67 pazienti affetti da BPCO in fase di stabilizzazione clinica ha dimostrato che i pazienti che presentavano microrganismi potenzialmente patogeni mostravano nel loro espettorato un più elevato numero e una maggiore capacità chemiotattica da parte dei neutrofili, nonché livelli più elevati di interleuchina IL-8, leucotriene B4, tumor necrosis factor-alfa (TNFalfa) ed elastasi neutrofila, rispetto ai soggetti che non presentavano colonizzazione batterica [21].

In un altro studio, pazienti fumatori con e senza ostruzione bronchiale sono stati sottoposti a lavaggio bronchioloalveolare (BAL) per valutare il pattern di infiammazione e la sua relazione con la colonizzazione microbica bronchiale [22]: il 40\% dei controlli fumatori e un terzo dei pazienti affetti da BPCO presentavano colonizzazione dell'albero bronchiale. Quando i pazienti che presentavano colonizzazione bronchiale da parte di microrganismi patogeni (di entrambi i gruppi) venivano confrontati con quelli privi di colonizzazione, la presenza di microrganismi potenzialmente patogeni si associava significativamente alla neutrofilia bronchiale e a concentrazioni più elevate di TNF-alfa [21].

Per confermare l'ipotesi di un ruolo da parte della colonizzazione batterica nel determinare l'infiammazione broncopolmonare che caratterizza il paziente affetto da BPCO in fase di stabilizzazione clinica, in un ulteriore studio sono stati sottoposti a BAL 3 gruppi di pazienti: ex fumatori con BPCO stabile, ex fumatori senza BPCO e soggetti sani non fumatori [20]; i pazienti affetti da BPCO "colonizzati" da germi potenzialmente patogeni mostravano un aumento significativo dei neutrofili, di IL-8, di metallopeptidasi-9 (MMP-9) e dei livelli di endotossina nel liquido di BAL, in confronto a quelli che non presentavano una colonizzazione con germi potenzialmente patogeni. Sempre nel liquido di BAL si osservava, nei pazienti con BPCO "colonizzati", un aumento significativo di diverse molecole infiammatorie rispetto agli ex fumatori e ai non fumatori. Questi risultati forniscono un ulteriore sostegno all'ipotesi che la colonizzazione batterica guidi l'infiammazione delle vie aeree distali in pazienti affetti da BPCO [20].

L'infezione latente da adenovirus si è dimostrata in grado di amplificare la risposta infiammatoria indotta dal fumo di tabacco [23]. Utilizzando metodiche di biologia molecolare, è stata provata la presenza nel tessuto polmonare di diversi altri virus, fra cui il virus respiratorio sinciziale, il virus di Epstein-Barr e altri germi patogeni (Pneumocystis e Chlamydia, per esempio). Il significato di tali osservazioni non è chiaro, ma questi patogeni potrebbero avere un significato nella patogenesi della BPCO, almeno in selezionati gruppi di pazienti.

\section{Infezione cronica e progressione della BPCO}

Nelle fasi iniziali, una volta che il paziente con BPCO ha smesso di fumare, il declino della funzione polmonare risulta essere del tutto simile rispetto a quello dei soggetti non fumatori. Questa evoluzione potrebbe non essere la stessa nella malattia avanzata. Come abbiamo già detto, nei pazienti ex fumatori la persistente infiammazione broncopolmonare è da porsi in relazione con la colonizzazione microbica. Non è tuttavia evidente se quest'ultima possa contribuire alla progressione della malattia. In un studio di piccole dimensioni, Wilkinson et al. [24] hanno tuttavia osservato che un incremento della carica batterica a livello bronchiale nel corso di un anno era da porsi in relazione a un declino della funzione ventilatoria. Sono però necessari studi di più ampie dimensioni per confermare il dato.

\section{Utilizzo di antibiotici in pazienti affetti da BPCO in fase stabile}

Un trattamento antibiotico profilattico o terapeutico è stato utilizzato anche in un recente passato nel tentativo di debellare le infezioni batteriche nei pazienti affetti da BPCO [25]. In una serie di studi eseguiti prima del 1970, si era osservato un beneficio statisticamente significativo nei pazienti sottoposti a profilassi antibiotica; tali trattamenti furono tuttavia sospesi poiché il beneficio era modesto e per il timore dell'insorgenza di resistenze batteriche. Attualmente sono in corso studi volti a valutare l'efficacia della terapia antibiotica intermittente avvalendosi di fluorochinolonici somministrati per via inalatoria o orale, oppure utilizzando basse dosi di macrolidi in pazienti affetti da BPCO che sono soggetti a frequenti riacutizzazioni della malattia. Il risultato di questi studi valuterà l'efficacia e la sicurezza di tali trattamenti. 


\section{Ruolo dell'infezione da HIV in pazienti con BPCO}

Diversi studi sembrano indicare che l'infezione da HIV sia da considerarsi come un fattore di rischio per l'insorgenza di BPCO [26]. Un'intrigante connessione fra HIV e BPCO è l'infezione da Pneumocystis. La frequenza della colonizzazione con Pneumocystis aumenta con la gravità dell'ostruzione bronchiale, suggerendo un possibile link patogenetico. Inoltre diverse pubblicazioni segnalano che i soggetti HIV positivi - che presentino un'inveterata abitudine tabagica sviluppano una forma accelerata di enfisema [27].

Ulteriori meccanismi contribuiscono sicuramente all'associazione fra HIV e BPCO, fra cui un alto tasso di fumatori fra i pazienti HIV positivi, la presenza del virus dell'HIV a livello polmonare, l'aumentato stress ossidativo da porre in relazione alla carica retrovirale e l'insorgenza di polmoniti ricorrenti. Anche il grado di immunodepressione e l'utilizzo di terapia antiretrovirale possono spiegare - almeno in parte - l'accelerata progressione della BPCO in pazienti affetti da HIV [26].

\section{Conclusioni}

È probabile che le infezioni respiratorie - sia acute sia croniche - svolgano un importante ruolo, forse anche maggiore di quello finora riconosciuto, nella patogenesi e nella storia naturale della BPCO. Questa è una malattia eterogenea; è pertanto probabile che le infezioni possano avere un diverso peso nelle varie forme in cui essa si manifesta, così come potrebbero avere una maggiore importanza nelle alterazioni bronchiali e bronchiolari della malattia rispetto a quelle alveolari.

Le infezioni bronchiali e la BPCO sembrano avere una relazione reciproca e causale, configurando pertanto la possibilità che l'infezione costituisca una condizione di comorbilità della BPCO. La predisposizione alle infezioni -tipica dei pazienti affetti da BPCO - è in parte legata al fumo di sigaretta, ma sembra peggiorare quando l'ostruzione bronchiale si sviluppa in soggetti fumatori. Una migliore conoscenza delle interazioni fra ospite e patogeno nei pazienti affetti da BPCO potrà portare all'elaborazione nuove strategie per la prevenzione delle riacutizzazioni e a nuovi trattamenti per la prevenzione della progressione della BPCO.

\section{Bibliografia}

[1] Gump DW, Phillips CA, Forsyth BR, McIntosh K, Lamborn KR, Stouch WH. Role of infection in chronic bronchitis. Am Rev Respir Dis 1976;113(4):465-74.

[2] McHardy VU, Inglis JM, Calder MA, Crofton JW, Gregg I, Ryland DA, et al. A study of infective and other factors in exacerbations of chronic bronchitis. Br J Dis Chest 1980;74(3):228-38.

[3] Tager I, Speizer FE. Role of infection in chronic bronchitis. N Engl J Med 1975;292(11):563-71.

[4] Hill AT, Campbell EJ, Hill SL, Bayley DL, Stockley RA. Association between airway bacterial load and markers of airway inflammation in patients with stable chronic bronchitis. Am J Med 2000;109(4):288-95.
[5] Sethi S, Evans N, Grant BJ, Murphy TF. New strains of bacteria and exacerbations of chronic obstructive pulmonary disease. $\mathrm{N}$ Engl J Med 2002;347(7):465-71.

[6] Sethi S, Wrona C, Eschberger K, Lobbins P, Cai X, Murphy TF. Inflammatory profile of new bacterial strain exacerbations of chronic obstructive pulmonary disease. Am J Respir Crit Care Med 2008;177(5):491-7.

[7] White AJ, Gompertz S, Bayley DL, Hill SL, O'Brien C, Unsal I, et al. Resolution of bronchial inflammation is related to bacterial eradication following treatment of exacerbations of chronic bronchitis. Thorax 2003;58(8):680-5.

[8] Ram FS, Rodriguez-Roisin R, Granados-Navarrete A, GarciaAymerich J, Barnes NC. Antibiotics for exacerbations of chronic obstructive pulmonary disease. Cochrane Database Syst Rev 2006; (2):CD004403.

[9] Roede BM, Bresser P, Bindels PJ, Kok A, Prins M, ter Riet G, et al. Antibiotic treatment is associated with reduced risk of a subsequent exacerbation in obstructive lung disease: an historical population based cohort study. Thorax 2008;63(11):968-73.

[10] Anthonisen NR, Manfreda J, Warren CP, Hershfield ES, Harding GK, Nelson NA. Antibiotic therapy in exacerbations of chronic obstructive pulmonary disease. Ann Intern Med 1987;106(2): 196-204.

[11] Daniels JM, Snijders D, de Graaff CS, Vlaspolder F, Jansen HM, Boersma WG. Antibiotics in addition to systemic corticosteroids for acute exacerbations of chronic obstructive pulmonary disease. Am J Respir Crit Care Med 2010;181(2):150-7.

[12] Luppi F, Beghé B, Richeldi L. Acute exacerbations of chronic obstructive pulmonary disease: are antibiotics needed? Am J Respir Crit Care Med 2010;181(2):102-3.

[13] Sethi S. Infection as a comorbidity of COPD. Eur Respir J 2010;35(6):1209-15.

[14] Almirall J, González CA, Balanzó X, Bolíbar I. Proportion of community-acquired pneumonia cases attributable to tobacco smoking. Chest 1999;116(2):375-9.

[15] Calverley PMA, Anderson JA, Celli B, et al. Salmeterol and fluticasone propionate and survival in chronic obstructive pulmonary disease. N Engl J Med 2007;356:775-89.

[16] Drummond MB, Dasenbrook EC, Pitz MW, Murphy DJ, Fan E. Inhaled corticosteroids in patients with stable chronic obstructive pulmonary disease: a systematic review and meta-analysis. JAMA 2008;300(20):2407-16.

[17] Singh S, Amin AV, Loke YK. Long-term use of inhaled corticosteroids and the risk of pneumonia in chronic obstructive pulmonary disease: a meta-analysis. Arch Intern Med 2009;169(3): 219-29.

[18] Sin DD, Tashkin D, Zhang X, Radner F, Sjöbring U, Thorén A, et al. Budesonide and the risk of pneumonia: a meta-analysis of individual patient data. Lancet 2009;374(9691):712-9.

[19] Global Initiative for Chronic Obstructive Lung Disease. Update 1 July 2008. A collaborative project of the National Health, Lung, and Blood Institute, NIH and the World Health Organisation. National Health, Lung, and Blood Institute, NIH. Bethesda, MD: 2008.

[20] Sethi S, Maloney J, Grove L, Wrona C, Berenson CS. Airway inflammation and bronchial bacterial colonization in chronic obstructive pulmonary disease. Am J Respir Crit Care Med 2006;173(9):991-8.

[21] Banerjee D, Khair OA, Honeybourne D. Impact of sputum bacteria on airway inflammation and health status in clinical stable COPD. Eur Respir J 2004;23(5):685-91.

[22] Soler N, Ewig S, Torres A, Filella X, Gonzalez J, Zaubet A. Airway inflammation and bronchial microbial patterns in patients with stable chronic obstructive pulmonary disease. Eur Respir J 1999;14(5):1015-22.

[23] Vitalis TZ, Kern I, Croome A, Behzad H, Hayashi S, Hogg JC. The effect of latent adenovirus 5 infection on cigarette smokeinduced lung inflammation. Eur Respir J 1998;11(3):664-9. 
[24] Wilkinson TM, Patel IS, Wilks M, Donaldson GC, Wedzicha JA. Airway bacterial load and FEV1 decline in patients with chronic obstructive pulmonary disease. Am J Respir Crit Care Med 2003;167(8):1090-5.

[25] Black P, Staykova T, Chacko E, Ram FS, Poole P. Prophylactic antibiotic therapy for chronic bronchitis. Cochrane Database Syst Rev 2003;(1):CD004105.
[26] Crothers K. Chronic obstructive pulmonary disease in patients who have HIV infection. Clin Chest Med 2007;28(3): 575-87. vi.

[27] Diaz PT, King MA, Pacht ER, Wewers MD, Gadek JE, Nagaraja HN, et al. Increased susceptibility to pulmonary emphysema among HIV-seropositive smokers. Ann Intern Med 2000;132(5): 369-72. 


\section{BPCO nell'anziano}

\section{Raffaele Antonelli Incalzi, Massimo Giusti}

\section{Messaggi chiave}

- L'età si associa a crescente comorbilità, indipendentemente dalla gravità della broncopneumopatia cronica ostruttiva (BPCO). Non sempre è possibile definire la malattia principale. Spesso è più appropriato il concetto di multimorbilità anziché quello di comorbilità.

- La rilevante percentuale di BPCO misconosciuta limita la conoscenza del rapporto BPCO-età-comorbilità.

- Il declino del FEV1\% del teorico al di sotto di 50 segna in genere un netto peggioramento dello stato di salute, ma esiste una notevole variabilità interindividuale ed è importante il ruolo della comorbilità. Inoltre, l'incerta definizione degli standard di normalità indebolisce la definizione di qualsiasi soglia quale potenziale correlato dello stato di salute.

- La comorbilità è determinante primario dello stato di salute nella BPCO lieve o moderata, mentre la patologia respiratoria diviene il principale determinante allorché è complicata da insufficienza respiratoria.

- Le molteplici linee guida prodotte per patologie croniche spesso coesistenti con la BPCO, ma non per la
BPCO, si applicano a popolazioni poco rappresentative di quella anziana con BPCO.

- Fattori sociali concorrono al determinismo dello stato di salute e del fabbisogno di cure.

- Le caratteristiche del paziente anziano con BPCO e comorbilità, anche se ancora autonomo, sono spesso quelle dell'anziano fragile, cioè ad alto rischio di perdere l'autonomia personale. Pertanto, il riconoscimento dell'anziano fragile può favorire la diagnosi di determinanti misconosciuti della fragilità, come la BPCO.

- L'impatto della BPCO sullo stato di salute dell'anziano riguarda in prevalenza le attività strumentali della vita quotidiana, finché non sopravviene insufficienza respiratoria.

- In presenza di insufficienza respiratoria la BPCO si associa a compromissione delle attività di base della vita quotidiana.

- La valutazione multidimensionale è un metodo standardizzato per esplorare globalmente lo stato di salute dell'anziano e i suoi determinanti, medici e non medici, respiratori e non respiratori, al fine di pianificare un piano assistenziale multidisciplinare e personalizzato che sia costo-efficace.

\section{Elementi di specificità della comorbilità nella BPCO dell'anziano}

Il rapporto tra età e broncopneumopatia cronica ostruttiva (BPCO) è modulato dalla comorbilità in modo alquanto complesso. Infatti la prevalenza della BPCO come tale aumenta in funzione dell'età, con valori del 7-8\% dopo i 70 anni. Al tempo stesso, esistono in queste fasce di età molte forme di BPCO misconosciuta, per il coesistere di numerose altre patologie o per l'erroneo convincimento che l'età in sé giustifichi una riduzione "del fiato" e della performance fisica, che porta a eludere così la ricerca sistematica di cause morbose.

In età avanzata ritroviamo forme di BPCO ormai molto serie, complicate da insufficienza respiratoria in quanto, con l'adozione dell'ossigenoterapia, la storia naturale della malattia si è sensibilmente allungata, e ritroviamo, altresì, forme lievi e moderate di BPCO. Le prime condizionano pesantemente lo stato di salute, mentre il ruolo delle seconde varia molto in rapporto alla comorbilità. La stessa definizione di malattia principale, e quindi di comorbilità, è spesso problematica, essendo difficile identificare la patologia che ha un 
peso predominante nel determinismo dello stato di salute. $\grave{E}$ questo il presupposto per il concetto di multimorbilità, più che di comorbilità, che frequentemente riscontriamo nel soggetto anziano; quindi, molteplici malattie coesistenti che variabilmente contribuiscono a influenzare lo stato di salute, ma fra le quali è obiettivamente difficile identificare la malattia principale [1]. Proprio questo è un limite alla stessa interpretazione del concetto di comorbilità nella BPCO del soggetto anziano. Una ricerca recente, condotta su soggetti anziani in Svezia, ha documentato che la BPCO tende ad associarsi con patologie cardio-cerebro-vascolari e con distiroidismi, ma spesso risulta difficile cogliere, in questo cluster di patologie, l'elemento dominante (fig. 1) [2].

Esistono almeno due elementi di specificità del complesso rapporto tra $\mathrm{BPCO}$, età e comorbilità. Il primo è rappresentato dallo stesso modificarsi della presentazione clinica in funzione dell'età e della comorbilità; per esempio, la presenza di patologia osteoarticolare, fortemente età-correlata e una delle più comuni comorbilità della BPCO, di per sé limita la mobilità e può prevenire perciò il raggiungimento della soglia per la dispnea, limitando quindi l'espressione clinica di un sintomo dominante il quadro della BPCO in età adulta; oppure, la presenza di insufficienza respiratoria può esprimersi più con disturbi dell'equilibrio e dello stato cognitivo, specie in corso di riacutizzazioni, che con peggioramento ulteriore della dispnea [3].

Altro elemento di specificità è il frequente misconoscimento o l'inadeguata valorizzazione sul piano terapeutico di patologie concomitanti, spesso occultate dalla complessità del quadro clinico che deriva dal coesistere di varie condizioni. Queste sono variamente oggetto di discussione nei capitoli precedenti. Tuttavia, almeno un breve cenno meritano patologie come il glaucoma che, limitando la capacità di interazione con il mondo circostante, possono drammaticamente peggiorare la qualità di vita di un persona già limitata a sua volta dal deficit della performance fisica [4]; o l'insufficienza renale, che può condizionare sia l'uso dei farmaci idrosolubili che l'interpretazione di condizioni morbose coesistenti [5]; o, ancora, le miopatie da carenza di vitamina D [6], che si attende siano altamente prevalenti in questi soggetti per la ridotta esposizione alla luce; oppure le parodontopatie, essendo la scarsa igiene orale associata con sviluppo di polmoniti i cui agenti eziologici coincidono con i germi ospitati nelle tasche parodontali [7,8]; o, ancora, le pneumopatie restrittive da causa extraparenchimale, specialmente in pazienti con osteoporosi e cifosi, scompenso cardiaco, obesità [9], e numerose altre. Tutte condizioni alle quali non viene spesso prestata la dovuta attenzione, eppure ciascuna di queste può avere un rilevante impatto sia cronico che acuto sulla storia naturale della BPCO dell'anziano; basti pensare che il crollo di una vertebra dorsale può ridurre la capacità vitale del 5-7\%, aggiungendo una componente restrittiva a una patologia ostruttiva di per sé invalidante [10].

La prevalenza delle più comuni comorbilità nell'anziano con BPCO, quale risulta da una recente indagine italiana, è riportata nella fig. 2 [11]. In questo, come negli studi precedenti, il metodo di rilevazione previene il riconoscimento di alcune patologie.

\section{Interazioni età-BPCO-comorbilità}

Queste interazioni riguardano sia la prevalenza che l'espressione stessa di condizioni cliniche, anche importanti. Un tipico esempio di tali interazioni è rappresentato dalla disfagia. L'età in sé, infatti, si associa con riduzione dell'aditus faringeo, ridotta efficienza della deglutizione, presbiesofago, caratterizzato dal deficit di peristalsi primaria e soprattutto di quella secondaria, evocata, cioè, dal bolo residuo o dal reflusso [12]. La BPCO, a sua volta, si associa con un alterato timing del rapporto deglutizione-respirazione, che è potenziale causa di $a b$ ingestis: in rapporto alla consistenza del cibo possono verificarsi inspirazioni durante la deglutizione (specie per $\mathrm{i}$

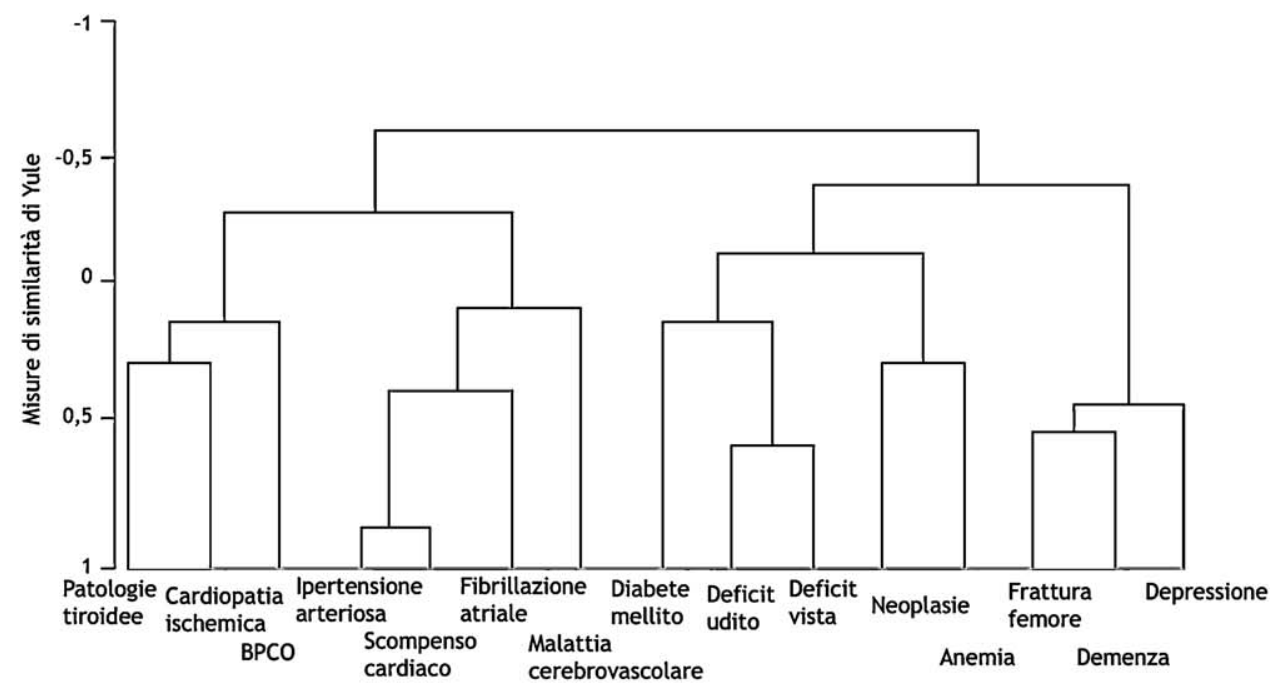

Fonte: modificata Marengoni A, et al. J Am Geriatr Soc 2009;57:225.

Figura 1 Il concetto di multimorbilità: il dendogramma mostra la distribuzione e l'aggregazione in cluster di patologie croniche nella popolazione svedese di età pari o superiore a 75 anni. 


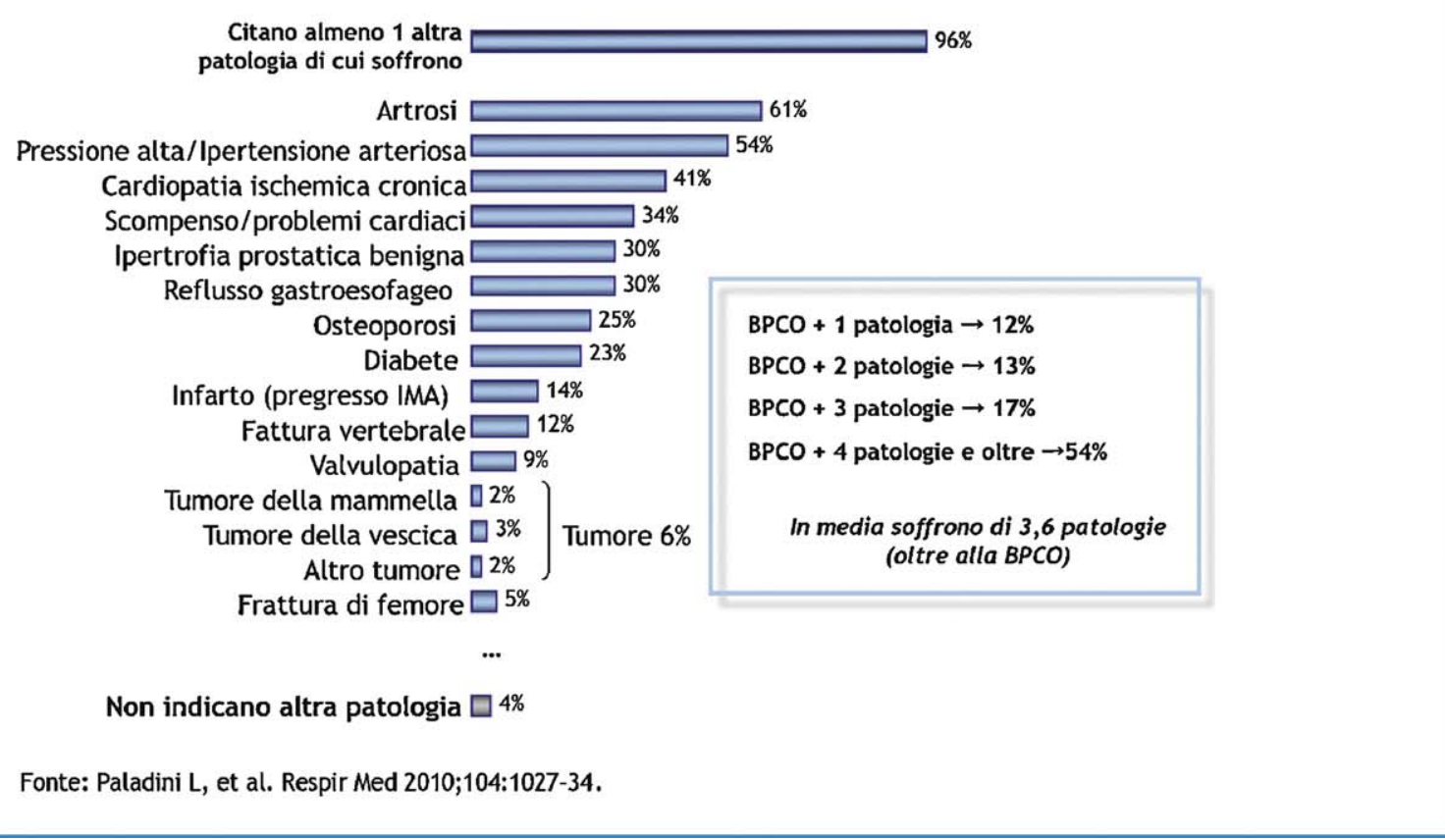

Figura 2 Patologia riferita da 200 pazienti ultrasettantenni affetti da BPCO quale malattia principale.

cibi solidi) o in immediata sequenza (specie per i cibi semiliquidi), come se fossero alterati i meccanismi protettivi intrinseci alla corretta sincronizzazione deglutizione-inspirazione [13]. Pertanto, ci si attende che il sommarsi dell'età in sé e della BPCO accentui notevolmente il problema disfagia. Al tempo stesso, la conoscenza del problema è il presupposto per la risoluzione; basti ricordare che la stessa possibilità di variare la consistenza del cibo, per esempio rendendola rugiadosa, può alleviare alcune forme di disfagia. Parimenti, esercizi che dilatano lo spazio sottoioideo, o ancora tecniche di deglutizione che prevedono l'inspirazione, l'apnea, la deglutizione del bolo e la successiva espirazione forzata, onde evitare l'ab ingestis, permettono di conseguire risultati non trascurabili in pazienti con questo tipo di disfagia [14].

Un altro esempio interessante è l'interazione tripla etàBPCO-fumo nel determinismo di pneumopatia mista. Infatti la BPCO di per sé si associa con osteoporosi vertebrale tramite diversi meccanismi: riduzione della filtrazione glomerulare e della fotoesposizione; malnutrizione, conseguente carenza di calcio e vitamina $\mathrm{D}$ e, quindi, incremento del paratormone, con effetto osteopenizzante che è più marcato a livello vertebrale rispetto a quello femorale; ridotto esercizio fisico; effetto osteopenizzante dell'eventuale ipercapnia. Quindi un'osteoporosi vertebrale rappresenta la regola nel paziente con BPCO [15]. A questi meccanismi BPCO-correlati si aggiunge l'effetto del fumo, che riduce gli estrogeni circolanti, aumenta la sex steroid binding globulin, accelera l'idrossilazione dell'estradiolo e quindi ne riduce l'efficacia biologica, favorendo, anche con altri meccanismi, la perdita di massa ossea [16]. Ne consegue che la donna fumatrice ha una vita fertile più corta di alcuni anni e un maggior rischio di osteoporosi, specialmente vertebrale e del radio; quindi l'età, il fumo e la BPCO concorrono al determinismo dell'osteoporosi vertebrale e, perciò, della pneumopatia restrittiva da causa extraparenchimale coesistente con quella ostruttiva di base.

La frattura vertebrale, oltre a condizionare negativamente la funzione respiratoria, è causa di dolore e del conseguente uso di farmaci antinfiammatori, con rischio a livello soprattutto gastrico e renale. Inoltre è causa di protrusione addominale, quindi senso precoce di sazietà, perdita di peso, ancora perdita dell'autostima, depressione, dipendenza da analgesici. Eppure molto raramente uno studio, anche semplicemente uno studio strutturato della radiografia del torace in laterale [17], viene effettuato per identificare un danno vertebrale, sebbene esistano modalità di analisi del radiogramma standardizzate. È infatti possibile mettere a punto uno score cumulativo della perdita di densità minerale del rachide dorsale, utile ai fini interpretativi dei sintomi e nel follow-up. Ancora più raramente, nel paziente anziano con BPCO, viene effettuata una mineralometria e sono avviate una profilassi o una terapia dell'osteoporosi (in proposito si rimanda al contributo dedicato all'osteoporosi nella presente monografia).

Un terzo e ultimo esempio di interazione età-BPCO si verifica a proposito dell'ipovitaminosi $D$. La BPCO comporta una scarsa qualità della dieta, una ridotta fotoesposizione, soprattutto nei paesi nordici, e un più rapido declino della funzione renale. L'età, a sua volta, implica una riduzione della funzione renale, specie nei diabetici, e spesso una dieta inadeguata. L'insieme di tali eventi esita nell'ipovitaminosi D. Anche soggetti anziani sani, per esempio partecipanti allo studio InCHIANTI [29], presentano, pur in una dieta adeguata in termini di macronutrienti, una rilevante carenza dell'introito di calcio e di vitamina D; tale carenza induce la sintesi di paratormone; infatti per livelli sierici di 25 idrossivitamina D inferiore a $15 \mathrm{ng} / \mathrm{mL}$ si riscontrano valori di paratormone superiori a $40 \mathrm{pg} / \mathrm{mL}$. Tali valori, a loro volta, si associano con induzione dell'insulinoresistenza e disfunzione della cellula 


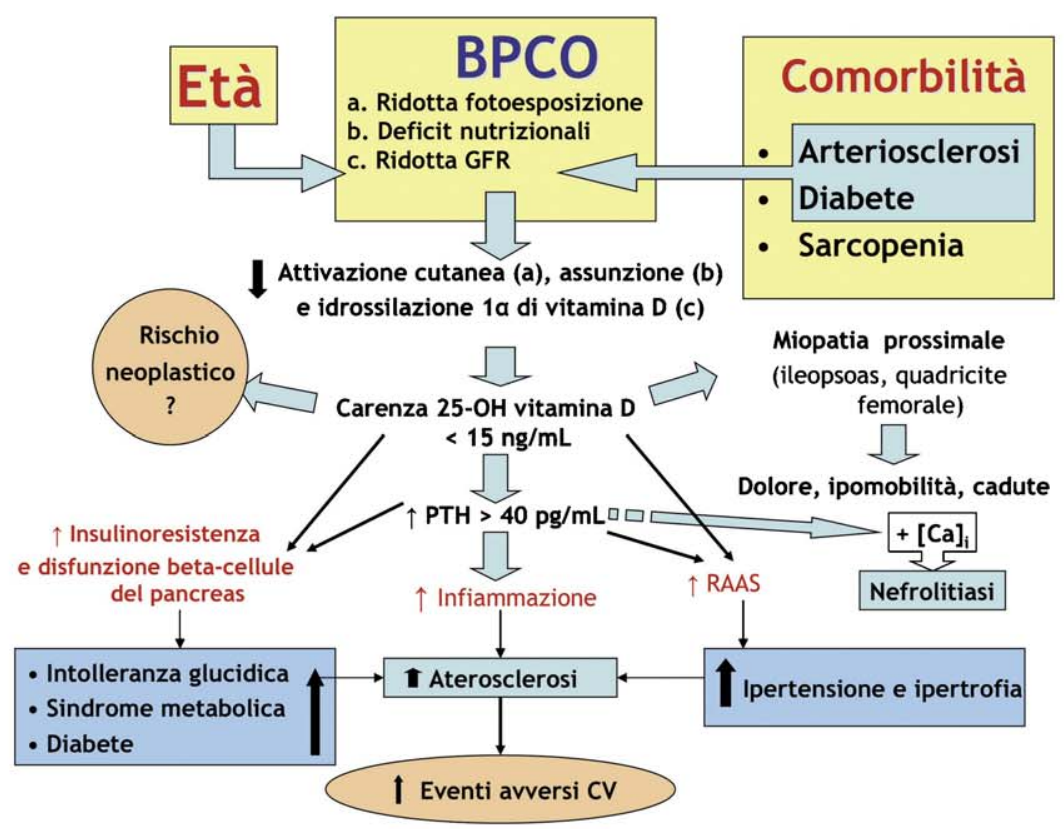

Figura 3 Schema riassuntivo delle molteplici conseguenze di un difetto di vitamina D.

beta pancreatica, flogosi ad azione aterogena, attivazione del sistema renina-angiotensina e quindi ipertensione, ipertrofia vascolare liscia e cardiaca [18]. Ecco quindi come, partendo da determinanti di tipo nutrizionale e ambientale, si passi a una ridotta disponibilità della vitamina $\mathrm{D} e$, infine, $\mathrm{a}$ effetti di tipo metabolico e vascolare; questo potrebbe essere un fattore contribuente alla componente, appunto, cardiovascolare e metabolica spesso associata con la BPCO (fig. 3).

I pochi esempi qui riportati mostrano come l'anziano con comorbilità e BPCO rappresenti una realtà complessa. Eppure, le linee guida ignorano l'anziano con comorbilità. Quelle prodotte per malattie importanti e frequentemente coesistenti con la BPCO, come il diabete, l'ipertensione, l'osteoartrite e l'osteoporosi, e le stesse linee guida prodotte per la BPCO, non tengono conto della particolare tipologia di paziente rappresentata dall'anziano e quindi non vi si applicano; anzi, l'acritica applicazione di quelle sviluppate per il paziente adulto porterebbe a condizioni paradossali. Per esempio, un paziente con BPCO e 3-4 comorbilità, quali comunemente si riscontrano, sarebbe gravato da un carico di procedure, medicazioni e rischio di interazioni quasi insostenibile [19]. Gli stessi grandi trial di intervento farmacologico nella BPCO escludono comorbilità respiratorie, come lo studio TORCH, o qualunque patologia in grado di condizionare la risposta alla terapia o il follow-up, come lo studio UPLIFT, selezionando così una popolazione non rappresentativa di quella reale, specie di quella più anziana [20,21].

Pertanto, la complessità della situazione e dell'interazione età-BPCO-comorbilità non trova riscontro nella letteratura in termini di indicazioni pratiche per il medico, ovvero di indicazioni per il medico pratico. Ne consegue che il ricorso alla personale esperienza e al buon senso devono spesso supplire a tale carenza di informazione. A tal fine è fondamentale sia avere una precisa cognizione della situazione clinica e dello stato di salute mediante lo screening sistematico delle condizioni che li determinano, evitando cioè omissioni diagnostiche, sia un inquadramento strutturato del paziente. A sostenere tale obiettivo è la valutazione multidimensionale, che discuteremo dopo avere puntualizzato alcuni concetti di gerontologia che si applicano all'anziano pneumopatico e possono aiutarci a comprenderne la complessa realtà.

\section{Fragilità, limitazione funzionale e disabilità vs comorbilità nell'anziano con BPCO}

L'interazione età-BPCO-comorbilità si riflette, anche, su tre dimensioni dello stato di salute: la fragilità, la limitazione funzionale e la disabilità, secondo un profilo particolare la cui analisi presuppone una premessa metodologica.

La fragilità può essere inquadrata e spiegata secondo tre livelli identificativi: il modello, la definizione e i criteri diagnostici.

- Modelli: sono descrizioni, anche analogiche, usate per aiutare a visualizzare qualcosa che non può essere direttamente osservato; infatti la fragilità è un concetto astratto, sebbene abbia conseguenza concrete.

- Definizione: è un'espressione della natura essenziale di qualcosa ed è concreta e chiara, poiché traduce in pratica il modello.

- Criteri diagnostici: rappresentano il mezzo per caratterizzare l'entità, che è concettuale nel modello ed è poi chiarita nella definizione.

Esistono più modelli di fragilità, ad attestare la varietà di opinioni al riguardo. Al modello apparentemente astratto del carico allostatico corrisponde la definizione di allostasi, 
Tabella 1 Biomarker del carico allostatico per la definizione di fragilità.

\begin{tabular}{lc}
\hline Biomarker & $\begin{array}{c}\text { Cutpoint quartile } \\
\text { alto rischio }\end{array}$ \\
\hline Pressione sistolica, $\mathrm{mmHg}$ & $\geq 148,00$ \\
Pressione diastolica, $\mathrm{mmHg}$ & $\geq 83,33$ \\
Colesterolo $\mathrm{HDL}, \mathrm{mg} / \mathrm{dL}$ & $\leq 36,00$ \\
Colesterolo totale/HDL & $\geq 5,92$ \\
Emoglobina glicata, \% & $\geq 7,10$ \\
Rapporto vita/fianchi & $\geq 0,94$ \\
Deidroepiandrosterone solfato, mg/dL & $\leq 5,00$ \\
Cortisolo urinario, $\mu \mathrm{g} / \mathrm{g}$ creatinina & $\geq 25,69$ \\
Norepinefrina urinaria, $\mu \mathrm{g} / \mathrm{g}$ creatinina & $\geq 48,12$ \\
Epinefrina urinaria, $\mu \mathrm{g} / \mathrm{g}$ creatinina & $\geq 5,00$ \\
Fibrinogeno, mg/dL & $\geq 336,00$ \\
Proteina C-reattiva, $\mathrm{mg} / \mathrm{L}$ & $\geq 3,19$ \\
Interleuchina-6, $\mathrm{pg} / \mathrm{mL}$ & $\geq 4,65$ \\
\hline
\end{tabular}

Fonte: Gruenewald TL, et al. J Am Geriatr Soc 2009;57(9): 1525-31.

intesa come l'abilità del corpo ad aumentare o a ridurre le funzioni vitali, in ultima analisi ad adottare il sistema del "wear and tear" in rapporto al variare degli stimoli. I relativi criteri sono una serie di parametri che vanno dalla pressione arteriosa a indicatori dello stato metabolico, fino al rapporto vita/fianchi, a indicatori ormonali, indicatori di flogosi e dell'attivazione di coagulazione (tabella 1) [22]. La maggior parte di tali parametri risultano mediamente elevati nel soggetto con BPCO, specie se anziano; e questo dato non è marginale perché, come vedremo tra breve, un'alterazione del carico allostatico ha immediate e precise conseguenze sul piano clinico e prognostico.

Alternative a quella fortemente preclinica, basata sul carico allostatico, sono due definizioni correnti e più semplici di fragilità: eccessiva vulnerabilità allo stress, con ridotta capacità di mantenere o recuperare l'omeostasi dopo un evento destabilizzante [23], o, secondo Fried et al. [24], condizione di rischio per perdita dell'autonomia o per ulteriore declino dell'autonomia. I criteri per ciascuna di queste definizioni identificano accuratamente il malato con BPCO. Per esempio i criteri di Fried (la perdita di peso, la ridotta forza del pugno, l'esauribilità, la ridotta velocità del passo, la riduzione dell'attività) sono proprio elementi tipici del paziente con BPCO, che è quindi un paziente fragile, cioè un paziente a rischio di perdere l'autonomia funzionale o di peggiorare un livello di disabilità in cui già si trova (tabella 2). Elemento singolare è che parte della fragilità cosiddetta primaria, cioè apparentemente non legata a comorbilità, è in realtà dovuta a comorbilità misconosciute e tra queste, non di rado, rientra la BPCO; purtroppo la semplice riduzione dell'attività fisica in funzione dell'età viene spesso erroneamente ascritta all'età in sé, il che porta a non identificare la BPCO e/o altre patologie responsabili della limitazione dell'autonomia funzionale.

V'è un'interessante relazione tra le diverse definizioni di fragilità: il carico allostatico predice e, perciò, predata esattamente la fragilità, espressa invece dai criteri di Fried; una condizione preclinica identifica quindi il soggetto che incorrerà in una grave limitazione dell'autonomia personale. Al tempo stesso, quei criteri preclinici annunziano spesso condizioni cliniche importanti. La loro elevata prevalenza nella BPCO identifica quindi soggetti che ci si attende possano sviluppare comorbilità cardiovascolare e metabolica. Pertanto, marcatori di fragilità sono anche indicatori di rischio per morbilità o spia di comorbilità misconosciuta. Ne deriva che il semplice screening sistematico della fragilità nella popolazione anziana sarebbe propedeutico al riconoscimento delle patologie croniche responsabili o corresponsabili della fragilità stessa, aprendo la strada all'identificazione - tra le altre - della BPCO. Un approccio di questo tipo appare meritevole di valutazione in quanto garantirebbe una selezione ragionata dei soggetti da sottoporre a screening spirometrico, aumentando il rapporto costo/efficacia dello screening stesso. Infatti, l'adozione sistematica dello screening non si è affermata in virtù di problemi metodologici e procedurali (logistica, costo, qualità della performance spirometrica ecc.) che una preselezione del campione di probandi ridurrebbe sensibilmente.

Per quanto riguarda il rapporto tra BPCO e autonomia personale nell'anziano, la limitazione dell'autonomia personale è soprattutto legata alla dimensione fisica (fig. 4). Disturbi del sonno, della sfera cognitiva, della sfera affettiva identificano un secondo set di fattori limitanti l'autonomia personale, ma domina la dimensione fisica. Ancora, l'analisi della "construct validity" delle attività della vita quotidiana, sia di base sia strumentali, nei malati anziani con BPCO identifica fattori che hanno un preciso equivalente nella vita di tutti i giorni; per esempio, il fattore che identifica mobilità outdoor è un ottimo marker surrogato di dispnea e identifica soggetti con degenza più lunga in caso di riacutizzazione della BPCO, mentre un gruppo di indicatori (essere in grado di usare il denaro, prendere le medicine, viaggiare, tagliare le unghie dei piedi) si associa con il livello di compliance agli inalatori [25].

Da questi dati emerge che un'analisi apparentemente astratta, quale lo studio delle dimensioni dell'autonomia

Tabella 2 Definizione oggettiva di fragilità secondo Fried et al.

\begin{tabular}{ll}
\hline Parametri & \multicolumn{1}{c}{ Indicatori di fragilità } \\
\hline 1. Dimagrimento & Perdita di peso $>10$ libbre in un anno \\
\hline 2. Forza nella stretta di mano & $<20 \%$ rispetto a quella della popolazione media \\
\hline 3. Affaticabilità & Self-report \\
\hline 4. Velocità del cammino & $<20 \%$ rispetto a quella della popolazione media \\
\hline 5. Ridotta attività fisica & Uomini $<383 \mathrm{kcal} /$ settimana Donne $<270 \mathrm{kcal} / \mathrm{settimana}$ \\
\hline * Fragilità definita dalla presenza di 3 o più dei suddetti criteri.Fonte: Fried LP, et al. J Gerontol A Biol Sci Med Sci 2001;56(3):M146-56.
\end{tabular}




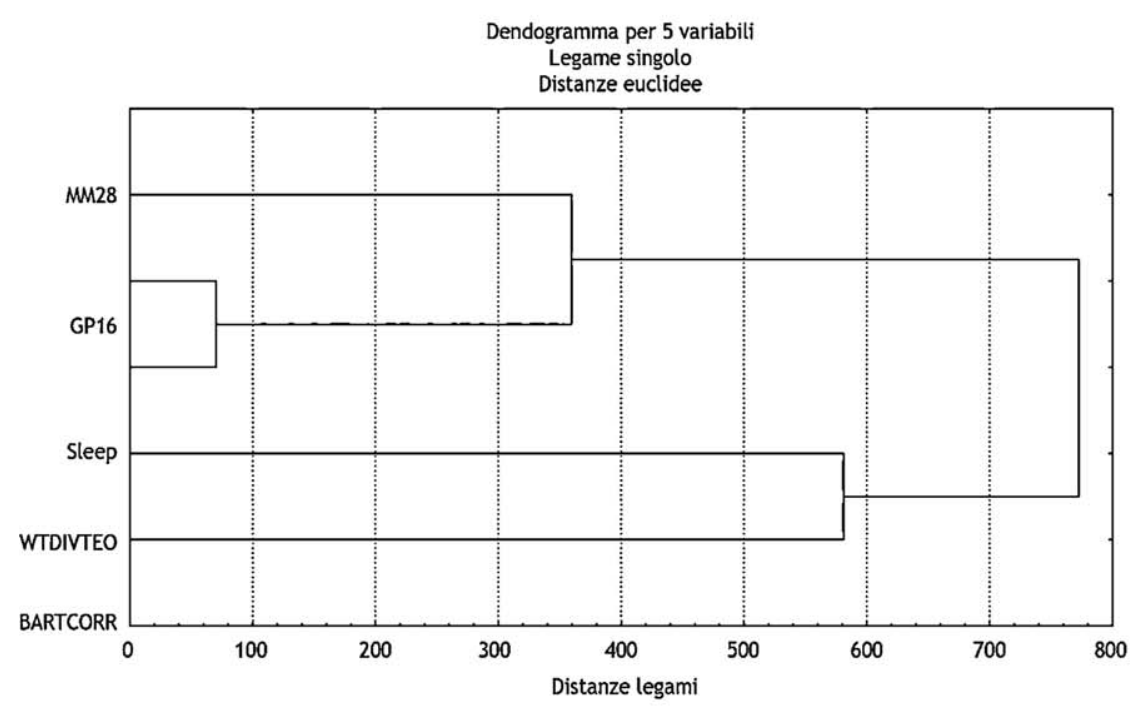

Legenda: MM28 = Mini Mental State Examination-28; GP16 = Geriatric Depression Scale-16; SLEEP = indice EPESE della qualità del sonno; WTDIVTEO = test del cammino per 6 min, espresso come percentuale del teorico; BARTCORR = indice di Barthel.

Fonte: Studio SaRA.

Figura 4 Dimensione fisica vs dimensione neuropsicologica nella definizione dello stato di salute in soggetti ultrasessantacinquenni con BPCO. Il dendrogramma evidenzia il ruolo preminente della dimensione fisica.

personale, si traduce nell'identificazione di limitazioni del fabbisogno. Ma tali limitazioni sono fortemente dipendenti dalle malattie coesistenti con la BPCO; nello studio GIFA [26] si è dimostrato come un numero di diagnosi pari o superiore a 5 si associ con un drammatico incremento del deficit cognitivo e della dipendenza nelle attività della vita quotidiana dei malati con BPCO, e quindi rappresenti un codeterminante fondamentale. $\dot{E}$ quindi chiaro che le patologie coesistenti condizionano fortemente l'autonomia personale e, prima ancora, le varie abilità di cui essa è la risultante.

Focalizzandoci infine sullo stato di salute percepito, questo è funzione della gravità della BPCO, della comorbilità e dei fattori sociali, secondo un rapporto che varia in funzione della gravità della BPCO. Infatti, negli stadi più avanzati, è la BPCO da sola che condiziona di gran lunga lo stato di salute, mentre nelle forme lievi e moderate risulta essere importante il contributo della comorbilità [27]. In tutti gli stadi, fondamentale è invece, e spesso misconosciuto, il contributo della dimensione sociale. In particolare, ricordiamo per esempio che $\mathrm{i}$ fattori predittivi di una degenza più lunga per BPCO riacutizzata includono tra l'altro la presenza di un nucleo familiare unipersonale; e che quest'ultima è tra le caratteristiche dei soggetti anziani con BPCO che hanno la peggior qualità di vita $[28,29]$. Soprattutto sottolinea il peso della dimensione sociale il fatto che sussista un nettissimo rapporto inverso tra il reddito e l'ospedalizzazione per BPCO: nei soggetti ultrasettantacinquenni, passando dal primo al decimo decile di reddito, si verifica un calo drammatico della frequenza del ricovero per BPCO, così come per altre malattie croniche, come lo scompenso e il diabete, o anche per malattie acute che hanno però una base cronica, come l'ictus, ma non per la frattura di femore, malattia acuta per eccellenza (fig. 5) [30]. Emerge quindi, in modo netto, per i malati con BPCO quella verità virchowiana secondo cui la malattia è sempre dotata di una forte dimensione sociale. Questa verità è tanto più significativa per i pazienti anziani, dove la distruzione o rarefazione del tessuto familiare e la contrazione del reddito possono anche sopravanzare la dimensione sanitaria nel determinismo dello stato di salute percepito e del fabbisogno di cura.

Ricordiamo infine che anche la BPCO non riconosciuta si associa con un significativo deterioramento dello stato di salute (fig. 6), il che rappresenta una precisa indicazione alla ricerca sistematica di tale patologia nel soggetto anziano [31].

I pochi esempi qui riportati dimostrano quindi il peso della dimensione sociale, ma anche di altri fattori, per esempio nutrizionali, nel determinismo dello stato di salute dell'anziano con BPCO e comorbilità. Purtroppo, questi non rientrano nell'assessment abituale; da ciò la necessità di una valutazione multidimensionale che esplori le diverse

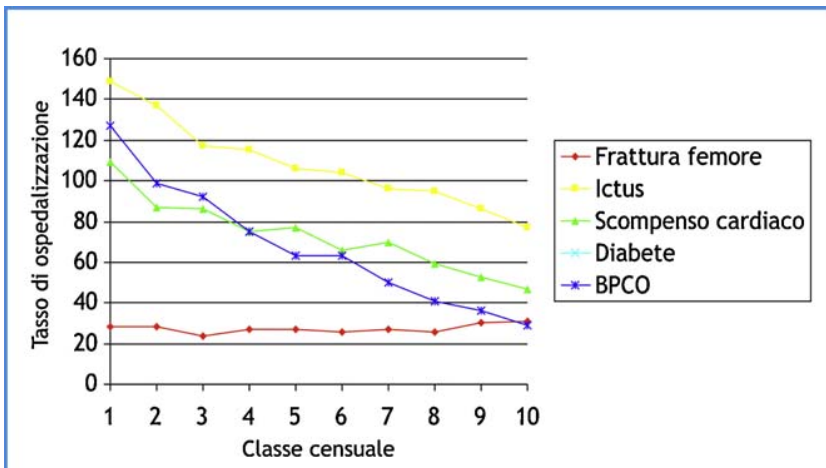

Fonte: modificata da Antonelli-Incalzi R, et al. BMC Public Health 2007;7:227.

Figura 5 Relazione tra classe censuale e tasso di ospedalizzazione in maschi ultrasettantacinquenni. 


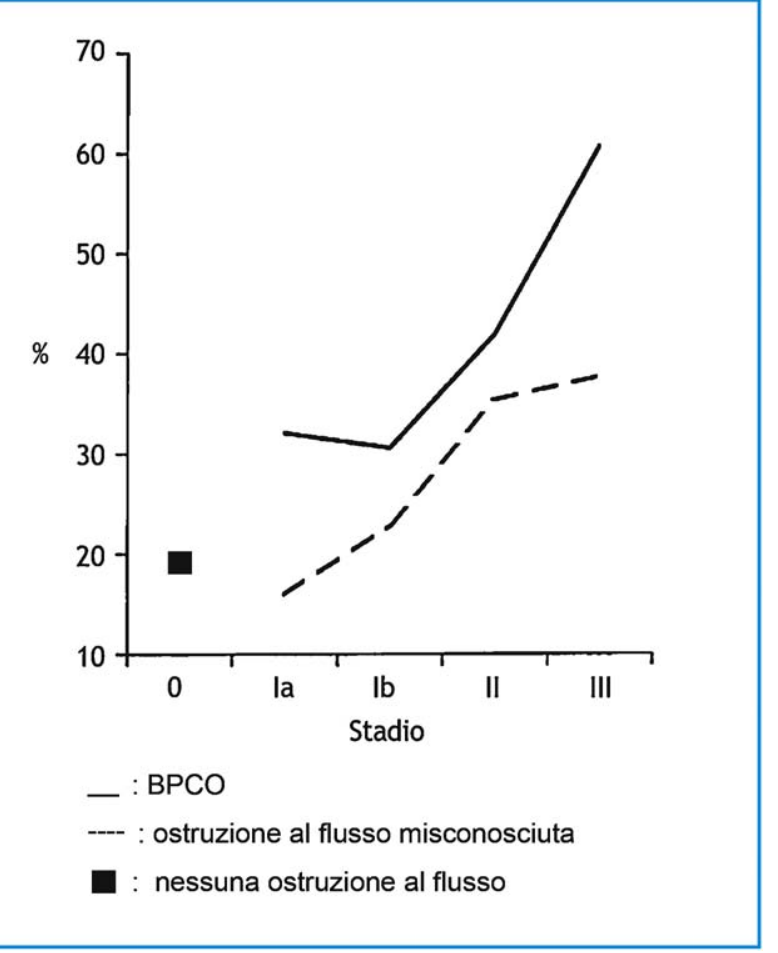

Figura 6 Livello di autonomia personale e BPCO: perfino la BPCO misconosciuta incide pesantemente sullo stato di salute. Fonte: modificata da Coultas DB, et al. Am J Respir Crit Care Med 2001;164(3):372-7.

dimensioni dello stato di salute del paziente anziano con BPCO nella prospettiva di identificarne i determinanti e, soprattutto, di proporre interventi terapeutici integrati, realmente multidimensionali, e quindi multidisciplinari.

\section{La valutazione multidimensionale per l'anziano con BPCO}

Un breve accenno a questo tema richiede un richiamo alle dimensioni della valutazione dimensionale (VMD), che vanno

Tabella 3 Dimensioni dello stato di salute teoricamente oggetto di valutazione multidimensionale ed esempi dei relativi strumenti.

Un approccio sistematico completo dovrebbe includere:

- Misure antropometriche

- Capacità funzionali della persona: attività di base della vita quotidiana, attività strumentali della vita quotidiana (o indice di Barthel)

- Performance cognitiva: Mini Mental State Examination, test dell'orologio

- Condizione affettiva: Geriatric Depression Scale a 15 item o scala di Hamilton

- Qualità del sonno: indice EPESE

- Status nutrizionale e qualità della dieta

- Valutazione standard delle comorbilità maggiormente prevalenti: si veda Tabella 4 dalla dimensione antropometrica e nutrizionale agli indici di autonomia personale, a quelli dello stato cognitivo, dello stato affettivo e della qualità del sonno (tabella 3). Preliminare alla VMD è un perfetto inquadramento nosografico che implica un assessment standardizzato della comorbilità. La stima della comorbilità, infatti, non può basarsi sul semplice questionario, ma, per alcune patologie, deve richiedere una valutazione strutturata, per esempio della densità minerale ossea tramite densitometria ossea a raggi $X$ (DEXA), della filtrazione glomerulare tramite le formule derivate dallo studio sulla modificazione della dieta nella malattia renale (MDRD), del tono oculare tramite tonometro ecc. (tabella 4).

Una VMD pressoché onnicomprensiva, tale cioè da abbracciare la maggior parte delle dimensioni, richiede tuttavia molto tempo, non è di agevole esecuzione, se non nel contesto di particolari programmi dedicati (per esempio trial clinici di ricerca) e, conseguentemente, non si presta a un uso sistematico. Tuttavia esistono strumenti di VMD di minima, che possono essere convenientemente utilizzati anche nell'anziano e richiedono anche meno di 10-15 minuti, o, nel caso degli indici surrogati, soltanto pochi minuti [32].

Gli stessi questionari dello stato di salute specifici per pneumopatici, come il St. George o il Chronic Respiratory Questionnaire, si applicano bene all'anziano, così come quelli generici, fra cui l'SF-12, surrogato del SF-36, che richiede pochi minuti e ha buona capacità classificativa e predittiva. Buone capacità classificative hanno le misure di performance fisiche, come il walking test, o psichiche, come il Mini Mental State Examination, o affettive, come la Geriatric Depression Scale, le misure di indipendenza, come le attività strumentali e di base della vita quotidiana o indice di Barthel, e ancora veri e propri indici surrogati che richiedono 1-2 minuti e che veicolano una rilevante informazione, come la scala Medical Research Council (MRC) o la visuoanalogica della dispnea (tabella 5).

Questi strumenti permettono di quantificare lo stato di salute del paziente, e costituiscono un mezzo prezioso sia per l'identificazione di problemi misconosciuti, sia per la stima di efficacia della terapia e la valutazione periodica e, quindi, per il precoce riscontro di un deterioramento dello stato di salute. Tuttavia, mentre sussistono chiare evidenze a supporto del ruolo classificativo e prognostico della VMD nell'anziano pneumopatico, non altrettanto può dirsi in merito all'utilità clinica della VMD. Mancano infatti studi di intervento guidati dalla VMD. Possiamo solo trarre conclusioni ipotetiche sulla scorta dei risultati che tali studi hanno prodotto in casistiche geriatriche complesse ed eterogenee, con rappresentazione variabile di pneumopatici. In tali casistiche la VMD, a integrazione e guida dell'assistenza medica, ha permesso di rallentare il declino funzionale sia fisico che psichico e di ridurre il fabbisogno di cure, specie ospedaliere [33]. È quindi verosimile che analoghe conclusioni si applichino agli pneumopatici cronici, dato che la BPCO si caratterizza per un importante declino dell'autonomia personale e un notevole ricorso alle cure ospedaliere.

Le esperienze di "comprehensive geriatric care" applicata all'anziano con BPCO, naturale sviluppo e applicazione della VMD, sono limitate e dall'esito controverso (tabella 6). In generale, sembrano efficaci gli interventi che prevedano anche una componente riabilitativa e un'accurata verifica della compliance alla terapia farmacologica e non farmacologica [32]. Una generica supervisione infermieristica non 
Tabella 4 Screening delle comorbilità più frequentemente misconosciute nell'anziano con BPCO.

\begin{tabular}{ll}
\hline Patologia & \multicolumn{1}{c}{ Screening } \\
\hline Scompenso cardiaco & Radiografia del torace, BNP \\
\hline Osteoporosi & Densitometria ossea a raggi X, morfometria della colonna dorsale \\
\hline Depressione & Geriatric Depression Scale \\
\hline Deficit cognitivo & Mini Mental State Examination, test dell'orologio \\
\hline Glaucoma & Tonometria oculare \\
\hline Insufficienza renale & Studio sulla modificazione della dieta nella malattia renale (stima \\
& indiretta: velocità di filtrazione glomerulare)
\end{tabular}

Legenda: BNP = Brain Natriuretic Peptide.

Tabella 5 Strumenti di VMD e relativi ambiti di applicazione nella BPCO.

\begin{tabular}{|c|c|c|c|c|}
\hline $\begin{array}{l}\text { Misure dello stato di salute } \\
\text { malattia-specifiche }\end{array}$ & $\begin{array}{l}\text { Misure generiche } \\
\text { dello stato di salute }\end{array}$ & $\begin{array}{l}\text { Misure di performance } \\
\text { fisica }\end{array}$ & $\begin{array}{l}\text { Misure di autonomia } \\
\text { funzionale }\end{array}$ & Indici surrogati \\
\hline $\begin{array}{l}\text { Chronic Respiratory } \\
\text { Questionnaire } \\
\text { St. George Respiratory } \\
\text { Questionnaire }\end{array}$ & $\begin{array}{l}\text { Short Form Health } \\
\text { Survey- } 36 \text { Short Form } \\
\text { Health Survey-12 }\end{array}$ & $\begin{array}{l}\text { Fisica: test del cammino } \\
\text { Cognitiva: Mini Mental } \\
\text { State Examination } \\
\text { Affettiva: Geriatric } \\
\text { Depression Scale-15 }\end{array}$ & $\begin{array}{l}\text { Attività di base della } \\
\text { vita quotidiana Attività } \\
\text { strumentali della vita } \\
\text { quotidiana Indice } \\
\text { di Barthel }\end{array}$ & $\begin{array}{l}\text { Medical } \\
\text { Research } \\
\text { Council }\end{array}$ \\
\hline $\begin{array}{l}\text { Buona capacità classificativa } \\
\text { e predittiva, specie delle } \\
\text { riacutizzazioni. Ottima } \\
\text { responsività agli interventi } \\
\text { terapeutici }\end{array}$ & $\begin{array}{l}\text { Rispetto ai questionari } \\
\text { specifici di malattia forse } \\
\text { preferibili in presenza } \\
\text { di rilevante comorbilità, } \\
\text { ma meno sensibili agli } \\
\text { effetti degli interventi } \\
\text { terapeutici }\end{array}$ & $\begin{array}{l}\text { Capacità classificativa } \\
\text { e predittiva: ottima } \\
\text { per la dimensione fisica; } \\
\text { buona per quella } \\
\text { affettiva e, nei pazienti } \\
\text { ipossiemici, cognitiva }\end{array}$ & $\begin{array}{l}\text { Capacità classificativa } \\
\text { e predittiva: ottima } \\
\text { nei pazienti ipossiemici }\end{array}$ & $\begin{array}{l}\text { Rapido, } \\
\text { ma efficace, } \\
\text { strumento } \\
\text { classificativo, } \\
\text { surrogato } \\
\text { di una VMD }\end{array}$ \\
\hline
\end{tabular}

riduce il ricorso alle cure ospedaliere [34], né un training cognitivo aggiunge valore a una cura multidisciplinare che includa la riabilitazione [35]. Degno di attenzione è il fatto che anche i soggetti con grave depressione si giovano di interventi multidisciplinari ben condotti, ad attestare la dipendenza dei disturbi affettivi dalla dimensione fisica della malattia [36].

Nell'insieme, quindi, la VMD del soggetto anziano con BPCO e comorbilità può articolarsi secondo varie modalità, in rapporto ai mezzi disponibili e anche allo scopo della medesima, ma dovrebbe costituire una componente costante, basilare, del nostro approccio, una sorta di forma mentis prima ancora che un metodo operativo, perché solo così è possibile acquisire una visione d'insieme di un paziente che, altrimenti, benché considerato complesso, dalle molteplici esigenze, rischia di essere, in realtà, curato come un paziente monodimensionale, di cui si ignorano le reali necessità.

Tabella 6 Esperienza di Comprehensive Geriatric Care (CGE) in pazienti anziani con BPCO.

\begin{tabular}{lll}
\hline \multicolumn{1}{c}{ Modello } & \multicolumn{1}{c}{ Risultati } & Note \\
\hline $\begin{array}{l}\text { Assistenza domiciliare } \\
\text { nurse-based }\end{array}$ & $\begin{array}{l}\text { Non previene le ospedalizzazioni. } \\
\text { È invece efficace in altre } \\
\text { patologie croniche }\end{array}$ & $\begin{array}{l}\text { L'acritica trasposizione alla BPCO di un modello } \\
\text { efficace in diabete, scompenso cardiaco, } \\
\text { ictus ha condizionato il risultato }\end{array}$ \\
\hline $\begin{array}{l}\text { Assistenza multidisciplinare } \\
\text { domiciliare }\end{array}$ & $\begin{array}{l}\text { Migliora lo stato di salute e riduce } \\
\text { le riacutizzazioni anche } \\
\text { in anziani depressi }\end{array}$ & $\begin{array}{l}\text { L'effetto sembra dipendere soprattutto } \\
\text { dalla componente riabilitativa }\end{array}$ \\
\hline $\begin{array}{l}\text { Ospedalizzazione domiciliare } \\
\text { Riattivazione cognitiva in }\end{array}$ & Riduce ricoveri e consumo di farmaci \\
$\begin{array}{l}\text { aggiunta all'assistenza } \\
\text { multidisciplinare } \\
\text { domiciliare }\end{array}$ & Non migliora i risultati della CGE & Si applica a una casistica selezionata \\
\hline
\end{tabular}




\section{Bibliografia}

[1] Tinetti ME, Fried T. The end of the disease era. Am J Med 2004;116(3):179-85.

[2] Marengoni A, Rizzuto D, Wang HX, Winblad B, Fratiglioni L. Patterns of chronic multimorbidity in the elderly population. J Am Geriatr Soc 2009;57(2):225-30.

[3] Incalzi RA, Fuso L, Serra M, Basso S, Carosella L, Tramaglino LM, et al. Exacerbated chronic obstructive pulmonary disease: a frequently unrecognized condition. J Intern Med 2002;252(1): 48-55.

[4] Soriano JB, Visick GT, Muellerova H, Payvandi N, Hansell AL. Patterns of comorbidities in newly diagnosed COPD and asthma in primary care. Chest 2005;128(4):2099-107.

[5] Antonelli Incalzi R, Corsonello A, Pedone C, Battaglia S, Paglino $G$, Bellia $V$, on behalf of the Extrapulmonary Consequences of COPD in the Elderly (ECCE) study investigators. Chronic renal failure: a neglected comorbidity of COPD. Chest (in press).

[6] Al-Said YA, Al-Rached HS, Al-Qahtani HA, Jan MM. Severe proximal myopathy with remarkable recovery after vitamin $D$ treatment. Can J Neurol Sci 2009;36(3):336-9.

[7] El-Solh AA, Pietrantoni C, Bhat A, Okada M, Zambon J, Aquilina $A$, et al. Colonization of dental plaques: a reservoir of respiratory pathogens for hospital-acquired pneumonia in institutionalized elders. Chest 2004;126(5):1575-82.

[8] Bassim CW, Gibson G, Ward T, Paphides BM, Denucci DJ. Modification of the risk of mortality from pneumonia with oral hygiene care. J Am Geriatr Soc 2008;56(9):1601-7.

[9] Scarlata S, Pedone C, Conte ME, Incalzi RA. Accuracy of spirometry in diagnosing pulmonary restriction in elderly people. $J$ Am Geriatr Soc 2009;57(11):2107-11.

[10] Yang HL, Zhao L, Liu J, Sanford Jr CG, Chen L, Tang T, et al. Changes of pulmonary function for patients with osteoporotic vertebral compression fractures after kyphoplasty. J Spinal Disord Tech 2007;20(3):221-5.

[11] Paladini L, Hodder R, Cecchini I, Bellia V, Incalzi RA. The MRC dyspnoea scale by telephone interview to monitor health status in elderly COPD patients. Respir Med 2010;104(7):1027-34.

[12] Ekberg O, Feinberg MJ. Altered swallowing function in elderly patients without dysphagia: radiologic findings in 56 cases. AJR Am J Roentgenol 1991;156(6):1181-4.

[13] Gross RD, Atwood Jr CW, Ross SB, Olszewski JW, Eichhorn KA. The coordination of breathing and swallowing in chronic obstructive pulmonary disease. Am J Respir Crit Care Med 2009;179(7):559-65.

[14] Kikawada M, Iwamoto T, Takasaki M. Aspiration and infection in the elderly: epidemiology, diagnosis and management. Drugs Aging 2005;22(2):115-30.

[15] Biskobing DM. COPD and osteoporosis. Chest 2002;121(2):60920.

[16] Akhter MP, Lund AD, Gairola CG. Bone biomechanical property deterioration due to tobacco smoke exposure. Calcif Tissue Int 2005;77(5):319-26.

[17] Genant HK, Wu CY, van Kuijk C, Nevitt MC. Vertebral fracture assessment using a semiquantitative technique. J Bone Miner Res 1993;8(9):1137-48.

[18] Lee JH, O'Keefe JH, Bell D, Hensrud DD, Holick MF. Vitamin D deficiency an important, common, and easily treatable cardiovascular risk factor? J Am Coll Cardiol 2008;52(24):1949-56.

[19] Boyd CM, Darer J, Boult C, Fried LP, Boult L, Wu AW. Clinical practice guidelines and quality of care for older patients with multiple comorbid diseases: implications for pay for performance. JAMA 2005;294(6):716-24.

[20] Calverley PM, Anderson JA, Celli B, Ferguson GT, Jenkins C, Jones PW, et al., TORCH investigators. Salmeterol and fluticasone propionate and survival in chronic obstructive pulmonary disease. N Engl J Med 2007;356(8):775-89.
[21] Tashkin DP, Celli B, Senn S, Burkhart D, Kesten S, Menjoge S, et al., UPLIFT Study Investigators. A 4-year trial of tiotropium in chronic obstructive pulmonary disease. N Engl J Med 2008; 359(15):1543-54.

[22] Gruenewald TL, Seeman TE, Karlamangla AS, Sarkisian CA. Allostatic load and frailty in older adults. J Am Geriatr Soc 2009;57(9):1525-31.

[23] Walston J, Hadley EC, Ferrucci L, Guralnik JM, Newman AB, Studenski SA, et al. Research agenda for frailty in older adults: toward a better understanding of physiology and etiology: summary from the American Geriatrics Society/National Institute on Aging Research Conference on Frailty in Older Adults. J Am Geriatr Soc 2006;54(6):991-1001.

[24] Fried LP, Tangen CM, Walston J, Newman AB, Hirsch C, Gottdiener J, et al., Cardiovascular Health Study Collaborative Research Group. Frailty in older adults: evidence for a phenotype. J Gerontol A Biol Sci Med Sci 2001;56(3):M146-56.

[25] Incalzi RA, Corsonello A, Pedone C, Corica F, Carbonin P, Bernabei R, GIFA Investigators. Construct validity of activities of daily living scale: a clue to distinguish the disabling effects of COPD and congestive heart failure. Chest 2005;127(3): $830-8$.

[26] Corsonello A, Pedone C, Carosella L, Corica F, Mazzei B, Incalzi RA, Gruppo Italiano di Farmacovigilanza nell'Anziano Investigators. Health status in older hospitalized patients with cancer or non-neoplastic chronic diseases. BMC Geriatr 2005;5:10.

[27] Ferrer M, Alonso J, Morera J, Marrades RM, Khalaf A, Aguar MC, et al. Chronic obstructive pulmonary disease stage and healthrelated quality of life. The Quality of Life of Chronic Obstructive Pulmonary Disease Study Group. Ann Intern Med 1997;127(12): 1072-9.

[28] Incalzi RA, Pedone C, Onder G, Pahor M, Carbonin PU, GIFA. Gruppo Italiano di Farmacovigilanza (Italian Group for Pharmacological Survey in the Elderly). Predicting length of stay of older patients with exacerbated chronic obstructive pulmonary disease. Aging (Milano) 2001;13(1):49-57.

[29] Incalzi RA, Bellia V, Maggi S, Imperiale C, Capparella O, Pistelli R, et al., SaRA. Study Group. Reversible bronchial obstruction and disease-related health status in COPD. Qual Life Res 2002;11(6):517-25.

[30] Antonelli-Incalzi R, Ancona C, Forastiere F, Belleudi V, Corsonello A, Perucci CA. Socioeconomic status and hospitalization in the very old: a retrospective study. BMC Public Health 2007;7:227.

[31] Coultas DB, Mapel D, Gagnon R, Lydick E. The health impact of undiagnosed airflow obstruction in a national sample of United States adults. Am J Respir Crit Care Med 2001;164(3): 372-7.

[32] Antonelli Incalzi R, Pedone C, Pahor M. Multidimensional assessment and treatment of the elderly with COPD. Eur Respir J Monograph 2009;43:35-55.

[33] Huss A, Stuck AE, Rubenstein LZ, Egger M, Clough-Gorr KM. Multidimensional preventive home visit programs for community-dwelling older adults: a systematic review and meta-analysis of randomized controlled trials. J Gerontol A Biol Sci Med Sci 2008;63(3):298-307.

[34] Pearson S, Inglis SC, McLennan SN, Brennan L, Russell M, Wilkinson $D$, et al. Prolonged effects of a home-based intervention in patients with chronic illness. Arch Intern Med 2006;166(6):645-50.

[35] Incalzi RA, Corsonello A, Trojano L, Pedone C, Acanfora D, Spada $A$, et al. Cognitive training is ineffective in hypoxemic COPD: a six-month randomized controlled trial. Rejuvenation Res 2008;11(1):239-50.

[36] Alexopoulos GS, Raue PJ, Sirey JA, Arean PA. Developing an intervention for depressed, chronically medically ill elders: a model from COPD. Int J Geriatr Psychiatry 2008;23(5): 447-53. 